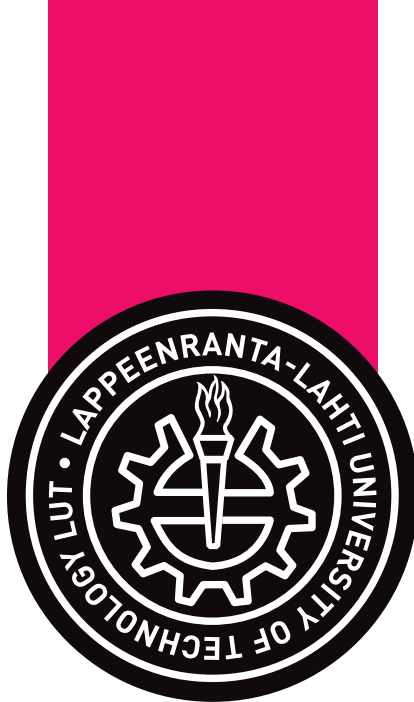

Deepika Lakshmi Ramasamy

SELECTIVE RECOVERY OF RARE EARTH ELEMENTS

FROM DILUTED AQUEOUS STREAMS USING

N- AND 0- COORDINATION LIGAND GRAFTED

ORGANIC-INORGANIC HYBRID COMPOSITES 


\section{SELECTIVE RECOVERY OF RARE EARTH ELEMENTS}

FROM DILUTED AQUEOUS STREAMS USING

N- AND 0- COORDINATION LIGAND GRAFTED ORGANIC-INORGANIC HYBRID COMPOSITES

Dissertation for the degree of Doctor of Science (Technology) to be presented with due permission for public examination and criticism in the Auditorium in Mikkeli University Consortium, MUC, Mikkeli, Finland on the $4^{\text {th }}$ of June, 2019 , at noon.

Acta Universitatis

Lappeenrantaensis 855 


\author{
Supervisors Professor Mika Sillanpää \\ LUT School of Engineering Science \\ Lappeenranta-Lahti University of Technology LUT \\ Finland \\ Associate Professor Eveliina Repo \\ LUT School of Engineering Science \\ Lappeenranta-Lahti University of Technology LUT \\ Finland
}

\author{
Reviewers Dr. Md Rabiul Awual \\ Japan Atomic Energy Agency \\ RENESA, Japan \\ Professor Marie-Odile Simonnot \\ Université de Lorraine \\ Vandœuvre-lès-Nancy, France \\ Opponent Professor Marie-Odile Simonnot \\ Université de Lorraine \\ Vandœuvre-lès-Nancy, France
}

ISBN 978-952-335-376-3

ISBN 978-952-335-377-0 (PDF)

ISSN-L 1456-4491

ISSN 1456-4491

Lappeenranta-Lahti University of Technology LUT

LUT University Press 2019 


\author{
ABSTRACT \\ Deepika Lakshmi Ramasamy \\ Selective recovery of rare earth elements from diluted aqueous streams using n- and o- \\ coordination ligand grafted organic-inorganic hybrid composites \\ Lappeenranta 2019 \\ $106 \mathrm{p}$. \\ Acta Universitatis Lappeenrantaensis 855 \\ Diss. Lappeenranta-Lahti University of Technology \\ ISBN 978-952-335-376-3, ISBN 978-952-335-377-0 (PDF) \\ ISSN-L 1456-4491, ISSN 1456-4491
}

The dominance exerted by the rare earth elements (REE) on the significant technological advancements of the past decades has been unmitigated and unparalleled. With such an eminent role played by REEs, there exists a constant battle in striking a balance between the supply to demand ratio, especially due to the geographical constraints imposed by the natural distribution of these elements. With China, the major producer of REE (over 95\%) imposing severe restrictions on exports, coupled with the closure of several operating mines has led to the dire need of finding alternate means to fulfill the resource requirement through sustainable and self-sufficient means. Hence, alternate routes for primary REE production to acquire a steady and self-reliant supply of these elements are constantly explored. Further, much emphasis has been laid on finding schemes that fit well within the scope of a circular economy. The utilization and re-use of waste resulting from a number of industrial processes hold the potential to function as secondary raw materials for REE procurement. However, the establishment of efficient schemes to accomplish this goal can be hugely challenging. One prominent example would be the recovery of low concentrated REEs effectively and selectively from diluted industrial streams i.e. from massive amounts of wastewater. For this purpose, adsorption would be of great relevance in metal recovery from dilute aqueous solutions with the domain being constantly updated through the state-of-the-art methodologies and design of efficient adsorbents for a variety of applications.

The synthesis and identification of adsorbents that exhibit high REE selectivity in conjuncture with excellent REE adsorption performance is the prime objective of this Ph.D. work. Recent evidence from literature point towards the efficacies of organic-inorganic hybrid adsorbents for metal sorption. Along this line, the present study aims to amalgamate the desirable feature of the organic supports (diverse functional groups) such as chitosan, carbon nanotubes, activated carbon and marine algae with those of inorganic silica (robust and thermally stable) through hybridization process using silane as a coupling agent. An in-depth characterization of the physicochemical 
attributes of these hybrid adsorbents was performed using various analytical techniques, the results of which are summarized in this thesis. Further, the study revealed that the hybridization coupled with ligand grafting step resulted in the improvement of REE binding affinity as well as selectivity of the materials owing to their synergic effects. Besides, it is also of prime importance to establish adept, easy and reproducible fabrication schemes for the design of hybrid composites bearing a wide range of tailor-made properties and functionalities utilizing the rich surface chemistry of the supports. Hence, during the course of this research work, two different synthetic pathways were analyzed namely the direct single-pot (single step) and the step-by-step telescopic synthesis. This comparative assessment led to the identification of the ideal ligand-grafting pathways for various support materials and their predominant role towards REE affinity/selectivity.

Given the importance of scandium (Sc) in cutting-edge applications, selective separation of Sc from REE mixture was attempted through the exploitation of its varying chemical reactivity among REEs. The findings of this study exposed the inability of the non-hybrid carbon nanotubes (CNT), activated carbon (AC) and chitosan adsorbents to adsorb any REE (except Sc) without silica hybridization. The knowledge gained from the aforementioned experiments helped to design a two-stage REE separation and concentration process, manifested from both the hybrid and the nonhybrid materials, to selectively separate Sc from REE mixtures. To ascertain the superiority of the synthesized adsorbents, the process was also tested with acidic mine drainage (AMD) and seawater, the results of which were used to identify the best adsorbents possessing enhanced REE selectivity and affinity.

Thus, a concise overview of the milestones reached during this Ph.D. would include the development of highly efficient hybrid adsorbents, particularly organic-inorganic hybrid composites that possess exemplary REE selectivity and the identification of viable commercial fabrication schemes that can be adopted with minimal effort. The analysis of REE intraseries adsorption trends would supplement the existing knowledge on REE-host interactions and the selectivity towards the light or heavy REEs for various materials. The insights gained from this comprehensive research work would help accelerate the progress towards a sustainable future through the efficient utilization of alternate resources for REEs.

Keywords: adsorption, activated carbon, carbon nanotubes, chitosan, hybrid composites, rare earth elements, scandium, silica 


\section{PREFACE}

In recent times, the continual growth of human population is exploding at a rapid rate along with which there is an ever-increasing, consistent and steep climb in the necessity of resources essential to suffice the enhancement of living standards. To supplement the expeditious rise in the requirement for these resources, the industrial and the research community constantly explore alternate routes for acquiring them via cleaner and environment-friendly pathways. Eventually, these methods hold the potential to replace the current trend in fossil fuel exploitation, however, their reliance on significant technological breakthroughs insist on the need for a constant supply of specialized raw materials. Subsequent efforts to meet the same have led to resource inadequacy, owing to several geographical constraints (especially in Europe). Hence, in order to accelerate the progression towards a low-carbon ecosystem, it is of the dire need to establish efficient raw material procurement schemes to attain a state of self-sufficiency. This further invigorates the thirst for the development of alternate, efficient and environmentally friendly ways to meet these challenges.

The framework of the current Ph.D. project lies within the scope of the circular economy, focusing on addressing the present-day challenges in procuring critical raw materials such as rare earth elements (REE) that instigates progressions towards the establishment of a cleaner and greener environment. The research work conducted in the direction of REE recovery, over the past few years, were challenging and often demanded the comprehensive application of theoretical scientific knowledge for relevant practical scenarios. The primary intent of the exhaustive experimental study was to synthesize high-performance adsorbents that can enable sufficient REE recovery from dilute aqueous solutions in real wastewater conditions. Extensive analyses were conducted to identify adsorbents with enhanced REE selectivity, exploring further into the interactions of heavy and light REEs with the host matrix. Among the REEs, more emphasis was shed on the performance of the synthesized adsorbents towards Scandium $(\mathrm{Sc})$ being an element of great significance that can serve as the spearhead for future technology.

I would like to sincerely thank the institutes and industrial partners involved in this project, for their financial and technical support extended throughout this research period:

* Lappeenranta-Lahti University of Technology (LUT) - Being one of the most laudable institutes of Finland since 1969, it is composed of a diverse population of about 6000 students alongside staff members with a thorough scientific background and extensive teaching abilities. The ethical standpoint of LUT, as represented in the following quote - "Our work supports our values: the courage to succeed, the passion for innovation through science, and the will to build well-being", is a testament to its commitment towards the betterment of humanity. The important domains where LUT extends its expertise are clean energy-based water resources and sustainable environments, the reflections of which can be evidently observed in this dissertation. This Ph.D. work shall be certified by the LUT School of Engineering Science, an institute of excellence whose research policy is focused on efficient 
resources utilization to address global challenges such as drastic climate changes, efficient methods to procure clean water and effective management of natural resources. A major part of the experimental analyses, composed in this thesis, was performed at the Department of Green Chemistry (DGC). The technologically advanced experimental facilities available at DGC provided the tools and resources to produce relevant results of extremely high quality. In addition, the efficient workflow and technically skilled co-researchers helped attain the research goals in a swift manner.

* Academy of Finland: At the forefront of scientific research in Finland, this research organization aims at promoting high-quality research in a variety of domains within the country. The current research project titled "Development of novel electrodeionization system for recovery and recycling precious metals and rare earth elements from mining effluents (decision number: 292542)" is directed towards this direction, and I am honored to acknowledge the funding obtained from the same during my Ph.D., with utmost sincerity.

I extend my heartfelt gratitude to my supervisors Prof. Mika Sillanpää and Assoc. Prof. Eveliina Repo for guiding me through the course of my Ph.D. study with their technical expertise. I would also like to express my thanks to them and reviewers (Dr. Md Rabiul Awual and Prof. Marie-Odile Simonnot) for their valuable comments to improve this dissertation.

I hope you find my research work to be illuminating and captivating.

Deepika Lakshmi Ramasamy 


\section{Acknowledgments}

First of all, I would like to express my heartfelt gratitude to my thesis supervisor, Prof. Mika Sillanpää, for providing me with this wonderful opportunity of carrying out my $\mathrm{Ph} . \mathrm{D}$. research work under his exemplary guidance. You have always been kind towards me and I cannot express how much they really mean. I sincerely thank you for all the support, motivation and recognition that you had bestowed upon me. You have always been an incredible supervisor and a good friend, not just to me, but also to all the researchers at DGC. Also, we have a lot of mutual friends who fall under the category of "best friends" too (haha). Secondly, I would also like to thank my secondary supervisor, Assoc. Prof. Eveliina Repo for offering me this $\mathrm{Ph}$.D. position and for her invaluable guidance during the project, which made this dissertation possible. You were always there in times of need and had always been easy to reach. Your constant interest and passion towards my research ideas helped me to materialize them with ease. When I look back, I still cannot forget the day that I read this project proposal and I realized with all my heart that I should never miss the chance to work on such an interesting domain. One of the other reasons that pushed me towards making this decision of taking up this Ph.D. project in Finland (besides the interest in the research topic, infrastructure and lab profile) is the usage of smileys by you and Mika :-; in emails. Although it sounds childish, it was so sweet and made me feel very comfortable. I don't think that I ever told you or Mika about my immediate instinct to accept the proposal. I knew for a fact that four years of Ph.D. can be challenging and frustrating at times. Hence, I had a feeling at the back of my mind that I need to keep myself surrounded with such friendly people during those times of hardships and those smileys definitely helped (:) Also, I had to leave all my friends and dear ones back in Germany and Belgium in order to relocate to Finland, but never have I ever regretted doing so. I loved Mikkeli right from the first day and it reminds me of one of my favorite places back in India. I must admit that accepting this Ph.D. position is one of the best decisions I have ever made. As a result, I had met some wonderful friends and made great memories that I would cherish for a lifetime. So, thank you Eveliina and Mika for everything that I mentioned here and beyond.

During the course of my Ph.D., I had some wonderful colleagues who are also my great friends here. In the initial days, Manta (Bengali fish curry), Varsha (Janu, walks, flaxseeds) Bhairavi (Khakra, my very first officemate), and Aylin made my life easy and thank them for all the wonderful memories. I would also like to thank Ville and Anna for their contributions to this research project. It was a great experience to cosupervise you during your master thesis work. Also, it was wonderful to have Shoaib and Avinash in our lab during their stay for a period of 6 months. I will always remember our lunch trips to Ravintola Kasarmina/Dexi and evening football games. If I reminisce of the joyous Ph.D. memories in the future, it would definitely be with my four closest friends here: Indu (coffees, lunch and long calls), Sarroura (I wish you worked at DGC full-time), Sidra (biryani, Urdu lessons, food, car rides and late-night talks) and Samia Semha (Italy, travel, pizza). I would like to reflect my gratefulness for all those wonderful memories through my love for you guys. You had always been there for me and supported me. Indu, I feel lucky to have shared all those special moments with you during your pregnancy. I really love seeing you both (Indu and Sidra) transcend to lovely moms you are now. I cannot also forget to mention the fun times that I had with my long-time office mate Fangping (the best I could ask for $\odot$ ) and short-time office mate Zhao (our socalled "motivating talks");). Finally, thanks to Mahsa (easter eggs), Mirka, Evgenia (David Garrett), Khum and all others at DGC who made this stay a wonderful one. A special thanks to EC team members who motivate me to give my best every day. I would also like to extend my appreciation to Ms. Sanna Tomperi for her kindness and administrative assistance during the past years. I cannot forget to mention one of the 
most important things that remained constant throughout my stay in Finland, "Paulig mocca coffee". Without you, sleepless nights would not have been possible $;-;$ :- . Cheers to coffee lovers $;$ :

It is an irony to write and relish about the memories at WETSUS today, as it is the exact same day as last year when I moved to Leeuwarden, Netherlands as a research exchange student. I had made some fabulous and joyous memories during my stay over there. Thank you, Dr. Maarten Biesheuvel and Dr. Slawomir Porada for facilitating this excellent research collaboration. My heartfelt appreciation to Maarten for your kind words, for introducing me to Dr. Mark van Loosdrecht, feeding me good dinners and challenging me to coffee wagers. Next, I cannot thank enough a very special friend of mine, my partner in crime and a wonderful supervisor Slawek (D-ko, Małpka) who introduced me to electrochemistry and had all the patience in the world to bear my ignorance and impart me with profound knowledge. It was always super fun to work beside you every day. I will definitely never forget the incident where I had punched a hole in the center of the spacer. I will always remember and cherish our honest and interesting life conversations, games (haha), dreams and future business plans. Thank you for all the assistance and care you provided me during my stay at WETSUS, making me feel right at home and maintaining a great working environment. Many wonderful memories pop right out of my mind (membrane, poem, coffee breaks and your classic "sure sure") but I think it would easily take a couple of pages to list them all. You were literally my babysitter for 6 months and I cannot thank you enough for all of that. You are one of the top tier young researchers in the field of CDI, but what impressed me the most is that you are an even better human being and friend with "one-of-a-kind" mind-:. I would also like to thank my two great friends there: Ettore (Foodie like me: Sin Jah, Tao and the list goes on) and Kaustub (lab, coffees, walks) for all the great moments at WETSUS. You people had the ability to bear my talk for hours and I will definitely relish all the wonderful times that I spent with you both. I would also like to thank Newton, Terica (football chats among others) and all my office colleagues (Ettore, Carlo, Janneke, Victor, Elias, Sebastian, GaoFeng, Xiaoxia) for making my stay at Leeuwarden memorable. I still miss those WETSUS ducks, especially Borrel, canals, Febo chicken and strawberry milkshake, Saturday open markets (Greek food, spring rolls, kip, kibbeling, etc.) and DE café, except for the annoying rain (-).

Last but not least, a special thanks to my family (Appa, Amma and my cute little brother Krishna) who have always been supportive and helped me fulfill my aspirations in life. I could never wish for anything more. I love you all so much and I cannot thank you people enough. I would also love to acknowledge my pillar of support, my boo Sathish, who has stood by me in every step of the way. Any number of odes or appreciation would not justify my love and gratitude to you, for being my motivation throughout this period. I thank my lovely brothers for life, Krishna (again) and Prashanth, and uncle, aunty and our whole family for all their support and wishes during these years. In addition, I want to express my indebtedness to my best friends for life, Anu and Siri, who had always been there for me, supporting me and putting up with me even at harder times.

Thank you, everyone $\odot$ Cheers!

Deepika Lakshmi Ramasamy

Mikkeli, October 31 1 st, 2018 


\title{
CONTENTS
}

\author{
ABSTRACT \\ PREFACE
}

ACKNOWLEDGMENTS

CONTENTS

LIST OF PUBLICATIONS .......................................................................................... 13

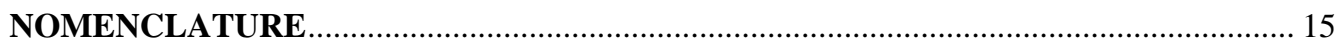

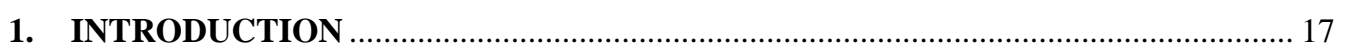

1.1. Economic importance and supply risk of critical metals: resource scarcity ................ 17

1.2. Rare earth elements .................................................................................................. 19

1.3. Transition to a circular economy and more sustainable future: exploration of REE

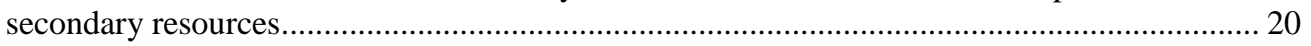

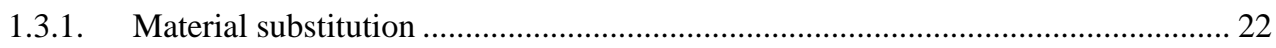

1.3.2. Recycling strategies using End-of-Life (EoL) products- Urban mining ............... 22

1.3.3. Recovery from waste streams- technospheric mining ......................................... 23

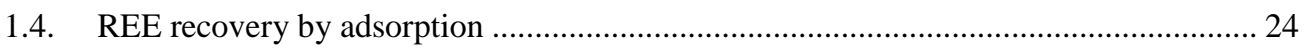

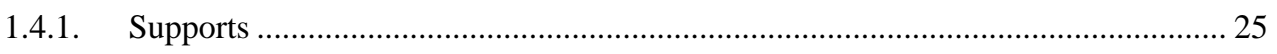

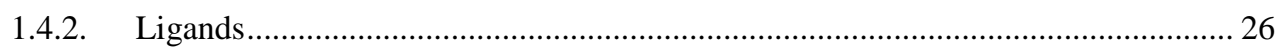

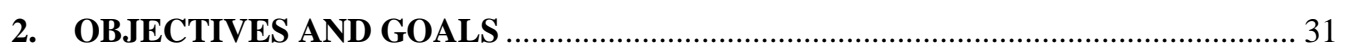

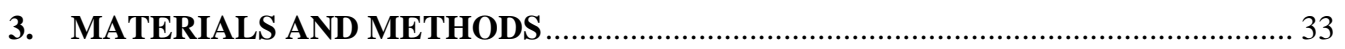

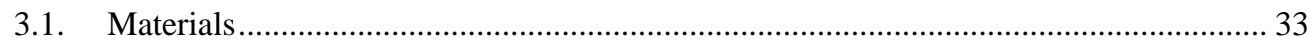

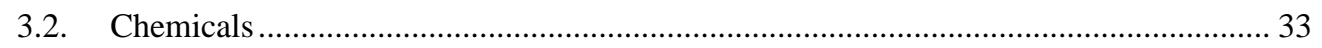

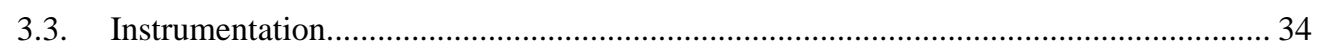

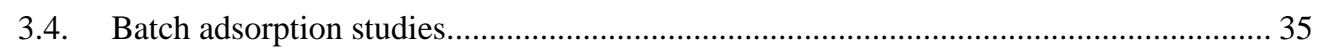

4. FUNCTIONALIZATION OF SILICA FOR REE SORPTION: INVESTIGATION OF SUITABLE SILANE AND PREPARATION METHOD …........................................... 37

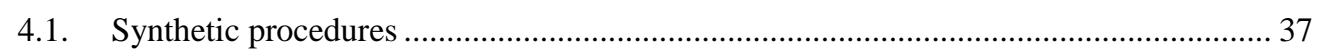

4.1.1. Method I: Chemical immobilization of ligand on silica surface............................ 37 
4.1.2. Method II: Physical loading or adsorption of ligand on silica surface

4.2. Main research outcomes: single-component and multi-component batch adsorption studies

5. HYBRIDIZATION OF SILICA WITH CHITOSAN FOR REE SORPTION: UNDERSTANDING THE ROLE OF PHYSICAL MODIFICATION AND CONDITIONING OF THE POL YMER ..................................................................... 43

5.1. Fabrication procedures for silica-chitosan hybrid composites ................................... 43

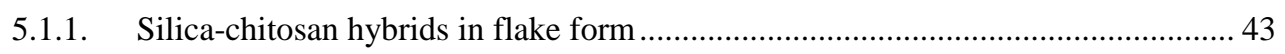

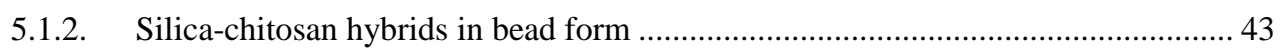

5.2. Main research outcomes: single-component batch adsorption studies ......................... 44

5.3. Main research outcomes: multi-component batch adsorption studies ......................... 44

6. HYBRIDIZATION OF SILICA WITH CARBON BASED MATERIALS: EXPLOITING SINGLE-POT AND STEP-BY-STEP TELESCOPIC SYNTHETIC PATHWAYS FOR THE DESIGN OF REE-SELECTIVE HYBRID COMPOSITES ....... 47

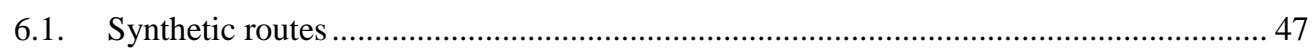

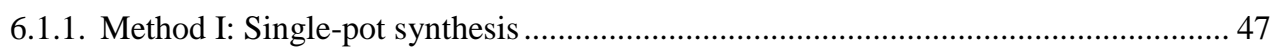

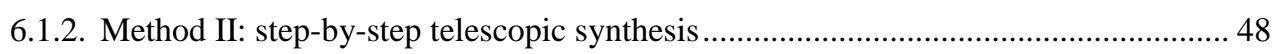

6.2. Main research outcomes: single-component batch adsorption studies ....................... 49

6.3. Main research outcomes: multi-component batch adsorption studies ......................... 49

7. GREEN, ECONOMIC AND EFFICIENT BIOSORBENT MARINE ALGAE FOR REE

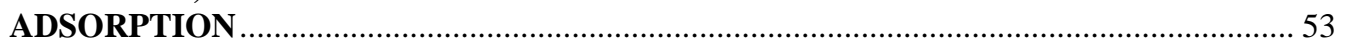

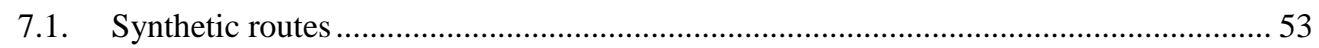

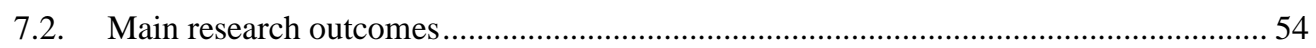

8. CHARACTERIZATION OF THE MATERIALS ............................................... 57

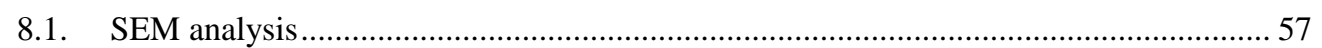

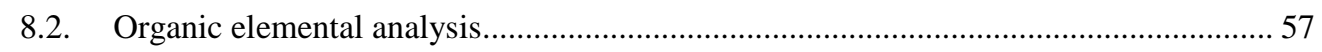

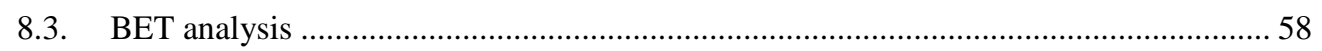

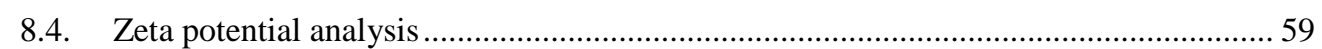

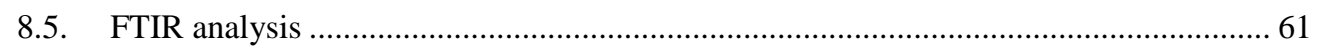

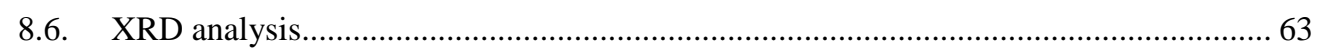

9. DISCUSSION OF SIGNIFICANT FINDINGS AND FUTURE REMARKS .............. 65

9.1. Can the same preparation method be adopted for all supports?...................................65

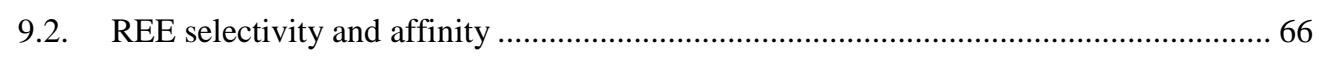


9.3. Differences in scandium interaction with host molecules in comparison to other REEs

9.4. Selective separation of scandium, REEs and other technological elements from diluted

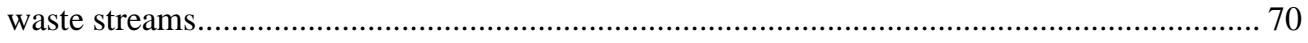

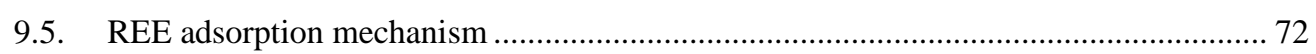

9.6. REE adsorption standardization metrics based on this work's findings ..................... 76

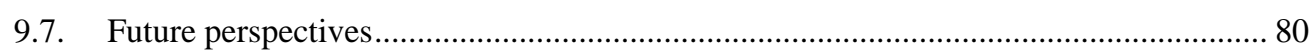

9.7.1. Potential of using PAN embedded matrix as an optical sensor for detection of REE

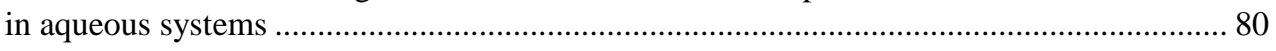

9.7.2. Transfer of knowledge to other separation and concentration technologies: ......... 82

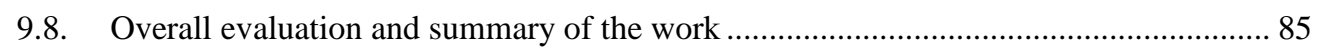

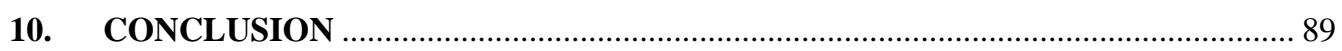

$\begin{array}{ll}\text { REFERENCES } & 93\end{array}$

$\begin{array}{ll}\text { PUBLICATIONS } & 107\end{array}$ 



\section{LIST OF PUBLICATIONS}

1) D.L.Ramasamy, E. Repo, V. Srivastava, M. Sillanpää, Chemically immobilized and physically adsorbed PAN/acetylacetone modified mesoporous silica for the recovery of rare earth elements from the waste water-comparative and optimization study, Water Research 114 (2017) 264-276. doi:10.1016/j.watres.2017.02.045.

2) D.L.Ramasamy, S. Khan, E. Repo, M. Sillanpää, Synthesis of mesoporous and microporous amine and non-amine functionalized silica gels for the application of rare earth elements (REE) recovery from the waste water-understanding the role of $\mathrm{pH}$, temperature, calcination and mechanism in Light REE and Heavy REE separation, Chemical Engineering Journal 322 (2017) 56-65. doi:10.1016/j.cej.2017.03.152.

3) D.L.Ramasamy, A. Wojtuś, E. Repo, S. Kalliola, V. Srivastava, M. Sillanpää, Ligand immobilized novel hybrid adsorbents for rare earth elements (REE) removal from waste water: Assessing the feasibility of using APTES functionalized silica in the hybridization process with chitosan, Chemical Engineering Journal 330 (2017) 1370-1379. doi:10.1016/j.cej.2017.08.098.

4) D.L.Ramasamy, V. Puhakka, S. Iftekhar, A. Wojtuś, E. Repo, S. Ben Hammouda, E. Iakovleva, M. Sillanpää, N- and O- ligand doped mesoporous silica-chitosan hybrid beads for the efficient, sustainable and selective recovery of rare earth elements (REE) from acid mine drainage (AMD): Understanding the significance of physical modification and conditioning of the polymer, Journal of Hazardous Materials 348 (2018) 84-91. doi:10.1016/j.jhazmat.2018.01.030.

5) D.L.Ramasamy, V. Puhakka, E. Repo, S. Ben Hammouda, M. Sillanpää, Two-stage selective recovery process of scandium from the group of rare earth elements in aqueous systems using activated carbon and silica composites: Dual applications by tailoring the ligand grafting approach, Chemical Engineering Journal 341 (2018) 351-360. doi:10.1016/j.cej.2018.02.024.

6) D.L.Ramasamy, V. Puhakka, B. Doshi, S. Iftekhar, M. Sillanpää, Fabrication of carbon nanotubes reinforced silica composites with improved rare earth elements adsorption performance, Chemical Engineering Journal 365 (2019) 291-304. doi:10.1016/j.cej.2019.02.057

7) D.L.Ramasamy, S.Porada, M.Sillanpää, Marine algae: A promising resource for the selective recovery of rare earth elements from aqueous systems, Chemical Engineering Journal 371 (2019) 759-768. doi:10.106/j.cej.2019.04.106

\section{THE AUTHOR'S CONTRIBUTION IN THE PUBLICATIONS}

Articles 1, 2 and 7: D.L.Ramasamy (principal author and investigator) planned, performed all the experiments, data analysis and prepared the first draft of the manuscript. Articles 3-6: D.L.Ramasamy planned, performed part of the experiments (characterization studies), supervised the rest of the experiments (adsorption studies), data analysis and prepared the first draft of the manuscript. 


\section{OTHER PUBLICATIONS BY THE SAME AUTHOR}

A. D.L.Ramasamy, V. Puhakka, E. Repo, S. Khan, M. Sillanpää, Coordination and silica surface chemistry of lanthanides (III), scandium (III) and yttrium (III) sorption on 1-(2-pyridylazo)-2-napththol (PAN) and acetylacetone (acac) immobilized gels, Chemical Engineering Journal 324 (2017) 104-112. doi:10.1016/j.cej.2017.05.025.

B. D.L.Ramasamy, V. Puhakka, E. Repo, M. Sillanpää, Selective separation of scandium from iron, aluminium and gold rich wastewater using various amino and non-amino functionalized silica gels - A comparative study, Journal of Cleaner Production 170 (2018) 890-901. doi:10.1016/j.jclepro.2017.09.199.

C. S. Iftekhar, D.L.Ramasamy, V. Srivastava, M.B. Asif, M. Sillanpää, Understanding the factors affecting the adsorption of Lanthanum using different adsorbents: A critical review, Chemosphere. 204 (2018) 413-430. doi:10.1016/j.chemosphere.2018.04.053.

D. S. Iftekhar, V. Srivastava, D.L.Ramasamy, W.A. Naseer, M. Sillanpää, A novel approach for synthesis of exfoliated biopolymeric-LDH hybrid nanocomposites via in-stiu coprecipitation with gum Arabic: Application towards REEs recovery, Chemical Engineering Journal 347 (2018) 398-406. doi:10.1016/j.cej.2018.04.126.

E. S.B. Hammouda, F. Zhao, Z. Safaei, V. Srivastava, D. L.Ramasamy, S. Iftekhar, S. kalliola, M. Sillanpää, Degradation and mineralization of phenol in aqueous medium by heterogeneous monopersulfate activation on nanostructured cobalt based-perovskite catalysts $\mathrm{ACoO} 3(\mathrm{~A}=\mathrm{La}, \mathrm{Ba}, \mathrm{Sr}$ and $\mathrm{Ce}$ ): Characterization, kinetics and mechanism study, Applied Catalysis B: Environmental 215 (2017) 60-73. doi:10.1016/j.apcatb.2017.05.051.

F. S.B. Hammouda, F. Zhao, Z. Safaei, I. Babu, D.L.Ramasamy, M. Sillanpää, Reactivity of novel CeriaPerovskite composites $\mathrm{CeO} 2$ - LaMO $3(\mathrm{MCu}, \mathrm{Fe})$ in the catalytic wet peroxidative oxidation of the new emergent pollutant 'Bisphenol F': Characterization, kinetic and mechanism studies, Applied Catalysis B: Environmental 218 (2017) 119-136. doi:10.1016/j.apcatb.2017.06.047.

G. S.B. Hammouda, F. Zhao, Z. Safaei, D.L.Ramasamy, B. Doshi, M. Sillanpää, Sulfate radical-mediated degradation and mineralization of bisphenol $\mathrm{F}$ in neutral medium by the novel magnetic $\mathrm{Sr} 2 \mathrm{CoFeO} 6$ double perovskite oxide catalyzed peroxymonosulfate: Influence of co-existing chemicals and UV irradiation, Applied Catalysis B: Environmental 233 (2018) 99-111. doi:10.1016/j.apcatb.2018.03.088.

H. S.B. Hammouda, C. Salazar, F. Zhao, D.L.Ramasamy, E. Laklova, S. Iftekhar, I. Babu, M. Sillanpää, Efficient heterogeneous electro -Fenton incineration of a contaminant of emergent concern-cotinine- in aqueous medium using the magnetic double perovskite oxide $\mathrm{Sr} 2 \mathrm{FeCuO6}$ as a highly stable catalayst: Degradation kinetics and oxidation products, Applied Catalysis B: Environmental 240 (2019) 201-214. doi:10.1016/j.apcatb.2018.09.002.

I. A.C.Arulrajan", D.L.Ramasamy\#, M.Sillanpää, A.v.d.Wal, P.M.Biesheuvel, S.Porada, J.E. Dykstra, Exceptional water desalination performance with anion-selective electrodes, Advanced Materials 2019, 31. doi:10.1002/adma.201806937

J. L.Boudriche, Z.Safaei, D.L. Ramasamy, M. Sillanpää, A. Boudjemaa, Sulfaquinoxaline oxidation by UV-C activated sodium persulfate: degradation kinetics and toxicological evaluation, Water Environment Research 2019, https://doi.org/10.1002/wer.1136 


\section{NOMENCLATURE}

\section{List of symbols}

$\mathrm{C}_{\mathrm{i}}$

$\mathrm{C}_{\mathrm{e}}$

M

V

$\mathrm{q}_{\mathrm{e}}$

$\mathrm{Q}_{\max }$

$\mathrm{K}_{\mathrm{d}}$

$\mathrm{S}_{\mathrm{A} / \mathrm{B}}$

$\mathrm{R}^{2}$

RE

T

CREE

$\mathrm{pK}_{\mathrm{a}}$

$\mathrm{k}_{1} \quad$ pseudo-first-order rate constant

$\mathrm{k}_{2} \quad$ pseudo-second-order rate constant

qt adsorption capacity at time ' $\mathrm{t}$ '

Qo maximum monolayer coverage capacity

$\mathrm{K}_{\mathrm{L}} \quad$ Langmuir isotherm constant

$\mathrm{K}_{\mathrm{f}} \quad$ Freundlich isotherm constant

$\mathrm{N} \quad$ surface heterogeneity $\mathrm{mg} / \mathrm{L}$ or ppm

$\mathrm{mg} / \mathrm{L}$ or ppm

g

L

$\mathrm{mg} / \mathrm{g}$

$\mathrm{mg} / \mathrm{g}$

$\mathrm{L} / \mathrm{g}$

$\%$

${ }^{\circ} \mathrm{C}$

$\min ^{-1}$

$\mathrm{g} \mathrm{mg}^{-1} \min ^{-1}$

$\mathrm{mg} / \mathrm{g}$

$\mathrm{mg} / \mathrm{g}$

$\mathrm{L} / \mathrm{mg}$

$\mathrm{mg} / \mathrm{g}$

\section{Abbreviations}

REE

rare earth elements

LREE

light rare earth elements

HREE

heavy rare earth elements

MREE

middle rare earth elements

AMD

acidic mine drainage

CRM

critical raw materials 


\begin{tabular}{|c|c|}
\hline PGM & platinum group metals \\
\hline LED & light emitting diode \\
\hline REO & rare earth oxides \\
\hline $\mathrm{AC}$ & activated carbon \\
\hline CNT & carbon nanotube \\
\hline SWNT & single-walled nanotube \\
\hline MWNT & multi-walled nanotube \\
\hline CDI & capacitive deionization \\
\hline ED & electrodialysis \\
\hline EDI & electrodeionization \\
\hline HSAB & hard and soft acids and bases \\
\hline EDTA & ethylenediaminetetraacetic acid \\
\hline DTPA & diethylenetriaminepentaacetic acid \\
\hline APTES & (3-aminopropyl)triethoxysilane \\
\hline APTMS & (3-aminopropyl)trimethoxysilane \\
\hline MTM & Trimethoxymethylsilane \\
\hline TMCS & Chlorotrimethylsilane \\
\hline PAN & 1-(2-pyridylazo)-2-naphthol \\
\hline acac & Acetylacetone \\
\hline CAS & chemical abstracts service \\
\hline FTIR & Fourier transform infrared spectroscopy \\
\hline ATR & attenuated total reflectance \\
\hline $\mathrm{XRD}$ & X-ray diffraction spectroscopy \\
\hline SEM & Scanning electron microscopy \\
\hline BET & Brunauer-Emmett-Teller \\
\hline BJH & Barrett-Joyner-Halenda \\
\hline LOD & limit of detection \\
\hline LOQ & limit of quantification \\
\hline $\mathrm{ZP}$ & zeta potential \\
\hline IEP & isoelectric point \\
\hline
\end{tabular}




\section{INTRODUCTION}

\subsection{Economic importance and supply risk of critical metals: resource scarcity}

There exist numerous scientific evidence to support the fact that a state of constant pressure is imposed on the Earth's environmental resources manifested from the steep increase in population growth. There is a continual search for energy and resources to supplement the needs of the everincreasing population, which is accompanied by a steady depletion of future resources. Hence, such trends can lead to a state of resource scarcity with drastic changes in the people's lifestyle, especially in growing economies, and eventually cause an immense burden on the available stash of natural wealth [1].

Ever since the time of the industrial revolution, the foundation of the modern industrial sector is strongly laid on a selective number of base metals (copper, iron, magnesium, zinc and aluminum) [2]. The properties of these metals can be advanced through the incorporation of additional metals to attain a spectrum of different and desirable features in terms of their strength, temperature resistance, ductility and hardness, suiting a wide array of applications. These technologically important elements including REEs (lanthanides, scandium), semiconducting materials (selenium, germanium) and precious metals (platinum, gold), serve superior roles due to their inherent properties such as conductivity, melting point, magnetic and optical properties. Besides, these technological metals are of great significance in progressing towards an energy efficient and green economy by subsidization of high-tech and green products $[3,4]$. To suffice the constant need for such materials, a set of 'critical elements' were identified, based on the supply disruption of which would cause serious economic harm from a global perspective. The European Commission had listed a set of 20 critical raw materials (CRM) in their report in 2014 (Figure 1.a), with further inclusion of 9 more in the year 2017 (Figure 1.b) [5,6]. The report provided a comprehensive overview of the demand to supply trend, highlighting the potential risks that need to be addressed in the forthcoming years. The major critical elements identified in this report are heavy rare earth elements (HREE) or light rare earth elements (LREE), along with scandium (Sc), bismuth, sulfur, phosphorus, indium, magnesium, niobium, antimony and platinum group metals (PGMs). As shown in Figure 1(a\&b), the risk involved with the continual supply of the Sc, LREEs and HREEs has increased at a significant rate over the past few years. In addition, due to the geographical constraints imposed in terms of resource availability (Figure 1.c) alongside the complications arising from the limitation of imports from China, European Union has prompted the search of alternate means for the efficient recovery of the REEs from secondary resources in a selfsustainable way [4,7]. The REEs of such commercial and environmental significance are the primary focus of this dissertation where alternate strategies to procure the same are analyzed exhaustively. 

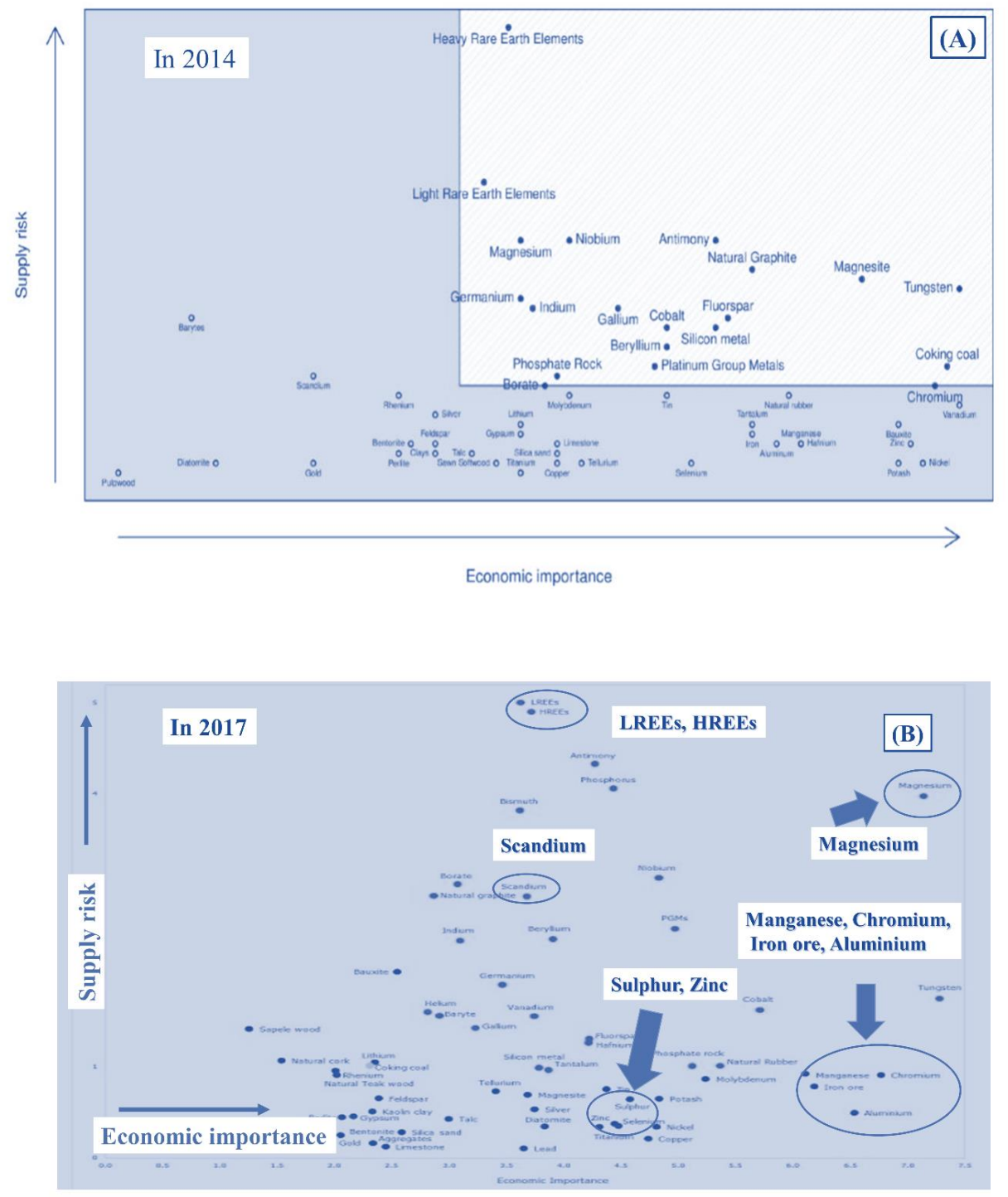


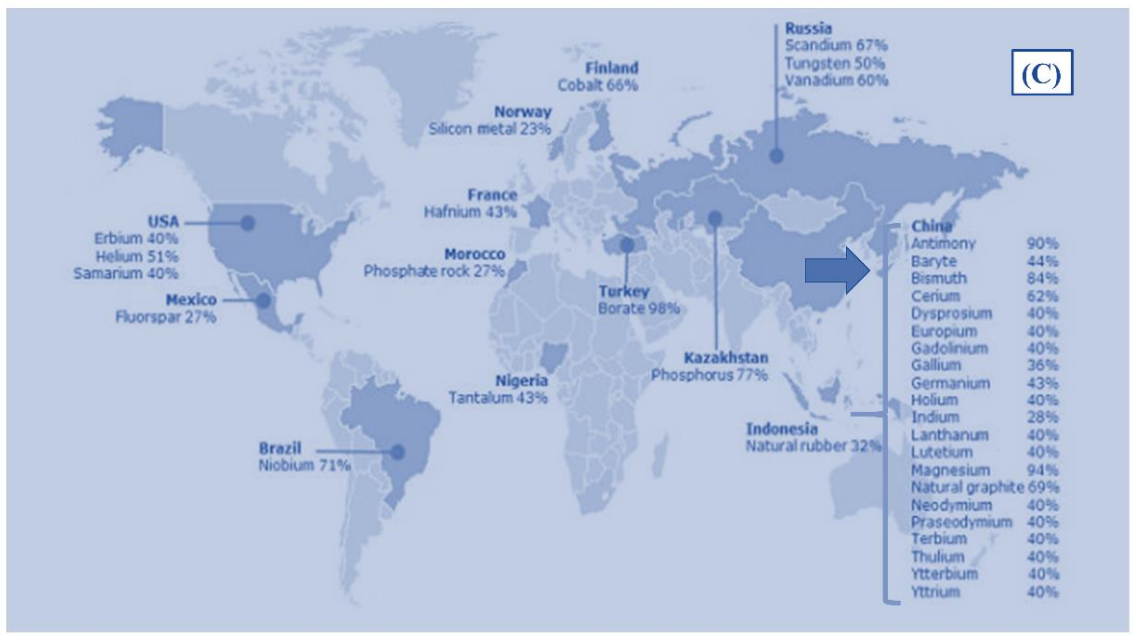

Figure 1: European Commission report on CRM (a) in 2014 (b) in 2017 and (c) overview of major suppliers of CRM to European Union highlighting REEs. All the subfigures are reproduced from the original EC reports on critical raw materials published in 2014 and 2017 [5,6].

\subsection{Rare earth elements}

The REEs or rare earth group contains 17 elements, encompassing scandium (Sc), yttrium (Y) and 15 lanthanides (atomic numbers 57-71). They belong to the group IIIB of the periodic table. They are generally classified into two categories namely LREE (from Lanthanum (La) through Gadolinium (Gd)) and HREE (from Terbium (Tb) through Lutetium (Lu)). Owing to similarities in properties, Sc and Y are often categorized as LREE and HREE, respectively[8]. Besides, the elements lying within the bounds of europium (Eu) to dysprosium (Dy) can be referred at times to middle REEs (MREEs). In general, REEs contain a common electron configuration (6 shells), large ionic radii and (III) oxidation states [9]. In contrast to the term "rare earths", REEs are actually abundant resources found in Earth's crust (lithophiles), with a concentration level of 9.2 ppm. These elements possess a tendency to occur naturally together owing to their analogous oxidation states, comparable ionic radii and unaltered valences with the increase in atomic number (mostly trivalent except $\mathrm{Ce}^{4+}$ and $\mathrm{Eu}^{2+}$ ). In general, LREEs are quite enriched in nature due to their larger ionic radii and hence occur in a concentrated state in comparison to HREEs. The knowledge associated with the rarity of these elements often emerges from those associated with their respective mineral ores, which serves as the primary source for REE extraction. Inherently, REEs do not possess the tendency to exist as individual elements. Instead, they occur collectively in a variety of rock-forming minerals as substitutes for oxides, carbonates and silicates. In other words, the physicochemical properties of the REEs are analogous to one another and hence, they can coexist together within a single mineral making their occurrence vast and their separation hugely challenging $[9,10]$. Despite the availability of a large number of minerals (approximately 200) 
containing REEs, their commercial viability can greatly reduce the available pool for efficient extraction. Although the REE concentrations vary over a wide range in these minerals, they contain significant amounts of either HREE or LREE. The available resources for REE primary extraction can be narrowed down to three major sources namely monazite, xenotime and bastnäsite, where these minerals are generally referred to by the predominant REE present in them (for example, bastnäsite-Ce). LREEs (Ce, La, Nd, etc.) and HREEs (Y, Dy, Er, Yb and Ho) can be primarily procured from monazite and bastnäsite, and xenotime, respectively [10,11].

Consideration of mining as the primary method of REE recovery is rather obsolete in the present scenario with some exceptions such as the ones in Mount weld (Western Australia) and Mountain Pass (California). In the present scenario, REEs are mostly obtained as by-products from various extraction and mining operations. Some of the notable examples include uranium mining (Canada), titanium extraction (Russia) and iron-ore extraction (China) [11]. Nevertheless, there are severe consequences to mining operations, in the form of soil erosion, depletion of biodiversity and eutrophication emanating from forest removal, and contamination of water and soil by toxic chemical by-products. Furthermore, the $\mathrm{CO}_{2}$ emission from the processing steps also adds to the demerits of such mining activities [12]. Hence, it is evident that the process of mining REEs is always associated with several environmental concerns, which often need to be monitored via the establishment of thorough regulations and the development of efficient schemes for their mitigation. Also, from a commercial perspective, due to the severe exploitation of geographical zones containing high quality/quantity ores that can be mined with minimal efforts, it is now essential to dwell further into remote areas with ore deposits of lower grade to fulfill the increasing demand. This, in turn, has established a market state associated with humongous price tags for resources with sub-par quality [13].

\subsection{Transition to a circular economy and more sustainable future: an exploration of REE secondary resources}

The wide range of REE based applications typically originates from a number of inherent desirable features like the electrical, nuclear, catalytic, optical and magnetic properties, in addition to their malleability, ductility and good chemical reactivity [9]. As we progress through the REE series from cerium to lutetium, it can be observed that their melting points increase (with some exceptions though), the knowledge of which can be crucial in the metallurgical extraction processes. Specifically, most of the REEs exhibit paramagnetic tendencies coupled with strong anisotropy. Here, because of their rare and unique physicochemical, magnetic and optical properties originating from their electron structures, REEs play a major role in the propulsion of technological developments in the field of wind energy, energy efficient light emitting diode (LED) sources and electrical automotive [13-15]. Some of the other notable advancements facilitated by the REEs are reflected in applications (Figure 2.b) such as digital camera lenses, automatic catalytic converters, high strength magnets, petroleum refinery, lasers, electronic devices, superconductors, 
catalysis, resonance imaging machines, high strength alloys, high voltage tension wires and lightweight aircraft components [13,14].

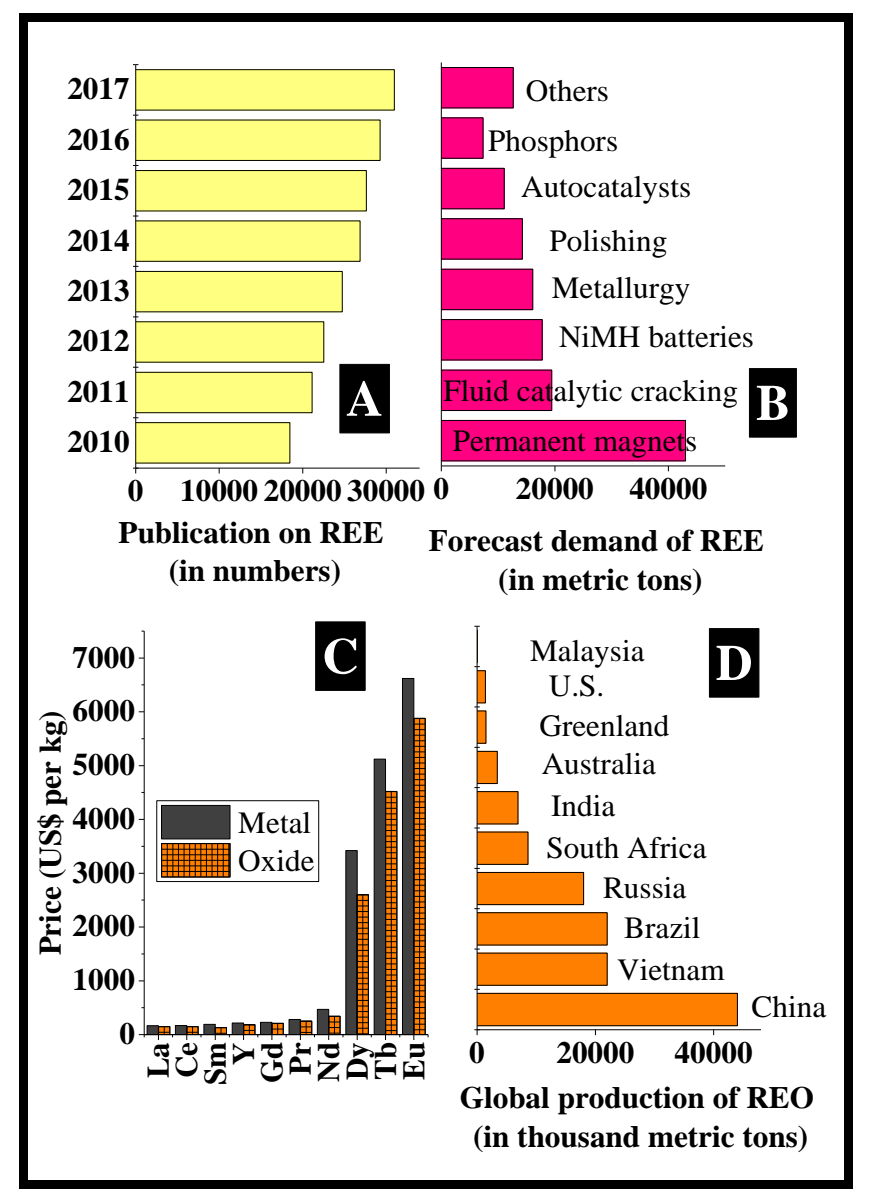

Figure 2: (a) Number of publications on REEs between 2010-2017 (b) the global forecast demand of REE in 2018, sorted by application (in metric tons) (c) REE prices REEs in 2011 (US\$ per kg) (d) Global production of rare earth oxides (REO), provided in thousand metric tons [16].

As mentioned earlier, due to the similarities in properties of Sc and $\mathrm{Y}$ in relation to lanthanides, they are generally categorized under the REE group. Typically, Sc is an abundant element found in the Earth's crust, of around $22 \mathrm{ppm}$. Despite this plethora, Sc does not occur as independent ores because of its inability to react with common ore-forming ions and is usually obtained in the form of by-products from REE/uranium ore processing [17]. Such scarcity is directly translated into a rise in its market value, and to put into perspective, the cost of scandium oxide is US\$ $5400 / \mathrm{kg}$ (99.99\% grade, 2014), in a scenario with a global Sc production of around 10 tons/year 
[18]. Such restricted availability has forced its utilization as a 'spice metal' in alloying elements, with a total concentration value of $<1 \%$. A relevant example would be the high strength scandiumaluminum (Sc-Al) alloys, being used predominantly in the manufacture of fighter jets, baseball bats and highly durable bicycle frames. These alloys are extremely competent in terms of lower weight, higher strength to durability ratio, and better thermal resistance. Another remarkable example would be the application of scandia-stabilized zirconia in solid oxide fuel cells as a highperformance electrolyte [19].

The aforementioned merits in combination with the steady increase in REE demand and consumption, alongside an erratic market value, has enforced renewed research interests (Fig 2 (ad)) from the industrial sector, in conjuncture with government incentives, for the efficient and economic separation/purification of REEs [13,20,21]. The potential and prominent role of REEs in the advancement of low carbon and sustainable energy based technologies would further heighten their economic significance in the near future as well [10]. In addition, the pre-existing geographical limitations in terms of resource acquisition from a global sense further complicate the current trend. These factors have major economic implications such as market fluctuations that need appropriate interventions to ensure stable progress of any nation. Furthermore, the challenges associated with REE extraction process from primary resources has been functioning as a driving force to recover them from secondary sources. Hence, there exists a continual hunt looking for viable and optimal processes, both economical as well as sustainable, for REE recovery based on the secondary sources such as processing residues, leachate solutions, mine tailings, industrial waste streams, consumer electronic wastes [13,20,22].

\subsubsection{Material substitution}

The identification of viable substitutes (such as alternate REEs and platinum group elements) for REEs is highly difficult and often non-economical. For instance, REEs are the most important components in LED lamps despite having a contribution of a mere $1 \%$ of the total weight of LED lamps. They are highly essential to emit light via electron excitations instead of the typical heat generation process. In some cases, the substitution process may demand larger technological changes in the end application, as observed in the case of REE-based gear-less wind turbine designs. Few other examples in this regard would include the usage of Europium in liquid crystal displays (LCDs) and REE magnets in hybrid electric vehicle motors [23]. Hence, the identification of suitable high-functioning alternatives for applications based on the unique optical, magnetic or chemical properties of REEs is a challenging task [24].

\subsubsection{Recycling strategies using End-of-Life (EoL) products- Urban mining}

The current price tag of REEs do not encourage the development of efficient recycling technologies, and hence, the majority of the proposed methods are still in stages of infancy, from a commercial perspective. This could be a manifestation of factors such as lack of incentives, 
requirements of high-energy input and complex technological issues. Statistics show that $<1 \%$ of the REE were recycled from scrap in the year of 2009, primarily from permanent magnets. Magnetic applications (Nd-Fe-B based), which are always on constant raises, can be considered as a potential source of scrap for REE recovery. However, it is highly difficult to recycle $\mathrm{Nd}$ from such scrap due to the formation of stable compounds during the recovery process. Several companies have dedicated resources towards the establishment of commercial REE recovery systems from EoL products. Some examples include the REE recovery by Hitachi from magnets utilized in motors and hard disks (experimental dry process), Mitsui Metal Mining Co. from NiMH batteries and General Electric from phosphor lights. Nevertheless, an important alternative to recycling is the reuse of components containing REEs [20,25]. The overall lifetime of these components could surpass their application and hence, can be recovered and reused further. However, to make this commercially viable, it is essential to overcome restraints such as the setting up of an economic EoL product collection routine and an intensive unit to perform the disassembly of primary product to recover the REE based components like electric motors and hard disks. In the end, for products with an elaborate lifespan, reuse of such REE components can be rewarding, as seen in certain cases like the wind turbines and electric automobiles. Europe, being an important player in the large-scale consumption of REEs and REE based products, the establishment of efficient recycling schemes could be an interesting source for REE procurement in the near future. It is also predicted that the energy and input requirements of the recycling phase can be considerably lower than the primary REE mining processes, and hence, can result in a decreased environmental impacts $[13,15,20]$.

\subsubsection{Recovery from waste streams- technospheric mining}

It is essential to realize the criticality of recycling EoL wastes as the only route for REE recovery, as there is a possibility of a reduction in their availability with an increase in product lifespan. Eventually, a point of imbalance might occur, as it would become difficult to meet the surge in market demand. Hence, it is of paramount importance to look into alternate sources for REE recovery such as wastewater streams, while simultaneously cutting short the cumulative wastage at every stage of the process cycle. By doing so, the expenditure on wastewater treatment or remediation can be reduced in a gradual manner [26]. A potential resource that could fit into the aforementioned profile for REE extraction from industrial waste streams is the acidic mine drainage (AMD), a metal-rich acidic solution from mines containing several valuable elements such as rare earths, uranium, aluminum, magnesium, sulfur, zinc and indium [27,28]. The utilization of AMD for REE recovery would also enable the circumvention of the leaching process for hydrometallurgical treatment. Hence, AMD was used in this work to validate the proposed REE recovery strategies and to determine the potentiality of the synthesized REE-selective materials for usage in real life applications.

It is projected that the aforementioned alternate and efficient routes can help to improve the economic and environmental standpoint of a nation, subsequently accelerating their progression 
towards self-sufficiency through a sustainable path. The typical linear economy-based approach can tend to cause serious damage in the end as it is primarily focused on the mere increase in production by the exploitation of available resources. In contrary, the circular economy sheds more emphasis on the reduction of current resource wastage while concurrently promoting recycling of material resources. Such a model would facilitate the closure of the material loop enabling a valueoriented approach, which fixates on the creation and preservation of the resources (Figure 3) [29]. Hence, the current demand for the continual supply of REEs from various domains has stimulated efforts to investigate efficient production strategies and alternate procurement resources while upholding the concepts of the circular economy. Deeper insights into this would eventually ascertain REE availability for the future while ensuring adept procurement techniques for the present, which is the primary motivation behind this Ph.D. work.

\section{Transition towards more sustainable future and circular economy}

LINEAR ECONOMY

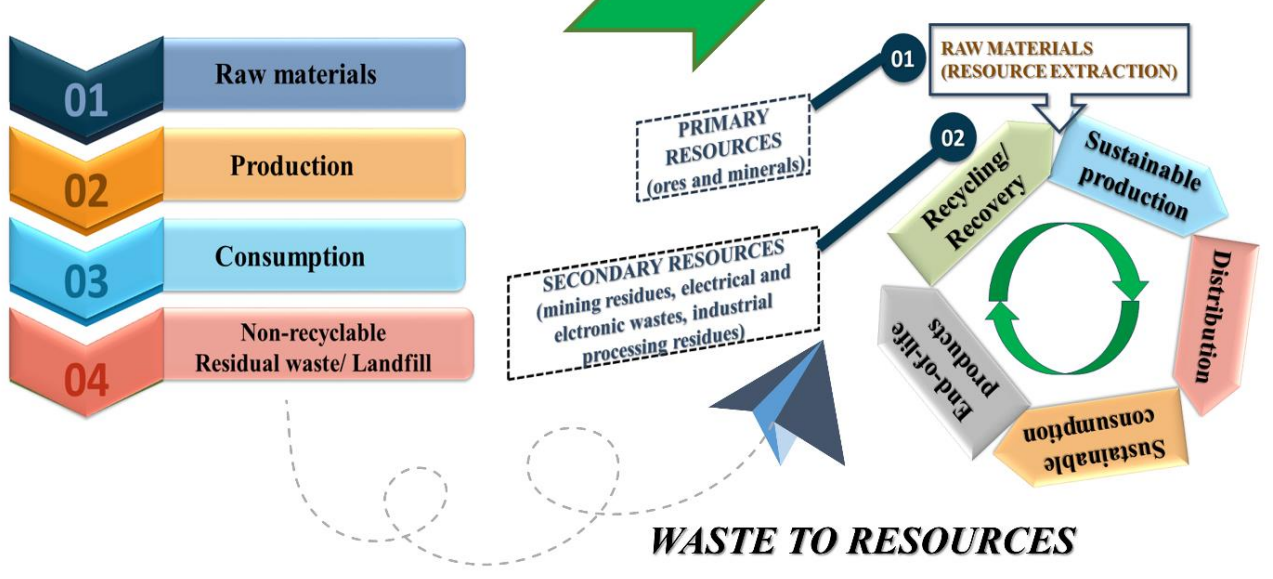

Figure 3: Illustration of the linear and circular economy model.

\subsection{REE recovery by adsorption}

Traditionally, there are numerous techniques available for metal extraction from aqueous solutions, such as adsorption, ion exchange, chemical precipitation, membrane filtration and solvent extraction. Among these methods, adsorption is one of the most versatile techniques utilized for a wide range of applications. Adsorption methods are typically straightforward and are of great commercial relevance due to the low installation and operation cost [8]. On the other hand, metal recovery from concentrated solutions in the industrial domain is conventionally facilitated 
through the solvent extraction process, however, the usage of the same for dilute aqueous systems would involve contamination risks [31]. Such issues can be efficiently negated through an adsorption/ion exchange process. 'Ion exchange' is a common term used to refer to such an adsorption process that occurs via the mutual exchange of ions between the adsorbent and the feed solution. Hence, these processes are ideal candidates to extract metal ions from dilute wastewater streams accompanied with numerous benefits, as shown in Figure 4 [32].

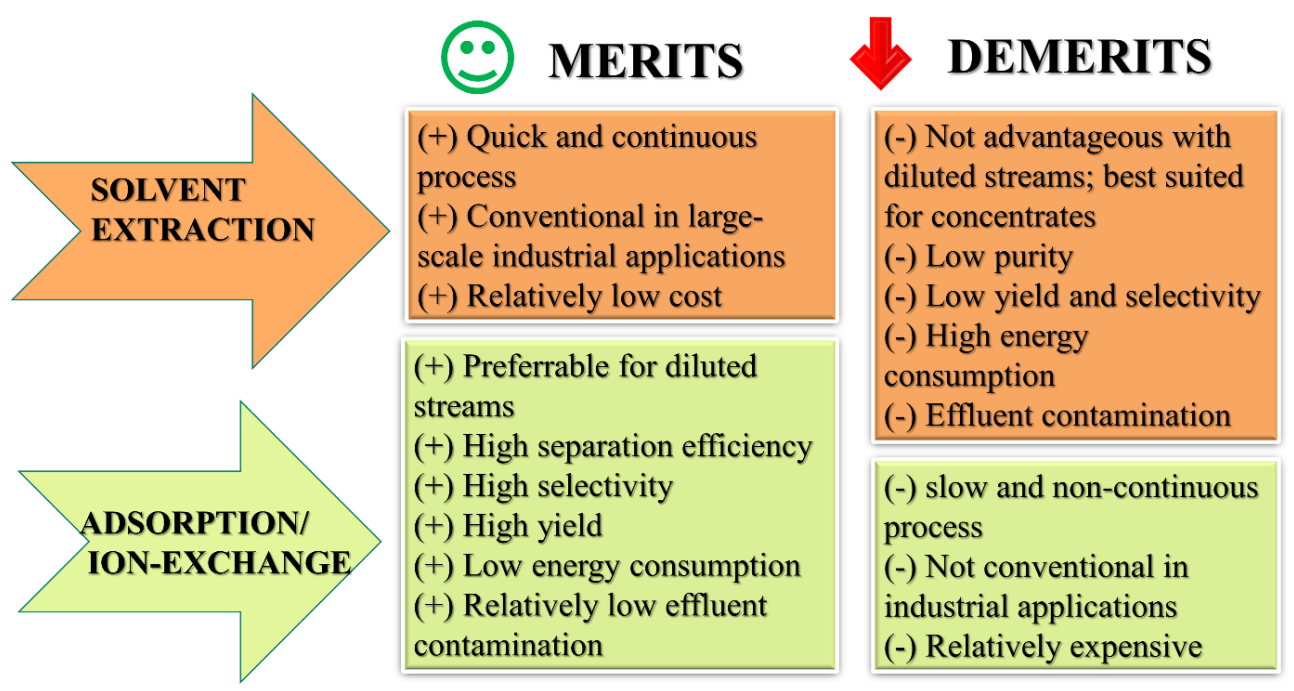

Figure 4: Some of the predominant merits and demerits associated with solvent extraction and ion exchange processes for metal recovery and separation.

\subsubsection{Supports}

Several works exist in the literature that studies the process of REE adsorption using a wide range of adsorbents. Many organic and inorganic support materials such as silica, cellulose, activated carbon (AC), carbon nanotubes (CNT), chitosan, Chelex-100, Cyanex, Amberlite and Dowex have been subjected to surface modification to study their effect on REE adsorption [22,33-41]. Among the various available support materials, inorganic silica was preferred in this research work, owing primarily to its mechanical and chemical stability. Silica, one of the most abundant elements on Earth's crust, has some desirable features that can be exploited efficiently in the field of adsorption, such as structural rigidity, controlled pore characteristics, high surface area and extremely low susceptibility to chemical and thermal degradation [42,43]. In addition to silica, other supports such as chitosan, marine algae, CNT and AC were also investigated in this study in terms of REE adsorption efficiency, with or without ligand modification. Due to the widespread availability of marine algae in comparison to other biomaterials, they were chosen for this work. Furthermore, 
they can also be of great commercial importance since they can be extracted with ease at low costs. In addition to marine algae, chitosan also holds an immense potential towards a greener ecosphere from an environmental perspective [44]. Chitosan is a natural biopolymer, the second-most abundant one, after cellulose. These polysaccharides contain both de-acetylated $\beta-(1,4)$-linked Dglucosamine and acetylated $\mathrm{N}$-acetyl-D-glucosamine units, acquired through the de-acetylation process (varying degree) of chitin. It is one of the most sought-after materials in the field of adsorption, possessing ideal features due to its non-toxic, economic and biodegradable in nature. Also, the surface functional groups of chitosan (amino and hydroxyl units) are inherently pHresponsive [45]. In contrast to silica, chitosan, as an independent matrix has some associated demerits such as poor mechanical strength and low chemical stability (dissolves at highly acidic $\mathrm{pH}$ conditions). Thus, it is desirable to use chitosan and silica in conjunction, to attain an efficient combination of appropriate properties [41]. Similarly, the unique properties and a wide range of variety in their structural properties make CNT a quintessential candidate for the production of advanced functional materials. Hence, they function as the building blocks of several modern-day applications [46,47], such as molecular wires, sensors, nano-scale semiconductor devices, batteries and high strength fibers [48-50]. In a similar sense, the utilization of economically viable granular $\mathrm{AC}$ has also been reported numerously in wastewater treatment applications [51-53]. The stateof-the-art separation and concentration technologies such as capacitive deionization (CDI) and electrodeionization (EDI) are prime examples where the usage of carbon-based electrodes are extensively promoted. Hence, in this thesis, REE adsorption was analyzed comprehensively for all the aforementioned supports, that are of great commercial relevance. Besides, due to the wellknown fact that the composite materials generally display enhanced adsorption properties (high surface to volume ratio) over traditional adsorbents, the same set of support materials were employed further to synthesize hybrid composites. Such hybrid materials with advanced material properties (heat resistance, stiffness, wear resistance, strength, thermal and electrical conductivity) have been reported numerous times in literature, where the influence of nanoscale reinforcements is pronounced to a greater extent on the overall material behavior [54,55]. Thus, the hybrid composite adsorbents were mainly targeted to study comparatively, in the direction of designing novel adsorbents with improved REE selectivity.

\subsubsection{Ligands}

In the past decades, researchers have focused on developing a cost-effective material displaying higher selectivity of target elements in the presence of common industrial pollutants. For instance, the complexing agents or ligands can be incorporated into the matrix to enhance selectivity towards a target metal of choice $[39,40]$. Based on the Pearson theory of hard and soft acids and bases (HSAB), metal ions show affinity towards complexing with ligands with one or more electronegative donor atoms based upon their hardness. Typically, from the perspective of coordination chemistry, ligands (containing donor atoms) are external molecules that form complexes with a central metal ion through the formation of a bond (ionic or covalent) via donation of electron pairs. The nature of the complexes thus formed are extensive and there are several 
pathways to describe the same. However, there exist possibilities where several donor atoms from the ligand (containing several lone electron pairs) involve in the bonding process with a single metal ion, resulting in the formation of chelate complexes [56,57]. Chelation, coordination and complexation are the common terms used to refer such processes and the number of non-adjacent bonds formed is represented through a value called denticity $(\kappa)$. Organic linkers establish the linkage between the ligand and the metal ion, for instance, ethylenediaminetetraacetic acid (EDTA), a hexadentate ligand, with a total of 6 binding linkages formed through the amines and carboxylate oxygen atoms $(\kappa=6)$. In common, the polydentate ligand is more stable than the monodentates due to the entropy effect resulting from the nested structure formed by the ligand group surrounding the central atom [58-61].

As elaborated earlier, modified silica has the potential to offer enhanced selectivity with improved chemical and mechanical properties. The immobilization of chelating agents on the silica surface has been successfully applied for the purpose of metal extraction from dilute aqueous solutions. The comprehensive review on numerous works based on functionalized silica with chelating agents, such as 1-nitroso-2-naphthol $\left(\mathrm{Co}^{2+}, \mathrm{Cu}^{2+}, \mathrm{Hg}^{2+}\right), 8$-hydroxyquinoline $\left(\mathrm{Cd}^{2+}, \mathrm{Pb}^{2+}, \mathrm{Zn}^{2+}\right.$, $\left.\mathrm{Cu}^{2+}, \mathrm{Fe}^{3+}, \mathrm{Mn}^{2+}, \mathrm{Ni}^{2+}, \mathrm{Co}^{2+}\right)$, 2-thioaniline $\left(\mathrm{Pd}^{2+}\right)$, 2-mercaptobenzothiazole $\left(\mathrm{Cu}^{2+}, \mathrm{Cd}^{2+}, \mathrm{Pb}^{2+}\right.$, $\left.\mathrm{Zn}^{2+}\right)$, crown ether carboxylic acid $\left(\mathrm{Na}^{+}, \mathrm{K}^{+}, \mathrm{Rb}^{+}, \mathrm{Cs}^{+}\right)$and aminomethylphosphonic acid (alkali earths and heavy metals), exist in literature [43]. In the recent years, ligands involving amino polycarboxylic acids such as EDTA and diethylenetriaminepentaacetic acid (DTPA) were studied extensively in relation to REE sorption and the results had demonstrated their competency towards REE selective separation $[58,59,62,63]$. Alternate chelating agents such as azo (PAN) and $\beta$ diketone reagents (acac) have also been successfully employed for REE extraction $[64,65]$. However, the application of these reagents within the domain of REE sorption is very confined and have not been studied comprehensively. Acac is a bidentate ligand (monoanionic) where the binding sites are typically the oxygen atoms, with a few exceptions involving the participation of the primary carbon atom. It is basically a $\beta$-diketone formed as a tautomeric keto and enol equilibrium mixture $[65,66]$. On the other hand, PAN is a ligand that forms tridentate complexes (sometimes $\mathrm{ML}_{2}$ type bidentate or ML type unidentate) with metal ions, via three linkages resulting from the pyridine nitrogen, the hydroxyl oxygen atom and one of the two azo group nitrogen atoms. It has to be noted that the abbreviation PAN here in this study refers to (1-2(pyridylazo)-2naphthol) in contrast to PAN (polyacrylonitrile) common in literature. Besides, PAN is essentially an organic chromophore. Hence, it has an inherent potential to form chelate complexes that can depict strong coloration on reacting with a large number of transition metals [66]. This property of PAN can be exploited to make them serve as optical sensors to locate specific target materials, by attaching them onto the polymer matrix. In addition, such a spectrophotometric behavior can be of specific interest in studies fixated on REE-PAN complexes. Besides, these organic ligands contain desirable functional groups ( $\mathrm{N}$ - and $\mathrm{O}$ - type) which could ensue high REE selectivity in the presence of right support under ideal synthesis conditions. The utilization of PAN as an analytical reagent to study colored metal chelates dates back to 1955 [67]. Over the years, several studies towards the utilization of PAN as a chelating agent to trap metal ions have been made, and 
Table 1 provides an extensive list of the same. It can be immediately realized that a significantly limited number of studies were performed with PAN, amongst which a majority of those works focused on mere loading of PAN onto the support via passing through the column or by the process of agitation. Besides, it is worth mentioning that the ideal sorption $\mathrm{pH}$ values reported in these studies (highlighted) were frequently $\geq 6$. Nevertheless, the phenomenon of REE precipitation or hydrolysis occurs at such higher $\mathrm{pH}$ values $(>6)$, and hence, it is reliable to design a process to recover REEs at acidic pHs. A potential way in this regard would be the enrichment of silica surface or other supports by the attachment of additional desirable functional groups.

The traditional chemical immobilization route involves the interaction between the hydroxyl groups of silica and commercial silanes, facilitating the incorporation of the preferable terminal functional group. $\mathrm{Si}-\mathrm{O}-\mathrm{Si}$ linkages thus formed because of silanization between bare silica and silane serve dual purposes: (1) provide chemical stability to silica and (2) function as a precursor for further immobilization step. A subsequent physical PAN loading via -NH group in (3aminopropyl) triethoxysilane (APTES) linkages can be achieved post surface functionalization of silica. In addition, it can be observed from Table 1 that metal sorption at $\mathrm{pH}<5$ was feasible through PAN immobilization onto the matrix, in conjunction with APTES (Please refer to green highlights). Based on these observations, in the current work, one of the hypotheses of this work is that the chemical immobilization of PAN onto the adsorbent surface should result in REE sorption at lower $\mathrm{pHs}(<5)$, with further contributions arising from other surface functional groups. However, rather than the toxic formaldehyde based azo-coupling or single-stage Mannich reactions, a simple and efficient solvent evaporation process was attempted in this study. Besides, these specific modifications (substrate-APTES-PAN) have not yet been employed for the purpose of REE sorption. It should also be mentioned that a prior study by Zhang et.al demonstrated the applicability of acac modified silica gel in gas chromatography analytical systems (using microcolumn) for the preconcentration of trace REEs (adsorption at $\mathrm{pH}$ 6-8). The derivatization reagent, acac, was chemically immobilized onto silica gel using APTES as a coupling agent [65]. Hence, this also served as a reference point to investigate and improve REE sorption properties via the comparison of PAN and acac modified supports (both physical and chemical modifications). These two coordination ligands (PAN and acac) were selected for this research work, to further explore their interactions with REEs and the support matrix. During the course of this exhaustive study, identification of an ideal functionalization scheme for the adsorbents was pursued, either via direct functionalization onto the support (physical adsorption) or via a coupling agent (chemical immobilization).

Studies reporting on APTES functionalization (with or without further ligand grafting) onto various supports can be found in the literature. Few notable ones are $\mathrm{AC}$ (for $\mathrm{Hg}^{2+}$ [68]), silica (with PVA for $\mathrm{Cd}^{2+}$ [69], $\mathrm{PVA} / \mathrm{Fe}_{3} \mathrm{O}_{4}$ for $\mathrm{Th}^{4+}$ [70], lysine modified for $\mathrm{Sc}^{3+}$ [71], with PVA for $\mathrm{Cu}^{2+}$ [72], with polyacrylonitrile for $\mathrm{Th}^{4+}, \mathrm{U}^{6+}, \mathrm{Cd}^{2+}$ and $\mathrm{Ni}^{2+}$ [73] ), chitosan (with Pebax/graphene oxide for $\mathrm{Cr}^{6+}$ [74]), $\mathrm{TiO}_{2}$ (with PVA for heavy metals [75]), kaolinite (for $\mathrm{Pb}^{2+}$ [76]) and cellulose (for $\mathrm{Ni}^{2+}, \mathrm{Cu}^{2+}$ and $\mathrm{Cd}^{2+}[77]$ ). In addition to APTES, this study also investigates the potential of 
an alternate amino silane (3-aminopropyl-trimethoxysilane, APTMS) and non-amino silanes (Trimethoxymethylsilane, MTM and Chlorotrimethylsilane TMCS), which have not been explored for REE sorption applications, to the best of the author's knowledge.

Table 1: PAN modifications found in the literature for metal sorption or extraction applications.

\begin{tabular}{|c|c|c|c|c|c|c|}
\hline No. & PAN-matrix & $\begin{array}{l}\text { Functionalization procedure } \\
\text { used }\end{array}$ & Application & $\begin{array}{l}\text { Adsorption/ } \\
\text { extraction } \\
\text { pH }\end{array}$ & Year & Ref. \\
\hline 1 & Paraffin & Just extractant with paraffin & REE extraction & - & 1993 & {$[78]$} \\
\hline 2 & Silica gel & $\begin{array}{l}\text { Physically loaded onto silica } \\
\text { gel using the solvent } \\
\text { evaporation process }\end{array}$ & $\begin{array}{l}\text { REE } \\
\text { preconcentration } \\
\text { for EDXRF } \\
\text { measurements }\end{array}$ & $7.5-9.5$ & 1998 & [64] \\
\hline 3 & $\begin{array}{l}\text { Amberlite } \\
\text { XAD-2 }\end{array}$ & $\begin{array}{l}\text { Physically loading (by passing } \\
\text { PAN-ethanol through column) }\end{array}$ & $\mathrm{Ni}^{2+}$ sorption & $6-11.5$ & 1999 & [79] \\
\hline 4 & $\begin{array}{l}\text { Polyurethane } \\
\text { powder }\end{array}$ & $\begin{array}{l}\text { Impregnation of polyurethane } \\
\text { powder with PAN was } \\
\text { performed by mixing the } \\
\text { powder and PAN solution for } \\
48 \text { h and followed by loading } \\
\text { (passing through the column) }\end{array}$ & $\begin{array}{l}\mathrm{Pb}^{2+}, \mathrm{Cu}^{2+}, \mathrm{Cd}^{2+} \\
\text { and } \mathrm{Zn}^{2+} \text { sorption }\end{array}$ & $8-12$ & 1999 & {$[80]$} \\
\hline 5 & Silica gel & $\begin{array}{l}\text { PAN, APTES, } \\
\text { paraformaldehyde \& silica gel } \\
\rightarrow \text { mixed at } 70^{\circ} \mathrm{C} \text { for } 5 \mathrm{~h} \rightarrow \\
\text { decanted, washed and dried at } \\
80^{\circ} \mathrm{C}\end{array}$ & $\mathrm{Cu}^{2+}$ sorption & - & 2000 & [81] \\
\hline 6 & $\begin{array}{l}\text { Amberlite } \\
\text { XAD-2 }\end{array}$ & $\begin{array}{l}\text { Coated with PAN (physical } \\
\text { loading) }\end{array}$ & $\begin{array}{l}\mathrm{Ga}^{3+} \text { and } \mathrm{In}^{3+} \\
\text { separation }\end{array}$ & $\begin{array}{l}4-7 \text { by } \\
\text { ammonia and } \\
6-7 \text { by } \\
\text { ammonium } \\
\text { chloride }\end{array}$ & 2001 & {$[82]$} \\
\hline 7 & alumina & $\begin{array}{l}\text { Alumina, sodium dodecyl } \\
\text { sulfate and PAN mixed } \\
\text { together ( } \mathrm{pH} 2-2.5) \text { with water } \\
\text { for } 15 \text { mins }\end{array}$ & $\begin{array}{l}\mathrm{Cd}^{2+} \text { sorption } \\
\text { (column studies) }\end{array}$ & 10.2 & 2001 & {$[83]$} \\
\hline 8 & Sol-gel silica & $\begin{array}{l}\text { TEOS and PAN/ethanol } \\
\text { reacted with ammonium } \\
\text { fluoride as catalyst (sol-gel } \\
\text { process) -> washed and dried }\end{array}$ & $\mathrm{Cd}^{2+}$ sorption & $>7$ & 2003 & [84] \\
\hline 9 & $\begin{array}{l}\text { Amberlite } \\
\text { XAD-2 }\end{array}$ & $\begin{array}{l}\text { Amberlite XAD- } 2 \text { mixed with } \\
\text { PAN/methanol for } 20 \text { min -> } \\
\text { filtered, washed and dried at } \\
110{ }^{\circ} \mathrm{C}\end{array}$ & $\begin{array}{l}\mathrm{Cu}^{2+}, \mathrm{Cd}^{2+} \text { and } \mathrm{Pb}^{2+} \\
\text { sorption }\end{array}$ & $\begin{array}{l}6-8 \text { for } \mathrm{Cu} \\
7.5-8.5 \text { for } \\
\mathrm{Cd} ; 8-11 \text { for } \\
\mathrm{Pb}\end{array}$ & 2003 & {$[85]$} \\
\hline 10 & C18-silica & $\begin{array}{l}\text { PAN loading (passing through } \\
\text { column) }\end{array}$ & $\begin{array}{l}\text { Preconcentration of } \\
\text { REEs }\end{array}$ & $7-8$ & 2005 & [86] \\
\hline 11 & $\begin{array}{l}\text { Amberlite IR- } \\
120\end{array}$ & Physical adsorption & $\begin{array}{l}\mathrm{Zn}^{2+} \text { and } \mathrm{Hg}^{2+} \\
\text { sorption (column } \\
\text { studies) }\end{array}$ & 6 & 2005 & [87] \\
\hline 12 & $\begin{array}{l}\text { Polyurethane } \\
\text { foam }\end{array}$ & $\begin{array}{l}\text { Physical loading using a } \\
\text { water-ethanol mixture }\end{array}$ & $\begin{array}{l}\mathrm{U}^{6+}, \mathrm{Tm}^{3+} \text { and } \mathrm{Eu}^{3+} \\
\text { sorption }\end{array}$ & - & $\begin{array}{l}2005- \\
06\end{array}$ & $\begin{array}{l}{[88-} \\
90]\end{array}$ \\
\hline 13 & naphthalene & $\begin{array}{l}\text { Coprecipitation of } \\
\text { PAN/acetone and }\end{array}$ & $\mathrm{Mn}^{2+}$ sorption & $8.8-9.7$ & 2007 & [91] \\
\hline
\end{tabular}




\begin{tabular}{|c|c|c|c|c|c|c|}
\hline & & $\begin{array}{l}\text { microcrystalline naphthalene } \\
\text { at } 50{ }^{\circ} \mathrm{C} \text { in water }->\text { filtered, } \\
\text { washed and dried }\end{array}$ & & & & \\
\hline 14 & $\begin{array}{l}\text { sol-gel } \\
\text { matrices }\end{array}$ & $\begin{array}{l}\text { PAN (in ethanol) + TEOS -> } \\
\text { gel formation }->\text { washed and } \\
\text { dried }\end{array}$ & $\mathrm{Tm}^{3+}$ sorption & 7 & 2007 & {$[92]$} \\
\hline 15 & $\begin{array}{l}\beta- \\
\text { cyclodextrin }\end{array}$ & $\begin{array}{l}\text { CD-epichlorohydrin as } \\
\text { extractant for } \mathrm{Cu}-\mathrm{PAN} \\
\text { complexes }\end{array}$ & $\mathrm{Cu}^{2+}$ uptake & 7 & 2008 & [93] \\
\hline 16 & silica & $\begin{array}{l}\text { Silanization using APTES as a } \\
\text { linker }>>\text { PAN grafting by } \\
\text { reacting with formaldehyde, } \\
\mathrm{HCl} \text { and silylated } \mathrm{SiO}_{2}\end{array}$ & $\mathrm{Hg}^{2+}$ sorption & $4-8$ & 2008 & [94] \\
\hline 17 & $\begin{array}{l}\text { Polymethacry } \\
\text { late matrix }\end{array}$ & $\begin{array}{l}\text { Physically adsorbed using } \\
\text { water-ethanol mixture }\end{array}$ & $\begin{array}{l}\text { Spectrophotometric } \\
\text { studies for } \mathrm{Cd}^{2+}, \\
\mathrm{Mn}^{2+}, \mathrm{Ni}^{2+}, \mathrm{Cu}^{2+} \\
\mathrm{Zn}^{2+} \text { and } \mathrm{Pb}^{2+}\end{array}$ & - & 2009 & [95] \\
\hline 18 & xenogels & $\begin{array}{l}\text { Xenogels doped with PAN } \\
\text { was obtained by mixing } \\
\text { methyltrioctylammonium } \\
\text { chloride modified } \\
\text { clinoptilolite and PAN/ethanol } \\
\text { (passed through the column) }\end{array}$ & $\begin{array}{l}\text { used as an indicator } \\
\text { for } \mathrm{Cd}^{2+}, \mathrm{Ni}^{2+}, \mathrm{Cu}^{2+} \\
\text { and } \mathrm{Pb}^{2+}\end{array}$ & 8.5 & 2009 & [96] \\
\hline 19 & $\begin{array}{l}\text { Benzophenon } \\
\text { e/naphthalene }\end{array}$ & - & $\begin{array}{l}\text { Preconcentration of } \\
\mathrm{U}^{6+} \text { ions }\end{array}$ & $10.5-11$ & 2009 & [97] \\
\hline 20 & $\mathrm{TiO}_{2}$ & $\begin{array}{l}\mathrm{TiO}_{2}+\mathrm{SDS}+\mathrm{PAN}->\text { stirred } \\
\text { for } 1 \mathrm{~h} \text { at } 60{ }^{\circ} \mathrm{C}->\text { filtered and } \\
\text { dried }\end{array}$ & $\begin{array}{l}\mathrm{Cd}^{2+} \text { and } \mathrm{Mn}^{2+} \\
\text { sorption }\end{array}$ & $\begin{array}{l}6 \text { for } \mathrm{Cd} ; 8.5 \\
\text { for } \mathrm{Mn}\end{array}$ & 2009 & [98] \\
\hline 21 & $\begin{array}{l}\text { Amberlite } \\
\text { XAD-4 }\end{array}$ & $\begin{array}{l}\text { Resin modification by } \\
\text { nitration and reduction to } \\
\text { amino compound, followed by } \\
\text { PAN loading in } \mathrm{NaOH} / \text { ethanol } \\
\text {-> washed and dried }\end{array}$ & $\begin{array}{l}\mathrm{Zn}^{2+}, \mathrm{Co}^{2+}, \mathrm{Ni}^{2+}, \\
\mathrm{Cu}^{2+} \text { and } \mathrm{Pb}^{2+} \\
\text { uptake (column } \\
\text { studies) }\end{array}$ & $8-9.2$ & 2010 & [99] \\
\hline 22 & nanoclay & $\begin{array}{l}\text { Commercial montmorillonite } \\
+ \text { PAN/ethanol -> stirred for } \\
8 \mathrm{~h} \text {, heated at } 50{ }^{\circ} \mathrm{C}->\text { washed } \\
\text { and dried at } 60^{\circ} \mathrm{C}\end{array}$ & $\begin{array}{l}\text { Thallium sorption } \\
\text { (column studies) }\end{array}$ & $3.5-6$ & 2011 & [100] \\
\hline 23 & $\begin{array}{l}\text { Poly(methacr } \\
\text { ylic acid) } \\
\text { polymer }\end{array}$ & $\begin{array}{l}\text { Precipitation polymerization } \\
\text { technique; } \mathrm{Pb}^{2+} \text { imprinted } \\
\text { poly(methacryclic acid) } \\
\text { loaded with PAN }\end{array}$ & $\begin{array}{l}\mathrm{Pb}^{2+} \\
\text { preconcentration }\end{array}$ & 5.7 & 2017 & [101] \\
\hline
\end{tabular}

Overall, it should be taken into account that the conventional practices entail certain improvements in the design and optimization of the synthesis process, thus foregoing the technical challenges accompanying the adsorption process. Hence, in this Ph.D. work, the demerits accompanying the REE adsorption process were targeted while developing an adept and efficient procedure to design high performing REE-selective hybrid materials for the selective separation and concentration of target REEs. 


\section{OBJECTIVES AND GOALS}

This research work lies within the domain of efficient use of secondary resources for REE recovery, through effective recycling of dilute aqueous waste streams reclaimed from industrial wastewater such as AMD, fitting the concept of the circular economy. The potentiality of valorization of these secondary resources has immense implications towards the establishment of sustainable and self-sufficient REE resources, in an eco-friendly manner. However, one of the huge challenges in accomplishing this goal is the presence of highly concentrated industrial impurities in the diluted REE waste streams. In other words, the higher concentration of other competing ions such as iron, aluminum, copper, magnesium, calcium, sodium, zinc and sulfur in the industrial wastewater would hinder REE selective adsorption. Therefore, along this line, a large body of research was dedicated towards expanding the present state-of-the-art in the field of selective REE recovery via adsorption process. This was targeted through the development of effective and selective adsorbents that could yield high performance in a REE multi-component system, akin to real-time wastewater conditions.

The novel part of this Ph.D. relies on the synthesis of REE-selective materials, in particular, the hybrid adsorbents, through a simple, straightforward, adept and easy to scale-up functionalization technique that has the potential to kindle further exploration. Through the course of this work, important aspects such as the impact of hybridization, ligand grafting, silanization, material's physical form and material's chemical composition on REE selective adsorption, were identified and studied extensively. Thus, the primary scope of this Ph.D. is directed towards the fabrication of highly efficient hybrid composites that demonstrate competent REE recovery displaying high selectivity. Further, different supports such as silica, chitosan, CNT, AC and marine algae were utilized for the fabrication of REE-selective materials and were analyzed exhaustively in terms of REE recovery. Inorganic silica offers rich surface chemistry for designing multifunctional materials with diverse tailor-made functionalities. Hence, it is preferred as the primary support for incorporating organosilanes with strong and stable $\mathrm{Si}-\mathrm{O}-\mathrm{Si}$ linkages that can be exploited extensively to attain hybrid polymer-silica adsorbents. Owing to the above-mentioned facts, the identification of the appropriate silane coupling agent for the organic-inorganic polymer network hybridization is significant and needs to be pursued. This further raises the question whether the ligand grafting through mere physical loading onto the adsorbent matrix or a strong chemical immobilization approach adopting silane as a linker, would serve better for REE affinity/selectivity. Further, the selection of an appropriate polymer for hybridization with silica, also plays a crucial role in the synthesis process as the REE adsorption capacities depend on the accessibility of functional groups on the hybrid polymer composite matrix. The study also aims to quantify and compare the REE adsorption behavior for pseudo-lanthanides (Sc and Y) and lanthanides. By doing so, selective separation of one of the most critical elements, Sc, can be achieved by exploiting the differences in properties such as ionic size, electronic configuration etc. 
Also, dedicated efforts were made to understand REE interaction with various support materials utilized in this work.

In summary, the main research hypothesis of this work is that high-performance hybrid composite materials can be developed for selective uptake and separation of REEs from dilute aqueous solutions. By following a combined approach involving the tuning of physical characteristics (size, shape, porosity) and the grafting of desired functionalities through hybridization and ligand attachment, the hybrid composites are expected to perform significantly better than the bare/pristine polymers. Further, it is targeted to recover REEs at acidic $\mathrm{pH}$ range through these physical/chemical modifications. The REE-selective materials should also be designed to enable smooth integration with other pertinent and important technologies such as CDI (usage as electrodes) and EDI (usage as resin bed) in the future.

The specific goals and aims of this research work are listed as follows:

To synthesize high-performance adsorbents that demonstrate enhanced REE affinity and selectivity. The synthesis is mainly targeted towards designing REE-selective hybrid composite materials by assimilating the desirable properties of different polymers to yield a superior hybrid material. This also necessitates the identification of adept and lucid functionalization or grafting technique to design high-performance REE-selective materials.

$>$ To characterize the synthesized adsorbents using state-of-the-art techniques before and after surface functionalization.

> To investigate the REE adsorption performance in terms of selectivity and adsorption efficiencies in both single/multi components systems, as a function of $\mathrm{pH}$, REE concentration, process temperature and contact time.

$>$ To determine the selectivity of the synthesized adsorbents towards REE in the presence of interferences. This is studied using a real AMD solution, spiked with REEs of low concentrations ( 1-5 ppm), comprising other common industrial impurities such as iron, aluminum, sulfur, calcium, magnesium and sodium. The adsorbents were also tested with sea water containing low concentrated REEs ( 1-2 ppm) along with other minerals.

$>$ To devise a strategy to selectively separate Sc from other REE mixtures using the synthesized materials.

$>$ To investigate the potential of using coordination ligand PAN in the enhancement of REE selectivity.

To assess the proficiency of using silanes as coupling agents for the hybridization of inorganic-organic polymers by studying their interactions with substrates. 


\section{MATERIALS AND METHODS}

\subsection{Materials}

Silica (CAS: 7631-86-9, Merck millipore): particle size -15-40 $\mu \mathrm{m}$, pore size - $60 \AA$, $\mathrm{pH}$ value $-6.5-7.5$ on $10 \%$ suspension and drying loss $-<7 \%$ at $150{ }^{\circ} \mathrm{C}$

$>$ Chitosan flakes (CAS: 9012-76-4, Aldrich): (a) high molecular weight chitosan 310-375 $\mathrm{kDa}$, deacetylated chitin of $75-85 \%$ degree and (b) highly viscous chitosan from crab shells $>400 \mathrm{mPa} . \mathrm{s}$

$>$ SWNT (CAS: 308068-56-6, Aldrich): carbon $\geq 85 \%,>70 \%$ carbon as SWNT, diameter $1.3-2.3 \mathrm{~nm}$

> MWNT (CAS: 308068-56-6, Aldrich): >90\% carbon basis, diameter 110-170 nm, length 5$9 \mu \mathrm{m}$

$>$ AC Norit ROW (CAS: 7440-44-0, Alfa Aesar): $0.8 \mathrm{~mm}$ pellets, steam activated

Nanosilica (CAS: 7631-86-9, Aldrich): nanopowder of particle size $12 \mathrm{~nm}$

$>$ Marine algae: procured from the Mediterranean Tunisian coasts.

\subsection{Chemicals}

REE salts: The solutions of target REEs (Sc, La, Y) used in monocomponent studies were prepared from their respective chloride or nitrate salts, procured from Sigma Aldrich or VWR. For the investigation of intraseries behavior throughout the course of this research work, LREE (La, Sc, Ce, Pr, Eu, Gd, Tb) and HREE (Y, Er, Dy, Ho, Lu, Yb, Tm) mixed solutions were prepared from the ICP stock solutions of $1000 \mathrm{ppm}$ (in $10 \% \mathrm{HNO}_{3}$, Alfa Aesar).

> AMD: It was extracted at a sampling depth of $720 \mathrm{~m}$, with an original $\mathrm{pH}$ of 2 . The concentration of REE was spiked between 1-5 ppm based on the test requirement. The composition of AMD along with the concentration of REEs and other competing ions is provided under associated figure captions or in text.

$>$ Seawater: certified reference material; minerals in seawater- whole volume (CAS: QC3136, Sigma Aldrich) containing Ca (10-100 ppm); Mg (2-40 ppm), K (4-40 ppm), alkalinity as $\mathrm{CaCO}_{3}$ of 10-10000 ppm, Ca hardness as $\mathrm{CaCO}_{3}$ of 8.7-275 ppm; conductivity of 0-100 mho/cm; pH 5-10 units and total solids of 0-100000 ppm.

$>$ Silanes and ligands: The chemical reagents used during the synthesis step are summarized in Table 2, alongside their chemical structures, chemical formulae and acronyms. Four different types of silanes, APTES (CAS: 919-30-2, 99\%), APTMS (CAS: 13822-56-5, 97\%), MTM (CAS: 1185-55-3, 98\%) and TMCS (CAS: 75-77-4, 99\%), were used as coupling agents for the substrate functionalization, procured from Sigma Aldrich. Two coordination ligands, PAN (CAS: 85-85-8, indicator grade) and acac (CAS: 123-54-6) were utilized to enhance the REE selectivity of the adsorbents. 
Other chemicals: Toluene, acetone, ethanol used during the synthesis were of analytical grade $(>99 \%)$ and were provided by Sigma Aldrich.

Table 2: Silanes and ligands used for the functionalization of the materials.

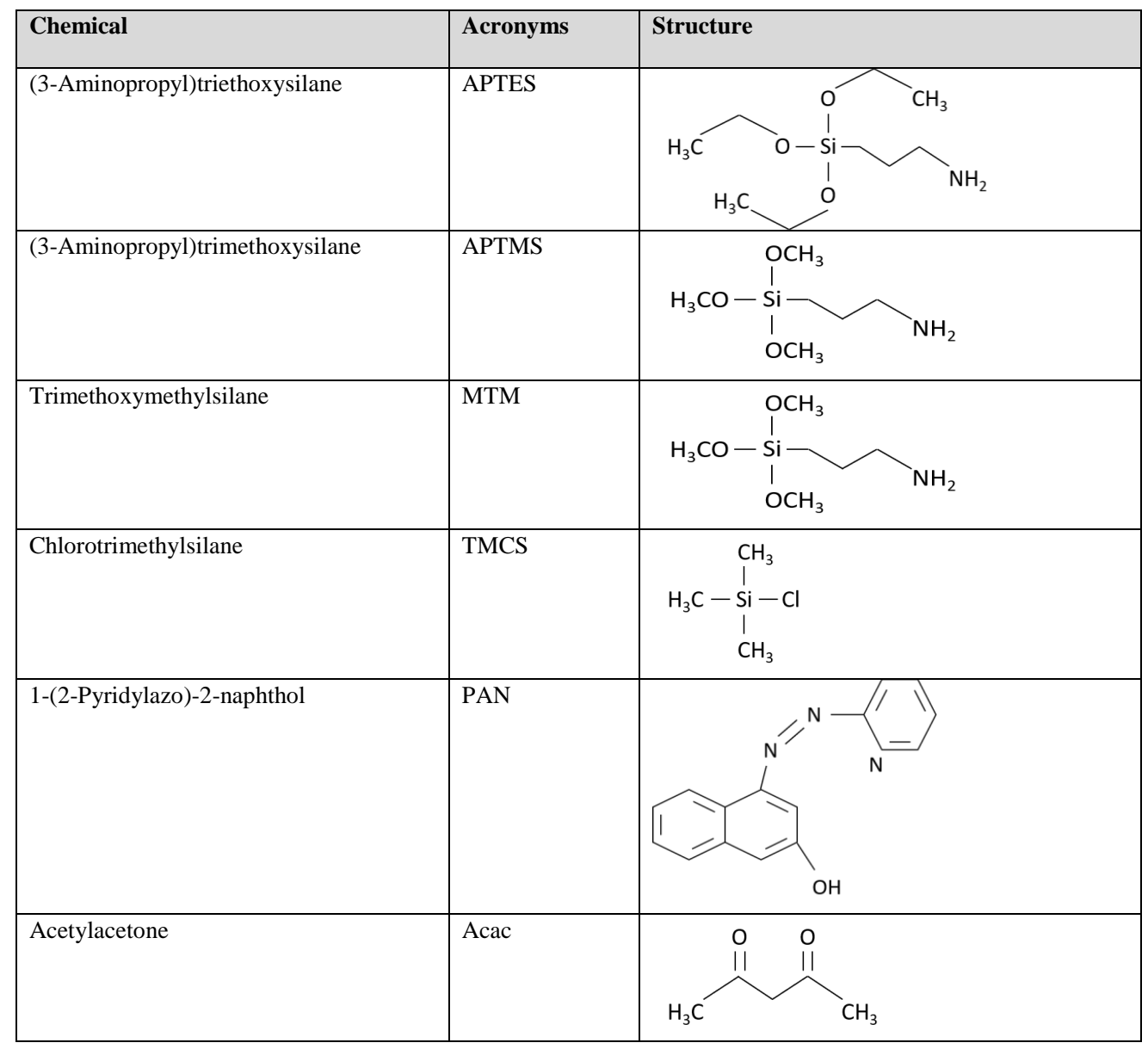

\subsection{Instrumentation}

Fourier transform infrared spectroscopy (FTIR-ATR mode, Vertex 70 by B Brucker Optics) was used to identify the functional groups present in the adsorbents and the associated changes in their vibrational frequencies (from 400 to $4000 \mathrm{~cm}^{-1}$ wavelength) after functionalization step as well as after REE adsorption process. The measurements were recorded at $4 \mathrm{~cm}^{-1}$ resolution and 100 scans rate per sample. Besides for the same purpose, X-ray diffraction spectroscopy (XRD) analysis was also performed using PANalytical instrument with the empyrean program applying $\mathrm{CoK} \alpha$ 
irradiation at $\lambda=1.78 \AA, 40 \mathrm{mV}$ and $30 \mathrm{~mA}$. The surface morphology of the materials was inspected by exploiting scanning electron microscopy (SEM, SU3500 fitted with ThermoScientific UltraDry SDD EDS for energy dispersive X-ray analysis). Micromeritic Tristar II plus with VacPrep 061 was employed to acquire specific surface area via multipoint $\mathrm{N}_{2}$ adsorption/desorption BrunauerEmmett-Teller (BET) isotherms in the relative pressure range $\mathrm{P} / \mathrm{P}_{\mathrm{o}}$ of $0.1-1$. Barrett-JoynerHalenda $(\mathrm{BJH})$ and $\mathrm{t}$-plot method yielded insightful information regarding the surface characteristics of the adsorbents such as pore volume, pore diameter and pore size distribution. The organic CHNS elemental analyzer (Flash 2000 Thermo scientific) provided the organic elemental analysis of the materials i.e. \% weight of $\mathrm{C}, \mathrm{N}, \mathrm{S}$ and $\mathrm{H}$. In order to determine the surface charge of the adsorbents, zeta potential analyzer (ZEN3500 Malvern) was utilized to analyze surface zeta potential of the materials as a function of electrolyte $\mathrm{pH}$. The solute concentration in the aqueous samples was measured by means of induced couple plasma optical emission spectroscopy (ICP-OES, Agilent 5110) exhibiting the limit of detection (LOD) and limit of quantification (LOQ) of 0.0001 and $0.0001-0.0005$ ppm for all REEs, respectively.

\subsection{Batch adsorption studies}

$10 \mathrm{mg}$ of adsorbent was mixed constantly with $10 \mathrm{~mL}$ of adsorbate solution (dosage: $1 \mathrm{~g} / \mathrm{L}$ ) at 220 $\mathrm{rpm}$ and at $20-23{ }^{\circ} \mathrm{C}$ using a temperature controlled orbital shaker for 24 hours in a batch mode if otherwise mentioned. For the single component $\mathrm{pH}$ tests $\left(\mathrm{t}-24 \mathrm{~h} ; \mathrm{T}-20-23{ }^{\circ} \mathrm{C} ; \mathrm{pH} 1-5 ; \mathrm{C}_{\mathrm{i}}-20-\right.$ $25 \mathrm{ppm}$ ), the initial $\mathrm{pH}$ of the feed solution was adjusted to 1-5 using $0.1 \mathrm{~N} \mathrm{HCl} / \mathrm{NaOH}$. Higher $\mathrm{pH}$ above 6 was not considered in this work since REE hydrolysis was found to predominantly occur from $\mathrm{pH} 6$ or 7 . Besides, the initial feed concentration $\left(\mathrm{C}_{\mathrm{i}}\right)$ after $\mathrm{pH}$ modification was verified by ICP-OES. Similar procedures were followed for adsorption isotherm $\left(\mathrm{t}-24 \mathrm{~h} ; \mathrm{T}-20-23{ }^{\circ} \mathrm{C}\right.$; $\left.\mathrm{pH} 4-5 ; \mathrm{C}_{\mathrm{i}}-1-200 \mathrm{ppm}\right)$, kinetic $\left(\mathrm{t}-1-24 \mathrm{~h} ; \mathrm{T}-20-23{ }^{\circ} \mathrm{C} ; \mathrm{pH} 5 ; \mathrm{C}_{\mathrm{i}}-20-25 \mathrm{ppm}\right)$ and thermodynamic tests $\left(\mathrm{t}-1 \mathrm{~h} ; \mathrm{T}-20-45^{\circ} \mathrm{C} ; \mathrm{pH} 3-5 ; \mathrm{C}_{\mathrm{i}}-25 \mathrm{ppm}\right)$. Primarily, these studies were performed in a single component (La, Sc, Y) system followed by investigations using multicomponent (16 REEs) systems at the latter stage. After 24 hours of mixing, the solutions were filtered using PTFE syringe filter $(0.2 \mu \mathrm{m})$ and the final adsorbate concentration $\left(\mathrm{C}_{\mathrm{e}}\right)$ in the solution was determined by ICP analysis. Since the direct assessment of retained solute metal ions on the adsorbent is difficult, in practice, a comparison between the initial and final metal ion concentrations are performed. The adsorption capacity ( $\mathrm{q}_{\mathrm{e}}$, in $\mathrm{mg} / \mathrm{g}$ ), removal efficiencies $(\%)$, the thermodynamic equilibrium constant $\mathrm{K}_{\mathrm{d}}(\mathrm{mL} / \mathrm{g})$ and selectivity coefficient $\mathrm{S}_{\mathrm{A} / \mathrm{B}}$ were calculated using the formulae below:

$$
\begin{gathered}
q_{e}(m g / g)=\frac{\left(C_{i}-C_{e}\right)}{M} V \\
\% \text { removal }=\frac{\left(C_{i}-C_{e}\right)}{C_{i}} * 100
\end{gathered}
$$




$$
\begin{gathered}
K_{d}=\frac{q_{e}}{C_{e}} \\
S_{A / B}=\frac{K_{A}}{K_{B}}
\end{gathered}
$$

where $C_{i}$ and $C_{e}$ denote the initial and equilibrium solution concentrations $(\mathrm{mg} / \mathrm{L})$, respectively, while $\mathrm{V}$ is the metal ion solution volume $(\mathrm{L})$ and $\mathrm{M}$ is the adsorbent mass $(\mathrm{g})$.

Fitting an analytical model to the experimental data can help to understand the underlying adsorption mechanism, and hence, the two extensively used kinetic models, pseudo-first-order (eqn.5) and pseudo-second-order (eqn. 6) were utilized [60].

$$
\begin{aligned}
\ln \left(q_{e}-q_{t}\right) & =\ln q_{e}-k_{1} t \\
\frac{t}{q_{t}} & =\frac{1}{k_{2} q_{e}^{2}}+\frac{1}{q_{e}} t
\end{aligned}
$$

Here $\mathrm{k}_{1}\left(\mathrm{~min}^{-1}\right), \mathrm{k}_{2}\left(\mathrm{~g} \mathrm{mg}^{-1} \mathrm{~min}^{-1}\right) \mathrm{q}_{\mathrm{t}}$ and $\mathrm{q}_{\mathrm{e}}(\mathrm{mg} / \mathrm{g})$ represent the pseudo-first-order rate constant, pseudo-second-order rate constant, adsorption capacity at a time ' $t$ ' and adsorption capacity at equilibrium, respectively. The rate of the adsorption can be determined by these kinetic expressions.

Further, the equilibrium concentrations (solid-liquid phase interactions) of the metal ions were assessed by fitting Langmuir (eqn. $7 \& 9$ ) and Freundlich isotherm (eqn. $8 \& 10$ ) models, the equations of which are denoted below. The former is based on the hypothesis of monolayer adsorption with finite adsorption sites while the latter relies on the conjecture of non-ideal multilayer adsorption for an energetic heterogenous surface [60,62,102].

$$
\begin{aligned}
& q_{e}=\frac{Q_{o} K_{L} C_{e}}{1+K_{L} C_{e}} \\
& q_{e}=K_{f} C_{e}^{1 / n}
\end{aligned}
$$

Linearizing these equations 5 and 6 , we get

$$
\begin{gathered}
\frac{1}{q_{e}}=\frac{1}{Q_{o}}+\frac{1}{Q_{o} K_{L} C_{e}} \\
\ln q_{e}=\ln K_{f}+\frac{1}{n} \ln C_{e}
\end{gathered}
$$

with $\mathrm{C}_{\mathrm{e}}, \mathrm{q}_{\mathrm{e}}$ and $\mathrm{Q}_{\mathrm{o}}$ being the adsorbate concentration at equilibrium $(\mathrm{mg} / \mathrm{L})$, adsorption capacity at equilibrium $(\mathrm{mg} / \mathrm{g})$, maximum monolayer coverage capacity $(\mathrm{mg} / \mathrm{g})$, respectively. $\mathrm{K}_{\mathrm{L}}$ and $\mathrm{K}_{\mathrm{f}}$ are the Langmuir isotherm constant $(\mathrm{L} / \mathrm{mg})$ and Freundlich isotherm constant $(\mathrm{mg} / \mathrm{g})$, while $\mathrm{n}$ is the surface heterogeneity. 


\section{FUNCTIONALIZATION OF SILICA FOR REE SORPTION: INVESTIGATION OF SUITABLE SILANE AND PREPARATION METHOD}

The bare silica gel was investigated initially to determine if they could adsorb REEs in the absence of surface functionalization. In its pristine state, they possess the ability to adsorb Sc (the only $\mathrm{REE}$ ) to a moderate extent (\%Sc removal $\sim 40$; feed $\mathrm{pH}$ - 5; Ci 20 ppm; t $24 \mathrm{~h}$; $\mathrm{T} 23{ }^{\circ} \mathrm{C}$ ). Therefore, in order to functionalize silica to enable REE adsorption, two ligand functionalization schemes were adopted [43], as represented in the equations below.

\subsection{Synthetic procedures}

\subsubsection{Method I: Chemical immobilization of ligand on the silica surface}

This approach involves the silanization reaction in which bare silica is allowed to react with an appropriate silane at the first step, followed by ligand grafting onto the silanized silica gel in step 2. The order of the steps adopted in this procedure can also be swapped with the ligand made to react with silane initially, which are then immobilized onto the silica gel. This can be summarized in eqn. 11 and 12 as:

$$
\begin{aligned}
& S i-O H+X S i-R \stackrel{\text { silanization }}{\longrightarrow} S i-O-S i-R+H X \\
& S i-O-S i-R+L \stackrel{\text { ligand immobilization }}{\longrightarrow} S i-O-S i-R-L
\end{aligned}
$$

where $\mathrm{R}$ - functional group on silane; $\mathrm{X}$ - hydrolyzable units on silane; $\mathrm{L}$ - ligand. For the current scheme, four types of silanes capable of modifying hydroxyl groups on bare silica were investigated. The primary idea for the utilization of silane is its ability to form $\mathrm{Si}-\mathrm{O}-\mathrm{Si}$ linkages during silanization reaction with silica, which in turn also offers thermal and hydrolytic stability to the silica matrix [43]. In this work, the same standard silanization procedure was followed with slight modifications for all the materials under evaluation [43]. To summarize in brief, 1 part of bare silica gel was reacted with 10 parts silane solution (10\% silane in toluene solution) by stirring at $150 \mathrm{rpm}$ for 24 hours to yield a silanized gel. The intermediate product was filtered, washed thoroughly with ethanol to remove excessive silane groups and toluene. Herein, we utilized four different silanes - two amino-propyl alkoxy silanes (APTES and APTMS), a non-amino alkoxysilane (MTM) and a non-amino chlorosilane (TMCS), the chemical structures of which are shown in Table 2. Following the silanization step, 1 part of silanized gel (intermediate) was then reacted with the ligand-solvent solution (PAN $-0.2 \% \mathrm{w} / \mathrm{v}$ in acetone or acac $-0.3 \mathrm{v} / \mathrm{v}$ in methanol) 
by mixing in room temperature via solvent evaporation process. This step 2 is typically the physical loading process, described below.

\subsubsection{Method II: Physical loading or adsorption of ligand on the silica surface}

In this technique, the solvent evaporation process was utilized to graft the ligand directly and physically onto the silica gel. Here, 1 part of bare silica was added to 20 parts of ligand solution (PAN - 0.2\% w/v in acetone or acac - $0.3 \mathrm{v} / \mathrm{v}$ in methanol). It was then mixed at $220 \mathrm{rpm}$ until the complete evaporation of the solvent solution, leaving behind the ligand units grafted onto silica, as shown in eqn 13. Here, a mere physical loading of the ligand was attained, in the absence of the coupling agent i.e. silane, which is an essential component in the chemical immobilization procedure of ligand.

$$
S i-O H+L \stackrel{\text { ligand loading/adsorption }}{\longrightarrow} S i-O-L
$$

\subsection{Main research outcomes: single-component and multi-component batch adsorption studies}

In addition to major factors such as solution $\mathrm{pH}$, initial REE concentration, contact time, dosage and process temperature, there are additional decisive factors that can largely influence the REE adsorption efficiencies, such as particle size [105-108], grafting techniques [109], drying procedures [110] and pore size distribution [111,112]. Hence, as a preliminary step, all these aforementioned parameters were assessed for the four silanes used in our study, in terms of REE affinity, selectivity and adsorption capacities. The detailed findings from these experiments can be found in Articles 1 and 2.

Some of the significant results recorded for the synthesized silica materials are summarized below:

Suitable silane: Amino silane APTES/ APTMS (Please refer article 2 for more details)

APTES and APTMS functionalized silica gels demonstrated superiority over MTM and TMCS silica gels (Figure 5). Amino-functionalized silica gels i.e. APTES and APTMS functionalized silica, showed maximum REE adsorption (> 90\%) from a pH value of $\mathbf{4}$, for an initial REE concentration of 20-30 ppm at room temperature, over a period of 4-5 hours. On the other hand, MTM and TMCS silanized gels displayed negligible REE adsorption $(<40 \%)$ in 24 hours until $\mathrm{pH} 5$ under the same process conditions. At higher $\mathrm{pH}(>7)$, REE adsorption efficiencies of the adsorbents increased. However, the results shown by MTM/TMCS modified materials can be ruled out in view of the existence of precipitation or hydrolysis of REEs from $\mathrm{pH} \geq 7$. Another important 
aspect to consider here is the interphase region affecting the wettability of the surface as the hydrophilicity of the substrates increases with the surface tension, typically observed with enhanced adsorptive behavior. Hence, the inferior outcomes from the MTM (also TMCS) gels can be justified via the relatively poor surface tension of MTM $(22.5 \mathrm{mN} / \mathrm{m})$ in relation to that of APTES $(35 \mathrm{mN} / \mathrm{m})$ and fused silica $(78 \mathrm{mN} / \mathrm{m})[113,114]$. Hence, these superior amino silanes were opted for the further ligand immobilization procedure with silica gels. In addition, based on adsorption capacities, APTES silane was chosen as the ideal adsorbent among the four silanes under evaluation and it was used further as a coupling agent for all the hybridization procedures with chitosan, AC and CNT in Chapters 5 and 6.

\section{Suitable preparation method: Method I Chemical immobilization (Please refer article 1 for more details)}

Both APTES and APTMS silanes were subjected to ligand immobilization as they returned comparatively similar outcomes when APTES and APTMS functionalized silica gels were investigated for REE adsorption. Silica gels with physically loaded PAN and acac (Method II) showed inadequate or very poor REE adsorption over the tested $\mathrm{pH}$ range, except for Sc. Substantial REE adsorption was observed for PAN/acac physically adsorbed onto silica gels only from $\mathrm{pH}>6$, as reported for similar PAN physically modified supports in Table 1. On the other hand, based on our hypothesis, PAN/acac chemically immobilized onto silica gels via silane delivered excellent adsorption ( $\sim 99 \%$ ) starting from a pH value of 4 with an equilibrium of 4 hours under the same process conditions, similarly to APTES/APTMS silanized gels without any ligand attachment.

\section{Is there a need for ligand grafting? Yes}

Despite the fact that the REE adsorption efficiencies recorded by silanized gels without any ligand grafting (APTES/APTMS functionalized silica gels) were as pronounced as PAN/acac immobilized onto silanized gels, the latter ones i.e. ligand grafted gels performed better in multicomponent systems in the presence of competition from co-REE ions (Figure 5). Further, comprehensive investigations on adsorbents' selectivity towards REE in AMD i.e. in the presence of other competing ions, water hardness, salinity or other industrial impurities could shed more light on this comparison, which will be addressed in the next Chapter 5. Nevertheless, it can be stated at this point that the silanized gels with chemically immobilized ligands were comparatively better than silanized gels without any ligand grafting. 


\section{Suitable ligand: PAN}

Comparison between PAN and acac immobilized silanized gels revealed that PAN modified adsorbents performed exceptionally well in terms of REE adsorption efficiencies considering adsorption $\mathrm{pH}$, adsorption capacity and equilibrium time. With PAN immobilized gels ( $\mathrm{pH} 4-5)$, an equilibrium for REE uptake can be reached within a period of 4-5 hours while it takes around 24 hours for acac immobilized gels even at optimal pH of 5-6 (See Article 1). This might be due to the number of protonated units (positive charges) available on its surface for REE uptake, as evidenced in zeta potential measurements. The isoelectric point (IEP) i.e. the point at which the substrates carry a neutral charge, for PAN ( 20 mV at $\mathrm{pH} 4-5)$ and acac $(\sim 0 \mathrm{mV}$ at $\mathrm{pH} 4-5)$ immobilized silica gels was found to be 8 and 4.5, respectively (Article 1).

\section{Effect of calcination or drying procedure: adverse at higher temperatures}

In Article 2, the silanized gels were also subjected to calcination at 400,600 and $800{ }^{\circ} \mathrm{C}$ at 6,4 and 2 hours, respectively, following the silanization reaction to study the impact of calcination on the synthesized materials. Calcination of the silanized gels resulted in a drastic reduction of REE removal efficiencies due to the loss of silane units responsible for REE binding. The silanized gels were subjected to FTIR and organic elemental analysis post-calcination, the results of which were in agreement with the suggestion of loss of carbon and nitrogen units after calcination. The decomposition of APTES units was evident on comparing the organic wt $\%$ of uncalcined gels $(2.58 \%$ of $\mathrm{N}, 10.30 \%$ of $\mathrm{C}$, and $2.48 \%$ of $\mathrm{H})$ and calcined gels at $200{ }^{\circ} \mathrm{C}(0.51 \%$ of $\mathrm{N}, 2.99 \%$ of $\mathrm{C}$ and $0.85 \%$ of $\mathrm{H})$. Further decomposition of aminopropyl groups was observed when calcined at $400{ }^{\circ} \mathrm{C}(0.0 \%$ of $\mathrm{N}, 0.23 \%$ of $\mathrm{C}$ and $0.32 \%$ of $\mathrm{H})$ and $600{ }^{\circ} \mathrm{C}(0.0 \%$ of $\mathrm{N}, 0.22 \%$ of $\mathrm{C}$ and $0.14 \%$ of $\mathrm{H})$. This behavior of APTES decomposition at higher temperatures was probed using thermal analysis in other works with APTES grafted onto mesoporous silica [115], SBA-15 [116], montmorillonite [117] and mesoporous alumina substrates [118]. This also further implies the major influence of amino functional groups on REE adsorption. Hence, drying these silica gels was found to be safe until a temperature of $100{ }^{\circ} \mathrm{C}$ and the same has also been adopted in the subsequent synthetic procedures.

These findings were used to design and optimize the synthetic procedures for all the materials reported ahead in this thesis. 


\section{Chemical immobilized ligand $\langle$ Silica $\Rightarrow$ Physically adsorbed ligand}

Step 1: Silanization (Silanes as linker)

\begin{tabular}{l} 
Amino silanes 1 Non-amino silanes \\
\hline APTES \\
\cline { 1 - 1 }
\end{tabular}

$>$ Affinity towards all REEs $>$ Affinity towards only Sc
Step 1: Ligand grafting via solvent evaporation

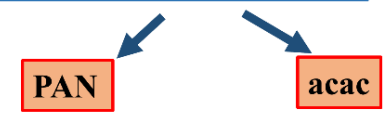

$>$ Higher affinity towards Sc (only)

$>$ Optimum $\mathrm{pH}: 6$ for $\mathrm{Sc}$

$>$ Equilibrium time: $<\mathbf{l h}$ for $\mathrm{Se}$

\section{Step 2: Ligand immobilization via solvent evaporation}

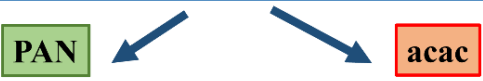

$>$ Higher affinity towards all REEs

$>$ Optimum pH : 4

$>$ Equilibrium time: $4 \mathrm{~h}$ except for Sc $(24 \mathrm{~h})$
$>$ Moderate affinity towards all REEs

$>$ Optimum pH : 5-6

Equilibrium time: $24 \mathrm{~h}$ for all REEs
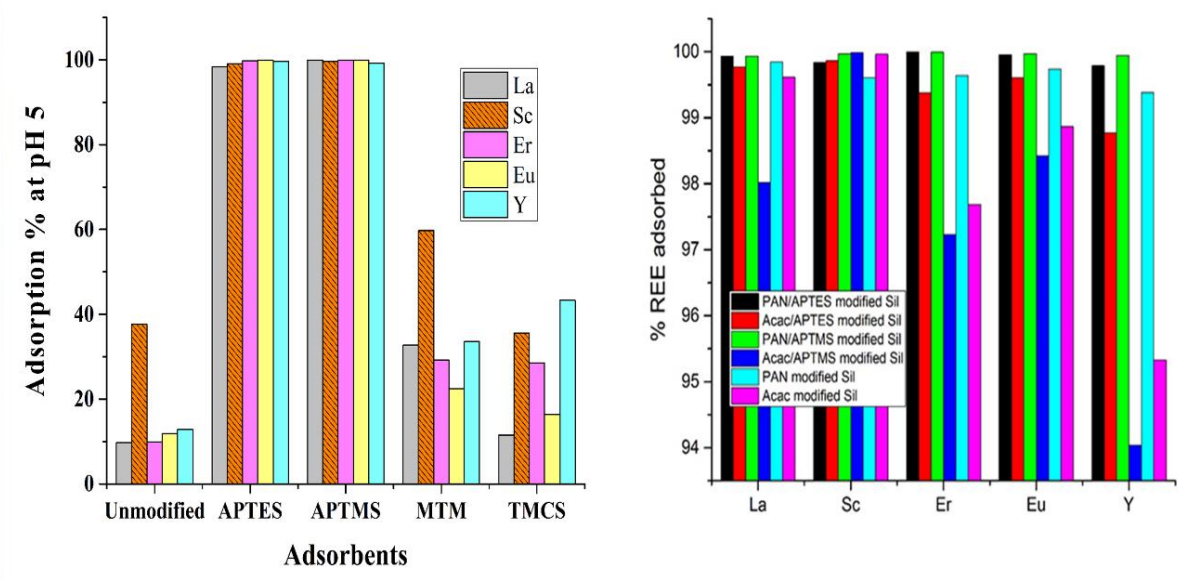

Figure 5: The top figure illustrates the summary of two ligand modification schemes used for silica surface functionalization. The bottom figure (on left) displays the REE adsorption efficiencies for silanized gels without ligand modification in the single component system ( $\mathrm{pH} 5, \mathrm{Ci} 20-30, \mathrm{t} 24 \mathrm{~h}$ and $\mathrm{T} 23^{\circ} \mathrm{C}$ ). The right figure at the bottom shows the results for ligand immobilized as well as physically adsorbed onto silica gels in the multi-component system ( $\mathrm{pH} 5, \mathrm{Ci} \sim 5 \mathrm{ppm}, \mathrm{t} 24 \mathrm{~h}$ and $\mathrm{T} 23^{\circ} \mathrm{C}$ ). The adsorbents (highlighted in green) on the top figure are the superior ones among the group in terms of REE adsorption efficiencies (Ref.: Articles 1 and 2). 


\section{HYBRIDIZATION OF SILICA WITH CHITOSAN FOR REE SORPTION: UNDERSTANDING THE ROLE OF PHYSICAL MODIFICATION AND CONDITIONING OF THE POLYMER}

Following the silica gel investigations, biopolymer chitosan was tested in order to understand the interaction of these host materials with REE. Analogous to bare silica, bare chitosan could not adsorb REE in the absence of any modification, excluding Sc. Further details underlying this distinct phenomenon towards Sc are discussed in Chapter 9.

\subsection{Fabrication procedures for silica-chitosan hybrid composites}

Synthesis of chitosan-silica hybrid composites was focused on identifying the best method of preparation, type of silane, type of chitosan, the significance of ligand attachment, physical modification (beads vs flakes) and conditioning of the polymer (Articles 3 and 4).

\subsubsection{Silica-chitosan hybrids in flake form}

The fabrication procedure is much alike to the standard solvent evaporation procedure adopted in our work mentioned in Chapter 4, except that chitosan is simultaneously included along with the other reactants. Here (Article 3), 1 part of bare chitosan flakes is reacted with 1 part of APTESfunctionalized gel and 20 parts of ligand solution (PAN $-0.2 \% \mathrm{w} / \mathrm{v}$ in acetone and acac $-0.3 \mathrm{v} / \mathrm{v}$ in methanol) for the hybridization procedure via the solvent-evaporation process (Figure 6).

\subsubsection{Silica-chitosan hybrids in bead form}

Three different synthesis procedures were implemented to recognize the best way to synthesize beads, which were also immobilized with ligands of our choice (Article 4).

Group A (H series): silica chitosan hybrid flakes were dissolved in glacial acetic acid (4\% w/w) and the obtained gel was used to prepare beads in $2.5 \mathrm{M} \mathrm{NaOH}$ bath.

Group B (B series): silica and chitosan were initially dissolved in acetic acid (4\% w/w) to form a gel, followed by bead preparation in $2.5 \mathrm{M} \mathrm{NaOH}$ bath. Further, 1 part of these silica-chitosan beads were immobilized with 20 parts of ligand via the solvent-evaporation process to yield ligand immobilized silica-chitosan beads.

Group C (S series): 20 parts of PAN was added along with 1 part of silica, 1 part of chitosan and acetic acid $(4 \% \mathrm{w} / \mathrm{w})$ in the first stage to produce a gel, with subsequent treatment in $2.5 \mathrm{M} \mathrm{NaOH}$ bath to form the beads. Hence, the ligand immobilization and silanization process occur side-by- 
side. Overall, Figure 6 summarizes various synthetic procedures employed for the preparation of silica-chitosan flakes and beads.

\subsection{Main research outcomes: single-component batch adsorption studies}

In summary, the bead performance was drastically higher than that of flakes in terms of REE adsorption efficiencies (Figure 6). REE adsorption was made possible by silica-chitosan hybrid beads even from a pH value of 2 whereas the REE adsorption by silica-chitosan hybrid flakes was found to be from $\mathrm{pH} 3$, reaching its maximum at 4 . With the hybridization of chitosan moieties along with silica, the REE adsorption occurred from $\mathrm{pH}$ 2-3 because of additional protonated binding sites, possibly from the amine, carboxylic acid and hydroxyl groups of chitosan, observed with chitosan and its derivatives for $\mathrm{Nd}^{3+}, \mathrm{Pr}^{3+}, \mathrm{Au}^{3+}, \mathrm{Pd}^{2+}$ and $\mathrm{Pt}^{4+}$ sorption [121-124]. Chitosan has the tendency to swell at acidic $\mathrm{pH}$; however, the synthesized hybrid chitosan-silica materials did not display any swelling behavior for the tested process conditions. Besides, the factors such as particle size, physical form, degree of deacetylation and chitosan were identified by C. Gerente et.al as some of the characteristics affecting metal uptake capacities to a large extent [122]. The most attractive feature about the hybrid bead materials is that they can undergo instantaneous REE adsorption ( $<5 \mathrm{~min}$ ) when tested for $\mathrm{La}^{3+}, \mathrm{Sc}^{3+}$ and $\mathrm{Y}^{3+}$ ion removal in a single-component system from $\mathrm{pH}$ 2. Further, the adsorption capacities of the silica-chitosan hybrid materials were determined to be remarkably better than the modified silica gels with the additional reactive sites for REE uptake. However, in order to gain profound knowledge about the contrasting behaviors detected among the silica-chitosan beads and flakes and their significance of hybridization/silanization, the materials had to be tested in a multi-component system.

\subsection{Main research outcomes: multi-component batch adsorption studies}

It is essential to establish the REE selectivity of the synthesized materials in the presence of other competing ions. Hence, natural AMD was utilized to study the performance of these materials, the results of which are presented in Figure 6. REE adsorption even at $\mathrm{pH}$ 2, as observed in a singleand multi-component system without any interference, was not feasible in the AMD case. $\mathrm{Fe}^{2+} / \mathrm{Fe}^{3+}$ ions deterred REE adsorption process until $\mathrm{pH} 4$ [125], beyond which their precipitation resulted in adsorption of REEs with increasing $\mathrm{pH}$. Except for the case of $\mathrm{Sc}^{3+}(\mathrm{pH} 4)$, the adsorption of other REEs commenced from a pH value of 5. Also, the increase in process temperature resulted in faster adsorption kinetics owing to ion migration across the energy barrier or increase in binding units with a decrease in the electric double layer thickness at higher temperatures [126]. A sufficient contact time of $1 \mathrm{~h}$ was used for these experiments although most of the adsorbents displayed rapid and instant REE adsorption to attain the equilibrium. The experimental conditions were $\mathrm{T} 45{ }^{\circ} \mathrm{C}, \mathrm{t} 1 \mathrm{~h}, \mathrm{pH} 1-5$, Ci $5 \mathrm{ppm}$, if otherwise indicated in texts/figures. 


\section{Beads vs flakes form}

When tested with AMD, both APTES and MTM silanized silica-chitosan flakes demonstrated poor REE adsorption even at pH 5. However, when their bead forms (Group 1) were used, they showed superior REE adsorption as depicted in Figure 6. The distinct disparity observed between beads and flakes form could be because of the drawbacks attributed to the diffusion resistance of large sized silica and chitosan particles [45]. Few other works also reported on enhanced metal adsorption capacities in beads form $(763 \mathrm{mg}$ [molybdate]/g, $402 \mathrm{mg}$ [vanadate]/g) in comparison to the flakes form (303 mg [molybdate]/g, $250 \mathrm{mg}$ [vanadate]/g) [127]. On comparing the subsets among the Group I beads, it was apparent that the MTM silica-chitosan beads worked better than APTES silica-chitosan beads whereas APTES silica-chitosan flakes displayed better REE adsorption efficiencies in comparison to MTM silica-chitosan flakes.

\section{Best method of preparation, best ligand, best silane and chitosan type}

In an overall perspective (Figure 6), the effectiveness of the adsorbents can be ordered as Group II > Group I > Group III, for all scenarios. Investigating further into our best group of adsorbents i.e. Group II, it was evident that PAN modified beads performed better than acac beads while MTM based beads were superior to APTES based beads. The decreased efficiencies of APTES silica-chitosan beads in comparison to MTM silica-chitosan beads could also be due to the presence of anions in the AMD water as chitosan could establish the formation of ion-pairs between $\mathrm{NH}_{3}{ }^{+}$groups and anions in the solution, as reported by Guibal et.al. [127]. Besides, the adverse effects on APTES were also reported in acidic synthesis conditions [116], which was the case with bead gel formation achieved by dissolving the reactants in acetic acid. It must be noted that PAN modified Group II beads demonstrated affinity towards HREEs (HREE $>$ LREE) whereas acac modified Group II beads displayed LREE>HREE affinity in the absence of interference. However, in the presence of other competing ions in AMD solution, HREE adsorption was more pronounced followed by LREEs irrespective of PAN/acac modifications. The type of chitosan did not exert any notable influence on the efficiency, for those with high molecular weight or high viscosity when used in beads form; however, the chemistry of acidic synthesis might have influenced the REE adsorption efficiencies of MTM/APTES based hybrid beads.

\section{Significance of hybridization and silanization}

PAN/acac modified silica-chitosan materials were distinctly superior to PAN/acac modified silica materials, in terms of adsorption $\mathrm{pH}$, attained equilibrium time and maximum adsorption capacities. In addition, a mere REE adsorption of $<20 \%$ when using AMD by non-hybrid silicaPAN materials indicates the significance of hybridization. Traditionally, silica-chitosan beads were reported for the metal sorption using bare silica or TEOS precursor with APTES silane [45]. 
However, this study revealed the importance of using APTES or MTM silanized gel instead of bare silica gel in the hybridization process. Between APTES and MTM, the MTM-based beads had an edge over the APTES-based beads in terms of REE selectivity.
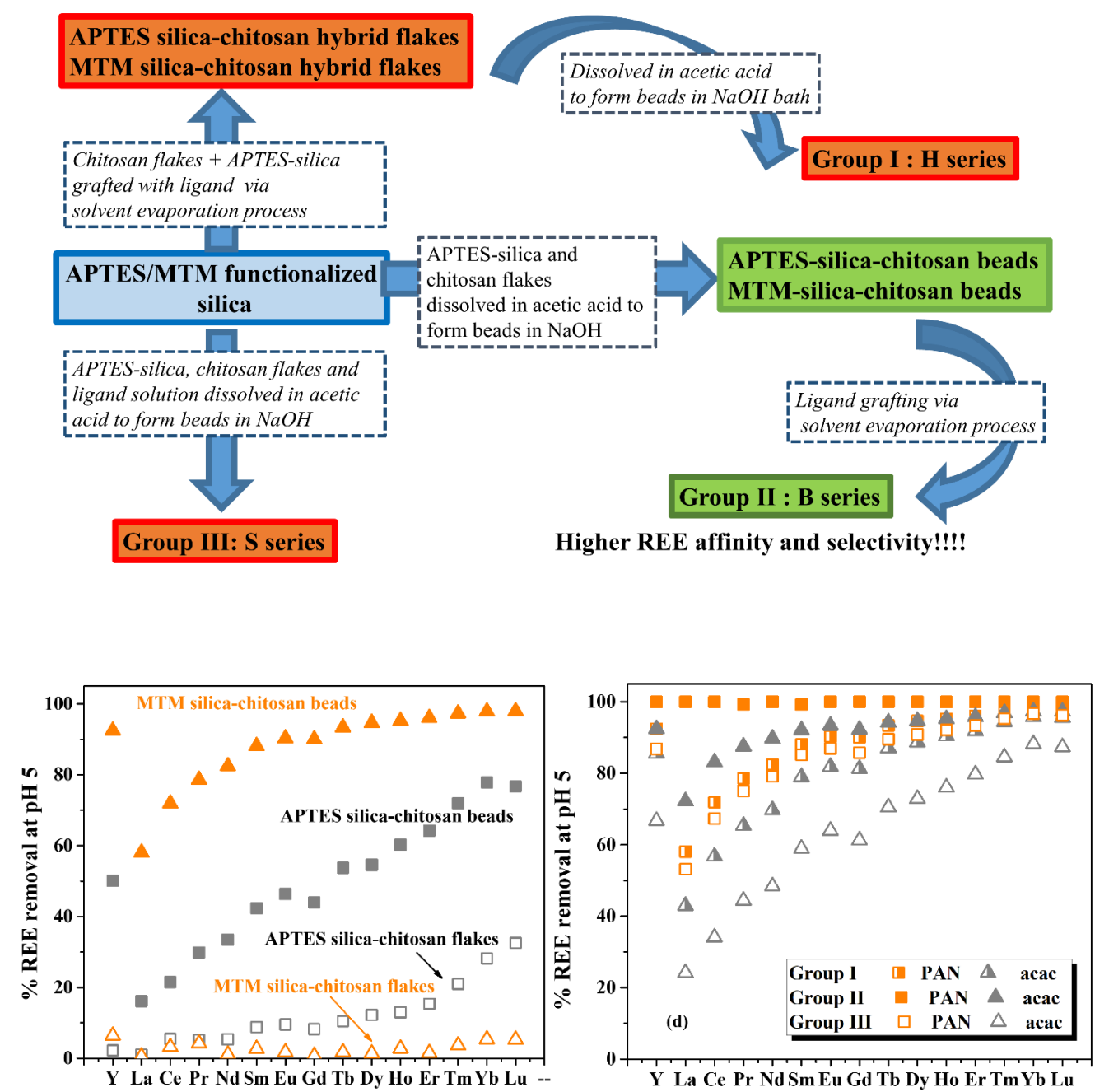

Figure 6: The top figure illustrates the overview of the synthesis of silica-chitosan hybrid flakes and beads. The bottom figures display the superiority of PAN-beads form to PAN-flakes form (on left), the superiority of Group II beads to Group I and III beads (on right) in terms of REE removal from AMD. The adsorbents (highlighted in green) on the top figure are the superior ones among the group in terms of REE adsorption efficiencies (Ref.: Article 4). 


\section{HYBRIDIZATION OF SILICA WITH CARBON BASED MATERIALS: EXPLOITING SINGLE-POT AND STEP-BY- STEP TELESCOPIC SYNTHETIC PATHWAYS FOR THE DESIGN OF REE-SELECTIVE HYBRID COMPOSITES}

Hybridization of CNT with other polymer substrates can be challenging because of the issues attributed to the dispersion of CNT in the matrix and interfacial adhesion between CNT and the matrix. The study by Chen et.al., Kathi et.al. and Ma et.al. demonstrated the impact of silanization process on the hybridization of CNT with epoxy resins, which in turn was also reflected in the enhancement of wear resistance, thermal and mechanical attributes [71,128,129]. Previous works have reported on the synthesis of CNT/AC-silica composites via APTES silane using surfactant, catalyst, carbonization, acid treatment by sonication with solvent (water, ethanol, water-oil emulsion), by sol-gel method using TEOS precursor or via donor-acceptor interactions [130-135]. In this study, the fabrication of CNT/AC-silica composites was performed by means of toluene condensation process using APTES as a linker to form amide groups instead of a direct reaction between $\mathrm{SiOH}$ and $\mathrm{COOH}-\mathrm{CNT} / \mathrm{AC}$. Further, two synthetic pathways to attach PAN onto the hybrid CNT/AC-silica composites were exploited: one-pot synthesis and step-by-step telescopic synthesis. Such an attempt to investigate REE adsorption through CNT-APTES-silica-PAN and AC-APTES-silica-PAN composites have never been done as far as our knowledge and this work could offer greater insights into the REE interaction with these supports. The comparative study of the hybrid composites by both the ligand-modification techniques is necessary to understand the importance of grafting technique to be adopted for enhancing REE affinity/selectivity. Due to the drawbacks associated with largely sized PAN grafted mesoporous silica (5-40 $\mu \mathrm{m})$, nano-silica was utilized with the hybridization process with carbon materials.

\subsection{Synthetic routes}

The procedure for CNTs (1:10 with silica) and AC (1:1 with silica) preparation remained the same, except for the ratio of carbon to silica (Articles 5 and 6). For CNTs, both SWNT and MWNT were exploited to compare and to study their interactions with REEs.

\subsubsection{Method I: Single-pot synthesis}

In this co-condensation procedure, all the reactants were put together in a single pot to undergo reaction. As a result, APTES silanization and ligand grafting occur simultaneously by means of a single-pot approach. Here, 1 part of CNT/10 parts of AC (in g), 10 parts of silica (in g), 10 parts of APTES silane solution (in ml) and 20 parts of PAN solution ( $0.2 \mathrm{~g}$ PAN in $100 \mathrm{ml}$ of acetone solution) were made to react together by stirring at $150 \mathrm{rpm}$ in an airtight container with $100 \mathrm{ml}$ of toluene solution. The hybridized CNT/AC-silica products were thus obtained by co- 
condensation reaction of APTES with the supports for a period of 24 hours. Post hybridization, the product composites were filtered, followed by washing them with ethanol to get rid of excessive toluene and unattached components. Finally, they were dried at $100^{\circ} \mathrm{C}$ overnight until a constant weight was achieved.

\subsubsection{Method II: step-by-step telescopic synthesis}

According to Method II (post-synthetic "grafting" approach), the synthesis procedure involved two steps. In the first step, CNT/AC-APTES-silica crosslinked composites were prepared by reacting 1 part of CNT/10 parts of AC (in g), 10 parts of silica (in g) and 10 parts of APTES silane solution (in $\mathrm{ml}$ ) in 100 parts of Toluene solution (in $\mathrm{ml}$ ). In the consequent second step, ligand (PAN) was grafted to the obtained CNT/AC-silica composites via solvent evaporation process by reacting 1 part of it with 20 parts of ligand solution. They were reacted until the solvent solution was fully evaporated and were then dried at room temperature.

In addition, APTES-silica-PAN materials (using nano silica) were also synthesized using these two methods, the difference being the absence of CNT or AC in the reactants. Besides, silicachitosan flakes were also fabricated using these two methods as the hybridization of silica and chitosan by merely mixing, as mentioned in Chapter 5, was not found to yield superior REE adsorption results as silica-chitosan beads, attributing to diffusion restrictions due to larger particle sizes. However, this chapter focuses only on CNT/AC materials and the results of silica-chitosan flakes utilizing nano silica are included in the discussion under Chapter 9. The schematic illustration of these synthetic pathways is represented in Figure 7.

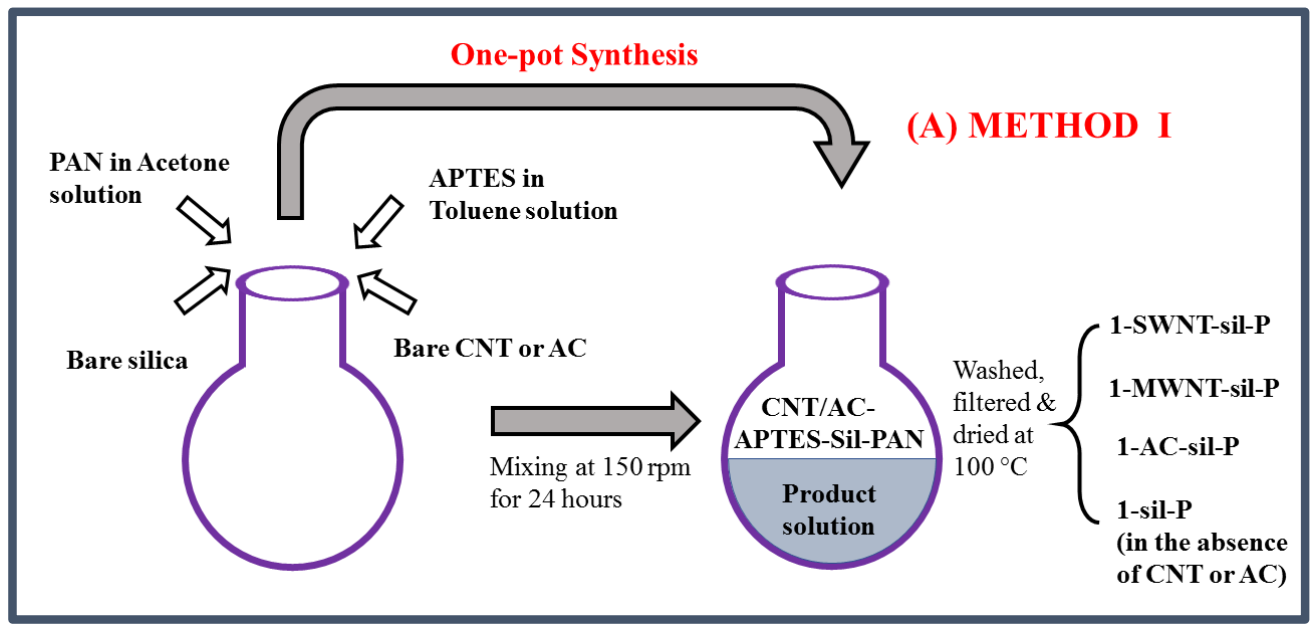




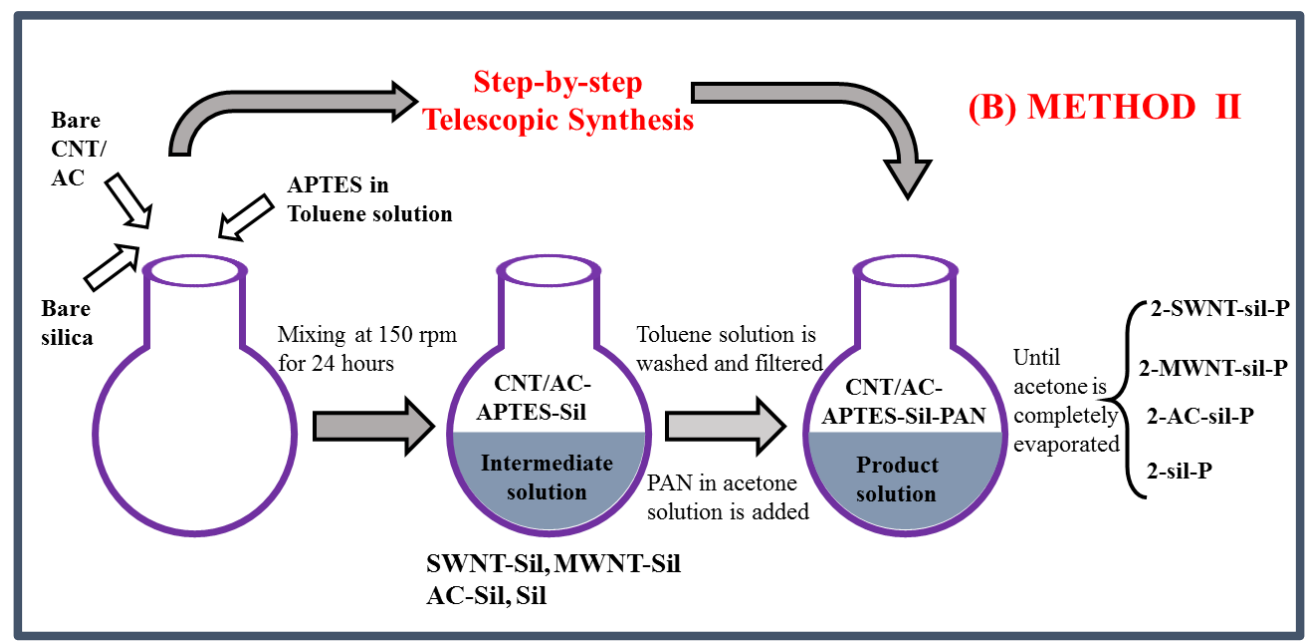

Figure 7: Schematic illustration of two synthetic pathways (a) one-pot procedure and (b) step-by-step telescopic procedure adopted for the fabrication of hybrid silica-carbon composites using APTES as a linker.

\subsection{Main research outcomes: single-component batch adsorption studies (Articles 5 and 6)}

$\mathrm{La}^{3+}, \mathrm{Sc}^{3+}$ and $\mathrm{Y}^{3+}$ sorption studies with CNT-sil-P and AC-sil-P adsorbents (Method I and II) in a single component system disclosed that the optimal $\mathrm{pH}$ was 4. Maximum REE adsorption was recorded at $\mathrm{pH} 5$ for all the adsorbents (>90\% removal at $\mathrm{pH} 4$ ). Besides, surface zeta potential measurements revealed overall positive charges of the adsorbents under $\mathrm{pH} 5$ implying that the ion-exchange mechanism would most likely occur between REE cations and protonated functional groups of CNT-silica and AC-silica. At a lower $\mathrm{pH}$ value, i.e. at $\mathrm{pH} 1$ and 2, REE adsorption was hindered due to the existence of competing ions in the form of protons [35,136]. The faster kinetics was observed for $\mathrm{La}^{3+}$ and $\mathrm{Y}^{3+}$ ions in comparison to $\mathrm{Sc}^{3+}$ ions, possibly due to the additional pore diffusion by $\mathrm{Sc}^{3+}$ ions.

\subsection{Main research outcomes: multi-component batch adsorption studies (Articles 5 and 6)}

An optimum $\mathrm{pH}$ value of 4 was selected as the process $\mathrm{pH}$ for further investigations using a multicomponent system. The adsorbents did not show any affinity towards REEs until $\mathrm{pH} 3$, as expected, in line with the results from the single component system. At $\mathrm{pH} 4$, there was significant REE adsorption observed with APTES functionalized CNT-sil, AC-sil and sil materials and the results are summarized below. 


\section{SWNT vs MWNT:}

Overall, MWNT based adsorbents showed superior REE adsorption in comparison to that of SWNT adsorbents (Figure 8). The adsorbents can be ordered in terms of their REE removal efficiencies as 2MWNTsilP > SWNTsil > 1SWNTsilP > 1MWNTsilP > 2SWNTsilP > MWNTsil. It is of importance to observe the impact of synthetic pathways in terms of REE removal efficiencies with both SWNT-silica and MWNT-silica adsorbents. Another key revelation from this work is the significant influence of PAN grafting onto functionalized MWNT-silica composites towards REE affinity. On the other hand, SWNT-silica composites display REE affinity even in the absence of PAN grafting. Besides, they perform better, in comparison to the ligand grafted SWNT-silica composites, which indicates that PAN grafting exerts a negative influence on REE adsorption.

\section{AC-silica vs sil materials:}

Method II AC-silica adsorbents yielded exceptional REE adsorption in relation to the Method I counterparts, with 2AC-silP $>2$ silP $=1$ silP $>1$ AC-silP $>2 \mathrm{AC}-\mathrm{P}>1 \mathrm{AC}-\mathrm{P}$ in the order of removal efficiencies.

\section{One-pot synthesis (Method I) vs step-by-step telescopic (Method II) synthesis:}

Overall, Method I work best for SWNT while it is Method II for MWNT and AC. Silica did not show any distinct superiority with these two methods. This observed contrast behavior is subjected to further discussion in Chapter 9.

\section{Significance of PAN grafting:}

On comparing Figure 8.b (before PAN grafting) and Figure 8.c (after PAN grafting), it can be seen that PAN grafting resulted in the enhancement of REE affinity and selectivity, especially when tested them with AMD solution in the presence of interfering co-competing ions.

\section{Significance of hybridization:}

Excluding Sc, PAN grafted CNT and AC materials did not display adsorption towards any other REE without silica hybridization. Further, it is also evident from Figure 8.c. that the hybridized composites, Method II AC-silica-PAN and Method II MWNT-silica-PAN, showed enhanced REE affinity and selectivity in comparison to silica-PAN when using AMD. 


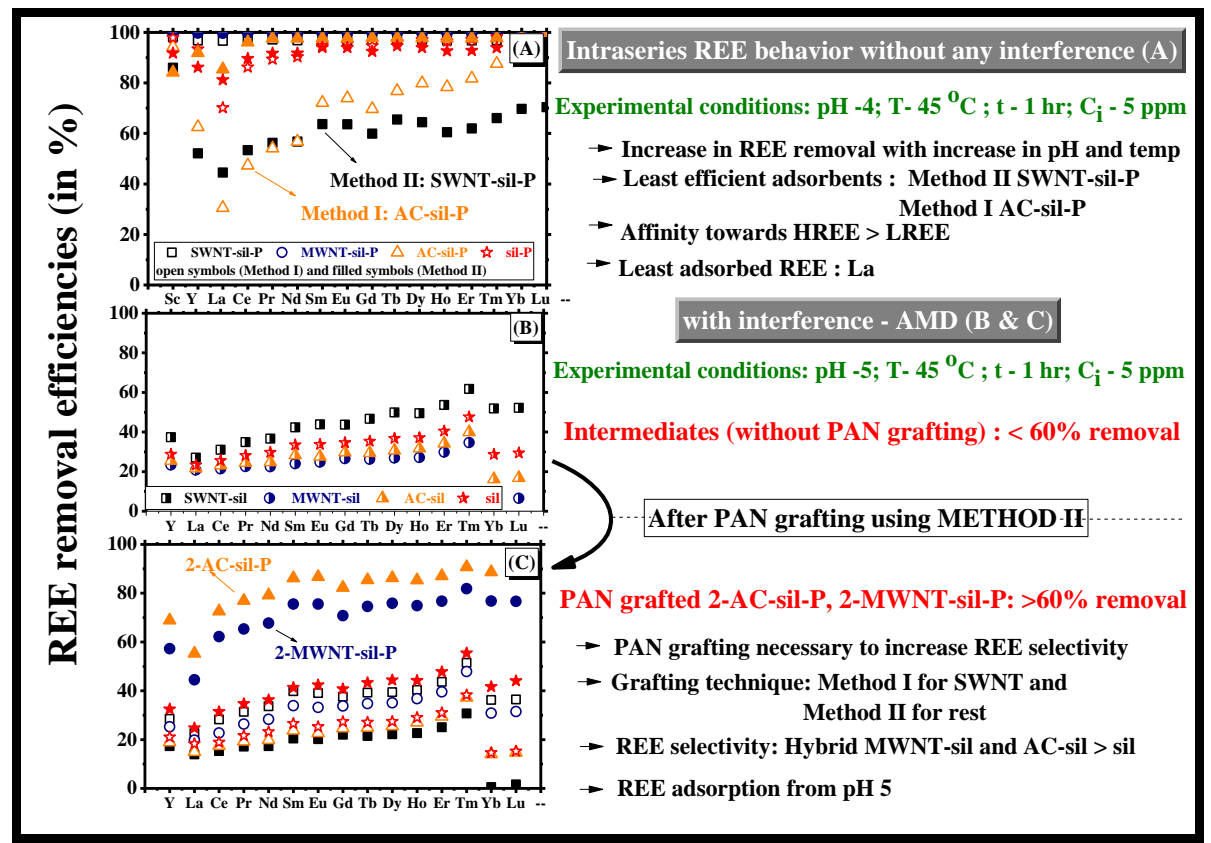

Figure 8: Comparison of silica-SWNT, silica-MWNT, silica-AC composite materials in terms of REE removal efficiencies in the absence of competing ions ((a) synthetic wastewater containing only 16 REEs) and in the presence of competing ions ((b\&c) AMD wastewater containing 16 REEs and other impurities) (Ref.: Articles 5 and 6). 


\section{GREEN, ECONOMIC AND EFFICIENT BIOSORBENT MARINE ALGAE FOR REE ADSORPTION}

In this section, REE adsorption by marine algae was analyzed as a function of different factors such as removal efficiency, stability and selectivity. Due to their widespread availability in comparison to other biomaterials such as bacteria, yeasts and fungi, they can be extracted with ease at low costs and hence, have great commercial importance. The use of APTES or hybridization procedure with silica was avoided as the bare marine algae was found to hold the inherent potential to adsorb REEs on their own without any need of surface modification.

\subsection{Synthetic routes}

The marine algae used in this study (Article 7) was collected from the Mediterranean coast of Tunisian beaches. The obtained biomass was then washed extensively, sun-dried, ground in a ball mill and sieved by means of 200-micron mesh. Following, the biomass (untreated) was grafted with the ligand, PAN to enhance selectivity (explored for the first time) via two solvent evaporation approaches resulting in (a) Method I-Algae-PAN using heat-induced water evaporation and (b) Method II-Algae-PAN using acetone evaporation without applying heat or temperature.

\section{Method I: Heat-induced water evaporation process}

In this process, water is used as a solvent, thereby applying temperature to stimulate water evaporation. 1 part of dry algae was stirred with 20 parts of PAN solution $(0.2 \%$ PAN w/w in water) at $220 \mathrm{rpm}$ to undergo water evaporation process under the application of heat at $60^{\circ} \mathrm{C}$ until all the water is evaporated.

\section{Method II: Non-heat acetone evaporation process}

On the other hand, in this process, instead of water, acetone was used as the solvent and PAN grafting was achieved by reacting 1 part of dry algae with 20 parts of PAN solution $(0.2 \%$ PAN w/w in acetone solution), similarly to the previously mentioned procedures. It should also be stated that the reaction was carried under the room temperature; hence, no heat was applied in this method. 


\subsection{Main research outcomes}

There are no prior studies exploring algal biomass and $\mathrm{Sc}^{3+}$ ions; however, limited studies investigated on $\mathrm{La}^{3+}, \mathrm{Ce}^{3+}, \mathrm{Eu}^{3+}$, and $\mathrm{Yb}^{3+}$ bio-sorption by macro and microalgae, can be found in the literature [137-139]. The presence of alkali, alkali earth metals and other functional groups present on the cell wall of algal biomass could facilitate ion exchange between protonated surface groups and REE cations in acidic $\mathrm{pH}$ range [137]. For the process conditions of temperature 23 ${ }^{\circ} \mathrm{C}$, initial concentration $25 \mathrm{ppm}$, contact time $30 \mathrm{mins}$ and $\mathrm{pH} 5$ in a single component system, $\mathrm{Sc}^{3+}$ adsorption was effectively seen for all the adsorbent materials with or without surface modification. It must be noted that $\mathrm{Sc}^{3+}$ adsorption efficiencies were around $\sim 65 \%$ at $\mathrm{pH} 3$ which further increased with increase in $\mathrm{pH}$, reaching $>90 \%$ at $\mathrm{pH}$ 5. It was also observed that the $\mathrm{Sc}^{3+}$ uptake ( $\sim 90 \%$ in $30 \mathrm{~min}$ ) was very quick in the beginning after which the slow equilibrium was attained ( $98 \%$ in $24 \mathrm{~h})$. Similar fast uptake of REE within $15 \mathrm{mins}$ to $1 \mathrm{hr}$ in the pH range of 35 was also reported by Vijayaraghavan et.al. and Birungi et.al. [137,139]. It was also interesting to find that among a studied lot of commercial adsorbents containing a group of 17 members (Figure 9.a), marine algae, bentonite, activated charcoal and nonclay demonstrated greater sorption for both $\mathrm{Sc}^{3+}$ and $\mathrm{Y}^{3+}$ in a binary system. Especially, adsorption performance of marine algae was commendable and hence, it has great capability to function as an efficient adsorbent for Sc and other REE recovery.

Subsequently, the effect of these adsorbents on the entire REE series was studied, where the unmodified algae performed as superior or slightly superior to the modified marine algae (Method II). The adsorption efficiencies can be ordered as untreated algae> Method II-algae-PAN > Method I-algae-PAN. Lanthanides belong to Pearson's class A of hard metals, according to which the ionic competition among REEs for the same binding sites on the biomass would most likely result in decreased sorption capacity in a multi-component system, as evidenced with these materials [140]. Also, it is necessary to observe the temperature effect on the performance of Method-I-algae-PAN from Figure 9.b. However, to study the adsorbent selectivity in the presence of other competing ions, two multi-component systems (Figure 9 (c-d)) composed of AMD ( $\mathrm{C}_{\mathrm{REE}} \sim 2 \mathrm{ppm}$ ) and sea water $\left(\mathrm{C}_{\mathrm{REE}} \sim 2 \mathrm{ppm}\right)$ were utilized, where Method II-algae-PAN yielded the best possible results. The poorest outcome was observed for $\mathrm{La}^{3+}$ with AMD while it was for $\mathrm{Y}^{3+}$ in case of seawater. The presence of other competing cations, anionic species and organic matter might have hindered the adsorption. The hindered $\mathrm{La}^{3+}$ sorption by freshwater algae in the sulfate medium reported by Diniz and Volesky further supports this argument [141]. The adsorbent selectivity towards various REEs is discussed in further detail under Chapter 9. It is also interesting to note that, in contrast to previous observations with most of the silica-based adsorbents, marine algae demonstrated affinity towards LREEs over HREEs. Similar to these findings, Vijayaraghavan et.al also observed the affinity of T.conoides biomass towards $\mathrm{Eu}>\mathrm{Ce}>\mathrm{La}>\mathrm{Yb}$ in a multi-component system [137]. In another study using Pseudomonas aeruginosa, preferential REE uptake in mixed solutions was found to be $\mathrm{Eu}^{3+}=\mathrm{Yb}^{3+}>\mathrm{La}^{3+}[138]$. 

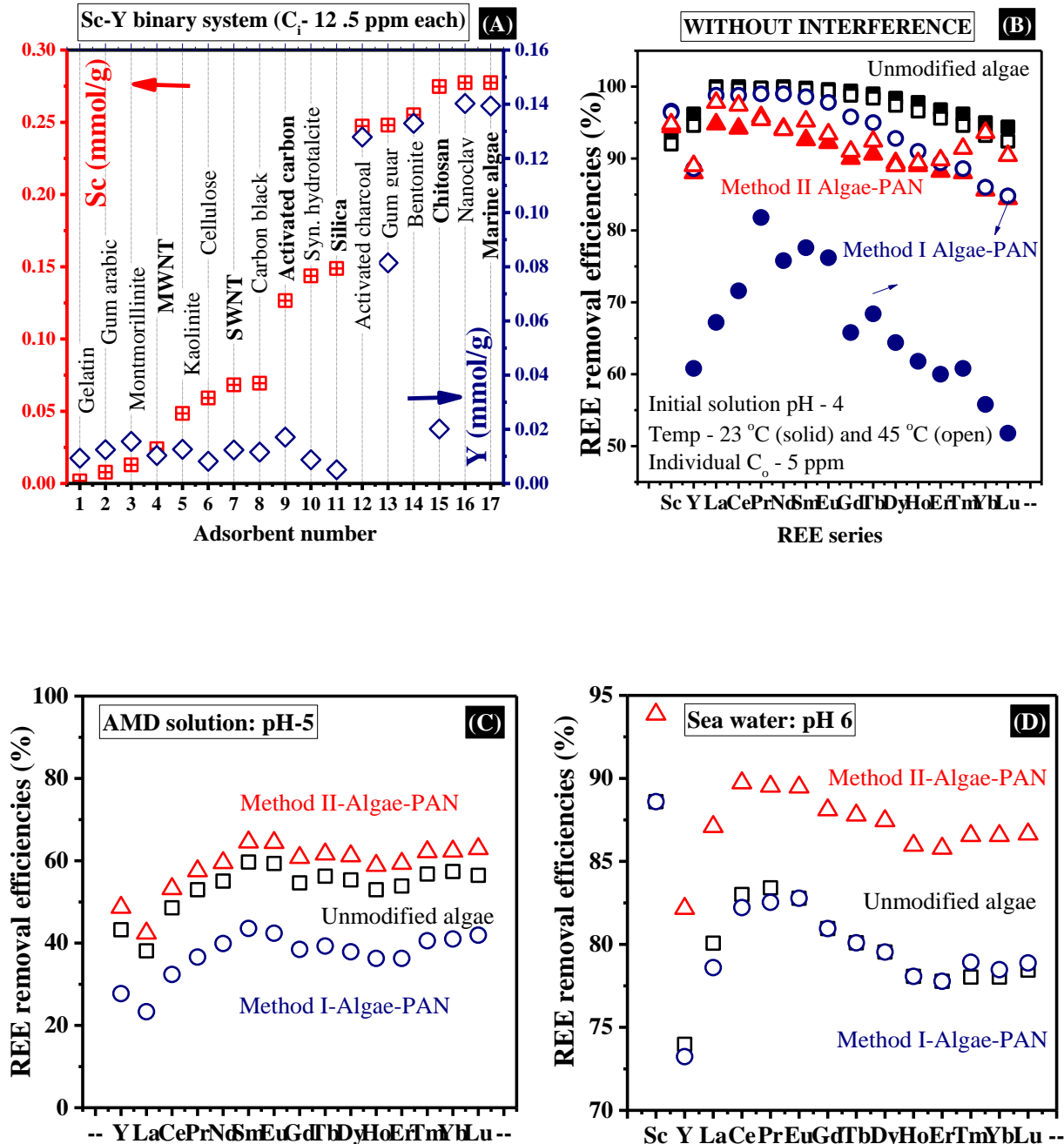

Figure 9: (a) Evaluation of various commercially available adsorbents for Sc and $\mathrm{Y}$ sorption in a binary system $\left(\mathrm{CSc}_{\mathrm{S}, \mathrm{Y}} \sim 12.5 \mathrm{ppm} ; \mathrm{t} 1 \mathrm{~h} ; \mathrm{T} 45^{\circ} \mathrm{C} ; \mathrm{pH}\right.$ 4). Intraseries REE adsorption behavior without interference (b) at 23 and $45^{\circ} \mathrm{C}$ by unmodified and modified algae and in the presence of other competing ions (c) with AMD solution ( $\mathrm{pH} \mathrm{5,} \mathrm{C}_{\mathrm{REE}} \sim 2 \mathrm{ppm}$ ) and (d) seawater (pH 6, $\mathrm{C}_{\mathrm{REE}} \sim 2 \mathrm{ppm}$ ) (Ref.: Article 7). 


\section{CHARACTERIZATION OF THE MATERIALS}

In this section, the characterization of the synthesized adsorbents during this research work is summarized. These analyses helped to study the materials before and after surface modification. Prior knowledge from literature assisted in interpreting and understanding the interaction between the adsorbents and REEs.

\subsection{SEM analysis}

The surface morphology of the synthesized adsorbents was investigated by SEM analysis at various magnifications from which the average diameter and particle size distribution were calculated. The attained data were found to be in good agreement with the data of pristine supports provided by the manufacturer. Functionalized silica materials were amorphous and showed slightly coarsened surface after the modification process. Further, upon grafting of silica units onto the supports such as chitosan, CNTs and AC, the hybridization of the support materials was clearly spotted from the images. The entanglement of CNTs into bundles or bunches because of van der Waal's interactions [132] and densification of the porous structure of AC after surface modification can also be seen evidently from figures shown in Articles 5 and 6. There was no distinct observation made between the pristine polymers and physically adsorbed PAN onto $\mathrm{CNT} /$ chitosan/AC/algae in the absence of silica. In general, there was an overall increase in particle size after modification. Besides these, there was no substantial information gathered from the SEM analysis for the adsorbents under scrutiny.

\subsection{Organic elemental analysis}

Table 3 presents the results from CHNS organic elemental analysis performed on the synthesized adsorbents. It can be seen from the table that the successful incorporation of amino/non-amino silanes onto silica matrix was confirmed by the presence of $\mathrm{C}, \mathrm{H}$ and $\mathrm{N}$ upon silanization. The presence of $\mathrm{N}$ was noticeable in all amino functionalized gels unlike the case of non-amino MTM and TMCS based gels. The APTES and APTMS gels showed a higher content of N, C and H (in $\%$ ), which increased further with PAN/acac grafting onto the adsorbents. A similar trend was also observed in the case of chitosan-silica, CNT-silica and AC-silica hybrid adsorbents with a sharp rise in $\mathrm{N}$ and $\mathrm{H}$ content after the attachment of APTES and PAN groups. In the case of carbonbased materials i.e. CNT and AC, \%C decreased substantially after hybridization with silica with a relative increase in $\% \mathrm{SiO}_{2}$. Another observation made here is a significant increase in $\% \mathrm{C}$ (from 21.09 to 46.15) for AC-APTES-silica after PAN grafting. This was not the case with SWNTAPTES-silica composites (from $24.96 \% \mathrm{C}$ to $17.15 \% \mathrm{C}$ ) and MWNT-APTES-silica (from 22.80 $\% \mathrm{C}$ to $23.98 \% \mathrm{C}$ ) with PAN modification. Besides, $\% \mathrm{~N}$ was increased after the interaction between MWNT/AC-silica composites and PAN moieties, indicating an enhanced PAN loading whereas a decrease in $\% \mathrm{~N}$ was observed for SWNT-silica composites post-grafting. These 
observations were in agreement with the experimental findings, with the REE adsorption efficiencies ordered as Method II AC-silica-PAN> Method II MWNT-silica-PAN> SWNT-silica $>$ Method II SWNT-silica-PAN. The superior REE removal depicted by MWNT/AC-silica-PAN adsorbents seemed to arise from the major contribution of PAN moieties in forming REE-chelates. In the case of algal biomass, PAN grafting resulted in just a meagre rise in \% (from 1.54 to 1.97) and $\% \mathrm{~N}$ (from 40.30 to 40.50 ) values.

\subsection{BET analysis}

The $\mathrm{N}_{2}$ adsorption and desorption isotherms were obtained at $77 \mathrm{~K}$ for adsorbents as a function of relative pressure $\mathrm{P} / \mathrm{P}_{\mathrm{o}}$. The bare $\mu$ silica and its amino/ non-amino functionalized materials exhibited a mesoporous network with a pore size in the range of $70 \AA$. They displayed BET type IV isotherm curves, according to IUPAC classification. This type is characteristic of mesoporous materials with multilayer adsorption phenomenon. Besides, the occurrence of H1 hysteresis loops between the adsorption and desorption plots in the $\mathrm{P} / \mathrm{P}_{\mathrm{o}}$ range of $0.5-0.9$ is due to the capillary condensation in the mesopores [142,143]. The silica-chitosan hybrid materials also demonstrated the same mesoporous network, following type IV isotherm [144,145]. On the other hand, ACsilica and CNT-silica hybrid composites displayed type III isotherm, suggesting unrestricted multilayer adsorption corresponding to adsorption on both external surface and internal capillary condensation. Despite this, the apparent hysteresis loops were present between $\mathrm{P} / \mathrm{P}_{\mathrm{o}}$ of 0.9 and 1 , although they are common with type IV and V isotherm curves. Similar loops were also reported in other works assigned as "pseudo type II-b" [146,147]. This could reveal that the pores might be narrow slit-like forms, filled with internal voids of irregular shapes, the sizes of which spanned over a broad range [146]. Besides, the average pore size of these CNT-silica and AC-silica composites were attained in the mesoporous range (50-120 $\mathrm{\AA}$ ), adhering to prior reports by other authors [131].

In comparison to pristine silica (200-400 $\mathrm{m}^{2} / \mathrm{g}$ ) and carbon (SWNT $-409.25 \mathrm{~m}^{2} / \mathrm{g}$ and AC -736.38 $\left.\mathrm{m}^{2} / \mathrm{g}\right)$, the BET surface area of chitosan $\left(0.724 \mathrm{~m}^{2} / \mathrm{g}\right)$ and marine algal biomass $\left(0.982 \mathrm{~m}^{2} / \mathrm{g}\right)$ was found to be very much nominal, which is typically common in the case of bio-sorbents. An additional inference made from the BET results (Table 3) was that the overall BET surface area and pore volume of the silica, CNT and AC based materials reduced substantially after the silanization process, with a further decrease in values after ligand grafting step. However, the average pore size seemed to increase subsequent to the modification process, probably due to the blockage of smaller pores resulting from the cross-linking or surface functionalization. This was in line with prior observations made in literature as well $[56,57,144]$. The observed phenomenon was not evident in low-surface bio-sorbents from this study, i.e. chitosan and algal biomass. Following surface modification and hybridization, the overall BET surface area and pore volume increased for chitosan (silica-chitosan flakes: from 0.724 to $71.89 \mathrm{~m}^{2} / \mathrm{g}$ and from 0.001 to 0.13 $\mathrm{cm}^{3} / \mathrm{g}$ ) and algal-based adsorbents (Algae-PAN: from 0.982 to $1.945 \mathrm{~m}^{2} / \mathrm{g}$ and from 0.001 to 0.003 
$\mathrm{cm}^{3} / \mathrm{g}$ ). However, the pore size of chitosan was not influenced significantly after PAN functionalization onto silica-chitosan (from $73.82 \AA$ to $68.87 \AA$ ). Similar findings were reported by Roosen et.al for bare chitosan $\left(1 \mathrm{~m}^{2} / \mathrm{g}, 0.003 \mathrm{~cm}^{3} / \mathrm{g}, 40 \AA\right.$ A), EDTA modified silica-chitosan (230 $\left.\mathrm{m}^{2} / \mathrm{g}, 0.718 \mathrm{~cm}^{3} / \mathrm{g}, 63 \AA\right)$ and DTPA modified silica-chitosan $\left(198 \mathrm{~m}^{2} / \mathrm{g}, 0.573 \mathrm{~cm}^{3} / \mathrm{g}, 58 \AA\right)$ composites [41]. On the other hand, the pore size of the algal biomass increased from $58.77 \AA$ to $78.09 \AA$, further supplemented by a reduction in t-plot micropore volume from 0.00027 to 0.0001 $\mathrm{cm}^{3} / \mathrm{g}$.

There is a significant enhancement in pore size of AC after silica hybridization (from $25.55 \AA$ to $55.04 \AA$ ), with an additional increase to $107.94 \AA$ after post-synthetic PAN grafting, onto ACsilica composites. Alternatively, the pore size of CNT- silica composites remained almost the same after PAN grafting, with 102.62-112.49 $\AA$ for SWNT and 107.58-115.77 $\AA$ for MWNT. An important remark to be made is that uniform pore size of about 100-116 $\AA$ was attained for all the CNT/AC-silica composites after post-synthetic PAN grafting, which underlines the possibility to control the pore-size characteristics using Method II grafting technique. This was not achievable (Article 5) when using Method I of one-pot co-condensation synthesis where the pore size of ACsilica-PAN was just $55.65 \AA$, equivalent to $55.04 \AA$ of AC-silica (without PAN). Likewise, in Article 6, the pore size of Method I SWNT-silica-PAN and MWNT-silica-PAN was determined to be $103.32 \AA$ (without PAN: $102.62 \AA$ ) and $105.74 \AA$ (without PAN: $107.58 \AA$ ), respectively. Besides, it should be noted that the pore volume decreases with increase in PAN loading, and this is comparable to the increase in $\% \mathrm{C}$ and $\% \mathrm{~N}$ from elemental analysis. This was reflected on the enhanced PAN grafting observed with AC-silica composites $\left(250.85 \mathrm{~m}^{2} / \mathrm{g}, 0.35 \mathrm{~cm}^{3} / \mathrm{g}, 55.04 \AA\right.$, $\% \mathrm{~N} 1.85, \% \mathrm{C} 21.09$ and $\% \mathrm{H} 1.54)$ after modification $\left(21.82 \mathrm{~m}^{2} / \mathrm{g}, 0.06 \mathrm{~cm}^{3} / \mathrm{g}, 107.94 \AA . \% \mathrm{~N} 2.91\right.$, $\% \mathrm{C} 46.15$ and $\% \mathrm{H} 2.23)$. These results show that PAN interacts competently with the reactive sites on AC-APTES-silica, which further necessitates the importance of grafting technique for designing multifunctional materials with tailor-made and desired functionalities.

\subsection{Zeta potential analysis}

The surface charge of the adsorbents was investigated through surface zeta potential studies via multiple runs, as a function of electrolyte $\mathrm{pH}$. Locating the isoelectric point (IEP) at which the adsorbent carries neutral charge would yield a better acumen of the adsorbate-adsorbent interactions, in terms of $\mathrm{pH}$ influence on the adsorbent's surface charge. The IEP of bare silica was found to be around $\mathrm{pH}$ 2-3. However, this value shifted to 5-8 after the amino-based APTES/APTMS grafting process, similar to chitosan with amine functions of $\mathrm{pK}_{\mathrm{a}}$ 6.5-6.7 [77,148,149]. Igberase et.al. [150] and Vieira et.al. [151] reported similar higher pHzPC of 4.4 and 6-7, respectively for EDTA grafted chitosan beads and glutaraldehyde/epichlorohydrin crosslinked chitosan membrane. The presence of surface carboxyl groups $\left(\mathrm{pK}_{\mathrm{a}} \sim 4\right)$ in bare $\mathrm{AC}$ and CNT resulted in an IEP value of 4 while the IEP values of hybrid AC-silica and CNT-silica materials were shifted to higher values after APTES functionalization due to the protonated amino groups 
[148]. This could be a clear implication of the facts that nature of the protonated surface was electropositive and the amino groups were effectively immobilized onto the adsorbent surface [126]. Further evidence of this can also be seen from the IEP values of MTM and TMCS modified adsorbents (non-amino gels), which are typically around 2-3 (Articles 1 and 2).

Table 3: BET and CHNS analysis results. *Inorganic $\mathrm{SiO} 2$ content (\%) was calculated by deducting the organic content in samples. When wt $\%$ of organic $\mathrm{O}$ in the samples was below the detection range, the boxes were left empty (-).

\begin{tabular}{|c|c|c|c|c|c|c|c|c|c|}
\hline \multirow[t]{2}{*}{ Adsorbents } & \multirow{2}{*}{$\begin{array}{l}\text { Particl } \\
\text { e size } \\
(\mathbf{n m})\end{array}$} & \multirow{2}{*}{$\begin{array}{l}\text { BET } \\
\text { surface } \\
\text { area } \\
\left(\mathrm{m}^{2} / \mathrm{g}\right)\end{array}$} & \multirow{2}{*}{$\begin{array}{l}\text { Pore } \\
\text { volume } \\
\left(\mathrm{cm}^{3} / \mathrm{g}\right)\end{array}$} & \multirow[t]{2}{*}{$\begin{array}{l}\text { Pore size } \\
\text { (̊) }\end{array}$} & \multicolumn{5}{|c|}{$\begin{array}{l}\text { Percentage of dry weight (\%) from organic } \\
\text { elemental analysis }\end{array}$} \\
\hline & & & & & $\mathbf{N}$ & $\mathbf{C}$ & $\mathbf{H}$ & $\mathbf{O}$ & $\mathrm{SiO}_{2}{ }^{*}$ \\
\hline \multicolumn{10}{|c|}{ Bare or pristine support material } \\
\hline$\mu$ silica & 40000 & 377.86 & 0.69 & 73.51 & - & - & - & - & $\sim 100$ \\
\hline chitosan & & 0.724 & 0.001 & 73.82 & 16.26 & 43.18 & 6.91 & 37.09 & - \\
\hline nanosilica & 24.05 & 249.52 & 0.38 & 61.57 & - & - & - & - & $\sim 100$ \\
\hline SWNT & 14.66 & 409.25 & 1.03 & 58.08 & - & 81.48 & 0.03 & $0-18^{\prime}$ & - \\
\hline MWNT & 536.8 & 11.18 & 0.04 & 65.56 & - & 99.52 & - & - & - \\
\hline $\mathrm{AC}$ & $0.3 \mathrm{~mm}$ & 736.38 & 0.47 & 25.55 & - & 63.49 & 0.54 & $0-35^{\prime}$ & - \\
\hline marine algae & 12573 & 0.982 & 0.001 & 58.77 & 1.54 & 40.30 & 5.12 & $0-50^{\prime}$ & - \\
\hline \multicolumn{10}{|c|}{ Hybrid materials before PAN modification } \\
\hline APTES- $\mu$ silica & & 174.19 & 0.32 & 73.87 & 2.58 & 10.30 & 2.48 & & $\sim 80$ \\
\hline MTM- $\mu$ silica & & 306.07 & 0.52 & & - & 3.33 & 1.1 & & $\sim 90$ \\
\hline $\begin{array}{l}\text { SWNT-APTES- } \\
\text { silica }\end{array}$ & 64.26 & 93.37 & 0.24 & 102.62 & 3.61 & 24.96 & 2.64 & $0-18^{\prime}$ & $\sim 50-70$ \\
\hline $\begin{array}{l}\text { MWNT-APTES- } \\
\text { silica }\end{array}$ & 46.78 & 128.25 & 0.35 & 107.58 & 0.97 & 22.80 & 0.99 & - & $\sim 75$ \\
\hline AC-APTES-silica & & 250.85 & 0.35 & 55.04 & 1.85 & 21.09 & 1.54 & $0-35$ & $\sim 40-75$ \\
\hline APTES-silica & 84.5 & 71.01 & 0.17 & 97.39 & 4.12 & 12.13 & 2.91 & - & $\sim 80$ \\
\hline \multicolumn{10}{|c|}{ APTES-functionalized/ hybrid materials after PAN modification } \\
\hline $\begin{array}{l}\text { APTES } \mu \text { silica - } \\
\text { PAN }\end{array}$ & & 118.06 & 0.24 & 79.79 & 3.58 & 11.39 & 2.57 & & $\sim 80$ \\
\hline $\begin{array}{l}\text { APTES } \mu \text { silica - } \\
\text { chitosan-PAN } \\
\text { flakes }\end{array}$ & & 71.89 & 0.13 & 68.87 & 10.99 & 26.02 & 4.02 & 22.69 & $\sim 36.28$ \\
\hline $\begin{array}{l}\text { MTM } \mu \text { silica - } \\
\text { chitosan-PAN } \\
\text { flakes }\end{array}$ & & 139.96 & 0.24 & 68.25 & 15.14 & 24.52 & 3.33 & 21.39 & $\begin{array}{c}5.62 \\
\sim\end{array}$ \\
\hline $\begin{array}{l}\text { SWNT-APTES - } \\
\text { silica-PAN }\end{array}$ & 44.74 & 134.11 & 0.38 & 112.49 & 2.32 & 17.15 & 1.65 & $0-18^{\prime}$ & $\sim 60-80$ \\
\hline $\begin{array}{l}\text { MWNT-APTES - } \\
\text { silica-PAN }\end{array}$ & 55.97 & 107.19 & 0.31 & 115.77 & 2.49 & 23.98 & 1.46 & - & $\begin{array}{l}70 \\
\sim 70\end{array}$ \\
\hline $\begin{array}{l}\text { AC-APTES - } \\
\text { silica-PAN }\end{array}$ & & 21.82 & 0.06 & 107.94 & 2.91 & 46.15 & 2.23 & $0-35^{\prime}$ & $\sim 15-35$ \\
\hline $\begin{array}{l}\text { APTES-silica- } \\
\text { PAN }\end{array}$ & & 109.21 & 0.34 & 123.43 & 2.56 & 9.58 & 1.96 & - & $\begin{array}{l}\sim 85 \\
\end{array}$ \\
\hline \multicolumn{10}{|c|}{ Non-hybrid materials with PAN modification } \\
\hline SWNT-PAN & 27.65 & 217.04 & 0.45 & 83.68 & 0.42 & 84.03 & 0.58 & $0-15^{\prime}$ & - \\
\hline MWNT-PAN & & \# & \# & \# & 0.94 & 93.37 & 0.46 & $\sim 5$ & - \\
\hline AC-PAN & & 466.39 & 0.33 & 28.28 & 0.73 & 72.20 & 0.92 & $0-25^{\prime}$ & - \\
\hline $\begin{array}{l}\text { Marine algae- } \\
\text { PAN }\end{array}$ & 12574 & 1.95 & 0.004 & 78.09 & 1.97 & 40.50 & 4.84 & $0-50$ & - \\
\hline$\mu$ silica-PAN & & 352.29 & 0.66 & 74.38 & 0.52 & 1.99 & 0.35 & - & $>95$ \\
\hline
\end{tabular}




\subsection{FTIR analysis}

With the aim of attaining a definitive account of the surface functional groups and for identifying the binding sites on the adsorbents for the target elements, FTIR analysis was performed. Figure 9 shows the IR plots of amine (APTES and APTMS) and non-amine (MTM and TMCS) functionalized silica gels (Article 2), divided into two subfigures, from 500 till $1000 \mathrm{~cm}^{-1}$ in Figure 10.a and from 1200 till $3200 \mathrm{~cm}^{-1}$ in Figure 10.b. The bands attained between 800 and $1260 \mathrm{~cm}^{-1}$ are due to the $\mathrm{Si}-\mathrm{OH}$ groups and superimposition of $\mathrm{SiO}_{2}$ peaks. Particularly, the bands obtained at $1100 \mathrm{~cm}^{-1}, 950 \mathrm{~cm}^{-1}, 800 \mathrm{~cm}^{-1}$ and $450 \mathrm{~cm}^{-1}$ are from asymmetric vibration of $\mathrm{Si}-\mathrm{O}$, asymmetric vibration of $\mathrm{Si}-\mathrm{OH}$, symmetric vibration and rocking mode of $\mathrm{Si}-\mathrm{O}$, respectively [152]. The broad band between 3300 and $3500 \mathrm{~cm}^{-1}$ stems from the $\mathrm{O}-\mathrm{H}$ stretching, arising from water molecules or $\mathrm{H}$-bonded $\mathrm{Si}-\mathrm{OH}$ moieties [153]. Besides, the incorporation of amine group can also be confirmed from the band at $\sim 3356 \mathrm{~cm}^{-1}$. The symmetric $-\mathrm{CH}_{3}$ and asymmetric $\mathrm{C}-\mathrm{H}$ groups attached to the surface of silica gels after the silanization process can also be detected between 2850 and $2950 \mathrm{~cm}^{-1}$ in all the modified gels under observation here. In addition to these bands, APTES/ APTMS modified silica gels displayed peaks in the territories of 1300, 1410 and 1480 $\mathrm{cm}^{-1}$, indicative of $\mathrm{CH}_{2}$ wagging mode from the backbone, bending mode of $\mathrm{CH}_{3}$ group near Si$\mathrm{CH}_{2}$ and symmetric $\mathrm{NH}_{2}$ groups, respectively. These bands observed in the domain of 1200-1600 $\mathrm{cm}^{-1}$ are characteristic of APTES and APTMS components [94,153]. This argument is also supported by the absence of these bands for MTM and TMCS modified gels. Besides, it should be noted that there is no distinct difference in peaks noticed between APTES and APTMS gels.

Further with PAN and Acac modifications (Article 1), additional bands were recorded between 1630 and $1686 \mathrm{~cm}^{-1}$, attributing to $\mathrm{N}=\mathrm{N}$ vibrations and asymmetric $\mathrm{COO}^{-}$groups[94]. The dissimilarities between PAN and Acac modified gels can be seen around the zone between 1200 and $1700 \mathrm{~cm}^{-1}$. The sharp bands at $1500 \mathrm{~cm}^{-1}(\mathrm{C}=\mathrm{C}$ stretching vibration modes from benzenoid and pyridyl units of PAN) and $1329 \mathrm{~cm}^{-1}(\mathrm{C}=\mathrm{N}$ stretching vibration of the benzenoid unit) are the characteristic peaks of PAN modified adsorbents [154]. The clear difference between the spectra of PAN/ Acac immobilized and physically loaded gels can be observed because of occurrence of additional bands in the territories of 500 to $900 \mathrm{~cm}^{-1}$, probably due to the superimposition of groups with the grafting of APTES and APTMS moieties.

Similarly, PAN physically adsorbed and chemically immobilized onto various supports (Article 37) used in this study were subjected to FTIR investigations, the results of which are provided in Figure 10 (c\&d). Additionally, the FTIR spectra of unmodified i.e. bare or pristine support materials were compared to confirm the functionalization of groups on the surface of supports. On comparing Figures 10.c \& 10.d, it can be stated that the functionalization or grafting process was successful with the appearance of additional bands because of surface modification. After the hybridization of carbon supports with silica groups with APTES as a linker, the characteristic silica bands appeared in the spectral plots of hybridized materials, as shown in Figure 10.d. The presence of symmetric $\mathrm{NH}_{2}$ groups $\left(1450-1480 \mathrm{~cm}^{-1}\right), \mathrm{Si}-\mathrm{CH}_{2}$ groups $\left(1410 \mathrm{~cm}^{-1}\right), \mathrm{C}-\mathrm{H}$ stretch $\left(1382 \mathrm{~cm}^{-}\right.$ 
$\left.{ }^{1}\right)$ and $\mathrm{CH}_{2}$ wagging modes $\left(1300 \mathrm{~cm}^{-1}\right)$ were witnessed as a result of APTES functionalization. In silica-chitosan materials, the bands arising from $\mathrm{Si}-\mathrm{O}$ linkages can be detected at around 450, 800 and $1000 \mathrm{~cm}^{-1}$. Further, on comparing the spectra for beads and flakes, distinct changes can be observed. It is quite apparent from the bead's spectra that the silica-chitosan has undergone significant structural modification. It was evidenced by a strong $\mathrm{C}-\mathrm{N}$ fingerprint at $896 \mathrm{~cm}^{-1}$, a sharp in-plane $\mathrm{C}-\mathrm{H}$ bending at $1381 \mathrm{~cm}^{-1}$, a weak band arising from $\mathrm{C}=\mathrm{O}$ amide group at 1629 $\mathrm{cm}^{-1}$ and superimposition of peaks $\left(\mathrm{C}-\mathrm{O}, \mathrm{C}-\mathrm{C}, \mathrm{CH}_{2}\right.$ rock and $\left.\mathrm{Si}-\mathrm{O}\right)$ at $1029 \mathrm{~cm}^{-1}$ [121,148]. On the other hand, these strong peaks were not attained for silica-chitosan flakes, except a peak corresponding to silica backbone, similarly observed with other hybrid materials. The peaks obtained for marine algae were assigned to polyphenolic/primary amine $\mathrm{O}-\mathrm{H}$ group $\left(3414 \mathrm{~cm}^{-1}\right)$, alkane $\mathrm{C}-\mathrm{H}$ stretching $\left(2924 \mathrm{~cm}^{-1}\right)$, amide $\mathrm{I}\left(1638 \mathrm{~cm}^{-1}\right)$, aromatic $\mathrm{C}-\mathrm{C}$ stretching $\left(1418 \mathrm{~cm}^{-1}\right)$, carboxylic acid $\mathrm{C}-\mathrm{O}$ stretching $\left(1243 \mathrm{~cm}^{-1}\right)$, aliphatic amine $\mathrm{C}-\mathrm{N}$ stretching $\left(1030 \mathrm{~cm}^{-1}\right)$ and sulfonate $\mathrm{S}-\mathrm{O}$ stretching $\left(813 \mathrm{~cm}^{-1}\right)$ [155]. For PAN grafted algal biomass, the additional convoluted peaks for $\mathrm{C}=\mathrm{C}$ and $\mathrm{C}=\mathrm{N}$ from PAN units were assigned at $1500 \mathrm{~cm}^{-1}$ and $1329 \mathrm{~cm}^{-1}$, like prior assignments on PAN modified supports of this study. Besides, in carbon-based supports, the other representatives of carbon units were also vaguely spotted possibly due to $\mathrm{C}-\mathrm{O}$ mode $\left(1355 \mathrm{~cm}^{-1}\right)$, intra-surface bending vibration of $\mathrm{C}-\mathrm{O}-\mathrm{H}\left(1398 \mathrm{~cm}^{-1}\right)$ and carbonyl stretch vibration of $\mathrm{C}=\mathrm{O}$ units $\left(1633-1650 \mathrm{~cm}^{-1}\right)$ [126]. Upon PAN grafting, the similar bands in the territories of 1200 to $1600 \mathrm{~cm}^{-1}$ were observed and were assigned analogously to the case of PAN grafted silica gels described earlier. APTES and silica backbone were evidently absent in the spectra (Figure 10.c) for PAN physically loaded onto the support materials, more specifically mentioned as "nonhybrid adsorbents" here. In the presence of chitosan moieties, the certain peaks were detected at $1559 \mathrm{~cm}^{-1}$ (C-N stretch) and $1370-1420 \mathrm{~cm}^{-1}$ (COO- units) $[41,65,156]$.
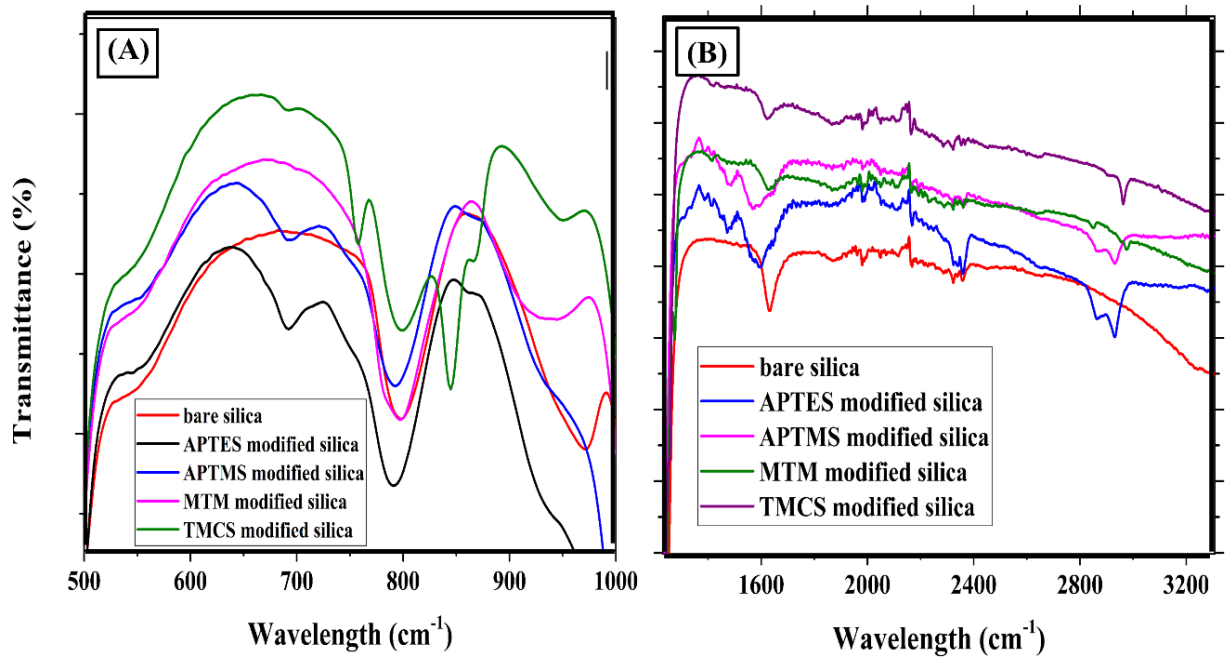


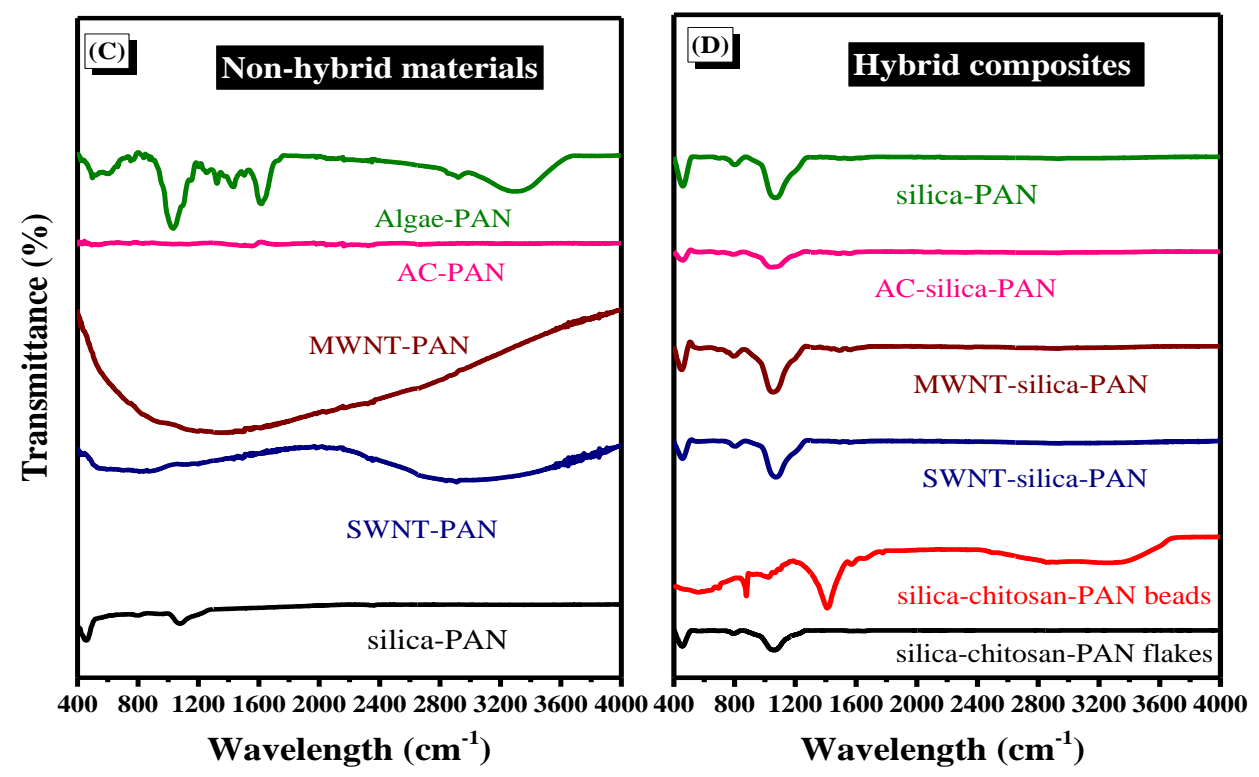

Figure 10: FTIR spectra for (a\&b) amino and non-amino functionalized $\mu$ silica gels (c) PAN physically grafted onto supports (d) Method II-hybrid composites.

\subsection{XRD analysis}

The XRD spectra obtained for bare as well as modified silica and chitosan materials provided a clear inference that these materials are disordered and amorphous in nature, established by the presence of a single broad halo peak in the $2 \Theta$ range of $20-26^{\circ}$ [157]. Figure 11.a shows the XRD diffraction patterns recorded for the unmodified supports prior to modification. In case of carbonbased materials (Articles 5 and 6), the typical peaks around $25-30^{\circ}, 45-50^{\circ}$ and $80-90^{\circ}$ are representatives of graphite structure, assigned to diffraction planes of (002), (100/101) and (112), respectively [158,159]. Subsequent to hybridization with silica groups and chemical immobilization of PAN units onto the pristine supports (Figure 11.b), the peaks in the area of 45$50^{\circ}$, characteristic of graphite backbone, were dispersed after surface modification. Further, the emergence of a broad halo peak around $20-26^{\circ}$ in the composite materials (both AC-silica and CNT-silica) confirmed the success of the hybridization process with silica. Examination of the XRD spectra from both unmodified materials and the PAN loaded non-hybrid materials (in the absence of silica) showed that there is no definite difference except the decrease in peak intensities after the ligand-grafting step. Similar occurrences were also reported earlier, the implication of which being the inconsequential effect of the functionalization process on cylindrical CNT 
structure, suggesting that the structure remained intact after the functionalization procedure $[160,161]$.
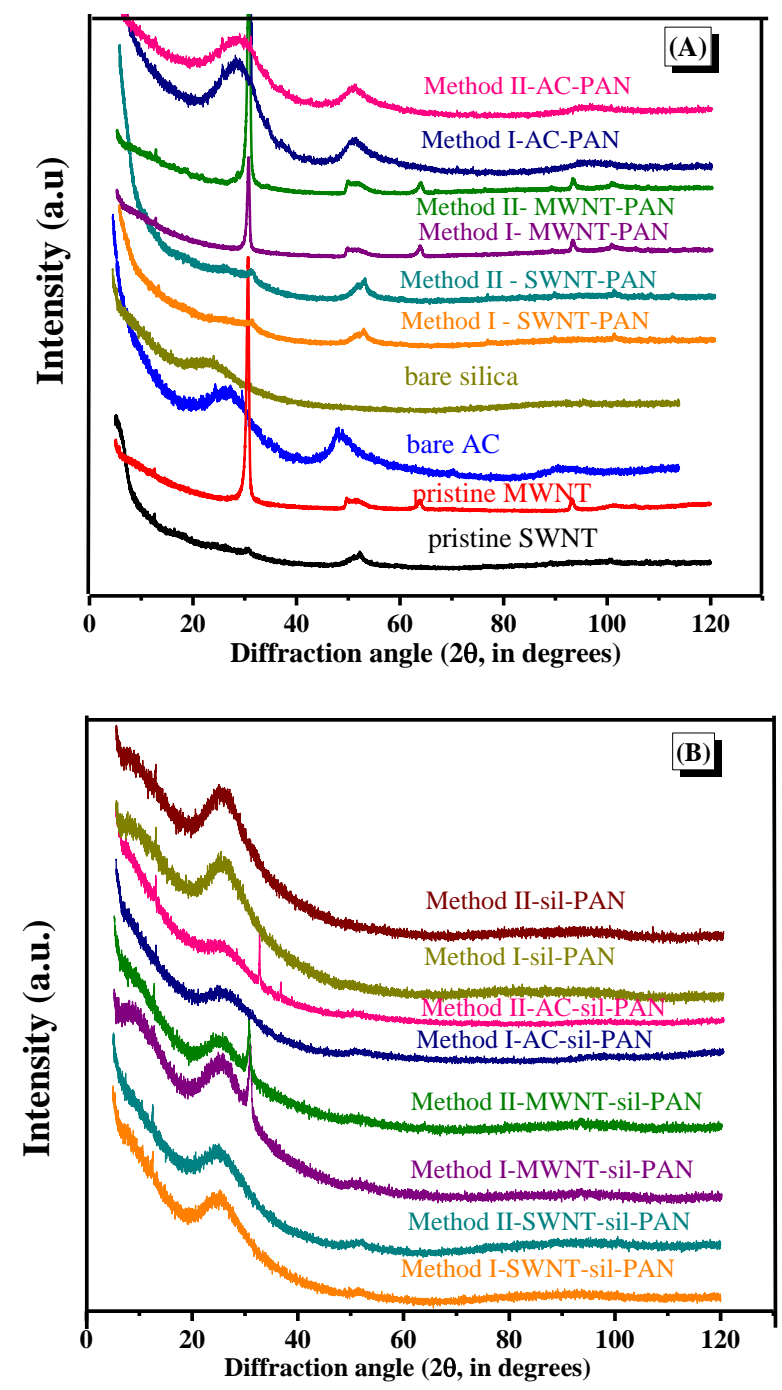

Figure 11: XRD spectra for (a) pristine and PAN grafted CNT/AC materials and (b) PAN grafted silica and hybrid composites. 


\section{DISCUSSION OF SIGNIFICANT FINDINGS AND FUTURE REMARKS}

\subsection{Can the same preparation method be adopted for all supports?}

The observations showed that the composites, which adopted hybridization and ligand modification approach via Method II, had a better performance for all the cases except for SWNT. On comparing SWNT and MWNT, it can be seen that the REE adsorption behavior of Method IIPAN grafted MWNT- silica composites was far more superior, and this might be due to the following reasons (a) number of surface binding sites on the composites, and (b) CNT and silica crosslinking ability/degree in the presence of APTES. Briefly (Figure 12), APTES functionalized SWNT-silica displayed commendable results in comparison to APTES functionalized MWNTsilica composites in the absence of PAN grafting. Further, the results revealed that the PAN grafting is essential to facilitate REE affinity in the case of the MWNT-silica composites, and this enunciates the dominating effect of PAN units on overall superior REE adsorption observed with Method II-MWNT-sil-PAN. This also further underlines the significance of chemical immobilization of PAN on MWNT-based adsorbents utilized in this study. As quoted earlier, the PAN moieties are not significant for SWNT adsorbents where the REE affinity primarily arises from the amino groups of APTES functionalized SWNT-sil composites. Hence, from this perspective, the effect of APTES crosslinking was more pronounced for SWNT-silica (3.6\% of N and $2.64 \%$ of $\mathrm{H}$ ) than MWNT-silica $(0.91 \%$ of $\mathrm{N}$ and $0.99 \%$ of $\mathrm{H})$, with the surface amino groups acting as the potential binding sites for REE adsorption in case of SWNT-sil without any positive influence from PAN grafting. On the contrary, the performance of MWNT-sil and 1-MWNT-sil$\mathrm{P}$ was below par, and this was rectified through the chemical immobilization of PAN via Method II. In this direction, 2-MWNT-sil-P displayed excellent results due to the enhancement of its surface properties via PAN grafting and eventually turned out to be one of the finest adsorbents from this research work with enhanced REE selectivity and affinity (Figure 12). Also, there are references in literature that point to the existence of $\mathrm{sp}^{2}$-hybridised carbon atom pyramidalization and the $\pi$-orbital misalignment in CNTs, in addition to other influential factors such as diameter, chirality, dispersion and configuration, that can ultimately lead to varying chemical reactivities among CNTs [162]. Thus, to obtain a thorough understanding of the basic mechanism of the adsorption process and the guest molecule interactions in CNTs, it is essential to analyze both SWNT and MWNT together. This can facilitate the development of nanostructure interfaces with great clarity. Hence, further studies are essential to apprehend the observed behavior of SWNT/MWNT-APTES-PAN and can be an article of future interest. 


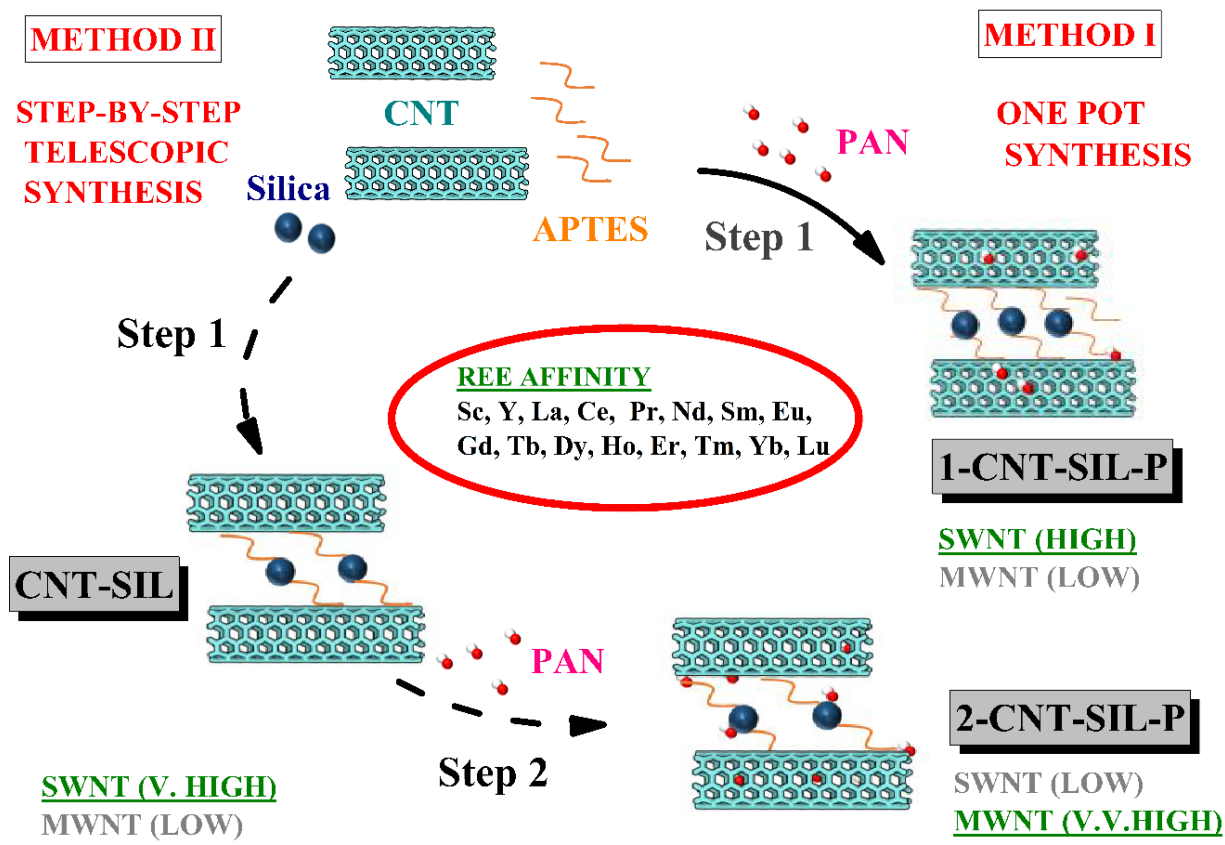

Figure 12: Contrasting behavior of SWNT and MWNT with the methods of preparation on REE affinity (Ref: Article 6)

\subsection{REE selectivity and affinity}

In this section, the hybrid composites synthesized via the most favorable preparation method (Method II) are compared altogether to identify the high-performance adsorbents in terms of their REE affinity and selectivity, by testing them in seawater (Figure 13.a) and AMD solution (Figure 13.b). As it can be seen, the hybrid adsorbents (Method II AC-sil-P and MWNT-sil-P) depicted REE removal of $>70 \%$ in an AMD solution maintained at a pH value of $5\left(\mathrm{C}_{\mathrm{REE}} \sim 2 \mathrm{ppm} ; \mathrm{t} 1 \mathrm{hr} ; \mathrm{T}\right.$ $45^{\circ} \mathrm{C}$ ). When using seawater, all the adsorbents depicted REE removal efficiencies of about 8099\%, as shown in Figure 13.a $\left(\mathrm{C}_{\mathrm{REE}} \sim 2 \mathrm{ppm} ; \mathrm{t} 1 \mathrm{hr} \mathrm{T} 45^{\circ} \mathrm{C}\right)$. The primary difference between these solutions (seawater and AMD) was their concentration of competing ions. As presented in Table 4, the existence of highly concentrated competing ions in AMD, such as $\mathrm{Mn}^{2+}, \mathrm{Al}^{3+}, \mathrm{K}^{+}, \mathrm{Mg}^{2+}$, $\mathrm{Zn}^{2+}, \mathrm{Ca}^{2+}, \mathrm{Na}^{+}$and $\mathrm{S}^{6+}$, resulted in effective competition between the ions and this was exploited to understand the differences of affinities in a multi-component system. With the availability of limited binding sites on the adsorbents' surface, it can be realized that the inequality in metal ion affinities influenced the binding of REEs or other metal ions onto the adsorbents. 


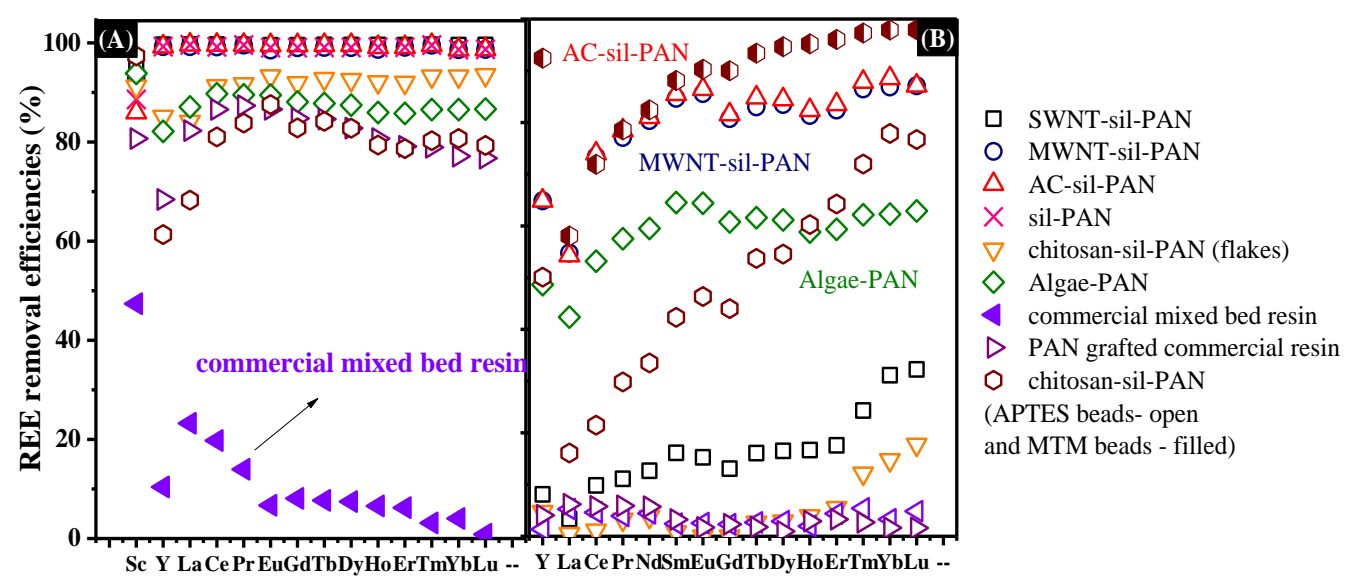

Figure 13: Comparison of adsorbents' performance using (a) seawater [CREE $\sim 2 \mathrm{ppm}$; $1 \mathrm{~h}$; $\mathrm{T} 45^{\circ} \mathrm{C}, \mathrm{pH}$ 6] and (b) AMD [CREE 2ppm; t $1 \mathrm{~h} ; \mathrm{T}^{\circ}{ }^{\circ} \mathrm{C}, \mathrm{pH}$ 5]. X- and Y-axes indicate the REE series (from Sc until $\mathrm{Lu}$ ) and REE removal efficiencies, respectively (modified from Ref.: Article 7) .

The selectivity of our synthesized adsorbents in the presence of interference can be comprehended from Figure 13.b, the inference of which showed the superiority of AC-sil-PAN, MWNT-sil-PAN and algae-PAN adsorbents amongst all the different materials. It should be noted that all the materials displayed very poor or negligible affinity towards $\mathrm{Mg}^{2+}, \mathrm{Mn}^{2+}, \mathrm{Ni}^{2+}, \mathrm{Co}^{2+}, \mathrm{Zn}^{2+}$ and $\mathrm{Ca}^{2+}$. On the other hand, co-removal of $\mathrm{Al}^{3+}, \mathrm{Cr}^{3+}, \mathrm{Cu}^{2+}$ and $\mathrm{Pb}^{2+}$ were observed at the $\mathrm{pH}$ range of 5-6. In addition, it must be remarked that the presence of Sulphur, sodium and other industrial impurities (e.g. anionic species and organic compounds) present in AMD could have also impacted the adsorption process contributing to the poor performance by most of the adsorbents.

Besides, in order to evaluate the REE removal efficiencies of these synthesized materials in comparison to commercial resins, Dowex resin (mixed bed containing anionic and cationic 1:1) was also evaluated with and without PAN grafting. As shown in Figure 13.a, akin to all the synthesized adsorbents, PAN grafted commercial resin also had the potential to adsorb all the REEs from seawater. However, with increased competing ions, i.e. in an AMD case, they performed miserably as a result of their low selectivity. In both the cases of AMD and seawater (Figure 13.a \& 13.b), bare commercial resin showed affinity towards $\mathrm{Sc}^{3+}$ alone, which further supported the earlier findings from prior research associated with the distinctive behavior of Sc among REEs. Moreover, on increasing the competition among REEs by spiking their concentrations to $5 \mathrm{ppm}$ in an AMD solution, it was understood that the REE adsorption efficiencies were in the order of AC-sil-PAN > MWNT-sil-PAN > Algae-PAN > sil-PAN (Figure 14). Prior works by Texier et.al. [138] concluded that the selectivity of Pseudomonas aeruginosa towards REEs was not hindered even in the presence of co-ions such as $\mathrm{Na}^{+}, \mathrm{K}^{+}, \mathrm{Ca}^{2+}, \mathrm{Cl}^{-}$, sulfate and nitrate, supporting our data. Besides, it should be mentioned that $\mathrm{AC}$-sil composites were 
hybridized with 1 part of AC and 1 part of silica while the MWNT-sil adsorbents were synthesized by the mere addition of 1 part of MWNT to 10 parts of silica. Hence, such a small quantity of MWNT reinforcement added to silica could result in an enhanced REE affinity. By the further increase in MWNT loading, the REE adsorption performance can either improve or not, and it is uncertain at this stage. However, it should also be noted that AC $(89.50 € / \mathrm{kg})$ is comparatively cheaper in relation to MWNT $(351 € / 10 \mathrm{~g})$. Besides, some of the prior works confirmed matrix/polymer reinforcement by the addition of a small amount $(<10 \%)$ of CNT, in terms of mechanical properties $[128,132,134,163]$. These studies also demonstrated the effect of silanization in promoting strong interactions between CNT and epoxy matrix. In this line, this study shows that the REE adsorption performance can be significantly enhanced by a minimal CNT loading ("spice polymer") to the silica support. This can be understood certainly from the large difference in distribution coefficient values $\left(\mathrm{K}_{\mathrm{D}}\right)$ of silica-PAN $(0.5$ to $1 \mathrm{~L} / \mathrm{g})$ and MWNTsil-PAN (1-6 L/g) for the same REE feed concentration of 5 ppm (Figure 14). Besides, the observed $K_{\mathrm{D}}$ values of this work are evidently higher than the reported ones for REE uptake in literature $[41,122,139]$.

Table 4: The composition of other competing ions in seawater and AMD before and after the adsorption process for various adsorbents. On adjusting to desired $\mathrm{pH} 5-6$, most of the competing ions including Fe and $\mathrm{Al}$ in $\mathrm{AMD}$ (original $\mathrm{pH} \sim 2$ ) resulted in precipitation. Hence, the concentration of these ions after the adjusted $\mathrm{pH}$ value of 5 and 6 are provided in this table, not the original concentration found in AMD. Additionally, it should be noted that the concentration of Sulphur was high > $1500 \mathrm{ppm}$; hence, it is not included in this table.

\begin{tabular}{|c|c|c|c|c|c|c|c|c|}
\hline \multirow{2}{*}{$\begin{array}{l}\text { Competing } \\
\text { ions }\end{array}$} & \multirow{2}{*}{$\begin{array}{l}\mathbf{C}_{\text {initial }} \\
(\mathbf{p p m})\end{array}$} & \multicolumn{7}{|c|}{$C_{\text {final }}(\mathbf{p p m})$} \\
\hline & & $\begin{array}{l}\text { SWNT- } \\
\text { sil-P }\end{array}$ & $\begin{array}{l}\text { MWNT-sil- } \\
\text { P }\end{array}$ & $\begin{array}{l}\text { AC- } \\
\text { sil-P }\end{array}$ & $\begin{array}{l}\text { Chitosan- } \\
\text { sil-P } \\
\text { (flakes) }\end{array}$ & $\begin{array}{l}\text { Chitosan- } \\
\text { sil-P } \\
\text { (beads) }\end{array}$ & $\begin{array}{l}\text { Marine } \\
\text { algae }\end{array}$ & $\begin{array}{l}\text { Marine } \\
\text { algae-P }\end{array}$ \\
\hline \multicolumn{9}{|c|}{ AMD solution at pH 5} \\
\hline Al & 1.83 & 0.4 & 0.93 & 1.08 & 0.13 & 0.009 & 1.08 & 0.67 \\
\hline Co & 2.36 & 2.01 & 2.34 & 2.4 & 1.77 & 1.71 & 2.45 & 0.53 \\
\hline $\mathrm{Cr}$ & 1.54 & 1.02 & 0.54 & 0.72 & 1.07 & 1.01 & 0.89 & 0.8 \\
\hline $\mathbf{C u}$ & 1.04 & 0.03 & 0.44 & 0.39 & 0.24 & 0.41 & 0.52 & 0.02 \\
\hline Mg & 113.17 & 113.31 & 112.32 & 112.6 & 113.81 & 111.58 & 111.91 & 113.43 \\
\hline Mn & 14.9 & 14.18 & 14.65 & 14.56 & 15.08 & 14.09 & 15.06 & 14.96 \\
\hline $\mathbf{N i}$ & 2.48 & 2.37 & 2.43 & 2.46 & 1.56 & 2.1 & 2.47 & 2.05 \\
\hline $\mathbf{P b}$ & 1.11 & 0.91 & 0.19 & 0.02 & 1.21 & 0.57 & 0.39 & 0.6 \\
\hline $\mathbf{Z n}$ & 86.13 & 80.12 & 70.54 & 75.57 & 74.49 & 79.58 & 84.19 & 84.47 \\
\hline \multicolumn{9}{|c|}{ Sea water at pH 6} \\
\hline $\mathbf{C a}$ & 11.79 & 11.41 & 11.26 & 11.39 & 11.5 & 11.71 & 11.7 & 11.72 \\
\hline Mg & 19.02 & 18.72 & 18.64 & 19.01 & 18.62 & 19.01 & 19.01 & 19.01 \\
\hline $\mathbf{C r}$ & 2.02 & 0.13 & 0.35 & 0.08 & 0.22 & 0.73 & 0.48 & 0.18 \\
\hline
\end{tabular}




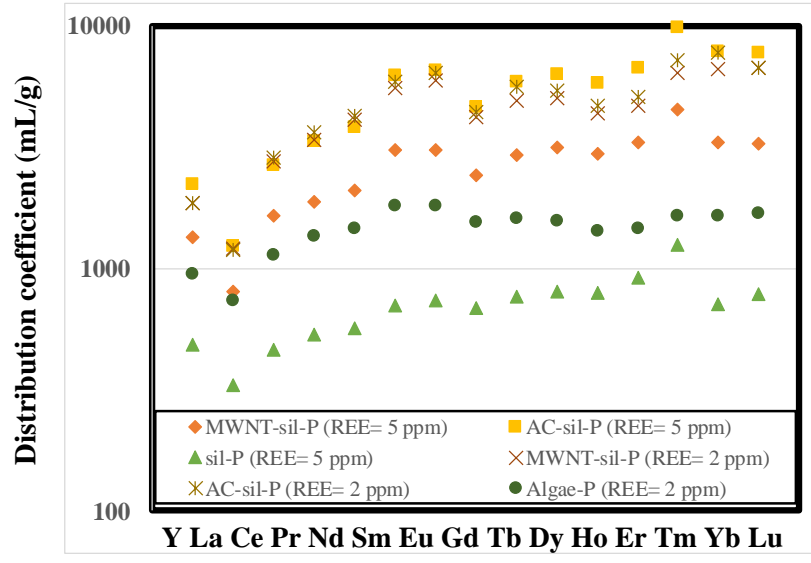

Figure 14: Distribution coefficients for REE adsorption by various adsorbents when AMD solution was used (pH 5, t 1 hr, T $45^{\circ} \mathrm{C}$ ) ( modified from Ref.: Article 6).

\subsection{Differences in scandium interaction with host molecules in comparison to other REEs}

The enhanced $\mathrm{Sc}^{3+}$ selectivity of the adsorbents might be a manifestation of its comparatively lower ionic radius. This is also in line with the trend in REE affinities observed with respect to HREEs/LREEs. In the atomic scale, the observed adsorption behavior can be explained via the lanthanide contraction effect, the phenomenon of which results in decreasing ionic radius with increasing atomic number/mass, because of the poor f-subshell shielding observed in the lanthanides [9,34]. Alongside the experimental study, Visual MINTEQ ver. 3.0 software was employed to understand the REE speciation, in an aqueous solution as a function of solution $\mathrm{pH}$. An initial concentration of $10 \mathrm{mmol} / \mathrm{L}$ was provided as input for this analysis. The speciation analysis reflected the fact that for all the REEs under consideration the behavior was similar, with Sc being an exclusion (Figure 15). In the case of lanthanides ( $\mathrm{Ln}$ ) and yttrium $(\mathrm{Y})$ solutions, until a $\mathrm{pH}$ value of 6 , the predominant species in the solution were $\mathrm{Ln}^{3+}$ and $\mathrm{Y}^{3+}$ while other ionic complexes such as $\mathrm{LnOH}^{2+}$ and $\mathrm{YOH}^{2+}$ (REE hydroxides) at higher $\mathrm{pH}$ values (>6) $[104,164]$. In contrast to the aforementioned cases, Sc simultaneously occurs as multiple species over the considered $\mathrm{pH}$ range (>4). Within $\mathrm{pH} 4-9$, different species such as $\mathrm{Sc}(\mathrm{OH})^{2+}, \mathrm{Sc}(\mathrm{OH})_{3}(\mathrm{aq})$ and $\mathrm{ScOH}^{2+}$ are formed, while for $\mathrm{pH}$ values $>9$ it occurs primarily as $\mathrm{Sc}(\mathrm{OH})^{4-}$. The existence of $\mathrm{Sc}^{3+}$ ions occurred until a pH value of 4 for the feed concentration of $10 \mathrm{mmol} / \mathrm{L}$. Such disparities in the response of Sc in relation to other REEs further highlights the differences in its interaction behavior with host molecules in comparison to other REEs, despite being categorized in general as REE. This also provided us with sufficient insight into why yttrium, another pseudo lanthanide, 
had a closer resemblance to lanthanides while Sc depicted definite variations in terms of their host matrix interaction. Hence, it can be stated with confidence that despite belonging to the REE category, Sc is notably different from all the other REEs.
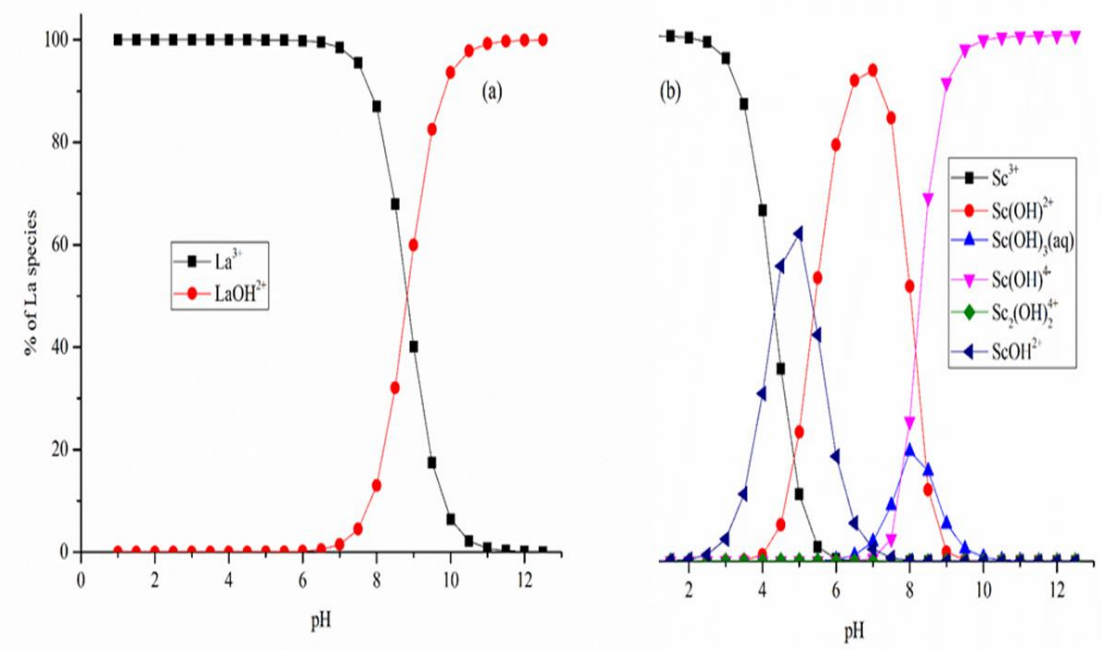

Figure 15: Varying REE speciation for (a) La and (b) Sc, simulated using Visual MINTEQ (Ref.: Article 1).

\subsection{Selective separation of scandium, REEs and other technological elements from diluted waste streams}

The findings from the single/multicomponent adsorption tests and speciation studies indicated the divergence in the Sc adsorption behavior in comparison to other REEs by the host matrix. This difference could be exploited further for selective $\mathrm{Sc}^{3+}$ separation from REE mixtures. As shown in Figure 16, PAN grafted CNT/AC adsorbents were capable of adsorbing Sc (only REE) at pH 4 or higher (Figure 16.b). On the other hand, the hybrid adsorbents i.e. PAN grafted CNT/AC-sil composites, did not demonstrate affinity towards any other REE at pH 4 (Figure 16.a) but showed higher affinity and selectivity towards all REEs from a pH value of 5 (Figure $13 \& 14$ ). Given the high selectivity and affinity towards REEs, Method II AC-sil-PAN and MWNT-sil-PAN can be considered as the ideal adsorbents for REE recovery at $\mathrm{pH} 5$. 


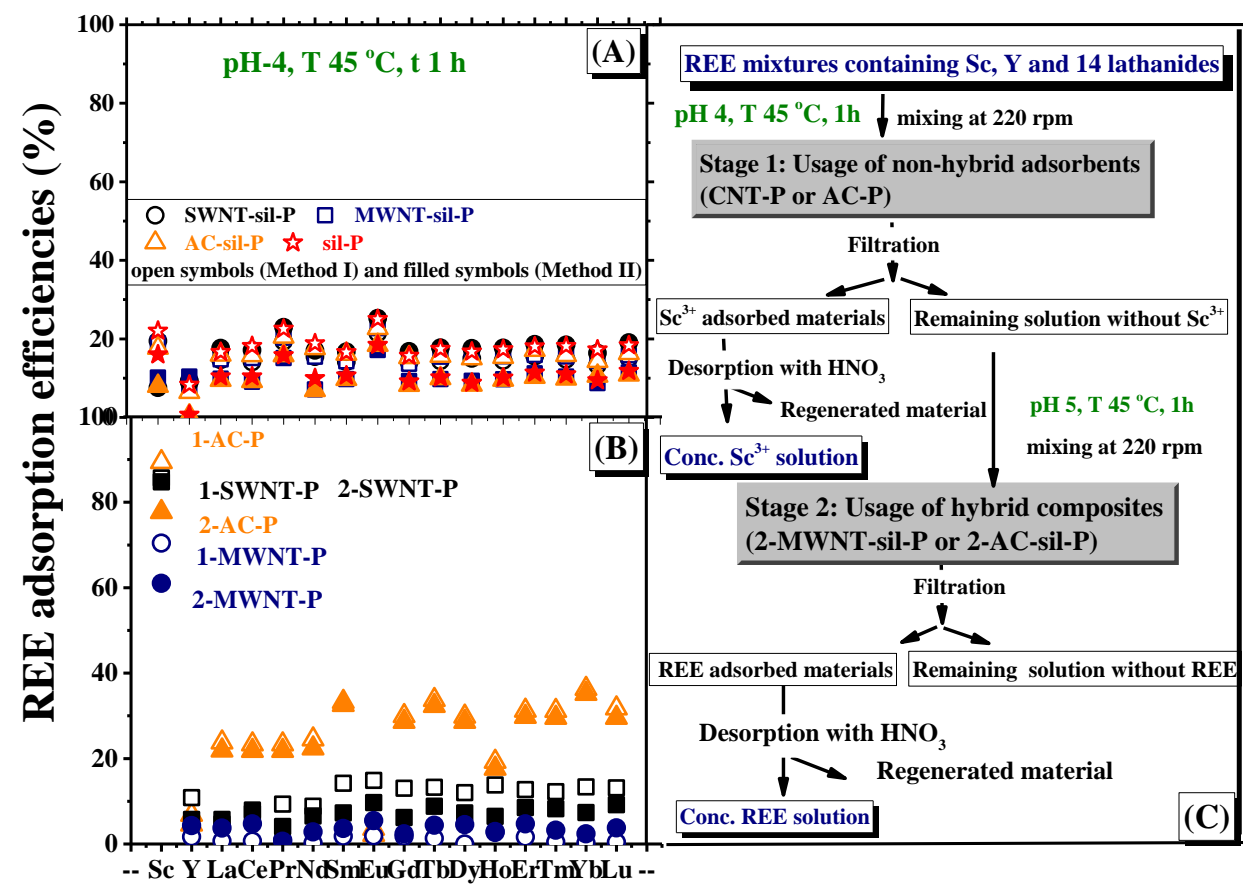

Figure 16: REE adsorption efficiencies at $\mathrm{pH} 4$ with AMD for (a) hybrid composites (b) non-hybrid AC/CNT materials and (c) two-stage selective separation of Sc and other REEs at $\mathrm{pH} 4$ and 5, respectively.

As shown in Figure 15, the PAN grafted CNT adsorbents (especially SWNT) could exhibit effective and efficient $\mathrm{Sc}^{3+}$ adsorption even under AMD conditions. Even though the same also held true for PAN grafted AC adsorbents, the relative co-removal of other REEs was undesirably higher (Figure 16.b). The recovery of $\mathrm{Sc}^{3+}$ at a solution $\mathrm{pH}$ of 4 is meaningful owing to the accompanied $\mathrm{Sc}^{3+}$ precipitation along with $\mathrm{Fe}^{2+} / \mathrm{Al}^{3+}$ typically observed at higher $\mathrm{pH}(\mathrm{pH} 5$ in our case), with an increase in solution concentration. Hence, the knowledge gained from these experimental analyses were employed to design a two-step recovery process to selectively separate $\mathrm{Sc}^{3+}$ from other REE mixtures, by controlling the solution $\mathrm{pH}$. A brief schematic of this proposed/developed strategy is presented in Figure 17.

Step 1: Selective Sc separation was accomplished by PAN grafted CNTs at $\mathrm{pH} 4$, yielding Sc free REE mixtures with other industrial impurities

Step 2: Selective separation of other REEs was achieved by PAN grafted hybrid AC-silica or hybrid MWNT-silica composites at $\mathrm{pH}$ 5. Unmodified marine algae can also be substituted at this stage when the concentrations of REEs/others are low in wastewaters. Consecutively, further separation of other valuable metals such as $\mathrm{Al}^{3+}, \mathrm{Zn}^{2+}, \mathrm{Mn}^{3+}$, and $\mathrm{Mg}^{2+}$ (one of the 27 critical 
elements) is possible, and hence, it can be of great implications to other high technology applications in various domains.

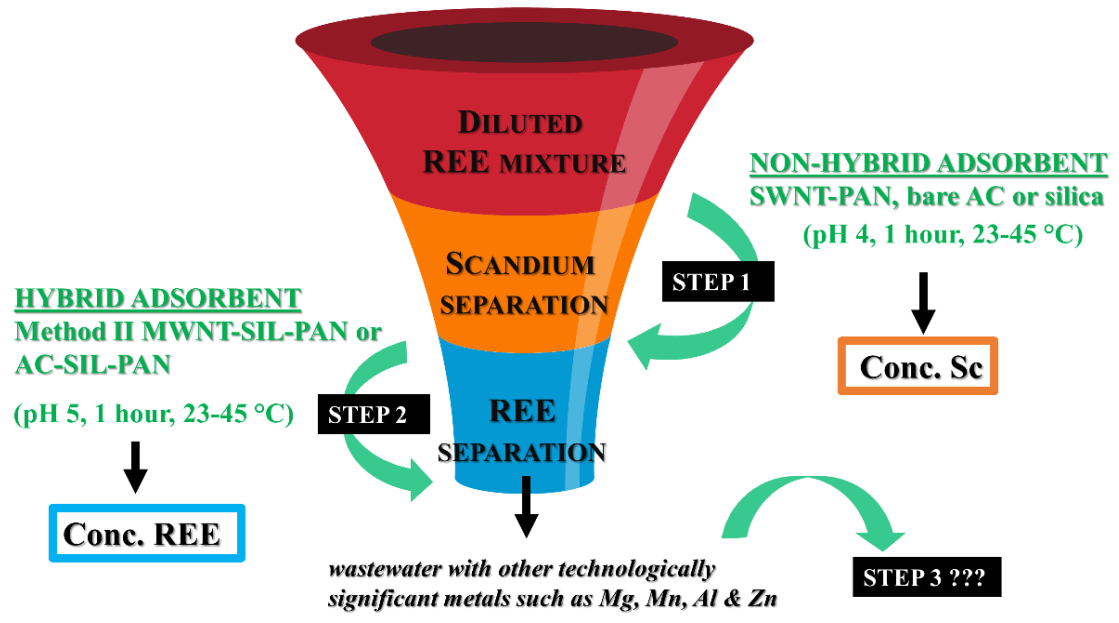

Figure 17: Schematic illustration of the proposed and developed strategy for two-stage selective removal of Sc and other REEs.

\subsection{REE adsorption mechanism}

In general, the significant features that affect the REE adsorption processes include solution $\mathrm{pH}$, initial REE concentration, process temperature, agitation rate, adsorbent dosage and contact period [165]. As discussed in single component studies under Chapters (4-7), among these parameters, $\mathrm{pH}$, temperature, initial concentration and time are the ones that exert a dominating influence on the adsorption process. The solution $\mathrm{pH}$ is considered as a crucial parameter limiting the REE sorption as it influences the dissociation state of the binding sites and protonation of surface groups during the process. In addition, this factor is also capable of affecting the degree to which the adsorbates are ionized at a certain $\mathrm{pH}$ [165]. Secondly, the initial REE concentration governs the maximum adsorption capacity of the adsorbent while the adsorption rate varies with the contact time in relation to the availability of binding sites for the target elements. In addition, the process temperature can also play a major role in the REE adsorption process. The results of singlecomponent studies are summarized in Figure 18(a-c). Besides, the maximum adsorption capacities for $\mathrm{La}^{3+}, \mathrm{Sc}^{3+}$ and $\mathrm{Y}^{3+}$ by our synthesized are provided in Table 5 (under Section 9.6) along with the optimal process conditions derived from single component system studies. 

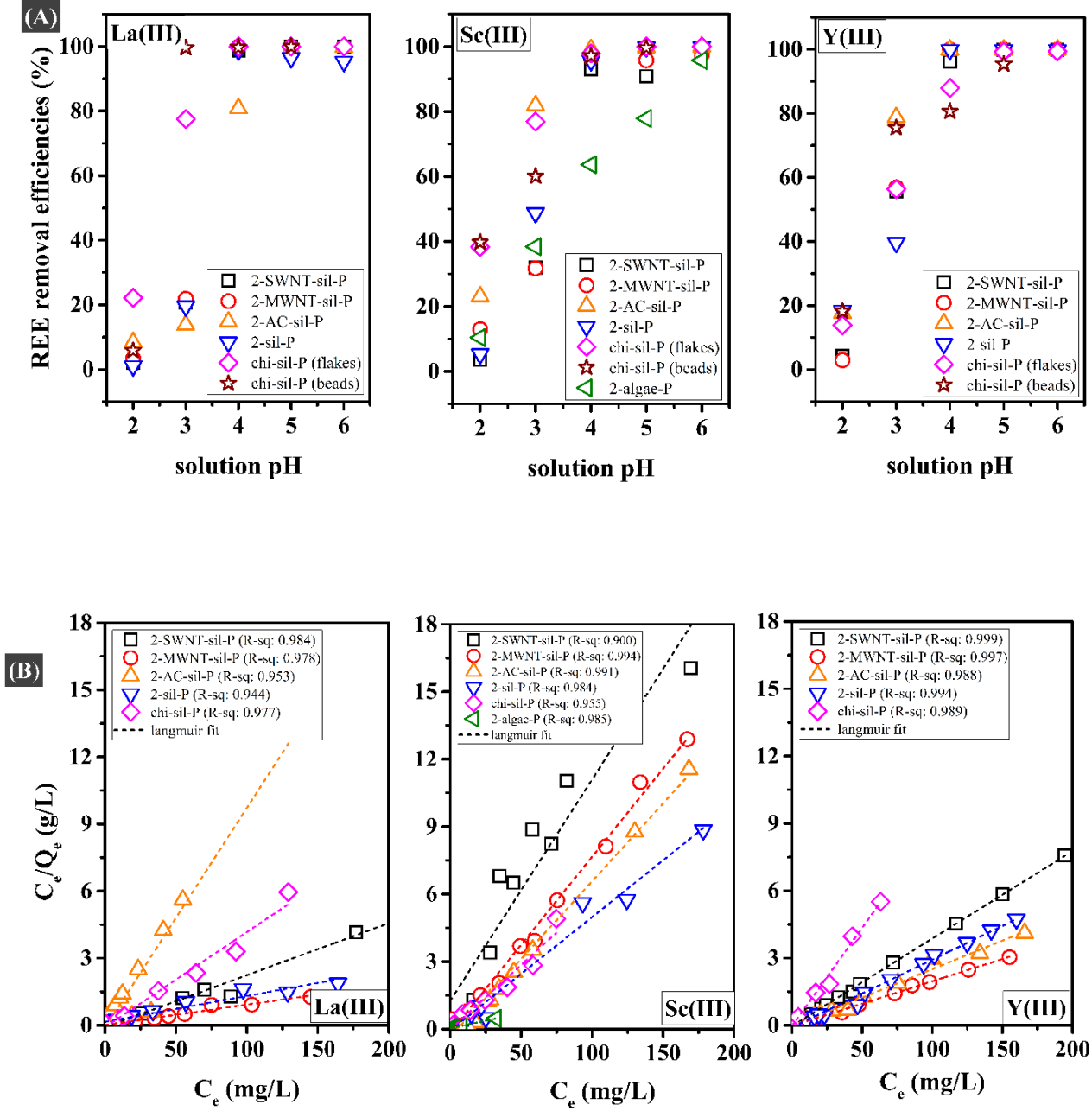

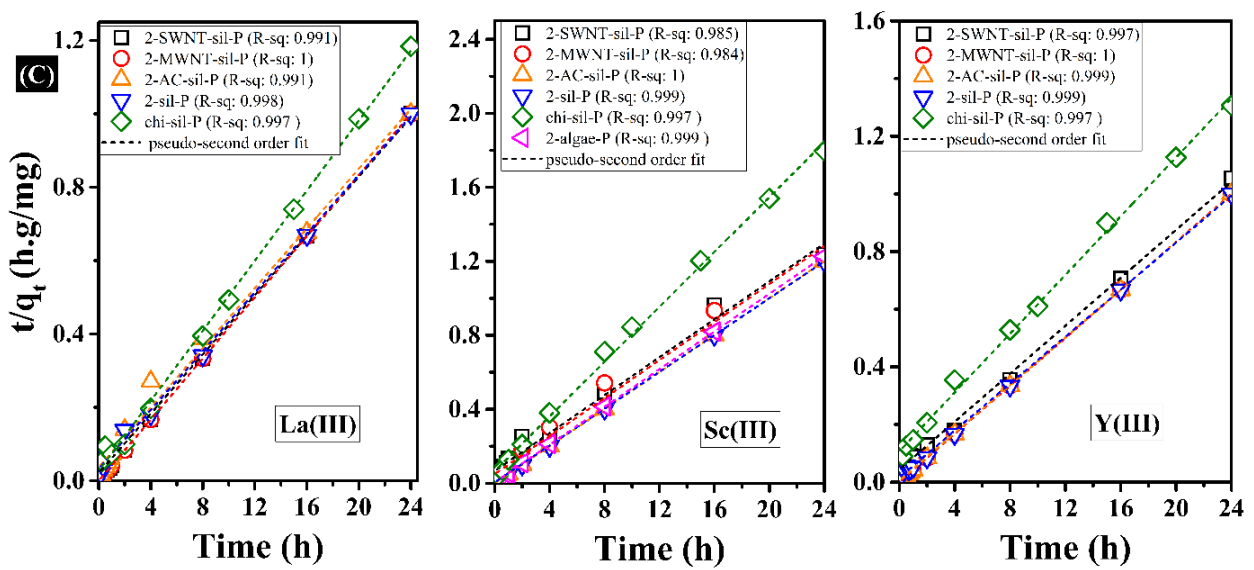

Figure 18: Single component REE batch adsorption studies (a) pH tests [CREE 20-25 ppm; $1 \mathrm{~g} / \mathrm{L}$; $24 \mathrm{~h}$; R.T.] (b) Isotherm tests [pH 4; 1 g/L; t 24 h; R.T.] and (c) Kinetic tests [pH 4; CREE 20-25 ppm; 1 g/L; R.T.] for the different adsorbents under evaluation.

Zeta potential surface charge measurements as a function of electrolyte $\mathrm{pH}(<5)$ displayed an overall positive surface charge for all the synthesized adsorbents functionalized with APTES. This helped to comprehend the host matrix-REE interaction where the ion-exchange mechanism might most likely occur between positively charged functional groups on the support and REE cations. This seemed to be relevant for the polymers used here and was supported by several works in literature $[22,41,62,122,124,137,139,148]$. Besides, ionic bonding can also be one of the factors owing to the predominantly electropositive nature of REE [9]. Furthermore, PAN is a tridentate ligand which forms a quasi-octahedral arrangement by two adjacent 5-membered coordination ring with REE cations via its N, N, O- donor atoms as shown in Figure 19.d. It is expected that metal to PAN ratio for the chelate complexes would be 1:2 for metals with coordination number 6 (commonly for REEs-lanthanides) while it would be 1:1 for metals with coordination number 4 [166]. There are three main binding sites $(-\mathrm{OH},-\mathrm{C}=\mathrm{N}-$ and pyridyl nitrogen group) on chromogenic reagent PAN which contributes to complexation/chelation between the PAN units and the REE cations. The protonation of the azo $(-\mathrm{N}=\mathrm{N})$ group is typically observed at acidic $\mathrm{pHs}$, while at basic pHs, ionization of $-\mathrm{OH}$ group of the phenolic unit has been reported [167]. On comparing the FTIR spectra (Figure 19 a-b) obtained for the adsorbents before and after REE adsorption revealed that the bands corresponding to $-\mathrm{C}=\mathrm{N}-\left(1329 \mathrm{~cm}^{-1}\right)$ group of PAN benzenoid unit, $-\mathrm{N}=\mathrm{N}\left(1590 \mathrm{~cm}^{-1}\right)$ azo group of PAN, $-\mathrm{NH}_{2}$ and $-\mathrm{CH}_{2}\left(1400-1480 \mathrm{~cm}^{-1}\right)$ group of the APTES silane were dispersed after REE adsorption process. Besides, the changes in bands at $665 \mathrm{~cm}^{-1}(\mathrm{Si}-$ $\mathrm{O}-\mathrm{C}$ bending vibration), $750-874 \mathrm{~cm}^{-1}$ (N-H deformation mode) and $1550 \mathrm{~cm}^{-1}$ (C-N stretching vibration) were also detected. Hence, it can be stated that the aforementioned groups involve in the REE adsorption process. Additionally, XRD spectra (Figure 19.c) of REE adsorbed materials 
showed the dispersion of diffraction peaks at $2 \Theta=10^{\circ}$ and $30^{\circ}$ after REE adsorption. These observations on FTIR and XRD spectra imply that REE sorption is mediated by chemisorption via coordination mechanism with PAN. The isotherm and kinetic modeling of experimental data, which displayed a perfect fit to Langmuir (L) isotherm, and pseudo-second-order (PS2) kinetic models with $\mathrm{R}^{2}>0.9$ (Figure 18) also support this argument of chemisorption. Most commonly, L-PS2 models, according to many works in literature, fits the best in terms of REE uptake via chemisorption. Some cases include $\mathrm{Ln}^{3+}$ uptake by grapefruit peel, crab shell, granular grafted hydrogel composites, chitosan nanoparticles, EDTA- $\beta$-cyclodextrin, Stichocooccus bacillaris, Chlorella vulgaris, Chlamydomonas reinhardtii, surface-modified mesoporous silica, graphene oxide and activated carbon [62,139,168-172]. Besides, the influence of temperature on the REE sorption process by these adsorbents further confirms the statement of chemisorption. As stated previously, the affinity towards HREE > LREE echoes the lanthanide contraction and tetrad effect, associated with the steady reduction of REE ionic radius with increasing atomic number/mass which is caused by the imperfect electron shielding within the same sub-shell [9]. Thus, the ionic radii of REE correlate the binding and affinity mechanism along with steric effects.

\section{(A)}

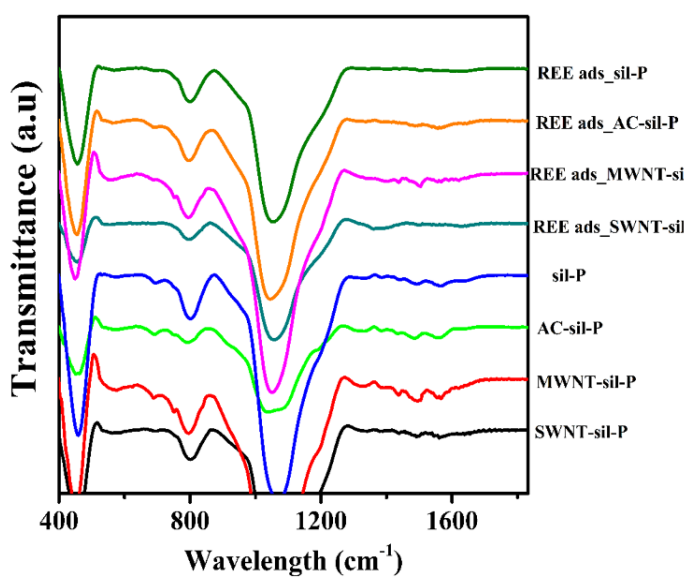

(B)

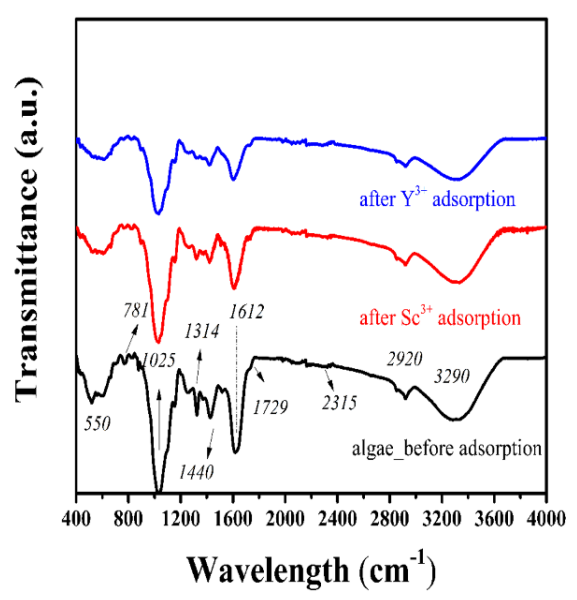


(C)

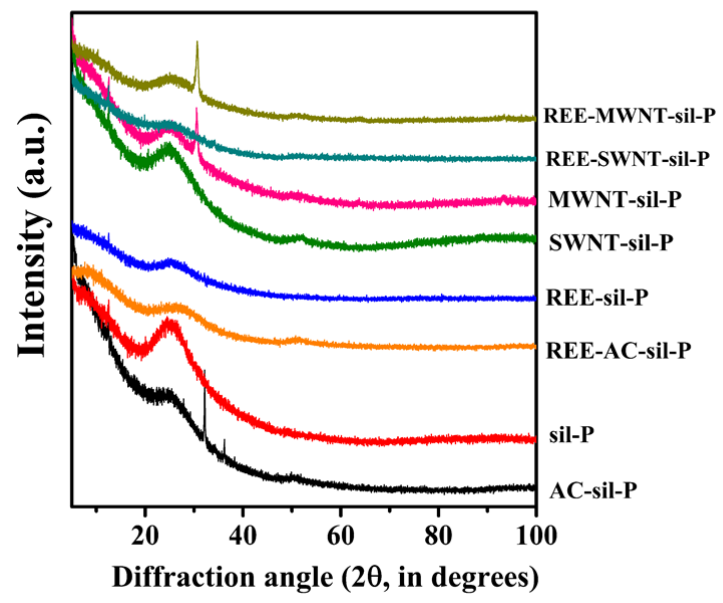

(D)

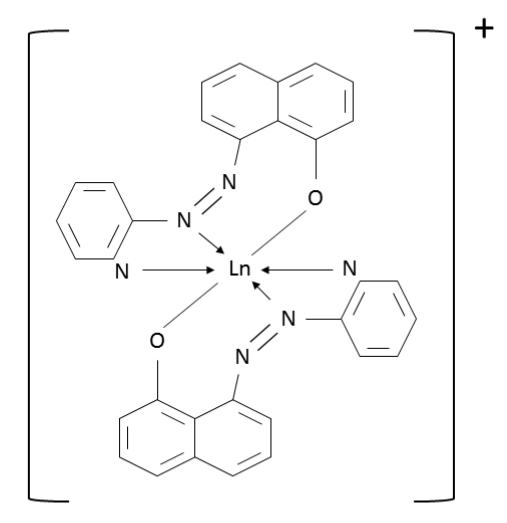

Figure 19: FTIR spectra of (a) CNT and AC composites (b) marine algae and (c) XRD spectra before and after REE adsorption process, (d) possible REE-PAN chelating mechanism

\subsection{REE adsorption standardization metrics based on this work's findings}

The field of REE recovery using adsorption has progressed enormously in the past decade, and the standardization of key performance metrics based on this Ph.D. work and literature data to support future progress is provided in this section. Best practices in REE sorption are recommended below based on the knowledge obtained from the findings of this work.

\section{Hydrolysis and precipitation of REEs at higher pH}

Adsorption processes to separate REEs in the lower $\mathrm{pH}$ regime $(<5)$ is recommended since REEs tend to precipitate as hydroxides at higher $\mathrm{pH}$. Hence, reporting adsorption values must be avoided for REE sorption at higher $\mathrm{pH}(>6)$, as there are inconsistencies with the phenomena behind REE removal. In other words, REE removal is not ruled by adsorption alone at higher $\mathrm{pH}$, as the surfacebased precipitation could be a contributing factor in this regime. Thus, it is important to present results at a lower $\mathrm{pH}$ to understand the full potentiality and maximum adsorption capacities of the materials.

\section{Amine groups - desired binding sites for REE}

Besides, for given operational parameters such as feed $\mathrm{pH}$, temperature, initial adsorbate concentration and contact time, $\mathrm{pH}$ seems to be a highly useful and insightful metric into REE sorption performance. Hence, it is crucial to graft or modify the support with functional groups 
that are highly accessible for REE binding in its protonated state. There are numerous functional moieties containing amine [22,41,62,149,173], carboxyl [22,58,150,174], hydroxyl [175] and phosphoryl [176,177], reported as efficient ones for REE sorption. Undoubtedly, amino groups prove to be one of the best-recommended ones, evidenced by this work as well.

Grafting amine groups to the substrate will enhance REE adsorption even from a lower $\mathrm{pH}$ value of 3 or 4 . This results from the attachment of reactive sites onto the surface, thus also enhancing the adsorption capacities of the support materials. However, the selectivity of these adsorbents could be lower in the presence of other competing ions from the solutions, as they depict higher affinities towards other elements (eg. heavy metals) as well.

\section{A trade-off between the adsorption capacities and selectivity: single-component vs multi- component system}

Measurements on REE sorption are most often accomplished based on experiments in singlecomponent systems and usually using synthetic solutions prepared in the lab. In addition, while testing the adsorbents for single REE uptake by varying the initial REE concentration gives a sense of maximum adsorption capacities by the materials. On the other hand, it is very essential to test them in whole REE mixtures or in multi-component systems with other competing ions to gain knowledge on the selectivity of the materials towards REEs or towards any single REE. The adsorbents can demonstrate higher REE removal in a single component system and simultaneously display poor selectivity in the presence of other REEs or other elements. Hence, testing them under harsh real water conditions is essential to perform a thorough assessment of the adsorbents. Failing to do so would result in the provision of a false picture in terms of higher performance, merely based on adsorption capacities of the adsorbents. In systems mimicking real-life wastewater conditions, these adsorbents may depict an unpredicted or poor response in the presence of interferences. One suitable example would be the superior adsorption of La in a single component system in comparison with that of an inferior one in a multi-component system showing negligible removal (La: poorest affinity among REEs). Further, the adsorbents that could demonstrate supreme adsorption even at $\mathrm{pH} 2$ do not necessarily deliver the same outcome in multi-component systems with interferences. Other metal ions such as $\mathrm{Fe}^{2+} / \mathrm{Fe}^{3+}, \mathrm{Al}^{3+}$ and $\mathrm{Au}^{3+}$ would most likely be adsorbed ahead of REEs when using wastewater. Although the synthetic leachate liquor, artificial sea water or wastewater simulated closer to real water conditions could be useful in investigating the REE selectivity and performance, other components such as total organic matter, solids, oil components, oxidized content and varying molar masses between the dissolved species may complicate the material performance to a great extent. Hence, it would be an ideal practice to use real industrial wastewater to ascertain and validate the performance of the adsorbents. 


\section{HREE> LREE in real water conditions}

LREE adsorption was always hindered by the competing ions despite the demonstration of affinity towards the same by the adsorbents in the single or multicomponent system (without any interference from other elements). For instance, in this work, marine algae and acac modified silica-chitosan beads demonstrated affinity towards LREEs in comparison to HREEs when assessed in a multi-component system with no competing ions. However, when using AMD (presence of highly concentrated competing ions), the affinity towards HREEs was higher, followed by LREEs.

\section{Enhanced HREE adsorption with enhanced temperature}

With an increase in temperature, there can be a reduction in the thickness of the electric double layer thereby increasing the potential adsorption sites and overcoming the diffusion resistance [126]. Thus, the ion migration between the solution and the adsorbent surface is enhanced with a rise in process temperature.

\section{Method of preparation}

The results also suggest that the characteristics and properties of the synthesized adsorbents are highly dependent upon the reaction conditions such as the composition of the reactants (a type of solvent), temperature and aging time, which will ultimately influence the polymerization reaction and densification of the polymer network [178]. Hence, the method of preparation is very significant in designing the materials with tailored functionalities. For the silanization reaction, it is recommended to use an appropriate solvent for the covalent binding of an organosilane to the polymer matrix to enhance the surface reactivity. Hence, in this study, a non-polar solvent, Toluene, was used to avoid the self-condensation or hydrolysis of APTES molecules, which in turn prevents polymerization reaction near the substrate or between APTES molecules when using polar solvents. Acetone/ethanol (or a mixture of solvents) can also be substituted for Toluene for the silanization reaction, reported in few works $[179,180]$.

\section{State-of-the-art adsorbents for REE sorption}

Table 5 lists the adsorbents of this study along with some of the state-of-the-art materials reported in the literature for REE sorption. As shown in the table, rapid uptake of $\mathrm{La}^{3+}$ accompanied by increased adsorption capacities was predominant among many reported works [8,164]. Besides the operational conditions discussed here, the type of support material also has an impact on REE sorption performance. However, as we mentioned earlier, it must be noted that comparing values of maximum adsorption capacities of the materials between different systems can be problematic 
without rigorously holding to the same $\mathrm{REE}$, operational $\mathrm{pH}$, temperature and the amount of material used (adsorbent dosage). Thus, when reporting adsorption capacities, all the relevant experimental conditions must be reported. A related question can be posed as to what the upper/lower limit is to be set on adsorption capacities to assign the best state-of-the-art adsorbent for REE sorption or to set a value for the trade-off between the REE adsorption capacity and selectivity of the material. It is difficult to answer the question, given the vast amount of efficient materials reported in the literature, based merely on adsorption capacities determined from the single-component system with no interferences. However, the research in the future should be focused on simulating the real wastewater conditions, specifically designing the material targeting an application or utilizing the materials across or integrating different technologies for an application. For instance, the ion exchange materials can also be utilized in electrodeionization process, which combines ion exchange and electro-dialysis technologies with a continuous "insitu" regeneration of the materials. Further, to commercialize or upscale them for industrial systems, other factors such as chemical stability and regeneration also comes into play.

Table 5: Comparison of state-of-the-art adsorbents in terms of REE sorption performance. The adsorption capacities and equilibrium time for REE uptake are provided in $\mathrm{mg} / \mathrm{g}$ and $\mathrm{min}$, respectively. The data converted from $\mathrm{mmol} / \mathrm{g}$ to $\mathrm{mg} / \mathrm{g}$ are indicated by *.

\begin{tabular}{|c|c|c|c|c|c|c|c|c|c|c|}
\hline \multirow[t]{2}{*}{ Adsorbents } & \multicolumn{3}{|c|}{$\begin{array}{l}\text { Maximum adsorption } \\
\text { capacities }(\mathrm{mg} / \mathrm{g})\end{array}$} & \multicolumn{3}{|c|}{$\begin{array}{l}\text { Equilibrium time } \\
\text { (in min) }\end{array}$} & \multicolumn{3}{|c|}{ Adsorption pH } & \multirow[t]{2}{*}{$\begin{array}{l}\text { Referen } \\
\text { ces }\end{array}$} \\
\hline & $\mathbf{L a}^{3+}$ & $\mathbf{S c}^{3+}$ & $\mathbf{Y}^{3+}$ & $\mathbf{L a}^{3+}$ & $\mathrm{Sc}^{3+}$ & $\mathbf{Y}^{3+}$ & $\mathbf{L a}^{3+}$ & $\begin{array}{l}\mathbf{S c}^{3} \\
+\end{array}$ & $\mathbf{Y}^{3+}$ & \\
\hline $\begin{array}{l}\text { PAN functionalized Activated } \\
\text { carbon-APTES nanosilica } \\
\text { (Method II) }\end{array}$ & 103.5 & 112.7 & 84.1 & $<30$ & $\begin{array}{l}<14 \\
40\end{array}$ & $<30$ & 4 & 4 & 4 & $\begin{array}{l}\text { This } \\
\text { study }\end{array}$ \\
\hline $\begin{array}{l}\text { PAN functionalized MWNT- } \\
\text { APTES nanosilica (Method II) }\end{array}$ & 103.2 & 32.92 & 68.78 & $<30$ & $\begin{array}{l}144 \\
0\end{array}$ & 30 & 4 & 4 & 4 & $\begin{array}{l}\text { This } \\
\text { study }\end{array}$ \\
\hline $\begin{array}{l}\text { MTM-silica-chitosan-PAN } \\
\text { beads (Method II) }\end{array}$ & 199.8 & 198.8 & 123.4 & $<5$ & $<5$ & $<5$ & 5 & 5 & 5 & $\begin{array}{l}\text { This } \\
\text { study }\end{array}$ \\
\hline $\begin{array}{l}\text { PAN functionalized SWNT- } \\
\text { APTES nanosilica (Method II) }\end{array}$ & 80.68 & 12.68 & 48.34 & 60 & $\begin{array}{l}144 \\
0\end{array}$ & $\begin{array}{l}144 \\
0\end{array}$ & 4 & 4 & 4 & $\begin{array}{l}\text { This } \\
\text { study }\end{array}$ \\
\hline $\begin{array}{l}\text { Marine algae-PAN (Method } \\
\text { II) }\end{array}$ & - & 66.81 & - & - & $<10$ & - & - & $5-6$ & - & $\begin{array}{l}\text { This } \\
\text { study }\end{array}$ \\
\hline $\begin{array}{l}\text { PAN functionalized -APTES } \\
\text { nanosilica (Method II) }\end{array}$ & 85.72 & 75.5 & 62.92 & 30 & 480 & 120 & 4 & 4 & 4 & $\begin{array}{l}\text { This } \\
\text { study }\end{array}$ \\
\hline $\begin{array}{l}\text { Cellulose-silica } \\
\text { nanocomposite }\end{array}$ & 29.48 & 23.76 & - & 50 & 50 & - & 6 & 6 & - & [35] \\
\hline $\begin{array}{l}\text { Gum arabic grafted } \\
\text { polyacrylamide-based silica } \\
\text { nanocomposites }\end{array}$ & 7.90 & 11.05 & - & 60 & 60 & - & 6 & 6 & 6 & [36] \\
\hline
\end{tabular}




\begin{tabular}{|l|l|l|l|l|l|l|l|l|l|l|}
\hline EDTA- $\beta$-cyclodextrin & $47.64^{*}$ & - & - & 120 & - & - & 4 & 4 & 4 & {$[62]$} \\
\hline $\begin{array}{l}\text { P507 grafted onto magnetic } \\
\text { silica via 3- } \\
\text { chloropropyltryethosysilane }\end{array}$ & 55.9 & - & - & $\begin{array}{l}30- \\
60\end{array}$ & - & - & 5 & - & - & {$[177]$} \\
\hline $\begin{array}{l}\text { N-(2- } \\
\text { hydroxyethyl)salicylaldimine- } \\
\begin{array}{l}\text { SBA- } \\
\text { chloropropyltriethoxysilane }\end{array}\end{array}$ & 8.32 & - & - & 45 & - & - & 5 & - & - & {$[181]$} \\
\hline Oxidized MWNT & 99.01 & - & - & 120 & - & - & 4 & - & - & {$[33]$} \\
\hline $\begin{array}{l}\text { Granular grafted hydrogel } \\
\text { composites }\end{array}$ & 333.3 & - & - & 40 & - & - & 4 & - & - & {$[182]$} \\
\hline Nano modified AC & - & 10.11 & - & - & 60 & - & - & 2 & - & {$[183]$} \\
\hline $\begin{array}{l}\text { Ionic liquid impregnated } \\
\text { Amberlite XAD.16/MCM-41- } \\
\text { silica }\end{array}$ & - & 16.18 & - & - & 90 & - & - & 3 & - & {$[184]$} \\
\hline $\begin{array}{l}\text { Ethylglycol teraacetic acid } \\
\text { functionalized silica-chitosan }\end{array}$ & - & 6.74 & - & - & 120 & - & - & 2 & - & {$[22]$} \\
\hline $\begin{array}{l}\text { Diethylenetriamine penta } \\
\text { acetic acid functionalized } \\
\text { silica-chitosan }\end{array}$ & - & 8.99 & - & - & 120 & - & - & 2 & - & {$[22]$} \\
\hline
\end{tabular}

\section{Regeneration and reusability}

The REEs adsorbed onto materials was successfully recovered by using $1 \mathrm{M} \mathrm{HNO}_{3}$ within a time period of 15 mins. A drop-in efficiency of 10-20\% was observed after the first stripping step. In subsequent cycles (tested until 5), regeneration efficiency of above $80 \%$ was observed with these composites. When the efficiency of the regenerated adsorbents declines significantly, they could be utilized as photocatalysts when the adsorbents are still loaded with REEs. For instance (Other publications: $\mathbf{E}$ and $\mathbf{F}$ ), the utilization of REE (Ce and $\mathrm{La}$ ) in the nanostructured perovskite catalysts was found to be efficient in the degradation and demineralization of pollutants such as phenol and Bisphenol F [185,186]. In another work [187], the REE loaded reused adsorbents were found to be efficient photocatalysts in the degradation of tetracycline. Hence, the REE-loaded composite materials could be investigated in the future for their applicability as photocatalysts, thus also converting waste to resources.

\subsection{Future perspectives}

\subsubsection{Potential of using PAN embedded matrix as an optical sensor for detection of REE in aqueous systems}

PAN has the potential to yield colored complexes on reaction with REEs and other transition metals (Figure 20). In the experimental study, adsorbents prepared via Method II PAN grafting procedure resulted in the formation of colored solutions. For a single component REE system, the 
resultant solution typically varied in the spectrum of yellow to orange color, where an increase in atomic number led to the increase in the color intensity (HREE > LREE). However, in an AMD solution, the usage of PAN, without and with the presence of a support (silica, CNT, chitosan and algae matrix), produced red and pink colored solutions, respectively. It can be a manifestation of the interactions with other metal ions belonging to the AMD solution (Please see Figure a). This observation is also supported by the work of Cheng et al. [67] who highlighted the colored complexes in a water matrix (may vary for alcohol or an organic solvent) to be yellow $\left(\mathrm{H}_{2} \mathrm{O}\right)$, brownish-red $\left(\mathrm{Co}^{2+}\right)$, deep red $\left(\mathrm{Cu}^{2+}\right.$ and $\left.\mathrm{Fe}^{3+}\right)$, red $\left(\mathrm{Pb}^{2+}, \mathrm{Ni}^{2+}, \mathrm{La}^{3+}, \mathrm{Sc}^{3+}, \mathrm{Eu}^{2+}, \mathrm{Cd}^{2+}\right.$ and $\left.\mathrm{Fe}^{2+}\right)$, pink $\left(\mathrm{Ce}^{4+}\right)$ and bright pink $\left(\mathrm{Zn}^{2+}\right)$. The absence of any complex formation with PAN was also reported with metal ions such as $\mathrm{Na}, \mathrm{Zr}, \mathrm{Mg}, \mathrm{Sb}, \mathrm{Al}, \mathrm{Ca}, \mathrm{Sr}, \mathrm{Li}$, fluoride, sulfite, sulfate, nitrate, nitrite, chloride, etc. [67]. Thus, the pink colored solution obtained in the AMD study could have emanated from a comparatively higher $\mathrm{Zn}^{2+}$ concentration (Fig a: pink solution with the absence of REE in AMD) and this was further supported by the formation of a yellow solution in a seawater environment containing no REEs.
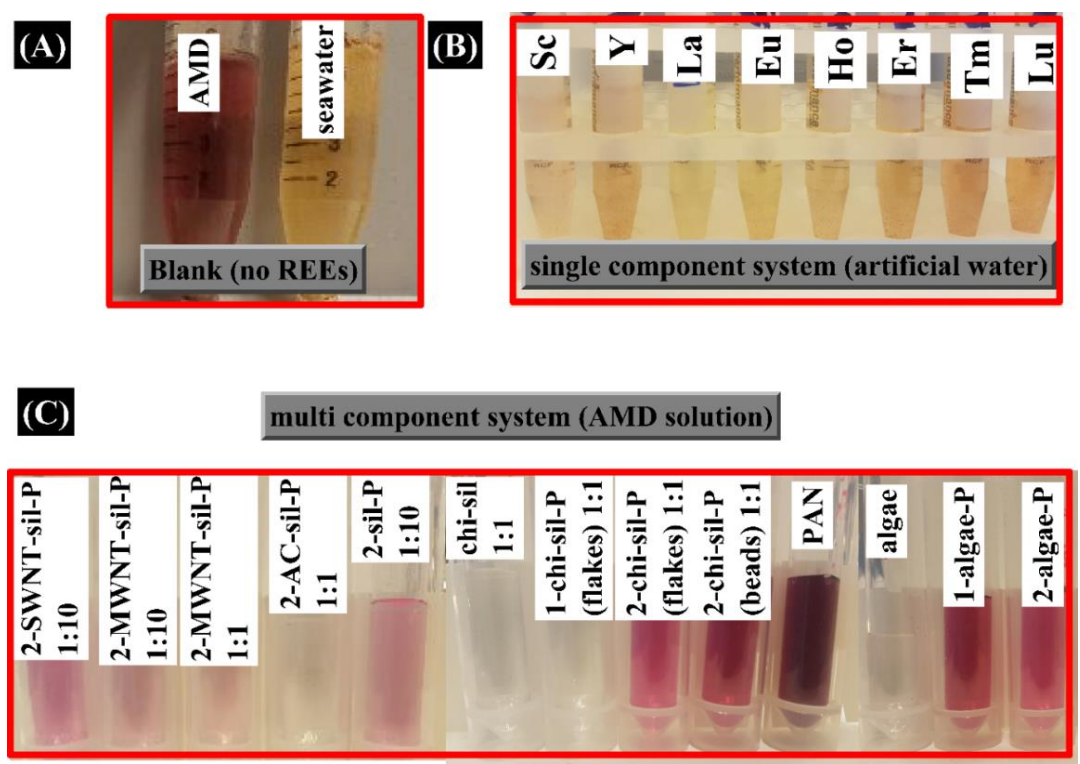

Figure 20: Colored complex formation on REE-PAN interactions for (a) Method II marine algae-PAN in blank AMD and seawater with no REE (b) Method II marine algae-PAN with REEs in a single component synthetic solutions and (c) all the adsorbents (labelled) in AMD containing REEs ( 2 ppm) (Ref.: Article 7).

It must be mentioned that the perception of color by the naked eye can provide a wide range of possibilities to interpret a single metal ion from an aqueous solution. Nevertheless, there exist several significant challenges that need to be addressed during the development process of costeffective sensors of commercial importance. Some of the notable ones include a high signal to 
noise ratio, enhanced selectivity in the presence of diverse/heavy interference, identification of various analytes, and improved LOD in relation to other state-of-the-art analytical instruments like ICP-OES. In the future, sensors can be developed with PAN embedded on different supports addressing the aforementioned drawbacks largely, in combination with a robust and reproducible framework.

The findings from this study can be of great scientific relevance and can help advance the present knowledge in the field of REE microextraction processes. For instance, grafting PAN on silica demonstrated predicted colored responses whereas grafting PAN on AC-silica (1:1) did not yield any colored solution. This can also be better realized from comparing the colored solutions obtained with MWNT-sil (1:10) and MWNT:sil (1:1), the inference of which shows the color intensity decreases with increase in carbon in the system which appears to be a masking agent. Silica, chitosan and algae seemed to be suitable supports to detect PAN-REE colored complexes. However, it should be remarked that this phenomenon occurs only if the PAN units are grafted onto supports via post-synthetic functionalization. The absence of colored complex formation with Method I- silica-chitosan-PAN further supports this case. This can be due to the incorporation of PAN units in the mesopores/micropores of the matrix when using Method I whereas PAN moieties are grafted onto the surface using Method II. Few studies on developing a sensor to detect metal ions have been reported with one prominent example being PAN embedded on PES-R4 membrane for $\mathrm{Zn}^{2+}$ assays [188]. Hence, in near future, these scientific outcomes may also stipulate advances in current micro-extraction methodologies and can be extended to the development of a rapid assay system for simultaneous qualitative detection as well as quantitative determination for REEs as well as other elements.

\subsubsection{Transfer of knowledge to other separation and concentration technologies:}

The innate potential of the synthesized materials can open new avenues for a wide range of diverse applications. The designed materials for REE adsorption process could be integrated with other separation and concentration technologies in water treatment applications. CDI and EDI are considered to be one of the most competent and energy efficient technologies in water treatment applications, especially in water desalination. These systems have economic advantages over conventional techniques like electrodialysis (ED) and reverse osmosis (RO) when using diluted streams. Besides, they possess the capability to function without any chemical regeneration. The power requirements are minimal and have a lesser environmental footprint. The ease of operation and low installation space are added benefits. Hence, CDI and EDI processes have been studied comprehensively over the past years for metal recovery [189-191]. Considering this, the following propositions are made, which could be an interesting area of further research as an extension of this Ph.D. study. 


\section{As electrode materials in CDI:}

CDI is an emerging technique for water desalination by utilizing electrodes, preferably porous carbon electrodes, placed parallel in a cell. The traditional setup involves the flow of feed water through two charging porous electrodes (anode and cathode) separated by ion-exchange membranes and spacers, operating via constant voltage or constant current mode. Majority of the existing CDI systems utilize high surface carbon in the form of activated carbon, templated carbons, carbon aerogels, carbon cloths, carbon sheets, carbon nanofibres and carbon nanotubes [189]. The feasibility of using APTES functionalized carbon material as an anion-selective electrode in a CDI system (two anion-selective electrodes separated by a cation exchange membrane, see Figure 21) was attempted for continuous desalination purpose. These positively charged APTES modified electrodes were synthesized using the silanization procedure adopted in this work (under the same reaction conditions). Utilization of APTES to provide net positive charges to the electrodes increased the charge efficiency of the process in comparison to the unmodified electrode (with no preference towards anions or cations). Besides, the surface functionalization was found to be stable under the influence of the electric field (For more details, please refer to other publications: I [192]). Hence, these findings show that the APTES functionalized carbon-based composites of this work possess the future potential to be utilized as ion-selective electrodes for the separation and concentration of REEs using CDI technology.

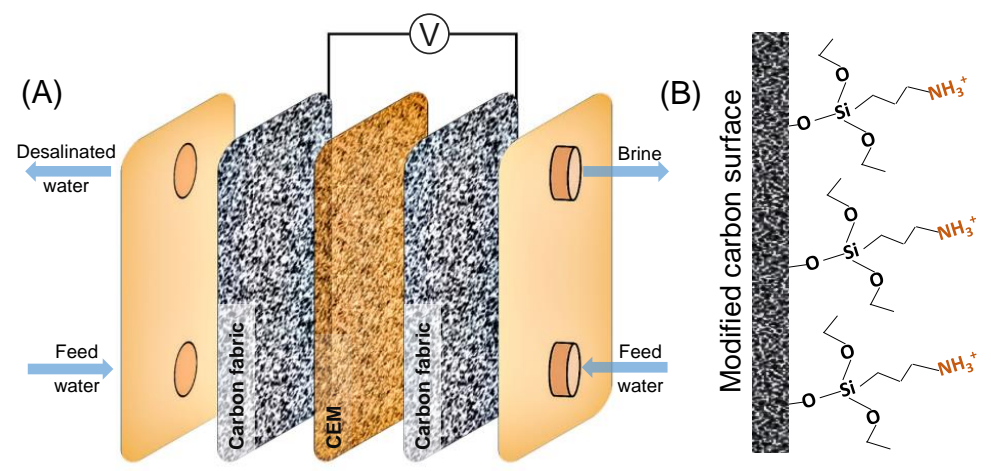

Figure 21: (a) CDI cell design and (b) APTES modified activated carbon fabric as an anion-selective electrode for desalination purpose by CDI (Ref: other publications I) [192]

\section{As ion-exchange resin bed in EDI:}

Electrodeionization is a hybrid separation process, combining the merits of both electrodialysis (ED) and ion exchange (IX) processes. The cation exchange (CM) and anion exchange (AM) membranes are situated between the electrodes, similar to an electrodialysis setup (Figure 22.a). By placing the ion-exchange materials in the central or dilute compartment in EDI setup, the ion migration is enhanced across the chambers with resin acting as a conductive bed on applying the 
electric field. The primary advantage of EDI is attributed to the absence of chemical usage in the regeneration step, owing to the continuous electro-regeneration of the ion-exchange resins from the $\mathrm{H}^{+}$and $\mathrm{OH}^{-}$ions of the water dissociation reactions, under the influence of electric field [190,191]. Marine algae, owing to its economic significance and REE adsorption performance, was exploited as resin bed in the EDI configuration, with the aim of understanding its effect on Sc separation and concentration. The initial test results suggested that the energy efficiencies of the process increased when the ion-exchange materials were utilized as it is expected to decrease the concentration polarization in the dilute compartment, a common issue with electrodialysis process, especially when using diluted systems [193]. The ionized surface groups on the resin bed acted as a conductive bed for the enhanced ion migration across the compartments. However, the energy consumption was higher when marine algae were used (Figure 22.b), in comparison to pretreated commercial adsorbents. This might be probably due to the increase in ionized groups due to the pretreatment of commercial resins using $\mathrm{H}_{2} \mathrm{SO}_{4} / \mathrm{NaOH}$ solutions. Thus, the pretreated or saturated marine algae can be expected to lower the overall energy consumption of the process, as reported in other works $[193,194]$. From the present knowledge attained, it is not possible to arrive at a conclusion on the nature of the ion exchange bed, if it acts as an ion-selective or just conductive bed. Further investigations will be conducted in the future using alternate composite adsorbents such as MWNT-silica and AC-silica composites to understand the underlying mechanism.
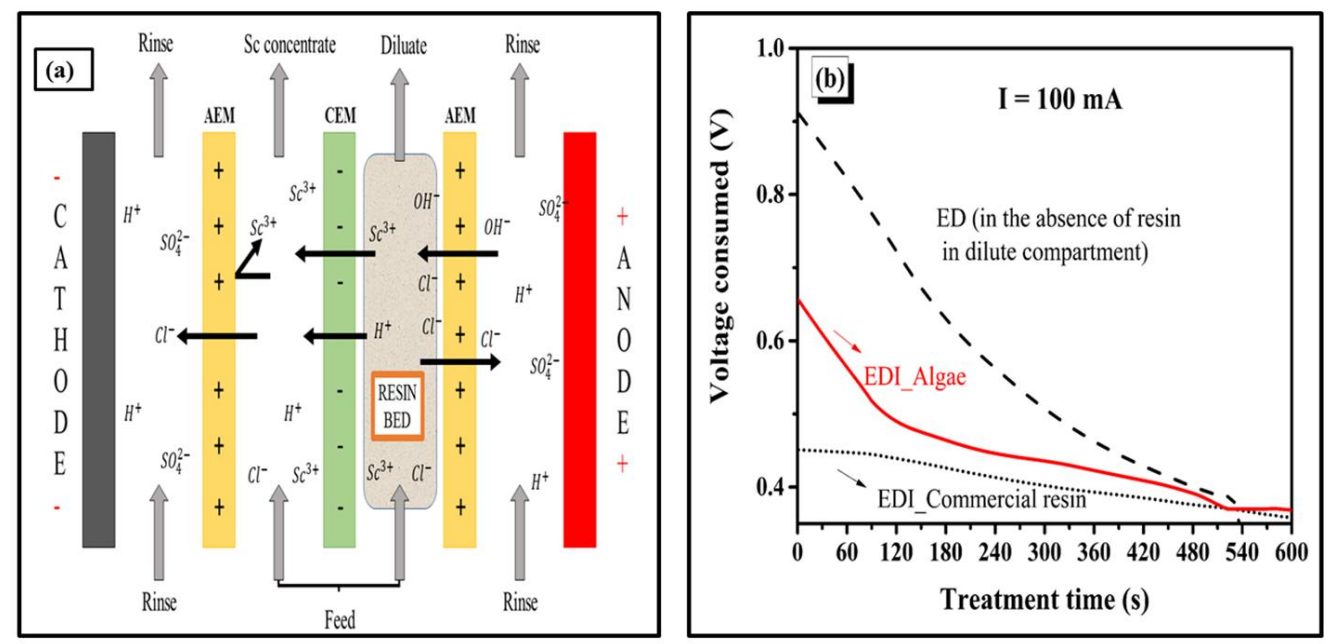

Figure 22: (a) Schematic illustration of $\mathrm{Sc}^{3+}$ separation and concentration using the EDI process and (b) Comparison of voltage consumption for ED and EDI. 


\subsection{Overall evaluation and summary of the work}

The significant findings and contributions to the research domain are summarized in Table 6 in three subsections. Firstly, in the framework of REE recovery, considerable research has been dedicated to the development of specialized, highly REE-selective adsorbents. By physical and chemical modifications to the polymer structure, it was aimed to obtain adsorbent materials with high potential for real large-scale applications. This required a dual focus during the research. On one hand, the synthesis procedures had to be economic, straightforward and easy to scale up. On the other hand, the materials had to show a high capability in terms of REE uptake, selectivity and reusability. As a result, high-performance hybrid composites were synthesized by employing organic amino silane (APTES) interpenetrating the inorganic silica and organic polymer (chitosan, CNT, AC) network yielding superior REE adsorption properties. Amino silanes (APTES/APTMS) were found to be the best coupling agents, which serve as a linker to allow chemical compatibility to other polymers in comparison to non-amino silanes (MTM/TMCS). Surface modification is maximized when silanes react with the substrate surface (silica>>carbon) and present the maximum number of accessible sites with appropriate surface energies. An additional consideration is the physical and chemical properties of the interphase region. It should be remarked that the surface tension of MTM is $22.5 \mathrm{mN} / \mathrm{m}$ while it is around $35 \mathrm{mN} / \mathrm{m}$ for APTES and $78 \mathrm{mN} / \mathrm{m}$ for silica (fused) [113]. The poor outcomes by MTM and TMCS could be due to the wettability of the surface as the hydrophilicity of the substrates increases with the surface tension, typically observed with adsorptive behavior.

The coordination ligand PAN was explored in this work for REE selectivity and it was found to be an effective one after a series of investigations in single- and multi-component systems. It showed great promise by demonstrating selectivity towards REE even when using AMD with very low interference from other common pollutants. The efficiencies of some of the best hybrid composites were found to be in the order: Chitosan-MTM-silica beads > AC-APTES-silica-PAN $>$ MWNT-APTES-silica-PAN > Algae-PAN > Chitosan-APTES-Silica-PAN beads. The differences in the performance of different polymers arise from their surface chemistry, the efficiency of the functionalization and the accessible surface functional groups available for REE binding. In this aspect, AC, MWNT and marine algae were found to be proficient concerning the surface reactivity towards the guest molecules (APTES, PAN as well as REEs). A straightforward and adept synthetic procedure for PAN functionalization was identified. It was revealed that it was necessary to graft PAN units onto the surface of hybrid composites via post-synthetic functionalization or step-by-step telescopic route (Method II) to fully utilize the potential of PAN in terms of interaction with REE. Further, the attachment of PAN groups yielded positive charge to the adsorbents with its functionalities protonated at acidic $\mathrm{pH}$, which was not the case with acacmodified adsorbents. The consequence of the availability of the protonated binding sites was clearly spotted with PAN-modified (optimal $\mathrm{pH} \sim 4$ ) and acac-modified (optimal $\mathrm{pH} \sim 6$ ) adsorbents. Besides, the exchanged REE cations would be most likely fully coordinated with the $\mathrm{N}$ - and/or O- ligand atoms when the surface free energy is minimal. 
It is also clear that cost is an important metric to which the synthesized materials were assessed in comparison to the conventional ones available in the current market, in order to elucidate the commercial viability. Here, the cost of the modified adsorbents is estimated to be comparable or more economic compared to the commercially available amino-functionalized silica gels (40-75 $\mu \mathrm{m}$ particle size; CAS: 79297; $862 € / \mathrm{kg}$ ). Secondly, in terms of REE adsorption, selective separation of Sc from REE mixtures was developed by exploiting the different chemical reactivity of Sc and other REEs. Finally, the realization of the preliminary studies validating the synthetic procedures (as an anion-selective electrode in CDI) and utilization of adsorbents (as resin beds in EDI) reveals the ability to interconnect and extend knowledge from/to multiple disciplines. Hence, these findings suggest that there is every likelihood that this study will be a premise of further research, education and applications.

Table 6: Overall evaluation and summary of this research work.

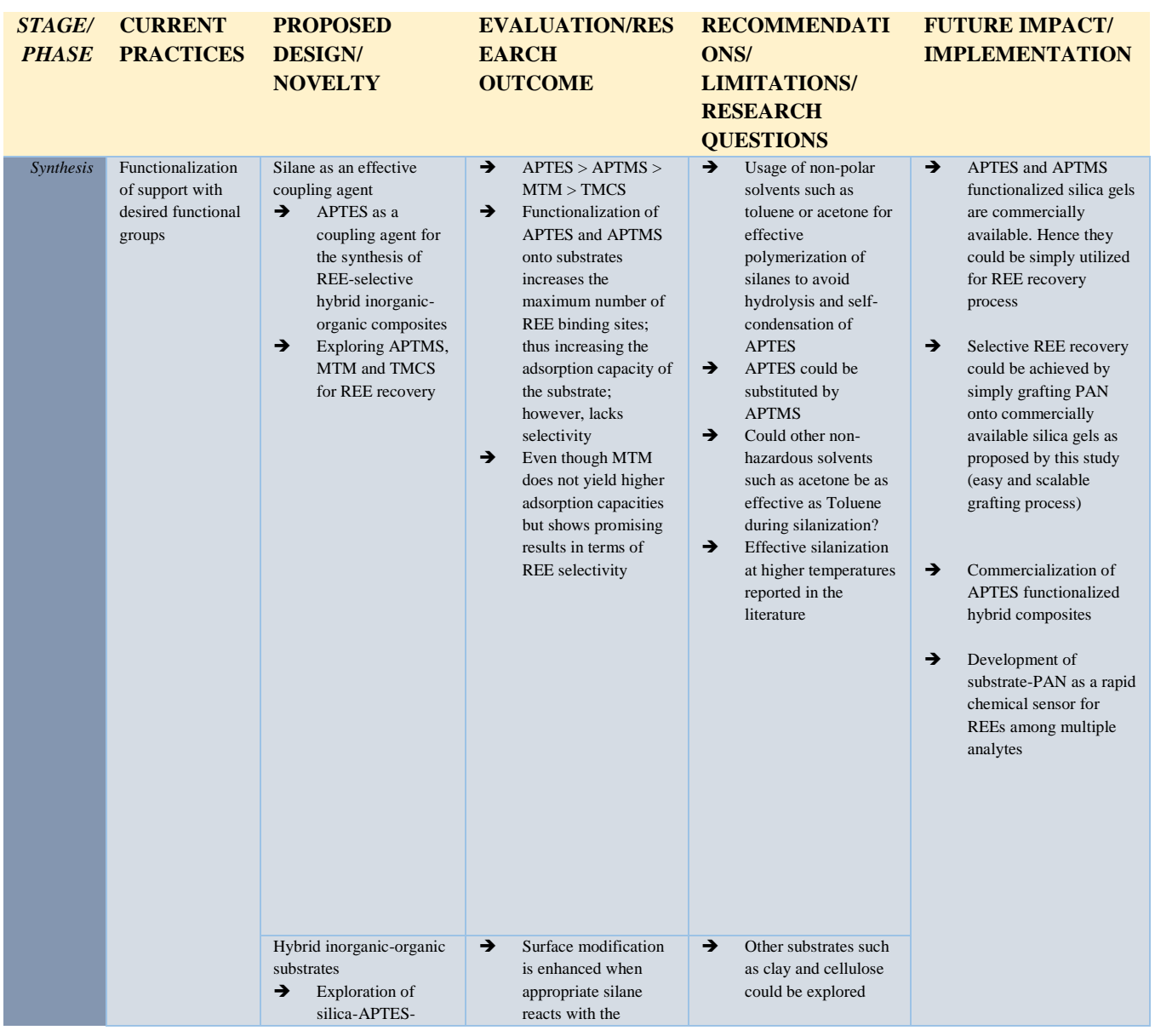




\begin{tabular}{|c|c|c|c|c|c|}
\hline & & $\begin{array}{l}\text { chitosan, silica- } \\
\text { APTES-SWNT, } \\
\text { silica-APTES- } \\
\text { MWNT, silica- } \\
\text { APTES-AC and } \\
\text { algae for selective } \\
\text { separation of REE }\end{array}$ & $\begin{array}{l}\text { appropriate } \\
\text { inorganic/organic } \\
\text { substrate to exhibit } \\
\text { utmost accessible } \\
\text { sites with suitable } \\
\text { surface energies } \\
\Rightarrow \quad \text { Hybrid polymer } \\
\text { composites (AC-sil } \\
\text { and MWNT-sil) } \\
\text { delivered improved } \\
\text { REE adsorption } \\
\text { performance due to } \\
\text { synergic effects }\end{array}$ & & \\
\hline & & $\begin{array}{l}\text { PAN as a selective ligand } \\
\text { for REE separation }\end{array}$ & $\begin{array}{l}\text { Grafting PAN enhances } \\
\text { REE selectivity; does not } \\
\text { show affinity towards } \mathrm{Mg} \text {, } \\
\mathrm{Ca}, \mathrm{Mn} \text { at the REE } \\
\text { adsorption pH range }\end{array}$ & $\begin{array}{l}\rightarrow \quad \text { Can it be used as a } \\
\text { colorimetric REE } \\
\text { indicator probe (like } \\
\text { pH indicator strip) for } \\
\text { the instant qualitative } \\
\text { detection of trace } \\
\text { REEs? }\end{array}$ & \\
\hline & & $\begin{array}{ll}\text { Method of preparation } \\
\rightarrow \quad & \text { Chemical } \\
\text { immobilization of } \\
& \text { PAN } \\
\rightarrow \quad & \text { Step by step } \\
\text { synthesis: (Step 1) } & \text { substrate-APTES- } \\
\text { substrate } & \text { (Step 2) substrate- } \\
\text { APTES-substrate- } & \text { PAN } \\
\text { PAN } & \text { Grafting method } \\
\text { (APTES } & \text { silanization } \\
\text { followed by solvent } \\
\text { evaporation } \\
\text { process) }\end{array}$ & 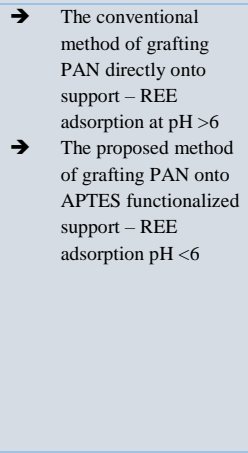 & $\begin{array}{ll}\rightarrow \quad & \begin{array}{l}\text { Substitution of } \\
\text { acetone with other }\end{array} \\
\text { solvents? }\end{array}$ & \\
\hline $\begin{array}{r}R E E \\
\text { adsorption }\end{array}$ & $\begin{array}{l}\text { Single-component } \\
\text { system (often); } \\
\text { limited testing in } \\
\text { the } \\
\text { multicomponent } \\
\text { system, especially } \\
\text { with real waste } \\
\text { water }\end{array}$ & $\begin{array}{l}\text { Two-stage recovery } \\
\text { process (1) selective } \\
\text { separation of scandium } \\
\text { from REE mixtures ( } 2 \text { ) } \\
\text { REE from other elements }\end{array}$ & $\begin{array}{l}\rightarrow \quad \begin{array}{l}\text { By controlling } \\
\text { solution pH, scandium } \\
\text { could be separated } \\
\text { from REE mixtures }\end{array} \\
\rightarrow \quad \begin{array}{l}\text { Sc behaves very } \\
\text { differently from other }\end{array} \\
\text { REEs } \\
\rightarrow \quad \begin{array}{l}\text { REE adsorption at } \\
\text { acidic pH is possible } \\
\text { by grafting amino } \\
\text { groups }\end{array} \\
\rightarrow \quad \begin{array}{l}\text { Temperature } \\
\text { influences the REE } \\
\text { adsorption process } \\
\text { Affinity HREE }> \\
\text { LREE }\end{array}\end{array}$ & 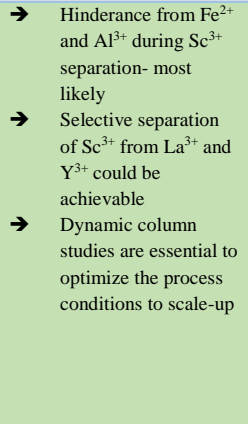 & $\begin{array}{l}\text { Valorization of secondary REE } \\
\text { resources adopting the } \\
\text { circular-economy concept }\end{array}$ \\
\hline $\begin{array}{r}\text { Process } \\
\text { integration }\end{array}$ & $\begin{array}{ll}\rightarrow \quad & \text { Typically } \\
\text { carbon } \\
\text { porous } \\
\text { electrodes; } \\
\text { limited } \\
\text { utilization }\end{array}$ & $\begin{array}{l}\text { CDI for REE recovery: } \\
\text { as electrode materials }\end{array}$ & $\begin{array}{l}\text { Successful development and } \\
\text { utilization in CDI as anion- } \\
\text { selective electrode (activated } \\
\text { carbon cloth modified with } \\
\text { APTES using the }\end{array}$ & $\begin{array}{l}\text { Immobilization of PAN onto } \\
\text { APTES-AC could result in } \\
\text { new coordination based CDI } \\
\text { electrodes, just like the } \\
\text { recent intercalation } \\
\text { electrodes introduced in CDI }\end{array}$ & $\begin{array}{ll}\rightarrow \quad & \text { No studies on REE } \\
\text { separation and } \\
\text { concentration using CDI } \\
\text { and EDI }>\text { future REE } \\
\text { separation and } \\
\text { concentration studies }\end{array}$ \\
\hline
\end{tabular}




\begin{tabular}{|c|c|c|c|c|c|}
\hline$\rightarrow$ & $\begin{array}{l}\text { of other } \\
\text { materials } \\
\text { For low } \\
\text { concentrate } \\
\mathrm{d} \text { brackish } \\
\text { water } \\
\text { desalination } \\
(\text { removal of } \\
\mathrm{Na}^{+}, \mathrm{K}^{+} \\
\text {etc.) }\end{array}$ & & $\begin{array}{l}\text { silanization procedure } \\
\text { adopted in this Ph.D. study) }\end{array}$ & & $\begin{array}{l}\text { with CDI and EDI could } \\
\text { open up easy } \\
\text { commercial avenues } \\
\text { Can hybrid materials be } \\
\text { the future of CDI/EDI? }\end{array}$ \\
\hline$\rightarrow$ & $\begin{array}{l}\text { Employs } \\
\text { commercial } \\
\text { resin; } \\
\text { limited use } \\
\text { of non- } \\
\text { commercial } \\
\text { materials } \\
\text { Convention } \\
\text { ally for } \\
\text { UPW } \\
\text { production } \\
\text { Ongoing } \\
\text { research } \\
\text { with heavy } \\
\text { metal ions }\end{array}$ & $\begin{array}{l}\text { EDI for REE recovery: } \\
\text { as resin bed }\end{array}$ & $\begin{array}{l}\text { Feasibility study to lower } \\
\text { the energy consumption of } \\
\text { the EDI process using } \\
\text { marine algae for separation } \\
\text { and concentration of Sc was } \\
\text { successful }\end{array}$ & $\begin{array}{l}\text { Can the resin bed contribute } \\
\text { to the selective separation of } \\
\text { REEs? }\end{array}$ & \\
\hline$\rightarrow$ & $\begin{array}{l}\text { REE-based } \\
\text { perovskite } \\
\text { catalysts - } \\
\text { emerging }\end{array}$ & $\begin{array}{l}\text { Heterogeneous catalysis: } \\
\text { as catalyst }\end{array}$ & $\begin{array}{l}\text { No feasibility studies using } \\
\text { the synthesized adsorbents } \\
\text { (PENDING); however } \\
\text { literature suggests that it } \\
\text { could show potential to be } \\
\text { an effective catalyst in } \\
\text { another process }\end{array}$ & $\begin{array}{l}\rightarrow \quad \begin{array}{l}\text { Photocatalyst for the } \\
\text { degradation of other } \\
\text { pollutants }\end{array} \\
\rightarrow \quad \begin{array}{l}\text { Catalyst for biodiesel } \\
\text { production }\end{array}\end{array}$ & $\begin{array}{l}\text { Promotes reusability of the } \\
\text { materials promoting "green, } \\
\text { sustainable and circular } \\
\text { economy concept" }\end{array}$ \\
\hline
\end{tabular}




\section{CONCLUSION}

The significant observations from this thesis work are summarized below:

Amino silanes (APTES and APTMS) are the ideal coupling agents to functionalize inorganic silica

The effect of surface functionalization on REE removal was realized through the extensive study conducted on different adsorbents modified with APTES, APTMS, MTM and TMCS. APTES/APTMS silica gels with amino modifications were predominantly superior to the MTM/TMCS silica gels with non-amino modifications, with regard to REE adsorption efficiencies.

Chemical immobilization of PAN onto the substrate is essential for REE adsorption at acidic pH (increased protonated binding sites)

This study revealed that the PAN grafting directly onto support is not ideal but instead grafting them via APTES strengthens the interaction between polymer and PAN. Chemically immobilized adsorbents demonstrated REE adsorption from a $\mathrm{pH}$ value of 4 due to the protonation of the functionalized groups while the physically loaded gels performed the same from a neutral $\mathrm{pH}$, predominantly through ionized $-\mathrm{OH}$ groups. In the $\mathrm{pH}$ range of 2-5, PAN physically adsorbed onto adsorbents were incapable of any REE adsorption, except for the case of Sc. In addition, PAN-modified adsorbents provided favorable results in comparison to acacmodified gels where the accessible binding sites on the adsorbents' surface played a major role in REE adsorption.

\section{PAN - an effective ligand for REE selectivity}

The attachment of PAN units onto the polymers resulted in enhancing REE selectivity. Furthermore, they have the potential to form colored complexes on reaction with REEs. This aspect is worthy of further exploration in order to facilitate the development of rapid REE detection sensors in the near future.

The post-synthetic grafting of PAN units onto hybrid substrates is highly significant in REE adsorption

The significance of the grafting pathway adopted to enhance REE adsorption/selectivity was understood through the comprehensive analysis conducted on the hybrid composites of this study. The ideal routes, i.e. one-pot synthesis (co-condensation and co-grafting) for SWNT 
and step-by-step telescopic synthesis (post-synthetic grafting) for MWNT/AC/chitosan, were also identified. Although this Ph.D. study focuses only on two coordination ligands, PAN (majorly) and acac, the findings suggest that the adopted grafting procedure could be simply extended to the grafting of other generally encountered ligands for REE coordination such as EDTA and DTPA, for further exploration.

\section{Marine algae is a promising resource identified with huge potential for REE adsorption}

Exploration of marine algae as REE adsorbents revealed their inherent potential to depict excellent REE affinity in the presence of common industrial pollutants, even without any surface modification. They could be exploited further to enhance their REE adsorption capacities through the attachment of desired binding sites.

\section{Scandium behaves in a unique manner in relation to other REEs}

Sc can be selectively separated from other REEs through the exploitation of differences in the chemical reactivity and the ionic sizes. To achieve the same, a two-stage selective separation strategy was developed during the course of this study, based on controlling the solution $\mathrm{pH}$ and surface characteristics of the adsorbents. Different binding mechanisms exhibited by $\mathrm{Sc}^{3+}$ (pore diffusion) and other REEs (the surface-based ion exchange and coordination mechanism) played a major role in selective separation of Sc from REE mixtures.

\section{Intraseries REE adsorption trend (Affinity towards HREE > LREE)}

The analysis of intraseries REE affinity trend demonstrated that $\mathrm{Sc}$ adsorption was supreme with meagre effort, followed by HREEs and LREEs, in a majority of the cases irrespective of the support matrix. In the presence of interference, adsorption was more inclined towards HREE irrespective of the substrate matrix, due to the prevalent co-competition of ions. Amongst all the REEs under scrutiny, Sc showed superior adsorption for all the adsorbents while La and Y presented the inferior outcomes.

There is no availability of prior works that enlighten on the intraseries REE adsorption trends for the whole lot of adsorbents utilized in this study, i.e. CNT-APTES-silica-PAN composites, AC-APTES-silica-PAN, chitosan-APTES-silica-PAN and marine algae-PAN. Hence, the comprehensive analyses reported in this dissertation can function as a benchmark for prospective studies focused on the development of efficient and enhanced functional materials for different applications, via alterations in ligand and matrix type, and the functionalization route. 


\section{Hybrid polymer composites depict ability to function as high-performance adsorbents}

PAN chemically immobilized onto hybrid composites (inorganic silica-polymer) demonstrated superior REE adsorption in comparison to PAN chemically immobilized onto silica gels, owing to the synergic effects that manifest from the amalgamation of the polymer surface characteristics. Among the synthesized hybrid composites, PAN chemically immobilized onto AC-silica, MWNT-silica and chitosan-silica were high-performance adsorbents in terms of REE adsorption capacities as well as REE selectivity. It should be noted that all these adsorbents were synthesized by adopting Method II. Hence, this study outlines the significance of PAN functionalization using Method II, which in turn provides relevance for the easy commercialization of PAN immobilized onto amino functionalized materials via solvent evaporation process.

\section{$>$ Promising future directions}

The potentiality of the synthesized materials to separate/concentrate REEs can be efficiently integrated with other existing technologies such as CDI and EDI, in the form of electrodes or resin beds. This can eventually open up new avenues that rely on efficient means to recover and concentrate REEs in diverse domains.

In summary, PAN is identified as an exceptional ligand for enhancing REE selectivity. Despite their inherent potential, it is important to attach them onto support through an appropriate scheme, thus facilitating enhanced PAN loading leading to improved REE affinity. Using APTES via toluene-condensation process allows the silane units to form a crosslinked structure via oligomerization interlocking supports and PAN units. Herein, we have proposed a convenient postsynthetic grafting approach via solvent evaporation process, through which adsorbents with uniform pore characteristics and higher ligand loading can be achieved. By doing so, high performing adsorbents with enhanced REE selectivity were developed as a part of this study. Further, the enhanced REE selectivity for MTM-silica-chitosan beads in comparison with APTESsilica-chitosan beads points towards a direction worthy of exploration, where MTM silane can be analyzed further instead of conventional APTES silane, specifically under acidic conditions. There exists no prior literature that reports on the usage of MTM silane for the silica-chitosan bead preparation. Further optimization of the synthesis routine using MTM silane for bead preparation can result in even higher adsorption capacities $(\sim 200 \mathrm{mg} / \mathrm{g}$ reported in this study). In addition to their superior adsorption capacities, they also possess enhanced REE selectivity, and hence, can be considered as the ideal adsorbent among the synthesized group of adsorbents. However, in terms of simplicity and commercial prospects, the subsequent composite with on par performance, AC-silica-PAN, can be recommended with confidence for further exploration in the domain of CDI and EDI. Further, CNT ( $<10 \%$ loading) was identified as a "spice polymer" to enhance the 
overall REE adsorption characteristics of silica materials, the performance of which was exhibited even under harsh AMD environments. The third best adsorbent, MWNT-silica-PAN, was found to be more efficient than SWNT-silica-PAN in terms of polymer-polymer, polymer-ligand and polymer-APTES interactions. Besides, the entanglement of SWNT even after surface functionalization was highly inconvenient for material handling and storage. Next in line were the PAN immobilized silica gels, which can prove their worthiness under comparatively moderate operating conditions, such as in the presence of lower competing ions. Finally, marine algae possessing the immense capability to adsorb all REEs can be a material suited for future studies. Modifications on marine algae are very scarce and need to be utilized largely in the hybridization process for further enhancement of its adsorption capacities.

The results from this research work can be of utmost interest to mining plants around the world, particularly for those in Finland. The knowledge obtained from this study can eventually facilitate the current players in the mining sector to develop strategies for efficient resource management through recycling, while concurrently offering alternative strategies to the projects under development. The methods proposed here can facilitate the incorporation of new techniques and processes without large-scale replacement of existing technology. The combination of expertise attained from the literature study and from the experimental study as such can serve as effective think tanks for different industries that depend on REE recovery from the diluted streams. Finally, the overall outcome from this project can be applied in time towards the efficient and sustainable usage of resources in the transition towards a circular economy, green and sustainable future. 


\section{REFERENCES}

[1] J. Rockström, W. Steffen, K. Noone, Å. Persson, F.S. Chapin, E.F. Lambin, T.M. Lenton, M. Scheffer, C. Folke, H.J. Schellnhuber, B. Nykvist, C.A. de Wit, T. Hughes, S. van der Leeuw, H. Rodhe, S. Sörlin, P.K. Snyder, R. Costanza, U. Svedin, M. Falkenmark, L. Karlberg, R.W. Corell, V.J. Fabry, J. Hansen, B. Walker, D. Liverman, K. Richardson, P. Crutzen, J.A. Foley, A safe operating space for humanity, Nature. 461 (2009) 472-475. doi:10.1038/461472a.

[2] T.E. Graedel, E.M. Harper, N.T. Nassar, P. Nuss, B.K. Reck, Criticality of metals and metalloids, Proc. Natl. Acad. Sci. 112 (2015) 4257-4262. doi:10.1073/pnas.1500415112.

[3] N.T. Nassar, X. Du, T.E. Graedel, Criticality of the Rare Earth Elements: Criticality of the Rare Earth Elements, J. Ind. Ecol. 19 (2015) 1044-1054. doi:10.1111/jiec.12237.

[4] A. Tukker, Rare Earth Elements Supply Restrictions: Market Failures, Not Scarcity, Hamper Their Current Use in High-Tech Applications, Environ. Sci. Technol. 48 (2014) 9973-9974. doi:10.1021/es503548f.

[5] European Commission Publishes New Critical Raw Materials List - 27 CRMs Confirmed - CRM Alliance, (n.d.). http://criticalrawmaterials.org/european-commission-publishes-new-critical-rawmaterials-list-27-crms-confirmed/ (accessed October 26, 2018).

[6] Critical raw materials for the EU: Report of the Ad-hoc Working Group on defining critical raw materials - European Commission, (n.d.). https://ec.europa.eu/growth/tools-databases/eip-rawmaterials/en/community/document/critical-raw-materials-eu-report-ad-hoc-working-groupdefining-critical-raw (accessed October 26, 2018).

[7] K. Binnemans, P.T. Jones, B. Blanpain, T. Van Gerven, Y. Yang, A. Walton, M. Buchert, Recycling of rare earths: a critical review, J. Clean. Prod. 51 (2013) 1-22. doi:10.1016/j.jclepro.2012.12.037.

[8] I. Anastopoulos, A. Bhatnagar, E.C. Lima, Adsorption of rare earth metals: A review of recent literature, J. Mol. Liq. 221 (2016) 954-962. doi:10.1016/j.molliq.2016.06.076.

[9] P. Henderson, Rare Earth Element Geochemistry, Elsevier, 2013.

[10] E. Machacek, P. Kalvig, Assessing advanced rare earth element-bearing deposits for industrial demand in the EU, Resour. Policy. 49 (2016) 186-203. doi:10.1016/j.resourpol.2016.05.004.

[11] Rare earth elements: a beginner's guide from the BGS | British Geological Survey (BGS), (n.d.). https://www.bgs.ac.uk/research/highlights/2010/rare_earth_elements.html (accessed October 26, 2018).

[12] X. Huang, G. Zhang, A. Pan, F. Chen, C. Zheng, Protecting the environment and public health from rare earth mining: Rare earths mining, Earths Future. 4 (2016) 532-535. doi:10.1002/2016EF000424.

[13] K. Binnemans, P.T. Jones, B. Blanpain, T. Van Gerven, Y. Yang, A. Walton, M. Buchert, Recycling of rare earths: a critical review, J. Clean. Prod. 51 (2013) 1-22. doi:10.1016/j.jclepro.2012.12.037.

[14] K. Zhang, A.N. Kleit, A. Nieto, An economics strategy for criticality - Application to rare earth element Yttrium in new lighting technology and its sustainable availability, Renew. Sustain. Energy Rev. (2017). doi:10.1016/j.rser.2016.12.127.

[15] T. Dutta, K.-H. Kim, M. Uchimiya, E.E. Kwon, B.-H. Jeon, A. Deep, S.-T. Yun, Global demand for rare earth resources and strategies for green mining, Environ. Res. 150 (2016) 182-190. doi:10.1016/j.envres.2016.05.052. 
[16] - Global demand rare earths by application 2018 Statistic, (n.d.). https://www.statista.com/statistics/449747/rare-earth-industry-prediction-demand-globally-byapplication/ (accessed October 26, 2018).

[17] W. Wang, Y. Pranolo, C.Y. Cheng, Metallurgical processes for scandium recovery from various resources: A review, Hydrometallurgy. 108 (2011) 100-108. doi:10.1016/j.hydromet.2011.03.001.

[18] C.R. Borra, B. Blanpain, Y. Pontikes, K. Binnemans, T. Van Gerven, Recovery of Rare Earths and Other Valuable Metals From Bauxite Residue (Red Mud): A Review, J. Sustain. Metall. 2 (2016) 365-386. doi:10.1007/s40831-016-0068-2.

[19] S. Riva, K.V. Yusenko, N.P. Lavery, D.J. Jarvis, S.G.R. Brown, The scandium effect in multicomponent alloys, Int. Mater. Rev. 61 (2016) 203-228. doi:10.1080/09506608.2015.1137692.

[20] R. Schulze, M. Buchert, Estimates of global REE recycling potentials from NdFeB magnet material, Resour. Conserv. Recycl. 113 (2016) 12-27. doi:10.1016/j.resconrec.2016.05.004.

[21] J. Kulczycka, Z. Kowalski, M. Smol, H. Wirth, Evaluation of the recovery of Rare Earth Elements (REE) from phosphogypsum waste - case study of the WIZÓW Chemical Plant (Poland), J. Clean. Prod. 113 (2016) 345-354. doi:10.1016/j.jclepro.2015.11.039.

[22] J. Roosen, S. Van Roosendael, C.R. Borra, T. Van Gerven, S. Mullens, K. Binnemans, Recovery of scandium from leachates of Greek bauxite residue by adsorption on functionalized chitosan-silica hybrid materials, Green Chem. 18 (2016) 2005-2013. doi:10.1039/C5GC02225H.

[23] Metals in a Low-Carbon Economy, SEI. (n.d.). https://www.sei.org/publications/metals-in-a-lowcarbon-economy-resource-scarcity-climate-change-and-business-in-a-finite-world-policy-brief/ (accessed October 26, 2018).

[24] R. Bleischwitz, C.M. Johnson, M.G. Dozler, Re-Assessing resource dependency and criticality. Linking future food and water stress with global resource supply vulnerabilities for foresight analysis, Eur. J. Futur. Res. 2 (2014). doi:10.1007/s40309-013-0034-1.

[25] 2010 - "Recycling - From E-Waste to Resources" | WEEE Forum, (n.d.). http://www.weeeforum.org/documents/2010-recycling-from-e-waste-to-resources (accessed October 26, 2018).

[26] C. Ayora, F. Macías, E. Torres, A. Lozano, S. Carrero, J.-M. Nieto, R. Pérez-López, A. FernándezMartínez, H. Castillo-Michel, Recovery of Rare Earth Elements and Yttrium from PassiveRemediation Systems of Acid Mine Drainage, Environ. Sci. Technol. 50 (2016) 8255-8262. doi:10.1021/acs.est.6b02084.

[27] M.G. Roig, T. Manzano, M. Díaz, Biochemical process for the removal of uranium from acid mine drainages, Water Res. 31 (1997) 2073-2083. doi:10.1016/S0043-1354(97)00036-5.

[28] D. Merten, G. B chel, Determination of Rare Earth Elements in Acid Mine Drainage by Inductively Coupled Plasma Mass Spectrometry, Microchim. Acta. 148 (2004) 163-170. doi:10.1007/s00604004-0260-0.

[29] B. Geissler, L. Hermann, M. Mew, G. Steiner, Striving Toward a Circular Economy for Phosphorus: The Role of Phosphate Rock Mining, Minerals. 8 (2018) 395. doi:10.3390/min8090395.

[30] Regions and cities are invited to plan circular economy with ACR+ - Miniwaste, (n.d.). http://www.miniwaste.eu/fr/accueil/regions-and-cities-are-invited-to-plan-circular-economy-withacrplus.html (accessed October 26, 2018).

[31] Chemical Engineers Handbook, Perry Vol 1, n.d. http://archive.org/details/Chemical_Engineers_Handbook_Perry_Vol_1 (accessed October 26, 2018). 
[32] K. Binnemans, P.T. Jones, B. Blanpain, T. Van Gerven, Y. Pontikes, Towards zero-waste valorisation of rare-earth-containing industrial process residues: a critical review, J. Clean. Prod. 99 (2015) 17-38. doi:10.1016/j.jclepro.2015.02.089.

[33] S.M.A. Koochaki-Mohammadpour, M. Torab-Mostaedi, A. Talebizadeh-Rafsanjani, F. NaderiBehdani, Adsorption Isotherm, Kinetic, Thermodynamic, and Desorption Studies of Lanthanum and Dysprosium on Oxidized Multiwalled Carbon Nanotubes, J. Dispers. Sci. Technol. 35 (2014) 244 254. doi:10.1080/01932691.2013.785361.

[34] S. Iftekhar, V. Srivastava, M. Sillanpää, Synthesis and application of LDH intercalated cellulose nanocomposite for separation of rare earth elements (REEs), Chem. Eng. J. 309 (2017) 130-139. doi:10.1016/j.cej.2016.10.028.

[35] S. Iftekhar, V. Srivastava, M. Sillanpää, Enrichment of lanthanides in aqueous system by cellulose based silica nanocomposite, Chem. Eng. J. 320 (2017) 151-159. doi:10.1016/j.cej.2017.03.051.

[36] S. Iftekhar, V. Srivastava, A. Casas, M. Sillanpää, Synthesis of novel GA-g-PAM/SiO 2 nanocomposite for the recovery of rare earth elements (REE) ions from aqueous solution, J. Clean. Prod. 170 (2018) 251-259. doi:10.1016/j.jclepro.2017.09.166.

[37] M.R. Awual, T. Yaita, H. Shiwaku, Design a novel optical adsorbent for simultaneous ultra-trace cerium(III) detection, sorption and recovery, Chem. Eng. J. 228 (2013) 327-335. doi:10.1016/j.cej.2013.05.010.

[38] M.R. Awual, T. Kobayashi, H. Shiwaku, Y. Miyazaki, R. Motokawa, S. Suzuki, Y. Okamoto, T. Yaita, Evaluation of lanthanide sorption and their coordination mechanism by EXAFS measurement using novel hybrid adsorbent, Chem. Eng. J. 225 (2013) 558-566. doi:10.1016/j.cej.2013.04.015.

[39] M.R. Awual, T. Kobayashi, Y. Miyazaki, R. Motokawa, H. Shiwaku, S. Suzuki, Y. Okamoto, T. Yaita, Selective lanthanide sorption and mechanism using novel hybrid Lewis base (N-methyl-Nphenyl-1,10-phenanthroline-2-carboxamide) ligand modified adsorbent, J. Hazard. Mater. 252-253 (2013) 313-320. doi:10.1016/j.jhazmat.2013.03.020.

[40] M.R. Awual, N.H. Alharthi, Y. Okamoto, M.R. Karim, M.E. Halim, M.M. Hasan, M.M. Rahman, M.M. Islam, M.A. Khaleque, M.C. Sheikh, Ligand field effect for Dysprosium(III) and Lutetium(III) adsorption and EXAFS coordination with novel composite nanomaterials, Chem. Eng. J. 320 (2017) 427-435. doi:10.1016/j.cej.2017.03.075.

[41] J. Roosen, J. Spooren, K. Binnemans, Adsorption performance of functionalized chitosan-silica hybrid materials toward rare earths, J. Mater. Chem. A. 2 (2014) 19415-19426. doi:10.1039/C4TA04518A.

[42] P. Jal, Chemical modification of silica surface by immobilization of functional groups for extractive concentration of metal ions, Talanta. 62 (2004) 1005-1028. doi:10.1016/j.talanta.2003.10.028.

[43] R.K. Sharma, S. Mittal, M. Koel, Analysis of Trace Amounts of Metal Ions Using Silica-Based Chelating Resins: A Green Analytical Method, Crit. Rev. Anal. Chem. 33 (2003) 183-197. doi:10.1080/713609163.

[44] N. Akhtar, M. Iqbal, S.I. Zafar, J. Iqbal, Biosorption characteristics of unicellular green alga Chlorella sorokiniana immobilized in loofa sponge for removal of Cr(III), J. Environ. Sci. 20 (2008) 231-239. doi:10.1016/S1001-0742(08)60036-4.

[45] E. Guibal, Heterogeneous catalysis on chitosan-based materials: a review, Prog. Polym. Sci. 30 (2005) 71-109. doi:10.1016/j.progpolymsci.2004.12.001.

[46] M.F.L. De Volder, S.H. Tawfick, R.H. Baughman, A.J. Hart, Carbon Nanotubes: Present and Future Commercial Applications, Science. 339 (2013) 535-539. doi:10.1126/science.1222453. 
[47] Y.-P. Sun, K. Fu, Y. Lin, W. Huang, Functionalized Carbon Nanotubes: Properties and Applications, Acc. Chem. Res. 35 (2002) 1096-1104. doi:10.1021/ar010160v.

[48] A.N. Amro, A.M. Abulkibash, M.A. Atieh, Carbon Nanotubes as Nanosensor for Differential Electrolytic Micropotentiometry, Am. J. Anal. Chem. 05 (2014) 879-890. doi:10.4236/ajac.2014.513096.

[49] J. Wang, Carbon-Nanotube Based Electrochemical Biosensors: A Review, Electroanalysis. 17 (2005) 7-14. doi:10.1002/elan.200403113.

[50] P.G. Collins, P. Avouris, Nanotubes for electronics, Sci. Am. 283 (2000) 62-69.

[51] C. Yin, M. Aroua, W. Daud, Review of modifications of activated carbon for enhancing contaminant uptakes from aqueous solutions, Sep. Purif. Technol. 52 (2007) 403-415. doi:10.1016/j.seppur.2006.06.009.

[52] Y.M. Ahmed, A. Al-Mamun, A.T. Jameel, M.F.R. AlKhatib, M.K. Amosa, M.A. AlSaadi, Synthesis and Characterization of Carbon Nanofibers Grown on Powdered Activated Carbon, J. Nanotechnol. 2016 (2016) 1-10. doi:10.1155/2016/1538602.

[53] J.M. Dias, M.C.M. Alvim-Ferraz, M.F. Almeida, J. Rivera-Utrilla, M. Sánchez-Polo, Waste materials for activated carbon preparation and its use in aqueous-phase treatment: A review, J. Environ. Manage. 85 (2007) 833-846. doi:10.1016/j.jenvman.2007.07.031.

[54] M. Jawaid, H.P.S. Abdul Khalil, Cellulosic/synthetic fibre reinforced polymer hybrid composites: A review, Carbohydr. Polym. 86 (2011) 1-18. doi:10.1016/j.carbpol.2011.04.043.

[55] N. Saba, P. Tahir, M. Jawaid, A Review on Potentiality of Nano Filler/Natural Fiber Filled Polymer Hybrid Composites, Polymers. 6 (2014) 2247-2273. doi:10.3390/polym6082247.

[56] M.R. Awual, Assessing of lead(III) capturing from contaminated wastewater using ligand doped conjugate adsorbent, Chem. Eng. J. 289 (2016) 65-73. doi:10.1016/j.cej.2015.12.078.

[57] M.R. Awual, Solid phase sensitive palladium(II) ions detection and recovery using ligand based efficient conjugate nanomaterials, Chem. Eng. J. $300 \quad$ (2016) 264-272. doi:10.1016/j.cej.2016.04.071.

[58] J. Roosen, K. Binnemans, Adsorption and chromatographic separation of rare earths with EDTAand DTPA-functionalized chitosan biopolymers, J Mater Chem A. 2 (2014) 1530-1540. doi:10.1039/C3TA14622G.

[59] F. Zhao, E. Repo, D. Yin, L. Chen, S. Kalliola, J. Tang, E. Iakovleva, K.C. Tam, M. Sillanpää, Onepot synthesis of trifunctional chitosan-EDTA- $\beta$-cyclodextrin polymer for simultaneous removal of metals and organic micropollutants, Sci. Rep. 7 (2017). doi:10.1038/s41598-017-16222-7.

[60] E. Repo, J.K. Warchoł, A. Bhatnagar, M. Sillanpää, Heavy metals adsorption by novel EDTAmodified chitosan-silica hybrid materials, J. Colloid Interface Sci. 358 (2011) 261-267. doi:10.1016/j.jcis.2011.02.059.

[61] E. Repo, L. Malinen, R. Koivula, R. Harjula, M. Sillanpää, Capture of Co(II) from its aqueous EDTA-chelate by DTPA-modified silica gel and chitosan, J. Hazard. Mater. 187 (2011) 122-132. doi:10.1016/j.jhazmat.2010.12.113.

[62] F. Zhao, E. Repo, Y. Meng, X. Wang, D. Yin, M. Sillanpää, An EDTA- $\beta$-cyclodextrin material for the adsorption of rare earth elements and its application in preconcentration of rare earth elements in seawater, J. Colloid Interface Sci. 465 (2016) 215-224. doi:10.1016/j.jcis.2015.11.069.

[63] R.M. Ashour, M. Samouhos, E. Polido Legaria, M. Svärd, J. Högblom, K. Forsberg, M. Palmlöf, V.G. Kessler, G.A. Seisenbaeva, Å.C. Rasmuson, DTPA-Functionalized Silica Nano- and 
Microparticles for Adsorption and Chromatographic Separation of Rare Earth Elements, ACS Sustain. Chem. Eng. 6 (2018) 6889-6900. doi:10.1021/acssuschemeng.8b00725.

[64] L. Cornejo-Ponce, P. Peralta-Zamora, M.I.M.S. Bueno, Pre-concentration of rare earths using silica gel loaded with 1-(2-pyridylazo)-2-naphthol (PAN) and determination by energy dispersive X-ray fluorescence, Talanta. 46 (1998) 1371-1378. doi:10.1016/S0039-9140(98)00002-2.

[65] N. ZHANG, C. HUANG, B. HU, ICP-AES Determination of Trace Rare Earth Elements in Environmental and Food Samples by On-line Separation and Preconcentration with Acetylacetonemodified Silica Gel Using Microcolumn, Anal. Sci. 23 (2007) 997-1002. doi:10.2116/analsci.23.997.

[66] Organic Reagents in Metal Analysis: International Series of Monographs in ... - K. Burger - Google Books,

(n.d.). https://books.google.fi/books?id=hu39BAAAQBAJ\&pg=PA265\&lpg=PA265\&dq=acetylacetone+ and + PAN\&source $=$ bl\&ots $=5$ ifH 8 HOfnV $\&$ sig $=$ uI - RboN-

HDdRBQA0plJd_WAGSVI\&hl=en\&sa=X\&ved=2ahUKEwjf3ZWb7aLeAhUECiwKHWGyC9A Q6AEwDHoECAEQAQ\#v=onepage \&q=acetylacetone $\% 20$ and $\% 20 \mathrm{PAN} \& \mathrm{f}=$ false $\quad$ (accessed October 26, 2018).

[67] K.L. Cheng, R.H. Bray, 1-(2-Pyridylazo)-2-naphthol as Possible Analytical Reagent, Anal. Chem. 27 (1955) 782-785. doi:10.1021/ac60101a024.

[68] J. Zhu, J. Yang, B. Deng, Enhanced mercury ion adsorption by amine-modified activated carbon, J. Hazard. Mater. 166 (2009) 866-872. doi:10.1016/j.jhazmat.2008.11.095.

[69] M. Irani, A.R. Keshtkar, M.A. Moosavian, Removal of cadmium from aqueous solution using mesoporous PVA/TEOS/APTES composite nanofiber prepared by sol-gel/electrospinning, Chem. Eng. J. 200-202 (2012) 192-201. doi:10.1016/j.cej.2012.06.054.

[70] G.H. Mirzabe, A.R. Keshtkar, Application of response surface methodology for thorium adsorption on PVA/Fe3O4/SiO2/APTES nanohybrid adsorbent, J. Ind. Eng. Chem. 26 (2015) 277-285. doi:10.1016/j.jiec.2014.11.040.

[71] J. Ma, Z. Wang, Y. Shi, Q. Li, Synthesis and characterization of lysine-modified SBA-15 and its selective adsorption of scandium from a solution of rare earth elements, RSC Adv. 4 (2014) 4159741604. doi:10.1039/C4RA07571D.

[72] A.R. Keshtkar, M. Irani, M.A. Moosavian, Comparative study on PVA/silica membrane functionalized with mercapto and amine groups for adsorption of $\mathrm{Cu}(\mathrm{II})$ from aqueous solutions, $\mathrm{J}$. Taiwan Inst. Chem. Eng. 44 (2013) 279-286. doi:10.1016/j.jtice.2012.10.002.

[73] A. Dastbaz, A.R. Keshtkar, Adsorption of Th4+, U6+, Cd2+, and Ni2+ from aqueous solution by a novel modified polyacrylonitrile composite nanofiber adsorbent prepared by electrospinning, Appl. Surf. Sci. 293 (2014) 336-344. doi:10.1016/j.apsusc.2013.12.164.

[74] M. Etemadi, S. Samadi, S.S. Yazd, P. Jafari, N. Yousefi, M. Aliabadi, Selective adsorption of Cr(VI) ions from aqueous solutions using Cr6+-imprinted Pebax/chitosan/GO/APTES nanofibrous adsorbent, Int. J. Biol. Macromol. 95 (2017) 725-733. doi:10.1016/j.ijbiomac.2016.11.117.

[75] S. Abbasizadeh, A.R. Keshtkar, M.A. Mousavian, Sorption of heavy metal ions from aqueous solution by a novel cast PVA/TiO2 nanohybrid adsorbent functionalized with amine groups, J. Ind. Eng. Chem. 20 (2014) 1656-1664. doi:10.1016/j.jiec.2013.08.013.

[76] I. Fatimah, Preparation, characterization and physicochemical study of 3-amino propyl trimethoxy silane-modified kaolinite for Pb(II) adsorption, J. King Saud Univ. - Sci. 30 (2018) 250-257. doi:10.1016/j.jksus.2017.04.006. 
[77] S. Hokkanen, E. Repo, T. Suopajärvi, H. Liimatainen, J. Niinimaa, M. Sillanpää, Adsorption of $\mathrm{Ni}(\mathrm{II}), \mathrm{Cu}(\mathrm{II})$ and $\mathrm{Cd}(\mathrm{II})$ from aqueous solutions by amino modified nanostructured microfibrillated cellulose, Cellulose. 21 (2014) 1471-1487. doi:10.1007/s10570-014-0240-4.

[78] J. Gao, G. Hu, J. Kang, G. Bai, 1-(2-pyridylazo)-2-naphthol (PAN) as extractant in solid-liquid extraction of some trivalent rare earth elements $\boldsymbol{w}^{2}$, Talanta. 40 (1993) 195-200. doi:10.1016/00399140(93)80321-H.

[79] S.L.C. Ferreira, C.F. de Brito, A.F. Dantas, N.M. Lopo de Araújo, A.C.S. Costa, Nickel determination in saline matrices by ICP-AES after sorption on Amberlite XAD-2 loaded with PAN, Talanta. 48 (1999) 1173-1177. doi:10.1016/S0039-9140(98)00339-7.

[80] D. Bohrer, P. Cícero do Nascimento, M. Guterres, M. Trevisan, E. Seibert, Electrothermal atomic absorption spectrometric determination of lead, cadmium, copper and zinc in high-salt content samples after simultaneous separation on polyethylene powder impregnated with 1-(2-pyridylazo)2-naphthol: application to the analysis of hemodialysis fluids, The Analyst. 124 (1999) 1345-1350. doi:10.1039/a903818c.

[81] V.A. Tertykh, V.V. Yanishpolskii, O.Y. Panova, Covalent Attachment of Some Phenol Derivatives to the Silica Surface by Use of Single-stage Aminomethylation, J. Therm. Anal. Calorim. 62 (2000) 545-549. doi:10.1023/A:1010187508531.

[82] P. Bermejo-Barrera, N. Martínez-Alfonso, A. Bermejo-Barrera, Separation of gallium and indium from ores matrix by sorption on Amberlite XAD-2 coated with PAN, Fresenius J. Anal. Chem. 369 (2001) 191-194. doi:10.1007/s002160000605.

[83] F. Shemirani, B.T.S. Akhavi, PRECONCENTRATION AND DETERMINATION OF TRACE CADMIUM USING 1-(2-PYRIDYLAZO)-2-NAPHTHOL (PAN) IMMOBILIZED ON SURFACTANT-COATED ALUMINA, Anal. Lett. 34 (2001) 2179-2188. doi:10.1081/AL100106849.

[84] A. Khan, F. Mahmood, S. Ahmed, M.Y. Khokhar, Removal of Cd Ions by Sol-Gel Silica Doped with 1-(2-Pyridylazo)-2-Naphthol, J. Sol-Gel Sci. Technol. 27 (2003) 221-224. doi:10.1023/A:1023762920505.

[85] M.A. Nancy, D.L. Cristina, B.B. Adela, P. Bermejo-Barrera, Use of Amberlite XAD-2 Loaded with 1-(2-Pyridylazo)-2-naphthol as a Preconcentration System for River Water Prior to Determination of $\mathrm{Cu} 2+, \mathrm{Cd} 2+$ and $\mathrm{Pb} 2+$ by Flame Atomic Absorption Spectroscopy, Microchim. Acta. 142 (2003) 101-108. doi:10.1007/s00604-003-0022-4.

[86] N. Bahramifar, Y. Yamini, On-line preconcentration of some rare earth elements in water samples using C18-cartridge modified with 1-(2-pyridylazo) 2-naphtol (PAN) prior to simultaneous determination by inductively coupled plasma optical emission spectrometry (ICP-OES), Anal. Chim. Acta. 540 (2005) 325-332. doi:10.1016/j.aca.2005.03.058.

[87] S. Nabi, A. Alim, A. Islam, M. Amjad, Column chromatographic separation of metal ions on 1-(2pyridylazo)-2-napthol modified Amberlite IR-120 resin, J. Sep. Sci. 28 (2005) 2463-2467. doi:10.1002/jssc.200500170.

[88] M.M. Saeed, R. Ahmad, Adsorption modeling and thermodynamic characteristics of uranium(VI) ions onto 1-(2-pyridylazo)-2-naphthol (PAN) supported polyurethane foam, Radiochim. Acta. 93 (2005). doi:10.1524/ract.93.6.333.65646.

[89] M.M. Saeed, M.M. Saeed, R. Ahmed, R. Ahmed, Temperature effected sorption of europium(III) onto 1-(2-pyridylazo)-2-naphthol impregnated polyurethane foam, J. Radioanal. Nucl. Chem. 267 (2005) 147-153. doi:10.1007/s10967-006-0021-0. 
[90] M. Mufazzal Saeed, Uptake of Tm(III) ions onto polyurethane foam from H2O - ethanol mixture containing 1-(2-pyridylazo)-2-naphthol (PAN), J. Radioanal. Nucl. Chem. 267 (2006) 427-433. doi:10.1007/s10967-006-0066-0.

[91] A.P. dos Anjos, L. Cornejo-Ponce, S. Cadore, N. Baccan, Determination of manganese by flame atomic absorption spectrometry after its adsorption onto naphthalene modified with 1-(2pyridylazo)-2-naphthol (PAN), Talanta. 71 (2007) 1252-1256. doi:10.1016/j.talanta.2006.06.026.

[92] R. Ahmad, M.M. Saeed, A. Ali, J.H. Zaidi, Removal of Tm(III) ions from aqueous solution using PAN-incorporated sol-gel matrices, Radiochim. Acta. 95 (2007). doi:10.1524/ract.2007.95.8.451.

[93] X. Zhu, M. Wu, J. Sun, X. Zhang, $\beta$-Cyclodextrin-Cross-Linked Polymer as Solid Phase Extraction Material Coupled Graphite Furnace Atomic Absorption Spectrometry for Separation/Analysis of Trace Copper, Anal. Lett. 41 (2008) 2186-2202. doi:10.1080/00032710802237749.

[94] A. Kaur, U. Gupta, A Preconcentration Procedure Using 1-(2-Pyridylazo)-2-napthol Anchored to Silica Nanoparticle for the Analysis of Cadmium in Different Samples, E-J. Chem. 5 (2008) 930939. doi:10.1155/2008/431916.

[95] N.A. Gavrilenko, N.V. Saranchina, Analytical properties of 1-(2-pyridylazo)-2-naphthol immobilized on a polymethacrylate matrix, J. Anal. Chem. 64 (2009) 226-230. doi:10.1134/S1061934809030034.

[96] H. Faghihian, A. Hajishabani, S. Dadfarnia, H. Zamani, Use of clinoptilolite loaded with 1-(2pyridylazo)-2-naphthol as a sorbent for preconcentration of $\mathrm{Pb}$ (II), $\mathrm{Ni}$ (II), $\mathrm{Cd}$ (II) and $\mathrm{Cu}$ (II) prior to their determination by flame atomic absorption spectroscopy, Int. J. Environ. Anal. Chem. 89 (2009) 223-231. doi:10.1080/03067310802262656.

[97] C.R. Preetha, T. Prasada Rao, Preparation of 1-(2-pyridylazo)-2-naphthol functionalized benzophenone/naphthalene and their uses in solid phase extractive preconcentration/separation of uranium(VI), Radiochim. Acta. 91 (2003). doi:10.1524/ract.91.5.247.20308.

[98] J.L. Manzoori, M. Amjadi, T. Hallaj, Preconcentration of trace cadmium and manganese using 1(2-pyridylazo)-2-naphthol-modified $\mathrm{TiO}_{2}$ nanoparticles and their determination by flame atomic absorption spectrometry, Int. J. Environ. Anal. Chem. 89 (2009) 749-758. doi:10.1080/03067310902736955.

[99] A. Islam, M.A. Laskar, A. Ahmad, Characterization and Application of 1-(2-Pyridylazo)-2-naphthol Functionalized Amberlite XAD-4 for Preconcentration of Trace Metal Ions in Real Matrices, J. Chem. Eng. Data. 55 (2010) 5553-5561. doi:10.1021/je100272s.

[100] R. Jamshidi, D. Afzali, Z. Afzali, Determination trace amounts of thallium after separation and preconcentration onto nanoclay loaded with 1-(2-pyridylazo)-2-naphthol as a new sorbent, Int. J. Environ. Anal. Chem. 91 (2011) 821-827. doi:10.1080/03067310903267356.

[101] A.M. Basaglia, M.Z. Corazza, M.G. Segatelli, C.R.T. Tarley, Synthesis of Pb( II )-imprinted poly(methacrylic acid) polymeric particles loaded with 1-(2-pyridylazo)-2-naphthol (PAN) for micro-solid phase preconcentration of $\mathrm{Pb}^{2+}$ on-line coupled to flame atomic absorption spectrometry, RSC Adv. 7 (2017) 33001-33011. doi:10.1039/C7RA02964K.

[102] P. Simha, A. Yadav, D. Pinjari, A.B. Pandit, On the behaviour, mechanistic modelling and interaction of biochar and crop fertilizers in aqueous solutions, Resour.-Effic. Technol. 2 (2016) 133-142. doi:10.1016/j.reffit.2016.07.006.

[103] D.L. Ramasamy, S. Khan, E. Repo, M. Sillanpää, Synthesis of mesoporous and microporous amine and non-amine functionalized silica gels for the application of rare earth elements (REE) recovery 
from the waste water-understanding the role of $\mathrm{pH}$, temperature, calcination and mechanism in Light REE and Heavy REE separation, Chem. Eng. J. 322 (2017) 56-65. doi:10.1016/j.cej.2017.03.152.

[104] D.L. Ramasamy, E. Repo, V. Srivastava, M. Sillanpää, Chemically immobilized and physically adsorbed PAN/acetylacetone modified mesoporous silica for the recovery of rare earth elements from the waste water-comparative and optimization study, Water Res. 114 (2017) 264-276. doi:10.1016/j.watres.2017.02.045.

[105] S.M. Olhero, J.M.F. Ferreira, Influence of particle size distribution on rheology and particle packing of silica-based suspensions, Powder Technol. 139 (2004) 69-75. doi:10.1016/j.powtec.2003.10.004.

[106] S. Poyet, A. Sellier, B. Capra, G. Foray, J.-M. Torrenti, H. Cognon, E. Bourdarot, Chemical modelling of Alkali Silica reaction: Influence of the reactive aggregate size distribution, Mater. Struct. 40 (2006) 229-229. doi:10.1617/s11527-006-9139-3.

[107] P. Michard, E. Guibal, T. Vincent, P. Le Cloirec, Sorption and desorption of uranyl ions by silica gel: pH, particle size and porosity effects, Microporous Mater. 5 (1996) 309-324. doi:10.1016/09276513(95)00067-4.

[108] R. Masuda, W. Takahashi, M. Ishii, Particle size distribution of spherical silica gel produced by solgel method, J. Non-Cryst. Solids. 121 (1990) 389-393. doi:10.1016/0022-3093(90)90163-G.

[109] a Simon, T. Cohen-Bouhacina, M.C. Porté, J.P. Aimé, C. Baquey, Study of two grafting methods for obtaining a 3-aminopropyltriethoxysilane monolayer on silica surface., J. Colloid Interface Sci. 251 (2002) 278-283. doi:10.1006/jcis.2002.8385.

[110] S.V. Kalinin, L.I. Kheifets, A.I. Mamchik, A.G. Knot'ko, A.A. Vertigel, Influence of the Drying Technique on the Structure of Silica Gels, J. Sol-Gel Sci. Technol. 15 (1999) 31-35. doi:10.1023/A:1008771829173.

[111] J. Alcañiz-Monge, M. Pérez-Cadenas, D. Lozano-Castelló, Influence of pore size distribution on water adsorption on silica gels, J. Porous Mater. 17 (2010) 409-416. doi:10.1007/s10934-009-93170 .

[112] S. Sato, T. Murakata, T. Suzuki, T. Ohgawara, Control of pore size distribution of silica gel through sol-gel process using water soluble polymers as additives, J. Mater. Sci. 25 (1990) 4880-4885. doi:10.1007/BF01129956.

[113] Y. Xie, C.A.S. Hill, Z. Xiao, H. Militz, C. Mai, Silane coupling agents used for natural fiber/polymer composites: A review, Compos. Part Appl. Sci. Manuf. 41 (2010) 806-819. doi:10.1016/j.compositesa.2010.03.005.

[114] S. Nuriel, L. Liu, A.H. Barber, H.D. Wagner, Direct measurement of multiwall nanotube surface tension, Chem. Phys. Lett. 404 (2005) 263-266. doi:10.1016/j.cplett.2005.01.072.

[115] K. Nakanishi, M. Tomita, K. Kato, Synthesis of amino-functionalized mesoporous silica sheets and their application for metal ion capture, J. Asian Ceram. Soc. 3 (2015) 70-76. doi:10.1016/j.jascer.2014.10.011.

[116] A.S. Maria Chong, X.S. Zhao, Functionalization of SBA-15 with APTES and Characterization of Functionalized Materials, J. Phys. Chem. B. 107 (2003) 12650-12657. doi:10.1021/jp035877+.

[117] Z. Qin, P. Yuan, J. Zhu, H. He, D. Liu, S. Yang, Influences of thermal pretreatment temperature and solvent on the organosilane modification of Al13-intercalated/Al-pillared montmorillonite, Appl. Clay Sci. 50 (2010) 546-553. doi:10.1016/j.clay.2010.10.011.

[118] V.D. Chaube, S. Shylesh, A.P. Singh, Synthesis, characterization and catalytic activity of Mn(III)and Co(II)-salen complexes immobilized mesoporous alumina, J. Mol. Catal. Chem. 241 (2005) 7987. doi:10.1016/j.molcata.2005.07.005. 
[119] D.L. Ramasamy, A. Wojtuś, E. Repo, S. Kalliola, V. Srivastava, M. Sillanpää, Ligand immobilized novel hybrid adsorbents for rare earth elements (REE) removal from waste water: Assessing the feasibility of using APTES functionalized silica in the hybridization process with chitosan, Chem. Eng. J. 330 (2017) 1370-1379. doi:10.1016/j.cej.2017.08.098.

[120] D.L. Ramasamy, V. Puhakka, S. Iftekhar, A. Wojtuś, E. Repo, S. Ben Hammouda, E. Iakovleva, M. Sillanpää, N- and O- ligand doped mesoporous silica-chitosan hybrid beads for the efficient, sustainable and selective recovery of rare earth elements (REE) from acid mine drainage (AMD): Understanding the significance of physical modification and conditioning of the polymer, J. Hazard. Mater. 348 (2018) 84-91. doi:10.1016/j.jhazmat.2018.01.030.

[121] M.S. Atrees, E. Metwally, M. Demerdash, H. Salem, Sorption behavior of Pr and Nd upon chitosan benzoyl thiourea derivatives, J. Radiat. Res. Appl. Sci. 9 (2016) 207-216. doi:10.1016/j.jrras.2015.02.004.

[122] C. Gerente, V.K.C. Lee, P.L. Cloirec, G. McKay, Application of Chitosan for the Removal of Metals From Wastewaters by Adsorption-Mechanisms and Models Review, Crit. Rev. Environ. Sci. Technol. 37 (2007) 41-127. doi:10.1080/10643380600729089.

[123] W.S. Wan Ngah, K.H. Liang, Adsorption of Gold(III) Ions onto Chitosan and $N$-Carboxymethyl Chitosan: Equilibrium Studies, Ind. Eng. Chem. Res. 38 (1999) 1411-1414. doi:10.1021/ie9803164.

[124] E. Guibal, Interactions of metal ions with chitosan-based sorbents: a review, Sep. Purif. Technol. 38 (2004) 43-74. doi:10.1016/j.seppur.2003.10.004.

[125] Z. Zhao, Y. Baba, W. Yoshida, F. Kubota, M. Goto, Development of novel adsorbent bearing aminocarbonylmethylglycine and its application to scandium separation, J. Chem. Technol. Biotechnol. 91 (2016) 2779-2784. doi:10.1002/jctb.4884.

[126] C. Tang, Y. Shu, R. Zhang, X. Li, J. Song, B. Li, Y. Zhang, D. Ou, Comparison of the removal and adsorption mechanisms of cadmium and lead from aqueous solution by activated carbons prepared from Typha angustifolia and Salix matsudana, RSC Adv. 7 (2017) 16092-16103. doi:10.1039/C6RA28035H.

[127] E. Guibal, C. Milot, J.M. Tobin, Metal-Anion Sorption by Chitosan Beads: Equilibrium and Kinetic Studies, Ind. Eng. Chem. Res. 37 (1998) 1454-1463. doi:10.1021/ie9703954.

[128] H. Chen, O. Jacobs, W. Wu, G. Rüdiger, B. Schädel, Effect of dispersion method on tribological properties of carbon nanotube reinforced epoxy resin composites, Polym. Test. 26 (2007) 351-360. doi:10.1016/j.polymertesting.2006.11.004.

[129] J. Kathi, K.-Y. Rhee, J.H. Lee, Effect of chemical functionalization of multi-walled carbon nanotubes with 3-aminopropyltriethoxysilane on mechanical and morphological properties of epoxy nanocomposites, Compos. Part Appl. Sci. Manuf. $40 \quad$ (2009) 800-809. doi:10.1016/j.compositesa.2009.04.001.

[130] J.H. Rouse, P.T. Lillehei, J. Sanderson, E.J. Siochi, Polymer/Single-Walled Carbon Nanotube Films Assembled via Donor-Acceptor Interactions and Their Use as Scaffolds for Silica Deposition, Chem. Mater. 16 (2004) 3904-3910. doi:10.1021/cm049708t.

[131] M. Zhang, X. Zhang, X. He, L. Chen, Y. Zhang, A facile method to coat mesoporous silica layer on carbon nanotubes by anionic surfactant, Mater. Lett. 64 (2010) 1383-1386. doi:10.1016/j.matlet.2010.03.032.

[132] M. Lavorgna, V. Romeo, A. Martone, M. Zarrelli, M. Giordano, G.G. Buonocore, M.Z. Qu, G.X. Fei, H.S. Xia, Silanization and silica enrichment of multiwalled carbon nanotubes: Synergistic 
effects on the thermal-mechanical properties of epoxy nanocomposites, Eur. Polym. J. 49 (2013) 428-438. doi:10.1016/j.eurpolymj.2012.10.003.

[133] H. Kamiya, M. Mitsui, H. Takano, S. Miyazawa, Influence of Particle Diameter on Surface Silanol Structure, Hydration Forces, and Aggregation Behavior of Alkoxide-Derived Silica Particles, J. Am. Ceram. Soc. 83 (2000) 287-293. doi:10.1111/j.1151-2916.2000.tb01187.x.

[134] M. Bottini, L. Tautz, H. Huynh, E. Monosov, N. Bottini, M.I. Dawson, S. Bellucci, T. Mustelin, Covalent decoration of multi-walled carbon nanotubes with silica nanoparticles, Chem. Commun. (2005) 758. doi:10.1039/b412876a.

[135] T. Sainsbury, D. Fitzmaurice, Templated Assembly of Semiconductor and Insulator Nanoparticles at the Surface of Covalently Modified Multiwalled Carbon Nanotubes, Chem. Mater. 16 (2004) 3780-3790. doi:10.1021/cm049151h.

[136] F. Wang, J. Zhao, F. Pan, H. Zhou, X. Yang, W. Li, H. Liu, Adsorption Properties toward Trivalent Rare Earths by Alginate Beads Doping with Silica, Ind. Eng. Chem. Res. 52 (2013) 3453-3461. doi:10.1021/ie302753q.

[137] K. Vijayaraghavan, M. Sathishkumar, R. Balasubramanian, Biosorption of Lanthanum, Cerium, Europium, and Ytterbium by a Brown Marine Alga, Turbinaria Conoides, Ind. Eng. Chem. Res. 49 (2010) 4405-4411. doi:10.1021/ie1000373.

[138] A.-C. Texier, Y. Andrès, P. Le Cloirec, Selective Biosorption of Lanthanide (La, Eu, Yb) Ions by Pseudomonas aeruginosa, Environ. Sci. Technol. 33 (1999) 489-495. doi:10.1021/es9807744.

[139] Z.S. Birungi, E.M.N. Chirwa, The kinetics of uptake and recovery of lanthanum using freshwater algae as biosorbents: Comparative analysis, Bioresour. Technol. 160 (2014) 43-51. doi:10.1016/j.biortech.2014.01.033.

[140] R.G. Pearson, Hard and Soft Acids and Bases, J. Am. Chem. Soc. 85 (1963) 3533-3539. doi:10.1021/ja00905a001.

[141] V. Diniz, B. Volesky, Effect of counterions on lanthanum biosorption by Sargassum polycystum, Water Res. 39 (2005) 2229-2236. doi:10.1016/j.watres.2005.04.004.

[142] M. Thommes, Physical Adsorption Characterization of Nanoporous Materials, Chem. Ing. Tech. 82 (2010) 1059-1073. doi:10.1002/cite.201000064.

[143] P.B. Balbuena, K.E. Gubbins, Theoretical interpretation of adsorption behavior of simple fluids in slit pores, Langmuir. 9 (1993) 1801-1814. doi:10.1021/la00031a031.

[144] M.R. Awual, New type mesoporous conjugate material for selective optical copper(II) ions monitoring \&amp; removal from polluted waters, Chem. Eng. J. 307 (2017) 85-94. doi:10.1016/j.cej.2016.07.110.

[145] M.R. Awual, M.M. Hasan, A novel fine-tuning mesoporous adsorbent for simultaneous lead(II) detection and removal from wastewater, Sens. Actuators B Chem. 202 (2014) 395-403. doi:10.1016/j.snb.2014.05.103.

[146] J.C. Groen, L.A.. Peffer, J. Pérez-Ramírez, Pore size determination in modified micro- and mesoporous materials. Pitfalls and limitations in gas adsorption data analysis, Microporous Mesoporous Mater. 60 (2003) 1-17. doi:10.1016/S1387-1811(03)00339-1.

[147] A. Korrir, A. Kasmi, M. Assebban, A. Souikny, S. Haffane, O. Achak, T. Chafik, Non-Calorimetric Determination of the Adsorption Heat of Volatile Organic Compounds under Dynamic Conditions, Catalysts. 5 (2015) 653-670. doi:10.3390/catal5020653. 
[148] M.O. Abd El-Magied, A.A. Galhoum, A.A. Atia, A.A. Tolba, M.S. Maize, T. Vincent, E. Guibal, Cellulose and chitosan derivatives for enhanced sorption of erbium(III), Colloids Surf. Physicochem. Eng. Asp. 529 (2017) 580-593. doi:10.1016/j.colsurfa.2017.05.031.

[149] A.A. Galhoum, K.M. Hassan, O.A. Desouky, A.M. Masoud, T. Akashi, Y. Sakai, E. Guibal, Aspartic acid grafting on cellulose and chitosan for enhanced Nd(III) sorption, React. Funct. Polym. 113 (2017) 13-22. doi:10.1016/j.reactfunctpolym.2017.02.001.

[150] E. Igberase, P. Osifo, A. Ofomaja, Chromium (VI) ion adsorption by grafted cross-linked chitosan beads in aqueous solution - a mathematical and statistical modeling study, Environ. Technol. 38 (2017) 3156-3166. doi:10.1080/09593330.2017.1290152.

[151] R.S. Vieira, M.M. Beppu, Interaction of natural and crosslinked chitosan membranes with $\mathrm{Hg}$ (II) ions, Colloids Surf. Physicochem. Eng. Asp. 279 (2006) 196-207. doi:10.1016/j.colsurfa.2006.01.026.

[152] A. Beganskiene, V. Sirutkaitis, M. Kurtinaitiene, R. Juskenas, A. Kareiva, FTIR, TEM and NMR Iinvestigations of Stöber Silica Nanoparticles, Mater. Sci. Medžiagotyra. 10 (2004) 287-290. doi:10.1016/j.jnoncrysol.2012.11.006.

[153] S.A. Kulkarni, S.B. Ogale, K.P. Vijayamohanan, Tuning the hydrophobic properties of silica particles by surface silanization using mixed self-assembled monolayers, J. Colloid Interface Sci. 318 (2008) 372-379. doi:10.1016/j.jcis.2007.11.012.

[154] J. Abolhasani, M. Behbahani, Application of 1-(2-pyridylazo)-2-naphthol-modified nanoporous silica as a technique in simultaneous trace monitoring and removal of toxic heavy metals in food and water samples, Environ. Monit. Assess. 187 (2015). doi:10.1007/s10661-014-4176-9.

[155] S. Rajeshkumar, C. Malarkodi, G. Gnanajobitha, K. Paulkumar, M. Vanaja, C. Kannan, G. Annadurai, Seaweed-mediated synthesis of gold nanoparticles using Turbinaria conoides and its characterization, J. Nanostructure Chem. 3 (2013) 44. doi:10.1186/2193-8865-3-44.

[156] F. Chen, Y. Zhu, Chitosan enclosed mesoporous silica nanoparticles as drug nano-carriers: Sensitive response to the narrow $\mathrm{pH}$ range, Microporous Mesoporous Mater. 150 (2012) 83-89. doi:10.1016/j.micromeso.2011.07.023.

[157] S. Xu, Z. Wang, Y. Gao, S. Zhang, K. Wu, Adsorption of Rare Earths(III) Using an Efficient Sodium Alginate Hydrogel Cross-Linked with Poly- $\gamma$-Glutamate, PLOS ONE. 10 (2015) e0124826. doi:10.1371/journal.pone.0124826.

[158] S. Mu, Electrospun Nanofibrous Materials and Their Hydrogen Storage, in: J. Liu (Ed.), Hydrog. Storage, InTech, 2012. doi:10.5772/50521.

[159] K. Babooram, R. Narain, Fabrication of SWNT/Silica Composites by the Sol-Gel Process, ACS Appl. Mater. Interfaces. 1 (2009) 181-186. doi:10.1021/am8001296.

[160] J.M. Tan, P. Arulselvan, S. Fakurazi, H. Ithnin, M.Z. Hussein, A Review on Characterizations and Biocompatibility of Functionalized Carbon Nanotubes in Drug Delivery Design, J. Nanomater. 2014 (2014) 1-20. doi:10.1155/2014/917024.

[161] A.K. Jain, V. Dubey, N.K. Mehra, N. Lodhi, M. Nahar, D.K. Mishra, N.K. Jain, Carbohydrateconjugated multiwalled carbon nanotubes: development and characterization, Nanomedicine Nanotechnol. Biol. Med. 5 (2009) 432-442. doi:10.1016/j.nano.2009.03.001.

[162] S. Banerjee, T. Hemraj-Benny, S.S. Wong, Covalent Surface Chemistry of Single-Walled Carbon Nanotubes, Adv. Mater. 17 (2005) 17-29. doi:10.1002/adma.200401340. 
[163] P.C. Ma, J.-K. Kim, B.Z. Tang, Effects of silane functionalization on the properties of carbon nanotube/epoxy nanocomposites, Compos. Sci. Technol. $67 \quad$ (2007) 2965-2972. doi:10.1016/j.compscitech.2007.05.006.

[164] S. Iftekhar, D.L. Ramasamy, V. Srivastava, M.B. Asif, M. Sillanpää, Understanding the factors affecting the adsorption of Lanthanum using different adsorbents: A critical review, Chemosphere. 204 (2018) 413-430. doi:10.1016/j.chemosphere.2018.04.053.

[165] N. Das, D. Das, Recovery of rare earth metals through biosorption: An overview, J. Rare Earths. 31 (2013) 933-943. doi:10.1016/S1002-0721(13)60009-5.

[166] S. Basu, S. Halder, I. Pal, S. Samanta, P. Karmakar, M.G.B. Drew, S. Bhattacharya, 1-(2'Pyridylazo)-2-naphtholate complexes of ruthenium: Synthesis, characterization, and DNA binding properties, Polyhedron. 27 (2008) 2943-2951. doi:10.1016/j.poly.2008.05.023.

[167] S. Tokalioglu, H. Büyükbas, S. Kartal, Preconcentration of trace elements by using 1-(2Pyridylazo)-2-naphthol functionalized Amberlite XAD-1180 resin and their determination by FAAS, J. Braz. Chem. Soc. 17 (2006) 98-106. doi:10.1590/S0103-50532006000100015.

[168] X. Zheng, C. Wang, J. Dai, W. Shi, Y. Yan, Design of mesoporous silica hybrid materials as sorbents for the selective recovery of rare earth metals, J. Mater. Chem. A. 3 (2015) 10327-10335. doi:10.1039/C4TA06860B.

[169] V.A. Anagnostopoulos, B.D. Symeopoulos, Sorption of europium by malt spent rootlets, a low cost biosorbent: effect of pH, kinetics and equilibrium studies, J. Radioanal. Nucl. Chem. 295 (2013) 7 13. doi:10.1007/s10967-012-1956-y.

[170] E.I. Cadogan, C.-H. Lee, S.R. Popuri, H.-Y. Lin, Efficiencies of chitosan nanoparticles and crab shell particles in europium uptake from aqueous solutions through biosorption: Synthesis and characterization, Int. Biodeterior. Biodegrad. 95 (2014) 232-240. doi:10.1016/j.ibiod.2014.06.003.

[171] T. Yao, Y. Xiao, X. Wu, C. Guo, Y. Zhao, X. Chen, Adsorption of Eu(III) on sulfonated graphene oxide: Combined macroscopic and modeling techniques, J. Mol. Liq. 215 (2016) 443-448. doi:10.1016/j.molliq.2015.11.030.

[172] M. Torab-Mostaedi, M. Asadollahzadeh, A. Hemmati, A. Khosravi, Biosorption of lanthanum and cerium from aqueous solutions by grapefruit peel: equilibrium, kinetic and thermodynamic studies, Res. Chem. Intermed. 41 (2015) 559-573. doi:10.1007/s11164-013-1210-4.

[173] D.L. Ramasamy, V. Puhakka, E. Repo, M. Sillanpää, Selective separation of scandium from iron, aluminium and gold rich wastewater using various amino and non-amino functionalized silica gels - A comparative study, J. Clean. Prod. 170 (2018) 890-901. doi:10.1016/j.jclepro.2017.09.199.

[174] S. Demir, N.K. Brune, J.F. Van Humbeck, J.A. Mason, T.V. Plakhova, S. Wang, G. Tian, S.G. Minasian, T. Tyliszczak, T. Yaita, T. Kobayashi, S.N. Kalmykov, H. Shiwaku, D.K. Shuh, J.R. Long, Extraction of Lanthanide and Actinide Ions from Aqueous Mixtures Using a Carboxylic AcidFunctionalized Porous Aromatic Framework, ACS Cent. Sci. 2 (2016) 253-265. doi:10.1021/acscentsci.6b00066.

[175] T. Kameda, K. Hoshi, T. Yoshioka, Uptake of Sc3+ and La3+ from aqueous solution using ethylenediaminetetraacetate-intercalated $\mathrm{Cu}-\mathrm{Al}$ layered double hydroxide reconstructed from $\mathrm{Cu}-$ Al oxide, Solid State Sci. 13 (2011) 366-371. doi:10.1016/j.solidstatesciences.2010.11.037.

[176] I.E. Veleshko, V.V. Nikonorov, A.N. Veleshko, E.V. Rumyantseva, S.N. Mikhailov, V.I. Lozinskii, R.V. Ivanov, L.S. Gal'braikh, N.R. Kil'deeva, Sorption of Eu(III) from solutions of covalently crosslinked chitosan cryogels, Fibre Chem. 42 (2011) 364-369. doi:10.1007/s10692-011-9287-2. 
[177] D. Wu, Y. Sun, Q. Wang, Adsorption of lanthanum (III) from aqueous solution using 2-ethylhexyl phosphonic acid mono-2-ethylhexyl ester-grafted magnetic silica nanocomposites, J. Hazard. Mater. 260 (2013) 409-419. doi:10.1016/j.jhazmat.2013.05.042.

[178] J. Zha, H. Roggendorf, Sol-gel science, the physics and chemistry of sol-gel processing, Ed. by C. J. Brinker and G. W. Scherer, Academic Press, Boston 1990, xiv, 908 pp., bound?ISBN 0-12134970-5, Adv. Mater. 3 (1991) 522-522. doi:10.1002/adma.19910031025.

[179] J. Kim, P. Seidler, L.S. Wan, C. Fill, Formation, structure, and reactivity of amino-terminated organic films on silicon substrates, J. Colloid Interface Sci. 329 (2009) 114-119. doi:10.1016/j.jcis.2008.09.031.

[180] J. Kim, P. Seidler, C. Fill, L.S. Wan, Investigations of the effect of curing conditions on the structure and stability of amino-functionalized organic films on silicon substrates by Fourier transform infrared spectroscopy, ellipsometry, and fluorescence microscopy, Surf. Sci. 602 (2008) 3323-3330. doi:10.1016/j.susc.2008.09.001.

[181] A. Tadjarodi, V. Jalalat, R. Zare-Dorabei, Adsorption of La(III) in aqueous systems by N-(2hydroxyethyl) salicylaldimine-functionalized mesoporous silica, Mater. Res. Bull. 61 (2015) 113119. doi:10.1016/j.materresbull.2014.09.036.

[182] Y. Zhu, Y. Zheng, A. Wang, Preparation of granular hydrogel composite by the redox couple for efficient and fast adsorption of La(III) and Ce(III), J. Environ. Chem. Eng. 3 (2015) 1416-1425. doi:10.1016/j.jece.2014.11.028.

[183] I.V. Burakova, A.E. Burakov, A.G. Tkachev, I.D. Troshkina, O.A. Veselova, A.V. Babkin, W.M. Aung, I. Ali, Kinetics of the adsorption of scandium and cerium ions in sulfuric acid solutions on a nanomodified activated carbon, J. Mol. Liq. 253 (2018) 277-283. doi:10.1016/j.molliq.2018.01.063.

[184] D. Avdibegović, M. Regadío, K. Binnemans, Recovery of scandium( ) from diluted aqueous solutions by a supported ionic liquid phase (SILP), RSC Adv. 7 (2017) 49664-49674. doi:10.1039/c7ra07957e.

[185] S.B. Hammouda, F. Zhao, Z. Safaei, I. Babu, D.L. Ramasamy, M. Sillanpää, Reactivity of novel Ceria-Perovskite composites $\mathrm{CeO} 2$ - $\mathrm{LaMO} 3(\mathrm{MCu}, \mathrm{Fe})$ in the catalytic wet peroxidative oxidation of the new emergent pollutant 'Bisphenol F': Characterization, kinetic and mechanism studies, Appl. Catal. B Environ. 218 (2017) 119-136. doi:10.1016/j.apcatb.2017.06.047.

[186] S.B. Hammouda, F. Zhao, Z. Safaei, V. Srivastava, D. Lakshmi Ramasamy, S. Iftekhar, S. kalliola, M. Sillanpää, Degradation and mineralization of phenol in aqueous medium by heterogeneous monopersulfate activation on nanostructured cobalt based-perovskite catalysts $\mathrm{ACoO} 3$ (A = La, Ba, $\mathrm{Sr}$ and $\mathrm{Ce}$ ): Characterization, kinetics and mechanism study, Appl. Catal. B Environ. 215 (2017) 60-73. doi:10.1016/j.apcatb.2017.05.051.

[187] S. Iftekhar, V. Srivastava, S.B. Hammouda, M. Sillanpää, Fabrication of novel metal ion imprinted xanthan gum-layered double hydroxide nanocomposite for adsorption of rare earth elements, Carbohydr. Polym. 194 (2018) 274-284. doi:10.1016/j.carbpol.2018.04.054.

[188] L.H. Mujawar, Z.A. Rehan, M.I. Rashid, S. Vattamkandathil, L. Gazzara, T. Almeelbi, J.M. Basahi, M.S. El-Shahawi, Polyethersulfone membrane printed with 1-(2-pyridylazo)-2-naphthol (PAN) sensor for sensitive enrichment and rapid determination of $\mathrm{Zn}^{2+}$ in water, RSC Adv. 6 (2016) 7373173740. doi:10.1039/C6RA15906K.

[189] S. Porada, R. Zhao, A. van der Wal, V. Presser, P.M. Biesheuvel, Review on the science and technology of water desalination by capacitive deionization, Prog. Mater. Sci. 58 (2013) 1388-1442. doi:10.1016/j.pmatsci.2013.03.005. 
[190] Ö. Arar, Ü. Yüksel, N. Kabay, M. Yüksel, Various applications of electrodeionization (EDI) method for water treatment-A short review, Desalination. 342 (2014) 16-22. doi:10.1016/j.desal.2014.01.028.

[191] L. Alvarado, A. Chen, Electrodeionization: Principles, Strategies and Applications, Electrochimica Acta. 132 (2014) 583-597. doi:10.1016/j.electacta.2014.03.165.

[192] A.C. Arulrajan, D.L. Ramasamy, M. Sillanpää, A. van der Wal, P.M. Biesheuvel, S. Porada, J.E. Dykstra, Exceptional Water Desalination Performance with Anion-Selective Electrodes, Adv. Mater. 31 (2019) 1806937. doi:10.1002/adma.201806937.

[193] Y. Xing, X. Chen, P. Yao, D. Wang, Continuous electrodeionization for removal and recovery of $\mathrm{Cr}(\mathrm{VI})$ from wastewater, Sep. Purif. Technol. 67 (2009) 123-126. doi:10.1016/j.seppur.2009.03.029.

[194] Z. Zhang, D. Liba, L. Alvarado, A. Chen, Separation and recovery of $\mathrm{Cr}(\mathrm{III})$ and $\mathrm{Cr}(\mathrm{VI})$ using electrodeionization as an efficient approach, Sep. Purif. Technol. 137 (2014) 86-93. doi:10.1016/j.seppur.2014.09.030. 


\section{Publication I}

D.L.Ramasamy, E. Repo, V. Srivastava, M. Sillanpää

Chemically immobilized and physically adsorbed PAN/acetylacetone modified mesoporous silica for the recovery of rare earth elements from the waste water-comparative and optimization study

Reprinted with permission from

Water Research

Vol. 114, pp. 264-276, 2017

(C) 2017, Elsevier 



\begin{tabular}{lc}
\hline Contents lists available at ScienceDirect & Con WATERCH \\
ELSEVIER & Water Research \\
\hline MESEARCH
\end{tabular}

Chemically immobilized and physically adsorbed PAN/acetylacetone modified mesoporous silica for the recovery of rare earth elements from the waste water-comparative and optimization study

Deepika Lakshmi Ramasamy ${ }^{\text {a, *, }}$ Eveliina Repo ${ }^{\text {a }}$, Varsha Srivastava ${ }^{\text {a }}$, Mika Sillanpää a, b

a Laboratory of Green Chemistry, Lappeenranta University of Technology, Mikkeli FI-50130, Finland

${ }^{b}$ Department of Civil and Environmental Engineering, Florida International University, Miami, FL 33174, USA

\begin{tabular}{l} 
A R T I C L E I N F O \\
\hline Article history: \\
Received 24 November 2016 \\
Received in revised form \\
16 February 2017 \\
Accepted 18 February 2017 \\
Available online 20 February 2017 \\
\hline Keywords: \\
Acac \\
Adsorption \\
Chemical immobilization \\
PAN \\
Resource recovery
\end{tabular}

\section{Introduction}

Technological growth in diversified domains with intriguing applications for REE has led to a surge in the need for the extraction of such elements from various possible sources. Waste water being one such source with a great potential, a wide range of methods have been employed for removal of REE from waste water with varied effectiveness. Among them, liquid-liquid extraction process is the most common and widespread method for the separation and pre-concentration of metal ions, with an appropriate complexing agent. Despite its advantages, there are several issues

\footnotetext{
* Corresponding author

E-mail addresses: deepika.ramasamy@lut.fi, deepu7187@gmail.com (D.L. Ramasamy).
}

http://dx.doi.org/10.1016/j.watres.2017.02.045

0043-1354/@ 2017 Elsevier Ltd. All rights reserved. associated with these techniques, which affect the economic efficacy. Some of them include operational costs associated with the amount of solvent/agent, emulsion formation between phases, reduction in sensitivity etc. Such problems have driven the development of solid phase extraction technique where the extraction of metal ions is assisted by complexing agents. The inherent advantages of such chelating agents are economic effectiveness (low amount of resin/solvent), selective determination of metal ions (target specific ligands in the resin), visual palpability of metal ion concentration etc. However, it has to be noted that the visual concentration etc. However, it has to be noted that the visual
estimation can be observed only if the metal complex formed possesses the ability to absorb visible wavelengths.

Silica is one of the most potential adsorbents for metal removal (Repo et al., 2011b) (Repo et al., 2009) (Repo et al., 2011a) (Srivastava and Sharma, 2014) due to its good mechanical stability, 
high surface area and high thermal resistance (Jal, 2004). The chelation is performed onto silica in order to improve the surface selectivity and the performance. The preparation of chelating silica gel can be done by two methods, chemical immobilization or adsorption of the agent onto the reacting silica surface. The forme process in turn can be achieved either by reacting silane functionalized silica gel with the chelating agent or by reacting the silane with the chelating agent followed by the reaction with silica. The first method involving functionalized silica gel demands the selection of an appropriate reagent for functionalizing the surface $-\mathrm{OH}$ groups, for example silane (very effective with silica). Silane coupling agent has an important advantage of forming thermally and hydrolytically stable $\mathrm{Si}-\mathrm{O}$ linkage. It is stronger than the surface $\mathrm{S}-\mathrm{O}-\mathrm{C}$ bond from the reaction betw alcohol. The latter process for the preparation of chelating silica gel involves the soaking of silica gel in a chelating agent solution, followed by the removal of supernatant and evaporation of solvent at room temperature (Sharma et al., 2003).

The removal of metal ions using PAN (Abolhasani and Behbahani, 2014; Cornejo-Ponce et al., 1998; Kaur and Gupta, 2009) and acetylacetone (Acac) (Airoldi and Alcântara, 1995; Babich et al., 1997; Gun'ko et al., 2000; Hajipour et al., 2015) modified silica gels have been studied earlier. There have been only few studies in the past dealing with physically adsorbed PAN onto silica whereas chemically immobilized Acac onto amine functionalized silica has been quite explored before for the purpose of REE removal from waste water.

Hence the aim of this study aims is to realize the efficiency of silica gels modified with PAN and Acac in REE removal, via analysis involving both the preparation techniques mentioned before. Since the chemical immobilization of Acac with APTES is better understood in the literature, APTMS modified silica gels are also investigated to exploit the potential of using other aminosilanes coupling agents. A comparative study conducted and the parameters such as $\mathrm{pH}$, contact time, initial REE concentration, calcination process and temperature are investigated for their effectiveness in REE removal. Fourier transform infrared spectroscopy (FTIR) has been employed to inspect the adsorbent surface for the effect of various functional groups present The characteristics of the adsorbents under scrutiny are perceived through Scanning electron microscopy (SEM) perceived through Scarning el Emmett-Teller (BET), X-ray diffraction (XRD), zeta potential analysis and elemental analysis.

\section{Materials and methods}

2.1. Chemical reagents

The functionalization of silica gel was carried out by 3 Aminopropyl triethoxysilane (APTES, $\left.\mathrm{H}_{2} \mathrm{~N}\left(\mathrm{CH}_{2}\right)_{3} \mathrm{Si}\left(\mathrm{OC}_{2} \mathrm{H}_{5}\right)_{3}\right)$ and 3-Aminopropyl trimethoxysilane (APTMS, $\mathrm{H}_{2} \mathrm{~N}\left(\mathrm{CH}_{2}\right)_{3} \mathrm{Si}\left(\mathrm{OCH}_{3}\right)_{3}$ ). The further immobilization or loading step was performed by using PAN and Acac solution. The solutions of target REEs such as Lanthanum $\left(\mathrm{La}^{3+}\right)$, Erbium $\left(\mathrm{Er}^{3+}\right)$, Scandium $\left(\mathrm{Sc}^{3+}\right)$, Europium $\left(\mathrm{Eu}^{3+}\right)$ and Yttrium $\left(\mathrm{Y}^{3+}\right)$ were used during the course of study. The attributes of the mesoporous silica gel used in this research include $60 \AA$ pore size, $0.015-0.040 \mathrm{~mm}$ particle size, $6.5-7.5 \mathrm{pH}(10 \%$ suspension) and $<7 \%$ drying loss at $150{ }^{\circ} \mathrm{C}$.

\subsection{Preparation of the adsorbent}

The adsorbents used in this study were prepared using the following two methods and the scheme for the modification of silica gels using PAN (Kaur and Gupta, 2009) and Acac (Zhang et al., 2007) is represented in Fig. 1.
Method I (Chemical immobilization) - The primary step involves the functionalization of silica gel through its reaction with $10 \%$ silane solution in toluene followed by a $72 \mathrm{~h}$ stirring time in a nitrogen atmosphere. The silane solutions are prepared for all the adsorbents involved, i.e. APTES and APTMS. The subsequent step includes filtration, followed by washing and drying at a temperature of $100^{\circ} \mathrm{C}$ for a time period of $24 \mathrm{~h}$. The solvents used for rinsing are toluene, ethanol and acetone ( $>99 \%$ purity).

A solution prepared using PAN $(0.2 \% \mathrm{w} / \mathrm{w}$ in acetone) and Acac ( $1 \mathrm{~g}$ in $30 \mathrm{~mL}$ methanol) is added to the functionalized silica obtained from the preceding step. The process of evaporation is then carried out through vigorous agitation at room temperature for an approximate period of $3-4 \mathrm{~h}$. The samples then undergo the drying stage at room temperature for a day.

Method II (Loading/physical adsorption) - The reaction between silica gel and PAN-Acac is carried out in the absence of any intermediate step involving silanization.

The following notations are used to denote SEP (APTES functionalized chemically immobilized PAN-silica gel), SMP (APTMS functionalized chemically immobilized PAN-silica gel), SEA (APTES functionalized chemically immobilized Acac-silica gel), SMA (APTMS functionalized chemically immobilized Acac-silica gel), SP (physically adsorbed PAN-Silica) and SA (physically adsorbed AcacSilica) over the course of this paper.

\subsection{Synthesis optimization}

PAN and Acac were allowed to react with functionalized or bare silica in different ratios of 1:5, 1:10 and 1:20 and the results are discussed in Section 3.2.6. For most of the cases, 1:20 was found to be very efficient in the removal of the target elements involved in this study.

\subsection{Adsorption experiments}

The aim of performing adsorption experiments is manifold. The important quantities determined through these experiments conducted in a batch system included $\mathrm{pH}$, equilibrium time, optimum temperature and adsorption capacity of the adsorbent. Also, the kinetic/isotherm model involved in the reaction mechanism could kinetic/isotherm model involved in the reaction mechanism could
be identified. The experiments were performed using a mixture of $10 \mathrm{mg}$ adsorbent and $10 \mathrm{~mL}$ of $25 \mathrm{ppm}$ metal ion solution while the mixing rate was maintained at $220 \mathrm{rpm}$ using a temperature controlled shaker. The instrument employed to measure the (ICP). The REE adsorption capacity and \% REE removal was then calculated using:

$q_{e}=\frac{\left(C_{o}-C_{e}\right) v}{m}$

\% REE removal $=\frac{\left(C_{o}-C_{e}\right)}{C_{o}} * 100$

Here $C_{0}$ and $C_{e}$ denote the initial and equilibrium REE concentrations $(\mathrm{mg} / \mathrm{l})$ while $\mathrm{m}$ and $\mathrm{v}$ are the amount of adsorbent $(\mathrm{g})$ and volume of the solution (1), respectively.

\subsection{Characterization}

The FTIR characterization of the samples was carried out using type Vertex 70 by B Bruker Optics (Germany). In order to identify the surface groups on silica surface, FTIR spectra were documented at $4 \mathrm{~cm}^{-1}$ resolution from 400 to $4000 \mathrm{~cm}^{-1}$ and at a rate of 100 scans per sample. SU3500 SEM system fitted with Thermo Scientific 


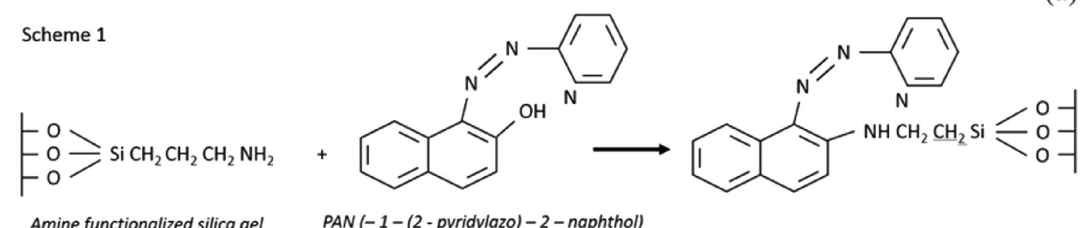

Amine functionalized silica gel

PAN (-1 - (2 - pyridylazo) -2 - naphthol

Scheme 2

${ }^{-} \mathrm{O}>\mathrm{SiCH}_{2} \mathrm{CH}_{2} \mathrm{CH}_{2} \mathrm{NH}_{2}$

Amine functionalized silica gel

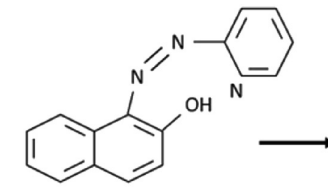

PAN (-1 - (2 - pyridylazo) - 2- naphthol)<smiles></smiles>

$上_{\mathrm{O}}^{\mathrm{O}}>\mathrm{SiOH}$

Silica gel

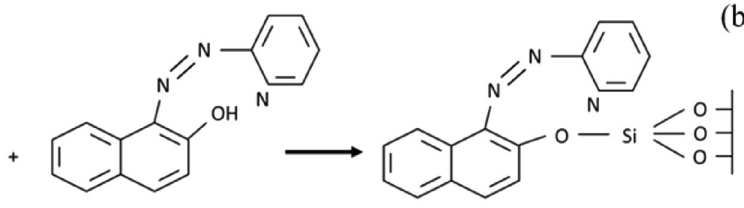

(PAN-1-(2 - pyridylazo) - 2-naphthol)

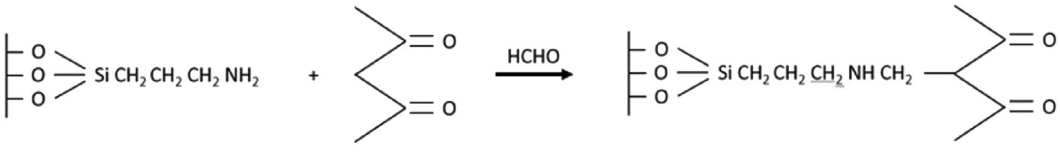

Amine functionalized silica gel

Acetylacetone

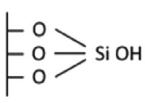

Silica gel
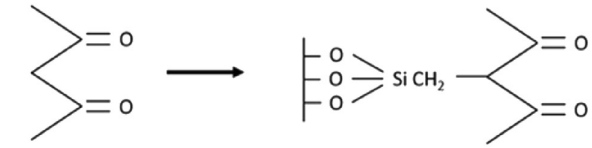

Acetvlacetone

Fig. 1. Reaction scheme for the preparation of a) PAN modified gels - Method I (Scheme 1 and/or Scheme 2) b) PAN modified gels - Method II c) Acac modified gels - Method I d) Acac modified gels - Method II.

UltraDry SDD EDS is employed for the examination of modified silica, in order to analyze its surface morphology and chemical composition. $\mathrm{C}, \mathrm{H}, \mathrm{O}$ and $\mathrm{N}$ determination was conducted using Organic Elemental Analyzer Flash 2000 (Thermo Scientific, Germany). A capsule built of tin or silver, housing $2 \mathrm{mg}$ (percent of dry mass) of the sample, was burnt at $920-1000{ }^{\circ} \mathrm{C}$ to analyze $\mathrm{C}$, $\mathrm{H}$ and $\mathrm{N}$ or O, respectively. BET from Micrometrics Tristar II plus with Vac Prep 061 conducted the porosity/surface area analysis while ICP iCAP 6000 series from Thermo Electron Corporation was used to measure the metal ion concentration before and after adsorption. 
The XRD measurements used in this study was executed by PANalytical Instrument and Empyrean program. Zeta potential Nano ZS (ZEN3500, Malvern) was used for performing isoelectric poin titration. This yields the zero charge point and the surface charge of the adsorbent as a function of $\mathrm{pH}$.

\section{Results and discussion}

3.1. Characterization of the adsorbents

The surface modification of the adsorbents after chemica immobilization and loading of PAN and Acac onto the silica gel was thoroughly characterized by using SEM, FTIR, XRD, Zeta potential study, elemental analysis, BET surface area and pore size analysis.

Morphological characteristics of modified silica gels were investigated by SEM analysis and the images showing successive magnifications are illustrated in Fig. S1 (Supplementary material). Estimation of diameter from the low-magnified images taken at $\times 100-200 \mathrm{k}$ of the adsorbents, yield an average diameter between 5 and $40 \mu \mathrm{m}$

Table 1 shows the elemental analysis and surface properties of modified adsorbents. The presence of PAN and Acac loadings can be confirmed from the existence of $\mathrm{N}, \mathrm{C}$ and $\mathrm{H}$ in method II adsorbent and an increased amount of the same in method I adsorbents, in comparison to the APTES/APTMS functionalized gels prior to chemical immobilization. Also the PAN and Acac modification can be visually seen from the orange and white color observed in the modified adsorbents, respectively. The table also shows that the BET surface area and pore volume decreased substantially after functionalization with APTES/APTMS and reduced even further to a lesser degree after the chemical immobilization step. However the average pore size increases after the modification step with amine groups as a result of clogging in the smaller pores (Supplementary information: Fig. S2). There are only minimal changes in surface properties of Method II adsorbents in relation to the bare silica gel. The decrease in BET surface area after modification has also been reported in literature (Awual, 2016a) (Awual et al., 2013) (Rabiu Awual et al., 2014) (Awual, 2017) (Awual, 2016b) (Awual et al. 2016).

Fig. 2(a) and (b) shows $\mathrm{N}_{2}$ adsorption and desorption isotherms at $77 \mathrm{~K}$ plotted as a function of $\mathrm{P} / \mathrm{P}$. According to IUPAC classification, the modified adsorbents exhibit Type IV isotherm for mesoporous materials with multilayer adsorption and capillary condensation in the pore showing $\mathrm{H} 1$ hysteresis loops between 0.5 and 0.8 (Thommes, 2010) (Balbuena and Gubbins, 1993). Fig. 2(c), (d) and (e) illustrates the FTIR spectra of unmodified and amine functionalized silica gels, PAN modified gels and Acac modified gels respectively. The transmittances at 1 and $450 \mathrm{~cm}^{-1}$ are associated with silica as a result of asymmetric

vibration of $\mathrm{Si}-\mathrm{O}$, asymmetric vibration of $\mathrm{Si}-\mathrm{OH}$, symmetric stretching vibration of $\mathrm{Si}-\mathrm{O}-\mathrm{Si}$ and bending vibration of $\mathrm{Si}-\mathrm{O}-\mathrm{Si}$, respectively (Beganskiene et al., 2004; Zhang et al., 2007). The bands occurring at $1621 \mathrm{~cm}^{-1}$ and $1201 \mathrm{~cm}^{-1}$ in all the modified gels are characteristic of $-\mathrm{C}=\mathrm{N}$ group and $-\mathrm{O}-\mathrm{H}$ group, respectively (Kulkarni et al , 2008). The spectra revealed stretching vibration bands of PAN at $1608 \mathrm{~cm}^{-1}(\mathrm{~N}=\mathrm{N}), 1598 \mathrm{~cm}^{-1}(\mathrm{C}-\mathrm{C}$ aromatic ring) and $1281 \mathrm{~cm}^{-1}(\mathrm{C}-\mathrm{N})$, indicating the grafting of PAN onto the silica gel (Abolhasani and Behbahani, 2014). It should be noted that the $\mathrm{C}-\mathrm{N}$ group is also seen at $1281 \mathrm{~cm}^{-1}$ in chemically immobilized Acac gels from the APTES/APTMS linkage. This is however not the case in Acac modified silica gel from Method II due to the absence of $\mathrm{N}$ group. The IR spectra of amine functionalized (that of further PAN/Acac modified APTES/APTMS gels. There are additional bands occurring around $1686 \mathrm{~cm}^{-1}$ and $1630 \mathrm{~cm}^{-1}$ in the PAN/Acac modified gels which are attributed to $\mathrm{N}=\mathrm{N}$ vibrations (Kaur and Gupta, 2009) and $v_{\text {as }}\left(\mathrm{COO}^{-}\right)$, respectively (Kaur and Gupta, 2009). The other characteristic peaks from PAN modified adsorbents are observed at $1500 \mathrm{~cm}^{-1}$ ( $\mathrm{C}=\mathrm{C}$ stretching vibration for the benzenoid and pyridyl unit), $1382 \mathrm{~cm}^{-1}\left(\mathrm{CH}_{2}\right.$ shear deformation vibration) and $1329 \mathrm{~cm}^{-1}$ $(\mathrm{C}=\mathrm{N}$ stretching vibration for the benzenoid unit) (Kaur and Gupta, 2009). The band at $1419 \mathrm{~cm}^{-1}$ due to $\nu\left(\mathrm{COO}^{-}\right)_{\text {sym }}$, appeared only in the spectra of chemically immobilized Acac gels (Kaur and Gupta, 2009).

Fig. 2 (f) represents the XRD spectra of the modified absorbents. The diffraction patterns (converted from $\mathrm{CoK}_{\alpha} \lambda=1.78 \AA$ to $\mathrm{CuK}_{\alpha}$, $\lambda=1.54 \AA$ ) obtained reveals that all the modified adsorbents are amorphous in nature due to the presence of a broad halo in the $2 \theta$ range of $16^{\circ}-26^{\circ}$ (Xu et al., 2015).

The isoelectric point (IEP) was determined by zeta-potential measurements for both chemically immobilized and physically adsorbed PAN/Acac silica gels and were plotted in Fig. 2(g). For PAN to be at a $\mathrm{pH}$ value of 3.5 and 4 , respectively, while it was observed in the range of $\mathrm{pH} 2-3$ for the unmodified silica gel (Supplementary material: Fig. S3). When APTES was used as a coupling agent, it shifted to a higher $\mathrm{pH}$ of 8 for PAN and 4.5 for Acac. A similar response was observed in the case of APTMS gels with the isoelectric point at 4.5 and 2.5 for PAN and Acac, respectively. To summarize, APTES and APTMS with PAN modification showed an expected increase in IEP due to the presence of amino groups while Acac modification displayed a decrease in $\mathrm{pH}$.

3.2. Adsorption studies-single component system

3.2.1. Effect of $p H$

It is important to understand the influence of $\mathrm{pH}$ on the adsorption of the REEs since the $\mathrm{pH}$ value of a solution has the

Table 1

Properties of adsorbents used in the experimental analysis.

\begin{tabular}{|c|c|c|c|c|c|c|}
\hline \multirow[t]{2}{*}{ Adsorbents } & \multirow[t]{2}{*}{ BET Surface area $\left(\mathrm{m}^{2} / \mathrm{g}\right)$} & \multirow[t]{2}{*}{ Pore volume $\left(\mathrm{cm}^{3} / \mathrm{g}\right)$} & \multirow{2}{*}{$\begin{array}{l}\text { Pore size } \\
\overline{\text { Adsorption average pore diameter (4 V/A by BET), in } \AA}\end{array}$} & \multicolumn{3}{|c|}{$\begin{array}{l}\text { Percentage of dry } \\
\text { weight }\end{array}$} \\
\hline & & & & $\mathrm{N}$ & c & $\mathrm{H}$ \\
\hline APTES/PAN modified & 118.06 & 0.24 & 79.79 & 3.58 & 11.39 & 2.57 \\
\hline APTES/Acac modified & 90.09 & 0.17 & 77.03 & 3.34 & 18.41 & 2.39 \\
\hline APTMS/PAN modified & 161.64 & 0.31 & 75.93 & 3.25 & 9.99 & 2.30 \\
\hline APTMS/Acac modified & 133.89 & 0.23 & 70.08 & 3.08 & 16.48 & 2.36 \\
\hline PAN modified & 352.29 & 0.66 & 74.38 & 0.52 & 1.99 & 0.35 \\
\hline Acac modified & 335.83 & 0.61 & 72.77 & 0 & 4.35 & 0.70 \\
\hline APTES functionalized silica gel & 174.19 & 0.32 & 73.87 & 2.58 & 10.30 & 2.48 \\
\hline APTMS functionalized silica gel & 176.79 & 0.32 & 73.18 & 2.37 & 8.84 & 2.17 \\
\hline Bare silica & 367.59 & 0.69 & 73.51 & - & - & - \\
\hline
\end{tabular}



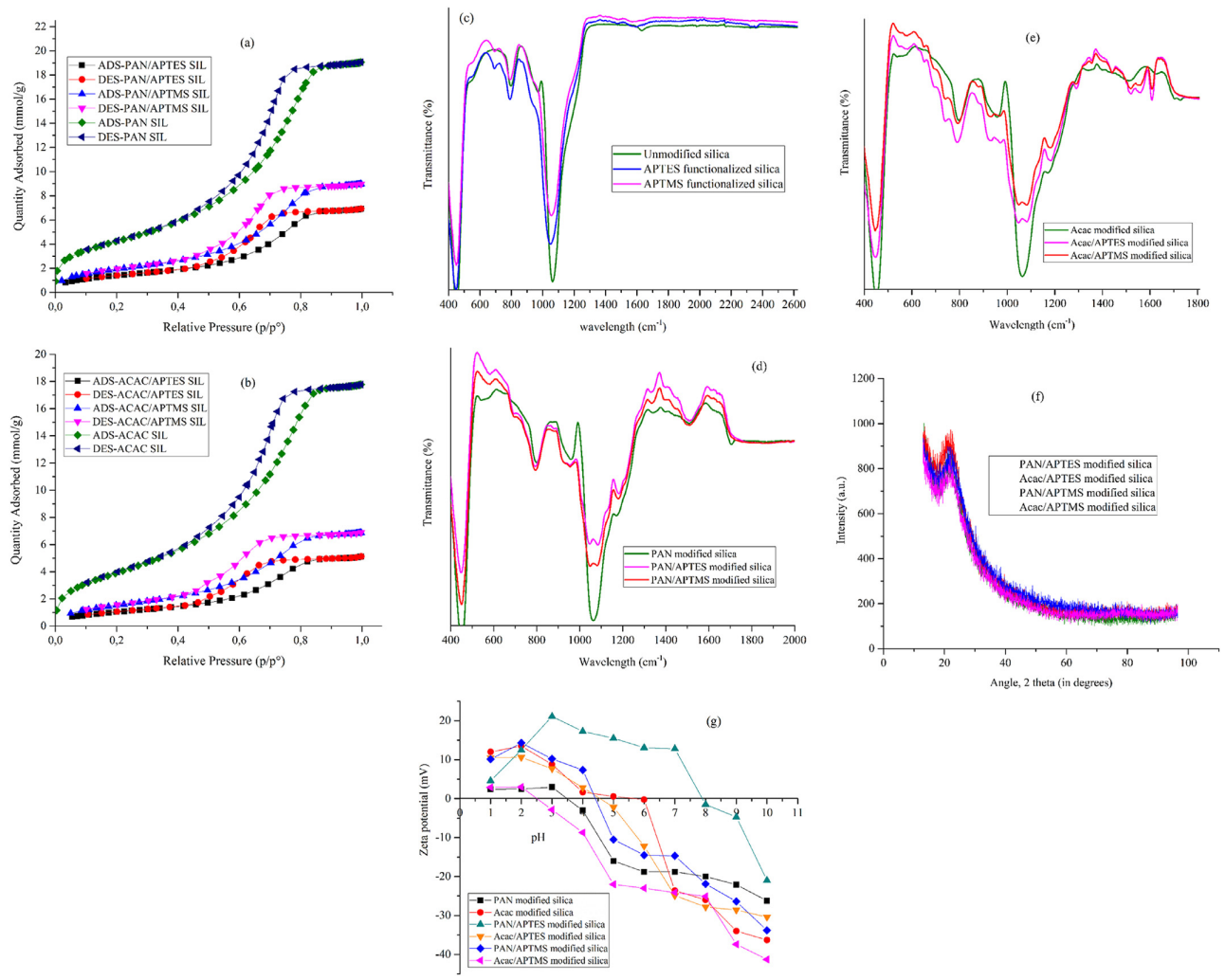

Fig. 2. Adsorption-Desorption BET curves for a) PAN modified adsorbents b) Acac modified adsorbents. FTIR curves for c) bare and just amine functionalized silica gels d) PAN modified silica gels e) Acac modified silica gels f) XRD spectra of PAN/Acac chemically immobilized gels g) Zetapotential curves for all modified adsorbents (Method I \& Method II).

tendency to affect the degree of adsorbates ionized and the protonation process of the surface groups. As predicted, the adsorption is very poor below a $\mathrm{pH}$ value of 3 . However, there is an adequate increase in the efficiency beyond $\mathrm{pH} 4$ for all the adsorbents (Kaur and Gupta, 2009). The pH dependence of metal removal is hugely associated with the zeta potential of the adsorbent (Ullah et al, 2014). Under the solution $\mathrm{pH}<\mathrm{pH}$ ZPG, the surface charge of the adsorbent is positive, thereby electrostatic repulsion being the main force between the positively charged surface and REE cations. Therefore, in general, under acidic conditions, $\mathrm{H}^{+}$competes with REE cations and causes difficulty for REEs to bind onto the active sites on the adsorbents. On the contrary, with the increase in $\mathrm{pH}$, the adsorbent gets deprotonated, more negatively charged sites are exposed towards the positively charged trivalent REE cations, enabling electrostatic attraction at higher $\mathrm{pHs}$.

The effect of $\mathrm{pH}$ was studied for the range of 2-8 and presented in Fig. 3. The tests were not conducted for $\mathrm{pH}$ above 8 since the hydrolysis of REE generally occurs in such conditions. In the case of La adsorption, the APTES/APTMS modified silica gels with PAN and Acac, reach the optimal $\mathrm{pH}$ value of 4 attaining maximum adsorption while the other two adsorbents SP and SA from method
II show a very minimal response to the increase in $\mathrm{pH}$, achieving a maximum potential of only $20-30 \%$. For $\mathrm{Sc}$, the optimal pH for SEP and SMP in attaining equilibrium is found to lie between 4 and 5 while the same status is reached at $\mathrm{pH} 6$ for the remaining adsorbents. In the case of Er, maximum adsorption is recorded at $\mathrm{pH} 4-6$ for all the adsorbents prepared by Method I while SP and SA demonstrate poor adsorption below pH 7. For Eu and Y, PAN modified silica gels from method I display better efficiency than ncy than Acac modified gels, as reported in other cases. Supreme efficacy is witnessed from $\mathrm{pH} 4$ for SEP and SMP while a similar behavior is recorded at $\mathrm{pH} 6$ for SEA and SMA. In case of PAN modified adsorbents, distinguishing purple to red color were seen due to the formation of lanthanide-PAN complexes, the phenomena which have been reported in the past as well (Cornejo-Ponce et al. 1998). In conclusion, for all the elements under examination, the method I adsorbents demonstrate superiority over the method II adsorbents. It can also be inferred from the graph that SEP and SMP appear to be slightly better than SEA and SMA in all cases, except for La in which the similar trends are noticed. The optimal $\mathrm{pH}$ value for REE adsorption in modified silanized gels from method $\mathrm{I}$ and loaded gels from method II for REE is found to be at pH 4-6 and 7, 

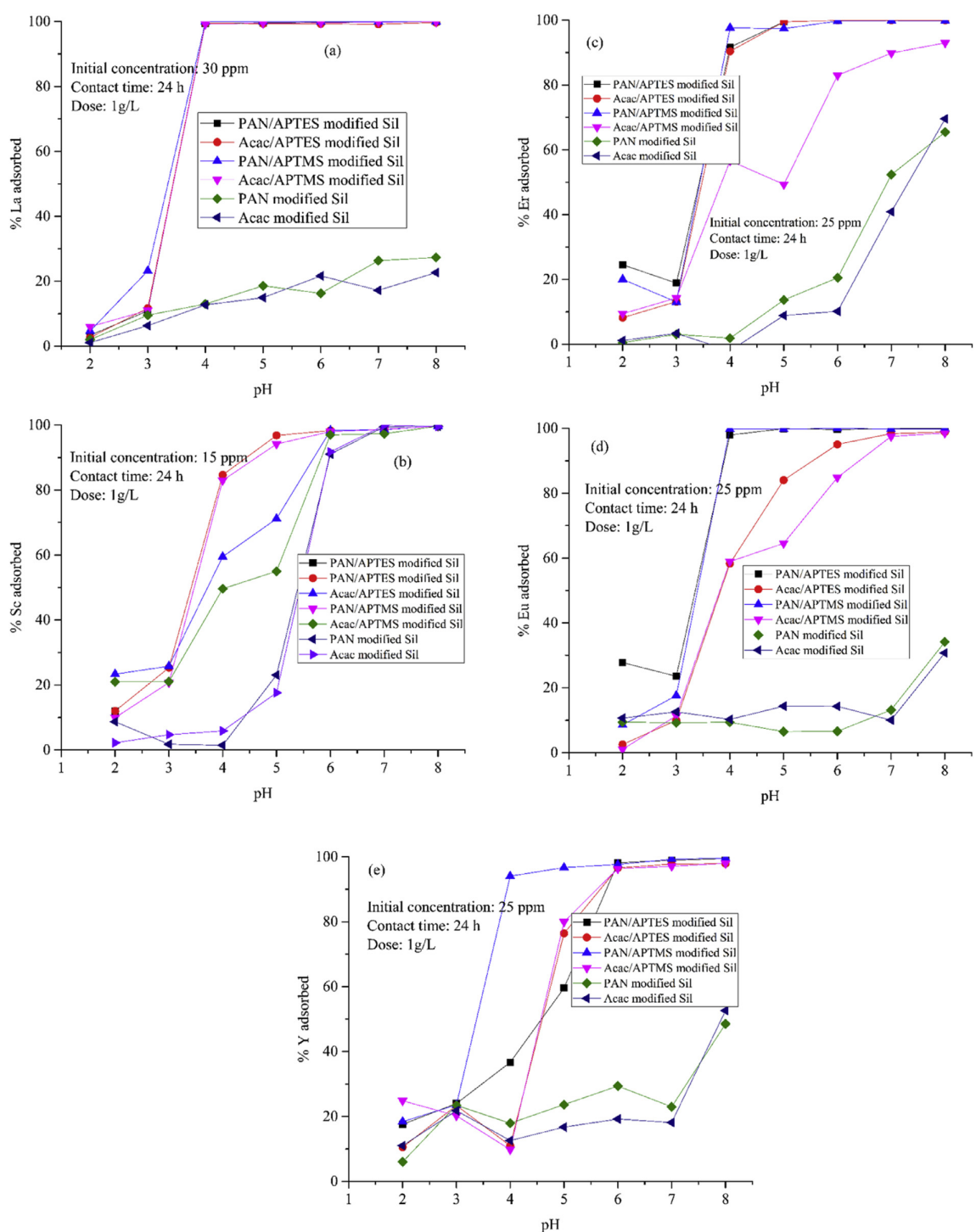

Fig. 3. Adsorption efficiency of different REEs as a function of $\mathrm{pH}$ for different adsorbents.

respectively. Hence, all further experiments were performed at $\mathrm{pH}$ 4 for method I adsorbents and $\mathrm{pH} 7$ for method II adsorbents in the consequent experimental analysis. The similar cases of extraction of metals at higher pHs have been often observed with PAN modified adsorbents (usually by Method II) in the literature (Alothman et al., 2015; Kaur and Gupta, 2009; Mor et al., 2007; Saeed et al., 2005).
3.2.2. Effect of concentration

Fig. 4 demonstrates the consequence of initial adsorbent concentration on the adsorption capacity of the adsorbent used in this comparative study. In majority of the cases, there is a coherent increase in the adsorption process till the attainment of equilibrium. The increase in the sorption capacity registered with an 

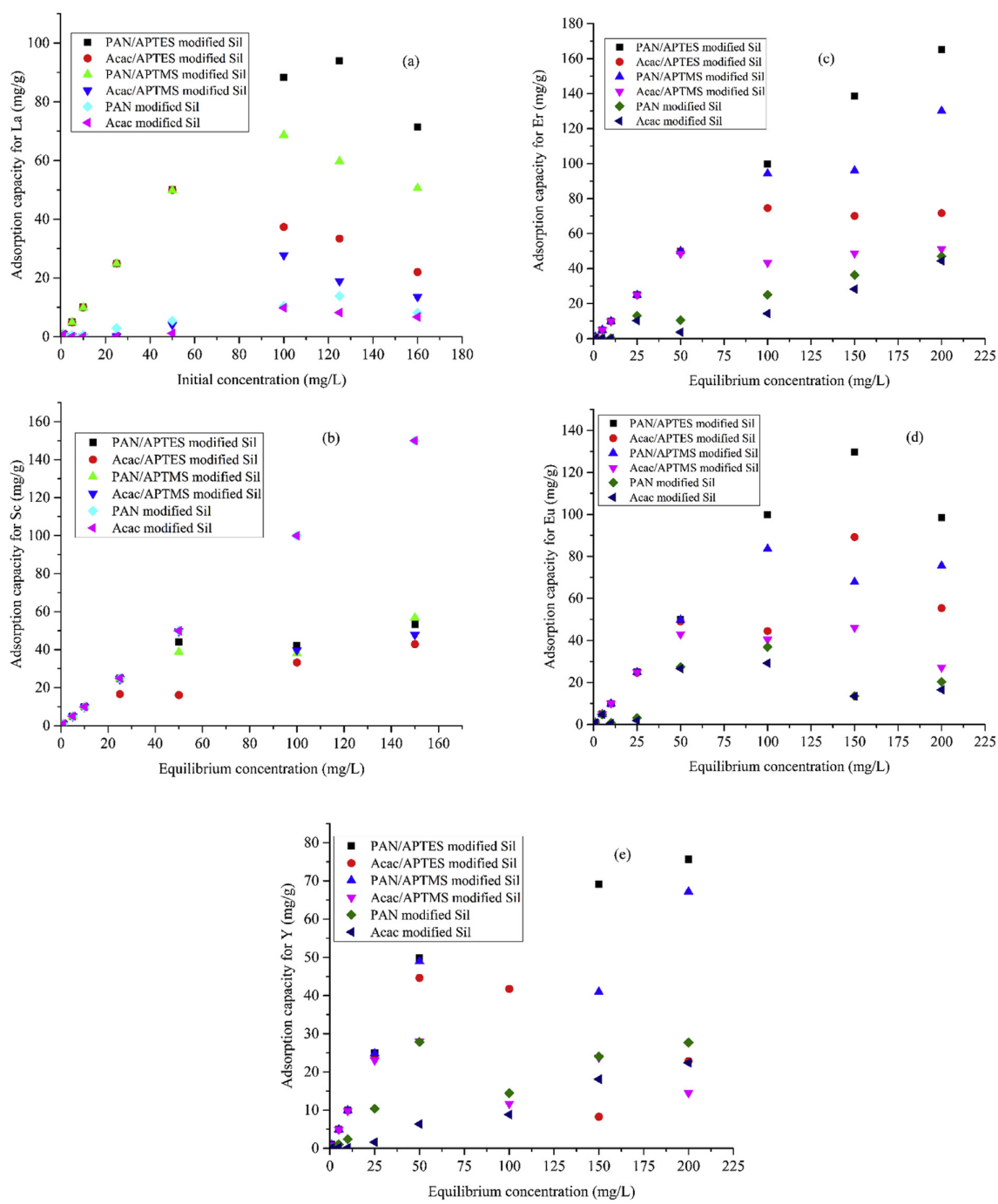

Fig. 4. Adsorption efficiency of different REEs as a function of equilibrium concentration for different adsorbents.

increase in concentration is an evidence of the fact pertaining to the availability of large number of active sites for the adsorption process. Maximum adsorption for La, Sc, Er and Eu adsorption is observed around $50 \mathrm{ppm}$, beyond which there is a no significant increase in the sorption capacity, except for SEP and SMP which shows good efficiency till $100 \mathrm{ppm}$. As a result, $50 \mathrm{ppm}$ is chosen as the optimized concentration for the kinetic study. Physically a adsorbed SP and and SA for concentration below $50 \mathrm{ppm}$ are undesirable for other REEs involved in the investigation. This behavior changes beyond $50 \mathrm{ppm}$ for La, Er and Y, but not as influential as in the case of chemically immobilized gels. The adsorption capacities of target REEs are in the following order: $\mathrm{Er}>\mathrm{Eu}>\mathrm{La}>\mathrm{Y}>\mathrm{Sc}$. The increase in the maximum adsorption quantity is directly proportional to the atomic number of REEs with higher afnnity depicted towards HREEs. It should be taken note of that the Lanthanide contraction effect (Iftekhar et al.,2016) causes a decrease in the ionic radius of 
$\mathrm{Ln}^{3+}$ ions with an increase in the atomic number $(\mathrm{La}>\mathrm{Eu}>\mathrm{Er})$

3.2.3. Effect of contact time

In this section, the adsorption efficiency of silica gels has been analyzed as a function of the contact time for the adsorption process and illustrated in Fig. 5. As understood from prior knowledge,
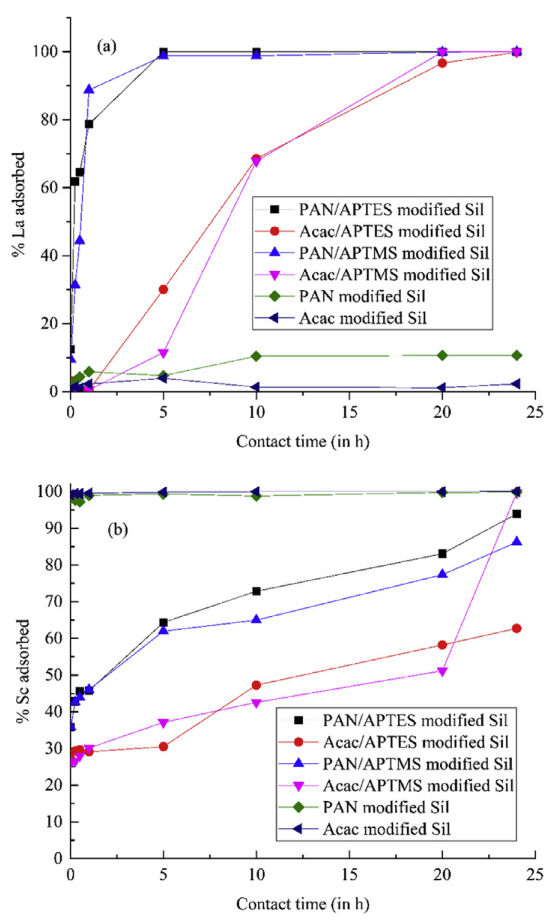

the availability of larger number of adsorption sites. In general, the behavior of different silica gels follows a similar trend for all the metals analyzed, except Sc. The PAN/Acac modified gels have a relatively larger pore volume and this might be the reason behind the rapid removal of $\mathrm{Sc}$ with comparatively smaller atomic radius. Hence the following discussion is initiated for $\mathrm{La}, \mathrm{Er}$, Eu and $\mathrm{Y}$, while Sc adsorption is separated from the lot. The PAN modified
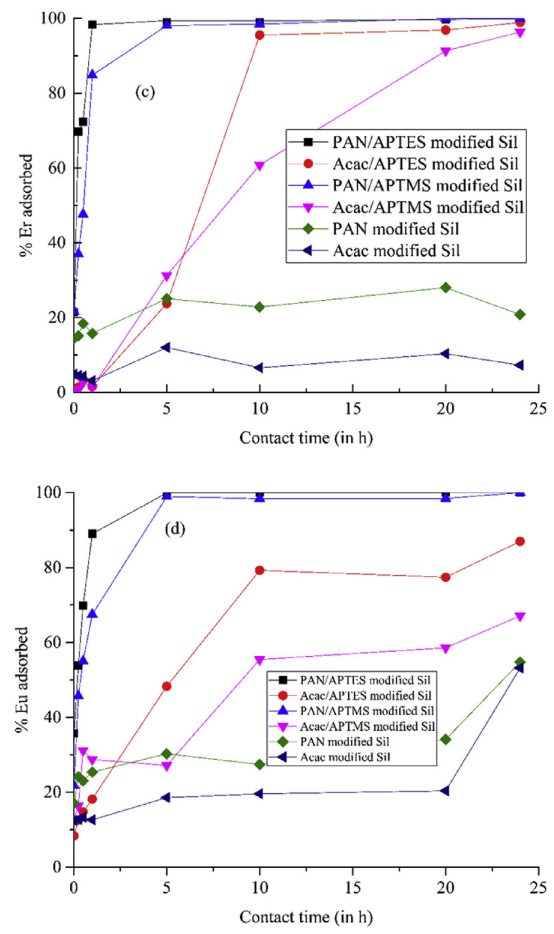

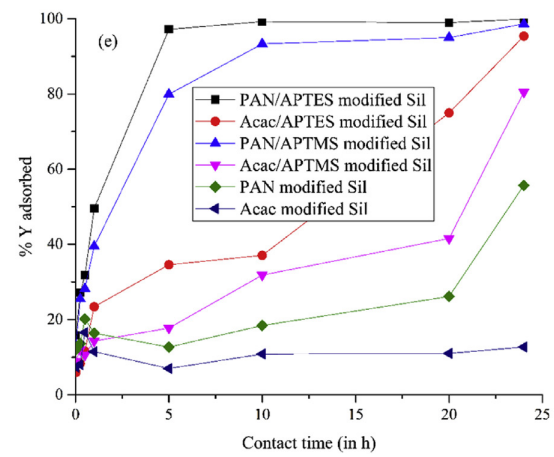

Fig. 5. Adsorption efficiency of different REEs as a function of contact time for different adsorbents 
adsorbents tend to record the most impressive adsorption behavior among all the modified gels. The adsorption percentage reaches around the maximum possible value i.e. $100 \%$, within a contact time of $5 \mathrm{~h}$ for all the metals involved. In the case of Acac modified gels, though the response to contact time is not as efficient as the PAN gels, a significant increase in the adsorption efficiency is demonstrated over time. However, SMA gel exhibits a potential of just $60 \%$ and $80 \%$ for Eu and Y, respectively. A general remark made on the basis of the inquiry is that the method I adsorbents exhibit better adsorption than method II adsorbents at any given contact time. On the other hand, the effect of contact time on the silica gels without PAN or Acac modifications is almost insignificant until a period of $24 \mathrm{~h}$, except in the case of Sc.

\subsubsection{Effect of temperature}

The effect of increase in the temperature from $25{ }^{\circ} \mathrm{C}$ (room temperature) to $60^{\circ} \mathrm{C}$ in the removal of REE is depicted in Table 2. In an overall perspective, the effect of raise in temperature has positive impact on the adsorption processes of all the adsorbents/ REEs. The most influential response for the temperature change was observed in the case of Acac silica gels with APTES/APTMS modifications, involving La, Er and Eu adsorption, with a drastic increase in the efficiency. Sc seems to be the least affected element among the various target elements under examination. The removal \% of SP and SA gels increased substantially with the increase in temperature. The FTIR spectra obtained for SP and SA after the adsorption process at both the temperatures did not show any change and were found to be similar (Supplementary material: Fig. S4). The increase in sorption capacity with temperature might be due to the following phenomena such as acceleration of sorption process, formation of new active or binding sites and transport against concentration gradient or diffusion across the energy barrier (Saeed et al., 2005)

The effect of temperature on the adsorption process has been studied by evaluating the thermodynamics of the underlying reaction in terms of the enthalpy $(\Delta \mathrm{H})$, entropy $(\Delta \mathrm{S})$ and Gibb's free energy $(\Delta G)$. The mathematical relations to obtain these parameters are given below (Iftekhar et al., 2016):

$\ln K_{C}=\frac{\Delta S^{\circ}}{R}-\frac{\Delta H^{\circ}}{R T}$

$\Delta G^{\circ}=-R T \ln K_{C}$

where $\mathrm{K}_{\mathrm{c}}$ is thermodynamic equilibrium constant $(\mathrm{L} / \mathrm{g}), \mathrm{R}$ is universal gas constant $(8.314 \mathrm{~J} / \mathrm{mol} / \mathrm{K}), T$ is temperature $(\mathrm{K}), \Delta \mathrm{G}^{\circ}$ is Gibbs free energy $(\mathrm{kJ} / \mathrm{mol}), \Delta \mathrm{S}^{\circ}$ is entropy $(\mathrm{J} / \mathrm{mol} / \mathrm{K})$ and $\Delta \mathrm{H}^{\circ}$ is enthalpy $(\mathrm{kJ} / \mathrm{mol})$.

Table S2 (Supplementary material) also summarizes the reactions constants for adsorbents involved in the analysis. From the free energy values, it can be understood that an increase in temperature has a negative impact, implying the fact that it increases the feasibility of the reaction. Also, majority of the reactions have a negative value for the $\Delta G$ values and hence room temperature is sufficient enough for instinctive reactions indicating it a spontaneous one. Except in Lanthanum adsorption by SA and Scandium adsorption by SP, all the enthalpy values remained positive and this can be related to the nature of the reaction being endothermic. In such endothermic reactions, an increase in temperature is an advantageous step in increasing the reaction efficiency. Further inspections of the $\Delta \mathrm{H}$ values yields a conclusive evidence for the dominance of chemisorption $(\Delta \mathrm{H}>50 \mathrm{~kJ} / \mathrm{mol}$ ) (Iftekhar et a 2016) in all elements except Sc. The values of $\Delta S>0$ imply a growth in the degrees of freedom (dofs) of the solid-liquid interface (La-SA, Sc-SEA and Sc-SP being an exception). A possible explanation might be that despite the solute molecules losing dome dofs during the conversion from the liquid phase to solidliquid interface, it is readily compensated by the release of water molecules (Saeed et al., 2005).

\subsubsection{Effect of calcination}

It can be readily observed from Table 3 that the process of calcination leads to a drastic degradation of the adsorption efficiency in method I adsorbents. For the gels without APTES/APTMS functionalization, the response to calcination is minimally positive though no such absolute changes in the efficiency are reported, with Eu being a sole exception. Among the REEs being analyzed, Sc in general is the least sensitive to changes in efficiency with the ments. Same behavior was observed in case of just the amine functionalized gels prior to modification with respect to REE removal.

\subsubsection{Effect of synthesis condition}

A concrete relation between the concentration of PAN/Acac used for the synthesis of adsorbents and the adsorption efficiency has not been observed. Table S1 (Supplementary material) summarizes the equilibrium concentrations of REEs (measured using ICP-OES) for different adsorbents used in the study. The parameters used for the adsorption process include - Initial pH 4 (method I) and pH 7 (method II); room temperature; $220 \mathrm{rpm} ; 24 \mathrm{~h}$; ratios 1:5, 1:10, 1:20; dose $1 \mathrm{~g} / \mathrm{L}$; Initial REE concentration of $25 \mathrm{ppm}$. The most effective adsorbent ratio was found to be $1: 20$, except Sc, for which the ratio of 1:5 returned superior results. Similar behavior was detected for La and Er adsorption in the case of amine functionalized Acac gels.

Table 2

Table 2
Adsorption efficiency of different adsorbents in REE removal, at room temperature and at $60^{\circ} \mathrm{C}$ after the contact time of $1 \mathrm{~h}$.

\begin{tabular}{|c|c|c|c|c|c|c|}
\hline \multirow[t]{2}{*}{ REE } & \multicolumn{6}{|c|}{ Adsorption efficiency (in \%) } \\
\hline & PAN/APTES & Acac/APTES & PAN/APTMS & Acac/APTMS & PAN & Acac \\
\hline La at R.T & 78.70 & 0.44 & 88.74 & 0.94 & 5.84 & 2.28 \\
\hline La at $60^{\circ} \mathrm{C}$ & 99.90 & 75.32 & 95.62 & 80.53 & 8.06 & 0.42 \\
\hline Sc at R.T & 45.72 & 29.10 & 46.00 & 30.12 & 98.94 & 99.52 \\
\hline Sc at $60^{\circ} \mathrm{C}$ & 52.68 & 30.30 & 58.02 & 35.90 & 97.03 & 99.93 \\
\hline Er at R.T & 98.31 & 1.56 & 84.82 & 1.32 & 15.78 & 3.14 \\
\hline Er at $60^{\circ} \mathrm{C}$ & 99.87 & 88.53 & 99.07 & 93.98 & 55.96 & 44.44 \\
\hline Eu at R.T & 89.05 & 8.38 & 67.50 & 31.16 & 25.40 & 12.64 \\
\hline Eu at $60^{\circ} \mathrm{C}$ & 99.99 & 97.02 & 96.77 & 82.99 & 74.08 & 20.96 \\
\hline Y at R.T & 49.56 & 26.60 & 39.46 & 14.30 & 16.38 & 11.46 \\
\hline $\mathrm{Y}$ at $60^{\circ} \mathrm{C}$ & 75.54 & 45.02 & 91.65 & 56.28 & 47.74 & 15.12 \\
\hline
\end{tabular}




\begin{tabular}{|c|c|c|c|c|c|c|}
\hline REE & APTES/PAN modified & APTES/Acac modified & APTMS/PAN modified & APTMS/Acac modified & PAN modified & Acac modified \\
\hline La without calcination & 99.97 & 30.06 & 98.75 & 11.52 & 4.72 & 3.94 \\
\hline La with calcination & 2.38 & 2.45 & 4.18 & 3.76 & 10.25 & 8.73 \\
\hline Sc without calcination & 64.34 & 30.52 & 61.98 & 37.12 & 99.32 & 99.80 \\
\hline Sc with calcination & 37.84 & 44.28 & 38.40 & 41.52 & 99.47 & 99.47 \\
\hline Er without calcination & 99.39 & 23.74 & 98.05 & 31.26 & 25.08 & 12.04 \\
\hline Er with calcination & 2.11 & 6.11 & 6.46 & 24.87 & 38.70 & 39.84 \\
\hline Eu without calcination & 99.91 & 48.30 & 98.97 & 27.76 & 30.28 & 18.58 \\
\hline Eu with calcination & 15.80 & 6.40 & 16.80 & 3.60 & 16.20 & 12.58 \\
\hline Y without calcination & 97.11 & 34.58 & 79.92 & 17.74 & 12.68 & 6.98 \\
\hline Y with calcination & 18.38 & 14.74 & 21.52 & 9.80 & 31.14 & 30.90 \\
\hline
\end{tabular}

\subsubsection{Effect of functionalization with APTES/APTMS}

The REE removal efficiency of functionalized silica gels prior to PAN/Acac modifications are displayed in Table 4. Since the aim of the investigation was also to learn if the adsorbents could be utilised for REE removal from acidic drainage, a pH value of 4 was chosen for all the experiments conducted. For La and $\mathrm{Y}$ adsorption, APTMS gels demonstrated a slightly better efficiency than APTES gels. However, in the case of $\mathrm{La}$ and Eu adsorption, maximum adsorption was achieved in APTES functionalized gels after the modification, unlike APTMS which exhibits maximum adsorption irrespective of the usage of modified/unmodified adsorbents. The effect of modification is negative in the case of Y adsorption for all the adsorbents with APTMS/PAN gel being an exclusion. In reference to the unmodified gels, the Acac functionalized gels registered unfavorable results while APTMS/PAN gels generated the most favorable outcome. To have a better insight into the effect of PAN/ Acac modifications, further experiments involving multicomponent adsorption and REE recovery from adsorbents in both single and multi-component systems, were conducted.

\subsection{Mixed adsorption}

Due to the existence of REEs in mixed state, it is necessary to investigate the selectivity of REEs on the modified adsorbents. Same operating conditions such as the initial REE concentration of

\section{Table 4}

Adsorption efficiency (in \%), Desorption efficiency (in \%) and silica leaching values (in $\mathrm{ppm}$ ) for all the modified adsorbents in single component system.

\begin{tabular}{lllllll}
\hline Adsorbents & & La & Sc & Er & Eu & Y \\
\hline APTES/PAN modified & Adsorption & 99.88 & 59.52 & 99.28 & 99.60 & 99.73 \\
& Desorption & 90.86 & 97.73 & 96.14 & 90.92 & 8.001 \\
& Si Leaching & 1.43 & 9.25 & 5.93 & 5.75 & 6.73 \\
APTES/Acac modified & Adsorption & 99.81 & 14.6 & 99.97 & 99.75 & 97.46 \\
& Desorption & 98.45 & 91.38 & 88.77 & 98.14 & 81.75 \\
& Si Leaching & 3.75 & 9.39 & 4.64 & 5.24 & 7.56 \\
APTMS/PAN modified & Adsorption & 99.93 & 79.29 & 99.98 & 99.54 & 97.98 \\
& Desorption & 96.97 & 94.67 & 91.53 & 95.27 & 98.54 \\
& Si Leaching & 2.88 & 10.01 & 5.19 & 6.61 & 5.94 \\
APTMS/Acac modified & Adsorption & 99.11 & 11.76 & 98.95 & 99.25 & 84.66 \\
& Desorption & 98.47 & 82.67 & 88.5 & 83.41 & 85.53 \\
& Si Leaching & 1.76 & 10.42 & 4.66 & 7.26 & 4.09 \\
PAN modified & Adsorption & 90.70 & 97.53 & 46.08 & 98.73 & 88.96 \\
& Desorption & 43.67 & 72.95 & 91.96 & 81.92 & 86.67 \\
Acac modified & Si Leaching & 2.54 & 7.99 & 3.24 & 3.61 & 4.28 \\
& Adsorption & 99.88 & 99.43 & 40.4 & 99.98 & 99.97 \\
& Desorption & 48.34 & 94.1 & 73.36 & 88.76 & 59.74 \\
APTES functionalized silica & Si Leaching & 3.45 & 3.93 & 3.97 & 4.44 & 3.69 \\
& Adsorption & 99.98 & 80.68 & 99.82 & 99.24 & 99.66 \\
& Desorption & 93.6 & 98.19 & 97.6 & 98.68 & 99.13 \\
APTMS functionalized silica & Si Leaching & 5.85 & 27.99 & 9.53 & 14.58 & 11.85 \\
& Adsorption & 99.53 & 89.27 & 99.68 & 99.92 & 99.68 \\
& Desorption & 94.47 & 92.81 & 98.55 & 96.58 & 98.85 \\
& Si Leaching & 7.37 & 27.21 & 9.11 & 7.78 & 10.08 \\
\hline
\end{tabular}

$5 \mathrm{ppm}$, mixing rate of $220 \mathrm{rpm}$, room temperature, mixing period of $24 \mathrm{~h}$, initial pH of 5 (for amine functionalized gels before modification and for method I modified gels) and 8 (method II) and $1 \mathrm{~g} / \mathrm{L}$ dose were used for conducting this study. The trend depicted in Fig. 6 shows that the adsorption of light rare earths (La, Eu, Sc) was better than those of heavy earths ( $\mathrm{Er}$ and $\mathrm{Y}$ ). A similar behavior has been observed in Kaur and Gupta (2009) and Iftekhar et al (2016). have proved to be the most efficient in mixed solution REE adsorption in comparison to Acac gels. In a further comparative analysis performed between modified and unmodified amine functionalized gels, a similar response was observed in single component system too.

\subsection{REE speciations}

The chemical equilibrium for the calculation of distribution of REE species was carried out using Visual MINTEQ ver. 3.0 software with the initial concentration set as $10 \mathrm{mmol} / \mathrm{L}$. This simulation was attempted in order to understand the behavior of REEs in the liquid phase which might give a better insight into the adsorption mechanism behind the REE ions and the adsorbents. With the help of this model, the concentration of free metal ions and other possible hydroxo complex species in aqueous solution can be possible hydroxo complex species in aqueous solution can be
determined from the solubility product as a function of $\mathrm{pH}$ (Worch, 2015). The concentration distribution of REEs over the $\mathrm{pH}$ range of $1-13$, computed by this model is shown in Fig. 7, according to which the REEs can form the mentioned species complexes. It can

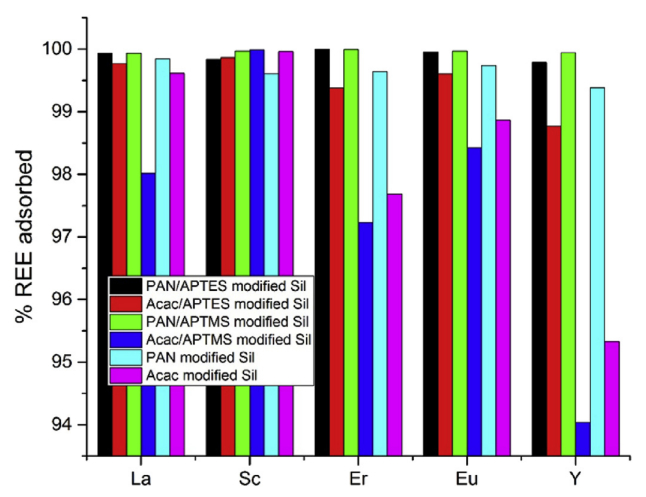

Fig. 6. Overall comparison of REE adsorption efficiency of different adsorbents in mixed solution. 

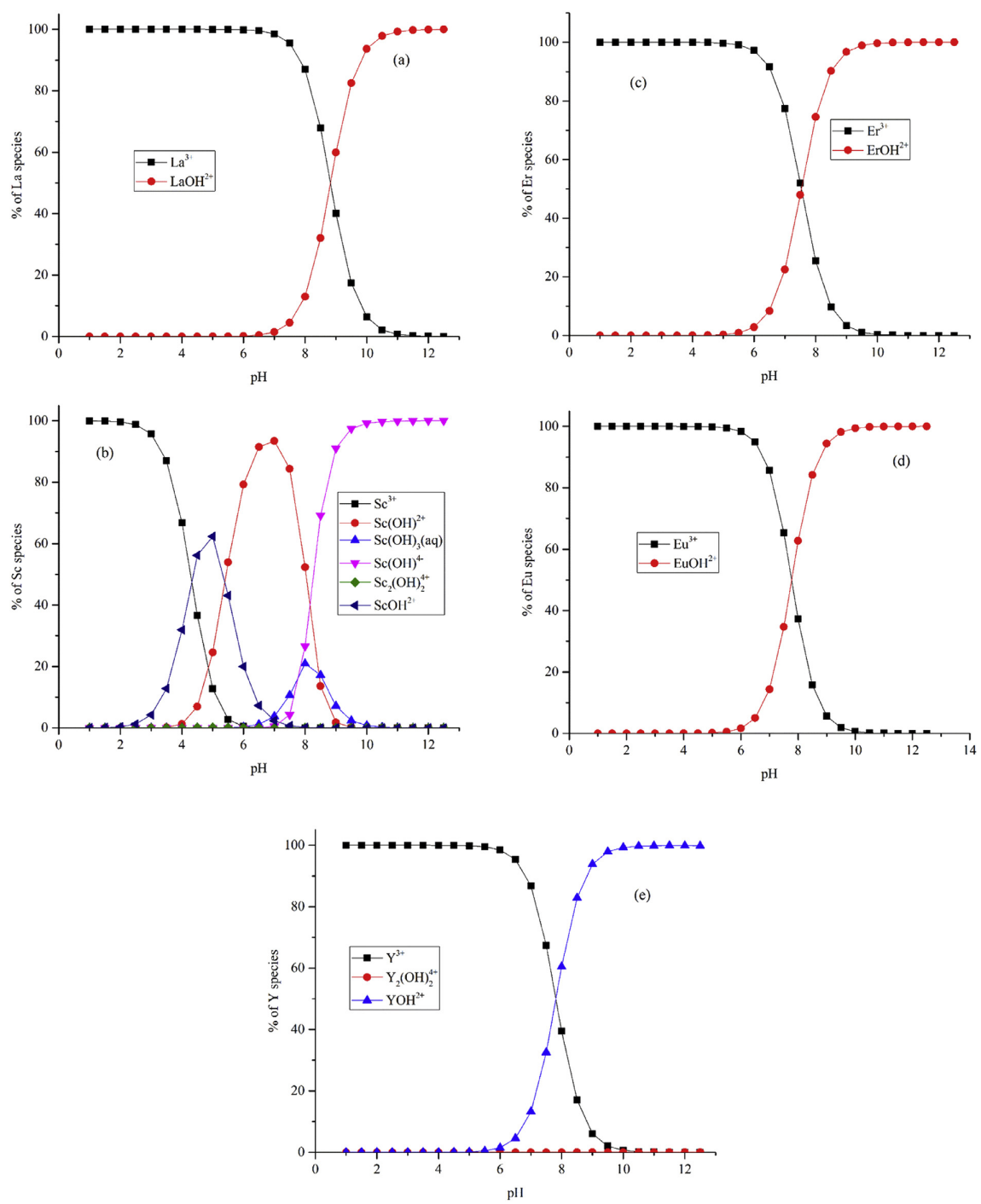

Fig. 7. REE speciations over the $\mathrm{pH}$ range of $1-12$

be seen from the diagrams that except Sc, all the REEs demonstrate an analogous behavior in the speciation study. Until $\mathrm{pH}$ value of 6 $\mathrm{La}^{3+}, \mathrm{Er}^{3+}, \mathrm{Eu}^{3+}$ and $\mathrm{Y}^{3+}$ are the predominant species present in the solution. With a further increase in the $\mathrm{pH}$, the corresponding ionic species of the REEs exist as $\mathrm{LaOH}^{2+}, \mathrm{ErOH}^{2+}, \mathrm{EuOH}^{2+}$ and $\mathrm{YOH}^{2+}$ reaching the maximum concentration around $\mathrm{pH}$ value of 9-10. It has to be noted that there are negligible traces of $\mathrm{Y}_{2}(\mathrm{OH})^{4+}$ ionic species present for the case of $\mathrm{Y}$, throughout the $\mathrm{pH}$ range under consideration. Unlike other REEs discussed earlier, Sc exists as multiple ionic species over the entire $\mathrm{pH}$ range. $\mathrm{Sc}^{3+}$ are distributed until $\mathrm{pH}$ of 5 above which the hydroxo complexes are formed. Though the predominant ionic form of $\mathrm{Sc}$ at $\mathrm{pH}>9$ is $\mathrm{Sc}(\mathrm{OH})^{4-}$, in the $\mathrm{pH}$ range of $4-9$ it exists simultaneously as $\mathrm{Sc}(\mathrm{OH})^{2+}, \mathrm{Sc}(\mathrm{OH})^{3}$ 


\subsection{Desorption studies}

Table 4 depicts a collective overview of the results from adsorption, desorption and leaching experiments in single component system. Desorption study is performed using $1 \mathrm{~N} \mathrm{HNO}_{3}$ chosen among various acids and various molar ratios, based on prior experience. This procedure is vital to understand if the prior experience. This procedure is vital to understand if the
restoration of original adsorption capacity is feasible even after restoration of original adsorption capacity is feasible even after
facilitating the recovery of valuable elements from waste water. In multi elemental system, the PAN modified gels demonstrated greater silica leaching in comparison to the Acac modified gels, which can been seen from Table S3 (Supplementary material). The desorption efficiency does not display any significant difference in the multi con the multi component system for different REEs under consideration. In the case of single element scenario, Method I adsorbents show slightly better desorption values than Method II adsorbents. However, there is no significant difference in REE desorption efficiency among the adsorbents under study. Also in the case of leaching, Sc demonstrated a more pronounced effect in comparison to other members of the lot. On a general note, PAN and Acac gels with APTES/APTMS modifications displayed increased desorption and silica leaching in comparison to the bare PAN and Acac modified gels. Also, silica leaching is the greatest in APTES modified gels. The study on the effect of leaching using APTES/APTMS functionalized silica gels with and without PAN/Acac modifications revealed that the effect of leaching is more pronounce in single and multicomponent system for unmodified and modified gels, respectively. The effect of desorption has also been analyzed and the results were in coherence with silica leaching experiments. The nucleophilic attack of the end amino groups to the $\mathrm{Si}-\mathrm{O}-\mathrm{Si}$ bond could explain the increased leaching of APTES groups from silica, seen in amino functionalized gels (Repo et al., 2009). The modification with PAN/Acac seems to protect the surface groups thereby enabling lesser leaching in those gels. This emphasizes the fact that chemically immobilized amine functionalized PAN/Acac gels are more preferable for multi-component desorption processes. These results suggest that the amine functionalized PAN modified silica gels are more applicable for the enrichment and recovery of mixed rare earth ions.

\subsection{Reaction mechanism}

Two possible mechanisms can explain the adsorption of REEs on Acac modified adsorbents. In acidic medium, the adsorption of REE is by its affinity towards $=\mathrm{O}$ of Acac. With the increase in $\mathrm{pH}$ and the negative surface potential, the binding of REE onto the adsorbent is predominantly through the $\mathrm{OH}^{-}$groups on the surface of the adsorbent (Mor et al., 2007). In case of PAN modifications, the interaction between the REE cations and the adsorbents are mainly interaction between the REE cations and the adsorbents are mainly
due to the electrostatic repulsion between the positively charged REE cations and the positively charged adsorbent (zero charge at $\mathrm{pH}=8$ for APTES/PAN, 4.5 for APTMS/PAN and 3.5 for just PAN modified silica) under $\mathrm{pH}<\mathrm{pH}_{\mathrm{ZPC}}$ or adsorption of metal ions onto the positively charged amino groups and minimally due to the ion exchange through hydroxyl groups till $\mathrm{pH}_{\mathrm{ZPC}}$ above which the affinity is owing to electrostatic attraction forces.

\section{Conclusion}

Based on the experimental analysis performed, a summary of the important observations has been presented below:

- The chemically adsorbed silica gels demonstrated greater adsorption in comparison to the physically adsorbed ones, among which, the efficiency of PAN modification was more pronounced than that of Acac. Except Sc, PAN/Acac physically adsorbed gels displayed poor adsorption in the lower $\mathrm{pH}$ range. - The extraction of REEs at lower pHs by amino functionalized gels makes it suitable for the removal of these elements from the acidic waste stream. The physically adsorbed PAN/Acac gels seem to be very efficient at extracting metals (as in $\mathrm{LaOH}^{2+}$ ) at higher $\mathrm{pHs}$ above 7 . The removal efficiency of these gels are expected to increase even higher for $\mathrm{pH}$ above 8 .

In comparison to the chemically immobilized amine function- In comparison to the chemically immobilized amine function-
alized gels, amine functionalized gels without any modification can yield better adsorption results in REE removal from waste water, irrespective of single/multi-component systems. However, REE recovery from a mixed solution is performed with greater efficiency by the chemically immobilized gels. Moreover silica leaching is lesser in chemically immobilized gels than the just amine functionalized gels without PAN/Acac modification.

- The optimal initial concentration for all the silica gels involved in the study lies within $50-100 \mathrm{ppm}$. The time necessary to attain the state of equilibrium is below $5 \mathrm{~h}$ for PAN modified gels, which is the least in comparison to other adsorbents where the recorded time is $24 \mathrm{~h}$. The adsorption process, however, is accelerated with an increase in temperature and affected with the calcination for all the amine functionalized gels.

- The cost of the modified adsorbents is estimated to be closer in range to the commercially available amino functionalized silica gels. The total estimate of the adsorbent $(1 \mathrm{~kg})$ needed for cleaning $1 \mathrm{~m}^{3}$ of waste water is found to be around $900-1200 €$ (Supplementary material: Table S4).

\section{Acknowledgments}

The authors are grateful to Academy of Finland (decision number 292542) for funding the project. The authors are also thankful to all the staff members of Laboratory of Green Chemistry for their support during the work and Mr. Toni Väkiparta from LUT School for Engineering Science for the SEM analysis.

\section{Appendix A. Supplementary data}

Supplementary data related to this article can be found at http:// dx.doi.org/10.1016/j.watres.2017.02.045.

\section{References}

Abolhasani, J., Behbahani, M., 2014. Application of 1-(2-pyridylazo)-2-naphtholmodified nanoporous silica as a technique in simultaneous trace monitoring and removal of toxic heavy metals in food and water samples. Environ. Monit. Assess. 187, 4176. http://dx.doi.org/10.1007/s10661-014-4176-9.

Airoldi, C., Alcantara, E.F.C., 1995. Silica-gel-immobilized acetylacetone-some (1)

Solid phase extraction of metal ions in environ nated activated carbon cloth. Ecotoxicol. Environ. Saf. 112, 74-79. http:ll dx.doi.org/10.1016/j.ecoenv.2014.10.032.

Awual, M.R., 2017. New type mesoporous conjugate material for selective optical copper(II) ions monitoring \& removal from polluted waters. Chem. Eng. J. 307,

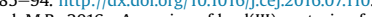

using ligand doped conjugate adsorbent. Chem. Eng . dx.doi.org/10.1016/i.cej 2015.12.078

Awual, M.R., 2016b. Solid phase sensitive palladium(II) ions detection and recovery using ligand based efficient conjugate nanomaterials. Chem. Eng. J. 300, 264-272. http://dx.doi.org/10.1016/j.cej.2016.04.071.

Awual, M.R., Hasan, M.M., Khaleque, M.A., Sheikh, M.C.,. 2016. Treatment of copper(II) containing wastewater by a newly developed ligand based facial conj.cej.2015.11.108.

Awual, M.R., Yaita, T., Shiwaku, H., 2013. Design a novel optical adsorbent for simultaneous ultra-trace cerium(III) detection, sorption and recovery. Chem. Eng. J. 228, 327-335. http://dx.doi.org/10.1016/j.cej.2013.05.010. 
Babich, I.V., Plyuto, Y.V., Van Der Voort, P., Vansant, E.F., 1997. Thermal transormations of chromium acetylacetonate on silica surface. J. Colloid Interface Sci. 189, 144-150. http://dx.doi.org/10.1006/jcis.1997.4798.

Balbuena, P.B., Gubbins, K.E., 1993. Theoretical interpretation of adsorption behavior of simple fluids in slit pores. Langmuir 9, 1801-1814. http://dx.doi.org/10.1021 la000312031,

Beganskiene, A., Sirutkaitis, V., Kurtinaitiene, M., Juskenas, R., Kareiva, A., 2004 FTIR, TEM and NMR iinvestigations of Stöber silica nanoparticles. Mater. Sci Cornejo-Ponce, L Peralta-Zamora. P Bueno MIMS, 1998. Pre-concentration of rare earths using silica gel loaded with 1-(2-pyridylazo)-2-naphthol (PAN) and determination by energy dispersive X-ray fluorescence. Talanta 46, 1371-1378. http://dx.doi.org/10.1016/S0039-9140(98)00002-2.

Gun'ko, V.M., Leboda, R., Skubiszewska-Zieba, J., Rynkowski, J., 2000. Silica ge modified due to pyrolysis of acetylacetone and metal ( $\mathrm{Ti}, \mathrm{Cr}, \mathrm{Co}, \mathrm{Ni}, \mathrm{Zn}, \mathrm{Zr}$ ) doi.org/10.1006

Hajipour, A., Shi

palladium rdashtzade, Z., Azizi, G., 2015. Silica-acetylacetone-supported palladium nanoparticles as an efficient and reusable catalyst in the
Heck-Mizoroki C-C cross-coupling reaction. Appl. Organomet. Chem. 29 143-146. http://dx.doi.org/10.1002/aoc.3259.

Iftekhar, S., Srivastava, V., Sillanpää, M., 2016. Synthesis and application of LDH intercalated cellulose nanocomposite for separation of rare earth elements j.cej.2016.10.028. Jal, P., 2004. Chemical modification of silica surface by immobilization of functional http://dx.doi.org/10.1016/jitalanta.2003.10.028

Kaur, A., Gupta, U., 2009. Preconcentration of Zinc and Manganese using 1-(2-

pyridylazo)-2-naphthol anchored $\mathrm{SiO}_{2}$. Nanoparticles 4, 234-244.
Kulkarni, S.A., Ogale, S.B., Vijayamohanan, K.P., 2008. Tuning the hydrophobic properties of silica particles by surface silanization using mixed self-assemble i.jicis.2007.11.012.

Mor, S., Ravindra, K. Bishnoi, N.R. 2007. Adsorption of chromium from aqueous solution by activated alumina and activated charcoal. Bioresour. Technol. 98, 954-957. http://dx.doi.org/10.1016/j.biortech.2006.03.018.

Rabiul Awual, M., Munjur Hasan, M., Ihara, T., Yaita, T., 2014. Mesoporous silica novel conjugate adsorbent for efficient selenium(IV) detection an removal from water. Microporous Mesoporous Mater 197, 331-338. http: o. Kurniawan, T

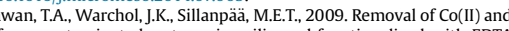
$\mathrm{Ni}(\mathrm{II})$ ions from contaminated water using silica gel functionalized with EDTA and/or DTPA as chelating agents. J. Hazact

Repo, E., Malinen, L., Koivula, R., Harjula, R., Sillanpää, M., 2011a. Capture of Co(II) from its aqueous EDTA-chelate by DTPA-modified silica gel and chitosan.

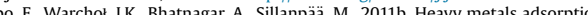

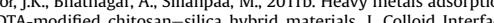
Sci. 358, 261-267. http://dx.doi.org/101016/jijcis. 2011.02.059,

Saeed, M.M., Saeed, M.M., Ahmed, R., Ahmed, R., 2005. Temperature effected sorption of europium(III) onto 1-(2-pyridylazo)-2-naphthol impregnated polyurethane foam. J. Radioanal. Nucl. Chem. 267, 147-153. http://dx.doi.org

Sharma, R.K., Mittal, S., Koel, M., 2003. Analysis of trace amounts of metal ions using silica-based chelating resins: a green analytical m

Srivastava, V., Sharma, Y.C., 2014. Synthesis and characterization of $\mathrm{Fe}_{3} \mathrm{O}_{4} @ n-\mathrm{SiO}_{2}$ $\mathrm{Cr}(\mathrm{VI})$ from aqueous solutions. Water. Air. Soil Pollut. 225, 1776. http:/

Thommes, M., 2010. Physical adsorption characterization of nanoporous materials. Chem. Ing. Tech. 82, 1059-1073. http://dx.doi.org/10.1002/cite.201000064. , B.K., Yousuf, M., Mollah, A., 2014. Synthesis and characterization of 135-145. http://dx.doide composites of different ratios. Int. J. Cor

Worch, E., 2015. Hydrochemistry: Basic Concepts and Exercises. Walter de Gruyter $\mathrm{GmbH} \&$ Co KG.

Xu, S., Wang, Z., Gao, Y., Zhang. S., Wu, K., 2015. Adsorption of rare earths(III) using an efficient sodium alginate hydrogel cross-linked with poly- $\gamma$-glutamate. PLOS .

ments in environ, Hu, B., 2007. ICP-AES determination of trace rare earth eleconcentration with acetylacetone-modified silica gel using microcolumn. Anal. Sci. 23, 997-1002. http://dx.doi.org/10.2116/analsci.23.997. 



\title{
Publication II
}

\author{
D.L.Ramasamy, S. Khan, E. Repo, M. Sillanpää
}

Synthesis of mesoporous and microporous amine and non-amine functionalized silica gels for the application of rare earth elements (REE) recovery from the waste water-understanding the role of pH, temperature, calcination and mechanism in Light REE and Heavy REE separation

$$
\begin{gathered}
\text { Reprinted with permission from } \\
\text { Chemical Engineering Journal } \\
\text { Vol. 322, pp. 56-65, } 2017 \\
\text { (C) 2017, Elsevier }
\end{gathered}
$$



Synthesis of mesoporous and microporous amine and non-amine functionalized silica gels for the application of rare earth elements (REE) recovery from the waste water-understanding the role of $\mathrm{pH}$, temperature, calcination and mechanism in Light REE and Heavy REE separation

Deepika Lakshmi Ramasamy ${ }^{a, *}$, Shoaib Khan ${ }^{a}$, Eveliina Repo ${ }^{a}$, Mika Sillanpääa ${ }^{a, b}$

a Laboratory of Green Chemistry, Lappeenranta University of Technology, Mikkeli FI-50130, Finland

\section{H I G H L I G H T S}

- Functionalization of silica gels by APTES, APTMS, MTM and TMCS were performed.

- REE recovery from waste water in th presence of competing ions was studied.

- Effect of calcination, $\mathrm{pH}$ and temperature in REEs separation has been reported.

- APTES/APTMS modifications

performed better among the four.

- REE fractionation due to $\mathrm{pH}$, metal

loading. $\mathrm{Ln}^{3+}$ contraction and tetrad effect.

\section{A R T I C L E I N F O}

Article history:

Received 3 March 2017

Received in revised form 30 March 2017

Accepted 31 March 2017

Available online 4 April 2017

\section{Keywords:}

Adsorptio

Lanthanides separatio

REE recovery

Silica functionalization
G R A P H IC A L A B S T R A C T

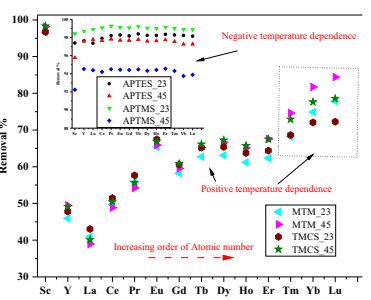

A B S T R A C T

The aim of this research project was to investigate the impact of surface modified silica for the purpose of rare earth elements (REE) recovery from both artificial and real waste water. The four silanes used for the functionalization of silica gels during the course of study were 3-Aminopropyl triethoxysilane (APTES), 3-Aminopropyl trimethoxysilane (APTMS), Trimethoxymethylsilane (MTM) and Chlorotrimethylsilane (TMCS). The analysis of silica gel surfaces was conducted using Fourier Transform Infrared Spectroscopy (FTIR), Scanning Electron Microscopy (SEM), Brunauer Emmett Teller (BET) and Zeta potential measurements to better understand about the surface modification of the gels. The important yardstick for experimental analysis is the comparative REE removal efficiency of the silica gels in real and yardstick for experimental analysis is the comparative REE removal efficiency of the silica gels in real and
artificial waste water and how the trend of Light REE (LREE) and Heavy REE (HREE) removal changes with artificial waste water and how the trend of Light REE (LREE) and Heavy REE (HREE) removal changes with
the effect of temperature and the presence of other competing ions. In addition, the influence of particle the effect of temperature and the presence of other competing ions. In addition, the influence of particle size, the effect of $\mathrm{pH}$, the significance of calcination post silanization in the process of the selective REE removal as well as the silica leaching in both real and test waste water conditions has also been studied and addressed. The most effective results were observed for mesoporous silica gel A, with a particle size of $15-20 \mu \mathrm{m}$, in most of the cases for both calcined and non-calcined adsorbents. Amino-functionalized

\footnotetext{
E-mail addresses: deepika.ramasamy@lut.fi, deepu7187@gmail.com (D.L. Ramasamy).
} 
APTES/APTMS silica gels demonstrated the most impressive behavior among the four adsorbents in all the cases. However, the calcination seems to have affected the performance of such gels in the removal of the target elements.

(ㄷ) 2017 Elsevier B.V. All rights reserved.

\section{Introduction}

REEs have gained reputation as critical elements in a variety of modern applications such as electronics etc. attributing to thei unique characteristics. They steer technological advancements through cleaner and energy efficient means as well as aiming towards coal-free techniques, thus serving as vital components for economical and industrial advancements. Intensive mining policies and inefficient recycling methods have grown to be important concerns in recent times, as a result of which the demand and availability deny to operate hand in hand. This serves as a severe motivation to look into alternate and compelling strategies to supplement the requirements via academic, industrial and administrative sectors, functioning in a conjoint manner. One of the most important methods identified as an economically viable and attractive option is the REE recovery from industrial waste and recyclable sources.

Though several methods for REE recovery have been proposed one of the most effective and economically sound methods is adsorption from aqueous solutions. Among the adsorbents, Silic gels serve as an ideal The efficiency of silica gels can be further augmented through chelating agents attached to the surface via chemical bonding or loading [1-3]. Due to the presence of silanol groups on the surface, silica remains as a weak ion exchanger with immense sorption capacity for metal ions like $\mathrm{Co}$, Ni etc. [4]. Silica particles can serve a wide range of applications including catalysis, chromatography etc. in additio industrial domain. This has always kindled rigorous interest in understanding the influence of surface chemistry and geometrica microstructure in the adsorption efficiency of silica gels. The surface selectivity of silica can be improved through direct graftin technique, where an organosilane reagent reacts with the silic surface to form covalent bonds using a suitable solvent under reflux conditions. The use of silane coupling agents for the grafting reflux conditions. The use of silane coupling agents for the grafting technique is referred to as silylation and aminosilanes are the most
prominent agents due to their bifunctional nature. Several documentations in literature have been dedicated to the studies on the factors affecting the performance of silica gels. Some of the imminent and decisive factors which influence the adsorption efficiency like the pore size distribution [5,6], particle size [7-11] grafting methods [12] and drying techniques [13] have been addressed extensively in the past years. As understood from previous works in the literature, there are many adsorption studies based on amino functionalized silica gels, but to the best of ou knowledge, the usage of MTM and TMCS functionalized silica gels for REE removal has not been exploited in the past in this regard as well. Hence an attempt has been made to analyze and compare the efficiency of functionalized silica gels, modified with two aminopropyl alkoxy silanes (APTES and APTMS), a non-amino but alkoxysilane MTM and a chlorosilane TMCS in the process of REE removal. In addition to particle size, the parameters such as adsorption $\mathrm{pH}$, silanization time and effect of calcination have bee examined and a comprehensive overview of the effectiveness of the adsorbents are presented in the discussion. The studies have been performed in both real and artificial waste water conditions to understand the trend of REE (both LREEs and HREEs) removal with respect to the effect of temperature as well.

\section{Experimental studies}

\subsection{Materials}

The REEs used for the current research work include Cerium group elements or LREEs (Lanthanum $\left(\mathrm{La}^{3+}\right)$, Scandium $\left(\mathrm{Sc}^{3+}\right)$, Cerium $\left(\mathrm{Ce}^{3+}\right)$, Praseodymium $\left(\mathrm{Pr}^{3+}\right)$, Europium $\left(\mathrm{Eu}^{3+}\right)$, Gadolinium $\left(\mathrm{Gd}^{3+}\right)$ and Terbium $\left(\mathrm{Tb}^{3+}\right)$ and Yttrium group elements or HREEs $\left(\mathrm{Yttrium}^{3+}\left(\mathrm{Y}^{3+}\right)\right.$, Erbium $\left(\mathrm{Er}^{3+}\right)$, Dysprosium $\left(\mathrm{Dy}^{3+}\right)$, Holmium
$\left(\mathrm{Ho}^{3+}\right)$, Lutetium $\left(\mathrm{Lu}^{3+}\right)$, Ytterbium $\left(\mathrm{Yb}^{3+}\right)$ and Thulium $\left.\left(\mathrm{Tm}^{3+}\right)\right) .3-$ $\left(\mathrm{Ho}^{3+}\right)$, Lutetium $\left(\mathrm{Lu}^{3+}\right)$, Ytterbium $\left(\mathrm{Yb}^{3+}\right)$ and Thulium $\left.\left(\mathrm{Tm}^{3+}\right)\right)$. 3-
Aminopropyl triethoxysilane $\mathrm{H}_{2} \mathrm{~N}\left(\mathrm{CH}_{2}\right)_{3} \mathrm{Si}\left(\mathrm{OC}_{2} \mathrm{H}_{5}\right)_{3}$ (APTES $98 \%$ Aminopropyl triethoxysilane $\mathrm{H}_{2} \mathrm{~N}_{(}\left(\mathrm{CH}_{2}\right)_{3} \mathrm{Si}\left(\mathrm{OC}_{2} \mathrm{H}_{5}\right)_{3}(\mathrm{APTES} 98 \%$
from Merck), 3-Aminopropyl trimethoxysilane $\mathrm{H}_{2} \mathrm{~N}\left(\mathrm{CH}_{2}\right)_{3} \mathrm{Si}$ $\left(\mathrm{OCH}_{3}\right)_{3}$ (APTMS 97\% from Aldrich), Trimethoxymethylsilane $\mathrm{CH}_{3} \mathrm{Si}\left(\mathrm{OCH}_{3}\right)_{3}$ (MTM 98\% from Aldrich) and Chlorotrimethylsilane C $\mathrm{C}_{3} \mathrm{H}_{9} \mathrm{CISi}$ (TMCS $99 \%$ from Merck) were used for the functionalization of silica gel. The other chemicals included analytical grade Toluene, Methanol, Acetone and Ethanol (purity for all, >99.5\%) are provided by Sigma Aldrich. The size of silica particles used in the experiments were of three different ranges - Sil A of 0.015$0.040 \mathrm{~mm}$, Sil B of $0.063-0.200 \mathrm{~mm}$ and Sil C $1-3 \mathrm{~mm}$. Sil A, B and $C$ are the notations used to label the silica particles of different the course of this article. Sil A and B (mesoporous), supplied by Merck, have a pore size of $60 \AA$, pH value of $6.5-7.5$ on $10 \%$ suspension and a loss on drying of $<7 \%$ at $150^{\circ} \mathrm{C}$. Sil C (microporous) exhibits a pH of 2.5 at $5 \%$ suspension with $1.5 \%$ loss on drying at $140{ }^{\circ} \mathrm{C}$ and water adsorption capacity of $25.2 \%$ at $23{ }^{\circ} \mathrm{C}(50 \% \mathrm{RH})$. The latter has been procured from VWR. The real waste water used for the adsorption procured from VWR. The real waste water used for the adsorption

\subsection{Synthesis}

The experimental procedure for the Silanization process was referred from the work of Zhang et al. [14]. A brief description of the procedure would include prior activation of silica gel by refluxing with $1: 1$ hydrochloric acid for a time period of $24 \mathrm{~h}$. The activation process is succeeded by filtration, distilled water rinsing and drying at $100^{\circ} \mathrm{C}$ for the same period as before. The consequent step is the suspension of activated silica gel in silane solution $(10 \mathrm{~g}$ stored in $100 \mathrm{~mL}$ of the soluti ne). Unlike the procedure followed in literature, a total reaction time of 24 and $72 \mathrm{~h}$ were adopted, followed by refluxing the mixture in nitrogen atmosphere for $4 \mathrm{~h}$. These reaction times were chosen with the aim of optimizing the silanization process in order to understand better about the nature of silane and hydrolyzed silica surface bonding To study the impact of calcination, the samples were calcined at 400,600 and $800^{\circ} \mathrm{C}$ for 6,4 and $2 \mathrm{~h}$ respectively.

\subsection{Characterization}

SU3500 SEM system fitted with Thermo Scientific UltraDry SDD EDS for energy dispersive X-ray analysis has been employed to perform the SEM analysis. The EDS employs a dual detector with 
the firmware from NSS. FTIR type Vertex 70 by B Bruker Optics (Germany) was used for recording the FTIR spectra while Micromeritics Tristar II plus performed the BET analysis. Organic Elemental Analyzer Flash 2000 (Thermo Scientific, Germany) was utilized for the elemental analysis. The determination of metal for the isoelectric point study (dependent on $\mathrm{pH}$ ) conducted on the surface charge and a zero charge point of the modified and unmodified adsorbents.

2.4. Batch adsorption studies

Adsorption equilibrium was achieved for $10 \mathrm{~mL}$ aliquot of all the metal salt solutions mentioned in Section 2.1 by mixing them with $10 \mathrm{mg}$ of adsorbents in test tubes, using a shaker at $220 \mathrm{ppm}$ for $24 \mathrm{~h}$. The temperature was maintained same as the room temperature during the entire mixing phase. Subsequent filtration of the solution was performed using $25 \mathrm{~mm}$ syringe filter of cellulose acetate membrane $(0.2 \mu \mathrm{m})$. The $\mathrm{pH}$ meter and ICP-OES were used to measure the $\mathrm{pH}$ and the metal ion concentration in aqueous solution before and after the analysis, respectively. The initial condition for the metal concentration was maintained around $20-30 \mathrm{ppm}$ while disparate $\mathrm{pH}$ values ranging between 2 and 8 were actuated. The concentration of adsorbed metal can be calculated from the metal mass balance relation. The calculation of adsorption capacity $\left(\mathrm{q}_{\mathrm{e}}\right)$ and the percentage of REE removal is given by the following formulae (A.1) and (A.2):

$q_{e}(m g / g)=\frac{\left(C_{o}-C_{e}\right)}{M} V$

$\%$ REE removal $=\frac{\left(C_{o}-C_{e}\right)}{C_{0}} 100$

$\mathrm{C}_{\mathrm{o}}$ and $\mathrm{C}_{\mathrm{e}}(\mathrm{mg} / \mathrm{L})$ are a measure of the initial and equilibrium concentrations while $\mathrm{M}(\mathrm{g})$ and $\mathrm{V}(\mathrm{L})$ represent the weight of the adsorbent and volume of the solution, respectively.

\section{Results and discussion}

\subsection{Characterization of adsorbents}

The functionalization of silanol groups onto silica surface is confirmed by CHNS analysis which shows the presence and absence of nitrogen in amino and non-amino silane functionalized silica gels respectively after modification. The results from the BET analysis

\section{Table 1}

BET and CHNS analysis results for different adsorbents silanized for a period of $72 \mathrm{~h}$.

\begin{tabular}{|c|c|c|c|c|c|}
\hline \multirow[t]{2}{*}{ Adsorbents } & \multirow[t]{2}{*}{ BET Surface area $\left(\mathrm{m}^{2} / \mathrm{g}\right)$} & \multirow[t]{2}{*}{ Pore volume $\left(\mathrm{cm}^{3} / \mathrm{g}\right)$} & \multicolumn{3}{|c|}{ Percentage of dry weight } \\
\hline & & & $\mathrm{N}$ & c & $\mathrm{H}$ \\
\hline Bare Silica A & 377.86 & 0.69 & - & - & - \\
\hline Bare Silica B & 485.90 & 0.65 & - & - & - \\
\hline Bare Silica C & 545.52 & 0.35 & - & - & - \\
\hline APTES modified Sil A & 174.19 & 0.32 & 2.58 & 10.30 & 2.48 \\
\hline APTES modified Sil B & 253.49 & 0.38 & 3.93 & 12.29 & 3.14 \\
\hline APTES modified Sil C & 395.97 & 0.25 & 2.15 & 7.74 & 2.33 \\
\hline APTMS modified Sil A & 176.79 & 0.32 & 2.37 & 8.84 & 2.17 \\
\hline APTMS modified Sil B & 212.59 & 0.31 & 2.21 & 7.93 & 2.01 \\
\hline APTMS modified Sil C & 549.43 & 0.34 & 0.07 & 2.12 & 1.31 \\
\hline MTM modified Sil A & 306.07 & 0.52 & - & 3.33 & 1.1 \\
\hline MTM modified Sil B & 376.17 & 0.50 & - & 2.73 & 0.97 \\
\hline MTM modified Sil C & 463.82 & 0.28 & - & 3.04 & 1.14 \\
\hline TMCS modified Sil A & 345.63 & 0.60 & - & 4.73 & 1.37 \\
\hline TMCS modified Sil B & 394.66 & 0.51 & - & 4.46 & 1.35 \\
\hline TMCS modified Sil C & 342.14 & 0.21 & - & 5.90 & 1.97 \\
\hline
\end{tabular}

and CHN content of modified adsorbents are shown in Table 1. The $\mathrm{N}_{2}$ adsorption- desorption isotherm curves obtained from BET for adsorbents before (Supplementary Material: Fig. S1) and after modification in Fig. 1(a-d) reveals that Sil A and B follows Type IV suggesting adsorption behavior of mesoporous materials along with hysteresis loops between the adsorption and desorption branch in the $\mathrm{P} / \mathrm{P}_{\mathrm{o}}$ range $0.5-0.9$ in all the modified and unmodified other hand, Sil C shows Type I curve in bare, MTM and TMCS modified silica gels indicating microporous materials with micropore filling with the absence of multilayer adsorption where as in APTES and APTMS modifications, a slight hysteresis behavior in the $\mathrm{P} / \mathrm{P}_{\mathrm{o}}$ range of 0.4-0.6 is observed [17]. The BET surface area are in the order of Sil A $<$ Sil B $<$ Sil C in all the gels showing decrease in surface area and pore volume after modifications. Similar results showing the reduction was previously reported in [18-21] indicating the groups occupying or blocking the mesopores after modification step.

In order to obtain a definitive account of the chemical bonds present on the surface of silica gel, the detailed analysis of the IR plots, obtained from the surface of different samples, was performed. The graphs depicting the spectra for unmodified and modified silica gels A are shown in Fig. 1(e-f). Sufficient references from literature help elaborate different bands observed in the spectral plots. $1100 \mathrm{~cm}^{-1}, 950 \mathrm{~cm}^{-1}$ and $800 \mathrm{~cm}^{-1}$ bands are a result of asymmetric vibration of $\mathrm{Si}-\mathrm{O}$, asymmetric vibration of $\mathrm{Si}-\mathrm{OH}$ and symmetric vibration of $\mathrm{Si}-\mathrm{O}$ [22], respectively. The transmission bands found in the regime between 800 and $1260 \mathrm{~cm}^{-1}$ are a consequence of $\mathrm{Si}-\mathrm{OH}$ bonding and $\mathrm{SiO}_{2}$ peaks superimposition [22]. The zone lying between $3300 \mathrm{~cm}^{-1}$ and $3500 \mathrm{~cm}^{-1}$ is the manifestation of $\mathrm{O}-\mathrm{H}$ stretching from $\mathrm{H}$-bonded water, hydroxyl terminals or $\mathrm{H}$-bonded $\mathrm{Si}-\mathrm{OH}$ chain [22]. Also, the rocking mode is assigned near $450 \mathrm{~cm}^{-1}$ [23]. Owing to the of the band corresponding to stretching modes of isolated silanols in modified silica, at $980 \mathrm{~cm}^{-1}$, it can be inferred that there is formation of new bonds on the silica surface [23]. The new bands 2850 and $2950 \mathrm{~cm}^{-1}$ are a contribution from the symmetric $-\mathrm{CH}_{3}$ and asymmetric $\mathrm{C}-\mathrm{H}$ while the band at $1600 \mathrm{~cm}^{-1}$ is due to water adsorption (physically or chemically). The band observed in the domain around $2200 \mathrm{~cm}^{-1}$ may be a result of Si-H stretching as such a finding has been reported in a study involving "reactive silica" contacted with hydrogen [23]. In the spectral plots of APTES/APTMS modified silica gel, the components in the territories of $1480-1450 \mathrm{~cm}^{-1}$, 1300 and $1410 \mathrm{~cm}^{-1}$ are a result of symmetric $\mathrm{NH}_{2}$ groups, $\mathrm{CH}_{2}$ wagging mode (APTES/APTMS backbone) and bending mode of $\mathrm{CH}_{3}$ group near $\mathrm{Si}\left(\mathrm{Si}-\mathrm{CH}_{2}\right)$ respectively. Electrostatic interactions or hydrogen bonding are the modes by which the surface amino adsorbents suggesting multilayer adsorption [15] [16]. On the 

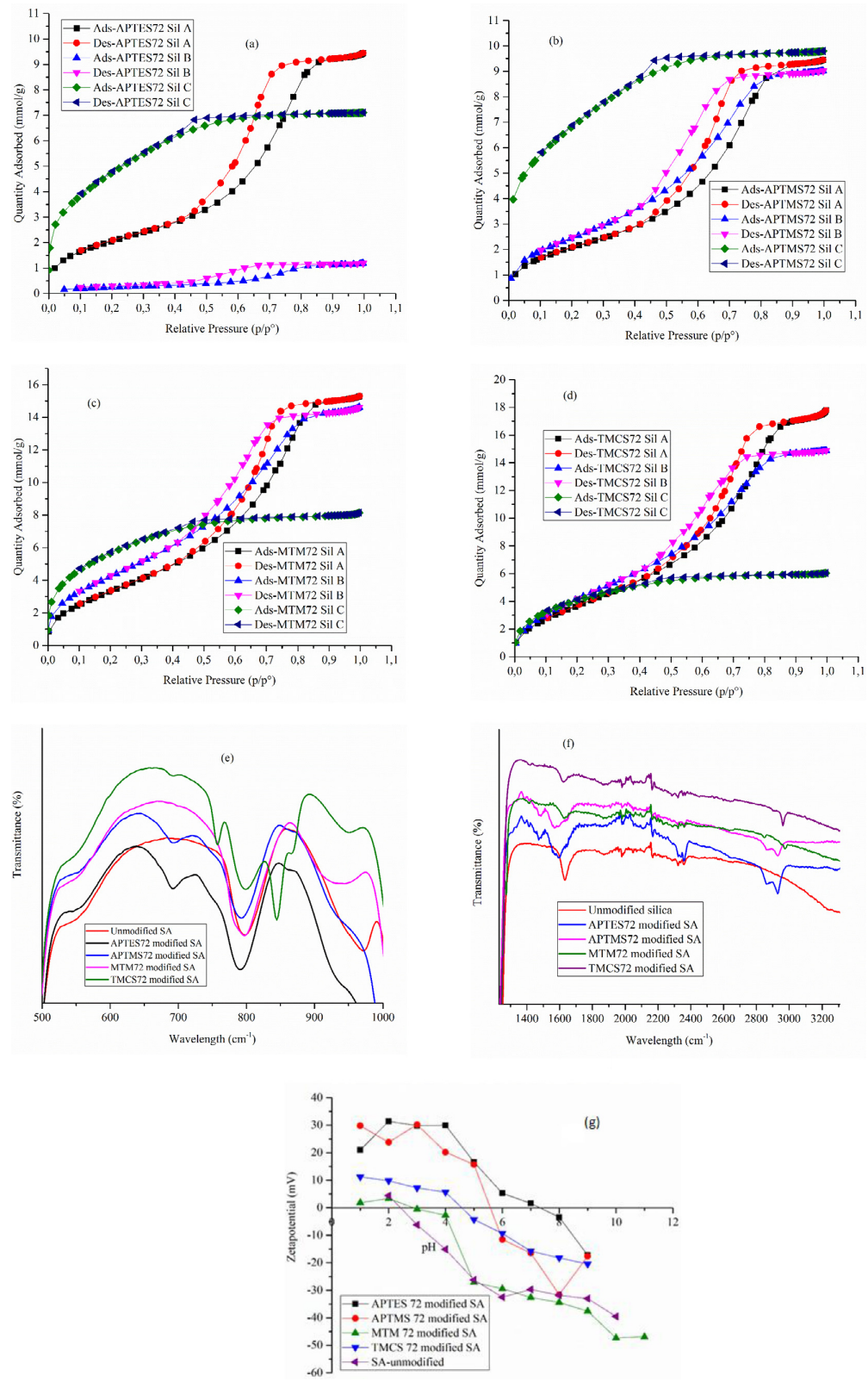

Fig. 1. BET isotherm curves for (a) APTES modified gels (b) APTMS modified gels (c) MTM modified gels (d) TMCS modified gels (e) FTIR spectra of silica gel A before and after

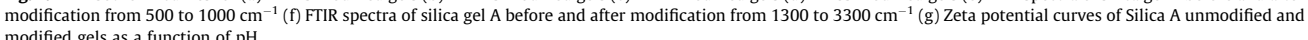


groups of the aforementioned silica gels are hinged and this is the argumentation behind the band observed at $1510 \mathrm{~cm}^{-1}$ with no peaks at 1575 and $1485 \mathrm{~cm}^{-1}$. The spectral plots of Sil B and C possess the same composition of bands in the plots with appreciable shifts in intensities.

The SEM results from the study of surface morphology of unmodified and modified silica gel are presented in Fig. S2 (Supplementary Material). The particle size of silica gels A and B lie within the range of 9.7-49 $\mu \mathrm{m}$ and $67-121 \mu \mathrm{m}$, respectively. The measurements are in sound agreement with the data from the manufacturer. On close observation of particle size changes after silane modification, Sil A had its lowest particle size within 4-5 $\mu \mathrm{m}$ and the highest lying within $30-38 \mu \mathrm{m}$, which represents a reduction in particle size. A similar behavior has observed in Sil B and C as well. Despite undergoing reduction in particle size, the percent of reduction is not significant in the modified silica gels.

The assessment of the zeta potentials of both modified and unmodified silica gels was conducted through multiple measurements, with the aim of addressing its $\mathrm{pH}$ dependency. Fig. $1(\mathrm{~g})$ depicts the overall mean zeta potential of modified silica gels $\mathrm{A}$, which seems to be the better adsorbent from the lot in this study. The zeta potential curves for other silica gels $B$ and $C$ along with $A$ as a function of $\mathrm{pH}$ for unmodified and modified adsorbents are provided in Supplementary Material (Fig. S3 (a-d)). Isoelectric pH values of unmodified Sil A and B were observed to be within 2-3, as supported by literature, but for the case of Sil C it has been observed to be around 5 . Also, the mean zeta potentials of samples $\mathrm{A}$ and $\mathrm{B}$ demonstrated a linear trend until a $\mathrm{pH}$ of 5 and they tend to remain a constant further beyond. Irrespective of the treatment times, the APTES modified silica samples A, B and C recorded IEP values of 7, 5.5 and 6.5, respectively. The IEP values for the APTMS gel remained a constant for all the sample of silica within the range of 4.5-6. This change in the IEP for the modified samples can be associated to the presence of surface amino groups. This argument can be further supported by the IEP values of MTM and TMCS modified samples (2-3) where the amine groups are absent and by the shift observed towards alkaline pH in case of APTES/ APTMS gels after amine functionalization, as seen in Chitosan, a similar amino based polymer.

\subsection{Selective removal of REEs in artificial water conditions}

3.2.1. Influence of particle size and effect of $p H$

The effect of $\mathrm{pH}$ on the adsorption of different REEs were studied and the results are presented in the forthcoming plots. There is sufficient evidence in literature to emphasis the fact that the $\mathrm{pH}$ level of the solution influences the surface charge of the adsorbent and the ionization degree of the adsorbate. This has served as a motivation to perform the adsorption studies as a part of this research work. The range of $\mathrm{pH}$ used for the analysis lies between 2 and 8 and all the subsequent plots would consider this range as the focal point. The removal\% for the elements at maximum pH of 8 for the unmodified silica gels are $30 \%, 99 \%, 45 \%, 70 \%$ and $45 \%$ fo $\mathrm{La}^{3+}, \mathrm{Sc}^{3+}, \mathrm{Er}^{3+}, \mathrm{Eu}^{3+}$ and $\mathrm{Y}^{3+}$ respectively. The maximum adsorption was observed for a $\mathrm{pH}$ value of 8 for all the cases under consideration except $\mathrm{Sc}^{3+}$, for which such a state is obtained even at lower $\mathrm{pH}$ value of 6 . For the three types of silica gels analyzed, adsorption pattern was the same for all the constituents except for the fact that Sil A shows slightly better adsorption.

The influence of $\mathrm{pH}$ on the sorption capacity of all the modified silica gels is analyzed for two different reaction times, 24 and $72 \mathrm{~h}$ and the adsorbents silanated for $72 \mathrm{~h}$ returned better results overall. This reaction time dependency was observed only for the case of Sil $\mathrm{C}$ and not for the other two silica gels under consideration. They do not exhibit major changes in the adsorption behavior.
APTES and APTMS modified silica gel - The APTES modified silica gel is expected to yield better adsorption than the case of unmodified silica gel and this can be affirmed from the unanimous increase in the adsorption efficiencies than the unmodified case for all the elements under examination where a sharp increase in adsorption is observed even at a lower $\mathrm{pH}$ range of 3-4 (Supplementary Material: Fig. S4). In addition, it is interesting to take note that though there is an increase in the adsorption process for the modified gels, Sil C has the least efficiency among the three gels. Sil C adsorption encounters a slight drop around $\mathrm{pH} 4-5 \mathrm{for}^{\mathrm{La}^{3+}}$, $\mathrm{Eu}^{3+}$ and $\mathrm{Y}^{3+}$. It is at this $\mathrm{pH}$ that the APTES modified Sil $\mathrm{C}$ recorded the highest positive potential of $30 \mathrm{mV}$, before descending down to the negative potential with increase in $\mathrm{pH}$. This behavior demonstrates that the adsorption process is primarily due to the electrostatic attraction between the negatively charged adsorbents and trivalent cations. The adsorption of REEs does not attain its maximum capacity below a pH value of 4 for all the cases and hence $\mathrm{pH} 4$ can be interpreted as the optimum value for maximum adsorption in APTES modified silica gel. In general, it can also be stated based on the observation that comparatively better adsorption efficiency has been exhibited by Sil $\mathrm{C}$ in the regime below the optimal pH. However Sil A and B demonstrate better adsorption at higher $\mathrm{pHs}$ with the adsorbents which underwent silanization for $72 \mathrm{~h}$. The variation in the APTMS silica gel adsorption potential with $\mathrm{pH}$, exhibit a relatively similar pattern to APTES for all the REEs except $\mathrm{La}^{3+}$

MTM modified silica gel - MTM modified silica gel is subjected to a similar experimental study as for the aforesaid cases. At $\mathrm{pH} 8$, the percent removal is around 40-50 for $\mathrm{La}^{3+}, \mathrm{Er}^{3+}$ and $\mathrm{Y}^{3+}, 70-80$ for $\mathrm{Eu}^{3+}$ and around $100 \%$ for $\mathrm{Sc}^{3+}$, which does not have much resemblance to the behavior observed for the earlier silica gels under study. The vast difference noticed in adsorption efficiency between pH 7 and 8 in some cases might also be due to the precipitation of REEs. If taken this into account, MTM modified gels could achieve maximum potential of nearly $100 \%$ only for $\mathrm{Sc}^{3+}$ where as for other elements, just $40 \%$ is attained. The increase in the reaction time from 24 to $72 \mathrm{~h}$ tends to increase the removal efficiency of $\mathrm{Y}^{3+}$ from 10 to $35 \%$. The response of $\mathrm{La}^{3+}$ to silanization time does not show any distinct changes despite the fact that the increase in synthesis time displays notable difference in adsorption efficiency of other REEs. The efficiency vs pH plots supporting the arguments other REEs. The efficiency vs pH plots supporting the argu
above are provided in Fig. S5 (Supplementary Information).

TMCS modified silica gel - The response of all the REEs can be outlined as an overall increase in the adsorption capacity than the case of unmodified silica gel (Supplementary Information: Fig. S6). The slopes of the silica gel plots for $\mathrm{Er}^{3+}, \mathrm{Eu}^{3+}$ and $\mathrm{Y}^{3+}$ adsorption are almost identical and the overall potential achieved at higher $\mathrm{pHs}$ is distinctly better than the unmodified scenario for all the $\mathrm{pHs}$ is distinctly better than the unmodified scenario for all the
adsorbents studied. The difference in the adsorption levels of $\mathrm{Y}^{3+}$ adsorbents studied. The difference in the adsorption levels of $\mathrm{Y}^{3+}$ are almost thrice that of the unmodified gels even at $\mathrm{pH}<7$, which is the maximum shift observed among all the REEs in the considmum adsorption in all the cases at higher pHs.

Overall comparison - Fig. 2(a-e) illustrates the overall adsorption levels of modified/unmodified silica gels A, for different REEs involved. From the overall comparative depiction, it can be seen that APTES and APTMS modified silica gels yield the best possible adsorption for any given REE, with the maximum admissible value attained between $\mathrm{pH} 4-5$. The MTM showed adsorption efficiency of around $38 \%, 99 \%, 80 \%, 60 \%$ and $40 \%$ for $\mathrm{La}^{3+}, \mathrm{Sc}^{3+}, \mathrm{Er}^{3+}, \mathrm{Eu}^{3+}$ and $\mathrm{Y}^{3+}$ respectively at the maximum $\mathrm{pH}$ of 8 fixed for the analysis. The MTM and TMCS modified silica gels demonstrate similar behavior for the REEs. However, TMCS recorded comparatively slightly better efficiency than MTM at pH 8 despite the supremacy of MTM over TMCS at $\mathrm{pHs}<7$. The significance of the adsorption pattern for specific $\mathrm{pH}$ values, i.e. $\mathrm{pH} 5$ and 8 , have been highlighted in 

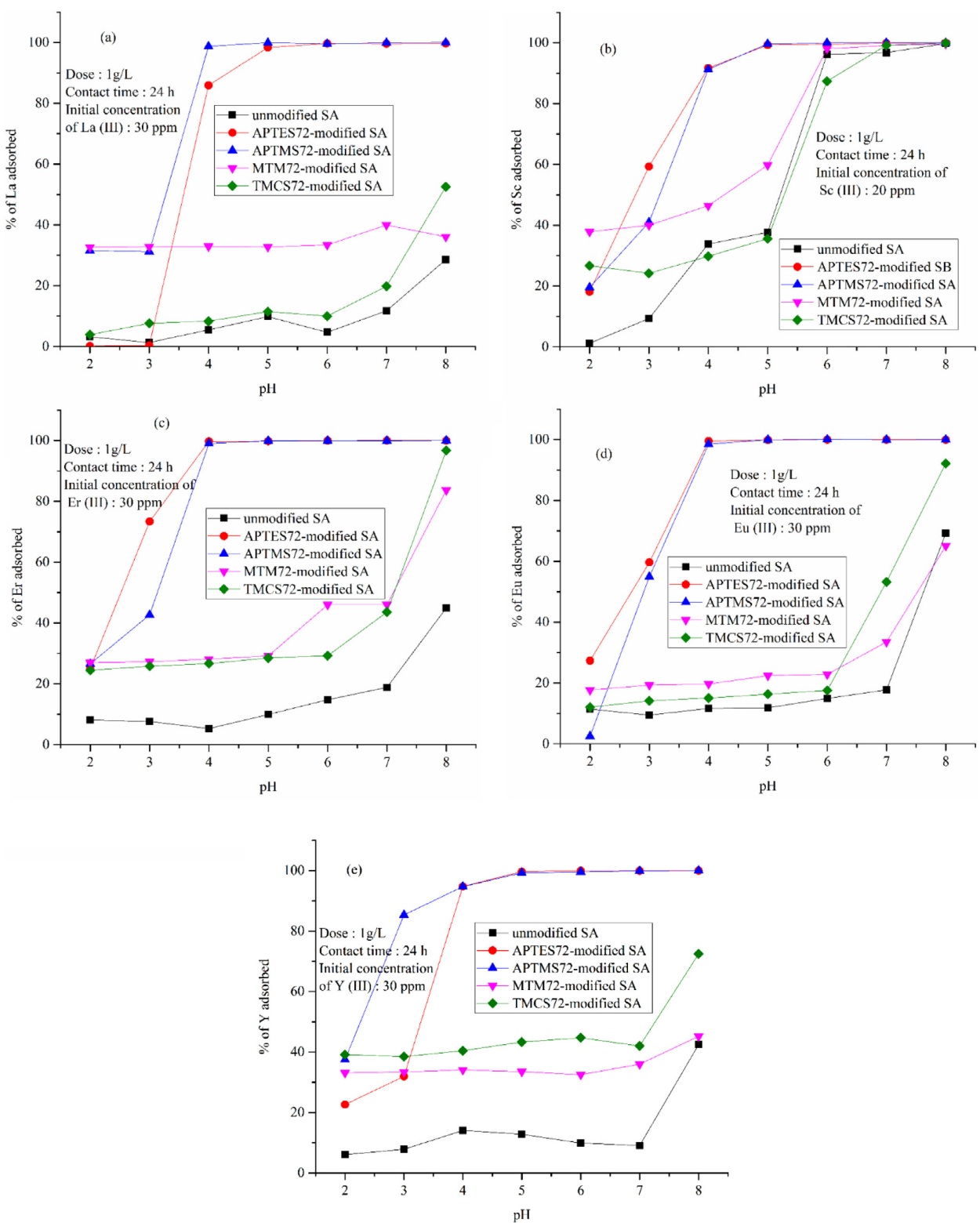

Fig. 2. Overall comparison of the adsorption efficiencies of various functionalized silica gels A for (a) La (b) Sc (c) $\operatorname{Er}$ (d) Eu and (e) Y

Fig. 3(a-b). The plots are a measure of adsorption efficiency versus different adsorbents involved in the analysis. As elaborated in the discussions earlier, the maximum efficiency of around $100 \%$ is achieved only for the APTES/APTMS modified gels at $\mathrm{pH} 5$.

3.2.2. Effect of calcination

The synopsis of the calcination experiments on all the silica adsorbents are sketched in the Fig. S6 (Supplementary Material). The adsorption percentage is conceived as a function of calcination 

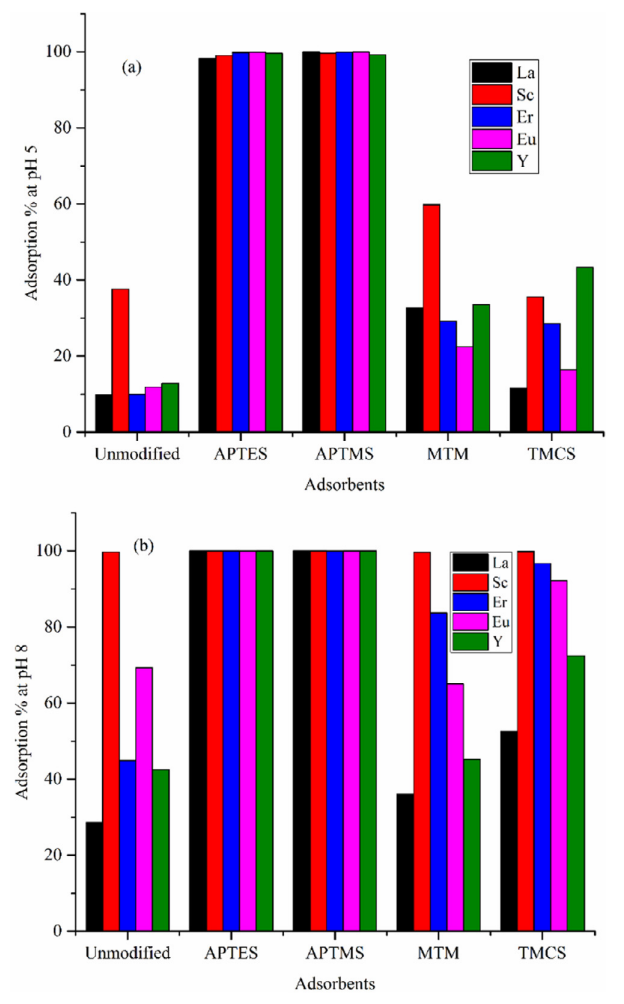

Fig. 3. Maximum adsorption efficiency at (a) $\mathrm{pH} 5$ (b) at $\mathrm{pH} 8$ for differen adsorbents for the selective removal of target REEs.

temperature for different silica gels, both calcined and uncalcined samples at $\mathrm{pH}$ 8. The samples prior to calcination return the bes results and the influence of calcination is always adverse for all the silica gels. The APTES/APTMS modified samples exhibit very large negative changes in the adsorption levels except for $\mathrm{Sc}^{3}$ where the differences are very much negligible in comparison to the uncalcined correspondent. On the contrary, the calcined MTM modified and calcined silica gels adsorb effectively the same amount of $\mathrm{La}^{3+}, \mathrm{Y}^{3+}$ and $\mathrm{Eu}^{3+}$ in relation to the uncalcined samples whereas the adsorption of $\mathrm{Er}^{3+}$ tends to increase by a small margin with calcination. Sil $\mathrm{C}$ displays a reduction in $\mathrm{Sc}^{3+}$ adsorption while the other two silica gels, A and B, do not show any interesting differences between the calcined and uncalcined samples. For the TMCS modified adsorbents, regardless of the silica gel used (A, B or $\mathrm{C}$ ), the efficiency is lesser than the uncalcined counterparts for $\mathrm{La}^{3+}, \mathrm{Er}^{3+}$ and $\mathrm{Y}^{3+}$ adsorption. In the case of $\mathrm{Eu}^{3+}$, Sil B and $\mathrm{C}$ do not establish any significant changes in the adsorption capacities while Sil A undergoes a drop in the potential. As observed in other cases, removal efficiency for $\mathrm{Sc}^{3+}$ does not change with calcination. Comparatively, the results of calcination study from the MTM and TMCS modified silica (for all REE) exhibited closer resemblance to the unmodified silica gel at the aforementioned $\mathrm{pH}$. The indication of the reduced adsorption capacities at $\mathrm{pH} 8$ shows that the precipitation is not the significant reason behind the higher removal of elements, recorded at $\mathrm{pH} 8$ in previous cases mentioned in Section 3.2.1.

From an overall perspective, APTES/APTMS modified samples demonstrated drastic reduction in adsorption efficiency for calcined samples. The same reduction behavior is also observed in the case of mesoporous silica sheets in lithium and copper ion removal, according to Nakanishi and his co-workers [24]. It is removal, according to Nakanishi and his co-workers [24]. It is
expected that the most of the amino groups are lost in the calcination process which is confirmed from the elemental analysis results shown in Table S1 (Supplementary Material). According to the observed values, there is small percent of nitrogen still present in amino functionalized gels post calcination at $400^{\circ} \mathrm{C}$ where as there is 100 trace of nitrogen when calcined at higher temperadecrease in carbon and hydrogen percent is also noticed in all calcined samples. For MTM/TMCS modified samples there were not much differences in the efficiency in most cases. However, the process of calcination in the latter case tends to affect Sil B and $\mathrm{C}$ more which can be related to the reduction of $\mathrm{C}$ and $\mathrm{H}$ content in Sil B and C than in Sil A.

Analysis of the IR spectra (Supplementary Material: Fig. S7) yields an important information about the disappearance of the band at $1600 \mathrm{~cm}^{-1}$ analogous to the adsorption of water during the process of calcination. Though these bands are observed with a weaker intensity for calcination at $400{ }^{\circ} \mathrm{C}$, they are completely absent for the $600^{\circ} \mathrm{C}$ and $800^{\circ} \mathrm{C}$ samples. Further, the bands around $700 \mathrm{~cm}^{-1}$ (asymmetric mode of $\mathrm{Si}-\mathrm{CH}_{3}$ ) and $1500 \mathrm{~cm}^{-1}$ (symmetric $\mathrm{NH}_{2}$ groups) from calcined sample plots, except for the case of MTM modified ones, are also removed due to the loss the case of MTM modified ones, are also removed due to the loss
of amino and carbon groups probably in the form of methane as a consequence of heating silated silica [25]. Similar behavior has also been detected from FTIR spectra for modified gels, both before and after REE adsorption which indicates the adsorption taking place at these groups.

3.3. Intra-series adsorption behavior of REEs in real and test waste water

3.3.1. Temperature dependence REE adsorption

The REE removal trend for the four modified adsorbents at room temperature (for $1 \mathrm{~h}$ ) and at $45^{\circ} \mathrm{C}$ (for $30 \mathrm{~min}$ ) with an initial $\mathrm{pH}$ of 7 and initial concentration of around 12 ppm for each REE is given in the Table 2. APTES and APTMS modified gels, for all the elements i.e. both LREEs and HREEs, demonstrated great efficiency with removal\% being comparatively the lowest for Scandium. However, in the case of MTM and TMCS adsorbents, $\mathrm{Sc}^{3+}$ showed highest removal of nearly $100 \%$ in comparison to other REEs whereas LREEs $\left(\mathrm{La}^{3+} \mathrm{Ce}^{3+}, \mathrm{Pr}^{3+}, \mathrm{Gd}^{3+}, \mathrm{Tb}^{3+}\right.$ and $\mathrm{Eu}^{3+}$ ) and HREEs $\left(\mathrm{Dy}^{3+}, \mathrm{Ho}^{3+}, \mathrm{Er}^{3+}\right.$ ( and $65-85 \%$, respectively. Yttrium among the HREEs demonstrated the poorest efficiency of around $40 \%$. As expected, the increase in temperature depicted a slight decrease in performance of APTES and APTMS modified gels, where a greater impact was observed for APTMS removal efficiency with a decrease of $\sim 5 \%$. On the other hand, MTM and TMCS demonstrated positive temperature dependence with the increase in atomic number especially from $\mathrm{Tb}$ to $\mathrm{Lu}$ in the periodic table (from atomic number 65 to 71) which are HREEs mostly including Y. In case of LREEs $\left(\mathrm{La}^{3+}, \mathrm{Ce}^{3+}, \mathrm{Pr}^{3+}\right.$, $\mathrm{Eu}^{3+}, \mathrm{Gd}^{3+}$ and $\left.\mathrm{Tb}^{3+}\right)$, they displayed slight drop in efficiency, indicating negative temperature dependence (from atomic number 57 to 64). Between these two adsorbents, TMCS showed comparatively better results than MTM.

3.3.2. Interference of competing ions and effect of $\mathrm{pH}$ in REE adsorption

The removal efficiency of the modified adsorbents (APTES, APTMS, MTM and TMCS) in real spiked and artificial waste water were further determined in the presence of various competing ions 
Table 2

The trend depicting the REE removal from both synthetic and real waste water in the presence and absence of competing ions at pH 5 and 7 .

\begin{tabular}{|c|c|c|c|}
\hline \multirow{2}{*}{\multicolumn{2}{|c|}{$\begin{array}{l}\text { Parameter } \\
\text { Based on Ionic radius of } \mathrm{Ln}^{3+} \text { ions }\end{array}$}} & \multirow{2}{*}{$\begin{array}{l}\text { Trend } \\
\mathrm{La}>\mathrm{Ce}>\mathrm{Pr}>\mathrm{Nd}>\mathrm{Pm}>\mathrm{Sm}>\mathrm{Eu}>\mathrm{Gd}>\mathrm{Tb}>\mathrm{Dy}>\mathrm{Ho}>\mathrm{Er}>\mathrm{Tm}>\mathrm{Yb}>\mathrm{Lu}\end{array}$} & \multirow[t]{2}{*}{ Affinity } \\
\hline & & & \\
\hline \multirow{5}{*}{$\begin{array}{l}\text { Adsorption at } p H 7 \text { (low metal loading) } \\
\text { Synthetic water in the absence of competing ions }\end{array}$} & & & \\
\hline & $\begin{array}{l}\text { MTM at } \\
23^{\circ} \mathrm{C}\end{array}$ & $\mathrm{Sc}>\mathrm{Lu}>\mathrm{Yb}>\mathrm{Tm}>\mathrm{Eu}>\mathrm{Ey}>\mathrm{Tb}>\mathrm{Er}>\mathrm{Ho}>\mathrm{Gd}>\mathrm{Pr}>\mathrm{Ce}>\mathrm{Y}>\mathrm{La}$ & HREEs $>$ LREES \\
\hline & $\begin{array}{l}\text { MTM at } \\
45^{\circ} \mathrm{C}\end{array}$ & $\mathrm{Sc}>\mathrm{Lu}>\mathrm{Yb}>\mathrm{Tm}>\mathrm{Er}>\mathrm{Dy}>\mathrm{Eu}>\mathrm{Tb}>\mathrm{Ho}>\mathrm{Gd}>\mathrm{Pr}>\mathrm{Y}>\mathrm{Ce}>\mathrm{La}$ & HREES $>$ LREES \\
\hline & $\begin{array}{l}\text { TMCS at } \\
23^{\circ} \mathrm{C}\end{array}$ & $\mathrm{Sc}>\mathrm{Lu}>\mathrm{Yb}>\mathrm{Tm}>\mathrm{Eu}>\mathrm{Dy}>\mathrm{Tb}>\mathrm{Er}>\mathrm{Ho}>\mathrm{Gd}>\mathrm{Pr}>\mathrm{Ce}>\mathrm{Y}>\mathrm{La}$ & HREES $>$ LREES \\
\hline & $\begin{array}{l}\text { TMCS at } \\
45^{\circ} \mathrm{C}\end{array}$ & $\mathrm{Sc}>\mathrm{Lu}>\mathrm{Yb}>\mathrm{Tm}>\mathrm{Er}>\mathrm{Dy}>\mathrm{Eu}>\mathrm{Tb}>\mathrm{Ho}>\mathrm{Gd}>\mathrm{Pr}>\mathrm{Ce}>\mathrm{Y}>\mathrm{La}$ & HREEs > LREEs \\
\hline \multirow[t]{2}{*}{$\begin{array}{l}\text { Real waste water in the presence of competing } \\
\text { ions }\end{array}$} & $\begin{array}{l}\text { MTM at } \\
23^{\circ} \mathrm{C}\end{array}$ & $\mathrm{Sc}>\mathrm{Yb}>\mathrm{Lu}>\mathrm{Tm}>\mathrm{Eu}>\mathrm{Dy}>\mathrm{Tb}>\mathrm{Ho}>\mathrm{Pr}>\mathrm{Gd} \geq \mathrm{Er}>\mathrm{Y}>\mathrm{Ce}>\mathrm{La}$ & HREES $>$ LREEs \\
\hline & $\begin{array}{l}\text { TMCS at } \\
23^{\circ} \mathrm{C}\end{array}$ & $\mathrm{Sc}>\mathrm{Lu} \geq \mathrm{Yb}>\mathrm{Tm}>\mathrm{Er}>\mathrm{Dy}>\mathrm{Ho}>\mathrm{Tb}>\mathrm{Eu}>\mathrm{Gd}>\mathrm{Pr} \geq \mathrm{Y}>\mathrm{Ce}>\mathrm{La}$ & HREES > LREES \\
\hline \multirow{3}{*}{$\begin{array}{l}\text { Adsorption at } \mathrm{pH} 5 \text { (high metal loading) } \\
\text { Synthetic water ( } \mathrm{pH} 5 \text { ) in the presence of } \\
\text { competing ions }\end{array}$} & & & \\
\hline & $\begin{array}{l}\text { MTM at } \\
23^{\circ} \mathrm{C}\end{array}$ & $\mathrm{Ce}>\mathrm{Y} \geq \mathrm{Lu}>\mathrm{Pr}>\mathrm{Yb}>\mathrm{Eu}>\mathrm{Tm} \geq \mathrm{Tb}>\mathrm{Dy}>\mathrm{Gd} \geq \mathrm{Ho} \geq \mathrm{La}>>\mathrm{Er}>\mathrm{Sc}$ & $\begin{array}{l}\text { Zig zag } \\
\text { patternLREEs }>\text { HREEs }\end{array}$ \\
\hline & $\begin{array}{l}\text { TMCS at } \\
23^{\circ} \mathrm{C}\end{array}$ & $\mathrm{Ce}>\mathrm{Y} \geq \mathrm{Lu}>\mathrm{Pr}>\mathrm{Yb}>\mathrm{Eu}>\mathrm{Tm}>\mathrm{Tb}>\mathrm{Dy}>\mathrm{Gd} \geq \mathrm{Ho}>\mathrm{La}>\mathrm{Er}>\mathrm{Sc}$ & $\begin{array}{l}\text { Zig zag pattern } \\
\text { LREEs > HREEs }\end{array}$ \\
\hline \multirow[t]{2}{*}{$\begin{array}{l}\text { Real waste water in the presence of competing } \\
\text { ions }\end{array}$} & $\begin{array}{l}\text { MTM at } \\
23^{\circ} \mathrm{C}\end{array}$ & $\mathrm{Yb}>\mathrm{La}>\mathrm{Pr} \geq \mathrm{Sc} \geq \mathrm{Tb}>\mathrm{Dy}>\mathrm{Y}>\mathrm{Eu}>\mathrm{Ce}>\mathrm{Ho} \geq \mathrm{Lu} \geq \mathrm{Tm}>\mathrm{Er}>\mathrm{Gd}$ & $\begin{array}{l}\text { Zig zag pattern } \\
\text { LREEs }>\text { HREEs }\end{array}$ \\
\hline & $\begin{array}{l}\text { TMCS at } \\
23^{\circ} \mathrm{C}\end{array}$ & $\mathrm{Ce}>\mathrm{Sc}>\mathrm{La}>\mathrm{Gd}>\mathrm{Er}>\mathrm{Ho} \geq \mathrm{Tb} \geq \mathrm{Tm} \geq \mathrm{Y} \geq \mathrm{Eu}>\mathrm{Pr}>\mathrm{Dy}>\mathrm{Yb}>\mathrm{Lu}$ & $\begin{array}{l}\text { Zig zag pattern } \\
\text { LREEs }>\text { HREEs }\end{array}$ \\
\hline
\end{tabular}

and are subjected to discussion under this section. The composition and concentration of the metal ions in all the solutions are given in Table S2 (Supplementary Material). The $\mathrm{pH}$ of waste water was adjusted to both 5 and 7 for carrying out the adsorption tests with all modified adsorbents. Also, the optimum pH for APTES APTMS and MTM/ TMCS, from earlier tests, were observed to be 5 and 7, respectively. In the case of APTES and APTMS adsorption, the removal efficiency of almost $99 \%$ was obtained in both natura and artificial conditions for tests involving the majority of the ions with $\mathrm{Er}^{3+}$ (all cases) and $\mathrm{Sc}^{3+}$ (for synthetic water at $\mathrm{pH} 5$ ) being an exception.

From the Fig. 4, it can be seen that greater removal efficiency was achieved in artificial waste water in comparison to real wate for MTM and TMCS absorbents. The adsorption at $\mathrm{pH} 7$ was found to be superior with these adsorbents in both the real/synthetic waste water and the adsorption efficiency of above $90 \%$ was obtained in both the cases. The observed behavior is consistent with the previous selective removal results from Section 1 as well. with the previous selective removal results from Section 1 as well.
However, in the case of artificial test water with an initial $\mathrm{pH}$ of 5 , However, in the case of artificial test water with an initial $\mathrm{pH}$ of 5 ,
nearly $50 \%$ removal could be attained for both the adsorbents but a removal of just $10 \%$ was recorded with the real waste water. It is expected that when the $\mathrm{pH}$ decreases, the competition among the ions increases due to the limited number of available sorption sites compared to the scenario at higher $\mathrm{pHs}$, thereby comparasites compared to the scenario at higher $\mathrm{pHs}$, thereby compara-
tively lower adsorption efficiencies at $\mathrm{pH}$ 5. Also the poor efficiency tively lower adsorption efficiencies at $\mathrm{pH}$ 5. Also the poor efficiency
observed in case of real waste water could be due to the fact that observed in case of real waste water could be due to the fact that
the maximum initial concentration of REEs in the real waste water was around $4-5 \mathrm{ppm}$ for each REE where as in synthetic waste water it was around 1-2 ppm, hence enabling higher sorption capacity (Supplementary Material: Table S2). However furthe characterization of waste water and experiments tailoring parameters such as concentration, organic content, $\mathrm{pH}$ etc. could shed more light into this behavior.

For artificial waste water at $\mathrm{pH} 5$, the maximum and minimum adsorption values for both TMCS and MTM adsorbents were reported for $\mathrm{Ce}^{3+}$ (followed by $\mathrm{Y}^{3+}$ ) and $\mathrm{Sc}^{3+}$ (followed by $\mathrm{Er}^{3+}$ ) respectively. But for real water based experiments, at $\mathrm{pH} 5$, maximum adsorption efficiency was seen for $\mathrm{Sc}^{3+}$ and $\mathrm{La}^{3+}$ in the case of MTM adsorbents and for $\mathrm{Ce}^{3+}$ and $\mathrm{La}^{3+}$ in the case of TMCS adsorbents whereas $\mathrm{Ce}^{3+}, \mathrm{Gd}^{3+}$ and $\mathrm{Er}^{3+}$ demonstrated poor efficiency with MTM while $\mathrm{Eu}^{3+}, \mathrm{Dy}^{3+}$ and $\mathrm{Yb}^{3+}$ were for TMCS. In case of
$\mathrm{pH} 7$, the trend seems to be similar for both the adsorbents with $\mathrm{Sc}^{3+}, \mathrm{Yb}^{3+}, \mathrm{Lu}^{3+}$ and $\mathrm{Tm}^{3+}$ depicting maximum removal while $\mathrm{Y}^{3+}$, $\mathrm{Ce}^{3+}$ and $\mathrm{La}^{3+}$ have the least adsorption. $\mathrm{Ce}^{3+}$ removal seemed efficient only in case of $\mathrm{pH}<5$ and returned poor removal at higher pHs similar to the results observed in [26]. A change in the pH value of the experiments involving real water from 5 to 7 resulted in significant difference in the hierarchy of adsorption efficiency which can be seen in Table 2. In artificial waste water, $\mathrm{Eu}^{3+}$ showed better results than $\mathrm{Er}^{3+}$ for both the adsorbents at $\mathrm{pH}^{5}$ and 7 . It should be noted that the efficiency was nearly $99 \%$ for all the REEs at the $\mathrm{pH}$ value of 5 (for synthetic) and 7 (both synthetic and real)

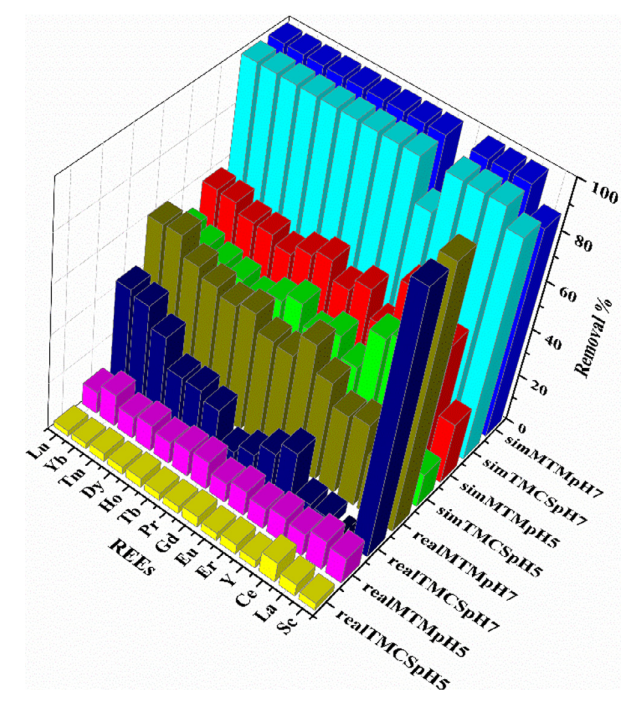

Fig. 4. REE separation behavior in the presence of competing ions in both synthetic (sim) and real waste water conditions at $\mathrm{pH} 5$ and 7 . 
in the case of all the adsorbents. In the presence of other metal ions, MTM performed better than TMCS with respect to REEs whereas it is quite opposite in the case of absence of competing ions.

At $\mathrm{pH} 5$, the distribution of patterns are in zig zag pattern mostly which may be due to the REE tetrad effect observed in some studies at lower pHs [27,28]. Also the affinity for LREEs at lower studies at lower pHs $[27,28]$. Also the affinity for LREEs at lower
$\mathrm{pHs}\left(\mathrm{D}^{\mathrm{LREE}}>\mathrm{D}^{\mathrm{HREE}}\right)$ in real water has been stated by Liu et al. [29]. In general, LREE removal seemed to be favored over HREE at $\mathrm{pH} 5$ [29] and vice versa at $\mathrm{pH} 7$ [30,31]. The observed results in the variation of REE removal may also be a consequence of the metal loading effect [32], an argument which cannot be easily supported via relations as it is also influenced by other parameters such as the pH dependency for the same and varied chemical comsuch as the pH dependency for the same and varied chemical com-
position of the natural water samples. Nonetheless, the distribution discussed in the previous sections are in correspondence with the expected patterns for metal loading effects in natura waste water [32]. Some evidence from literature [33-35], in support of lanthanide contraction effect and fractionation of REE patterns at $\mathrm{pH} 5$ insists that the heterogeneity in adsorbent binding sites have a consequence on the complexation of REE, thus leading to HREE-enriched REE patterns at low metal loading and domination of abundant weaker sites at high metal loading. The observed REE patterns in the latter case possess MREE downward concavity according to some works in literature. The binding site density and surface functional group heterogeneity thus play a dominant role in the determination of observed distribution patterns in REE removal. This trend shown in the table has been demonstrated despite the concentration of Sulphur/Potassium being $45 / 120 \mathrm{ppm}$ and $8 / 15 \mathrm{ppm}$ for artificial and real waste water, respectively. Hence, it can also be inferred that the adsorption process in our study proved to be quite efficient even in the presence of sulphate media without the interference of $\mathrm{K}^{+}, \mathrm{Mg}^{2+}, \mathrm{Na}^{+}$and $\mathrm{Ca}^{2+}$, simpharly reported in [36-38]. The APTES and APTMS samples of both and waste water experiments show negligible removal of $\mathrm{K}^{+}, \mathrm{S}^{6-}$ and $\mathrm{Mg}^{2+}$ ions. In case of real waste water, as anticipated, APTES and APTMS showed supreme removal efficiency of metal ions. This might be due to the occurrence of ions in lower concentrations which in turn facilitate the capture of additional ions onto the adsorbent.

The amount of silica leached (in ppm) are illustrated in Fig. 5. From a perspective of solution $\mathrm{pH}$, silica leaching is greater for higher $\mathrm{pH}$ irrespective of the adsorbents. TMCS and MTM adsorbents demonstrate the maximum and minimum leaching among the four, while APTES adsorbents display slightly better efficiency than the APTMS adsorbents.

\subsection{Mechanism}

The process of metal ion adsorption in APTES/APTMS modified gel occurs by adsorption via amino groups $\left(-\mathrm{NH}_{2}\right)$ or by ion exchange through hydroxyl groups on the silica surface. This statement is supported by the results from FTIR, CHN elemental analysis and zeta potential measurements. The ion exchange reaction manifests through Si-O-M-O-Si bridging species which facilitates the reaction between $\mathrm{M}^{3+}$ and surface hydroxyl groups [39]. Both the process can occur simultaneously implying the fact that neither of the procedure is exclusive under the same given conditions. The interaction between the trivalent REE cations and the positively charged adsorbents are mainly due to the electrostatic repulsion or adsorption of metal ions onto the positively charged amino groups. There is also a minimal contribution of ion exchange through hydroxyl groups till $\mathrm{pH} 7$, beyond which, there is a very strong electrostatic attraction between them as adsorbents have a negative potential. This is very much evident from the result of calcined samples which demonstrated very poor adsorption efficiency until a pH value of 7 but could reach $100 \%$ adsorption only

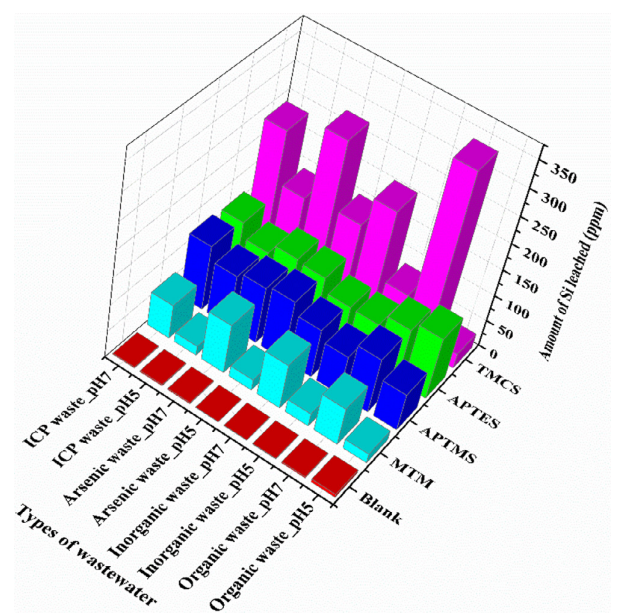

Fig. 5. Amount of Silicon leached from the adsorbents after REEs adsorption under various waste water conditions.

at $\mathrm{pH}$ 8. This is in contrast to the uncalcined adsorbents where the maximum removal percentage is attainable even from $\mathrm{pH} 4$. Due to the loss of amino groups and hydroxyl groups after thermal treatment, poor adsorption was recorded. In case of MTM and TMCS, the adsorption was highly successful only at pH 7 or above for both the below $-30 \mathrm{mV}$. It is apparent that the electrostatic attraction is strong enough for the interaction between ions and positively charged adsorbents only at $\mathrm{pH} 7$ or higher. Also poor adsorption is unquestionably a result of the absence of amino groups which are primarily responsible for the successful adsorption, as in APTES/ APTMS modified silica gels.

\subsection{Desorption studies}

The overall behavior of the different modified silica samples with respect to adsorption/desorption for the single element system can be summarized from the Table S3 (Supplementary Material). The desorption efficiency of the modified silica gels can be ordered as Sil A > Sil B > Sil C, in most of the cases with respect of REE removal. Also, the single component desorption behavior seems to be slightly superior to the corresponding multi component counterparts which is quite expected due to the competition among the ions for the active sites.

\section{Conclusion}

The comprehensive inference from the use of three different silica gels, Sil A, B and C, to assess the REE adsorption efficiency, is that Sil A exhibits the most favorable and competent characteristics in comparison to the rest. The efficiencies of the silica gels under study can be ordered as $\mathrm{A}>\mathrm{B}>\mathrm{C}$. The modifications performed on the silica gels using APTES, APTMS, MTM and TMCS help understand the impact of functionalization of silica gels with respect to REE recovery. The detailed observations from the results presented shows that the APTES/APTMS modified gels perform better than the other two gels in terms of adsorption efficiency in both test and real waste water conditions. The calcination and the adsorption with increase in temperature seemed to affect the efficiency of APTES/APTMS modified gels. There are no significant 
changes for the other two cases except some HREEs showed positive temperature dependence. The trend for REE separation by these adsorbents showed distinct changes with the initial solution $\mathrm{pH}$ and the metal loading effect. LREEs removal seemed to be favorable over HREEs at pH 5 and HREEs over LREEs at pH 7. The adsorbents also proved to be quite efficient in the presence of Sulphur, Potassium and many other competing ions.

\section{Acknowledgements}

The authors are thankful to the Academy of Finland (decision number 292542) for funding the project, all the staff members of Laboratory of Green Chemistry for their support during the work and Mr. Toni Väkiparta from LUT School of Engineering Science for the SEM analysis.

\section{Appendix A. Supplementary data}

Supplementary data associated with this article can be found, in the online version, at http://dx.doi.org/10.1016/j.cej.2017.03.152.

\section{References}

[1] D.L. Ramasamy, E. Repo, V. Srivastava, M. Sillanpää, Chemically immobilized and physically adsorbed PAN/acetylacetone modified mesoporous silica for the recovery of rare earth elements from the waste water-comparative an optimization study, Water
$10.1016 /$. watres.2017.02.045.

[2] M.R. Awual, N.H. Alharthi, Y. Okamoto, M.R. Karim, M.E. Halim, M.M. Hasan, M. M. Rahman, M.M. Islam, M.A. Khaleque, M.C. Sheikh, Ligand field effect for Dysprosium(III) and Lutetium(III) a a dor. novel composite nanomaterials, Chem. Eng. J. 320 (2017) 427-435, http://dx.

doi.org/10.1016/j.cej.2017.03.075.
3] S. Iftekhar, V. Srivastava, M. Sillanpä, Enrichment of lanthanides in aqueous system by cellulose based silica nanocomposite,
159, http://dx.doi.org/10.1016/j.cej.2017.03.051.

[4] E. Repo, T.A. Kurniawan, J.K. Warchol, M.E.T. Sillanpää, Removal of Co(II) and (II) ions from contaminated water using silica gel functionalized with EDTA and/or DTPA as chelating agents, J. Hazard. Mater. 171 (2009) 1071-1080, http://dx.doi.org/10.1016/j.jhazmat.2009.06.11

[5] C. Minguillón, P. Franco, L. Oliveros, P. López, Bonded cellulose-derived highperformance liquid chromatography chiral stationary phases I. Influence of th degree of fixation on selectivity. J. Chromat

[6] S. Sato, T. Murakata, T. Suzuki, T. Ohgawara, Control of pore size distribution of silica gel through sol-gel process using water soluble polymers as additives, Mater. Sci. 25 (1990) 4880-4885, http://dx.doi.org/10.1007/BF01129956.

[7] K.C. Vrancken, P. Van Der Voort, K. Possemiers, E.F. Vansant, Surface an Structural Properties of Silica Gel in the Modification with $\gamma$ Aminopropyltriethoxysilane, J. Colloid

[8] S.M. Olhero, J.M.F. Ferreira, Influence of particle size distribution on rheolog and particle packing of silica-based suspensions, Powder Technol. 139 (2004) 69-75, http://dx.doi.org/10.1016/j.powtec.2003.10.004.

[9] S. Poyet, A. Sellier, B. Capra, G. Foray, J.-M. Torrenti, H. Cognon, E. Bourdarot, Chemical modelling of Alkali Silica reaction: Influence of the reactive aggregate size distribution, Mater. Struct. 40 (2006), http://dx.doi.org/

10] P. Michard, E. Guibal, T. Vincent, P. Le Cloirec, Sorption and desorption of Mater. 5 (1996) 309-324, http://dx.doi.org /10.1016/0927-6513(95)00067-4.

11] R. Masuda, W. Takahashi, M. Ishii, Particle size distribution of spherical silica gel produced by sol-gel method, J. Non-Cryst. Solids 121 (1990) 389-393. http://dx.doi.org/10.1016/0022-3093(90)90163-C.

[12] A. Simon, T. Cohen-Bouhacina, M.C. Porté, J.P. Aimé, C. Baquey, Study of two grafting methods for obtaining a 3-aminopropyltriethoxysilane monolayer o $10.1006 /$ icis. 2002.8385

[13] S.V. Kalinin, L.I. Kheifets, A.I. Mamchik, A.G. Knot'ko, A.A. Vertigel, Influence of the drying technique on the structure of silica gels, J. Sol-Gel. Sci. Technol. 15 (1999) 31-35, http://dx.doi.org/10.1023/A:1008771829173.

[14] N. Zhang, C. Huang, B. Hu, ICP-AES determination of trace rare earth element in environmental and food samples by on-line separation an preconcentration with acetylacetone-modified silica gel using microc
Anal. Sci. 23 (2007) 997-1002, http://dx.doi.org/10.2116/analsci.23.997. [15] M.R. Awual, Novel nanocomposite materials for efficient and selective
mercury ions capturing from wastewater, Chem. Eng. J. 307 (2017) 456-465, http://dx.doi.org/10.1016/j.cej.2016.08.108.
[16] M.R. Awual, M.M. Hasan, A novel fine-tuning mesoporous adsorbent for simultaneous lead(II) detection and removal from wastewater, Sens. Actuator springer.com/10.1007/b102056, 2005 (accessed January 24, 2017).

[18] M.R. Awual, M.M. Hasan, M.A. Khaleque, M.C. Sheikh, Treatment of copper(II) containing wastewater by a newly developed ligand based facial conjugate materials, Chem. Eng. J. 288 (2016) 368-376, http://dx.doi.org/10.1016/. cej.2015.11.108.

M.R. Awual, New type mesoporous conjugate material for selective optical copper(II) ions monitoring \& removal from polluted waters,
(2017) 85-94, http://dx.doi.org/10.1016/j.cej.2016.07.110.

20] M.R. Awual, Solid phase sensitive palladium(II) ions detection and recovery using ligand based efficient conjugate nanomaterials, Chem. Eng. J. 300 (2016) 264-272, http://dx.doi.org/10.1016/j.cej.2016.04.071

21] M.R. Awual, Assessing of lead(III) capturing from contaminated wastewater using ligand doped conjugate adsorbent, Chem. Eng. J. 289 (2016) 65-73,

2] A. Beganskiene, V. Sirutkaitis, M. Kurtinaitiene, R. Juskenas, A. Kareiva, FTIR,

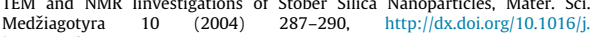
jnoncrysol.2012.11.006.

23] S.A. Kulkarni, S.B. Ogale, K.P. Vijayamohanan, Tuning the hydrophobic properties of silica particles by surface silanization using mixed selfassembled monolayers, J. Colloid Interface Sci. 318 (2008) 372-379, http://

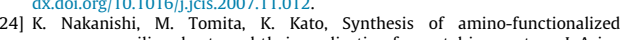
mesoporous silica sheets and their application for metal ion capture, J. Asian
Ceram. Soc. 3 (2015) 70-76, http://dx.doi.org/10.1016/i.jascer.2014.10.011.

25] S.V. Slavov, K.T. Chuang, A.R. Sanger, Modification of the surfaces of silica,
Suct. silica-alumina, and aluminum silicate with chlorotrimethylsilane, J. Phys. Chem. 100 (1996) 16285-16292, http:///x.doi.org/10.1021/jp961229x.

26] M.R. Awal, M.M. Hasan, A. Shahat, M. Naushad, H. Shwaku, T. Yaita, Investigation of ligand immobilized nano-composite adsorbent for efficien dx.doi.org/10.1016/j.cej.2014.12.052

[27] T. Monecke, U. Kempe, J. Monecke, M. Sala, D. Wolf, Tetrad effect in rare earth element distribution patterns: a method of quantification with application to rock and mineral samples from granite-related rare metal deposits, Geochim. Cosmochim. Acta 66 (2002) 1185-1196, http://dx.doi.org/10.1016/S0016-

28] T. Akagi, Rare earth element tetrad effect, (1998) 543-544. doi:10.1007/1-

29] C. Liu, Controls of interactions between iron hydroxide colloid and water on REE fractionations in surface waters: Experimental study on pH-controlling mechanism, Sci. China Ser. D 45 (2002) 449, http://dx.doi.org/10.1360/

02yd9047.
[30] Y. Gao, K.-H. Lee, M. Oshima, S. Motomizu, Adsorption behavior of metal ions cross-linked chitosan and the determination of oxoanions after http://dx.doi.org/10.2116/analsci.16.1303. phosphonate modified mesoporous TiO2 leading to improved rare-earth element extraction, Eur. J. Inorg. Chem. 2014 (2014) 2268-2277, http://dx. doi.org/10.1002/ejic.201400027.

[32] R. Marsac, M. Davranche, G. Gruau, A. Dia, Metal loading effect on rare earth element binding to humic acid: Experimental and modelling evidence, j.gca.2009.12.006

[33] J.E. Sonke, V.J.M. Salters, Lanthanide-humic substances complexation. I. Experimental evidence for a lanthanide contraction effect, Geochim. cosmochim. Acta 70 (2006) 1495-1506, http://dx.doi.org/10.1016/j. gca.2005.11.017.

I. J.C. J.E. Sonke, V.J.M. Salters, A capillary electrophoresis-ICP-MS study of rare earth element complexation by humic acids, Chem
180 , http://dx.doi.org/ $10.1016 / j$.chemgeo.2007.09.008.

35] O. Pourret, M. Davranche, G. Gruau, A. Dia, Rare earth elements complexation with humic acid, Chem. Geol. 243 (2007) 128-141, http://dx.doi.org/10.1016/j. chemgeo.2007.05.018.

[36] M.R. Awual, T. Kobayashi, H. Shiwaku, Y. Miyazaki, R. Motokawa, S. Suzuki, Y. Okamoto, T. Yaita, Evaluation of lanthanide sorption and their coordination mechanism by EXAFS measurement using novel hybrid adsorbent,

37] M.R. Awual T. Kobayashi Y. Miyazaki R. Motokawa. H. Shiwaku S. Suzuki, Y. Okamoto, T. Yaita, Selective lanthanide sorption and mechanism using novel hybrid Lewis base ( $\mathrm{N}$-methyl-N-phenyl-1,10-phenanthroline-2-carboxamide) ligand modified adsorbent, J. Hazard. Mater. 252-253 (2013) 313-320, http://

dx.doi.org/10.1016/j.jhazmat.2013.03.020.
[38] S. Iftekhar, V. Srivastava, M. Sillanpäa, Synthesis and application of LDH intercalated cellulose nanocomposite for separation of rare earth elements 10.028

[39] S. Hokkanen, E. Repo, T. Suopajärvi, H. Liimatainen, J. Niinimaa, M. Sillanpä, Adsorption of $\mathrm{Ni}(\mathrm{II}), \mathrm{Cu}(\mathrm{II})$ and $\mathrm{Cd}(\mathrm{II})$ from aqueous solutions by amino modified nanostructured microfibrillated cellulose, Cellulose 21 (2014) 1471- 


\title{
Publication III
}

\author{
D.L.Ramasamy, A. Wojtuś, E. Repo, S. Kalliola, V. Srivastava, M. Sillanpää
}

Ligand immobilized novel hybrid adsorbents for rare earth elements (REE) removal from waste water: Assessing the feasibility of using APTES functionalized silica in the hybridization process with chitosan

Reprinted with permission from

Chemical Engineering Journal

Vol. 330, pp. 1370-1379, 2017

(C) 2017, Elsevier 

Ligand immobilized novel hybrid adsorbents for rare earth elements (REE) removal from waste water: Assessing the feasibility of using APTES functionalized silica in the hybridization process with chitosan

Deepika Lakshmi Ramasamy ${ }^{\mathrm{a}, *}$, Anna Wojtuś ${ }^{\mathrm{b}}$, Eveliina Repo ${ }^{\mathrm{a}}$, Simo Kalliola ${ }^{\mathrm{a}}$, Varsha Srivastava $^{\mathrm{a}}$, Mika Sillanpää ${ }^{\mathrm{a}, \mathrm{c}}$

a Laboratory of Green Chemistry, Lappeenranta University of Technology, Mikkeli FI-50130, Finland

${ }^{b}$ Rzeszow University of Technology, Department of Water Purification and Protection, 12 Powstańców Warszawy Street, 35 - 959 Rzeszow, Poland c Department of Civil and Environmental Engineering, Florida International University, Miami FL-33174, USA

\section{G R A P H I C A L A B S T R A C T}

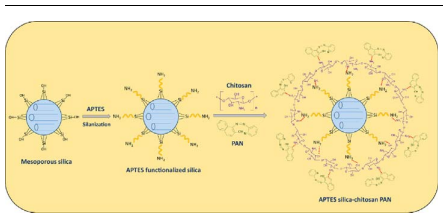

A R T I C L E I N F O

\section{Keywords:}

Adsorption

Chitosan

PAN

REE removal

\section{A B S T R A C T}

This experimental study was aimed at checking the potential of employing commercially available amino functionalized silica gels in synthesizing the ligand immobilized hybrid materials rather than the conventional method of utilizing Tetrathyl orthosilicate (TEOS) precursors for the removal of REE from the waste water. The method of utilizing Tetraethyl orthisilcate (THOS) precursors for the removal of REE from the waste water. The parameters used for the optimization of the syntesis process included the influence of silanes (3-Aminopropy triethoxysilane AP (2-Pyridylazo) 2-naphthol (PAN)

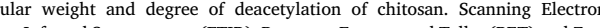
Microscopy (SEM), Fourier Transform potential (ZP) analysis were employed to understand the surface characterization of the hybridized adsorbents. The adsorption of $\mathrm{La}^{3}, \mathrm{Sc}^{3}$ and $\mathrm{Y}^{3}$ was investigated further in detail using the hybridized PAN adsorbent to understand the effect of initial solution $\mathrm{pH}$, contact time, temperature and initial adsorbate concentration Single/multi-component system was studied through batch adsorption tests to assess the affinity towards target REEs and the intra series adsorption behavior of light/heavy REEs was also inspected.

\section{Introduction}

Rare Earth Elements (REE) hold a great potential to serve a variety of industrial applications [1]. Hence, there has been a lot of resources spent towards the recovery and recycling of REEs in recent times, especially with its greater demand in the development of sustainable and ecofriendly technologies $[2,3]$. This has served as a motivation for collaborations between industries and governmental agencies for the recovery of these elements from secondary wastes such as mining waste water, bauxite residue etc. [4,5]. Owing to the lower concentrations of REEs in the waste sources or leachate solution, recovery is much more viable through processes such as ion exchange, biosorption, adsorption

Corresponding author

E-mail addresses: deepika.ramasamy@lut.fi, deepu7187@gmail.com (D.L. Ramasamy).

http://dx.doi.org/10.1016/j.cej.2017.08.098

Received 5 July 2017; Received in revised form 13 August 2017; Accepted 19 August 2017 ine 21 August 2017

1385-8947/ (c) 2017 Elsevier B.V. All rights reserved. 
etc. Biosorption is a good example of an environment friendly and efficient process with an abundance of resources involved in the metal ion recovery [6].

Chitosan is the second most abundant natural biopolymer after cellulose and is one of the most favored ones among the biopolymers due to its low-cost, non-toxicity and biodegradable nature. These polysaccharides are composed of deacetylated component, $\beta-(1,4)$ linked D-glucosamine and acetylated unit of N-acetyl-D-glucosamine, obtained through the deacetylation (varying degree) from Chitin. However, due to poor mechanical and surface properties, they are often coupled with other supports such as alumina, silica etc. to combine the properties of these materials [7]. The hybridization of materials have been explored many times in literature [8-10]. Among them, Silica is one of the most preferred supports as it can also be utilized in chromatographic applications because of its increased porosity and surface area of the material [11].

In the past, silica-chitosan hybrid adsorbents prepared by the conventional sol-gel process of hydrolysis and condensation using TEOS precursors, have been used to study the process of metal recovery from aqueous solutions $[12,13]$. According to the literature, during the synthesis of such adsorbents, silica precursor, predominantly TEOS, undergoes a catalytic reaction with chitosan followed by the ligand immobilization. Utilization of adsorbents based solely on amino/nonamino functionalized silica gels with Chitosan for the hybridization process as well as silica-chitosan-PAN/Acac modifications have not yet been performed, within the scope of the authors' knowledge. The usage of APTES functionalized gels for the synthesis of hybrid materials is simple and less time consuming in comparison to the method using TEOS precursors. The mesoporous properties of the hybrid materials can be further exploited in chromatographic applications too. This serves as a motivation for the present research work, thereby mainly focusing on understanding the behavior of hybrid adsorbents prepared via the reaction between surface functionalized silica gels and chitosan flakes with 1 - (2-Pyridylazo) 2-naphthol (PAN) and acetylacetone (Acac) ligand modifications, towards REE recovery. In our recent work, PAN/Acac functionalized silica gels demonstrated promising results in terms of REE removal efficiency at $\mathrm{pH} 4$ [14]. Hence, these ligands were opted for use with silica-chitosan, in the current work to shift the optimum REE adsorption to even lower $\mathrm{pH}$ regime.

The primary objective of this study was to analyze the REE removal efficiency of these hybridized materials by studying the impact of molecular weight of chitosan, types of ligands (PAN/Acac) and silanes (amino/non-amino) for the same. In this study, the adsorption process was focused mainly on the three target elements $\left(\mathrm{La}^{3+}, \mathrm{Sc}^{3+}\right.$ and $\left.\mathrm{Y}^{3+}\right)$ as they behave quite differently from the lot compared to other REEs based on our previous studies [15]. The most favorable adsorbent identified was further utilized for understanding the effect of aqueous feed $\mathrm{pH}$, contact time, initial solution concentration and temperature in the adsorption process. The adsorption isotherm and kinetic modelling were employed to predict the adsorption mechanism as well. The selectivity of the adsorbent toward Heavy REEs and Light REEs was also

Table 1

Organic elemental (\% wt) and BET analysis of various adsorbents.

\begin{tabular}{llllllll}
\hline Adsorbents & $\mathrm{N}$ & $\mathrm{C}$ & $\mathrm{H}$ & $\mathrm{O}$ & BET surface area $\left(\mathrm{m}^{2} / \mathrm{g}\right)$ & Pore volume $\left(\mathrm{cm}^{3} / \mathrm{g}\right)$ & Pore size $(\AA)$ \\
\hline Bare silica & & & & - & 377.86 & 0.69 & 73.51 \\
C3 & 16.26 & 43.18 & 6.91 & 37.09 & 0.7244 & 0.00133 & 73.82 \\
APTES-silica & 3.79 & 8.15 & 2.29 & 4.56 & 174.19 & 0.32 & 73.87 \\
MTM-silica & 3.54 & 3.03 & 0.77 & 1.69 & 306.07 & 0.52 & 68.33 \\
APTSE-C3-PAN & 10.99 & 26.02 & 4.02 & 22.69 & 71.89 & 0.13 & 68.87 \\
APTES-C3-Acac & 15.69 & 33.54 & 4.04 & 26.89 & 56.80 & 0.24 & 67.81 \\
MTM-C3-PAN & 15.14 & 24.52 & 3.33 & 21.39 & 139.96 & 0.27 & 68.25 \\
MTM-C3-Acac & 19.79 & 30.52 & 3.52 & 22.64 & 160.09 & 0.135 & 67.45 \\
APTES-CC-PAN50 & 14.32 & 28.76 & 3.83 & 22.56 & 74.535 & 0.24 & 79.79 \\
APTSE-silica-PAN & 3.58 & 11.39 & 2.57 & - & 118.06 & 0.17 & 77.03 \\
APTES-silica-Acac & 3.34 & 18.41 & 2.39 & - & 90.09 & & \\
\hline
\end{tabular}

inspected by assessing the intra series REE separation behavior. To gain a better insight into the surface chemistry and binding mechanism of the adsorbents, characterization of the hybrid materials was performed before and after the adsorption process.

\section{Experimental}

\subsection{Materials}

The characteristics of the silica gel used in the study included the pore and particle size of $60-70 \AA$ and $15-40 \mu \mathrm{m}$, respectively. Functionalized adsorbents were synthesized using APTES $\left(\mathrm{H}_{2} \mathrm{~N}\right.$ $\left(\mathrm{CH}_{2}\right)_{3} \mathrm{Si}\left(\mathrm{OC}_{2} \mathrm{H}_{5}\right)_{3},>98 \%$, from Merck) and MTM $\left(\mathrm{CH}_{3} \mathrm{Si}\left(\mathrm{OCH}_{3}\right)_{3}\right.$ $98 \%$, from Aldrich). Chitosan flakes, used in the preparation of hybrid adsorbents, were purchased from Sigma-Aldrich. Four different types of chitosan were utilized for the synthesis, denoted by C1, C2 and C3 (deacetylated chitin; Poly (D-glucosamine), 75-85\%), and C4 (Poly(1,4- $\beta$-D-glucopyranosamine), $<75 \%$ ) in this study. They are of low (50.000-190.000 Da; $20-300 \mathrm{mPa}$ ), medium (200-800 mPas) and high viscosity ( $>400 \mathrm{mPa} . \mathrm{s}$ ), respectively. The ligand immobilization of the adsorbents was performed using PAN and Acac supplied by Sigma-Aldrich. The 1000 ppm stock solutions of the respective La (III), Sc (III) and Y (III) salts were used to prepare their desired concentrations required for the tests.

\subsection{Fabrication of PAN/Acac modified silica-chitosan hybrid adsorbents}

APTES/MTM functionalized silica gels were prepared as mentioned in our previous work [16]. The functionalized gels were then allowed to react with chitosan flakes (C1-C4) and ligands (PAN/acac) under solvent evaporation as stated in [15]. The reaction was carried out at room temperature with continuous stirring at $250 \mathrm{rpm}$. The scheme of this synthesis process is illustrated in Graphical abstract. Different ratios were utilized for the optimization step (silica: chitosan: PAN/Acac $1: 1: 5 ; 1: 1: 20$ and $1: 1: 50$ ).

Different notations are used throughout the course of this paper to indicate the adsorbents based on the type of silanes, ligands and molecular weight of the chitosan present. For example, APTES functionalized silica gel-chitosan with PAN modification is represented as APTESC (1-4)-PAN where as MTM functionalized silica gel-chitosan hybrid adsorbent with PAN modification is denoted by MTM-C (1-4)-PAN.

\subsection{Characterization of the adsorbents}

The instruments employed for characterization of the adsorbents involved in the current study included Scanning Electron Microscopy (SEM, SU3500 fitted with Thermo Scientific UltraDry SDD EDS), Organic Elemental Analyzer (Flash 2000, Thermo Scientific), Brunauer Emmett and Teller surface area and pore size analyzer (BET, Tristar I Plus), Fourier Transform Infrared Spectroscopy (FTIR, Bruker Vertex 

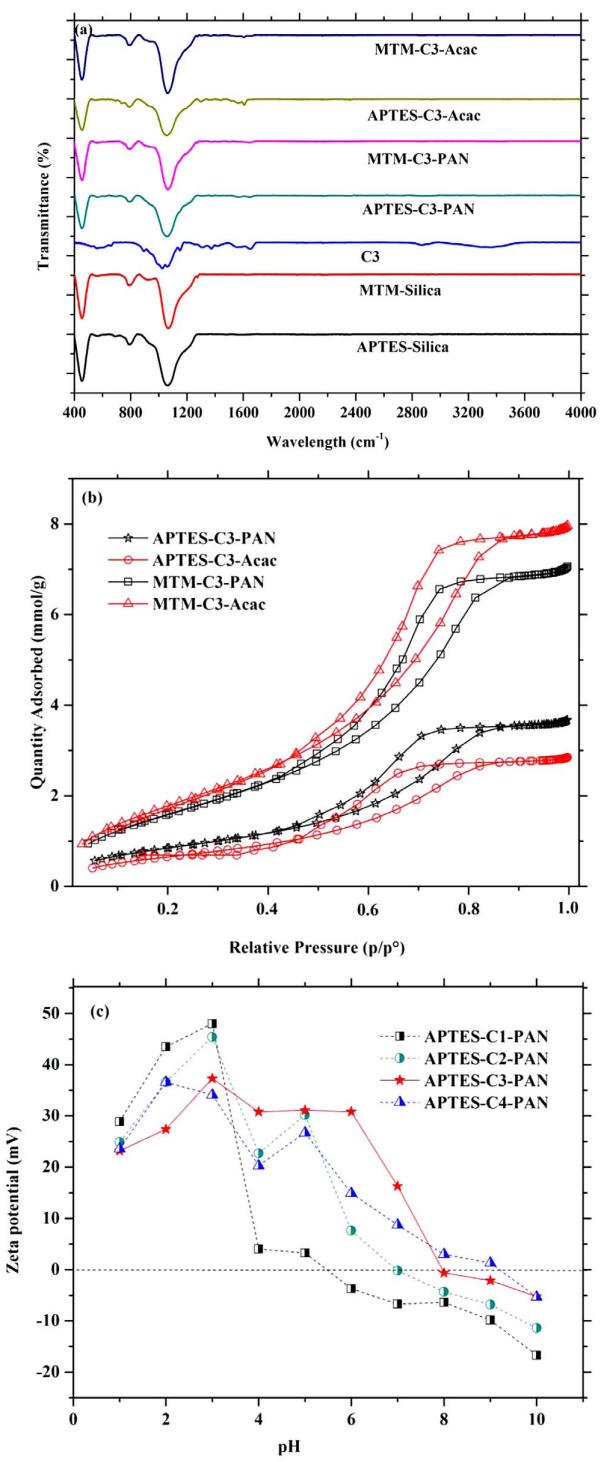

Fig. 1. Characterization of various adsorbents by a) FTIR b) BET c) Zeta potential.

70), Surface Zeta potential analyzer (Zetasizer nano ZS) and Total Organic Carbon analyzer (TOC- $\mathrm{V}_{\mathrm{CPH}}$, Shimadzu).

\subsection{Adsorption tests}

In the removal of $\mathrm{La}^{3+}, \mathrm{Sc}^{3+}$ and $\mathrm{Y}^{3+}$ from aqueous solutions, the feasibility of the synthesized adsorbents can be understood through the batch adsorption studies. In a batch system, $10 \mathrm{mg}$ of adsorbent was reacted with $10 \mathrm{ml}$ of target metal ion solution for a period of $24 \mathrm{~h}$, at room temperature. The influence of $\mathrm{pH}$ was investigated by varying the $\mathrm{pH}$ range of the metal ion solution between 2 and 7 above which REE hydrolysis or precipitation occurs $[15,17]$. Additionally, all the initial REE solutions used during this study were measured by ICP-OES and no precipitation was found till $\mathrm{pH} 7$. The initial concentration of the metal ion solution containing $\mathrm{La}^{3+}, \mathrm{Sc}^{3+}$ and $\mathrm{Y}^{3+}$ was set at $25 \mathrm{ppm}$ for $\mathrm{pH}$ and kinetic studies. Further to check the influence of initial concentration and the adsorption capacity of the adsorbents for REE removal, solutions with concentrations varying between 1 and $250 \mathrm{ppm}$ were used for isotherm tests, performed at the optimal $\mathrm{pH}$ and 24-h contact time. The kinetic tests were also conducted to determine the contact time required to attain the equilibrium. All the above mentioned experiments were operated at room temperature except in the case of temperature studies where the assessments were also carried out at $40^{\circ} \mathrm{C}$ and $60{ }^{\circ} \mathrm{C}$. After adsorption, the filtered solution (using $0.45 \mu \mathrm{m}$ polypropylene syringe filter) was analyzed using inductively coupled plasma optical atomic emission spectroscopy (ICP-OES, iCAP 6300 , Thermo Electron Corporation) to determine the initial as well as the equilibrium concentration. The formulae below (Eqs. (A.1) and (A.2)) were used to calculate the adsorption capacities $\left(\mathrm{q}_{\mathrm{e}}, \mathrm{mg} / \mathrm{g}\right)$ and efficiencies (\%),

$q_{e}(m g / g)=\frac{\left(C_{0}-C_{e}\right)}{M} V$

\% removal $=\frac{\left(C_{0}-C_{e}\right)}{C_{0}} * 100$

where $\mathrm{C}_{o}, \mathrm{C}_{\mathrm{e}}, \mathrm{M}$ and $\mathrm{V}$ are the initial concentration (mg/L), equilibrium concentration $(\mathrm{mg} / \mathrm{L})$, adsorbent mass $(\mathrm{g})$ and the solution volume $(\mathrm{L})$, respectively.

\section{Results and discussion}

3.1. Screening of adsorbents - preliminary tests

As mentioned in Section 2.2, various adsorbents were synthesized and all these modified adsorbents were then investigated for $\mathrm{La}^{3+}, \mathrm{Sc}^{3+}$ and $\mathrm{Y}^{3+}$ removal over the $\mathrm{pH}$ regime of 2-7. The $\mathrm{pH}$ above 7 was not studied as the hydrolysis of REE occurs at higher pHs $[17,18]$. For the following experiments, initial concentration of $\mathrm{La}^{3+}, \mathrm{Sc}^{3+}$ and $\mathrm{Y}^{3+}$ was $25 \mathrm{ppm}$. The batch adsorption tests were executed at the room temperature for $24 \mathrm{~h}$ using these modified adsorbents and the results are illustrated in Fig. SF1 (a-i) (Supplementary material). The pH was chosen as the main parameter to investigate the REE removal efficiencies of these adsorbents as the study is mainly focused on removing REE at lower $\mathrm{pH}$ regime which could be potentially utilized for the treatment of acidic mine water and electroplating industrial waste.

3.1.1. Influence of ligand and silanes used

Irrespective of ligand (Fig. SF1 (a, c, d and f)), APTES functionalized silica-chitosan mixture displayed superior removal of $\mathrm{La}^{3+}$ and $\mathrm{Y}^{3+}$ However, for the removal of $\mathrm{Sc}^{3+}$ with PAN and Acac modifications, greater adsorption was recorded by APTES silica gels for the former and MTM silica gels for the latter (Fig. SF1 (b and c)). The maximum adsorption for APTES-C-PAN was achieved at the $\mathrm{pH}$ value of 4 for all the three elements under consideration where as it was $40-70 \%, 90-100 \%$ and $20-50 \%$ for $\mathrm{La}^{3+}, \mathrm{Sc}^{3+}$ and $\mathrm{Y}^{3+}$, respectively for Acac gels. Also MTM based adsorbents showed great potential for selective removal of $\mathrm{Sc}^{3+}$ in the presence of $\mathrm{La}^{3+}$ and $\mathrm{Y}^{3+}$.

3.1.2. Influence of molecular weight of chitosan

In case of PAN modifications (Fig. SF1 (a-c)), C3 (high molecular weight) based adsorbents demonstrated higher efficiencies than $\mathrm{C} 1$ (low) and C2 (medium) based adsorbents, irrespective of the target 

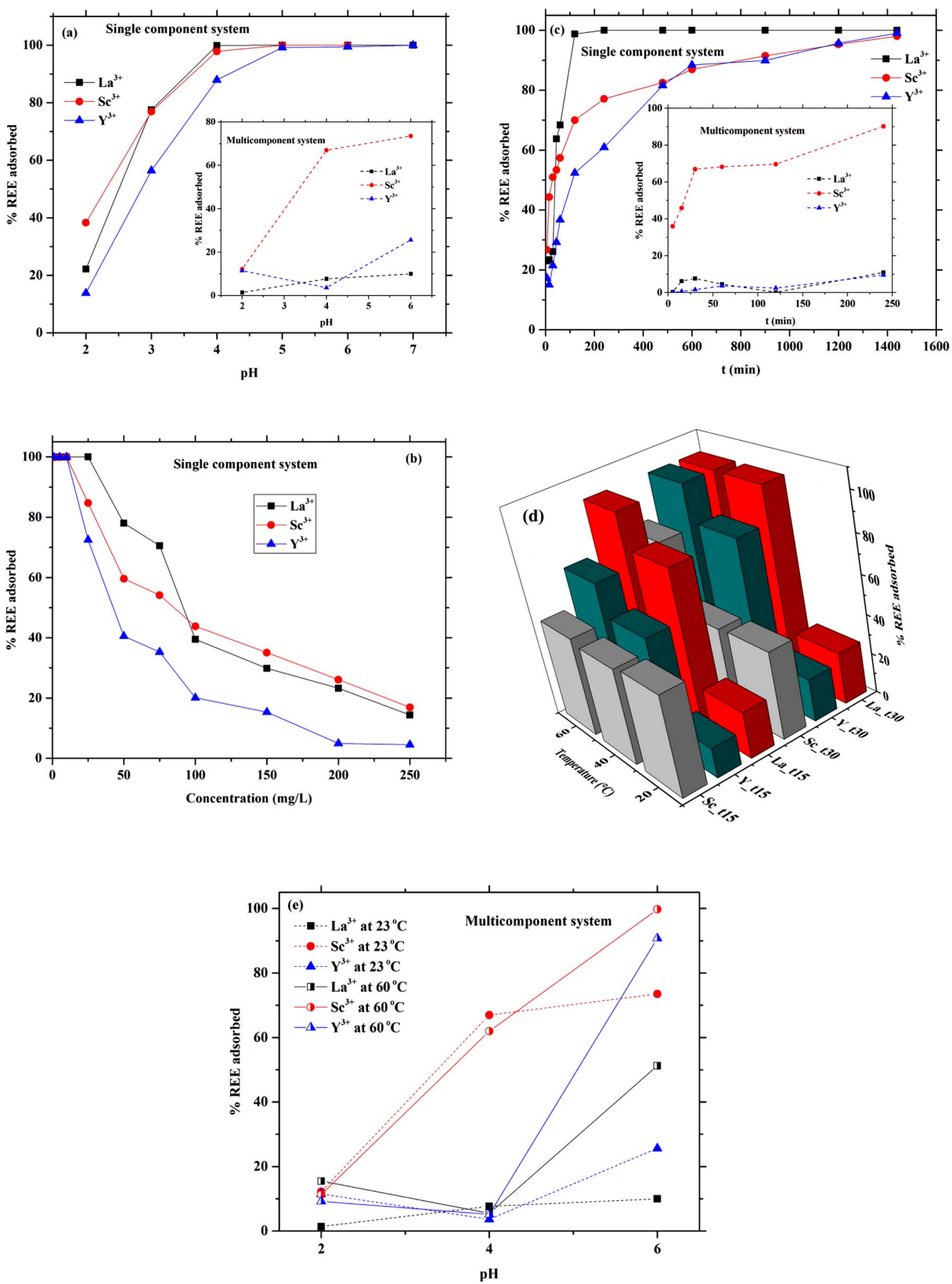

Fig. 2. \% REE adsorbed by APTES-C3-PAN as a function of a) pH b) initial adsorbate concentration c) contact time d) temperature in single component system e) temperature in multicomponent system. 
Table 2

\begin{tabular}{|c|c|c|c|c|}
\hline \multicolumn{2}{|c|}{ Modelling parameters } & $\mathrm{La}^{3+}$ & $\mathrm{Sc}^{3+}$ & $\mathrm{Y}^{3+}$ \\
\hline \multicolumn{5}{|c|}{ Adsorption isotherm parameters } \\
\hline \multicolumn{2}{|c|}{$\mathrm{Q}_{\mathrm{e}, \exp }(\mathrm{mg} / \mathrm{g})$} & 120.7 & 175.22 & 158.8 \\
\hline \multicolumn{2}{|l|}{ Langmuir } & 0.9359 & 0.8052 & 0.6358 \\
\hline \multirow{2}{*}{ isotherm } & $\mathrm{q}_{\mathrm{o}}(\mathrm{mg} / \mathrm{g})$ & 116.27 & 172.414 & 140.85 \\
\hline & $\mathrm{K}_{\mathrm{L}}(\mathrm{L} / \mathrm{mg})$ & 0.1172 & 0.0734 & 0.0422 \\
\hline $\begin{array}{l}\text { constants } \\
\text { Freundlich }\end{array}$ & $\mathrm{R}^{2}$ & 0.7382 & 0.8581 & 0.8227 \\
\hline \multirow{2}{*}{$\begin{array}{l}\text { isotherm } \\
\text { constants }\end{array}$} & $\mathrm{K}_{\mathrm{f}}(\mathrm{L} / \mathrm{mg})$ & $2.41 \times 10^{-5}$ & $9.49 \times 10^{-5}$ & $1.01 \times 10^{-4}$ \\
\hline & $\mathrm{n}$ & 0.328 & 0.366 & 0.341 \\
\hline \multicolumn{5}{|c|}{ Kinetic parameters } \\
\hline \multicolumn{2}{|c|}{$\mathrm{Q}_{e, \exp }(\mathrm{mg} / \mathrm{g})$} & 21.514 & 13.36 & 18.37 \\
\hline \multirow{3}{*}{$\begin{array}{l}\text { Pseudo-first- } \\
\text { order }\end{array}$} & $\mathrm{Q}_{\mathrm{e}, \mathrm{cal}}(\mathrm{mg} / \mathrm{g})$ & 2.869 & 63.91 & 447.01 \\
\hline & $\mathrm{k}_{1}\left(\min ^{-1}\right)$ & $8.751 \times 10^{-3}$ & $5.067 \times 10^{-3}$ & $6.448 \times 10^{-3}$ \\
\hline & & 0.503 & 0.985 & 0.976 \\
\hline \multirow{3}{*}{$\begin{array}{l}\text { Pseudo- } \\
\text { second- } \\
\text { order }\end{array}$} & $\mathrm{Q}_{\mathrm{e}, \mathrm{cal}}(\mathrm{mg} / \mathrm{g})$ & 20.96 & 13.495 & 19.61 \\
\hline & $\begin{array}{l}\mathrm{k}_{2}(\mathrm{~g} \\
\left.\mathrm{mg}^{-1} \min ^{-1}\right)\end{array}$ & $1.406 \times 10^{-3}$ & $1.417 \times 10^{-3}$ & $4.045 \times 10^{-3}$ \\
\hline & $\mathrm{R}^{2}$ & 0.998 & 0.997 & 0.997 \\
\hline
\end{tabular}

elements under study. There is not much change in the adsorption trend among these adsorbents over the $\mathrm{pH}$ range under examination. However, for Acac modifications, the behavior reversed with C1 and C2 performing superior than C3 (Fig. SF1 (d-f)). An exclusion to this pattern being $\mathrm{Sc}^{3+}$ adsorption, where beyond the $\mathrm{pH}$ value of 4 , C3 displayed greater adsorption than its counterparts. Overall, APTES-C3PAN showed greater efficacy in terms of REE removal. The modification with higher molecular weight of Chitosan have shown significantly better results than the lower ones in literature, due to the bridging effects of macromolecular chitosan and poor stability with low molecular weight chitosan based materials [19]. The notable performance by APTES silica-high (nitso be due to the increased weight $\%$ of $\mathrm{O}$ and $\mathrm{H}$ content in the materials, represented in Table 1 and Table S1 (Supplementary material).

3.1.3. Influence of deacetylation

Fig. SF1 ( $g$-i) provides an overview of the influence of deacetylation on the REE adsorption process. The degree of acetylation plays a huge role in characterizing Chitosan as it indicates the availability of free amino groups present in Chitosan after the removal of acetyl groups by the process of deacetylation [20]. In case of $\mathrm{La}^{3+}$ and $\mathrm{Y}^{3+}$, between C3 and C4, APTES-C3-PAN elucidated superior results than the rest. A nearly $100 \%$ removal efficiency has been recorded at the same $\mathrm{pH}$ value of 4. The MTM adsorbents, irrespective of the ligand or the type of chitosan, returned very poor results for $\mathrm{La}^{3+}$ and $\mathrm{Y}^{3+}$ adsorption. It is interesting that for $\mathrm{Sc}^{3+}$ adsorption, maximum adsorption efficiency of around $100 \%$ was achieved at higher $\mathrm{pHs}$ for all the adsorbents being analyzed, mostly driven by the hydroxyl groups on silica surface in that followed by MTM-C3-PAN/Acac adsorbents. APTES-C4-PAN adsorbents returned poor results in this study which might be attributable to the physical form of C4 (shells, unpowdered) compared to the coarse and powder form of $\mathrm{C} 3$ which might have resulted in poor hybridization with C4 adsorbents. It is also evident from the lower oxygen wt\%, Core volume obtained for $\mathrm{C} 4$ adsorbents as shown in Table 1 and Table S1 (Supplementary information).

\subsubsection{Influence of synthesis ratio}

The results from the optimization tests with different ratios of $1: 5$, $1: 20$ and 1:50, 1:20 did not show any large difference in $\mathrm{La}^{3+}, \mathrm{Sc}^{3+}$ and $\mathrm{Y}^{3+}$ removal. This can also be understood from the elemental analysis results shown in Table 1 where APTES-C3-PAN (1:50) exhibited only slight increase in $\mathrm{N}$ content. Moreover the surface area and pore volume did not have any significant change after 1:20. Therefore, the adsorbents prepared with the ratio of 1:20 were utilized for all the tests in this study.

\subsection{Characterization of the adsorbents}

The FTIR spectra recorded for all the modified adsorbents are shown in Fig. 1(a). The bands obtained at $450 \mathrm{~cm}^{-1}, 800 \mathrm{~cm}^{-1}$ and $1100 \mathrm{~cm}^{-1}$ are characteristic of silica gel indicating bending vibration, symmetric stretching vibration and asymmetric vibration of $\mathrm{Si}-\mathrm{O}-\mathrm{Si}$ linkage which is seen in all the adsorbents which confirms the modification on silica gels $[15,21]$. The broad band observed in Chitosan around $3360 \mathrm{~cm}^{-1}$ is due to the consequence of $\mathrm{O}-\mathrm{H}$ and $\mathrm{N}-\mathrm{H}$ stretch. around $3360 \mathrm{~cm}^{-1}$ is due to he $\mathrm{Cnse}^{-1}$ re of $\mathrm{O}-\mathrm{H}$ and $\mathrm{N}-\mathrm{H}$ stret

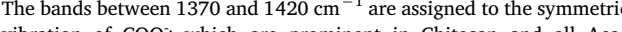
vibration of $\mathrm{COO}^{-}$which are prominent in Chitosan and all Acac modified gels [13]. The presence of Chitosan on all adsorbents is ascertained by the peak observed at $1559 \mathrm{~cm}^{-1}$ which is the result of C-N stretch, present in all the modified hybrid adsorbents and bare chitosan except in unmodified APTES-silica and MTM-silica [22]. Modification of PAN is established by $\mathrm{C}=\mathrm{C}$ stretching vibration from benzenoid and pyridyl unit $\left(1500 \mathrm{~cm}^{-1}\right)$ and $\mathrm{C}=\mathrm{N}$ stretching vibration of benzenoid group $\left(1329 \mathrm{~cm}^{-1}\right)$, noted in all PAN modified adsorbents $[15,23]$.

To obtain a clear apprehension of the surface properties and composition of the modified hybrid adsorbents, elemental and BET analysis were conducted, the results of which are summarized in Table 1. From the Fig. 1(b), it can be seen that the adsorbents demonstrated Type IV isotherm as per IUPAC classification, which is an ardent evidence to the synthesis of hybrid adsorbent with modifications leading to the formation of a mesoporous network [24,25]. The pore size distribution (PSD) of the synthesized hybrid materials are provided in Supplementary Material (Fig. SF2). The successful hybridization of the silica gel with chitosan is well represented by the significant raise in the $\%$ of $\mathrm{C}, \mathrm{N}$ and $\mathrm{H}$, in comparison with the APTES-PAN/ Acac and APTESSilica gels. There was a reduction in the surface area and pore volume of the silica particles post hybridization, which was the case for the the silica particles post hybridization, which was the case for the
functionalization and immobilization steps, noticed in other works as functionalization and immobilization steps, noticed in other works as
well [26-28]. The pore size of the hybrid adsorbents with PAN modifications is lesser than APTES functionalized silica-PAN modifications which can be attributed to the cross linking of chitosan to silica. The pore size of the adsorbents was about $70 \AA$, proving them to be of great value to chromatographic applicalions as the hybridized adsorbents are value to chrom were also supported by SEM analysis and the images are provided in Fig. SF3 (Supplementary information). The obtained images after modification displayed coarse structure confirming the hybridization process.

The zeta potential (ZP) measurements (average value) as a function of $\mathrm{pH}$ was carried out and the results are illustrated in Fig. 1(c). The isoelectric point (IEP) of C1, C2, C3 and C4 based adsorbents was found to be $5.8,7,8$ and 9 respectively. The ZP trend obtained for APTES-C3PAN was found to be similar to the trend of APTES-PAN [15]. Also the IEP of bare silica gel was observed at $\mathrm{pH} 2$ and it shifted to higher $\mathrm{pHs}$ after modification due to the presence of amino groups according to ou previous work. The same behavior might be the reason behind the shift in IEP with the modified adsorbents, being higher with adsorbents with in $\mathrm{N}$ group (Table 1). The positive surface charge of the hybrid ad sorbents were detected above $+30 \mathrm{mV}$ for the $\mathrm{pH}$ value of $1-3$ whereas with Silica-PAN adsorbents from our previous studies were spotted around $+10 \mathrm{mV}$ [15]. This increase in potential at this $\mathrm{pH}$ range is attributed to the chitosan moieties, as the surface charge of unmodified chitosan was determined to lie in the same range (Supplementary information, Fig. SF4).

\subsection{Adsorption studies}

\subsubsection{Effect of $p H$}

The plot (Fig. 2a) relates the\% REE adsorbed to the feed solution $\mathrm{pH}$, for both single and multi-component systems. Poor results obtained 
at $\mathrm{pH} 2$ might be the consequence of competition of $\mathrm{La}^{3+}, \mathrm{Sc}^{3+}$ and $\mathrm{Y}^{3+}$ ions with $\mathrm{H}^{+}$ions $[13,12]$. In the single component system, maximum adsorption was observed at a $\mathrm{pH}$ value of 4 for $\mathrm{La}^{3+}$ and $\mathrm{Sc}^{3+}$ whereas at 5 for $\mathrm{Y}^{3+}$. APTES-C3-PAN showed increase in the adsorption efficiency with increasing pHs due to the positive in the potential of the adsorbents enhancing electrostatic interaction between the positively charged REEs and the surface of the adsorbent. It should be noted that the adsorption efficiency of the hybridized materials showed $50-70 \%$ removal of REEs even at $\mathrm{pH} 3$. This was not the case with our Silica- PAN adsorbents where the poor adsorption of $20 \%$ was registered at $\mathrm{pH} 2$ and 3 which indicates that the adsorption at lower $\mathrm{pH}$ regime $<4$ resulted from the chitosan units [15]. In the case of multicomponent system, only $\mathrm{Sc}^{3+}$ demonstrated a supreme adsorption from $\mathrm{pH} \mathrm{4}$, while $\mathrm{La}^{3+}$ and $\mathrm{Y}^{3+}$ recorded a maximum adsorption of

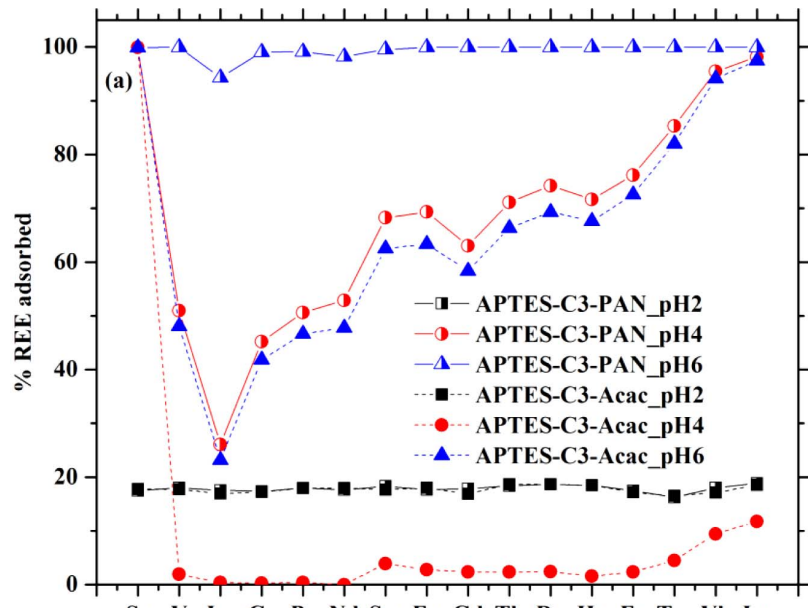

Sc Y La Ce Pr Nd Sm Eu Gd Tb Dy Ho Er Tm Yb Lu

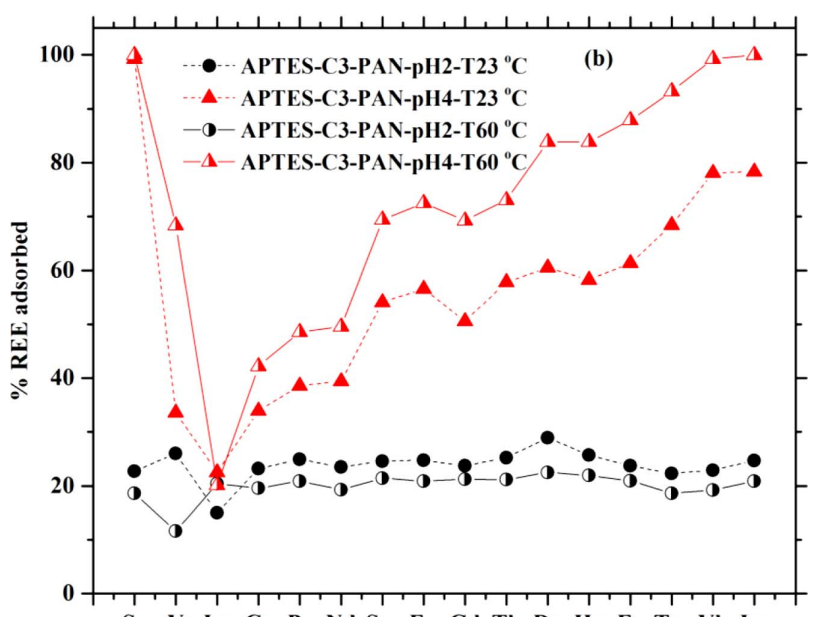

Sc Y La Ce Pr Nd Sm Eu Gd Tb Dy Ho Er Tm Yb Lu
$20 \%$ and $10 \%$, respectively, displaying a tremendous drop in $\mathrm{La}^{3+}$ and $\mathrm{Y}^{3+}$ adsorption in the multicomponent system in the presence of $\mathrm{Sc}^{3+}$

\subsubsection{Effect of initial concentration}

The Fig. $2 \mathrm{~b}$ shows that with the increase in the initial adsorbate concentration, adsorption capacity of APTES-C3-PAN for $\mathrm{La}^{3+}, \mathrm{Sc}^{3+}$ and $\mathrm{Y}^{3+}$ removal increased in the beginning until it reached the plateau indicating the maximum metals uptake. The plateau at higher concentrations is due to the fact that the available binding sites are significantly lesser than the number of competing ions and the saturation of binding sites at the higher concentrations [18]. The lowest REE adsorption among the lot was depicted by $\mathrm{Y}^{3+}$, while $\mathrm{Sc}^{3+}$ and $\mathrm{La}^{3+}$ showed a slightly higher adsorption under consideration. To explore more about the sorption equilibria, the experimental data points were

Fig. 3. REE series separation behavior as a function of a) $\mathrm{pH}$ b) temperature. 


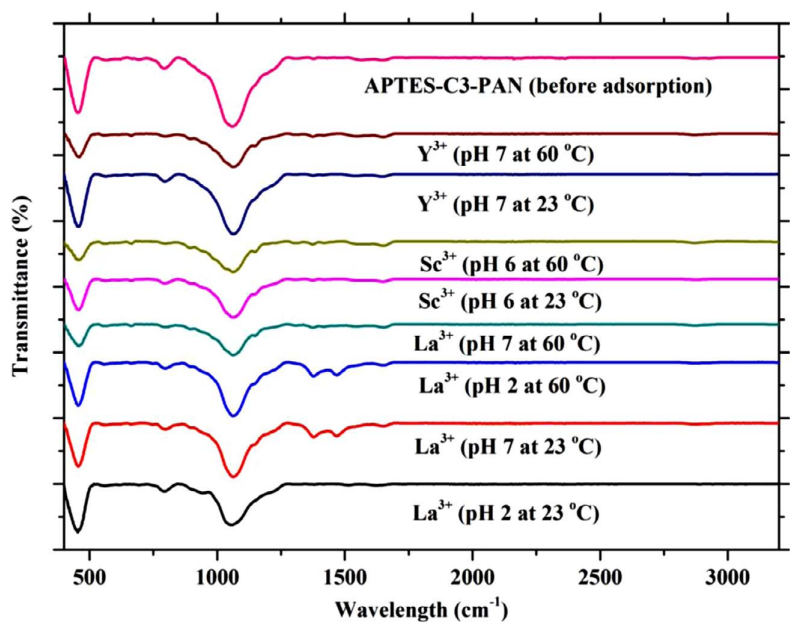

Fig. 4. FTIR spectra of APTES-C3-PAN obtained before and after adsorption.

fitted by two frequently used isotherm models such as Langmuir (Eq (B.1)) and Freundlich (Eq. (B.2)) [17,29]. In short, Langmuir model assumes the monolayer adsorption on homogenous surface containing finite number of adsorption sites. On the other hand, Freundlich model is based on non-ideal and multilayer adsorption containing heterogeneous surface without the saturation of binding sites.

$\frac{C_{e}}{q_{e}}=\frac{1}{K_{L} Q_{o}}+\frac{C_{e}}{Q_{o}}$

$\log q_{e}=\log K_{f}+\frac{1}{n} \log C_{e}$

where $\mathrm{q}_{e}, \mathrm{C}_{e}$ and $\mathrm{Q}_{\mathrm{o}}$ are the equilibrium adsorption capacity of the adsorbent $(\mathrm{mg} / \mathrm{g})$, equilibrium concentration of the adsorbate $(\mathrm{mg} / \mathrm{L})$, and the maximum adsorption capacity of the adsorbent $(\mathrm{mg} / \mathrm{g})$ reand the maximum adsorption capacity of the adsorbent (mg/g) reergy of the adsorption $(\mathrm{L} / \mathrm{mg})$, unit capacity coefficient $(\mathrm{L} / \mathrm{mg})$ and Freundlich parameter indicating how heterogeneous the system is, respectively. The isotherm parameters obtained from these models are listed in Table 2 and Fig. SF5 (Supplementary material). It can be seen that the experimental adsorption capacity for REEs is in close agreement with the adsorption capacities obtained by Langmuir model implying monolayer adsorption of $\mathrm{La}^{3+}, \mathrm{Sc}^{3+}$ and $\mathrm{Y}^{3+}$ onto APTES-CPAN. It should be noted that based on the high coefficient of correlation $\left(\mathrm{R}^{2}\right)$, Freundlich model fits better than Langmuir for $\mathrm{Sc}^{3+}$ and $\mathrm{Y}^{3+}$ which implicates the possibility of heterogeneous binding sites and multilayer adsorption [13].

\subsubsection{Effect of contact time}

According to Fig. 2(c), the increase in contact time had a positive impact on the adsorption process in the single component system for all the REEs under study, with the fastest kinetic equilibrium achieved by $\mathrm{La}^{3+}$ in $1.5 \mathrm{~h} . \mathrm{Sc}^{3+}$ and $\mathrm{Y}^{3+}$ required at least $10 \mathrm{~h}$ to reach the adsorption efficiency over $80 \%$. On the other hand, in the multicomponent system, $\mathrm{Sc}^{3+}$ adsorption is noticeably higher (similar to the $\mathrm{pH}$ study) compared to $\mathrm{La}^{3+}$ and $\mathrm{Y}^{3+}$. The adsorption kinetics was investigated by the pseudo-first-order (Eq. (C.1)) and pseudo-secondorder model (Eq. (C.2)), which are expressed as

$\log \left(q_{e}-q_{t}\right)=\log q_{e}-\frac{k_{1}}{2.303} t$ $\frac{t}{q_{t}}=\frac{1}{k_{2} q_{e}^{2}}+\frac{1}{q_{e}} t$

where $\mathrm{q}_{\mathrm{t}}$ and $\mathrm{q}_{\mathrm{e}}(\mathrm{mg} / \mathrm{g})$ denotes the adsorption capacity at time $\mathrm{t}$ and at equilibrium, respectively; $\mathrm{k}_{1}\left(\mathrm{~min}^{-1}\right)$ and $\mathrm{k}_{2}\left(\mathrm{~g} \mathrm{mg}^{-1} \min ^{-1}\right)$ are the rate constants for pseudo-first-order and pseudo-second-order, respectively. The kinetic parameters obtained by using these models are shown in Table 2 and Fig. SF6 (Supplementary material). It can be inferred that the adsorption processes follow the second-order kinetics, from both the $\mathrm{R}^{2}$ values and very small difference between the theoretical and experimental adsorption capacities, supporting the theory of chemisorption $[17,30]$. The sorption behavior of APTES-C-PAN in REE adsorption is well predicted by the pseudo-second-order model, which can be attributed to the lower initial concentration of the REE, according to Azizian's theory [31]. The observed behavior provides a clear notion that the kinetic process is driven by the surface reaction rates.

\subsubsection{Effect of temperature}

In general, the effect of elevated temperatures in a single component system is favorable to REE adsorption. Maximum adsorption of around $100 \%$ was noticed for $\mathrm{La}^{3+}$ within 15 mins at $60{ }^{\circ} \mathrm{C}$ and 30 mins at $40^{\circ} \mathrm{C}$ while it was acquired in 30 mins by $\mathrm{Y}^{3+}$ at $60^{\circ} \mathrm{C}$ (Fig. $2 \mathrm{~d}$ ). $\mathrm{Sc}^{3+}$ displayed the least response to the increase in temperature, similarly as in [15]. The enhanced removal with increase in temperature might be due to the acceleration of the mobility of ions in the materials. In a multicomponent system (Fig. 2e), similar to previous results, $\mathrm{Sc}^{3+}$ showed greater removal compared to $\mathrm{La}^{3+}$ and $\mathrm{Y}^{3+}$. Until $\mathrm{pH}_{4} \mathrm{La}^{3+}$ and $\mathrm{Y}^{3+}$ did not show any increase in efficiences but at $\mathrm{pH} 6, \mathrm{Y}^{3+}$ recorded $90 \%$ remo real at the same $\mathrm{pH}$. This dominance of $\mathrm{Y}^{3+}$ sorption at higher $\mathrm{pHs}$ was also spotted in our previous studies with Silica-PAN modifications where the optimal $\mathrm{pH}_{\text {for }} \mathrm{Y}^{3+}$ removal of APTES-PAN adsorbents was found to be $6[15]$

\subsection{Intraseries REE behavior}

The Fig. 3(a) elucidates the adsorption trend of REEs over different pHs at room temperature with the contact time of $24 \mathrm{~h}$ by both APTES C3-PAN and APTES-C3-Acac gels. It can be readily inferred that there was not much change in the adsorption trend for both PAN (at $\mathrm{pH}$ 2) 
Table 3

Table 3
Comparison of maximum adsorption capacities of La (III), Sc(III) and $\mathrm{Y}$ (III) on various adsorbents.

\begin{tabular}{|c|c|c|c|c|c|}
\hline \multirow[t]{2}{*}{ Adsorbents } & \multirow[t]{2}{*}{ Adsorption conditions } & \multicolumn{3}{|c|}{ Adsorption capacity (mg/g) } & \multirow[t]{2}{*}{ References } \\
\hline & & $\mathrm{La}^{3+}$ & $\mathrm{Sc}^{3+}$ & $\mathrm{Y}^{3+}$ & \\
\hline Kaolin & $\mathrm{pH}-4.8 ; \mathrm{C}_{0}-120 \mathrm{ppm}$ & 1.73 & - & 0.974 & Xiao et al. [37] \\
\hline Carbon black from recycled tires & $\mathrm{C}_{0}-100 \mathrm{ppm} ; \mathrm{pH}-$ natural & 1.91 & - & 1.79 & Smith et al. [38] \\
\hline Cellulose based silica nanocomposite & $\mathrm{pH}-6 ; \mathrm{t}-50 \mathrm{~min} ; \mathrm{T}-23^{\circ} \mathrm{C}$ & 29.48 & 23.76 & - & Iftekhar et al. [17] \\
\hline Cellulose-Zn/Al layered double hydroxide & $\mathrm{C}_{0}-50 \mathrm{ppm} ; \mathrm{t}-10 \mathrm{~min} ; \mathrm{T}-23^{\circ} \mathrm{C} ; \mathrm{pH}-7$ & 92.51 & - & 102.25 & Iftekhar et al. [18] \\
\hline Acac modified silica gel using micro column & $\mathrm{pH}-6$ & 24.01 & 25.65 & 23.23 & Zhang et al [21] \\
\hline APTES silica-PAN & $\mathrm{C}_{0}-25 \mathrm{ppm} ; \mathrm{t}-5 \mathrm{~h} ; \mathrm{T}-23^{\circ} \mathrm{C} ; \mathrm{pH}-5$ & 115.03 & 42.41 & 76.04 & $\begin{array}{l}\text { Ramasamy et al [14] } \\
\text { \#previous work }\end{array}$ \\
\hline APTES silica-chitosan-PAN & $\mathrm{C}_{0}-25 \mathrm{ppm} ; \mathrm{t}-24 \mathrm{~h} ; \mathrm{T}-23^{\circ} \mathrm{C} ; \mathrm{pH}-4$ & 120.7 & 175.22 & 158.8 & Present study \\
\hline
\end{tabular}

and Acac (at $\mathrm{pH} 2$ and 4) modified APTES-C3 gels, revealing the adsorption percentage of only about $20 \%$ for all the REEs. At pH 4 , the adsorption trend increased with increase in the atomic number for the PAN modified gels with $\mathrm{La}^{3+}$ exhibiting the lowest removal and $\mathrm{Sc}^{3+}$ at the highest. Around $\mathrm{pH} 6$, all the REEs showed tremendous efficiencies by APTES-C3-PAN. On the other hand, Acac modified gels showed significant change only at higher $\mathrm{pHs}$, i.e. from $\mathrm{pH}$ value of 6 . It should also be noted that there was a direct coherence with the zig zag plots observed in the case of $\mathrm{PAN}$ at $\mathrm{pH} 4$ and Acac at $\mathrm{pH} 6$, probably due to the tetrad effect of REEs [32]. With the increase in temperature (Fig. 3b), the adsorption efficiencies were substantially enhanced with $\mathrm{Y}^{3+}$ displaying greater response. In both the cases of elevated $\mathrm{pHs}$ and temperatures, the affinity of APTES-C3 gels were depicted towards HREEs, which is in agreement with $[33,34]$.

\subsection{Adsorption behavior}

$\mathrm{La}^{3+}, \mathrm{Sc}^{3+}$ and $\mathrm{Y}^{3+}$ sorption by APTES-C3-PAN were fittingly represented well by the Langmuir model and pseudo-second-order kipresented well by the Langmuir model and pseudo-second-order ki-
netics, per prior results. However $\mathrm{Sc}^{3+}$ and $\mathrm{Y}^{3+}$ also demonstrated netics, per prior results. However $\mathrm{Sc}^{3+}$ and $\mathrm{Y}^{3+}$ also demonstrated
good correspondence to the Freundlich model, which is indicated in Table 2. This supports the hypothesis of different binding mechanism by these elements onto the hybrid materials. Therefore further analysis of the materials and solutions were carried out after the REE adsorption processes.

In the FTIR spectra of the adsorbents post-adsorption in Fig. 4, it can be seen that there is an occurrence of additional peaks at $1400-1450 \mathrm{~cm}^{-1}$ in $\mathrm{La}^{3+}$ adsorbed materials, which can be attributed to the bending vibration of $\mathrm{C}-\mathrm{H}$ [35]. This is however not the case for $\mathrm{Sc}^{3+}$ and $\mathrm{Y}^{3+}$ adsorption, the implication of which being the difference in mechanisms. The reason behind such peaks might be the existence of ion exchange with the hydroxyl groups in chitosan moieties. This is also ion exchange with the hydroxyl groups in chitosan moieties. This is also
in coherence with the increase in $\mathrm{pH}$ beyond 3 subsequent to $\mathrm{La}^{3+}$ in coherence with the increase in $\mathrm{pH}$ beyond 3 subsequent to $\mathrm{La}^{3+}$ adsorption (Table S2: Supplementary material), and it can be ascertained by the absence of peaks below $\mathrm{pH} 2$, where there was minimal adsorption. Irrespective of (at $60^{\circ} \mathrm{C}$ ) after adsorption. The former is a consequence of the surface interactions of the $\mathrm{Si}-\mathrm{OH}$ and $\mathrm{Si}-\mathrm{O}-\mathrm{Si}$ linkage and the latter is due to the higher silica leaching at $60^{\circ} \mathrm{C}$ (Table S3: Supplementary material). The band observed at $2887 \mathrm{~cm}^{-1}$ prior adsorption is absent or minimal for $\mathrm{La}^{3+}$ and $\mathrm{Y}^{3+}$ cases at $\mathrm{pH} 2$ and 7 , respectively. The band is usually characteristic of the axial stretching mode of the C-H group [20]. The TOC results from the filtered samples after adsorption are given in Table S2. The FTIR results appear to be consistent with the TOC results, where the $\mathrm{La}^{3+}$ and the $\mathrm{Y}^{3+}$ solutions demonstrated a decrease in TOC content $\mathrm{La}^{3+}$ and the $\mathrm{Y}^{3+}$ solutions demonstrated a decrease in TOC content
with increasing pHs and significantly higher TOC content at $\mathrm{pH}$ 7, rewith increasing $\mathrm{pHs}$ and significantly higher TOC content at $\mathrm{pH}$ 7, re-
spectively. The differences in the TOC measurements of $\mathrm{Sc}^{3+}$ adsorption before and after the sorption process was negligible. Overall, in all the cases, TOC found in the samples are low, which ascertains the presence of acetyl carbonyl groups of chitosan inside the network and PAN on the surface, as depicted in the scheme. Table S3 summarizes the silicon concentration (in ppm) measured in the liquid phase after adsorption. It can be immediately interpreted that the silica leaching is comparatively lesser in $\mathrm{Sc}^{3+}$ adsorption process than in the other two cases. Also, the increase in $\mathrm{pH}$ and temperature has a positive impact on leaching, which can be directly related to the increase in adsorption $[15,36]$. Electrostatic repulsion between the positively charged adsorbent and the REE cations seemed to be the driving force of these processes, showing compliance to surface zeta potential of the adsorbents. To summarize, the adsorption of REEs was driven through amine groups from chitosan at lower $\mathrm{pHs}$, coordination mechanism with pyridine and azo $\mathrm{N}$ - group of PAN and electrostatic interactions via silica groups from $\mathrm{pH} 4$.

\subsection{Superiority of the synthesized adsorbent}

The adsorption performance of the materials were evaluated based on comparison with other works found in literature. Table 3 highlights the fact the adsorption capacities of our hybrid materials, for the target elements under study, were relatively high in relation to other adelements under study, were relatively high in relation to other ad-
sorbents $[14,17,18,21,37,38]$. It should also be noted that grafting of chitosan to APTES silica-PAN resulted in higher adsorption capacities, owing to enhanced binding sites, in agreement with elemental analysis

Table 4

REE adsorption with and without the presence of competing ions.

\begin{tabular}{llllll}
\hline Elements & Removal \% & & & & \\
\cline { 2 - 5 } & $\begin{array}{l}\text { With } \\
\text { competing } \\
\text { ions (1:1) }\end{array}$ & $\begin{array}{l}\text { With } \\
\text { competing } \\
\text { ions (1:5) }\end{array}$ & $\begin{array}{l}\text { With } \\
\text { competing } \\
\text { ions }(1: 10)\end{array}$ & $\left.\begin{array}{l}\text { Without } \\
\text { competing } \\
\text { ions }(23\end{array}{ }^{\circ} \mathrm{C}\right)$ & $\begin{array}{l}\text { Without } \\
\text { competing } \\
\text { ions }\left(60{ }^{\circ} \mathrm{C}\right)\end{array}$ \\
\hline $\mathrm{Al}$ & 94.86 & 94.38 & 88.77 & & \\
$\mathrm{Au}$ & 91.37 & 97.56 & 93.81 & & \\
$\mathrm{Fe}$ & 100.00 & 99.68 & 97.81 & & \\
$\mathrm{Mg}$ & 0.90 & 2.13 & 1.51 & & \\
$\mathrm{Mn}$ & 0.82 & 0.39 & 10.71 & & \\
$\mathrm{Zn}$ & 11.81 & 1.01 & 2.29 & & \\
$\mathrm{Sc}$ & 97.58 & 98.19 & 93.35 & 99.25 & 99.96 \\
$\mathrm{Y}$ & 49.88 & 6.08 & 10.46 & 33.59 & 68.34 \\
$\mathrm{La}$ & 33.51 & 4.08 & 9.06 & 22.53 & 20.16 \\
$\mathrm{Ce}$ & 55.48 & 7.10 & 10.97 & 33.92 & 42.21 \\
$\mathrm{Pr}$ & 57.89 & 3.05 & 8.59 & 38.59 & 48.55 \\
$\mathrm{Nd}$ & 64.13 & 8.21 & 12.46 & 39.43 & 49.59 \\
$\mathrm{Sm}$ & 74.10 & 8.87 & 10.79 & 54.12 & 69.41 \\
$\mathrm{Eu}$ & 74.25 & 9.58 & 10.78 & 56.57 & 72.51 \\
$\mathrm{Gd}$ & 67.25 & 6.80 & 10.33 & 50.58 & 69.26 \\
$\mathrm{~Tb}$ & 72.65 & 9.40 & 11.11 & 57.81 & 73.05 \\
$\mathrm{Dy}$ & 73.21 & 10.28 & 12.77 & 60.48 & 83.87 \\
$\mathrm{Ho}$ & 70.95 & 9.50 & 11.73 & 58.27 & 83.86 \\
$\mathrm{Er}$ & 72.49 & 10.60 & 11.17 & 61.33 & 87.89 \\
$\mathrm{Tm}$ & 78.47 & 14.29 & 13.04 & 68.42 & 93.23 \\
$\mathrm{Yb}$ & 83.04 & 16.37 & 13.45 & 78.11 & 99.25 \\
$\mathrm{Lu}$ & 83.51 & 17.02 & 13.30 & 78.31 & 99.96 \\
\hline
\end{tabular}


(Table 1).

The interference of the competing ions were also investigated to check the effect on adsorption of whole series of REEs since the other cations of similar ionic size could easily substitute REEs in the adsorbent. The results from the assessment of REE adsorption along with other competing ions $\left(\mathrm{Fe}^{3+}, \mathrm{Al}^{3+}, \mathrm{Au}^{3+}, \mathrm{Mg}^{2+}, \mathrm{Mn}^{2+}\right.$ and $\left.\mathrm{Zn}^{2+}\right)$ are other competing ions $\left(\mathrm{Fe}^{3+}, \mathrm{Al}^{3}, \mathrm{Au}^{3+}, \mathrm{Mg}^{2+}, \mathrm{Mn}^{2+}\right.$ and $\left.\mathrm{Zn}^{2+}\right)$ are
shown in Table 4. As depicted in the table, adsorption of $\mathrm{Fe}^{3+}, \mathrm{Al}^{3+}$ shown in Table 4. As depicted in the table, adsorption of $\mathrm{Fe}^{3+}, \mathrm{Al}^{3+}$, and $\mathrm{Au}^{3+}$ was effortless on the hybrid material where as $\mathrm{Mg}^{2+}$,
$\mathrm{Mn}^{2+}$ and $\mathrm{Zn}^{2+}$ adsorption was negligible in all cases. These results imply that the trivalent cations are easily adsorbed on the material. Another reason could be the $\mathrm{pH}$ dependency of $\mathrm{Fe}^{3+}, \mathrm{Al}^{3+}$ and $\mathrm{Au}^{3+}$ adsorption, favorable in acidic pHs, similar behavior of which is reported in literature [39-41]. When the competing ions were added in equal parts to REEs (1:1), removal\% did not get affected by a large margin. However, with 5 fold and 10 fold excess, REE adsorption returned poor results.

Recovery of REEs plays a significant role in assessing the application potential of the adsorbents. Desorption studies were performed by adsorbing REEs onto the materials which were then later desorbed by using $1 \mathrm{~N} \mathrm{HNO}_{3}$. Nitric acid was used as stripping agent based on prior using $1 \mathrm{~N} \mathrm{HNO}_{3}$. Nitric acid was used as stripping agent based on prior
works. It was found that the REE recovery $\%$ of above 90 was obtained works. It was found that the REE recovery \% of above 90 was obtained
within the contact time of 30 mins (Fig. SF7: Supplementary material).

\subsection{Conclusion}

The PAN modified mesoporous adsorbents synthesized with APTES silica and higher molecular weight of chitosan particles demonstrated the best results, thus also presenting the possibility of using these materials for REE separation in further column studies. The ability to extract REEs from the acidic solutions (from $\mathrm{pH}$ 3), even better than just the APTES-PAN gels, attracts many potential to suit a variety of industrial applications such as treating acidic leaching solutions, acidic mine water etc.

\section{Acknowledgement}

The authors are thankful to Academy of Finland for funding the project (decision number 292542) and Mr. Toni Väkiparta from LUT School of Engineering Science for SEM analysis.

\section{Appendix A. Supplementary data}

Supplementary data associated with this article can be found, in the online version, at http://dx.doi.org/10.1016/j.cej.2017.08.098.

\section{References}

[1] K. Zhang, A.N. Kleit, A. Nieto, An economics strategy for criticality - application to are earth element Ytrrium in new lighting technology and its sustainable ava 2016.12.127.
ability, Renew.

[2] I.B.D. Lima, W.L. Filho, Rare Earths Industry: Technological, Economic, and

Environmental Implications, Elsevier, 2015.

[3] E. Machacek, P. Kalvig, Assessing advanced rare earth element-bearing deposits for industrial demand in the EU, Resour. Policy 49 (2016) 186-203, http://dx.doi.org/ 10.1016/j.resourpol.2016.05.004

4] C. Klauber, M. Gräfe, G. Power, Bauxite residue issues: II. Options for residue utilization, Hydrometallu
hydromet.2011.02.007.

[5] J. Roosen, S. Van Roosendael, C.R. Borra, T. Van Gerven, S. Mullens, K. Binnemans, Recovery of scandium from leachates of Greek bauxite residue by adsorption on functionalized chitosan-silica hybrid materials, Green Chem. 18 (2016) 2005-2013, http://dx.doi.org/10.1039/C5GC02225H.

[6] M. Fomina, G.M. Gadd, Biosorption: current perspectives on concept, definition and application, Bioresour. Technol. 160 (2014) 3-14, http://dx.doi.org/10.1016/j.

[7] Y. Liu, X. Cao, R. Hua, Y. Wang, Y. Liu, C. Pang, Y. Wang, Selective adsorption of uranyl ion on ion-imprinted chitosan/PVA cross-linked hydrogel, Hydrometallurgy 104 (2010) 150-155, http://dx.doi.org/10.1016/j.hydromet.2010.05.009. [8] Y. Chen, J.O. Iroh, Synthesis and characterization of polyimide/silica hybrid com-
posites, Chem. Mater. 11 (1999) 1218-1222, http://dx.doi.org/10.1021/ cm9804281.

[9] Z.H. Huang, K.Y. Qiu, The effects of interactions on the properties of acrylic polymers/silica hybrid materials prepared by the in situ sol-gel process, Polymer 38
(1997) 521-526, http://dx.doi.org/10.1016/S0032-3861(96)00561-7.

[10] K. Xie, Y. Yu, Y. Shi, Synthesis and characterization of cellulose/silica hybrid materials with chemical crosslinking, Carbohydr. Polym. 78 (2009) 799-805, http:// dx.doi.org/10.1016/j.carbpol.2009.06.019.

[11] F. Li, X.-M. Li, S.-S. Zhang, One-pot preparation of silica-supported hybrid immobilized metal affinity adsorbent with macroporous surface based on surface imprinting coating technique combined with polysaccharide incorporated sol-gel
process, J. Chromatogr. A 1129 (2006) 223-230, http://dx.doi.org/10.1016/j. chroma.2006.07.009.

[12] E. Repo, J.K. Warchoł, A. Bhatnagar, M. Sillanpää, Heavy metals adsorption by novel EDTA-modified chitosan-silica hybrid materials, J. Colloid Interface Sci. 358 (2011) 261-267, http:// dx.doi.org/10.1016/j.jpis.2011.02.059,

[13] J. Roosen, J. Spooren, K. Binnemans, Adsorption performance of functionalized chitosan-silica hybrid materials toward rare earths, J. Mater. Chem. A 2 (2014)

[14] D.L. Ramasamy, V. Puhakka, E. Repo, S. Khan, M. Sillanpää, Coordination and silic surface chemistry of lanthanides (III), scandium (III) and yttrium (III) sorption on 1(2-pyridylazo)-2-napththol (PAN) and acetylacetone (acac) immobilized gels, Chem. Eng. J. 324 (2017) 104-112, http://dx.doi.org/10.1016/j.cej.2017.05.025.

15] D.L. Ramasamy, E. Repo, V. Srivastava, M. Sillanpää, Chemically immobilized an physically adsorbed PAN/acetylacetone modified mesoporous silica for the recovery of rare earth elements from the waste water-comparative and optimization
study, Water Res. 114 (2017) 264-276, http://dx.doi.org/10.1016/. watres.2017 02.045 .

[16] D.L. Ramasamy, S. Khan, E. Repo, M. Sillanpää, Synthesis of mesoporous and microporous amine and non-amine functionalized silica gels for the application of rare earth elements (REE) recovery from the waste water-understanding the role of $\mathrm{pH}$ temperature, calcination and mechanism in Light REE and Heavy REE separation, Chem. Eng. J. (2017), http:///x.doi.org/10.1016/j.cej.2017.03.152.

17] S. Iftekhar, V. Srivastava, M. Sillanpää, Enrichment of lanthanides in aqueous system by cellulose based silica nanocomposite,

[18] S. Iftekhar, V. Srivastava, M. Sillanpää, Synthesis and application of LDH intercalated cellulose nanocomposite for separation of rare earth elements (REEs), Chem. Eng. J. 309 (2017) 130-139, http://dx.doi.org/10.1016/j.cej.2016.10.028 [19] C. Zhang, X. Zhai, G. Zhao, F. Ren, X. Leng, Synthesis, characterization, and controlled release of selenium nanoparticles stabilized by chitosan of different molecular weights, Carbohydr. Polym. 134 (2015) 158-166, hitp:// dx.doi.org/10.1016,
j.carbpol.2015.07.065.

[20] B. Doshi, E. Repo, J.P. carboxymethyl chitosan on destabilization of Marine Diesel, Diesel and Marine-2T oil for oil spill treatment, Carbohydr. Polym. 167 (2017) 326-336, http://dx.doi. org/10.1016/j.carbpol.2017.03.064.

[21] N. Zhang, C. Huang, B. Hu, ICP-AES determination of trace rare earth elements in environmental and food samples by on-line separation and preconcentration with acetylacetone-modified silica gel using microcolumn,
997-1002, http://dx.doi.org/10.2116/analsci.23.997.

[22] F. Chen, Y. Zhu, Chitosan enclosed mesoporous silica nanoparticles as drug nanocarriers: Sensitive response to the narrow pH range, Microporous Mesoporous
Mater. 150 (2012) 83-89, http://dx.doi.org/10.1016/j.micromeso.2011.07.023.

23] A. Kaur, U. Gupta, A preconcentration procedure using 1-(2-pyridylazo)-2-naptho anchored to silca nanoparticle for the analysis of cadmium in different samples, Eur. J. Chem. 5 (2008) 930-939, hittp.//x.doi.org/10.1155/2008/431916.

24] M.R. Awual, New type mesoporous conjugate material for selective optical coppe 85-94, http://dx.doi.org/10.1016/j.cej.2016.07.110.

[25] M.R. Awual, M.M. Hasan, A novel fine-tuning mesoporous adsorbent for simultaneous lead(II) detection and removal from wastewater, Sens. Actuators B Chen. 202 (2014) 395-403, http://dx.doi.org/10.1016/j.snb.2014.05.103.

[26] M.R. Awual, Solid phase sensitive palladium(II) ions detection and recovery using lgand based efficient conjugate nanomaterials,

[27] M.R. Awual, Assessing of lead(III) capturing from contaminated wastewater usin ligand doped conjugate adsorbent, Chem. Eng. J. 289 (2016) 65-73, http://dx do org/10.1016/j.cej.2015.12.078.

[28] M.R. Awual, M.M. Hasan, M.A. Khaleque, M.C. Sheikh, Treatment of copper(II) containing wastewater by a newly developed ligand based facial conjugate materials, Chem. Eng. J. 288 (2016) 368-376, http://dx.doi.org/10.1016/j.cej.2015.11.
108.

[29] E. Repo, J.K. Warchol, T.A. Kurniawan, M.E.T. Sillanpää, Adsorption of Co(II) and Ni(II) by EDTA- and/or DTPA-modified chitosan: kinetic and equilibrium modeling

[30] Y.-S. Ho, Review of second-order models for adsorption systems, J. Hazard. Mater 136 (2006) 681-689, http://dx.doi.org/10.1016/j.j.hazmat.2005.12.043.

131] S. Azizian, Kinetic models of sorption: a theoretical analysis, J. Colloid Interface Sci. 276 (2004) 47-52, http.//dx.doi.org/10.1016/j.jcis.2004.03.048.

[32] T. Monecke, U. Kempe, J. Monecke, M. Sala, D. Wolf, Tetrad effect in rare earth element distribution patterns: a method of quantification with application to and mineral samples from granite-related rare metal deposits, Geochim.
Cosmochim. Acta 66 (2002) 1185-1196, http://dx.doi.org/10.1016/S00167037(01)00849-3, [33] Y. Gao, K.-H. Lee, M. Oshima, S. Motomizu, Adsorption behavior of metal ions on
cross-linked chitosan and the determination of oxoanions after pretreatment with a 
D.L. Ramasamy et al.

chitosan column, Anal. Sci. 16 (2000) 1303-1308, http://dx.doi.org/10.2116/ M.P. Moloney, J. Causse, C Loubat A. Grandjean, Sodium "activation" of silanophosphonate modified mesoporous $\mathrm{TiO}_{2}$ extraction, Eur. J. Inorg. Chem. 2014 (2014) 2268-2277, http:///dx.doi.org/10. 1002/ejic. 201400027.

[35] Y. Yu, X. Li, J. Cheng, A comparison study of mechanism: $\mathrm{Cu}^{2+}$ adsorption on different adsorbents and their surface-modified adsorbents, J. Chem. 2016 (2016) 1-8, http://dx.doi.org/10.1155/2016/7936258.
E. Repo, T.A. Kurniawan, J.K. Warchol, M.E.T. Sillanpäa, Removal of Co(II) and Ni
(II) ions from contaminated water using silica gel functionalized with EDTA and/or DTPA as chelating agents, J. Hazard. Mater. 171 (2009) 1071-1080, http://dx.doi. org/10.1016/j.jhazmat.2009.06.111.

[37] Y. Xiao, L. Huang, Z. Long, Z. Feng, L. Wang, Adsorption ability of rare earth ele-
ments on clay minerals and its practical performance, J. Rare Earths 34 (2016)
Chemical Engineering Journal 330 (2017) 1370-1379

543-548, http://dx.doi.org/10.1016/S1002-0721(16)60060-1.

Y.R. Smith, D. Bhattacharyya, T. Willhard, M. Misra, Adsorption of aqueous rare (2016) 102-111, http:/dx.doi.

[39] M.R. Awual, M.A. Khaleque, M. Ferdows, A.M.S. Chowdhury, T. Yaita, Rapid recognition and recovery of gold(III) with functional ligand immobilized novel mesoporous adsorbent, Microchem. J. 110 (2013) 591-598, http://dx.doi.org/10. 1016/j.microc.2013.07.010.

[40] Z. Zhao, Y. Baba, W. Yoshida, F. Kubota, M. Goto, Development of novel adsorben bearing aminocarbonylmethylglycine and its application to scandium separation, J.
Chem. Technol. Biotechnol. 91 (2016) 2779-2784, http://dxdoi.org /10.1002/jctb.

[41] M.R. Awual, M. Ismael, Efficient gold(III) detection, separation and recovery from urban mining waste using a facial conjugate adsorbent, Sens. Actuators B Chem. 196 (2014) 457-466, http://dx.doi.org/10.1016/j.snb.2014.02.055. 


\title{
Publication IV
}

D.L.Ramasamy, V. Puhakka, S. Iftekhar, A. Wojtuś, E. Repo, S. Ben Hammouda, E. Iakovleva, M. Sillanpää

$\mathrm{N}$ - and $\mathrm{O}$ - ligand doped mesoporous silica-chitosan hybrid beads for the efficient, sustainable and selective recovery of rare earth elements (REE) from acid mine drainage (AMD): Understanding the significance of physical modification and conditioning of the polymer

\author{
Reprinted with permission from \\ Journal of Hazardous Materials \\ Vol. 348, pp. 84-91, 2018 \\ (C) 2018, Elsevier
}



$\mathrm{N}$ - and O- ligand doped mesoporous silica-chitosan hybrid beads for the efficient, sustainable and selective recovery of rare earth elements (REE) from acid mine drainage (AMD): Understanding the significance of physical modification and conditioning of the polymer

Deepika Lakshmi Ramasamya,*, Ville Puhakka ${ }^{\mathrm{a}}$, Sidra Iftekhar ${ }^{\mathrm{a}}$, Anna Wojtuś ${ }^{\mathrm{b}}$, Eveliina Repo ${ }^{\mathrm{a}}$, Samia Ben Hammouda ${ }^{a}$, Evgenia Iakovleva ${ }^{a}$, Mika Sillanpääa,c

a Laboratory of Green Chemistry, Lappeenranta University of Technology, Mikkeli FI-50130, Finland

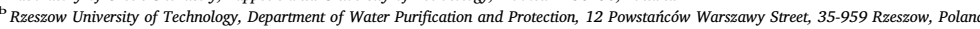
'Department of Civil and Environmental Engineering, Florida International University, Miami, FL-33174, USA

\section{G R A P H I C A L A B S T R A C T}

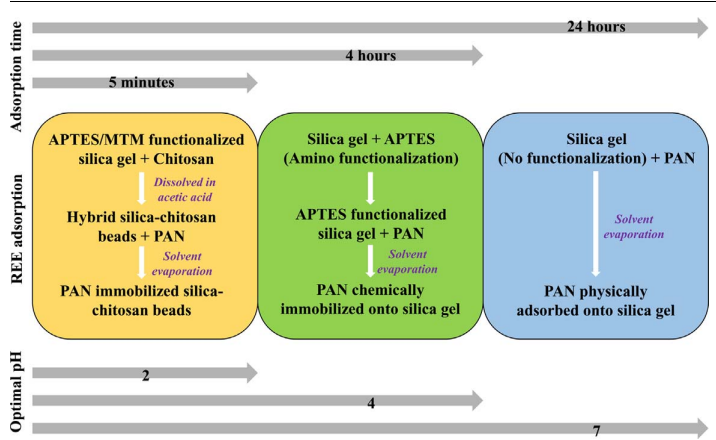

A R T I C L E I N F O

\section{Keywords:
AMD}

Adsorption

Chitosan

REE recover

Silica functionalization

\begin{abstract}
A B S T R A C T
Silica-chitosan hybrid beads were synthesized via three different methods to investigate the selective recovery of REE from AMD. The influence of amino/non-amino silanes, high molecular weight/high viscous chitosan and $\mathrm{N}$-/O- based ligands were studied and their effects on REE removal efficiencies were analyzed. The adsorption efficiencies of three various groups of modified beads were inspected with respect to feed $\mathrm{pH}$, in a single and efficiencies of three various groups of modified beads were inspected with respect to feed $\mathrm{pH}$, in a single and a multi-component system, and their affinities towards the light and heavy rare earth elements (LREE/ HREEs) were interpreted to understand the intra-series REE separation behavior. The focus of the study was mainly directed towards utilizing these fabricated beads for the recovery of valuable REEs from the real AMD obtained at three different sampling depths which was found rich in iron, sulfur and aluminum. Moreover, the selectivity of the beads towards REEs improved with silanized and ligand immobilized gels and their impacts on REE recovery in the presence of competing ions were successfully presented in this paper. Also, the synthesized beads
showed rapid REE adsorption and recovery within a process time of $5 \mathrm{~min}$. Group II adsorbents, synthesized by
\end{abstract}

* Corresponding autho

(D.L. Ramasamy).

https://doi.org/10.1016/j.jhazmat.2018.01.030

Received 23 October 2017; Received in revised form 4 January 2018; Accepted 15 January 2018 


\section{Introduction}

REE represents a group of elements with a common electron configuration ( 6 shells), that include 2 pseudo lanthanides (scandium, Sc, and yttrium, Y) and 14 lanthanides. They possess large ionic radii and oxidation (III) states. Among the REEs, the elements with atomic numbers ranging from 57 (lanthanum, La) through 64 (gadolinium, Gd) are categorized as light rare earth elements (LREEs) while elements from 65 (terbium, $\mathrm{Tb}$ ) through 71 (lutetium, Lu) are termed as heavy rare earth elements (HREEs). Owing to the similarities in their properties, $\mathrm{Sc}$ is often categorized as LREE and $\mathrm{Y}$ as HREE. Their comparable oxidation states and unchanging valences (mostly trivalent except $\mathrm{Ce}^{4+}$ and $\mathrm{Eu}^{2+}$ ) with increasing atomic number, contribute to the fact that they occur in a combined state and are enriched in Earth's crust (lithophile elements) [1]. There has been an escalating demand for such REEs in recent years, attributed to their several modern applications such as lasers, high strength permanent magnets, electronic devices, superconductors and catalysis [2]. This serves as a motivation for the development of new techniques, both economical and sustainable, aimed at their recovery from secondary sources like mining tailings and industrial residues $[3,4]$.

Polluted mine water has always been considered a waste product and in the present scenario, the mining industry is in constant search of economically viable options to purify the mine water. The purified water can then be decanted into receiving streams after disposing of the concentrated sludge/brine. During the course of this procedure, the valuable components are dissipated and several techniques are being investigated, aimed at their recovery. The accompanying challenges often include the acidity of the effluents, with variable compositions of the ionic species present. Also, the amounts of recoverable elements, such as REEs, occur in small quantities. Hence, the development of novel processes focusing on the selective recovery of such elements at low concentrations, from the mining effluents, is of high priority [5]. There are several existent technologies including ion exchange, solvent extraction, bio-sorption and adsorption for REE recovery [6-9]. The most efficient one, in practice, for the removal of target elements from aqueous solutions is adsorption [10-14].

The development and utilization of nanomaterials, green adsorbents and hybrid conjugates/composites for the selective removal and recovery of valuable metals have attracted enormous attention over the last decade [15-20]. Chitosan, a linear polysaccharide produced by the deacetylation of chitin, is biodegradable and non-toxic in nature. Chitin deacetylation of chitin, is biodegradable and non-toxic in nature. Chitin
occurs in natural sources such as the exoskeleton of crustacea (crabs occurs in natural sources such as the exoskeleton of crustacea (crabs
and shrimp shells), making it both abundant and procurable at a low cost. The presence of $\mathrm{pH}$-responsive functional groups with primary amino and hydroxyl groups contribute to chitosan's hydrophilicity. Hence, they can serve as effective sites for the chelation process, while the immobilization of ligands would further enhance the selectivity of the adsorbent [21-25]. Owing to the poor mechanical properties and porosity, chitosan is occasionally hybridized with supports such as silica that provide stability and increased surface properties. From earlier works in literature, it can also be understood that the supports such as Chitosan and silica are favorable for the process of metal ion recovery from wastewater [26-28].

This study was targeted on the removal of REEs from acidic media such as mine wastewater, even at a lower $\mathrm{pH}$ value of 2 . In our earlier works, the functionalization of silica gels for REE removal was performed using the silanes, 3-aminopropyl triethoxysilane (APTES), 3-aminopropyl trimethoxysilane (APTMS), Trimethoxymethoxymethylsilane (MTM) and Chlorotrimethylsilane (TMCS) [29]. In a further extension of the work, the ligands, (1-(2-pyridylazo) 2-naphthol (PAN) and acetyl acetone (acac)) immobilized silica gels were compared for their effectiveness in REE removal and the adsorption parameters were optimized [30]. From a pH value of 4, the silica-based adsorbents showed excellent REE adsorption. In this work, novel hybrid beads were synthesized for selective REE recovery from the acidic mine drainage, attempting to shift the optimal adsorption he analysis provided us with nificance of adsorbents' form and their methods of preparation in the successive removal of low concentrated REEs in a highly acidic medium. From the experimental data, it could be safely concluded that the bead form was highly preferable to the flake form. The augmentation of adsorbent selectivity towards REE recovery from acid mine drainage (AMD) through APTES/MTM silane modifications, different chitosan types and N-/O- dono advantages over traditional silica-chitosan hybrid beads were also brought into the light, especially in terms of REE selectivity after silanization and ligand functionalization step.

Hence, the aim of the current study was to utilize various PAN/ acac grafted silica-chitosan hybrid beads for REE recovery from acidic media. The hybrid beads, prepared and modified, using three different methods, were tested in both single and multi-component system, for REE recovery from wastewater. The intra-series REE behavior was studied to understand the separation trend and the adsorbents' affinity towards LREEs/HREEs. The validation of the process was conducted using real AMD to ascertain the selectivity of the adsorbents towards REEs in the presence of competing ions. The impact of ligand modification, method of preparation, type of chitosan and silane used, was also investigated to optimize the adsorption process. Fourier Transform Infrared Spectroscopy (FTIR), organic elemental and zeta potential (ZP) analyzer were used for the characterization as well as to understand the REE adsorption behavior of the materials.

\section{Experimental section}

2.1. Chemicals

APTES ( $\geq 99.0 \%$ pure), MTM ( $\geq 99.0 \%$ pure), PAN and Acac were supplied by Sigma Aldrich. High molecular weight chitosan C1 (310000-375,000 Da; 800-2000 mPa.s; deacetylated chitin; Poly (Dglucosamine)) and chitosan of high viscosity, obtained from crab shells C2 (> 400 mPa.s; Poly-(1, 4- $\beta$-D-glucopyranosamine)), were also procured from Aldrich. Mesoporous silica of particle and pore size of $0.015-0.040 \mathrm{~mm}$ and $60-70 \AA$, and glacial acetic acid, used for the gel bead preparation were supplied by Merck and VWR chemicals, respectively. The chloride salts of the REEs were utilized for the preparation of solutions of desired concentrations for the adsorption tests. The conditioning of the polymer beads was performed using Sodium hydroxide ( $\mathrm{NaOH}$ pellets, from Merck) alkaline coagulation bath.

\subsection{Synthesis of hybrid beads}

The gel beads were prepared using prior techniques described in the literature with some alterations [31], where equal parts of silica gel and chitosan were mixed in acetic acid $(4 \% \mathrm{w} / \mathrm{w})$ and the resulting viscous solution was dropped into $2.5 \mathrm{M} \mathrm{NaOH}$ bath and left undisturbed for $5-6 \mathrm{~h}$. This was followed by the washing and drying $\left(100^{\circ} \mathrm{C}\right.$ in the oven) of the beads until a constant weight was attained. Three different bead preparation methods, depicted in Table 1, were exploited, with aim of gaining a sound knowledge on the effect of their adsorbent efficiencies and selectivity towards REEs. To summarize the methodologies: (1) Group I adsorbents were synthesized by dissolving ligand 
Table 1

Organic elemental analysis of synthesized beads via three methods of preparation.

\begin{tabular}{|c|c|c|c|c|c|}
\hline \multicolumn{2}{|l|}{ Adsorbents } & \multirow{2}{*}{$\begin{array}{l}\text { Notations } \\
\text { H1P }\end{array}$} & \multirow{2}{*}{$\begin{array}{l}\mathrm{N} \\
2.15\end{array}$} & \multirow{2}{*}{$\begin{array}{l}\mathrm{C} \\
13.15\end{array}$} & \multirow{2}{*}{$\begin{array}{l}\mathrm{H} \\
3.97\end{array}$} \\
\hline GROUP I & APTES-C1-PAN & & & & \\
\hline \multirow{3}{*}{$($ Silica + Chitosan + PAN/Acac $)$} & APTES-C2-PAN & $\mathrm{H} 2 \mathrm{P}$ & 2.05 & 13.08 & 4.20 \\
\hline & MTM-C1-PAN & H3P & 2.01 & 14.05 & 4.20 \\
\hline & MTM-C2-PAN & H4P & 1.63 & 12.17 & 4.07 \\
\hline$\downarrow$ & APTES-C1-Acac & H1A & 4.15 & 30.27 & 4.51 \\
\hline \multirow{2}{*}{ Modified flakes } & APTES-C2-Acac & $\mathrm{H} 2 \mathrm{~A}$ & 2.25 & 15.64 & 4.22 \\
\hline & MTM-C1-Acac & H3A & 2.71 & 23.66 & 3.87 \\
\hline$\downarrow$ & MTM-C2-Acac & $\mathrm{H} 4 \mathrm{~A}$ & 1.89 & 18.58 & 3.34 \\
\hline \multicolumn{6}{|l|}{$\begin{array}{l}\text { Mixed with acetic acid to form } \\
\text { beads }\end{array}$} \\
\hline GROUP II & Sil-C1-PAN & B1P & 1.32 & 14.20 & 4.50 \\
\hline \multirow{3}{*}{$\begin{array}{l}\text { Silica and chitosan mixed with } \\
\text { acetic acid to form beads }\end{array}$} & Sil-C2-PAN & B2P & 1.02 & 14.80 & 3.77 \\
\hline & APTES-C1-PAN & B3Р & 2.88 & 22.00 & 4.14 \\
\hline & APTES-C2-PAN & B4P & 1.79 & 17.27 & 3.67 \\
\hline & MTM-C1-PAN & B5P & 4.42 & 30.58 & 4.44 \\
\hline$\downarrow$ & MTM-C2-PAN & $\mathrm{B} 6 \mathrm{P}$ & 1.36 & 15.23 & 4.11 \\
\hline \multirow[t]{6}{*}{ Modified with PAN/ Acac } & Sil-C1-Acac & B1A & 0.69 & 40.06 & 6.17 \\
\hline & Sil-C2-Acac & B2A & 0.10 & 38.93 & 6.02 \\
\hline & APTES-C1-Acac & B3A & 1.80 & 39.81 & 6.21 \\
\hline & APTES-C2-Acac & B4A & 0.75 & 39.96 & 5.88 \\
\hline & MTM-C1-Acac & B5A & 1.27 & 39.24 & 6.12 \\
\hline & MTM-C2-Acac & B6A & 1.00 & 40.15 & 6.26 \\
\hline GROUP III & Sil-C1-PAN & S1P & 5.71 & 34.09 & 5.49 \\
\hline \multirow{4}{*}{\begin{tabular}{|c}
$\begin{array}{l}\text { Silica, chitosan and PAN/Acac are } \\
\text { mixed together with acetic acid to } \\
\text { form gel }\end{array}$ \\
\end{tabular}} & Sil-C2-PAN & S2P & 7.02 & 39.19 & 5.51 \\
\hline & APTES-C1-PAN & S3P & 3.79 & 24.36 & 4.62 \\
\hline & APTES-C2-PAN & S4P & 3.07 & 20.42 & 4.12 \\
\hline & MTM-C1-PAN & S5P & 3.59 & 24.03 & 4.52 \\
\hline & MTM-C2-PAN & S6P & 7.12 & 39.93 & 5.56 \\
\hline$\downarrow$ & Sil-C1-Acac & S1A & 2.36 & 20.86 & 4.41 \\
\hline \multirow[t]{5}{*}{ Beads } & Sil-C2-Acac & S2A & 2.03 & 20.55 & 4.09 \\
\hline & APTES-C1-Acac & S3A & 4.19 & 32.54 & 5.46 \\
\hline & APTES-C2-Acac & S4A & 1.55 & 16.00 & 3.85 \\
\hline & MTM-C1-Acac & S5A & 1.63 & 21.52 & 4.12 \\
\hline & MTM-C2-Acac & S6A & 1.78 & 20.19 & 4.81 \\
\hline
\end{tabular}

modified hybridized silica-chitosan flakes in acetic acid to obtain a gel, followed by beads preparation in a $\mathrm{NaOH}$ bath, (2) Group II beads were produced by preparing silica-chitosan beads at first, followed by ligand modification via solvent evaporation, and (3) Group III silica gels were obtained by mixing silica, chitosan and PAN/acac with acetic acid into a gel form, eventually leading to the formation of beads. In all these procedures, 1 part of the support (silica-chitosan, APTES silica-chitosan and MTM silica-chitosan) was allowed to react with 20 parts of PAN $(0.2 \% \mathrm{w} / \mathrm{w}$ in acetone) or Acac $(1 \mathrm{ml}$ in $30 \mathrm{ml}$ of methanol). Table 2 presents the information on silanes and chelating agents used for the synthesis. Also, the notations from the Tables 1 and 2 were adopted to remain consistent throughout the study.

\subsection{Characterization}

FTIR (Vertex 70, Bruker Optics, Germany) was used for the investigation of the surface functional groups and for the confirmation of the adsorbent modifications. Organic Elemental Analyzer (Flash 2000, Thermo Scientific, Germany) was employed to estimate the content of $\% \mathrm{C}, \mathrm{H}$ and N. Induced Coupled Plasma (ICP-OES, Agilent 5110) was $\% \mathrm{C}, \mathrm{H}$ and $\mathrm{N}$. Induced Coupled Plasma (ICP-OES, Agilent 5110) was
utilized to determine the metal ion concentration before and after the adsorption process. The surface ZP measurements were obtained by Nano ZS (ZEN3500, Malvern) as a function of solution pH. The Total Organic Carbon (TOC) content was analyzed by TOC- $\mathrm{V}_{\mathrm{CPH}}$, Shimadzu.

\subsection{Batch adsorption tests}

The adsorption tests were conducted by mixing $10 \mathrm{mg}$ of adsorbent and $10 \mathrm{ml}$ of adsorbate solution in an orbital shaker at $220 \mathrm{rpm}$, for a fixed period in batch mode. The solution $\mathrm{pH}$ (range: 1-5) was adjusted using $0.1 \mathrm{M} \mathrm{HCl}$ or $\mathrm{NaOH}$. Since the process of REE hydrolysis occurs beyond $\mathrm{pH} 6$ and the primary aim being the focus on the acidic regime, a $\mathrm{pH}$ limit of 5 was adopted for the analyses. With the ICP-OES

Table 2

Silanes and Ligands used in this study.

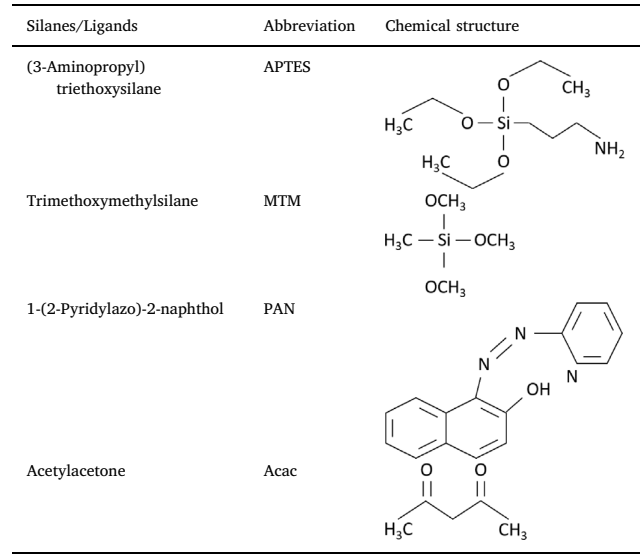


measurements of the initial and final solutions, \% removal of REEs can be calculated from Eq. (1) as shown below:

$\%$ removal $=\frac{\left(C_{0}-C_{e}\right)}{C_{0}} * 100$

where $\mathrm{C}_{\mathrm{o}}$ and $\mathrm{C}_{\mathrm{e}}$, are the initial concentration $(\mathrm{mg} / \mathrm{L})$ and equilibrium concentration $(\mathrm{mg} / \mathrm{L})$, respectively.

\section{Results and discussion}

3.1. Selective removal of REE over the acidic $p H$ range

Initially, the synthesized adsorbents were examined for selective REE removal from the synthetic test water in a single-component system, over a pH range of $1-5$ for $24 \mathrm{~h}$ at room temperature Fig. SF1 (Supplementary material). $\mathrm{La}^{3+}, \mathrm{Y}^{3+}$, and $\mathrm{Sc}^{3+}$ were preferred for this study as they behave differently among the REEs. $\mathrm{Sc}^{3+}$ had demonstudy as they behave differently among the REEs. $\mathrm{Sc}^{3}$ had demon-
strated rapid and supreme adsorption in our prior studies with silicastrated rapid and supreme adsorption in our prior studies with silicabased adsorbents while $\mathrm{La}^{3+}$ and $\mathrm{Y}^{3+}$ were not on the same level
$[30,32]$. The adsorption of the beads was negligible at a $\mathrm{pH}$ value of 1 $[30,32]$. The adsorption of the beads was negligible at a $\mathrm{pH}$ value of 1
and this may be a direct influence of the competing $\mathrm{H}^{+}$ions in the regime. Unlike our silica-based adsorbents with same PAN/acac modifications in powder form (optimal $\mathrm{pH}$ of 4 ), these hybrid beads displayed potential $\mathrm{REE}$ sorption, even from $\mathrm{pH} 2$ due to the protonation of amine groups from chitosan and with further increase in $\mathrm{pH}$, a positive impact on the adsorption process was observed due to both chitosan as well as silica groups.

Experiments were also conducted using a three-component system containing $\mathrm{La}^{3+}, \mathrm{Sc}^{3+}$, and $\mathrm{Y}^{3+}$ to understand the competition among the ions in the solution. The findings from this inspection are reported in Table S1 (Supplementary material). In a global sense, the beads in Table S1 (Supplementary material). In a global sense, the beads
depicted good adsorption of $\mathrm{La}^{3+}, \mathrm{Sc}^{3+}$ and $\mathrm{Y}^{3+}$, in the current system, depicted good adsorption of $\mathrm{La}^{3+}, \mathrm{Sc}^{3+}$ and $\mathrm{Y}^{3+}$, in the current system, irrespective of the silane, chitosan or ligand used. The affinity of the adsorbents towards $\mathrm{Sc}^{3+}$ ions was marginally better than that towards $\mathrm{La}^{3+}$ and $\mathrm{Y}^{3+}$ ions, in a multi-component system, which might be due
to the smaller atomic size of Sc. The significance of beads over the flakes form (prior to the bead fabrications in Group I) of the hybrid adsorbents was highlighted through the distinct disparity in the adsorption efficiencies of both cases, with the bead form being exceptional in comparison to the flake form (Fig. 1). Also, Group I flakes demonstrated poor efficacies with regards to $\mathrm{La}^{3+}$ and $\mathrm{Y}^{3+}$ sorption while $\mathrm{Sc}^{3+}$ was adsorbed very effectively in the three component system [33]. However, the synthesized Group I beads showed maximum adsorption for all three elements, even at a $\mathrm{pH}$ value of 2 . The limitations with

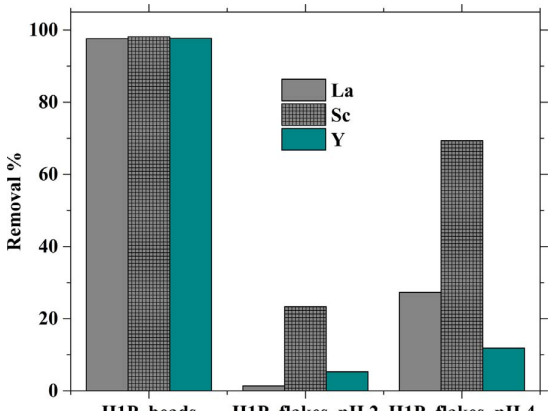

Fig. 1. Adsorption performance of H1P adsorbent in beads and flakes form at an initi solution $\mathrm{pH}$ of 2 and 4 in La-Sc-Y multi-component system (Dosage-1g/L, T-23 ${ }^{\circ} \mathrm{C}$ and initial REE concentration-8 ppm each) flakes form can be attributed to the diffusion restrictions due to the size of the chitosan particles [31].

\subsection{Intra-series REE behavior}

The entire REE series was investigated to gain a better insight into the adsorption trend and the affinities of the beads towards LREEs/ HREEs. The three groups of adsorbents were screened from a $\mathrm{pH}$ value of 2 , at $23^{\circ} \mathrm{C}$ and $45^{\circ} \mathrm{C}$. In coherence with our earlier studies involving PAN/Acac modified silica gels, higher the temperature, higher the REE adsorption, the reason being the acceleration of ion mobility in the adsorbent [32]. Fig. SF2 (Supplementary material) indicates that all the beads from Group I and III (except H3P), recorded poor adsorption at the considered $\mathrm{pH}$. However, the $\mathrm{C} 2$ modified Group II adsorbents (B4P, $\mathrm{B} 6 \mathrm{P}, \mathrm{B} 4 \mathrm{~A}$, and B6A) demonstrated superior REE adsorption at an initial REE concentration of $5 \mathrm{ppm}$. Fig. 2(a,b) is a representation of the temperature effect on \% REE removal of Group I (H1P and H3P) and Group II (B4P, B6P, B4A, B6A) adsorbents, for a contact time of $1 \mathrm{~h}$, at the aforementioned operating conditions of $\mathrm{pH}$ and temperatures. The effect of temperature was positive as in the earlier case, with it being more pronounced for B4A and B6A beads, which possess the tendency to register inferior outcomes at room temperature. Also, based on these findings from Fig. 2b, it could be stated that C2-based acac modified Group II beads were highly selective towards LREE. HREE adsorption was significantly augmented by temperature in case of Silica-PAN adsorbents, according to our previous studies. Nonetheless, C2-acac Group sorbents, according to our previous studies. Nonetheless, C2-acac Group
II adsorbents contradicted this behavior and depicted high affinity and II adsorbents contradicted this behavior and depicted high affinity and
selectivity towards $\mathrm{La}^{3+}, \mathrm{Ce}^{3+}, \mathrm{Pr}^{3+}$, and $\mathrm{Nd}^{3+}$. It could also be due to selectivity towards $\mathrm{La}^{3+}, \mathrm{Ce}^{3+}, \mathrm{Pr}^{3+}$, and $\mathrm{Nd}^{3+}$. It could also be due to
the fact that the affinity towards LREEs was stronger than HREEs at lower pHs, which was also the case in the literature $[32,34]$. In addition to such merits, it must be noted with the attention that these adsorbents expressed poor $\mathrm{Sc}^{3+}$ adsorption, a feat that was achievable even by bare silica gels without any surface functionalization and modification [29]. The capability of B4P and B6P to exhibit maximum REE adsorption, despite an increase in the initial REE concentrations to $10 \mathrm{ppm}$, is illustrated in Fig. 2c. Under the same conditions of increased concentrations, B4A was reluctant to undergo any adsorption while B6A underwent partial adsorption involving LREEs. Conclusively, the adsorption efficiencies can thus be ordered as $\mathrm{B} 4 \mathrm{P} \approx \mathrm{B} 6 \mathrm{P}>>\mathrm{B} 6 \mathrm{~A}>$ B4A.

The effectiveness of the ligands in the adsorption process could be inferred from the fact that B4P and B6P established maximum removal at $\mathrm{pH} 2$, thus establishing the primacy of PAN modifications over the Acac modified beads. It must also be remarked that the $\mathrm{C} 2$ based (high viscous chitosan) adsorbents were the only effective members of the Group II category. Also, PAN modified adsorbents expressed greater potential for the removal of $\mathrm{Sc}^{3+}$ than Acac based gels.

\subsection{Removal of REE from AMD}

A further evaluation of the performance of modified beads was conducted using real AMD, the composition of which is provided in Table S2 (Supplementary material). The AMD was extracted from different depths of $270 \mathrm{~m}, 500 \mathrm{~m}$ and $720 \mathrm{~m}$, with an original $\mathrm{pH}$ value of 2. The initial concentration of each REE was spiked around $5 \mathrm{ppm}$ in AMD and the process temperature of $45^{\circ} \mathrm{C}$ was adopted for these tests based on the results from the previous section.

3.3.1. Optimum $p H$

The presence of $\mathrm{Fe}^{3+}$ served as a hindrance to the adsorption process, thus resulting in minimal REE removal until a pH value of 4 [35]. The increase in the solution $\mathrm{pH}$ resulted in the precipitation of $\mathrm{Fe}$ and this seemed to favor the adsorption process, due to the lower concentration in the samples at this stage (Table S2). REE removal was investigated for all the beads over the $\mathrm{pH}$ range of 2-5. Until $\mathrm{pH} 4$, the $\%$ removal was almost negligible, except for $\mathrm{Sc}^{3+}$. At $\mathrm{pH} 5$, the 


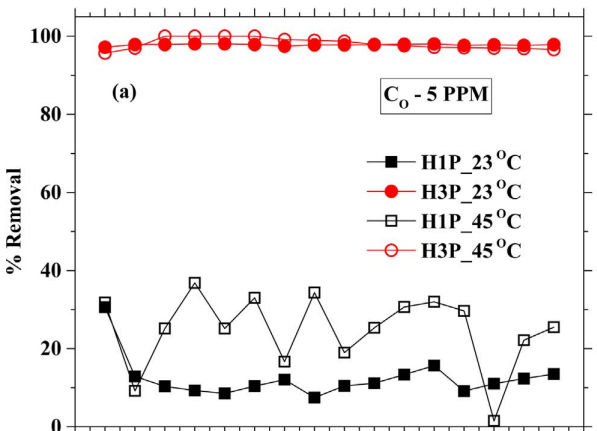

Sc Y La Ce Pr NdSm Eu Gd Tb Dy Ho ErTm Yb Lu

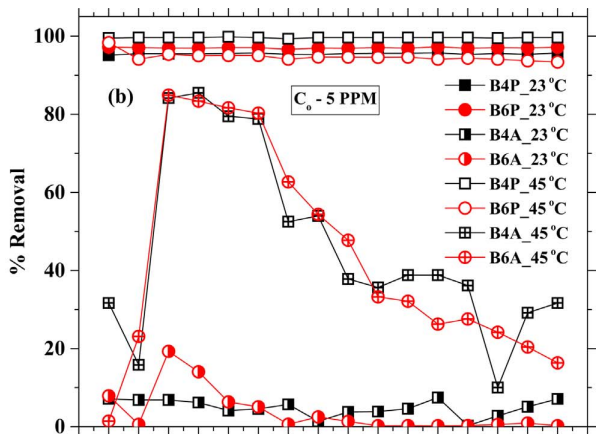

Sc Y La Ce Pr NdSmEu Gd Tb Dy Ho ErTmYb Lu

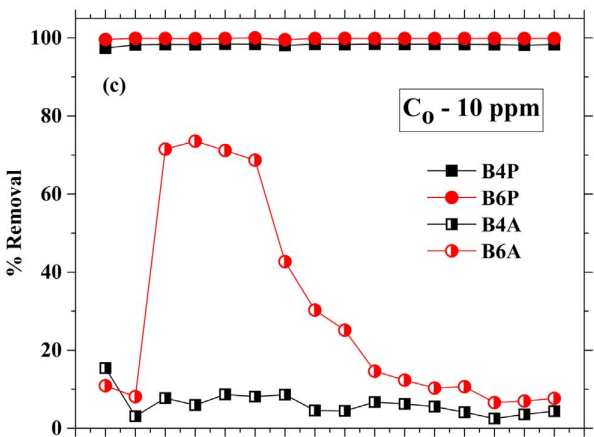

Se Y La Ce Pr NdSmEu GdTb Dy Ho ErTmYb Lu

Fig. 2. (a) Effect of temperature: Group I (b) Group II and (c) Effect of initial adsorbate concentration on \% REE removal: Group II. Experimental conditions: synthetic water, initial feed $\mathrm{pH}-2$, dosage-1g/L, T-45 ${ }^{\circ} \mathrm{C}$ and initial REE concentration-5 ppm each unless otherwise mentioned.

adsorbents exuded potential with respect to REE removal, the results of which are presented in Fig. 3.

\subsubsection{Sampling at different depths}

Fig. 3a (Group II) and Supplementary Fig. SF3a, b (Group I and III) paints an overall picture of the removal efficiencies of the adsorbents for samples obtained from different depths. In general, AMD obtained from a depth of $720 \mathrm{~m}$, generated the most favorable results in comparison to its counterparts. This may be attributed to the decrease in metal concentration with increase in sampling depth (Table S2), as a consequence of which, the interference from the other competing ions are lower. HREEs (including $\mathrm{Y}^{3+}$ ) were adsorbed more effectively than the LREEs. Since the adsorption of $\mathrm{Sc}^{3+}$ was superior in all cases, it was excluded from the figures. A notable outcome of the study highlights the fact that the sorption of REEs increases with the increase in atomic number, also supported firmly by our previous works [30,32]. The series separation trend implies the similarities of REE tetrad and the lanthanide contraction effect [36].

\subsubsection{Significance of silanization}

The significance of functionalized silica gels (APTES and MTM based) over bare silica in the preparation of hybrid beads was better understood through the comparison of REE removal efficiencies and selectivity of the adsorbents under scrutiny, with less co-removal of competing ions such as $\mathrm{Mn}^{2+}, \mathrm{Cu}^{2+}, \mathrm{Zn}^{2+}, \mathrm{S}^{6+}$, and $\mathrm{Mg}^{2+}$. The coremoval of $\mathrm{Mg}^{2+}$ and $\mathrm{S}^{6+}$ was negligible, in contrast to the adsorption of $\mathrm{Zn}^{2+}$, by all the beads under study. Silanized gels favored the selectivity of the beads towards REEs over $\mathrm{Mn}^{2+}$ and $\mathrm{Cu}^{2+}$, the effect of the same being more pronounced in the case of MTM silanes (Fig. 3b), as similarly observed during selective $\mathrm{Sc}^{3+}$ removal in our previous study [37]. This dictates the necessity of activating the silica support by means of amino or non-amino derivative silanes by attaching reactive functional groups onto their surface [31]. In summary, the MTM silanes possessed an edge over the APTES and bare silica gels with regard to REE selectivity (Supplementary material: Fig. SF3(c)).

\subsubsection{Significance of ligand modification}

To realize the effect of ligand modification in the adsorption process, APTES/MTM silanized Group II gels were inspected before and after PAN modifications. The reduction in competing ion removal after the ligand grafting is denoted in Fig. $3 \mathrm{~b}$ and c. The ligand modified silanized beads recorded a lower level of competing ion removal in relation to the bare silica beads. This provides a sound motivation towards the usage of APTES/ MTM based beads for ligand modification. Despite the efficiencies of PAN grafted gels being more favorable than that of acac grafted gels, the latter displayed higher selectivity in comparison to the former, depicting imperceptible removal of competing ions $(<10 \%)$, as shown in Fig. 3c. Nearly $100 \%$ REE removal was an unattainable task even for the best adsorbent among the acac based silica beads (B6A) under the given conditions (Supplementary material: Fig. SF3(d)) 

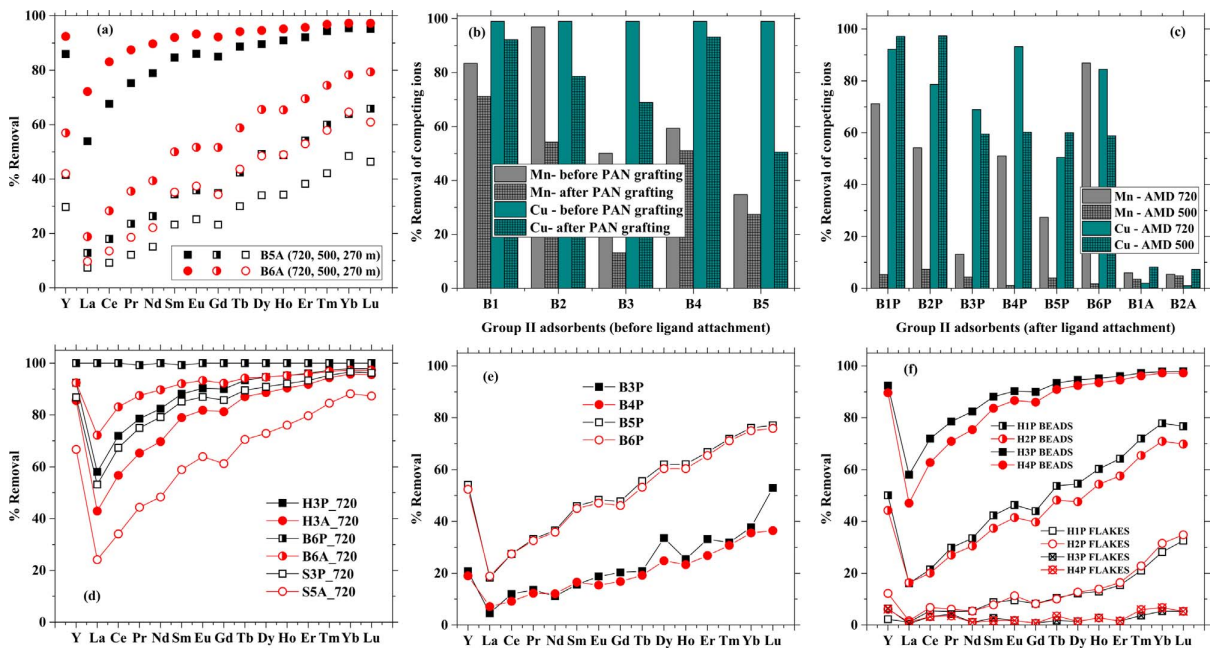

Fig. 3. \% REE removal from AMD (a) for samples obtained at different depths (Group II) (b) Significance of silanization and ligand grafting on co-removal of other competing ions (c) PAN vs Acac grafting on the selectivity of adsorbents towards REEs from AMD of different sampling depths (d) Comparison of three group of adsorbents (e) PAN vs Acac modifications of Group II adsorbents and (f) Beads vs Flakes form. Experimental conditions: AMD water, initial feed pH-5, dosage-1g/L, T-45 ${ }^{\circ} \mathrm{C}$ and initial REE concentration-5 ppm each unless otherwise mentioned.

3.3.5. Comparison of PAN vs Acac, APTES vs MTM and C1 vs C2

The effective members of each group with their respective modifications were scrutinized, and the results of the pertinent adsorption experiments are presented in Fig. 3(d). An analysis of the different group of adsorbents revealed that the Group II adsorbents were the most effective, followed by Group I and Group III adsorbents, in all the scenarios. PAN modifications were advantageous over the Acac modifications, in most of the situations, especially among Group II adtested on samples obtained from different depths and the REE removal efficiencies of the beads were assessed. The results from $500 \mathrm{~m}$ samples emphasize that the MTM-C based gels (B5P and B6P) demonstrated

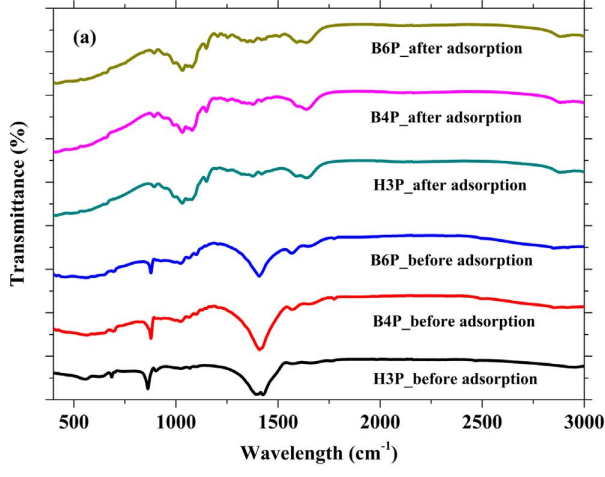

good HREE adsorption over the APTES-C based gels (B3P and B4P), also shown in Fig. 3e.

3.3.6. Beads vs flakes form

In line with Fig. 1, the Group I adsorbents in the flake form delivered poor adsorption efficiencies in relation to their bead counterparts, for REE removal from AMD at $\mathrm{pH} 5$ (Fig. 3f). As per Group I results, MTM based beads were superior to APTES based beads. On the contrary, in the flake form, the behavior was reversed, with APTES-C1 gels being the adept ones. Such a disparity in the behavior can be attributed to the indigent silica-chitosan hybridization process, the degree of deacetylation, chitosan molecular weight and bridging effect [38]. The

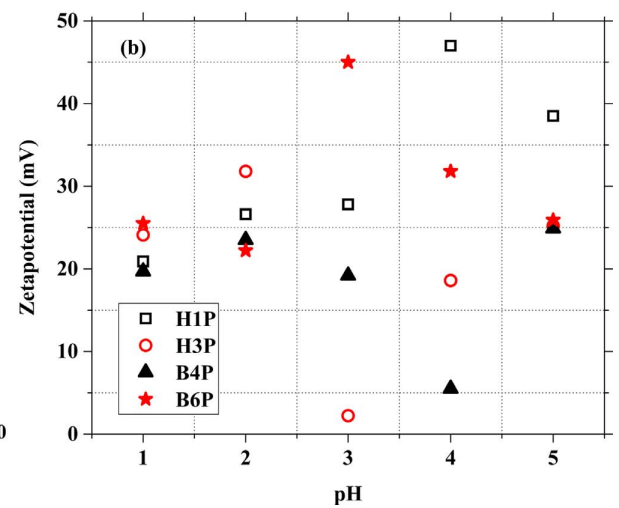

Fig. 4. a) FTIR spectra of adsorbents before/after adsorption and (b) Surface zeta potential values of the adsorbents as a function of solution pH. 
impact of viscosity on the conditioning the polymer can be realized by the highly potent nature of the highly viscous $\mathrm{C} 2$ gels.

\subsubsection{Significance of hybridization}

PAN/Acac modified silica gels were analyzed to gain a better insight into the impact of chitosan moieties in REE removal from AMD. Chemically immobilized APTES and MTM functionalized silica gels and physically loaded bare silica gels, with PAN/Acac, from our previous studies were utilized for this purpose [30]. It was observed that REE removal of silica gels was drastically lower than hybrid beads (Supplementary material: Table S3). This may be a result of the lower adsorntion capacities in the flake form, in comparison to the bead for the adsorbents or the different binding mechanisms involved in the process.

Additionally, the contrasting behavior with respect to bead adsorption efficiencies can be a result of accessibility of active binding sites, polymer network structure, diffusion restrictions, and rheological properties of the chitosan (repeating unit length, viscosity, molecular weight, chain stiffness and cooling) $[31,39,40]$. As a final step, the REEs adsorbed $(>150 \mathrm{ppm})$ by the beads were successfully eluted and recovered using $1 \mathrm{~N} \mathrm{HNO}_{3}$ and $2 \mathrm{M} \mathrm{HCl}$, the results of which are shown in Fig. SF4 (Supplementary material).

\subsection{Characterization}

The organic elemental analysis (Table 1) provides an account for the $\mathrm{wt} \%$ of $\mathrm{C}, \mathrm{N}$, and $\mathrm{H}$ present in the synthesized beads. It was noted that the $\% \mathrm{C}$ is higher in all the beads, followed by that of $\mathrm{H}$ and $\mathrm{N}$. The availability and accessibility of the unattached amino group metal binding sites, devoid of polymer crosslinking, might be one of the causes of the variation in bead performances, despite the approximately equivalent $\% \mathrm{~N}$.

FTIR spectra (Fig. 4a) was utilized to ascertain the hybridization and ligand modification of the adsorbents developed. The bands around $700-850 \mathrm{~cm}^{-1}, 1400 \mathrm{~cm}^{-1}$ and $1500-1600 \mathrm{~cm}^{-1}$ of the obtained spectra were characteristics of silica, chitosan (symmetric vibration of $\mathrm{COO})$ and PAN $(\mathrm{C}=\mathrm{C}$ and $\mathrm{C}=\mathrm{N}$ stretching vibration of benzenoid and pyridyl units) moieties, respectively [41-43]. MTM gels reported sharp bands at $700 \mathrm{~cm}^{-1}$ and $850 \mathrm{~cm}^{-1}$ while the broad peaks were observed for the APTES modified adsorbents. As a result of the ion adsorption process, the bands at $700 \mathrm{~cm}^{-1}$ (asymmetric mode of $\mathrm{Si}-\mathrm{CH}_{3}$ ), $850 \mathrm{~cm}^{-1}$ (Si-O vibration) and $1400 \mathrm{~cm}^{-1}$ (symmetric $\mathrm{NH}_{2}$ groups) disappeared, indicating the occurrence of sorption in these sites. New bands, observed post adsorption around $1680-1700 \mathrm{~cm}^{-1}$, may be a result of water adsorption [29] [44]. The notion of these probable binding sites is also supported by the readings of total nitrogen and TOC recorded after the adsorption process, as a result of C- or N- leaching recorded after the adsorption process, as a result of C- or N-leaching
from the hybridized beads (Supplementary material: Table S4). The from the hybridized beads (Supplementary material: Table S4). The
bead stability was further ascertained in both acidic and basic conditions, in relation to the leaching. The polymer stability was commendable depending upon the adsorbate concentration and extent of the adsorption process. The dissolution of the beads was not innate after the metal binding process, irrespective of the solution $\mathrm{pH}$, under synthetic test water conditions. However, with AMD, the beads formed soluble complexing macromolecules, in turn, retained by the censoluble complexing macromolecules, in turn, retained by the cen-
trifugation and filtration, to successfully recover the adsorbed elements. To enable recycling, polymer re-conditioning is an essential step. The beads ineffective in REE removal from AMD are the most prominent ones during silica leaching (Supplementary material: Table S5), and hence it was observed that the amount of silicon leached is inversely proportional to the REE adsorption efficiencies of the beads. Also, the role of temperature was minimal in the leaching step.

From the surface zeta potential measurements represented as a function of $\mathrm{pH}$ (Fig. 4b), it can be realized that the beads possessed a positive surface potential until the $\mathrm{pH}$ value of 5 . The behavior is in agreement with the observations from our previous studies, emphasizing the role of the amino groups or PAN in increasing the positive potential of the adsorbent, displaying an isoelectric point at higher $\mathrm{pHs}$ (around 7-8). This ascertains the possibility of electrostatic interaction forces or ion-exchange reactions between the positively charged adsorbent and cations, which might be one of the driving forces behind the adsorption process.

\subsection{REE adsorption behavior}

There is a distinct difference in the REE adsorption behavior of heterogeneous silica-chitosan beads and other silica gels from our previous works, with PAN/ acac modifications [30]. The primary REE binding mechanisms in the case of the latter are electrostatic interactions, ion-exchange reactions and chelating/coordination mechanism with ligands manifested from the protonation of pyridine/azo $\mathrm{N}$ group and ionization of the $\mathrm{OH}$ group [32]. However, the adsorption process with the chitosan moieties of our current hybrid beads resulted in ad sorption from a $\mathrm{pH}$ value of 2 , where an extended contributing mechanism in the form of protonation of amine groups from chitosan emerged, along with the coordination/ chelation mechanism with ligands and electrostatic interaction forces with $\mathrm{NH}_{2}{ }^{+}$and $\mathrm{OH}$ groups of silica. The possible conjectures for the observed $\mathrm{pH}$-dependent behavior is also supported by prior knowledge from literature [40], stated as (a) In a protonated state, at acidic $\mathrm{pHs}$, ion pair formation is by exchange mechanism (b) In an unprotonated state, REE coordination occurs through $\mathrm{N}-/ \mathrm{O}-$ donor ligand exchange mechanism (c) Ion pair binding mechanism is followed by slow ligand exchange or metal complexation process.

\section{Conclusion}

In a nutshell, the synthesized beads were highly effective in removing REFs ( $>150 \mathrm{ppm}$ ) from AMD instantly within 1-5 min s. In the majority of the cases, PAN modified gels were more efficient than acacmodified gels; MTM silanized gels demonstrated greater potency than APTES gels and C2 was more competent than C1. Overall, Group I beads synthesized by dissolving silica and chitosan into a gel form, followed by ligand modifications, were exemplary for REE adsorption. Among them, B6A would be an ideal adsorbent for HREE adsorption at lower concentrations whereas at higher REE concentrations, B4P and B6P would be an imminent choice.

\section{Acknowledgement}

The authors are thankful to the Academy of Finland for funding the project (decision number: 292542)

\section{Appendix A. Supplementary data}

Supplementary material related to this article can be found, in the online version, at doi:https://doi.org/10.1016/j.jhazmat.2018.01.030.

\section{References}

[1] P. Henderson, Rare Earth Element Geochemistry, Elsevier, 2013. K. rare earth element Yttrium in new lighting technology and its sustainable avail1016/j.rser.2016.12.127

[3] K. Binnemans, P.T. Jones, B. Blanpain, T. Van Gerven, Y. Yang, A. Walton, M. Buchert, Recycling of rare earths: a critical review, J. Clean. Prod. 51 (2013) 1-22, http://dx.doi.org/10.1016/j.jclepro. 2012.12.037.

[4] J. Kulczycka, Z. Kowalski, M. Smol, H. Wirth, Evaluation of the recovery of rare earth elements (REE) from phosphogypsum waste - case study of the WIZÓW chemical plant (Poland), J.

[5] M.R. Awual, M. Ismael, Efficient gold(III) detection, separation and recovery from urban mining waste using a facial conjugate adsorbent, Sens. Actuators B Chem. 196 (2014) 457-466, http://dx.doi.org/10.1016/j.snb.2014.02.055. 
[6] C. Ayora, F. Macías, E. Torres, A. Lozano, S. Carrero, J.-M. Nieto, R. Pérez-López, A. Fernández-Martínez, H. Castillo-Michel, Recovery of rare earth elements and
yttrium from passive-remediation systems of acid mine drainage, Environ. Sci. yttrium from passive-remediation systems of acid mine drainage, Environ. Sci.

[7] S. Iftekhar, V. Srivastava, M. Sillanpää, Synthesis and application of LDH intercalated cellulose nanocomposite for separation of rare earth elements (RFFs), Chem. Eng. J. 309 (2017) 130-139, http://dx.doi.org/10.1016/j.cej.2016.10.028.
C.

[8] S. Iftekhar, V. Srivastava, M. Sillanpää, Enrichment of lanthanides in aqueous
system by cellulose based silica nanocomposite, Chem. Eng. J. 320 (2017) 151-159, system by cellulose based silica nanocomposite

[9] J. Roosen, S. Van Roosendael, C.R. Borra, T. Van Gerven, S. Mullens, K. Binnemans,

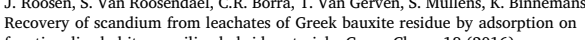
functionalized chitosan-silica hybrid materials, Green Chem. 18 (2016) 2005-2013, http://dx.doi.org/10.1039/C5GCO2225H.

[10] M.R. Awual, New type mesoporous conjugate material for selective optical copper (II) ions monitoring \& removal from polluted waters, Chem. Eng. J. 307 (2017) 85-94, http://dx.doi.org/10.1016/j.cej.2016.07.110.

[11] M.R. Awual, Novel nanocomposite materials for efficient and selective mercury ions 456-465, http://dx.doi.ors/

2] M.R. Awual, Solid phase sensitive palladium(II) ions detection and recovery using
ligand based efficient conjugate nanomaterials, Chem. Eng. J. 300 (2016) 264-272, http://dx.doi.org/10.1016/j.cej.2016.04.071.

[13] E. Repo, J.K. Warchoł, A. Bhatnagar, A. Mudhoo, M. Sillanpää, Aminopolycarboxylic acid functionalized adsorbents for heavy metals removal from water, Water Res. 47 (2013) 4812-4832, http://dx.doi.org/10.1016/j.watres.2013. 06.020.

[14] E. Repo, T.A. Kurniawan, J.K. Warchol, M.E.T. Sillanpää, Removal of Co(II) and Ni DTPA as chelating agents, J. Hazard. Mater. 171 (2009) 1071-1080, http://dx.doi.
Dition $\mathrm{org} / 10.1016 / \mathrm{j}$.jhazmat.2009.06.111.

[15] S. Iftekhar, V. Srivastava, A. Casas, M. Sillanpää, Synthesis of novel GA-g-PAM/SiO nanocomposite for the recovery of rare earth elements (REE) ions from aqueous solution, J. Clean. Prod. 170 (2018) 251-259, http://dx.doi.org/10.1016/j.jclepro. 2017.09 .166$.

a.R. Awual, A novel facial composite adsorbent for enhanced copper(II) detection org/10.1016/j.cej.2014.12.094.

17] M.R. Awual, N.H. Alharthi, M.M. Hasan, M.R. Karim, A. Islam, H. Znad, M.A. Hossain, M.E. Halim, M.M. Rahman, M.A. Khaleque, Inorganic-organic based novel nano-conjugate material for effective cobalt(II) ions capturing from waste1016/j.cej.2017

[18] M.R. Am

M.R. Awual, M.M. Hasan, H. Znad, Organic-inorganic based nano-conjugate ad-
sorbent for selective J. 259 (2015) 611-619, httt://dx.doi.org/10.1016/j.cej.2014.08.028.

19] F. Zhao, E. Repo, Y. Song, D. Yin, S.B. Hammouda, L. Chen, S. Kalliola, J. Tang, K.C. Tam, M. Sillanpää, Polyethylenimine-cross-linked cellulose nanocrystals for highly efficient recovery of rare earth elements from water and a mechanism study,

(201

F. Zhao, E. Repo, D. Yin, L. Chen, S. Kalliola, J. Tang, E. Iakovleva, K.C. Tan,
M. Sillanpää, One-pot synthesis of trifunctional chitosan-EDTA- $\beta$-cyclodextrin polymer for simultaneous removal of metals and organic micropollutants, Sci. Rep. polymer for simultaneous removal of metals and organic $\mathrm{m}$
7 (2017), http://dx.doi.org/10.1038/s41598-017-16222-7.

21] M.R. Awual, Assessing of lead(III) capturing from contaminated wastewater using ligand doped conjugate adsorbent, Chem. Eng. J. 289 (2016) 65-73, http://dx.doi.

[22] M.R. Awual, N.H. Alharthi, Y. Okamoto, M.R. Karim, M.E. Halim, M.M. Hasan, M.M. Rahman, M.M. Islam, M.A. Khaleque, M.C. Sheikh, Ligand field effect for
dysprosium(III) and lutetium(III) adsorption and EXAFS coordination with novel

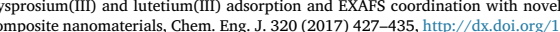
composite nanomaterials,

23] M.R. Awual, M.M. Hasan, A. Shahat, M. Naushad, H. Shiwaku, T. Yaita, Investigation of ligand immobilized nano-composite adsorbent for efficient cerium (III) detection and recovery, Chem. Eng. J. 265 (2015) 210-218, http://dx.doi.org/

4] M.R. Awual, G.E. Eldesoky, T. Yaita, M. Naushad, H. Shiwaku, Z.A. AlOthman S. Suzuki, Schiff based ligand containing nano-composite adsorbent for optical
copper(II) ions removal from aqueous solutions, Chem. Eng. J. 279 (2015) 639-647, http://dx.doi.org/10.1016/j.cej.2015.05.049,

[25] M.R. Awual, T. Kobayashi, Y. Miyazaki, R. Motokawa, H. Shiwaku, S. Suzuki, Y. Okamoto, T. Yaita, Selective lanthanide sorption and mechanism using novel
hybrid Lewis base ( $N$-methyl- $N$-phenyl-110-phenanthroline-2-carboxamide) ligand modified adsorbent, J. Hazard. Mater. 252-253 (2013) 313-320, http://dx.doi.org/

26] E. Repo, J.K. Warchoł, A. Bhatnagar, M. Sillanpää, Heavy metals adsorption by novel EDTA-modified chitosan-silica hybrid materials, J. Collo
(2011) 261-267, http://dx.doi.org /10.1016/j.jcis.2011.02.059.

[27] E. Repo, L. Malinen, R. Koivula, R. Harjula, M. Sillanpää, Capture of Co(II) from its aqueous EDTA-chelate by DTPA-modified silica gel and chitosan, J. Hazard. Mater. 187 (2011) 122-132, http:///dx.doi.org/10.1016/j.jhazmat.2010.12.113.

[28] J. Roosen, J. Spooren, K. Binnemans, Adsorption performance of functionalize chitosan-silica hybrid materials toward rare earths, J. Mater. Chem. A 2 (2014) 19415-19426, http://dx.doi.org/10.1039/C4TA04518A.

[29] D.L. Ramasamy, S. Khan, E. Repo, M. Sillanpää, Synthesis of mesoporous and microporous amine and non-amine functionalized silica gels for the application of rar
earth elements (REE) recovery from the waste water-understanding the role of $\mathrm{pH}$, temperature, calcination and mechanism in Light REE and Heavy REE separation, Chem. Eng. J. 322 (2017) 56-65, http://dx.doi.org/10.1016/j.cej.2017.03.152. [30] D.L. Ramasamy, E. Repo, V. Srivastava, M. Sillanpää, Chemically immobilized an physically adsorbed PAN/acetylacetone modified mesoporous silica for the recovery of rare earth elements from the waste water-comparative and optimization
study, Water Res. 114 (2017) 264-276, http://dx doi org /10.1016/j watres 2017 . 02.045

[31] E. Guibal, Heterogeneous catalysis on chitosan-based materials: a review, ProgPolym. Sci. 30 (2005) 71-109, http://dx.doi.org/10.1016/j.progpolymsci.2004.12

[32] D.L. Ramasamy, V. Puhakka, E. Repo, S. Khan, M. Sillanpää, Coordination and silica surface chemistry of lanthanides (III), scandium (III) and yttrium (III) sorption on $1-$
(2-pyridylazo-2-napththol (PAN) and acetylacetone (acac) immobilized gels, (2-pyridylazo)-2-napththol (PAN) and acetylacetone (acac) immobilized gels,
Chem. Eng. J. 324 (2017) 104-112, http://dx.doi.org/10.1016/j.cej.2017.05.025.

33] D.L. Ramasamy, A. Woituś, E. Repo, S. Kalliola, V. Srivastava, M. Sillanpää, Ligan immobilized novel hybrid adsorbents for rare earth elements (REE) removal from waste water: assessing the feasibility of using APTES functionalized silica in the hybridization process with chitosan, Chem. Eng. J. 330 (2017) 1370-1379, http:/ dx.doi.org/10.1016/j.cej.2017.08.098

(teractions between iron hydroxide colloid and water on REE fractionations in surface waters: experimental study on pH-controlling mechanism,
Sci. China Ser. D 45 (2002) 449, http://dx.doi.org/10.1360/02yd9047.

[35] Z. Zhao, Y. Baba, W. Yoshida, F. Kubota, M. Goto, Development of novel adsorben bearing aminocarbonylmethylglycine and its application to scandium separation, J.

[36] T. Monecke, U. Kempe, J. Monecke, M. Sala, D. Wolf, Tetrad effect in rare earth element distribution patterns: a method of quantification with application to rock Cos 7037(01)00849-3.

[37] D.L. Ramasamy, V. Puhakka, E. Repo, M. Sillanpää, Selective separation of scandium from iron, aluminium and gold rich wastewater using various amino and nonamino functionalized silica gels - A comparative study, J. Clean. Prod. 170 (2018)

[38] C. Zhang, X. Zhai, G. Zhao, F. Ren, X. Leng, Synthesis, characterization, and controlled release of selenium nanoparticles stabilized by chitosan of different molecular weights, Carbohy

[39] E. Guibal, Interactions of metal ions with chitosan-based sorbents: a review, Sep. Purif. Technol. 38 (2004) 43-74, http://dx.doi.org/10.1016/j.seppur.2003.10.004 40] E. Guibal, N. Von Offenberg Sweeney, T. Vincent, J. Tobin, Sulfur derivatives of
chitosan for palladium sorption, React. Funct. Polym. 50 (2002) 149-163, http:// dx.doi.org/10.1016/S1381-5148(01)00110-9

Aaur, U. Gupta, A preconcentration procedure using 1-(2-pyridylazo)-2-napthol anchored to silica nanoparticle for the analysis of cadmium in different samples, $\mathrm{E}-$

42] S.A. Kulkarni, S.B. Ogale, K.P. Vijayamohanan, Tuning the hydrophobic properties of silica particles by surface silanization using mixed self-assembled monolayers, $J$. Colloid Interface Sci. 318 (2008) 372-379, http://dx.doi.org/10.1016/j.jcis.2007. 11.012

[43] N. Zhang, C. Huang, B. Hu, ICP-AES determination of trace rare earth elements in environmental and food samples by on-line separation and preconcentration with acetylacetone-modified silica gel using microcolumn, [44] A. Beganskiene, V. Sirutkaitis, M. Kurtinaitiene, R. Juskenas, A. Kareiva, FTIR, TEM
and NMR linvestigations of Stöber silica nanoparticles, Mater. Sci. Medžiagotyra 10 (2004) 287-290, http://dx.doi.org/10.1016/j.jnoncrysol.2012.11.006. 


\section{Publication V}

D.L.Ramasamy, V. Puhakka, E. Repo, S. Ben Hammouda, M. Sillanpää

Two-stage selective recovery process of scandium from the group of rare earth elements in aqueous systems using activated carbon and silica composites: Dual applications by tailoring the ligand

grafting approach

Reprinted with permission from

Chemical Engineering Journal

Vol. 341, pp. 351-360, 2018

(C) 2018, Elsevier 



\begin{tabular}{|c|c|c|}
\hline 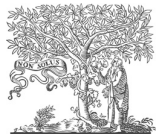 & $\begin{array}{l}\text { Contents lists available at ScienceDirect } \\
\text { Chemical Engineering Journal }\end{array}$ & 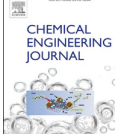 \\
\hline ELSEVIER & journal homepage: www.elsevier.com/locate/cej & \\
\hline
\end{tabular}

Two-stage selective recovery process of scandium from the group of rare earth elements in aqueous systems using activated carbon and silica composites: Dual applications by tailoring the ligand grafting approach

Deepika Lakshmi Ramasamy ${ }^{\mathrm{a}, *}$, Ville Puhakka ${ }^{\mathrm{a}}$, Eveliina Repo ${ }^{\mathrm{b}}$, Samia Ben Hammouda ${ }^{\mathrm{a}}$, Mika Sillanpää ${ }^{\mathrm{a}, \mathrm{c}}$

a Laboratory of Green Chemistry, Lappeenranta University of Technology, Mikkeli FI-50130, Finland

baboratory of Separation Technology, Lappeenranta University of Technology, P.O. Box 20, FI-53851 Lappeenranta, Finland

'Department of Civil and Environmental Engineering, Florida International University, Miami, FL 33174, USA

\section{H I G H L I G H T S}

- Two different ligand grafting techniques were explored.

- Grafting via solvent evaporation method was found to be effective for REE recovery.

- Ligand doped activated carbon demonstrated selective scandium recovery.

- Hybrid composites with ligand attachments depicted selective REE recovery.

- Two-stage recovery technique was also validated using real mining effluents.

\section{A R T I C L E I N F O}

\section{Keywords:}

Activated carbon

Adsorption

Rare earth elements

Rare earth
G R A P H I C A L A B S T R A C T

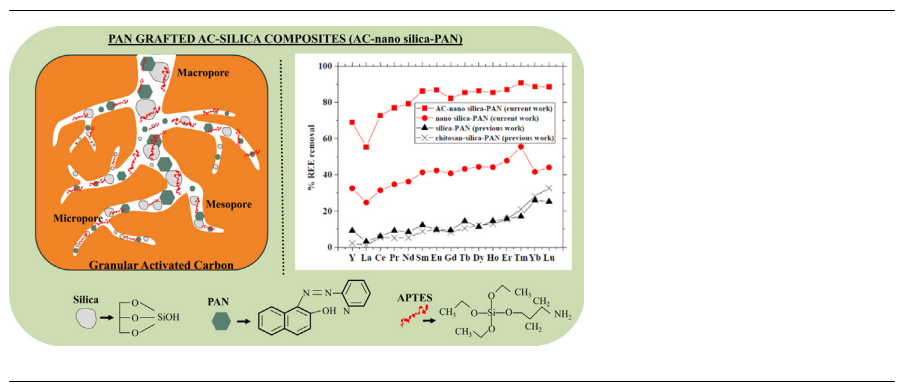

A B S T R A C T

A steady, reliable and enhanced scale of scandium (Sc) supply is of paramount importance in the current inA steady, reliable and enhanced scale of scandium (Sc) supply is of paramount importance in the current in
dustrial sector, specifically, in the production of solid oxide fuel cells and scandium based aluminum alloys. dustrial sector, specifically, in the production of solid oxide fuel cells and scandium based aluminum alloys.
Despite an expensive price quote, the remarkable physical properties of Sc drive the need to foster alternate Despite an expensive price quote, the remarkable physical properties of Sc drive the need to foster alternate
supply pools, including industrial wastes and stockpiles, to tackle the ever-increasing need in global markets. supply pools, including industrial wastes and stockpiles, to tackle the ever-increasing need in global markets.
However, they are most often obtained as a combined by-product with other metals, Sc-Y silicate minerals or rare earth elements (REE). To achieve this, activated carbon (AC) was utilized together with nano silica to synthesize two groups of adsorbents varying in terms of the ligand grafting technique. The study revealed that the Method II composites were highly effective in REE recovery, even under the process conditions of high salinity and water hardness, and in the presence of oil and organic compounds. As a conclusive step, the REE adsorption process was also successfully validated with real acidic mine drainage (AMD). Additionally, the synthesized adsorbents were characterized by scanning electron microscopy (SEM), Fourier transform infrare spectroscopy (FTIR), Brunauer-Emmett-Teller (BET), X-ray diffraction spectroscopy (XRD), organic elemental and zeta potential (ZP) analysis to gain a better insight into the underlying mechanism characterizing the adsorption process.

Corresponding author

E roil address: deepilo ramasamy@lut fi (D.L. Ramasamy).

https://doi.org/10.1016/j.cej.2018.02.024

Received 27 December 2017; Received in revised form 5 February 2018; Accepted 6 February 2018

1385-8947/ ( 2018 The Authors. Published by Elsevier B.V. This is an open access article under the CC BY license

(http://creativecommons.org/licenses/BY/4.0/). 


\section{Introduction}

The demand and cost of REEs are in a state of constant escalation, attributed primarily to their potential in accelerating the path towards a low-carbon, clean and circular economy. Some present-day applications include nickel metal hydride batteries in electric vehicles, permanent magnets in wind turbines and disk drives, compact fluorescent lights, magnetic resonance imaging machines, and catalytic converters. REEs, in general, include 15 metallic elements of the lanthanide series, along with scandium (Sc) and yttrium (Y). They are further subdivided into light rare-earth elements (LREEs) from lanthanum (La) to europium (Eu) and heavy rare-earth elements (HREEs) from gadolinium (Gd) to lutetium (Lu). Among the REEs, Sc is the most valuable element, with its market price being 5000 US $\$ / \mathrm{kg}$ (as scandium oxide, $99.9 \%$ purity) [1]. Also, a non-interrupted supply of Sc is an important part of the industrial chain in the manufacture of aluminum alloys, high voltage tension wires and, state of the art 3D printing techniques. The aviation sector is heavily reliant on the usage of Sc in the direction of developing lightweight aircraft components. REE recovery from secondary resources such as industrial waste streams, processing residues, leachate liquors, mine tailings, bauxite residue, electrical and electronic waste (end-of-life consumer goods), seems to be a promising option to overcome high supply risk [2]. Especially, mine tailings and mine waters, such as AMD containing considerable REE amounts, facilitate an easy and efficient means of procurement. Also, such a recovery path would serve beneficial in the remediation of mine sites, which is an added advantage from the economic and environmental standpoint. However, due to similar chemical properties, separation of individual REEs is extremely complicated. There is a persistent search looking for viable options to develop and optimize innovating technologies in utilizing these secondary REE resources, taking the model process economics, energy use and environmental impact into the consideration.

Several technologies such as solvent extraction, adsorption, biosorption, ion exchange process and precipitation, have been explored in the recent years to recover REEs from industrial wastes [3-6]. Among these, solvent extraction is usually preferred for recovery and recycling of REEs from concentrated aqueous waste systems. However, this process is not recommendable for usage with diluted streams as the organic solvents could cause an imminent contamination of the aqueous phase. Leaching process is also widely used for metal recovery from wastewaters, but, it also possesses certain disadvantages such as high acid waters, but, it also possesses certain disadvantages such as high acid
consumption and complications in the reuse of residues. Thus, adconsumption and complications in the reuse of residues. Thus, adsorption and ion exchange processes are preferred for recovery pro-
cesses involving diluted aqueous waste streams and relatively extensive attention has been paid to these technologies over the last decade [7-10].

Silica and activated carbon (AC) are one of the exhaustively used adsorbents for metal removal from the aqueous phase, supported by their versatility, high surface area, better thermal and mechanical stability [11-14]. The unique chemistry of REEs by virtue of properties such as high charge density, variable coordination number, and slightly differed atomic radii from each other, the functionalization of the adsorbents with potential ligands would enhance their selectivity in separation from gangue elements and for intra-element separation from paration from gangue elements and for intra-element separation from
mixed REE concentrates [15]. In our prior works, the functionalization mixed REE concentrates [15]. In our prior works, the functionalization
of mesoporous silica gel (particle size of $\sim 40 \mu \mathrm{m}$ ) was performed with the most common silane, 3-aminopropyl triethoxysilane (APTES), by attaching the organic amino-polycarboxylic acid groups to the inorganic support. APTES functionalized silica gels revealed to be highly successul in recovering REEs and the adsorbent selectivity was further the ligand attachment of 1-(2-Pyridylazo) 2-naphthol (PAN) to the organic-inorganic silica support via solvent-evaporation process [16].

In this study, nano silica $(\sim 12 \mathrm{~nm}$ particle size) and AC $(0.8 \mathrm{~mm}$ pellets) were utilized to augment the adsorbent effectiveness through the modification of physical and chemical attributes, to develop affinities towards REEs. Two different types of PAN grafting techniques were adopted to investigate the REE removal efficiencies via individual (AC-P, SilP) as well as hybridized (AC-silP) adsorbents. This novel analysis on the chosen combination of ligand and adsorbent yielded interesting and promising results that can facilitate the development of Sc separation strategy from REE mixtures, using a two-stage setup, by merely tailoring the hybridization and ligand grafting approach. The existent literature focusses on simple (usually single component) systems with elevated individual REE concentrations. However, there is an absolute need to test the efficiencies of the functionalized adsorbents under conditions of real wastewater compositions in the presence of increased salinity, water hardness, and environmentally relevant industrial impurities. Hence, investigations were also performed using real AMD to understand the REE separation behavior from mixtures, as they occur so in real wastewater.

Hence, the objective of this study was to ascertain the selective separation of $\mathrm{Sc}^{3+}$ from REE mixtures by means of the synthesized adsorbents. This would motivate the production of economically feasible REE concentrates from low concentration industrial effluents, which are available in ample amounts. This objective was established through the following steps: (a) functionalization of AC, silica and hybrid AC-silica with ligands, (b) identification of the significant ligand grafting procedure, (c) characterization of the synthesized adsorbents to understand the physio-chemical aspects and the underlying mechanism, (d) investigation of REE adsorption efficiencies in real wate conditions, and (e) validation of process parameters for REE recovery and selective $\mathrm{Sc}^{3+}$ separation from AMD in a two-stage process.

\section{Experimental section}

\subsection{Chemical agents, materials, and methods}

Activated Carbon, AC (Norit ROW $0.8 \mathrm{~mm}$ pellets, steam activated, CAS: 7440-44-0) and silica (nanopowder, $12 \mathrm{~nm}$ particle size, CAS: 7631-86-9) were obtained from Alfa Aesar and Aldrich, respectively. REE salts (in the form of chlorides or nitrates), APTES silane (for silanization), PAN (for ligand grafting) and Toluene (reagent grade, > $99 \%$, for synthesis) were attained from Sigma Aldrich as well. For the synthesis step, PAN solution was prepared by dissolving $0.2 \% \mathrm{w} / \mathrm{w}$ PAN in reagent grade acetone. Two different types of ligand grafting procedures, adopted from our earlier works [16-18], were utilized in this study. Briefly, ligand grafting was done simultaneously by reacting PAN solution along with supports (AC and silica with APTES or just silica with APTES) in Toluene mixture, referred to as Method I. These PAN impregnated Method I adsorbents are denoted as 1AC-silP (AC and silica with APTES), 1silP (silica with APTES) and 1AC-P (just AC). On the other hand, in Method II, PAN grafting was achieved via solvent evaporation process onto hybrid composites, i.e. AC and APTES functionalized nano-silica. These PAN grafted supports are referred to as $2 \mathrm{AC}$ silP, 2silP and 2AC-P, analogous to the naming convention followed for Method I adsorbents. The notations expressed in Table 1 were used throughout the course of this paper. The chemical structures of APTES, PAN and silica are provided in the graphical abstract for the better understanding of the readers.

\subsection{Instrumentation}

The infrared spectroscopy measurements were conducted by FTIR (Vertex 70 by B Brucker Optics) in order to ascertain the ligand modification, by identifying the vibrational frequencies in the functional groups of the adsorbents using $4 \mathrm{~cm}^{-1}$ resolution at 100 scans rate per groups of the adsorbents using $4 \mathrm{~cm}^{-1}$ resolution at 100 scans rate per
sample ranging from 400 to $4000 \mathrm{~cm}^{-1}$ wavelength. The ligand modsample ranging from 400 to $4000 \mathrm{~cm}^{-1}$ wavelength. The ligand mod-
ification and hybridization process were also investigated by means of XRD measurements (PANalytical instrument with the empyrean program) using $\mathrm{CoK}_{\alpha}$ irradiation at $\lambda=1.78 \AA$. The SEM analysis (SU3500 fitted with Thermoscientific UltraDry SDD EDS) provided information 
Table 1
BET and Organic elemental analysis results for all the adsorbents of this study.

\begin{tabular}{|c|c|c|c|c|c|c|c|c|}
\hline \multirow[t]{2}{*}{ Adsorbents } & \multirow[t]{2}{*}{ Notations } & \multirow[t]{2}{*}{$\begin{array}{l}\text { BET surface } \\
\text { area, in } \mathrm{m}^{2} / \mathrm{g}\end{array}$} & \multirow{2}{*}{$\begin{array}{l}\text { Single point adsorption total } \\
\text { volume of pores less than } 403 \AA \\
\text { width at } \mathrm{p} / \mathrm{p}^{\circ}=0.95, \text { in } \mathrm{cm}^{3} / \mathrm{g}\end{array}$} & \multirow{2}{*}{$\begin{array}{l}\text { BJH adsorption cumulative } \\
\text { volume of pores between } 17 \\
\text { and } 3000 \AA \text {, in } \mathrm{cm}^{3} / \mathrm{g}\end{array}$} & \multirow{2}{*}{$\begin{array}{l}\text { Adsorption average pore } \\
\text { diameter (4 V/A by } \\
\text { BET), in } \AA\end{array}$} & \multicolumn{3}{|c|}{$\begin{array}{l}\text { Organic elemental analysis (\% } \\
\text { wt) }\end{array}$} \\
\hline & & & & & & $\mathrm{N}$ & c & $\mathrm{H}$ \\
\hline \multicolumn{9}{|l|}{ Before modification } \\
\hline Activated carbon & AC & 736.38 & 0.47 & 0.23 & 25.55 & - & 63.49 & 0.54 \\
\hline Bare silica & Bare sil & 249.52 & 0.38 & 0.62 & 61.57 & - & - & - \\
\hline \multicolumn{9}{|c|}{ Without PAN functionalization } \\
\hline $\begin{array}{l}\text { Activated carbon- } \\
\text { APTES silica }\end{array}$ & AC-sil & 250.85 & 0.35 & 1.02 & 55.04 & 1.85 & 21.09 & 1.54 \\
\hline APTES silica & sil & 71.01 & 0.17 & 0.89 & 97.39 & 4.12 & 12.13 & 2.91 \\
\hline \multicolumn{9}{|c|}{ With PAN functionalization (Method I) } \\
\hline $\begin{array}{l}\text { PAN grafted Activated } \\
\text { carbon-APTES- } \\
\text { silica }\end{array}$ & 1AC-SilP & 134.06 & 0.19 & 0.42 & 55.65 & 2.58 & 37.09 & 1.74 \\
\hline $\begin{array}{l}\text { PAN grafted APTES } \\
\text { silica }\end{array}$ & 1SilP & 128.71 & 0.36 & 1.63 & 111.16 & 2.43 & 10.46 & 1.71 \\
\hline $\begin{array}{l}\text { PAN grafted activated } \\
\text { carbon }\end{array}$ & 1AC-P & 185.99 & 0.16 & 0.17 & 34.31 & 3.26 & 80.76 & 1.19 \\
\hline \multicolumn{9}{|c|}{ With PAN functionalization (Method II) } \\
\hline $\begin{array}{l}\text { PAN grafted Activated } \\
\text { carbon-APTES } \\
\text { silica }\end{array}$ & 2AC-SilP & 21.82 & 0.06 & 0.21 & 107.94 & 2.91 & 46.15 & 2.23 \\
\hline $\begin{array}{l}\text { PAN grafted APTES } \\
\text { silica }\end{array}$ & 2SilP & 109.21 & 0.34 & 1.38 & 123.43 & 2.56 & 9.58 & 1.96 \\
\hline $\begin{array}{l}\text { PAN grafted activated } \\
\text { carbon }\end{array}$ & 2AC-P & 466.39 & 0.33 & 0.19 & 28.28 & 0.73 & 72.20 & 0.92 \\
\hline
\end{tabular}

about the microstructure and morphology of the materials. The surface parameters such as surface area, pore volume, and pore diameter were determined by $\mathrm{N}_{2}$ adsorption/desorption BET isotherms (Micromeritic determined by $\mathrm{N}_{2}$ adsorption/desorption BET isotherms (Micromeritic
Tristar II plus with VacPrep 061). The organic elemental analysis (Flash 2000 Thermo scientific) of the materials yielded the \% weight of C, N, and $\mathrm{H}$ whereas the surface charge of the adsorbents was determined by surface zeta potential analysis (ZEN3500 Malvern). The initial and final concentration of the metal ion solution before and after process were measured by using ICP-OES (Agilent 5110).

\subsection{Experimental conditions}

The behavior of metal ions in the REE adsorption process was studied in a static condition (batch mode) by contacting $10 \mathrm{mg}$ of the adsorbent with $10 \mathrm{ml}$ of adsorbate solution in a centrifuge tube. The mixture was reacted for a fixed period of time on a temperature controlled orbital shaker. Primarily, the tests $\left(\mathrm{t}-24 \mathrm{~h} ; \mathrm{C}_{\mathrm{o}}-25 \mathrm{ppm}\right)$ were performed in a single component system $\left(\mathrm{La}^{3+}, \mathrm{Sc}^{3+}\right.$, and $\left.\mathrm{Y}^{3+}\right)$ to determine the optimal $\mathrm{pH}$ from the desired $\mathrm{pH}$ range of $2-6$ at room determine the optimal $\mathrm{pH}$ from the desired $\mathrm{pH}$ range of $2-6$ at room
temperature. The $\mathrm{pH}$ above 6 was neglected during the analyses due to the fact that the REEs have a tendency to precipitate from or beyond a $\mathrm{pH}$ value of 7. It needs to be emphasized that the initial adsorbate concentration (after $\mathrm{pH}$ adjustment) was verified by ICP-OES measurements before utilizing the solutions for batch tests. The adsorption isotherm (t-24 h; pH 4; $\mathrm{C}_{0}$ - varied) and kinetic tests $\left(\mathrm{C}_{0}-25 \mathrm{ppm} ; \mathrm{pH} 4\right.$; $\mathrm{t}$ - varied) were then conducted at room temperature for the determi$\mathrm{t}-$ varied) were then conducted at room temperature for the determirespectively. Following the initial tests, further experiments were executed in a multi-component system with all 16 REEs together, with the aim of assessing the effect of temperature, salinity, water hardness, the presence of oil compounds and organics in wastewater, on REE recovery. The intraseries RFE adsorption trend was analyzed based on the influence of these parameters, in the direction of the adsorbents' affiinfluence of these parameters, in the direction of the adsorbents' affi-
nities towards LREEs and HREEs. Finally, the process was validated using real mining effluents (spiked with REEs of 5 ppm each) containing higher amounts of $\mathrm{S}^{6+}(>800 \mathrm{ppm}), \mathrm{Ca}^{2+}(>100 \mathrm{ppm}), \mathrm{Na}^{+}$ $(>100 \mathrm{ppm}), \mathrm{Mg}^{2+}(\sim 76 \mathrm{ppm}), \mathrm{Mn}^{2+}(\sim 12 \mathrm{ppm})$ and $\mathrm{Zn}^{2+}$
( $\sim 70 \mathrm{ppm})$. The static equilibrium adsorption capacities $\left(\mathrm{q}_{\mathrm{e}}\right.$ in $\left.\mathrm{mg} / \mathrm{g}\right)$ and the REE removal efficiencies (in \%) were determined by using the below-mentioned Eqs. (1.1) and (1.2), respectively. In general, the experiments were performed in duplicates and the estimated average values were considered for the calculation.

$q_{e}=\frac{\left(C_{o}-C_{e}\right)}{M} V$

\% removal $=\frac{\left(C_{o}-C_{e}\right)}{C_{o}} \times 100$

where $\mathrm{C}_{0}, \mathrm{C}_{e}, \mathrm{M}$, and $\mathrm{V}$ denote the REE concentration in the initial solution $(\mathrm{mg} / \mathrm{L}$ ), equilibrium REE concentration after adsorption (mg/ $\mathrm{L})$, dry adsorbent mass $(\mathrm{g}$ ) and volume of the solution (L), respectively. It must be noted that the measured concentration (in ppm) by ICP-OES was found to be in the range of $C \pm 0.5$ of theoretical value where the limit of detection (LOD) and limit of quantification of these samples were 0.0001 and $0.0001-0.0005 \mathrm{ppm}$, respectively.

\section{Results and discussion}

\subsection{Material characterization}

The synthesized adsorbents were subjected to different characterization techniques to establish the surface modification and functionalization. The surface morphology of the adsorbents was studied by SEM analysis, the images of which are provided in Fig. 1a. From the figure, it can be seen that the PAN grafted hybrid adsorbents appeared to be porous carrier materials with roughened surfaces, unlike the PAN grafted silica adsorbents. The surface of both these group of adsorbents was coarsened post the surface modification. The adsorbents were subjected to organic elenental analysis and the BET analysis, and the immediately seen on resulted in the increase of $\mathrm{C}, \mathrm{H}$, and $\mathrm{N} \%$. The hybrid materials were largely composed of $\mathrm{C}, \mathrm{Si}$, and $\mathrm{O}$. An apparent reduction in the BET surface area and pore volume was recorded with a simultaneous increase in the average pore width of the adsorbents. This is a direct consequence of the functionalization process 


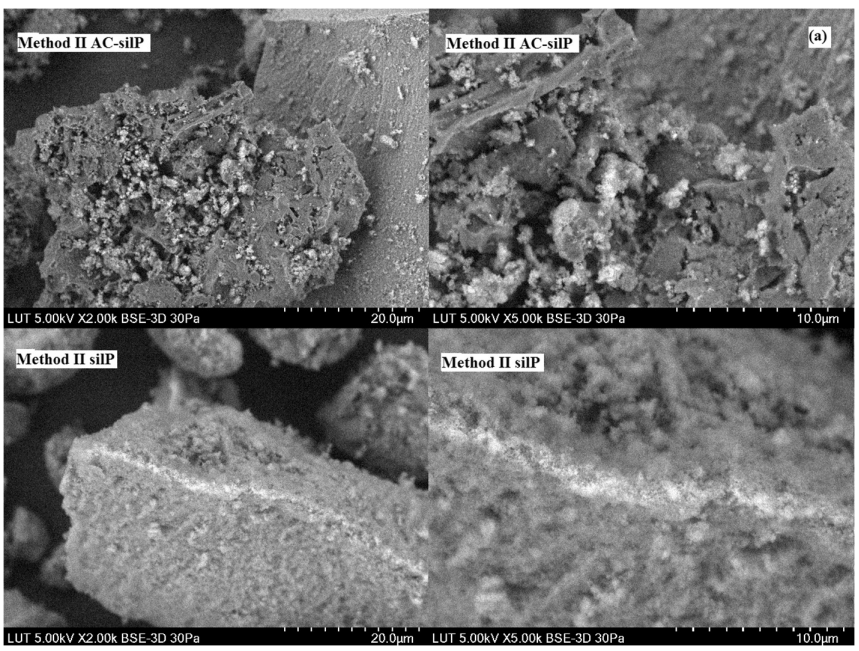

Fig. 1. (a) SEM images of Method II AC-silP (top) and silP (bottom) at $20 \mu \mathrm{m}$ (left) and $10 \mu \mathrm{m}$ magnification (right) (b-d) FTIR spectra and (e, f) XRD spectra of all the synthesized adsorbents.

which led to the blocking of the small pores and densification of the porous structure by the attached groups $[19,20]$. The $\mathrm{N}_{2}$ adsorption and desorption BET isotherms plotted as a function of $\mathrm{P} / \mathrm{Po}$ and $\mathrm{BJH}$ pore distribution, with pore volume versus pore width curves, are provided in the Supplementary material (Fig. SF1(a-f)). In line with the IUPAC classification, all the adsorbents, convex to the x-axis, followed Type III isotherm, indicative of unrestricted multilayer adsorption. The nature of the isotherm provides a valuable insight into the lateral interactions between the adsorbed molecules compared to the adsorbent-adsorbate interactions. A significant behavior observed from the study was the existence of distinct hysteresis loops (usually with Type IV and V) from the mid-range of P/Po present in PAN grafted AC adsorbents, due to the capillary condensation in mesopores. This would also imply that the pores can be essentially characterized to be narrow (slit-like) with broad size distribution and irregular shaped internal voids [21].

To gather additional information on the surface functional groups attached to the adsorbents, FTIR spectroscopic analysis was employed (Fig. 1(b-d)). From Fig. 1b, it can be recognized that the characteristic peaks at 400,800 and $1100 \mathrm{~cm}^{-1}$ were from the silica units, corresponding to the bending vibration of $\mathrm{Si}-\mathrm{O}-\mathrm{Si}$, the symmetric stretching vibration of $\mathrm{Si}-\mathrm{O}-\mathrm{Si}$ and asymmetric vibration of $\mathrm{Si}-\mathrm{O}$, respectively $[16,18]$. With APTES functionalization, there were occurrences of a small number of peaks obtained around 550 and $700 \mathrm{~cm}^{-1}$, owing to the asymmetric mode of $\mathrm{Si}-\mathrm{CH}_{3}$ groups from silanes. In addition to these peaks, continuous bands from 1200 to $1600 \mathrm{~cm}^{-1}$ were also observed as a result of amine functionalization, indicating the existence of symmetric $\mathrm{NH}_{2}$ groups $\left(1480-1450 \mathrm{~cm}^{-1}\right), \mathrm{CH}_{2}$ wagging mode $\left(1300 \mathrm{~cm}^{-1}\right), \mathrm{C}-\mathrm{H}$ stretch or deformation vibration $\left(1382 \mathrm{~cm}^{-1}\right)$ and bending mode of $\mathrm{Si}-\mathrm{CH}_{2}$ groups $\left(1410 \mathrm{~cm}^{-1}\right)$ [17]. Besides, the peaks obtained at 1355,1398 and $1633-1650 \mathrm{~cm}^{-1}$ were assigned to $\mathrm{C}-\mathrm{O}$ mode, the intra-surface bending vibration of $\mathrm{C}-\mathrm{O}-\mathrm{H}$, the carbonyl stretch vibration $\mathrm{C}=\mathrm{O}$, respectively [22]. The band intensities of the APTES functionalized silica (SIL) were smoothened after the hybridization process with AC, as shown in Fig. 1b. From a comparative sense, the spectra from Method I and II PAN grafted silica adsorbents, 1 silP and 2silP, (Fig. 1c and d), did not indicate any distinct changes in the peaks spotted. However, in the case of PAN grafted hybrid AC-sil adsorbents, 1AC-silP shared similarities with AC-sil (without ligand doping). On the other hand, 2AC-silP demonstrated the occurrence of new peaks around $750 \mathrm{~cm}^{-1}$, primarily due to the ligand attachment on the $\mathrm{Si}-\mathrm{CH}$ of APTES moieties. Moreover, the band intensities witnessed in the territories of APTES and PAN units, between 1200 and $1600 \mathrm{~cm}^{-1}$, are visually sharper for Method II adsorbents, in comparison with Method I adsorbents. The bands associated with silica were clearly absent in PAN grafted AC adsorbents (both 1AC-P and 2AC-P). In all PAN functionalized materials, the transmittances featuring PAN groups can be detected at 1500,1686 and $1329 \mathrm{~cm}^{-1}$ as a direct consequence of $\mathrm{C}=\mathrm{C}$ stretching vibration arising from benzenoid and pyridyl units, $\mathrm{N}=\mathrm{N}$ vibrations and $\mathrm{C}=\mathrm{N}$ stretching vibration from the benzenoid group, respectively [23].

XRD diffraction patterns for the synthesized adsorbents before and after the modifications are shown in Fig. SF2 (Supplementary material) and Fig. 1 (e and f). As depicted by the spectra, the broad peaks in the $2 \theta$ range of $20-26^{\circ}$ indicate the disordered amorphous nature of the materials [24]. Upon hybridization with silica, the AC diffraction peaks obtained at $45-50^{\circ}$ indicative of a graphite structure were almost nonexistent (Fig. 1e) while these typical peaks were still observed for ACPAN adsorbents (Fig. 1f), serving as an affirmation of the hybridization PAN adsorbents (Fig. 1f), serving as an affirmation of the hybridization
process. The acquired peaks at $26^{\circ}, 44^{\circ}$ and $83^{\circ}$ correspond to the diffraction plane 002, 100/ 101 and 112 of a graphite structure, respectively, which are distinctive for all AC based materials [25]. Also, the peak at $12-15^{\circ}$ was seen specifically after APTES functionalization. In line with FTIR results, there were no apparent changes in XRD peak patterns between 1silP and 2silp. However, definite differences were noticed in the case of $1 \mathrm{AC}$-SilP and 2AC-SilP adsorbents, with new peaks emerged at the end of the amorphous halo around $30-35^{\circ}$. PAN grafted AC adsorbents (Fig. 1f) displayed a sharp intensity peak at $25^{\circ}$ for $1 \mathrm{AC}$-silP while the analogous peak intensity was reduced in the case of AC and 1AC-P adsorbents.

The zeta potential measurements (Supplementary Fig. SF3) of modified adsorbents showed that the net surface potential was positive for the APTES functionalized adsorbents, owing to the protonated amino groups and $\mathrm{H}^{+}$ions, similar to the observations from our previous works $[27,28]$. It must also be remarked that the isoelectric $\mathrm{pH}$ (IEP) of bare silica and AC was around 2 and 4 , respectively, the possible explanation of which might be the excess $\mathrm{OH}^{-}$ions on silica and 

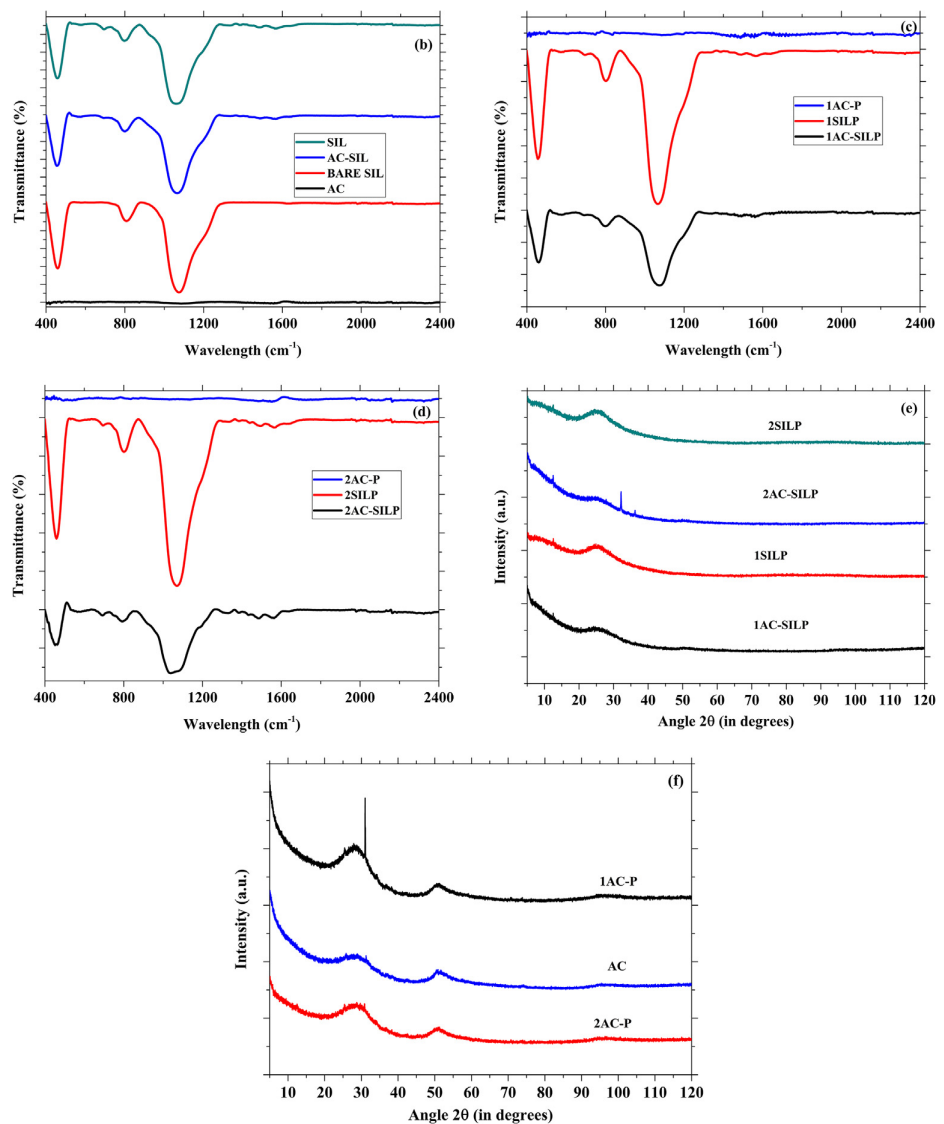

Fig. 1. (continued)

carboxyl groups on the surface of AC. Hence, post ligand grafting and APTES functionalization, the IEP of the adsorbents shifted to a higher $\mathrm{pH}$ value, indicating an increase in the electropositive nature of the surface [22].

\subsection{Single component adsorption studies}

The synthesized adsorbents were subjected to $\mathrm{pH}$, isotherm and kinetic tests in a single component system to assess the removal of $\mathrm{La}^{3+}, \mathrm{Sc}^{3+}$, and $\mathrm{Y}^{3+}$. The results of these experiments are provided in $\mathrm{La}^{3+}, \mathrm{Sc}^{3+}$, and $\mathrm{Y}^{3+}$. The results of these experiments are provided in
Supplementary information (Fig. SF4(a-f)). The aforementioned REEs were chosen as target elements for the single component batch tests as they demonstrate a different behavior in relation to their counterparts. Fig. SF4 shows that the modified silica and AC-silica composites delivered maximum adsorption from a $\mathrm{pH}$ value of 4 , irrespective of PAN grafting method adopted On comparing the two groups of adsorbents, Method II adsorbents returned the best results with the hybrid AC-silP depicting marginal superiority over silP. However, with the absence of silica moieties, AC with ligand grafting yielded inferior outcomes under the given process conditions $\left(\mathrm{C}_{\mathrm{o}}-25 \mathrm{ppm} ; \mathrm{T}-23^{\circ} \mathrm{C}\right)$. The adsorption capacities of the synthesized materials from this study are summarized in
Table 2 together with the optimum conditions for the $\mathrm{La}^{3+}, \mathrm{Sc}^{3+}$, and $\mathrm{Y}^{3+}$ sorption process. The comparison shows that the adsorbents are evidently superior to or at the least on par with a majority of similar materials found in the literature $[9,11,26,27]$.

3.3. Multi-component adsorption studies

\subsubsection{REE adsorption trend}

From the single component experiments, an optimum $\mathrm{pH}$ value of 4 was selected as the process $\mathrm{pH}$ for further investigations using a multicomponent system. The tests were also conducted at lower $\mathrm{pH}$ values of 2 and 3, however, returned poor adsorption results, in line with the inference from the previous section. At $\mathrm{pH} \mathrm{4}$, there was significant adsorption with Method II adsorbents with enhanced REE removal over the Method I adsorbents (Fig. 2a). The REE removal efficiencies were found to be in the order of $2 \mathrm{AC}$-silP $>2$ silP $=1$ silP $>1 \mathrm{AC}$-silP $>$ 1AC-P. Among the REEs, $\mathrm{Sc}^{3+}$ adsorption was supreme while the adsorption of $\mathrm{La}^{3+}$ was the worst. With 1AC-silP, it was also witnessed that the adsorption of HREEs was comparatively higher than the LREEs. A similar behavior was also reported in our previous works with $\mathrm{Sc}^{3+}$ with its smallest ionic size displaying superior adsorption while 
Table 2

Comparison of adsorption capacities and process parameters with other works.

\begin{tabular}{|c|c|c|c|c|c|c|c|c|c|c|}
\hline \multirow[t]{2}{*}{ Adsorbents } & \multicolumn{3}{|c|}{ Maximum adsorption capacities $(\mathrm{mg} / \mathrm{g})$} & \multicolumn{3}{|c|}{ Equilibrium time (in min) } & \multicolumn{3}{|c|}{ Adsorption $\mathrm{pH}$} & \multirow[t]{2}{*}{ References } \\
\hline & $\mathrm{La}^{3+}$ & $\mathrm{Sc}^{3+}$ & $\mathrm{Y}^{3+}$ & $\mathrm{La}^{3+}$ & $\mathrm{Sc}^{3+}$ & $\mathrm{Y}^{3+}$ & $\mathrm{La}^{3+}$ & $\mathrm{Sc}^{3+}$ & $\mathrm{Y}^{3+}$ & \\
\hline PAN functionalized Activated carbon-APTES nanosilica & 103.5 & 112.74 & 84.1 & 30 & 1440 & 30 & 4 & 4 & 4 & This study \\
\hline PAN functionalized -APTES nanosilica & 85.72 & 75.5 & 62.92 & 30 & 480 & 120 & 4 & 4 & 4 & This study \\
\hline Cellulose-silica nanocomposite & 29.48 & 23.76 & - & 50 & 50 & - & 6 & 6 & - & Iftekhar et al. [11] \\
\hline $\begin{array}{l}\text { Gum arabic grafted polyacrylamide based silica } \\
\text { nanocomposites }\end{array}$ & 7.90 & 11.05 & - & 60 & 60 & - & 6 & 6 & 6 & Iftekhar et al. [26] \\
\hline EDTA- $\beta$-cyclodextrin & 47.64 & - & - & 120 & - & - & 4 & 4 & 4 & Zhao et al. [9] \\
\hline
\end{tabular}

* Converted from the original unit of $\mathrm{mmol} / \mathrm{g}$ presented in literature.

$\mathrm{La}^{3+}$ and $\mathrm{Y}^{3+}$ adsorption were insignificant in a multi-component system [28]. This behavior can be attributed to their larger ionic sizes in comparison to the HRFEs, resulting from the lanthanide contraction effect, the implication of which being the decrease in ionic size with an increase in atomic size and weight [29]. Although Y belongs to the HREEs, the ionic size of $Y$ is relatively larger and possess different electronic configuration level compared to the rest of the HREE members. It must be noted that the hybrid adsorbents work exceptionally well even without any PAN modification. AC-sil and sil showed nearly $100 \%$ adsorption, akin to 2AC-silP, under the given conditions. This demanded further tests to examine the performance of the synthesized adsorbents in detail as the real water applications constantly pose severe challenges and interferences that hinder favorable REE adsorption with the existence of competing species. 1AC-P and 2AC-P did not show any meaningful REE removal and were hence not incorporated in further assessments with the whole REE series.

3.3.2. Effect of salinity, water hardness, and oil contamination

Several environmental factors such as the presence of competing ions, hardness ions, dissolved organic compounds and oil contamination from the waste sites, can eventually exert a negative influence on the effectiveness of the REE adsorption process. Fig. $2 \mathrm{~b}$ illustrates the effect of salinity (presence of $\mathrm{Na}^{+}$until $25 \mathrm{ppm}$ ) on the REE removal efficiencies of the adsorbents. The tests revealed that the influence of salinity was adverse on all the adsorbents except AC-Sil, Sil and 2ACSilP. Both the PAN grafted silica gels and 1AC-SilP showed a drastic declination of the $\%$ REE removal in the presence of $\mathrm{Na}^{+}$ions. The occurrence of $\mathrm{Na}^{+}$ions hampered $\mathrm{Sc}^{3+}$ removal significantly where Method II adsorbents were affected considerably in comparison to Method I adsorbents. On the other hand, the presence of $\mathrm{Na}^{+}$ion demonstrated no interference with $\mathrm{Sc}^{3+}$ removal by AC-Sil and Sil adsorbents without PAN grafting. Based on the knowledge from surface chemistry studies [30], it can be s sorption efficiencies might be a result of the expansion of the diffused double layer thickness, which encloses the adsorbent-adsorbate contained in an electrolyte.

Analogously, the adsorbents were also studied in the presence of hardness ions $\left(\mathrm{Ca}^{2+}\right.$ and $\mathrm{Mg}^{2+}$ ions up to $25 \mathrm{ppm}$ each). It can be inferred from the Fig. $2 \mathrm{c}$ that except for 2AC-SilP, all the adsorbents' efficacies were influenced by the existence of $\mathrm{Ca}^{2+}$ and $\mathrm{Mg}^{2+}$ ions as well owing to competitive adsorption of the ions. It should be noted that the water hardness impacted the REE removal proficiencies of ACSil and Sil adsorbents without any PAN grafting while water salinity had a negligible effect on the same. Among the above-mentioned adsorbents, AC-sil was extensively influenced with a recorded removal efficiencies of $20-50 \%$ for LREEs and $60-80 \%$ for HREEs. In case of Sil, \%erive
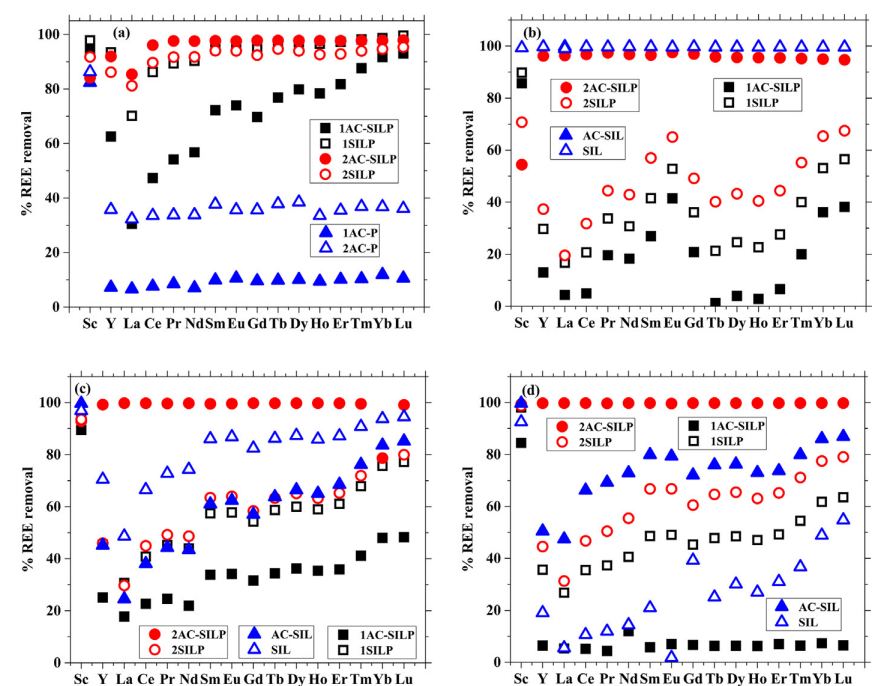

Fig. 2. Comparison of REE removal efficiencies in the (a) absence of competing ions (b) presence of $\mathrm{Na}^{+}$(c) presence of $\mathrm{Ca}^{2+}$ and $\mathrm{Mg}^{2+}$ and (d) presence of heptane. 
these effects of the parameters on the adsorbents in terms of $\mathrm{Sc}^{3+} \mathrm{re}$ moval. On the other hand, all the adsorbents indicated maximum $\mathrm{Sc}^{3}$ removal (>90\%) in the presence of $\mathrm{Ca}^{2+}$ and $\mathrm{Mg}^{2+}$ ions.

The presence of the oil and alkane compound, heptane (up to $100 \mathrm{ppm}$ ), in the wastewater (Fig. 2d), does not affect the adsorption efficiency of $2 \mathrm{AC}$-silP (nearly $100 \%$ ) under the given process conditions. Similar to the earlier cases, 1 silp and 2silP demonstrated declination in the \%REE removal from wastewater containing oil compounds. An interesting and surprising observation was the tremendous drop in REE removal efficiencies of APTES functionalized nano silica (sil) and APTES functionalized AC-silica without any PAN grafting (ACsil). Similarly, the decline in the system performance in the presence of oil compound octane was also reported in other works [31]. This could be due to the formation of non-adsorbable complexes, competition for the available binding sites or restriction of the mobility of REE as a result of clogged pores in the presence of heptane.

3.4. Development of two-step recovery process to separate $\mathrm{Sc}^{3+}$ and other REES

A viable and efficient strategy for the selective procurement of the high technology element, $\mathrm{Sc}^{3+}$ from the whole REE mixture is proposed in the following section based on the prior investigations of this study. The results from Section 3.3 disclosed that hybrid, as well as silica adsorbents (Method I and II) with and without PAN grafting, demonstrated superior selectivity towards all REEs. Among them, 2AC-SilP strated superior selectivity towards all REEs. Among them, 2AC-SilP held the maximum potential for the same, exhibiting superior REE
adsorption without any interference from $\mathrm{Na}^{+}, \mathrm{Ca}^{2+}, \mathrm{Mg}^{2+}$, oil and organic compounds. Alternatively, PAN grafted AC adsorbents displayed greater selectivity towards $\mathrm{Sc}^{3+}$, with only $40 \%$ co-removal of rest of the REEs by 2AC-P and less than $10 \%$ of co-removal of other REEs by $1 \mathrm{AC}-\mathrm{P}$. Therefore, further tests were conducted to identify the process conditions for the acquisition of $\mathrm{Sc}^{3+}$ and rest of the REEs separately. Real AMD was utilized for this purpose as a meaningful resource to validate the proposed strategy.

Fig. 3a and b present the REE removal efficiencies of the adsorbents from AMD at $\mathrm{pH} 4$ and 5 at $45^{\circ} \mathrm{C}$ for the process time of $1 \mathrm{~h}$. The figures denote that there was no $\mathrm{Sc}^{3+}$ removal at $\mathrm{pH} 4$ except for the case of PAN grafted AC adsorbents. 1AC-P and 2AC-P recorded $\mathrm{Sc}^{3+}$ removal of around $90 \%$ and $80 \%$, respectively, with only about $20 \%$ of co-removal around $90 \%$ and $80 \%$, respectively, with only about $20 \%$ of co-removal
of other REEs. At pH 5, 2AC-silP was the only adsorbent successful in removing REEs ( $>70 \%$ ) from the AMD solution comprising high concentrations of $\mathrm{Zn}^{2+}, \mathrm{Mg}^{2+}, \mathrm{Mn}^{3+}, \mathrm{Al}^{3+}$, and $\mathrm{S}^{6+}$. The effect of temperature was also studied with real AMD (Fig. 3c) for the given time period of $1 \mathrm{~h}$. 2AC-silP illustrated lesser $\%$ REE removal at $23^{\circ} \mathrm{C}$ compared to $45^{\circ} \mathrm{C}$ with no significant effect on other adsorbents. A viable pared to $45^{\circ} \mathrm{C}$ with no significant effect on other adsorbents. A viable double electric layer thickness on the adsorbent surface with the temperature, which in turn would influence the REE diffusion resistance [22]. Thus, it can be inferred that an increase in temperature resulted in the enhanced migration of ions in the solution and into the adsorbents. Therefore, a two-step approach can be utilized to accomplish the The $\mathrm{pH} 4$ and (b) 2AC-silP for the recovery of rest of the REEs at pH 5. It should be noted at a pH value of 4 , the poor adsorption of REEs was recorded probably due to the competition from $\mathrm{Al}^{3+}$ ions $(\sim 120 \mathrm{ppm})$, reported in other works $[8,32]$. Regardless, $\mathrm{Sc}^{3+}$ could be separated selectively from the AMD solution at this $\mathrm{pH}$ using PAN grafted AC adsorbents. Though bare $\mathrm{AC}$ and silica also demonstrated affinity towards $\mathrm{Sc}^{3+}$, the co-separation of REEs was considerably higher compared to PAN grafted AC adsorbents. At $\mathrm{pH} 5, \mathrm{Sc}^{3+}$ ions are prone to precipitation from the concentrate along with $\mathrm{Fe} / \mathrm{Al}$. Hence, the recovery at $\mathrm{pH} 4$ seems to be a viable and ideal option for $\mathrm{Sc}^{3+}$ ions. As a final course of action, the REEs were eluted successfully from these adsorbents by using $1 \mathrm{M} \mathrm{HNO}_{3}$ within $15 \mathrm{~min}$.

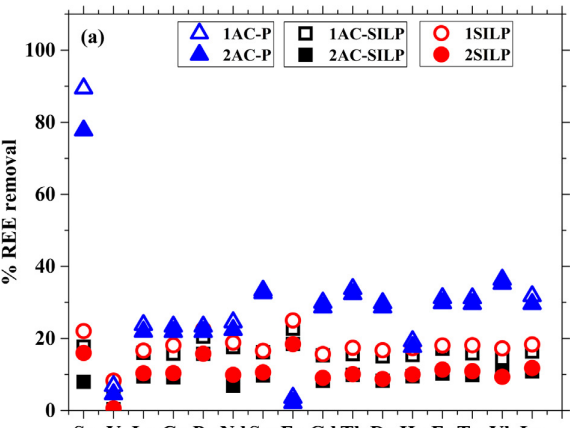

Sc Y La Ce Pr NdSm Eu Gd Tb Dy Ho ErTm Yb Lu
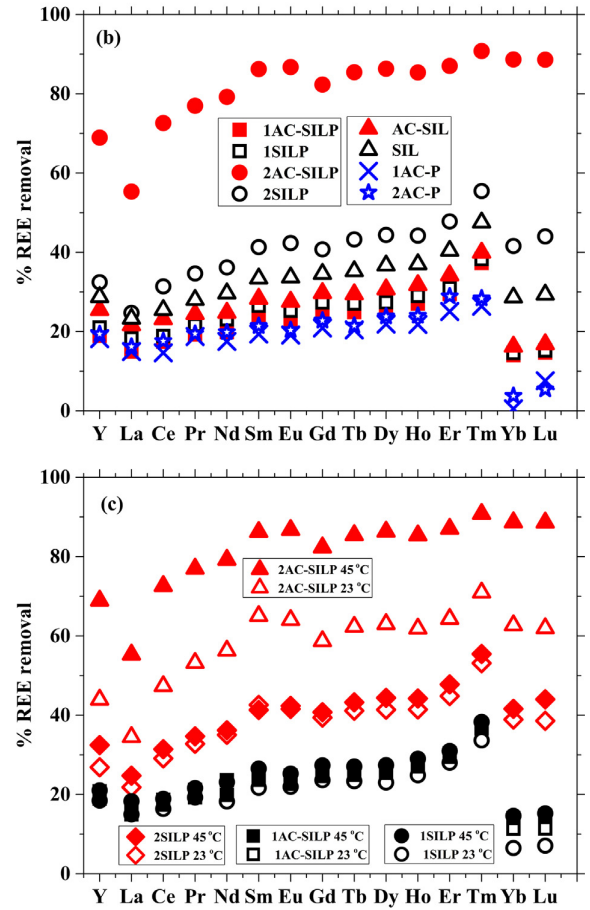

Fig. 3. Recovery of (a) $\mathrm{S}^{3+}$ at $\mathrm{pH}_{4} 4$ (b) rest of the $\mathrm{REFs}$ at $\mathrm{pH} 5$ from $\mathrm{AMD}$. (c) Influence of temperature on REE recovery from AMD.

\subsection{Adsorption behavior}

The increase in the solution $\mathrm{pH}$ and temperature had a favorable impact of the REE adsorption process. Since the net positive surface charge was below $\mathrm{pH}_{\mathrm{IEP}}$, within the studied $\mathrm{pH}$ range (1-5), confirmed by the zeta potential results, the adsorption by the synthesized adsorbents seemed to be driven by electrostatic interactions, physical adsorption and largely via ion-exchange reactions, in line with silica leaching from the adsorbents during REE adsorption. This, in turn, 

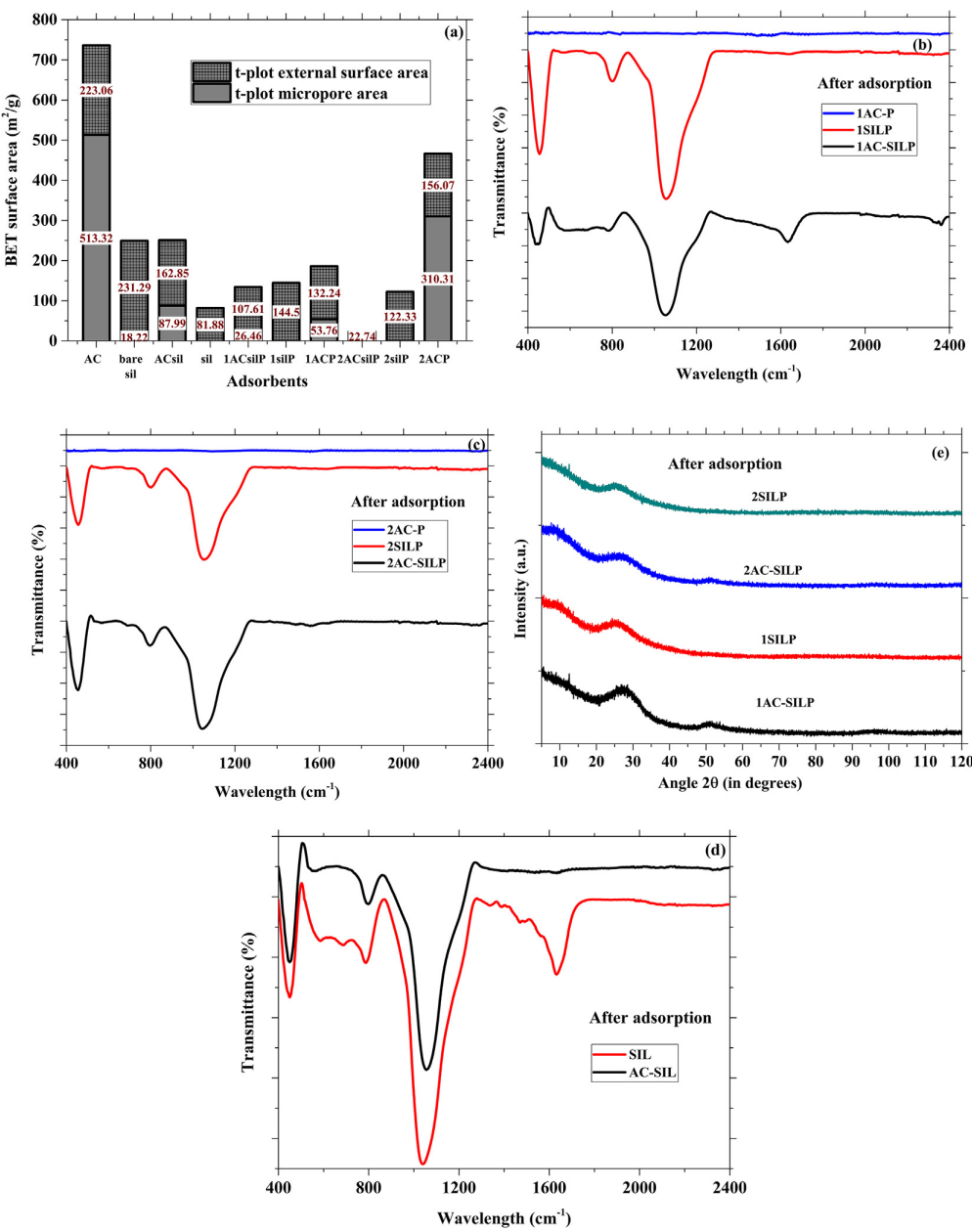

Fig. 4. (a) T-plot micro-pore and external surface area of the synthesized adsorbents (b-d) FTIR spectra of all the adsorbents after REE adsorption (e) XRD spectra after REE adsorption.

restricted the reusability of the composites due to the loss of groups during ion exchange process. An additional mechanism that can serve as a suitable explanation is the chelation or complexation of metal ions to the protonated pyridine - $\mathrm{N}$ group of PAN [28]. The affinity of the adsorbents towards $\mathrm{Sc}^{3+}$, subsequently followed by the HREEs, might be attributed to the lower ionic radii of the same in relation with that of LREEs. The general adsorption trend reflects lanthanide contraction effect of imperfect shielding of electrons from the same sub-shell, with an increase in atomic number. Also, the dominant binding sites in the studied $\mathrm{pH}$ regime can also exert some amount of influence.

It is worth mentioning that the most efficient adsorbent of this study, 2AC-silP, presented a very low BET surface area, however, demonstrated the highest REE adsorption capacities among the adsorbents under scrutiny. Also, the maximum REE uptake coincided with the accessible pore volume rather than the internal surface area. With the pore size and cumulative pore volume of 1AC-silP and 2AC-silP being 55.65 and $107.94 \AA$, and 0.42 and $0.21 \mathrm{~cm}^{3} / \mathrm{g}$, respectively, the latter proved to the best effective adsorbent among the group. Despite the greater pore volume and pore width, PAN grafted silica adsorbents were inferior to $2 \mathrm{AC}$-silP. The probable explanation might be the presence of accessible heterogeneous binding sites on both external and internal surfaces of 2AC-silP.

In the absence of nano silica hybridization, PAN grafted AC materials and bare silica have increased affinities towards $\mathrm{Sc}^{3+}$, governed by pore diffusion. Owing to the higher surface area of AC, it is expected to have larger microporous granular surfaces (Fig. 4a). Hence, adsorbents such as bare AC and PAN grafted AC, with higher micropore volume and lesser width were more effective in selective $\mathrm{Sc}^{3+}$ adsorption (smallest ionic radii of $0.75 \AA$ among the REEs). On the other hand, in PAN grafted silica and hybrid AC-silica composites, mesopore volume 
increased substantially with the decrease in the micropore volume, post-functionalization, leading to enhanced affinities towards all REEs. The band shift and disappearance of peaks in FTIR spectra after adsorption from 400 to $900 \mathrm{~cm}^{-1}$ and from 1200 to $1600 \mathrm{~cm}^{-1}$ (Fig. 4(b-d)) affirmed the silica groups, APTES backbone and PAN units as probable functional groups or centers that were a part of the adsorption process (Supplementary material: Fig. SF5). XRD analysis was also performed on the adsorbents subsequent to the adsorption process (Fig. 4(e)). PAN grafted silica adsorbents did not show any change in the peaks while 1AC-silP depicted an increased intensity of the diffraction peak for a graphite structure at $50^{\circ}$. The realizations were coherent with the inference from the FTIR analysis as well. On the other hand, the intensity of peaks around $30-40^{\circ}$ was diminished after the REE uptake onto 2AC-silP which indicates the formation of complexes between REE cations and silane/ PAN groups.

\section{Conclusion}

The following conclusions can be drawn from the investigations of the synthesized adsorbents for the REE removal process:

- A strategy for selective recovery of scandium, as well as the rest of the REE concentrate from the AMD solution, was successfully devised as a two-step adsorption process using the synthesized adsorbents, at $\mathrm{pH}$ values of 4 and 5 , respectively.

- PAN grafted AC yielded selective $\mathrm{Sc}^{3+}$ recovery while the same grafting technique performed on the hybrid AC-APTES-silica or just APTES-silica ensued the selectivity towards all REEs.

- An exploration of the two ligand grafting approaches revealed that the PAN grafting onto hybridized AC-Sil composites via solvent evaporation process (Method II) was predominantly superior to the simultaneous hybridization and ligand grafting process via one-pot synthesis (Method I). For Method I and II PAN grafted silica adsorbents, the influence of grafting procedure seemed insignificant. The effectiveness of the synthesized adsorbents could be arranged in the following order: 2AC-SilP $>2$ SilP $\geq 1$ SilP $>1$ AC-SilP.

- The REE removal process was enhanced with the increase in temperature, $\mathrm{pH}$ and contact time.

- Desorption of REEs could be carried out by $1 \mathrm{M} \mathrm{HNO}_{3}$ within the contact time of $15 \mathrm{~min}$.

\section{Acknowledgement}

The authors are grateful to Academy of Finland (decision number 292542) for funding the project. The authors are also thankful to Mr. Toni Väkiparta from LUT School of Engineering Science for the SEM analysis.

\section{Appendix A. Supplementary data}

Supplementary data associated with this article can be found, in the online version, at http://dx.doi.org/10.1016/j.cej.2018.02.024.

\section{References}

[1] C.R. Borra, B. Blanpain, Y. Pontikes, K. Binnemans, T. Van Gerven, Recovery of rare earths and other valuable metals from bauxite residue (red mud): a review, J.
Sustain. Metall. 2 (2016) 365-386, http://dx.doi.org/10.1007/s40831-016-0068-2.

[2] K. Binnemans, P.T. Jones, B. Blanpain, T. Van Gerven, Y. Yang, A. Walton, M. Buchert, Recycling of rare earths: a critical review, J. Cleaner Prod. 51 (2013) 1-22, http://dx.doi.org/10.1016/.j.clepro.2012.12.037.

[3] C. Ayora, F. Macías, E. Torres, A. Lozano, S. Carrero, J.-M. Nieto, R. Pérez-López, A. Fernández-Martínez, H. Castillo-Michel, Recovery of rare earth elements and yttrium from passive-remediation systems of acid mine drainage, Environ. Sci.
Technol. 50 (2016) 8255-8262, http://dx.doi.org/10.1021/acs.est.6b02084.

[4] J. Kulczycka, Z. Kowalski, M. Smol, H. Wirth, Evaluation of the recovery of rare J. Kulczycka, Z. Kowalski, M. Smol, H. Wirth, Evaluation of the recovery of rare
earth elements (REE) from phosphogypsum waste - case study of the WIZÓW chemical plant (Poland), J. Cleaner. Prod. 113 (2016) 345-354, http://dx.doi.org/ 10.1016/j.jclepro.2015.11.039.
[5] J. Roosen, S. Van Roosendael, C.R. Borra, T. Van Gerven, S. Mullens, K. Binnemans, Recovery of scandium from leachates of Greek bauxite residue by adsorption on T.

6] W. Wang, C.Y. Cheng, Separation and purification of scandium by solvent extrac1237-1246, http://dx.doi.org/10.1002/jetb.2655.

[7] M.R. Awual, T. Yaita, H. Shiwaku, Design a novel optical adsorbent for simultaneous ultra-trace cerium(III) detection, sorption and recovery, Chem. Eng. J. 228 (2013) 327-335, http://dx.doi.org/10.1016/j.cej.2013.05.010

[8] S. Iftekhar, V. Srivastava, M. Sillanpää, Synthesis and application of LDH intercalated cellulose nanocomposite for separation of rare earth elements (REEs),
Chem. Eng. J. 309 (2017) 130-139, http://dx.doi.org/10.1016/j.cej.2016.10

[9] F. Zhao, E. Repo, Y. Meng, X. Wang, D. Yin, M. Sillanpää, An EDTA- $\beta$-cyclodextrin material for the adsorption of rare earth elements and its application in preconcentration of rare earth elements in seawater, J. Colloid Interface Sci. 465 (2016) 215-224, http://dx.doi.org /10.1016/j.jcis.2015.11.069.

[10] D.L. Ramasamy, V. Puhakka, S. Ttekhar, A. Wojtuś, E. Repo, S. Ben Hammouda, E. Iakovleva, M. Sillanpää, N- and O- ligand doped mesoporous silica-chitosan hybrid beads for the efficient, sustainable and selective recovery of rare earth ele-
ments (REE) from acid mine drainage (AMD): Understanding the significance of physical modification and conditioning of the polymer, J. Hazard. Mater. 348 (2018) 84-91, http://dx.doi.org/10.1016/j.jhazmat.2018.01.030.

[11] S. Iftekhar, V. Srivastava, M. Sillanpää, Enrichment of lanthanides in aqueous system by cellulose based silica nanocomposite, Chem. Eng. J. 320 (2017) 151-159,

http://dx.doi.org/10.1016/j.cej.2017.03.051.
[12] M. Rabiul Awual, M. Munjur Hasan, T. Ihara, T. Yaita, Mesoporous silica based novel conjugate adsorbent for efficient selenium(IV) detection and removal from
water, Microporous Mesoporous Mater. 197 (2014) 331-338, http://dx.doi.org/10 1016/j.micromeso.2014.07.005.

[13] E. Repo, T.A. Kurniawan, J.K. Warchol, M.E.T. Sillanpää, Removal of Co(II) and N (II) ions from contaminated water using silica gel functionalized with EDTA and/o DTPA as chelating agents, J. Hazard. Mater. 171 (2009) 1071-1080, http://dx.do org/10.1016/j.jhazmat.2009.06.111.

14] C. Yin, M. Aroua, W. Daud, Review of modifications of activated carbon for enhancing contaminant uptakes from aqueous solutions, Sep. Purif.
(2007) 403-415, http://dx.doi.org/10.1016/j.seppur.2006.06.009.

[15] C.W. Noack, K.M. Perkins, J.C. Callura, N.R. Washburn, D.A. Dzombak, A.K. Karamalidis, Effects of ligand chemistry and geometry on rare earth element partitioning from saline solutions to functionalized adsorbents, ACS Sustain. Chem Eng. 4 (2016) 6115-6124, http:// dx.doi.org/10.1021/acssuschemeng.6b01549.

[16] D.L. Ramasamy, E. Repo, V. Srivastava, M. Sillanpää, Chemically immobilized an physically adsorbed PAN/acetylacetone modified mesoporous silica for the recovery of rare earth elements from the waste water-comparative and optimization
study, Water Res. 114 (2017) 264-276, http://dx.doi.org/10.1016/i.watres.2017. 02.045 .

[17] D.L. Ramasamy, S. Khan, E. Repo, M. Sillanpää, Synthesis of mesoporous and microporous amine and non-amine functionalized silica gels for the application of rare earth elements (REE) recovery from the waste water-understanding the role of $\mathrm{pH}$ temperature, calcination and mechanism in Light REE and Heavy REE separation,

[18] N. Zhang. C. Huang B. Hu, ICP-AFS determination of trace rare earth elements in environmental and food samples by on-line separation and preconcentration with acetylacetone-modified silica gel using microcolumn, Anal. Sci. 23 (2007) 997-1002, http://dx.doi.org/10.2116/analsci.23.997.

[19] M.R. Awual, New type mesoporous conjugate material for selective optical coppe (II) ions monitoring \& removal from polluted waters, Chem. Eng. J. 307 (2017) 85-94, http://dx.doi.org/10.1016/j.cej.2016.07.110.

M.R. Awual, Assessing of lead(III) capturing from contaminated wastewater using
ligand doped conjugate adsorbent, Chem. Eng. J. $289(2016) 65-73$ h htp org/10.1016/i.cej.2015.12.078

[21] J.C. Groen, L.A. Peffer, J. Pérez-Ramírez, Pore size determination in modified micro- and mesoporous materials. Pitfalls and limitations in gas adsorption da analysis, Microporous Mesoporous Mater. 60 (2003) 1-17, http://dx.doi.org/10.

[22] C. Tang, Y. Shu, R. Zhang, X. Li, J. Song, B. Li, Y. Zhang, D. Ou, Comparison of the removal and adsorption mechanisms of cadmium and lead from aqueous solution Adv. 7 (2017) 16092-16103, http://dx.doi.org/10.1039/C6RA28035H.

[23] A. Kaur, U. Gupta, A preconcentration procedure using 1-(2-Pyridylazo)-2-naptho anchored to silica nanoparticle for the analysis of cadmium in different samples, $\mathrm{E}$ -

J. Chem. 5 (2008) 930-939, http://dx.doi.org/10.1155/2008/431916.
[24] S. Xu, Z. Wang, Y. Gao, S. Zhang, K. Wu, Adsorption of rare earths(III) using an efficient sodium alginate hydrogel cross-linked with poly- $\gamma$-glutamate, PLoS One 10

en storage, in: J. Liu (Ed.), Hydrog. Storage, InTech, 2012doi:10.5772/50521.

[26] S. Iftekhar, V. Srivastava, A. Casas, M. Sillanpää, Synthesis of novel GA-g-PAM/SiO 2 nanocomposite for the recovery of rare earth elements (REE) ions from aqueous solution, J. Cleaner Prod. 170 (2018) 251-259, http://dx.doi.org/10.1016/j. jclepro. 2017.09 .166 .

27] D.L. Ramasamy, A. Wojtuś, E. Repo, S. Kalliola, V. Srivastava, M. Sillanpää, Ligand immobilized novel hybrid adsorbents for rare earth elements (REE) removal from
waste water: assessing the feasibility of using APTES functionalized silica in the hybridization process with chitosan, Chem. Eng. J. 330 (2017) 1370-1379, http:// dx.doi.org/10.1016/j.cej.2017.08.098. 

[28] D.L. Ramasamy, V. Puhakka, E. Repo, S. Khan, M. Sillanpää, Coordination and silica
surface chemistry of lanthanides (III), scandium (III) and yttrium (III) sorption on 1(2-pyridylazo)-2-naphthol (PAN) and acetylacetone (acac) immobilized gels,

[29] P. Henderson, Rare Earth Element Geochemistry, Elsevier, 2013 .

[30] L.I. Osipow, Surface Chemistry: Theory and Industrial Applications, Krieger
[31] Y.-J. Kim, J. Hur, W. Bae, J.-H. Choi, Desalination of brackish water containing oil compound by capacitive deionization process, Desalination 253 (2010) 119-123,

http://dx.doi.org/10.1016/j.desal.2009.11.022.
32] D.L. Ramasamy, V. Puhakka, E. Repo, M. Sillanpäa, Selective separation of scandium from iron, aluminium and gold rich wastewater using various amino and non890-901, http://dx.doi.org/10.1016/j.jclepro.2017.09.199. 


\section{Publication VI}

D.L.Ramasamy, V. Puhakka, B. Doshi, S. Iftekhar, M. Sillanpää

Fabrication of carbon nanotubes reinforced silica composites with improved rare earth elements adsorption performance

Reprinted with permission from

Chemical Engineering Journal

Vol. 365, pp. 291-304, 2019

(C) 2019, Elsevier 

Chemical Engineering Journal 365 (2019) 291-304

\begin{tabular}{|c|c|c|}
\hline 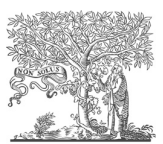 & $\begin{array}{l}\text { Contents lists available at ScienceDirect } \\
\text { Chemical Engineering Journal }\end{array}$ & $\begin{array}{l}\text { CHEMICAL } \\
\text { ENGINERING } \\
\text { JOURNAL } \\
\text { OAR }\end{array}$ \\
\hline ELSEVIER & journal homepage: www.elsevier.com/locate/cej & $0=3$ \\
\hline
\end{tabular}

Fabrication of carbon nanotubes reinforced silica composites with improved rare earth elements adsorption performance

Deepika Lakshmi Ramasamy*, Ville Puhakka, Bhairavi Doshi, Sidra Iftekhar, Mika Sillanpää

Department of Green Chemistry, Lappeenranta-Lahti University of Technology, Mikkeli FI-50130, Finland

\section{H I G H L I G H T S}

- REE-selective CNT-silica composites were successfully synthesized.

Single-pot co-condensation process and post-synthetic ligand functionalization procedures were explored for the synthesis.

- Different ligand grafting techniques were required for SWNT and MWNT. - 1-(2-pyridylazo)-2-naphthol cilitated coordination mechanism with REE cations forming chelate com-$$
\text { plexes. }
$$

- Composites were also used to recover REEs successfully from acidic mine drainage.

\section{A R T I C LE INFO}

\section{Keywords:}

Amino functionalization

Carbon nanotubes

Ligand immobilizatio

Silica

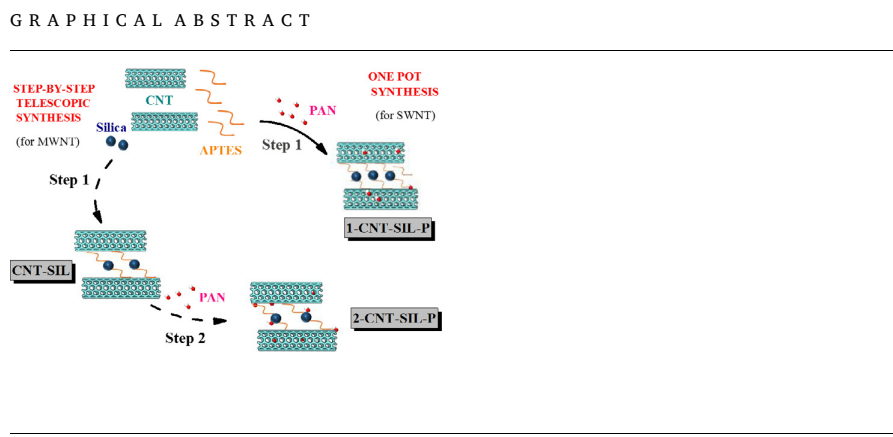

A B S T R A C T

The continuous exploration of carbon nanotubes (CNTs) in terms of their chemical functionalization attributes, has engrossed the members of both the research and industrial community for scientific advancements alongside a variety of potential applications. Hence, in this article, we explored the different modification schemes to chemically tailor the surface properties of CNT by hybridizing them in the organic-inorganic network for the selective sorption of rare earth elements (REEs). We utilized both single-walled- (SWNT) and multi-walled carbon nanotubes (MWNT) for functionalization with nano-silica through the silanization process, with (3aminopropyl)triethoxy silane (APTES) acting as a coupling agent. In addition, a coordination ligand, 1-(2-pyridylazo)-2-naphthol (PAN), was loaded onto these nanocomposites to enhance the selectivity via two differen grafting routes, i.e. one-pot synthesis and step-by-step telescopic synthesis process. The comprehensive physigrafting routes, i.e. one-pot synthesis and step-by-step telescopic synthesis process. The comprehensive physicochemical characterization of these CNT-silica nanocomposites using the current state of techniques ascertained its promise in the direction of REE selective sorption (all REEs), whereby this achievement was not possible by pristine CNT or bare silica (except scandium). Furthermore, in terms of REE sorption, CNT reinforced silica composite materials (mere CNT loading of 10\%) have shown to be far more advantageous over the PAN grafte onto APTES-silica. The findings from this work also revealed the relevance of different synthetic strategies needed to be adopted for SWNT and grafting technique towards REE affinity. Moreover, the selective REE recovery from AMD demonstrated by these adsorbents (no affinity towards water hardness ions such as $\mathrm{Ca}^{2+}$ and $\mathrm{Mg}^{2+}$ ) can attract many industrial applications.

\footnotetext{
* Corresponding author.

E-mail address: deepika.ramasamy@lut.fi (D.L. Ramasamy).
}

https://doi.org/10.1016/j.cej.2019.02.057

Received 7 January 2019; Received in revised form 6 February 2019; Accepted 9 February 2019

Available online 11 February 2019

1385-8947/ ( C) 2019 The Authors. Published by Elsevier B.V. This is an open access article under the CC BY-NC-ND license

(http://creativecommons.org/licenses/BY-NC-ND/4.0/). 


\section{Introduction}

The Rare earth elements (REE), including scandium (Sc), yttrium (Y) and 14 lanthanides, belong to group IIIB of the periodic table of the elements. Because of their rare and unique physicochemical, magnetic and optical properties, REEs hold great potential for various industrial applications like compact fluorescent and LED lights, automatic catalytic converters, high-performance magnets, superconductors, catalysis, resonance imaging machines, electric vehicle batteries, high strength alloys, and lightweight aircraft components [1,2]. Particularly, the scarcity of Sc has inflated the market value of the ingot metal to be purity) is around USD 5000 per $\mathrm{kg}$ [3]. A steady and regular supply of $\mathrm{Sc}$ is a crucial factor for the continuous existence of diverse industrial establishments such as the generation of light-weight aircraft components, the production of high-strength aluminum alloys and advanced 3D printing systems [2,4]. Besides, the European Commission based on their assessment of the current market trends and supply risks has also identified REEs and Sc as some of the major critical elements. The presence of steady technological advancements in articulation with ever-increasing demand in a variety of applications over the years, REE recovery from secondary sources (such as industrial wastes) has prompted interests from varied communities adopting the concept of circular economy and sustainable future [2,5-7]. Hence, it is worthwhile to find a simple and efficient scheme to fabricate a material with

The field of carbon science, despite containing developments from

The field of carbon science, despite containing developments from
over 100 years, is regarded as an "old but new" domain and still holds huge promise to steer the current trends in scientific developments along unconventional paths. With constant, rapid and revolutionary progress in the field of nanoscience in conjunction with an evergrowing need for technological advancements to suit the current and future demands, carbon nanostructures hold immense potential for significant breakthroughs by unfolding groundbreaking opportunities for the discovery of new science and applications. The diversity observed in the structural forms of carbon along with its associated special properties makes it a unique building block and an ideal candidate for the synthesis of nanomaterials [12]. Explicitly, CNTs encompass a diverse range of unique physicochemical properties, serving as objects of interest for innovation along various research $d$ ideas are constantly driven towards the CNT manufacturing methods, their characterizations and the development of viable applications. Expedition in the direction of CNT based water treatment applications has been continuously hindered by factors such as selectivity and dispersibility. For instance, SWNTs have the tendency to entangle themselves into ropes or bundles owing to the natural Van der Waals attraction between the tubes, thus limiting their use in the coating of electrodes, resins or thermoplastics [13]. Hence, suitable options to circumvent this issue and to design an efficient CNT material for an extensive range of applications have been investigated in recent years $[13,14]$. Over the years, the improved CNT properties were successfully manifested through surface functionalization via the attachment of organic, inorganic or organometallic groups, through covalent or nonother compounds such as organic chemicals, metal complexes and gases has been studied and reported in the past [16-18].

In addition to the above-mentioned features, CNTs can also function as efficient composite material platforms. From a mechanical viewpoint, the notable advantage of nanocomposites over the conventional ones is the exceptionally high surface to volume ratio of the reinforcing phase. The reinforcing material can be composed of particles (e.g. miphase. The reinforcing material can be composed of particles (e.g. mi-
nerals), sheets (e.g. exfoliated clay stacks) or fibers (e.g. CNTs or nerals), sheets (e.g. exfoliated clay stacks) or fibers (e.g. CNTs or
electrospun fibers). Such a large reinforcement of surface area can have electrospun fibers). Such a large reinforcement of surface area can have
a tremendous impact on the macroscale composite properties, even in a tremendous impact on the macroscale composite properties, even in
the presence of relatively lesser nanoscale reinforcement. To quote a common instance, the addition of CNT improves the electrical and thermal conductivity of the material. Likewise, other kinds of nanoparticles may yield enhanced optical properties, dielectric properties, heat resistance or mechanical properties, such as stiffness, strength and resistance to wear and damage $[19,20]$. Despite having phenomenal electrical properties, the high mechanical and chemical stability of the CNTs always can act as a hindrance to undergo selective, covalent functionalization. Hence, in this direction, we have chosen robust inorganic silica for the hybridization process, owing to its intriguing properties such as the large surface area and greater resistance to mechanical, chemical and temperature effects [21]. However, other significant factors such as dispersion of CNTs and CNT-matrix interfacial adhesion can deter the hybridization process of CNT with other polymers in synthesizing competent hybrid composite materials. There is less documentation in literature elaborating the enhancement of thermal and mechanical properties (e.g. wear resistance) of epoxy based CNT hybridization, attained through the process of silanization $[22,23]$. In this line, we attempted to crosslink organic CNT and inorganic silica by means of toluene condensation process using APTES (amino silane) as a coupling agent. APTES moieties containing terminal $-\mathrm{NH}_{2}$ groups act as a linker to form amide bonds between two polymers.

In our recent works, PAN was proved to be an effective ligand for REE sorption when chemical immobilized onto mesoporous silica (micro- and nano-sized silica) [24-26]. In the present study, we attempted to improve the REE affinity and selectivity by reinforcing CNTs to the hybrid support matrix, exploiting PAN as the ligand. However, an alternate ligand grafting procedure was utilized, thus enabling comparative analysis of various grafting techniques and identifying the right grafting procedure for enhancing REE selectivity. It is worth mentioning that PAN and APTES were also employed for the same purpose in our earlier study on activated carbon (AC) [26]. Nonetheless, herein, we have assessed APTES and PAN interactions with different substrate CNT (SWNT and MWNT) in relation to AC-silica and silica materials, with the focus of understanding the ease of functionalization for different substrates. The utilization of CNT-APTES-silicaPAN composites for the purpose of REE recovery, demonstrated in this work, is a novel attempt and has the potential to help understand further the interactions between multifunctional supports with various REEs. Besides, it is essential to identify the appropriate substrate surface for silane modification, the effect of which will be reflected in terms of enhanced adsorption sites with suitable surface energies. This offers a through motivation to study the implications of APTES interactions with SWNTs and MWNTs hand-in-hand. Such an approach would help narrow down the efficient substrates that can enhance REE adsorption in multifunctional composites. Furthermore, other fabrication strategies to produce CNT-silica composites using APTES silane can also be found in literature, mediated by surfactant, catalyst, acid treatment or simply by sol-gel method using TEOS precursor to insert silica units [27-29]. However, they have not been exploited for REE sorption which serves as the primary motivation of this study.

Concisely, the primary facet of this research work is focused on the development of a facile, efficient and adept strategy for the fabrication of REE selective CNT-silica composites that can eventually pave the way for various novel applications. The fabricated hybrid nanocomposites were also thoroughly characterized and tested under specific real water conditions with an aim to examine the superiority of the synthesized materials. The assessments revealed distinct trends for both SWNTs and MWNTs, the observations of which are presented in this article. The proficiencies of the synthesized materials in REE recovery from AMD would also be of great appeal to the mining industries from a financial standpoint. 


\section{Experimental}

\subsection{Materials and chemicals}

Pristine SWNT (carbon $\geq 85 \%,>70 \%$ carbon as SWNT, dia. $1.3-2.3 \mathrm{~nm}$ ), MWNT ( $>90 \%$ carbon basis, dia. $110-170 \mathrm{~nm}$, length 5-9 $\mu \mathrm{m}$ ) and silica nanopowder (particle size of $12 \mathrm{~nm}$ and $99.8 \%$ trace metals basis) were purchased from Aldrich. The functionalization agents, 1-(2-pyridylazo)-2-naphthol (PAN) and 3'-(aminopropyl) triethoxy silane (APTES, $\mathrm{NH}_{2}\left(\mathrm{CH}_{2}\right)_{3} \mathrm{Si}(\mathrm{OEt})_{3}, 99 \%$ ), were obtained from Sigma Aldrich. Other chemicals such as toluene, acetone and ethanol used during the synthesis process (for reaction and cleaning), were of analytical grade and obtained from VWR chemicals, Merck and/or Sigma Aldrich. The AMD used for this study (sampling depth $270 \mathrm{~m}$; original $\mathrm{pH}$ 2) contains the following: $\mathrm{Cr}(1.54 \mathrm{ppm}), \mathrm{Co}(2.36 \mathrm{ppm}), \mathrm{Ni}$ (2.48 ppm), Cu (1.04 ppm), Fe (52.6 ppm), Zn (86.13 ppm), Mn (14.9 ppm), $\mathrm{Mg}(113.17 \mathrm{ppm})$ and sulfate $(3470 \mathrm{ppm})$.

2.2. Procedure for the synthesis of PAN-CNT-APTES-Silica, PAN-APTESsilica and PAN-CNT (Method I)

The silanization procedure adopted in this article was similar to the procedure reported by Zhang et al. [30] and were also used in our previous works with AC and silica with minor modifications $[24,26]$. In Method I single-pot synthesis i.e. co-condensation procedure, 1 part of CNT (in g), 10 parts of silica (in g), 10 parts of APTES silane solution (in $\mathrm{ml}$ ) and 20 parts of PAN solution $(0.2 \mathrm{~g}$ PAN in $100 \mathrm{ml}$ of acetone solution) were allowed to react in a single pot containing 100 parts of Toluene solution (in $\mathrm{ml}$ ). The container was sealed airtight and the solution was subjected to a standard toluene-condensation process by mixing it at $150 \mathrm{rpm}$ for a period of $24 \mathrm{~h}$. The resulting mixture was then filtered, washed with ethanol and finally with deionized water to remove the excess of APTES and Toluene. The product was then dried overnight at $100^{\circ} \mathrm{C}$ until a constant dried weight was attained. The PAN grafted CNT-silica nanocomposites from Method I are labeled as 1SWNTsil-P and 1-MWNT-sil-P.

In a similar manner, PAN grafted silica gel was synthesized without the presence of CNT, following the same procedure, denoted as 1-sil-P while the PAN grafted CNT was obtained without adding silica and while the PAN grafted CNT was obtained without adding silica and
APTES silane solution, referred to as 1-sil-P, and 1-SWNT-P and 1APTES silane solution,

\subsection{Procedure for the synthesis of PAN-CNT-APTES-Silica (Method II)}

The Method II step-by-step telescopic synthetic procedure, otherwise called as "post-synthetic functionalization grafting" procedure
contained two steps. In the primary step, CNT-APTES-silica (i.e. SWNTcontained two steps. In the primary step, CNT-APTES-silica (i.e. SWNT-
sil and MWNT-sil) crosslinked adsorbents were obtained by reacting 1 part of CNT (in g), 10 parts of silica (in g) and 10 parts of APTES silane solution (in $\mathrm{ml}$ ) in 100 parts of Toluene solution (in $\mathrm{ml}$ ). It should be noted that the addition of ligand PAN was not involved in Ste for the case of APTES-silica (i.e. sil), the reaction was conducted without the addition of $\mathrm{CNT}$ to the mixture, as mentioned under Method I.

In the secondary step, PAN was grafted to the CNT-silica composites via solvent evaporation process by reacting 1 part of CNT-silica composites with 20 parts of PAN solution. They were allowed to react until the acetone solution was completely evaporated and were then dried at room temperature. This yielded 2-SWNT-sil-P and 2-MWNT-sil-P where the numbers 1 and 2 in the labels denote the preparation method type. Similarly, 2-sil-P, 2-SWNT-P and 2-MWNT-P were prepared by adding 20 parts of PAN solution to 1 part of APTES-silica (sil from step 1), pristine SWNT and pristine MWNT, respectively.

\subsection{Materials characterization}

The materials were characterized by using scanning electron microscopy (SEM), Organic elemental analysis, Brunauer-Emmett-Telle (BET), X-ray photoelectron spectroscopy (XPS), Fourier transform infrared spectroscopy (FTIR), X-ray diffraction spectroscopy (XRD), Raman spectroscopy and zeta potential (ZP) analysis. The synthesized adsorbents were subjected to FTIR (ATR mode, Vertex 70, Bruker Optics) and XRD (PANalytical instrument employing CoKa irradiation at $\lambda=1.78 \AA, 40 \mathrm{mV}$ and $30 \mathrm{~mA}$ ) analysis to ascertain the existence of surface functionalization and ligand modification. XPS data was attained with an ESCALAB 250Xi spectrometer (Thermo Fisher Scientific, UK) with a mono $\alpha$ radiation $(1486.6 \mathrm{eV})$. The surface assessment of the adsorbents, including pore size distribution, BET surface area, particle size and pore volume, was performed by means of surface area and porosimetry analyzer (Micromeritics ${ }^{\oplus}$, Gemini V1.00) via nitrogen adsorption, at $77 \mathrm{~K}$. The $\%$ weight content of $\mathrm{C}, \mathrm{H}, \mathrm{N}$ and $\mathrm{S}$ was determined by an organic elemental analyzer (Flash 2000, Thermo Scientific, Germany). The surface ment studied by SEM (SU3500 system) analysis. Raman spectroscopic analysis was performed by using LabRAM HR 800UV from Horiba-Jobin YVON, attached with Olympus BX41 microscope. The measurement wavelength for samples was $514.53 \mathrm{~nm}$. Surface ZP (ZEN3500, Malvern) analysis provided information on isoelectric point and the surface charge of the materials as a function of electrolyte $\mathrm{pH}$.

\subsection{Batch adsorption studies}

The batch adsorption experiments in a single component system were performed by continuously mixing the samples $(10 \mathrm{mg}$ of adsorbent in $10 \mathrm{ml}$ of REE solution) at $220 \mathrm{rpm}$ in a thermos-regulated oscillatory shaker, at room temperature for a period of $24 \mathrm{~h}$, if otherwise stated. To determine the optimal $\mathrm{pH}$, the solutions were first tested over a $\mathrm{pH}$ range of 1-6 for a contact time of $24 \mathrm{~h}$. The initial concentration of all the REE solutions, prepared by dissolving th priate amount of REE salts was measured by ICP-OES (Agilent 5110). After the determination of optimal $\mathrm{pH}$ for REE adsorption, further tests were carried out to understand the effect of initial adsorbate concentration and kinetics in order to obtain the maximum adsorption capacities of the adsorbents and equilibrium time, respectively. For a multi-component system, the experiments were conducted using the multi-cos of $2-5 \mathrm{ppm}$ indicated next to texts or figures. The conditions adopted for in-
vestigating intraseries REE adsorption behavior varied based on the process temperature $\left(23^{\circ} \mathrm{C}\right.$ and $\left.45^{\circ} \mathrm{C}\right)$ and time $(1-24 \mathrm{~h})$, with the primary aim of arriving at the optimal conditions for further evaluation. To inspect the effect of salinity $\left(2.5-25 \mathrm{ppm}\right.$ of $\left.\mathrm{Na}^{+}\right)$, hardness (2.5-10 ppm of each $\mathrm{Mg}^{2+} / \mathrm{Ca}^{2+}$ ) and the oil compound heptane (50-100 ppm), the attained optimal conditions $\left(45^{\circ} \mathrm{C} ; 1 \mathrm{~h} ; 5 \mathrm{ppm}\right.$ REE each) were then utilized.

After the completion of batch adsorption tests, the solutions were centrifuged, filtered with $0.2 \mu \mathrm{m}$ syringe filter and analyzed using ICPOES for residual or equilibrium REE concentration in the samples. The maximum capacities (mg/g) and REE adsorption efficiencies (\%) were calculated by applying the following equations:

$q_{e}(m g / g)=\frac{\left(C_{o}-C_{e}\right)}{M} V$

REE adsorption efficiencies $(\%)=\frac{\left(C_{o}-C_{e}\right)}{C_{o}} * 100$

where $\mathrm{C}_{\mathrm{o}}, \mathrm{C}_{\mathrm{e}}, \mathrm{M}$ and $\mathrm{V}$ are the initial concentration ( $\mathrm{mg} / \mathrm{L}$ ), equilibrium concentration $(\mathrm{mg} / \mathrm{L})$, adsorbent mass $(\mathrm{g})$ and the solution volume $(\mathrm{L})$, respectively. 


\section{Results and discussion}

3.1. Synthesis and characterization of CNT-silica composites

In general, there can exist two types of CNT functionalization based on covalent or non-covalent interactions. In the former, the functionalization groups are attached through chemical interactions onto the tube ends/walls while the latter deals with the supramolecular adsorption onto CNT walls. In this work, the chemical crosslinking of CNT-silica composites was accomplished through a linker or coupling agent, APTES silane containing $\mathrm{NH}_{2}$ groups, which would facilitate the amide bond formation between silica and carbon units via П-П stacking interactions [31]. APTES silane condenses in the presence of Toluene, generating Si-O-Si and Si-O-C networks to crosslink silica and CNT matrix. Furthermore, PAN was grafted onto the nanocomposites using two synthetic approaches i.e. the one-pot and step-by-step telescopic synthesis method. PAN units are expected to undergo one or more of the following covalent or non-covalent attachments based on the grafting technique. There can be direct interaction of PAN to the CNT sidewall, functionalization to the inner side of CNTs and physical adsidewall, functionalization to the inner side of CNTs and physical ad-
sorption of PAN to the silica units and chemical immobilization of PAN to the APTES functionalized silica and/or CNT units, as shown in Fig. 1. As mentioned earlier, we used both single-walled (SWNT) and multiwalled (MWNT) carbon nanotubes for the hybridization purpose with silica. The SWNTs can be visualized as a rolled graphite sheet and is essentially an allotrope of $\mathrm{sp}^{2}$ carbon, analogous to fullerenes. The orientation, diameter and properties of CNTs are best explained by chirality, whether they are of armchair/ zig-zag or metallic/semiconducting in nature. MWNTs can be envisioned as a series of SWNTs nested within one another, with 2 (double walled) or more (100 plus) concentric walls, with diameters larger than that of SWNTs. In general, SWNTs and MWNTs display prominent differences, despite sharing certain resemblances [32].

Investigations were also performed on the composites without any PAN functionalization (CNT-sil) in order to study the extent of coordination mechanism involving REE and PAN complex. For the chemical structure of APTES and PAN, please refer to Fig. 1, which also illustrates the proposed functionalization mechanism for our synthesized composite materials. For the convenience of the readers, the notations adopted for the functionalized adsorbents of this work are denoted in Fig. 2 and are used throughout this article. These materials were subjected to thorough analyses during the course of the investigation, i.e. before functionalization (unmodified materials), after functionalization (modified materials) and after the selective REE adsorption process (REE-adsorbed materials). The significant results are grouped together in the upcoming segments of this article.

\subsubsection{SEM, BET and XPS analysis}

SEM pictures obtained before and after the functionalization of the synthesized composites (see Fig. 3) show evidence of CNT-silica crosslinking. After hybridization, the densely packed composite structure with dispersed silica groups in the intertwined network of both SWNT and MWNT matrix can be observed with clarity. The aggregation of CNTs to form bundles under the influence of van der Waals force between the tubes can also be seen in the figure [33]. Overall, the diameter and the surface roughness of CNT-silica composites increased after the hybridization procedure, which can be attributed primarily to the attachment of APTES, PAN and silica moieties to CNT backbone.

Looking into the surface properties of these nanocomposites (Fig. 4), overall the BET surface area of the composites decreased after the hybridization process for the case of SWNT while an increase in surface area was observed with MWNT-silica composites. However, for both the cases, the average pore volume and pore diameter (in mesoporous range) increased with functionalization, probably due to the densification and attachment of groups in the small pores [34-38]. The IUPAC classification of BET isotherms reveals that the materials exhibit Type III isotherm indicating that the unrestricted multilayer adsorption takes place in the case of our synthesized materials. Typically, the hysteresis loops were seen absent, implying no capillary condensation in mesopores [26].

Moreover, the contribution of the attached groups and the composition of the synthesized composites can also be seen from the XPS spectra (Fig. 5a). The pristine SWNT showed a strong carbon C peak at 284-285 eV ( $\mathrm{sp}^{2}$ hybridized carbon) along with a small protrusion, indicating the presence of $\mathrm{C}=\mathrm{O}$ and a weak oxygen $\mathrm{O}$ peak at $532 \mathrm{eV}$. After the functionalization step, a drop in the C peak intensity along with an increase in the $O$ peak intensity was witnessed, owing to the crosslinking of CNT-silica with APTES silane and the binding of PAN units. The observed band energy shift in C1s spectra (Fig. 5b) was likely to occur with a reduction in $\mathrm{sp}^{2} / \mathrm{sp}^{3}$ ratio. The presence of $\mathrm{sp}^{2}-\mathrm{sp}^{3}$

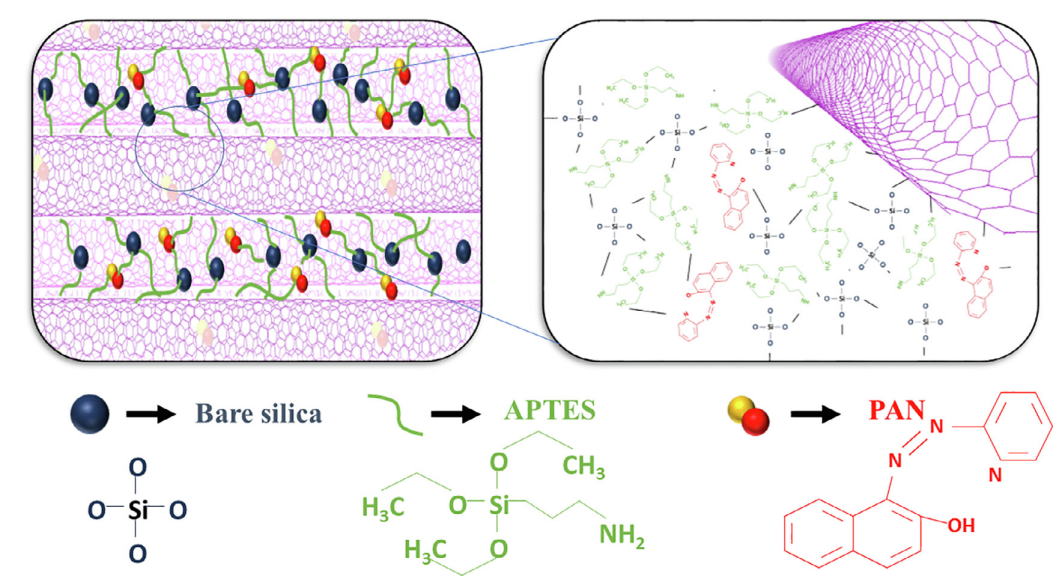

Fig. 1. Probable functionalization scheme of PAN grafted CNT-silica composites. It should be noted that these graphic illustrations do not demonstrate the precise type or configuration of CNT or the degree of functionalization used in this study. 


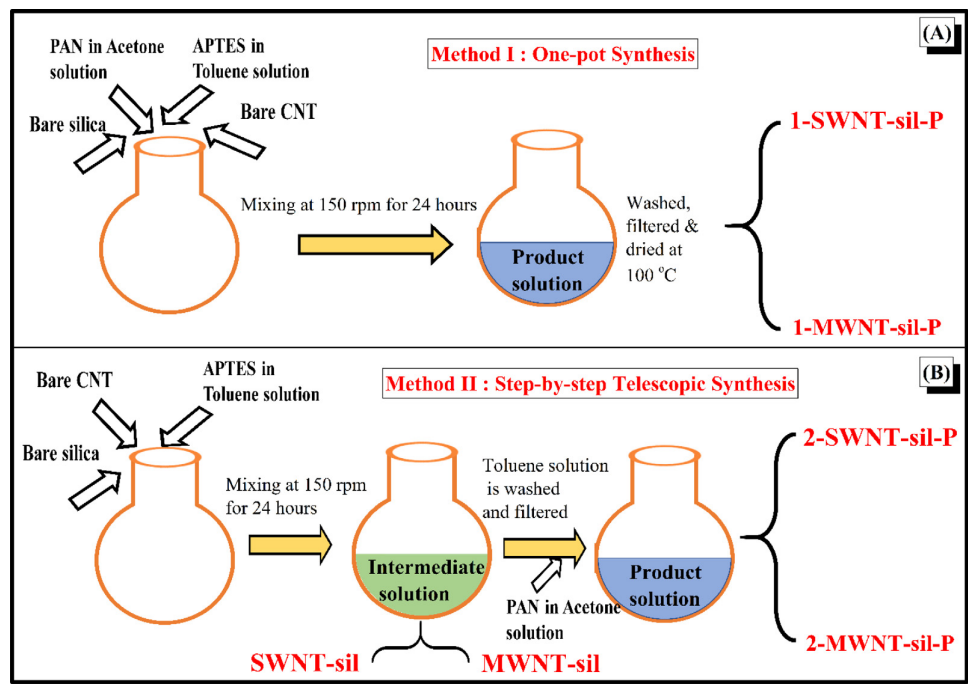

Fig. 2. Synthetic routes for CNT-silica nanocomposites (a) one-pot synthesis (top) and (b) step-by-step telescopic synthesis via silanization and solvent evaporation process (bottom).

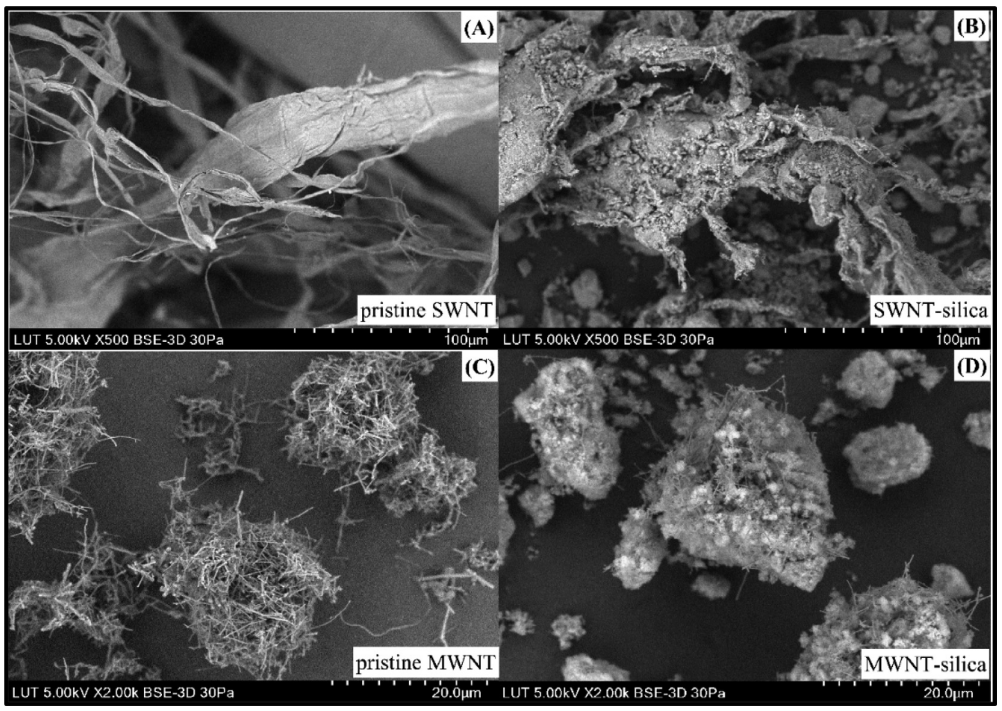

Fig. 3. The SEM images of the CNT-silica composites (a\&c) pristine CNT before functionalization and (b\&d) after functionalization with APTES and silica.

bonding can be manifested via the asymmetry observed in $C$ peak, separated by a value of $0.7-0.9 \mathrm{eV}$ for corresponding $\mathrm{sp}^{2}(284 \mathrm{eV})$ and sp ${ }^{3}$ $(285 \mathrm{eV})$ configurations. Furthermore, a single asymmetric C peak denotes the amorphous nature of the carbon material. In addition, new peaks corresponding to silicon $\mathrm{Si}$ (at $103 \mathrm{eV}$ ) and nitrogen $\mathrm{N} \mathrm{(400} \mathrm{eV)}$ were detected post-modification [39]. The presence of $\mathrm{N}$ and $\mathrm{Si}$ confirmed the successful incorporation of APTES and PAN units in the final product. Notably, the carbon content was reduced after the silica hybridization process. This was also in great relevance with the organic elemental analysis results, shown in Fig. 4, which displayed an increase in $\% \mathrm{~N}$ and $\% \mathrm{H}$ along with the $\% \mathrm{C}$ reduction post-functionalization step. 


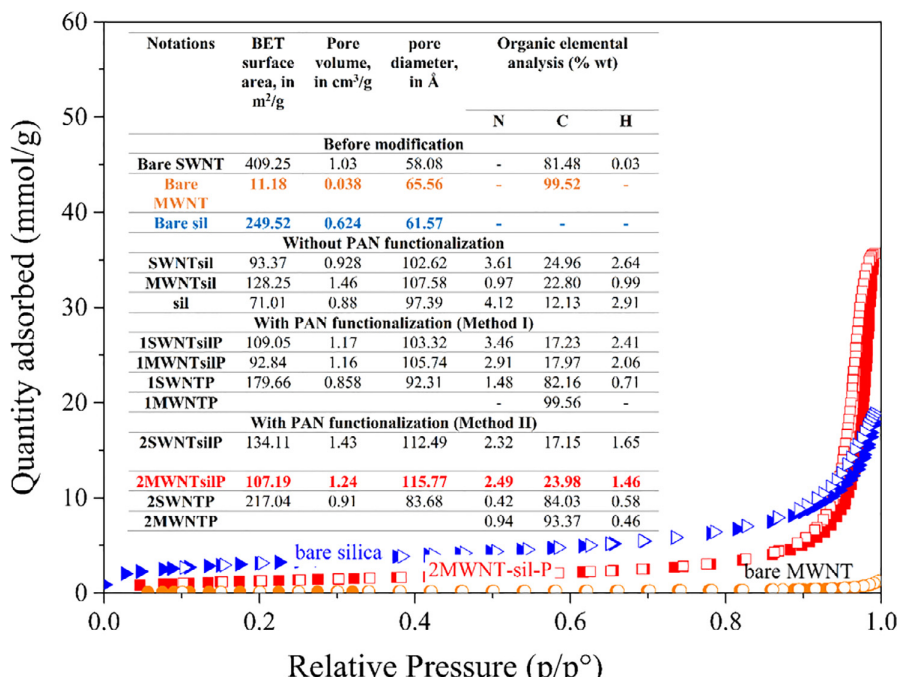

Fig. 4. $\mathrm{N}_{2}$ adsorption and desorption BET isotherm curves for the unmodified and modified composites. The figure inlet presents the overview of the BET surface area, pore volume, pore diameter along with the organic elemental CHNS analysis results.

\subsection{FTIR, XRD and RAMAN analysis}

Furthermore, FTIR (Fig. 6a) and XRD analysis (Fig. 6b) was performed on the pristine CNTs, silica and the modified composite materials to identify the surface functional groups and to ascertain the CNTsilica functionalization. In the bare silica spectrum, characteristic bands were observed at $450 \mathrm{~cm}^{-1}$ (bending vibration of $\mathrm{Si}-\mathrm{O}-\mathrm{Si}$ ), $800 \mathrm{~cm}^{-1}$ (symmetric stretching vibration of $\mathrm{Si}-\mathrm{O}-\mathrm{Si}$ ) $950 \mathrm{~cm}^{-1}$ (asymmetric vibration of $\mathrm{Si}-\mathrm{OH}$ ) and $1031 \mathrm{~cm}^{-1}$ (asymmetric vibration of $\mathrm{Si}-\mathrm{O}$ ) $[40,41]$. Meanwhile, the IR analysis of pristine SWNT and MWNT exhibited just a long and broad stretch band in the regime between 500 and $3600 \mathrm{~cm}^{-1}$. A weak peak at $1590 \mathrm{~cm}^{-1}$ can be detected in pristine $\mathrm{CNTs}$ which indicates the presence of the carboxylate $\mathrm{COO}^{-}$groups. Following the crosslinking of silica and CNT, distinct changes were witnessed with peaks appearing in the zones around $500-800 \mathrm{~cm}^{-1}$ and $1300-1600 \mathrm{~cm}^{-1}$. Moreover, the appearance of bands only in APTES functionalized materials at $1210 \mathrm{~cm}^{-1}\left(\mathrm{C}-\mathrm{N}^{+}\right.$stretching vibration), $1300 \mathrm{~cm}^{-1}$ (C-N stretch), $1554 \mathrm{~cm}^{-1}$ (N-H stretch) and $2927 \mathrm{~cm}^{-1}$ indicated the existence of alkylsilane group [39]. Additional peaks were also detected at $928 \mathrm{~cm}^{-1}$ (C-H out-plane bending mode), $1190 \mathrm{~cm}^{-1}$
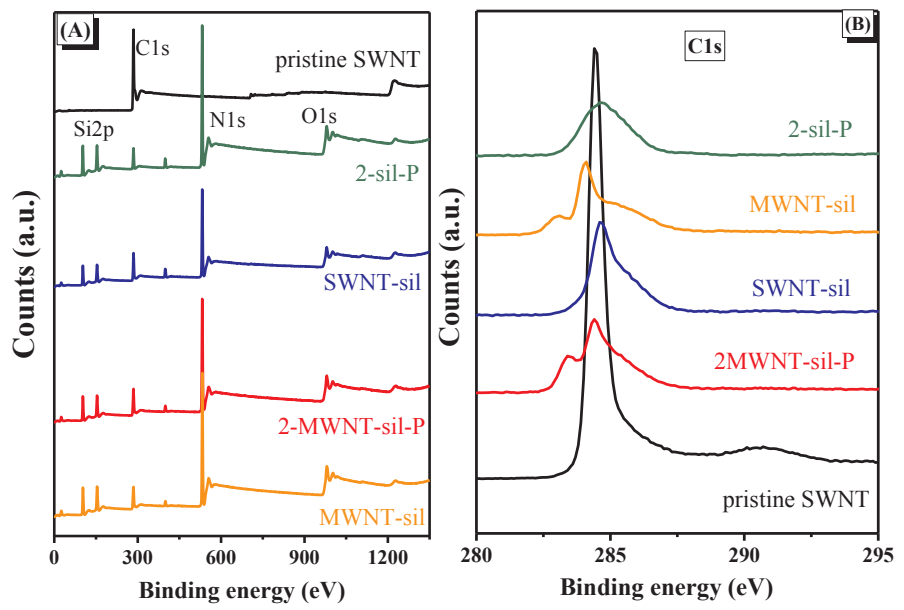

Fig. 5. XPS spectra for pristine and functionalized CNT-silica composite materials (a) whole spectra (b) C1s spectra. 

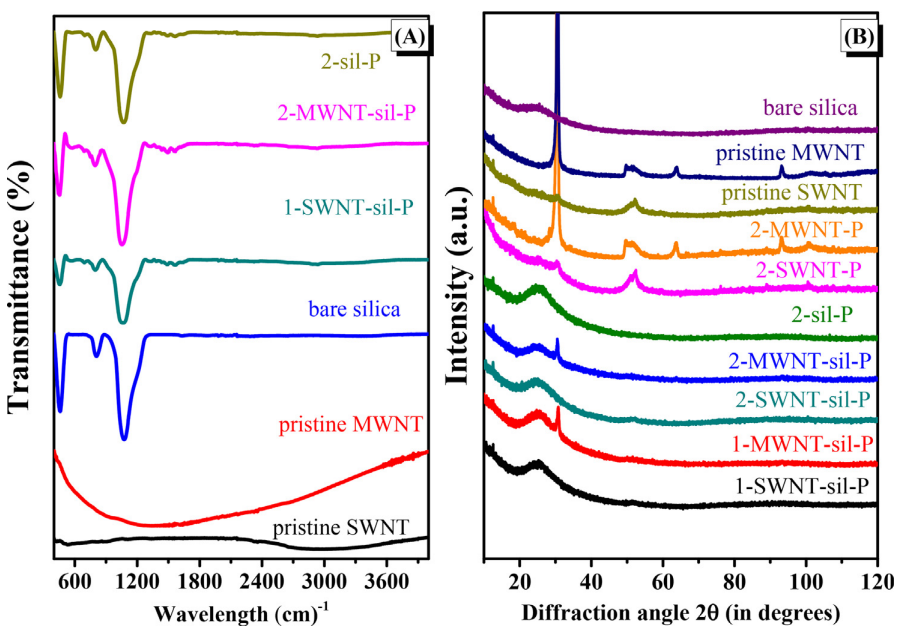

Fig. 6. (a) FTIR and (b) XRD spectra for CNT and silica functionalized materials.

(C-N vibration), 1036 and $1300 \mathrm{~cm}^{-1}$ (C-H in-plane vibration) as a result of the functionalization [42]. The bands at $762 \mathrm{~cm}^{-1}$ and $874 \mathrm{~cm}^{-1}$ corresponded to $\mathrm{N}-\mathrm{H}$ deformation mode and primary amine $\mathrm{NH}_{2}$ group from silane, respectively [33]. Alongside the enhanced intensity of the characteristic band at $700 \mathrm{~cm}^{-1}$ for aromatic $\mathrm{C}-\mathrm{H}$ tensity of the characteristic band at $700 \mathrm{~cm}$. for aromatic $\mathrm{C}-\mathrm{H}$ blending, it can be interpreted that the PAN moieties are grafted
dominantly onto the APTES-silica moieties [39]. In addition, the peak intensity at $1554 \mathrm{~cm}^{-1}$ increased with the addition of $-\mathrm{N}$ group to the matrix, after PAN grafting. The bands corresponding to $\mathrm{N}=\mathrm{N}$ vibrations (1686 and $\left.1630 \mathrm{~cm}^{-1}\right), \mathrm{C}=\mathrm{C}$ stretching vibration for the benzenoid and the pyridyl unit $\left(1500 \mathrm{~cm}^{-1}\right), \mathrm{CH}_{2}$ sheer deformation vibration $\left(1382 \mathrm{~cm}^{-1}\right)$ and $\mathrm{C}=\mathrm{N}$ stretching vibration for benzenoid units $\left(1329 \mathrm{~cm}^{-1}\right)$, were also recorded [24].

XRD patterns of the pristine and modified materials are shown in Fig. 6(b). For pristine SWNT and MWNT, a strong peak, indicative of graphite structure, was observed at around $25-30^{\circ}$ [31]. The other peaks observed for SWNT and MWNT can be examined from the XRD spectra. On further inspection into the XRD spectra for functionalized silica gels, the only detected peaks were seen at $12^{\circ}$ and $25^{\circ}$, pointing towards an amorphous nature of the material. On hybridization with silica, a broad peak corresponding to amorphous silica was detected at 20-30 after the successful CNT-silica crosslinking [39], for all of the composites. As a result, the other peaks are smoothened except for the peaks at $55^{\circ}$ (SWNT) and $30^{\circ}$ (MWNT). The governing factor for such a response could be due to the predominant bulk silica composition in the response could be due to the predominant bulk silica composition in the the PAN functionalized CNTs, where the cylindrical CNT structure remains unaltered by the PAN functionalization and thus causing no distinct change over the XRD spectra other than variations in peak intensities.

In order to verify the presence of $\mathrm{sp}^{2}-\mathrm{sp}^{3}$ hybridization, to probe into the existence of chemical impurities, defects and crystal disorder, to analyze the metallic vs semiconducting nature, and to reveal the electronic and phonon properties of the CNT composite materials, electronic and phonon properties of the CNT composite materials,
Raman spectra for the pristine and modified carbon-hybrid materials
were attained [12]. The obtained spectra from the modified and unwere attained [12]. The obtained spectra from the modified and unand $1590 \mathrm{~cm}^{-1}$ which can essentially be linked to the in-plane vibrations along the circumferential direction ( $\mathrm{G}^{-}$feature) and in-plane vibrations along the tube axis $\left(\mathrm{G}^{+}\right.$feature) of $\mathrm{sp}^{2}$ carbon atoms, respectively. Furthermore, the D band (one-phonon at $\sim 1350 \mathrm{~cm}^{-1}$ ), $\mathrm{G}$ band (two-phonon at $\sim 2700 \mathrm{~cm}^{-1}$ ), $\mathrm{M}$ band (two-phonon at $\sim 1750 \mathrm{~cm}^{-1}$ ), iTOLA band (two-phonon at $\sim 1950 \mathrm{~cm}^{-1}$ ) and $2 \mathrm{G}$ band (DR) scattering processes. Due to the fact that the G' band was a mere overtone of D band, occurring from the inter-valley two-phonon scattering processes, it can be considered to be free from the influence of defects which possess comparable intensities to that of the $G$ band. The primary G' peak at $\sim 2700 \mathrm{~cm}^{-1}$ is usually a dispersive DR peak while the band at $\sim 2450 \mathrm{~cm}^{-1}$ can arise as a consequence of a weaker nondispersive phonon charge transfer between the host and guest moieties and, therefore, it appeared characteristically in all of the spectra as a direct consequence of the functionalization. Furthermore, the overtone of $\mathrm{G}$ band, i.e. the $2 \mathrm{G}$ band feature, observed at $\sim 3100 \mathrm{~cm}^{-1}$ was universal, and the intensity of which was enhanced after REE adsorption. It should be remarked that the radial breath mode (RBM) from 120 to $300 \mathrm{~cm}^{-1}$ is unique to he SWNT spectra. The $\mathrm{G}^{-}$band feature (sharp and strong at $\left.\sim 1560-90 \mathrm{~cm}^{-1}\right)$, in conjecture with weak RBM $\left(\sim 180 \mathrm{~cm}^{-1}\right)$, M band (overtone of out of plane transverse optic OTO at $\sim 1750 \mathrm{~cm}^{-1}$ ) and iTOLA band (combination of in-plane Transverse optic iTO and longitudinal acoustic LA at $\sim 1950 \mathrm{~cm}^{-1}$ ), can be a manifestation of the semiconducting nature of the material. This is also analogous to the findings from the literature [12].

The extent of functionalization and REE adsorption (Supplementary material: Fig. SF1) to the carbon backbone is typically reflected in the structural defects of $\mathrm{sp}^{2}$ carbon hexagonal lattice structure to $\mathrm{sp}^{3}$ bonded carbons, accompanied by a change in $\mathrm{D}$ band intensity. The extremely low D band intensity at $1300-1350 \mathrm{~cm}^{-1}$, which is a characteristic feature of non-graphitic materials, multiwall tubes, points towards a very low $\mathrm{sp}^{3}$ amorphous carbon content [39]. Furthermore, due to the absence of apparent differences between the two spectra (pre- and post-functionalization), it can be interpreted that the CNT structure remains intact and undisrupted. This can be an indication of the functionalization process occurring at the defects or at the end groups of CNT [31]. This also supports the argument that APTES acts as a linker between CNT and silica, easing off the 


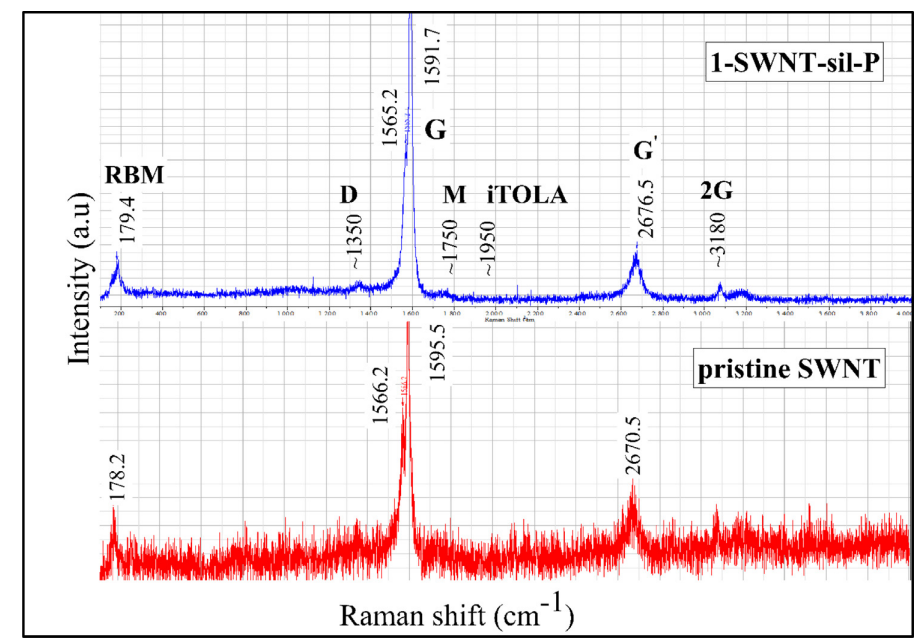

Fig. 7. Raman spectra of SWNT before (bottom one) and after functionalization with silica (top one).

strain between supports and unmasking the effects from CNTs, even in the presence of higher silica content.

\subsection{Adsorption studies: Single component system}

After detailed characterization studies, the REE affinity of the synthesized nanocomposites was analyzed using batch mode in a single as well as a multi-component system. The major parameters ( $\mathrm{pH}$, initial REE concentration, contact time and process temperature) affecting the REE adsorption process were investigated in a univariate optimization experimental design procedure. The optimal parameters were determined by conducting $\mathrm{pH}\left(\mathrm{pH} 1-6,25 \mathrm{ppm}, 24 \mathrm{~h}, 20^{\circ} \mathrm{C}\right)$, isotherm ( $\mathrm{pH}$ 4 , C $\left.1-250 \mathrm{ppm}, 24 \mathrm{~h}, 20^{\circ} \mathrm{C}\right)$, kinetic $\left(\mathrm{pH} 4,25 \mathrm{ppm}, \mathrm{t} 0-24 \mathrm{~h}, 20^{\circ} \mathrm{C}\right)$ and thermodynamic $\left(\mathrm{pH} 4,25 \mathrm{ppm}, 1 \mathrm{~h}, \mathrm{~T} 20-45^{\circ} \mathrm{C}\right)$ tests. $\mathrm{pH}$ values

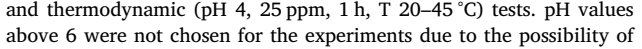
REE hydrolysis or precipitation at higher pHs [24]. The results from single component systems are provided in Supplementary information (Fig. SF2). To summarize in brief, the adsorption studies in the single component system for $\mathrm{La}^{3+}, \mathrm{Sc}^{3+}$ and $\mathrm{Y}^{3+}$ sorption demonstrated that the optimal $\mathrm{pH}$ for REE removal was 4. Surface zeta potential studies disclosed $\mathrm{pH}$-induced surface charge effects with our composite matedisclosed $\mathrm{pH}$-induced surface charge effects with our composite mate-
rials. Overall, the synthesized materials carried a positive charge under the tested $\mathrm{pH}$ value of 5 (See Supplementary information: Fig. SF3). Hence, at a lower $\mathrm{pH}$ (pH 1 and 2), REE adsorption via ion exchange processes onto the composites was not favorable because of the competing protons in this range. With an increase in $\mathrm{pH}$, REE adsorption was enhanced, reaching the maximum at a $\mathrm{pH}$ value of 5 . Beyond $\mathrm{pH} 4$, all the adsorbents recorded a maximum efficiency of $>90 \%$ under the subjected test conditions. The registered equilibrium time for $\mathrm{La}^{3+}$, $\mathrm{Sc}^{3+}$ and $\mathrm{Y}^{3+}$ adsorption, under ambient temperature conditions, were below 2, 4 and $2 \mathrm{~h}$, respectively, for a majority of the synthesized composites. From these findings, it can be realized that the $\mathrm{La}^{3+}$ and $\mathrm{Y}^{3+}$ ions exhibited faster kinetics, in comparison with $\mathrm{Sc}^{3+}$. It appears so that $\mathrm{Sc}^{3+}$ adsorption could emerge from surface adsorption/ion-exchange with the functional groups on the composite surface as well as the pore diffusion over the time [43]. It also implies that the binding sites responsible for $\mathrm{Sc}^{3+}$ and $\mathrm{La}^{3+} / \mathrm{Y}^{3+}$ sorption could vary due to the differences in ionic sizes (Sc $<\mathrm{Y}<\mathrm{La}$ ) and the distribution of ionic species (Sc differs from rest of the REEs) in aqueous samples [24]. The disparities observed for the case of Sc in comparison to other REEs have also been noticed in functionalized silica materials $[26,40,43,44]$. Moreover, the inherent surface characteristics of bare silica gels are adequate enough to adsorb Sc $\left(\sim 40 \%\right.$ at $\left.\mathrm{pH} 5, \mathrm{C}_{\mathrm{i}}=20 \mathrm{ppm}, \mathrm{t} 24 \mathrm{~h}\right)$, while the same is not true for other REEs in the absence of surface modification $[40,45]$.

Further, the adsorption performance of our synthesized composites was found comparable (on par if not higher) to other several state-ofthe-art materials in literature, the comprehensive list of which is provided in Table 1. It is interesting to note that rapid and excellent $\mathrm{La}^{3+}$ adsorption can be commonly observed for a number of cases $[46,47]$. However, it is of utmost importance to evaluate the adsorption capacities of equivalent systems (in terms of target REE, solution $\mathrm{pH}$ and process temperature) in order to attain a global picture In addition, the typical lab experiments are based on synthetic solutions containing a single component REE system. However, to mimic real wastewater conditions where REEs exist together, it is essential to perform experiments using multi-component systems, as it is possible for the high performing adsorbents for a particular REE in a single component system to demonstrate a poor performance when REE mixtures are used (for example poor La adsorption in multi-component system). This can help to understand the REE selectivity of the adsorbents in the presence of co-ion competition among REEs and from other competing ions existing in the aqueous systems. Besides, several other hindrances can occur in the form of solids, oil particles, total organic matter and varying molar concentrations when using real wastewater. Therefore, experiments based on mere synthetic wastewaters can provide a pseudo inference of the adsorption proficiency of an adsorbent and hen essential to validate their behavior under harsh industrial wastewater environments.

\subsection{Adsorption studies: multi-component system}

REE adsorption in the multicomponent system, i.e. the whole REE mixture, was assessed to investigate the intraseries behavior. In addition, it is also necessary to understand the affinity of materials towards light- (LREEs) and heavy (HREEs) rare earth elements under real wastewater conditions, where they usually exist together. Fig. 8(a and b) illustrates the intraseries REE adsorption trend for SWNT-sil-P and 
Table 1

Adsorption capacities of the synthesized composite materials along with state-of-the-art materials found in literature (* converted from $\mathrm{mmol} / \mathrm{g}$ to $\mathrm{mg} / \mathrm{g}$ ).

\begin{tabular}{|c|c|c|c|c|c|c|c|c|c|c|}
\hline \multirow[t]{2}{*}{ Adsorbents } & \multicolumn{3}{|c|}{ Maximum adsorption capacities $(\mathrm{mg} / \mathrm{g})$} & \multicolumn{3}{|c|}{ Equilibrium time (in min) } & \multicolumn{3}{|c|}{ Adsorption $\mathrm{pH}$} & \multirow[t]{2}{*}{ Refs } \\
\hline & $\mathrm{La}^{3+}$ & $\mathrm{Sc}^{3+}$ & $\mathrm{Y}^{3+}$ & $\mathrm{La}^{3+}$ & $\mathrm{Sc}^{3+}$ & $\mathrm{Y}^{3+}$ & $\mathrm{La}^{3+}$ & $\mathrm{Sc}^{3+}$ & $\mathrm{Y}^{3+}$ & \\
\hline $\begin{array}{l}\text { PAN grafted Activated carbon-APTES nanosilica (Method II: 2-AC- } \\
\text { sil-P) }\end{array}$ & 103.5 & 112.7 & 84.1 & $<30$ & $<1440$ & $<30$ & 4 & 4 & 4 & [26] \\
\hline PAN grafted MWNT-APTES nanosilica (Method II: 2-MWNT-sil-P) & 103.2 & 32.92 & 68.78 & $<30$ & 1440 & 30 & 4 & 4 & 4 & $\begin{array}{l}\text { This } \\
\text { study }\end{array}$ \\
\hline PAN grafted SWNT-APTES nanosilica (Method II: 2-SWNT-sil-P) & 80.68 & 12.68 & 48.34 & 60 & 1440 & 1440 & 4 & 4 & 4 & $\begin{array}{l}\text { This } \\
\text { study }\end{array}$ \\
\hline PAN grafted-APTES nanosilica (Method II: 2-sil-P) & 85.72 & 75.5 & 62.92 & 30 & 480 & 120 & 4 & 4 & 4 & [26] \\
\hline Cellulose-silica nanocomposite & 29.48 & 23.76 & - & 50 & 50 & - & 6 & 6 & - & [59] \\
\hline Gum arabic grafted polyacrylamide based silica nanocomposites & 7.90 & 11.05 & - & 60 & 60 & - & 6 & 6 & 6 & [60] \\
\hline $\begin{array}{l}\text { P507 grafted onto magnetic silica via } 3- \\
\text { chloropropyltryethosysilane }\end{array}$ & 55.9 & - & - & $30-60$ & - & - & 5 & - & - & [61] \\
\hline $\begin{array}{l}\text { N-(2-hydroxyethyl)salicylaldimine-SBA- } \\
\text { chloropropyltriethoxysilane }\end{array}$ & 8.32 & - & - & 45 & - & - & 5 & - & - & [62] \\
\hline Oxidized MWNT & 99.01 & - & - & 120 & - & - & 4 & - & - & [63] \\
\hline Granular grafted hydrogel composites & 333.33 & - & - & 40 & - & - & 4 & - & - & [64] \\
\hline Nano modified AC & - & 10.11 & - & - & 60 & - & - & 2 & - & [65] \\
\hline Ionic liquid impregnated Amberlite XAD.16/MCM-41-silica & - & $16.18^{*}$ & - & - & 90 & - & - & 3 & - & [66] \\
\hline Ethylglycol teraacetic acid functionalized silica-chitosan & - & 6.74 & - & - & 120 & - & - & 2 & - & [6] \\
\hline Diethylenetriamine penta acetic acid functionalized silica-chitosan & - & 8.99 & - & - & 120 & - & - & 2 & - & [6] \\
\hline
\end{tabular}

MWNT-sil-P, respectively, at $23^{\circ} \mathrm{C}$ and $45^{\circ} \mathrm{C}$ for a period of 1 and $24 \mathrm{~h}$. It can be immediately interpreted from the Fig. 8a that the REE adsorption was exceptionally well (nearly $>99 \%$ ) for 1-SWNT-sil-P adsorbents. Irrespective of the temperature, both LREES (Sc, La, Ce, Pr, sorbents. Irrespective of the temperature, both LREEs (Sc, La, Ce, Pr,
$\mathrm{Nd}, \mathrm{Sm}, \mathrm{Eu}, \mathrm{Gd}$, and Tb) and HREEs (Y, Dy, Ho, Er, Tm, Yb, and Lu) $\mathrm{Nd}, \mathrm{Sm}, \mathrm{Eu}, \mathrm{Gd}$, and $\mathrm{Tb}$ ) and HREEs (Y, Dy, Ho, Er, Tm, Yb, and $\mathrm{Lu}$ )
depicted exemplary adsorption even within a contact time of $1 \mathrm{~h}$. On depicted exemplary adsorption even within a contact time of $1 \mathrm{~h}$. On
the other hand, the adsorption efficiencies of 2-SWNT-sil-P were poor and the overall trend showed that HREE adsorption was comparatively greater than its counterpart with the lowest efficiency recorded for the case of $\mathrm{La}^{3+}$. It should be noted that $\mathrm{Sc}^{3+}$ adsorption was superior irrespective of the adsorbent under consideration. Fig. $8 \mathrm{~b}$ shows that the REE adsorption was remarkable with MWNT composites in relation to SWNTs, from an overall standpoint. Among the MWNTs, 2-MWNT-sil-P composites were superior to 1-MWNT-sil-P composites, unlike in the case of SWNTs where the reverse held true. Maximum REE adsorption was never observed within the stipulated reaction time of $1 \mathrm{~h}$ for both the group of MWNT composites at room temperature. However, with an increase in temperature to $45^{\circ} \mathrm{C}$, maximum REE adsorption was achieved by MWNT composites synthesized by both the Methods. The significance of PAN immobilization onto the hybrid CNTs and silica gel was studied, and the results are provided in Fig. 8c. MWNT-sil adsorbents without PAN modification were not efficient in REE adsorption, similar to 2-SWNT-sil-P adsorbents. The influence of temperature on the adsorption process also seemed insignificant with these two kinds, i.e. MWNT-sil and 2-SWNT-sil-P. To sum up, both 1-SWNT-sil-P and SWNT-sil adsorbents were effective amongst the SWNTs while MWNTs with PAN grafting from both the methods (1-MWNT-sil-P and 2-MWNT-sil-P) showed a desirable REE removal efficiency. The key finding from this investigative study is that PAN grafting is a pre-requisite for functionalized MWNT-silica composites to adsorb REEs. However, despite the absence of PAN immobilization, SWNT-silica composites are capable of depicting phenomenal REE adsorption, which inherently implies the fact that the role of PAN in REE adsorption is inconsequential.

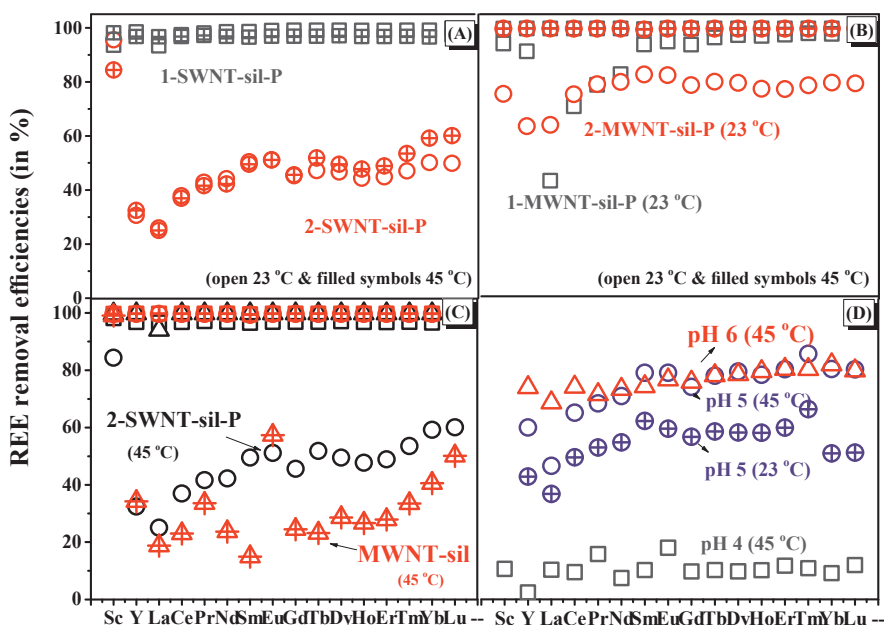

Fig. 8. REE adsorption efficiencies of the synthesised composites (A) Method I and II SWNT composites at 23 and $45^{\circ} \mathrm{C}$ (B) Method I and II MWNT composites at 23 and $45^{\circ} \mathrm{C}$ (C) Comparison of SWNT and MWNT composites a $45^{\circ} \mathrm{C}$ (D) REE recovery efficiency of 2-MWNT-silP from AMD at 23 and $45^{\circ} \mathrm{C}$. For all these tests, the following conditions were used: the initial $\mathrm{pH}$ the following condions were used: the initial $\mathrm{pH}$ centration $-5 \mathrm{ppm}$; contact time $-1 \mathrm{~h}$. 
Further to simulate the real wastewater system, the effect of salinity, hardness and oil compounds on REE intraseries behavior was further examined with these set of composites and the comprehensive results are presented under Supplementary information (Fig. SF4). The main outcome of this study is that SWNT-sil (without PAN modification) and 2- MWNT-sil-P (with PAN modification) can deliver commendable results. Further, as an attempt to validate the results and to ascertain the inherent potentiality of the synthesized composites in real water applications, they were employed for REE recovery from AMD. The composition of other competing ions in AMD is provided under Section 2.1. Until a $\mathrm{pH}$ value of 5 , the adsorbents did not display any REE adsorption. In line with the results procured earlier, the effectiveness of the adsorbents was the greatest for 2-MWNT-sil-P, followed by SWNTsil. In terms of their REE adsorption efficiencies, they can be ordered as 2-MWNT-sil-P > SWNT-sil > 1-SWNT-sil-P > 1-MWNT-sil-P > 2SWNT-sil-P > MWNT-sil. Hence, 2-MWNT-sil-P was found to be the desirable one, while 2-SWNT-sil-P and MWNT-sil (no PAN grafting) were the least efficient members of the tested adsorbents. These findings show that PAN attachment onto MWNT-silica composites via Method II step-by-step grafting route is necessary in order to display higher selectivity towards REEs amidst other competing ions. In order to provide an account of the effect of process parameters on REE recovery from AMD, the most favorable adsorbent, 2MWNTsilP, was subjected to different temperatures $\left(23\right.$ and $\left.45^{\circ} \mathrm{C}\right)$, contact times $(1 \mathrm{~h}$ and $24 \mathrm{~h})$ and $\mathrm{pH}$ (4, 5 and 6), the results of which are shown in Fig. 8d. As observed earlier, the commencement of REE adsorption started from $\mathrm{a} \mathrm{pH}$ value of 5 while the increase in temperature and $\mathrm{pH}$ had a positive impact on the REE adsorption efficiencies. The observations made in this section were in sound agreement with the inference from experiments involving artificial water conditions. Overall, it was clear from Fig. 8 that HREE adsorption was comparatively better than that of LREEs. Excluding $\mathrm{Sc}^{3+}$, no other LREE displayed superior adsorption in comparison to HREEs with $\mathrm{La}^{3+}, \mathrm{Ce}^{3+}$ and $\mathrm{Y}^{3+}$ recording inferior outcomes. Although Sc is considered as LREE, the affinity towards $\mathrm{Sc}^{3+}$ was superior in comparison to other LREE or HREE in all cases, which is further discussed in detail under Section 3.6. Besides, it should be stated here that HREEs i.e. $\mathrm{Yb}^{3+}$ and $\mathrm{Lu}^{3+}$ adsorption was superior in artificial water conditions. But, when using AMD, their affinities dropped in comparison to middle REEs (from Nd to Dy) and other HREEs (from Ho to $\mathrm{Tm}$ ), as evident in Fig. 8 .

\subsection{Selective separation of scandium from other REEs}

Further, due to the ever-increasing demand of Sc in cutting-edge applications, selective separation of Sc from other RFFs by exploiting
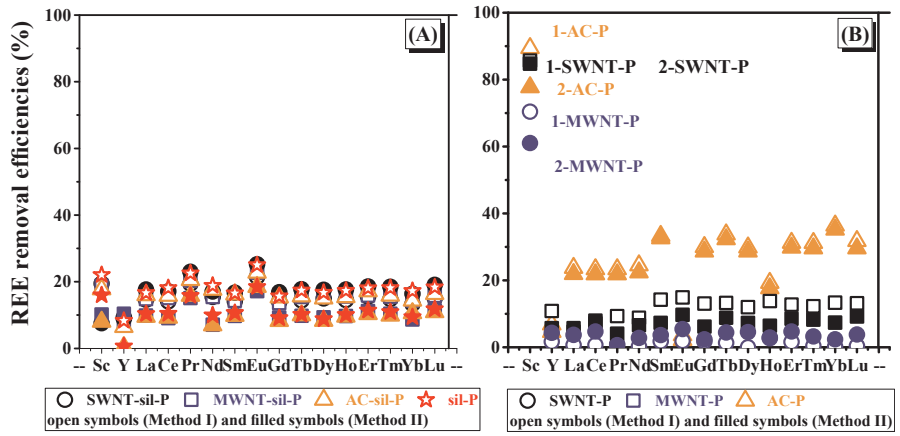

Fig. 9. REE removal efficiencies for (a) CNT/AC-silica-PAN composites and (b) CNT/AC-PAN adsorbents (without APTES and silica). Process conditions: $C_{\text {REE }}-$ $5 \mathrm{ppm}$ (each), $\mathrm{pH} 4,45^{\circ} \mathrm{C}$ and $1 \mathrm{~h}$ the difference in ionic size and adsorptive behavior was attempted. As shown in Fig. 9a, REE binding was not observed for CNT-silica composites at $\mathrm{pH}$ 4. However, at this $\mathrm{pH}$ (Fig. 9b), PAN grafted CNTs (i.e. 1 SWNT-P, 2-SWNT-P, 1-MWNT-P and 2-MWNT-P) demonstrated affinity towards $S c$ (the only REE). Hence, these findings led to the development of selective $\mathrm{Sc}^{3+}$ separation from other REEs at $\mathrm{pH} 4$ using SWNT/ MWNT-PAN while the rest of the REEs were selectively separated by Method II MWNT-sil-P at pH 5 by controlling the adsorption $\mathrm{pH}$. It should be remarked here that SWNT-PAN adsorbents displayed higher $\mathrm{Sc}^{3+}$ selectivity ((less co-removal of other REEs), in comparison to ACPAN adsorbents from our previous work, compared in Fig. 9b [26]. The enhanced selectivity towards $\mathrm{Sc}^{3+}$ could be a manifestation of its lowe ionic radii $(0.75 \AA)$, in relation to other REEs. Hence, the trend of higher $\mathrm{Sc}^{3+}$ affinity observed in our experiments, followed by a higher affinity of HREEs over LREEs, might be the effect of the lower ionic radii. The general REE adsorption trend followed the Lanthanide contraction ef fect, owing to the imperfect shielding of electrons within the same subshell, with increasing atomic number (See Fig. 8). A similar trend was also observed in our previous works $[25,26,44]$.

\subsection{The superiority of the adsorbents}

It can be seen from Table 1 that the REE adsorption by 2-sil-P was single component system. However, it must be noted that the latter depicted enhanced REE selectivity and affinity in the AMD solution i.e. in a multi-component system. A comparative assessment among all the PAN grafted silica-based composites (hybridized with other polymers such as chitosan, AC, SWNT and MWNT) from our previous as well as the current studies is presented in Fig. 10 in terms of REE removal efficiencies (in \%) and REE distribution coefficients (in $\mathrm{mL} / \mathrm{g}$ ). These investigations highlighted the fact that the MWNT loading (as low as $10 \%$, "spice polymer") to the silica support can greatly influence the REE selectivity of the synthesized hybrid adsorbents. The distribution coefficient $\left(\mathrm{K}_{\mathrm{D}}\right)$ of the adsorbents under comparison (Fig. 10b), i.e. silica-PAN $(0.5-1 \mathrm{~L} / \mathrm{g})$ and MWNT-sil-PAN (1-6 L/g), strongly support the aforementioned effect of MWNT loading. It should be noted that the distribution coefficients correspond to a $5 \mathrm{ppm}$ REE feed concentration in both the cases. Also, at the same concentration, the $\mathrm{K}_{\mathrm{D}}$ value of $\mathrm{AC}$ sil-PAN (AC. silica-1:1) was higher than that of MWNT-sil-PAN (MWNT: silica-1:10). Nevertheless, even for such a small fraction of the MWNT reinforcements, a notable increase in REE affinity was recorded, and it is uncertain at this stage if a further rise in MWNT loading will have a positive or a neutral effect on the performance, which could be relevant studies in future. In relation to the $K_{D}$ values procured from literature more pronounced than that of 2-MWNT-silica-PAN composites in a 
(A)

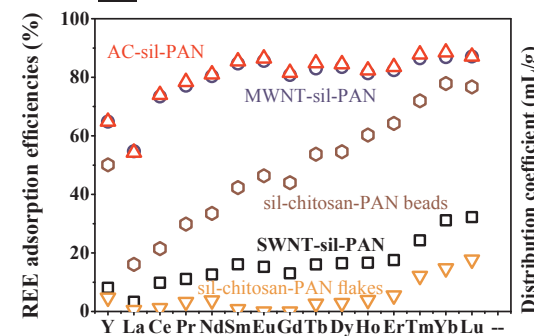

(B)

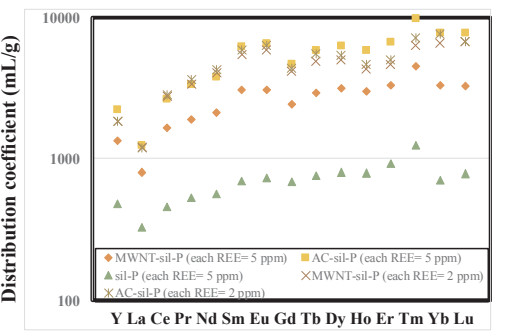

Fig. 10. (a) REE removal efficiencies (in \%, $\mathrm{C}_{\mathrm{REE}}-2 \mathrm{ppm}$ each in AMD solution, $\mathrm{pH} 5,45^{\circ} \mathrm{C}, 1 \mathrm{~h}$ ) and (b) REE distribution coefficients (in $\mathrm{mL} / \mathrm{g}$, $\mathrm{C}_{\mathrm{REE}}-$ two tested concentrations ( $2 \mathrm{ppm}$ and $5 \mathrm{ppm}$ each) in AMD solution, $\mathrm{pH} 5,45^{\circ} \mathrm{C}, 1 \mathrm{~h}$ ) for various adsorbents.

sources $[8,48,49]$, the ones from this study are distinctly larger, with the synthesized adsorbents depicting a negligible affinity towards $\mathrm{Ni}$, $\mathrm{Co}, \mathrm{Mg}, \mathrm{Mn}, \mathrm{Zn}$ and $\mathrm{Ca}$, probably because the adsorption (for some of these elements) is found favorable in basic $\mathrm{pH}$ regime $[38,50,51]$. However, co-removal of $\mathrm{Pb}, \mathrm{Cu}, \mathrm{Cr}$ and $\mathrm{Al}$ was observed at $\mathrm{pH} 5$ (Supplementary material: Table S1). Nonetheless, it is also essential to consider the adverse effects imparted by other industrial contaminants consider the ac to have affected the REE sorption performance by a majority of the adsorbents in this study. Besides, the usage of carbon-based materials is widely promoted in other separation and concentration technologies like capacitive deionization (CDI). Recently, Arulrajan et al. investigated the utilization of APTES functionalized AC fabric as an anion-selective electrode for desalination purpose in a CDI system [52]. In this line, the fabricated CNT based materials can be potentially utilized as CDI electrode to separate and concentrate REEs in future works. Furthermore, from the practical aspect, CNT functionalized silica particles have already found its use in column studies for the separation of polycyclic aromatic hydrocarbons (PAHs) and nitro-aromatics [53,54]. One suitable example related to our work would be the microcolumn studies by Zhang et al for the pre-concentration and separation of REEs using acetylacetone (acac) modified silica particles [30]. Besides, the composites were also tested for regeneration and reusability for practical applications. REEs were recovered $(\sim 99.99 \%)$ from the adsorbents using $1 \mathrm{M} \mathrm{HNO}_{3}$ just by mixing for $<15 \mathrm{~min}$. In the subsequent cycles (tested up to 5 cycles), a slight drop in regeneration efficiency was observed i.e. around $80-85 \%$ by the used composites.

\subsection{Proposed functionalization and REE binding mechanism}

Some of the major findings from the previous studies on silica materials could help elucidate the probable binding sites on our CNT-silica composites. It should be remarked that the bare silica had the potential to adsorb $\mathrm{Sc}^{3+}$ without any functionalization while the pristine CNTs were not effective in doing the same without surface modification. PAN were not effective in doing the same without surface modification. PAN
grafting onto CNT (especially MWNT) was needed in order to adsorb grafting onto CNT (especially MWNT) was needed in order to adsorb
$\mathrm{Sc}^{3+}$. However, both bare silica and CNT cannot adsorb the rest of the REEs without surface modification. Hence, it can be specified that the REE affinities stem from the silane and PAN moieties of our composites.

Now, summarizing our significant findings from the current work (See Fig. 11 as well as Graphical abstract) establishes that APTES crosslinked SWNT-silica composites without PAN modification showed higher REE affinities while the APTES cross-linked MWNT-silica composites without PAN modification fails to bind REEs efficiently. The hybrid MWNT-silica composites require PAN grafting and, therefore, the PAN units on the surface of the composite seem to play a major role in the binding mechanism in case of MWNT. This also aligns with the

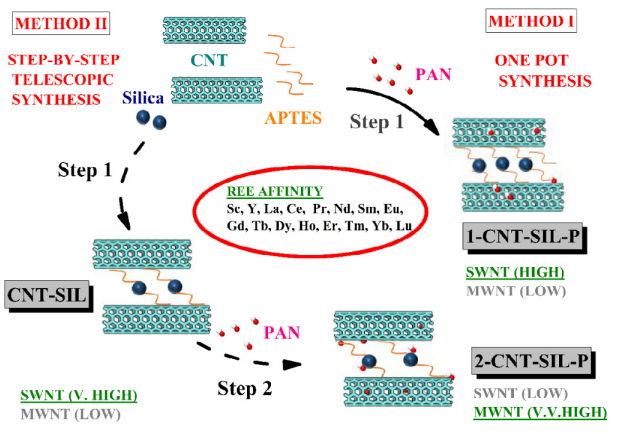

Fig. 11. Contrasting REE adsorption behavior of SWNT-silica and MWNT-silica composites based on the PAN grafting technique.

fact that Method II PAN grafting is superior to Method I for MWNT. This might be probably due to the high loading of PAN units via Method II in comparison to Method I. In particular, the chemical immobilization of PAN via APTES (i.e. PAN units grafted onto the surface of CNT-APTESsilica) seems to be highly effective through the adoption of Method II step-by-step synthesis. These chemically immobilized PAN units are necessary for enhancing REE sorption. However, this does not hold true for the case of SWNT composites. PAN groups on the surface of SWNT seem to be less efficient compared to MWNT composites. Hence, it can point to the fact that the enhanced REE affinities arise from the amino groups of the SWNT composites, not the PAN groups. Based on this an 2-SWNT sil-P, which is in line with our experimental findings from these studies. With the effect of PAN grafting being minimal, the role of APTES crosslinking in creating potential surface binding sites for REE uptake was more pronounced for the case of SWNT-silica (3.6\% of N and $2.64 \%$ of $\mathrm{H}$ ) in comparison to MWNT-silica $(0.91 \%$ of $\mathrm{N}$ and $0.99 \%$ of $\mathrm{H})$. In this line, the improved surface properties of 2-MWNT-sil-P from PAN grafting manifested in terms of high REE selectivity and affinity, with the same being one of the best adsorbents of this study.

The FTIR spectra of the synthesized adsorbents pre- and post-REE adsorption are presented in Supplementary material (Fig. SF5). The dispersion of bands was observed after REE adsorption at $1329 \mathrm{~cm}^{-1}$, $1590 \mathrm{~cm}^{-1}$ and $1400-1480 \mathrm{~cm}^{-1}$ corresponding to $-\mathrm{C}=\mathrm{N}-$ of PAN benzenoid group, $-\mathrm{N}=\mathrm{N}$ of PAN azo group and $-\mathrm{NH}_{2} /-\mathrm{CH}_{2}$ of APTES silane group, respectively. This is in line with the PAN coordination mechanism to bind metal ions to form tridentate chelate complexes via the hydroxyl group, pyridine nitrogen and one of the two azo $\mathrm{N}$ atoms. 
In addition, bands characteristic of $\mathrm{Si}-\mathrm{O}-\mathrm{C}$ bending vibration $\left(665 \mathrm{~cm}^{-1}\right), \mathrm{N}-\mathrm{H}$ deformation mode $\left(750-874 \mathrm{~cm}^{-1}\right)$ and $\mathrm{C}-\mathrm{N}$ stretching vibration $\left(1550 \mathrm{~cm}^{-1}\right)$ also underwent visible changes. These reduction in band intensities are in turn a reflection of the groups involved in the adsorption process. In addition to the FTIR spectra, the dispersion of XRD diffraction peaks was also seen at $2 \Theta=10$ and $30^{\circ}$ in the XRD spectra (Fig. SF5) after REE adsorption. The information gathered from these spectra eventually point toward the underlying mechanism of the chemisorption process. Furthermore, the theoretical modeling of experimental data demonstrated a perfect fit to Langmuir (L) isotherm with pseudo-second-order (PS2) kinetic models $\left(\mathrm{R}^{2}>0.9\right)$, and this functions as additional evidence to the aforementioned arguments (Supplementary material: Fig. SF6). There also exist prior works that arrive at similar conclusions as well [49,55-57]. The temperature effects on the adsorption process also affirm the inference based on the chemisorption mechanism. Besides, all the hybrid composites carried an overall positive surface zeta potential $(\mathrm{pH}<5)$, and this can point toward the fact that the composite matrix-REE interaction was made feasible via an ionic exchange between the positively charged support functional groups and the REE cations. Hence, it is expected that REE binding mechanism can commonly occur through coordination between REE-PAN complexes or through ion exchange between REE cations and the protonated binding sites on the surface.

Notably, the REE affinities of SWNT-silica and MWNT-silica composites are quite at odds due to the ligand grafting technique. On comparing the characterization and REE affinity studies, we estimate that the disparities arise from the number of active binding units on the that the disparities arise from the number of active binding units on the
composites' surface, ease of functionalization and extent of APTES composites' surface, ease of functionalization and extent of APTES
polymerization reaction to crosslink CNT and silica, which in turn exert a dominant influence on REE adsorption. To gain in-depth knowledge about CNTs and to explore them further for innovative applications, it is essential to study both SWNT and MWNT together. This could reveal interesting and useful inferences that can facilitate our understanding of their interactions with guest molecules and help create well-deof their interactions with guest molecules and help create well-de-
scribed interfaces between nanostructures. There are prior studies that scribed interfaces between nanostructures. There are prior studies that
illustrate the differential chemical reactivity of the CNT arising from the illustrate the differential chemical reactivity of the CNT arising from the
strain induced by $\mathrm{sp}^{2}$-hybridised carbon atom pyramidalization and the $\pi$-orbital misalignment. Similarly, the parameters, such as dispersion, diameter, configuration, chirality, electronic nature etc., can also influence the surface chemistry and chemical reactivity of CNT [58]. With the current knowledge, it is not possible to comprehend the whole the current knowledge, it is not possible to comprehend the whole
phenomenon behind the disparities observed with SWNT/MWNTAPTES-PAN interactions in our work and it is surely an object of interest for future studies.

\section{Conclusion}

To summarize, we have shown experimentally how two different grafting approaches can alter the REE affinity of APTES cross-linked CNT-silica nanocomposites. This can be considered as a direct inference pointing towards the importance of the type of grafting techniques in the enhancement of REE affinity. It stresses the relevance of what kind of synthesis route works best based on the type of CNT. For SWNT, the desired procedure would be one-pot synthesis whereas step-by-step desired procedure would be one-pot synthesis whereas step-by-step
telescopic synthesis must be implemented for MWNT to induce a fatelescopic synthesis must be implemented for MWNT to induce a fa-
vorable REE-composite interaction. The adopted functionalization and ligand grafting approaches presented here are straightforward and can be reciprocated with ease to yield REE-selective nanocomposites. Further, the study exposed that the small addition of $10 \%$ of MWNT to the CNT-silica composites could result in enhanced REE selectivity, demonstrated by up to 5 -fold increase in RFE distribution coefficient demonstrated by up to 5 -fold increase in REE distribution coefficient
from 0.5 to $1 \mathrm{~L} / \mathrm{g}$ (silica-PAN) to $1-5 \mathrm{~L} / \mathrm{g}$ (MWNT-silica-PAN) when from 0.5 to $1 \mathrm{~L} / \mathrm{g}$ (silica-PAN) to $1-5 \mathrm{~L} / \mathrm{g}$ (MWNT-silica-PAN) when
tested with AMD. We also find that the CNT-PAN materials from this study demonstrate enhanced selectivity towards Sc in comparison to AC-PAN and other adsorbents from our prior works. Hence, CNT-PAN can be effectively utilized to separate Sc from the rest of the REEs in a two-stage separation process. The intraseries REE behavior, as a whole, has not been explored for CNT-silica composites, to the best of our knowledge. Therefore, this work with CNT-silica composite materials provides a benchmark for the use of other ligands, matrix supports and/ or functionalization procedures to enhance REE affini These critical findings from this work continue to establish that the CNTs are ideal nanomaterials for constructing advanced functional materials for various applications.

\section{Acknowledgments}

The authors are grateful to the Academy of Finland (decision number 292542) for funding the project. The authors would also like to thank Mr. Toni Väkiparta (SEM analysis, LUT School of Engineering Science, Finland) and Mr. Santtu Heinilehto (XPS analysis, University of Oulu, Finland).

\section{Appendix A. Supplementary data}

Supplementary data to this article can be found online at https:// doi.org/10.1016/j.cej.2019.02.057.

\section{References}

[1] K. Zhang, A.N. Kleit, A. Nieto, An economics strategy for criticality - application to rare earth element Yttrium in new lighting technology and its sustainable avail-
ability, Renew. Sustain. Energy Rev. (2017), https://doi.org/10.1016/.j.rer.2016. ability, Renew. Sustain. Energy Rev. (2017), https://doi.org/10.1016/j.rser. 12.127 .

[2] K. Binnemans, P.T. Jones, B. Blanpain, T. Van Gerven, Y. Yang, A. Walton, M. Buchert, Recycling of rare earths: a critical review, J. Clean. Prod. 51 (2013) 1-22, https://doi.org/10.1016/.j.jclepro.2012.12.037.

3] W. Wang, C.Y. Cheng, Separation and purification of scandium by solvent extraction and related technologies: a review, J. Chen.

[4] C.R. Borra, B. Blanpain, Y. Pontikes, K. Binnemans, T. Van Gerven, Recovery of rare earths and other valuable metals from bauxite residue (Red Mud): a review, J. Sustain. Metall. 2 (2016) 365-386, https://doi.org/10.1007/s40831-016-0068-2. [5] K. Binnemans, P.T. Jones, B. Blanpain, T. Van Gerven, Y. Pontikes, Towards zerowaste valorisation of rare-earth-containing industrial process residues: a critical 02.089

[6] J. Roosen, S. Van Roosendael, C.R. Borra, T. Van Gerven, S. Mullens, K. Binnemans, Recovery of scandium from leachates of Greek bauxite residue by adsorption on functionalized chitosan-silica hybrid materials, Green Chem. 18 (2016) 2005-2013, https://doi.org/10.1039/C5GC02225H.

[7] M.R. Awual, M. Ismael, Efficient gold(III) detection, separation and recovery from urban mining waste using a facial conjugate adsorbent, Sens. Act
196 (2014) 457-466, https://doi. org $/ 10.1016 /$ j.snb.2014.02.055.

[8] J. Roosen, J. Spooren, K. Binnemans, Adsorption performance of functionalize chitosan-silica hybrid materials toward rare earths, J. Mater. Chem. A. 2 (2014) 19415-19426, https://doi.org/10.1039/C4TA04518A.

[9] M.R. Awual, T. Yaita, H. Shiwaku, Design a novel optical adsorbent for simulta neous ultra-trace cerium(III) detection, sorption and recovery, Chem. Eng. J. 228 (2013) 327-335, https://doi.org/10.1016/j.cej.2013.05.010,

[10] M.R. Awual, T. Kobayashi, H. Shiwaku, Y. Miyazaki, R. Motokawa, S. Suzuki, Y. Okamoto, T. Yaita, Evaluation of lanthanide sorption and their coordination
mechanism by EXAFS measurement using novel hybrid adsorbent, Chem. Eng. J. mechanism by EXAFS measurement using novel hybrid adsorben,
225 (2013) 558-566, https://doi.org/10.1016/j.cej.2013.04.015

[11] M.R. Awual, N.H. Alharthi, Y. Okamoto, M.R. Karim, M.E. Halim, M.M. Hasan M.M. Rahman, M.M. Islam, M.A. Khaleque, M.C. Sheikh, Ligand field effect for Dysprosium(III) and Lutetium(III) adsorption and EXAFS coordination with novel composite nanomaterials, Chem. Eng. J. 320 (2017) 427-435, https://doi.org/10

12] M.S. Dresselhaus, A. Jorio, carbon nanotubes and graphene rmann, G. Dresselhaus, R. Saito, Perspectives on carbon nanotubes and graphene raman spectross

[13] Y.-P. Sun, K. Fu, Y. Lin, W. Huang, Functionalized carbon nanotubes: properties an applications, Acc. Chem. Res. 35 (2002) 1096-1104, https://doi.org/10.1021/ ar010160v.

Molder, S.H. Tawfick, R.H. Baughman, A.J. Hart, Carbon nanotubes: present and future commercial ap
doi.org/10.1126/science. 1222453 .

le-walled carbon nanotubes, Angew. Chem. Int. Ed Engl. 41 (2002) 1853-1859.

16] B. Pan, B. Xing, Adsorption mechanisms of organic chemicals on carbon nanotubes, Environ. Sci. Technol. 42 (2008) 9005-9013, https://doi.org/10.1021/es801777n, 17] A. Nikitin, X. Li, Z. Zhang, H. Ogasawara, H. Dai, A. Nilsson, Hydrogen storage in 
162-167, https://doi.org/10.1021/nl072325k.

[18] M.A. AlSaadi, A. Al Mamun, M.Z. Alam, M.K. Amosa, M.A. Atieh, Removal of cadmium from Water by CNT-PAC composite: effect of functionalization, Nano 11

91650011

Marcos C. Prieto, M. Valletzano, I. Izquierdo-Barba, A. de Andrés, J. SánchezMarcos, C. Prieto, M. Vallet-Regi, Carbon nanotubes-mesoporous silica composites
as controllable biomaterials, J. Mater. Chem. 19 (2009) 7745, https://doi.org/10. 1039/b909628k.

[20] B.C. Satishkumar, S.K. Doorn, G.A. Baker, A.M. Dattelbaum, Fluorescent single walled carbon nanotube/silica composite materials, ACS Nano. 2 (2008)

2283-2290, https://doi.org/10.1021/nn8003839.

groups for extractive concentration of metal ions, Talanta 62 (2004) 1005-102 groups for extractive concentration of metal ions

[22] H. Chen, O. Jacobs, W. Wu, G. Rüdiger, B. Schädel, Effect of dispersion method on tribological properties of carbon nanotube reinforced epoxy resin composites,
Polym. Test. 26 (2007) 351-360, https://doi.org/10.1016/j.polymertesting.2006. 11.004 .

[23] J. Kathi, K.-Y. Rhee, J.H. Lee, Effect of chemical functionalization of multi-walled carbon nanotubes with 3-aminopropyltriethoxysilane on mechanical and morpho-
logical properties of epoxy nanocomposites, Compos. Part Appl. Sci. Manuf. 40 logical properties of epoxy nanocomposites, Compos. Part Appl. Sci.
(2009) 800-809, https://doi.org/10.1016/j.compositesa.2009.04.001.

[24] D.L. Ramasamy, E. Repo, V. Srivastava, M. Sillanpää, Chemically immobilized and physically adsorbed PAN/acetylacetone modified mesoporous silica for the recovery of rare earth elements from the waste water-comparative and optimization
study, Water Res. 114 (2017) 264-276, https://doi.org/10.1016/j.watres.2017.02. study,

[25] D.L. D.L. Ramasamy, V. Puhakka, E. Repo, S. Khan, M. Sillanpää, Coordination and silica
surface chemistry of lanthanides (III), scandium. (II) and yttrium (III) sorption 1 . (2-pyridylazo)-2-2napththol (PAN) and acetylacetone (acac) immobilized gels, (2-pyridylazo)-2-napththol (PAN) and acetylacetone (acac) immobilized gels,
Chem. Eng. J. 324 (2017) 104-112, https://doi.org/10.1016/j.cej.2017.05.025.

[26] D.L. Ramasamy, V. Puhakka, E. Repo, S. Ben Hammouda, M. Sillanpää, Two-stage selective recovery process of scandium from the group of rare earth elements in aqueous systems using activated carbon and silica composites: dual applications by
tailoring the ligand grafting approach, Chem. Eng. J. 341 (2018) 351-360, https://
doi.org/10.1016/j.cej.2018.02.024.

[27] J.H. Rouse, P.T. Lillehei, J. Sanderson, E.J. Siochi, Polymer/single-walled carbon nanotube films assembled via donor-acceptor interactions and their use as scaffolds
for silica deposition, Chem. Mater. 16 (2004) 3904-3910, https://doi.org/10.1021/

] M. Zhang, X. Zhang, X. He, L. Chen, Y. Zhang, A facile method to coat mesoporo silica layer on carbon nanotubes by anionic surfactant, Ma

[29] M. Bottini, L. Tautz, H. Huynh, E. Monosov, N. Bottini, M.I. Dawson, S. Bellucci, . Mustelin, Covalent decoration of multi-walled carbon nanotubes with silica n

noparticles, Chem. Commun. (2005) 758, https://doi.org/10.1039/b412876a.
[30] N. Zhang, C. Huang, B. Hu, ICP-AES determination of trace rare earth elements in environmental and food samples by on-line separation and preconcentration wit acetylacetone-modified silica gel using microcolumn, Anal. Sci. 23 (2007)

997-1002, https://doi.org/10.2116/analsci.23.997.

K. Babooram, R. Narain, Fabrication of SWNT/Silica composites by the sol-gel am8001296.

[32] M.S. Dresselhaus, G. Dresselhaus, R. Saito, A. Jorio, Raman spectroscopy of carbon nanotubes, Phys. Rep. 409 (2005) 47-99, https://doi.org/10.1016/j.physrep.2004 10.006 .

[33] J.M. Tan, P. Arulselvan, S. Fakurazi, H. Ithnin, M.Z. Hussein, A review on characterizations and biocompatibility of functionalized carbon nanotubes in drug de-
livery design, J. Nanomater. 2014 (2014) 1-20, https://doi.org/10.1155/2014/ 917024 . [34] M.R. Awual, M.M. Hasan, H. Znad, Organic-inorganic based nano-conjugate ad-
sorbent for selective palladium(II) detection, separation and recovery, Chem. Eng. J. 259 (2015) 611-619, https://doi.org/10.1016/j.cej.2014.08.028

[35] M.R. Awual, New type mesoporous conjugate material for selective optical copper (II) ions monitoring \& removal from polluted waters, Chem. Eng. J. 307 (2017)

] M. Rabiul Awual, M. Munjur Hasan, T. Ihara, T. Yaita, Mesoporous silica based novel conjugate adsorbent for efficient selenium(IV) detection and removal from
water, Microporous Mesoporous Mater. 197 (2014) 331-338, https://doi.org/10 1016/j.micromeso. 2014.07.005.

[37] K. Abbas, H. Znad, M.R. Awual, A ligand anchored conjugate adsorbent for effective mercury(II) detection and removal from aqueous media, Chem. Eng. J. 334 (2018) 432-443, https:///doi.org/10.1016/j.cej. 2017.10.054.

38] M.R. Awual, A.M. Asiri, M.M. Rahman, N.H. Alharthi, Assessment of enhanced nitrite removal and monitoring using ligand modified stable conjugate materials,

[39] S. Li, Z. Wang, J. Jia, C. Hou, X. Hao, H. Zhang, Preparation of hydroxyl and (3aminopropyl)triethoxysilane functionalized multiwall carbon nanotubes for use as conductive fillers in the polyurethane composite, Polym. Compos. 39 (2018)

1212-1222, https://doi.org/10.1002/pc.24054.
[40] D.L. Ramasamy, S. Khan, E. Repo, M. Sillanpäa, Synthesis of mesoporous and microporous amine and non-amine functionalized silica gels for the application of rare earth elements (REE) recovery from the waste water-understanding the role of $\mathrm{pH}$,

Chem. Eng. J. 322 (2017) 56-65, https://doi.org/10.1016/j.cej.2017.03.152.
[41] A. Beganskiene, V. Sirutkaitis, M. Kurtinaitiene, R. Juskenas, A. Kareiva, FTIR, TEM and NMR Iinvestigations of Stöber silica nanoparticles, Mater. Sci. Medžiagotyra. 10 (2004) 287-290, https://doi.org/10.1016/j.jnoncrysol.2012.11.006.

H. Mi, X. Zhang, Y. Xu, F. X.No, Synhesis, Characterization and electrochemica behavior of polypyrrole/carbon nanotube composites using organometallic-functionalized carbon nanotubes, App

[43] D.L. Ramasamy, A. Wojtuś, E. Repo, S. Kalliola, V. Srivastava, M. Sillanpää, Ligan immobilized novel hybrid adsorbents for rare earth elements (REE) removal from waste water: assessing the feasibility of using APTES functionalized silica in the hybridization process with chitosan, Chem. Eng. J. 330 (2017) 1370-1379, https:/ doi.org/10.1016/j.cej.2017.08.098.

44] D.L. Ramasamy, V. Puhakka, S. Iftekhar, A. Wojtuś, E. Repo, S. Ben Hammoud E. Iakovleva, M. Sillanpää, $\mathrm{N}$ - and O-, ligand doped mesoporous silica-chitosan hybrid beads for the efficient, sustainable and selective recovery of rare earth elephysical modification mine drainage (AMD): understanding the significance of (2018) 84-91, https://doi.org/10.1016/j.jhazmat.2018.01.030

[45] D.L. Ramasamy, V. Puhakka, E. Repo, M. Sillanpää, Selective separation of scandium from iron, aluminium and gold rich wastewater using various amino and nonamino functionalized silica gels - a comparative study, J,
890-901, https:///doi.org/10.1016/j.jclepro. 2017.09.199.

[46] I. Anastopoulos, A. Bhatnagar, E.C. Lima, Adsorption of rare earth metals: a review of recent literature, J. Mol. Liq. 221 (2016) 954-962, https://doi.org/10.1016/j. molliq. 2016.06.076.

[47] S. Iftekhar, D.L. Ramasamy, V. Srivastava, M.B. Asif, M. Sillanpää, Understanding the factors affecting the adsorption of Lanthanum using different adsorbents: a critical review, Chemosphere. 204 (2018) 413-430, https://doi.org/10.1016/j.

[48] C. Gerente, V.K.C. Lee, P.L. Cloirec, G. McKay, Application of chitosan for the removal of metals from wastewaters by adsorption-mechanisms and models review,
Crit. Rev. Environ. Sci. Technol. 37 (2007) 41-127, https://doi.org $/ 10.1080 /$

[49] Z.S. Birungi, E.M.N. Chirwa, The kinetics of uptake and recovery of lanthanum using freshwater algae as biosorbents: comparative analysis, Bioresour
160 (2014) 43-51, https://doi.org/10.1016/j.biortech. 2014.01.033.

[50] A. Shahat, H. M.A. Hassan, M.F. Fl-Shahat, O. El Shahawy, M.R. Awual, Visual nickel(II) ions treatment in petroleum samples using a mesoporous composite adsorbent, Chem. Eng. J. 334 (2018) 957-967, https://doi.org/10.1016/j.cej.2017. 10.105 .

[51] A. Shahat, H.M.A. Hassan, H.M.E. Azzazy, E.A. El-Sharkawy, H.M. Abdou, M.R. Awual, Novel hierarchical composite adsorbent for selective lead(II) ions capturing from wastewater samples, Chem. Eng. J. 332 (2018) 377-386, https://

2.C. Arulrajan, D. Ramasamy M. Su

S. Porada, J.E. Dykstra Exceptional water ää, A. van der Wal, P.M. Biesheuvel,

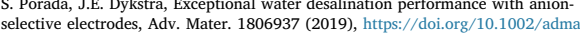
201806937.

[53] E. Menna, F.D. Negra, M. Prato, N. Tagmatarchis, A. Ciogli, F. Gasparrini, D. Misiti, C. Villani, Carbon nanotubes on HPLC silica microspheres, Carbon. 44 (2006)

1609-1613, https.

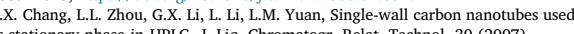
as stationary phase in HPLC, J. Liq. Chromatogr. Relat. Tec

[55] F. Zhao, E. Repo, Y. Meng, X. Wang, D. Yin, M. Sillanpää, An EDTA- $\beta$-cyclodextrin material for the adsorption of rare earth elements and its application in preconcentration of rare earth elements in seawater, J. Colloid Interface Sci. 465

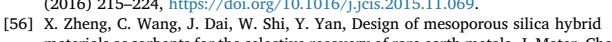
materials as sorbents for the selective recovery of rare earth metals, $J$.
A. 3 (2015) 10327-10335, https:/doi.org/10.1039/C4TA06860B.

[57] E.I. Cadogan, C-H. Lee, S.R. Popuri, H.-Y. Lin, Efficiencies of chitosan nanoparticles and crab shell particles in europium uptake from aqueous solutions through biosorption: Synthesis and characterization, Int. Biodeterior. Biodegrad. 95 (2014) 232-240, https://doi.org/10.1016/j. ibiod.2014.06.003.

[58] S. Banerjee, T. Hemraj-Benny, S.S. Wong, Covalent surface chemistry of singleled carbon nanotist

S. Iftekhar, V. Srivastava, M. Sillanpä, Enrichment of lanthanides in aqueous
system by cellulose based silica nanocomposite, Chem. Eng. J. 320 (2017) 151-159,

https://doi.org/10.1016/j.cej.2017.03.051.
[60] S. Iftekhar, V. Srivastava, A. Casas, M. Sillanpäa, Synthesis of novel GA-g-PAM/SiO 2 nanocomposite for the recovery of rare earth elements (REE) ions from aqueou solution, J. Clean. Prod. 170 (2018) 251-259, https://doi.org/10.1016/j.jclepro.

1] D. Wu, Y. Sun, Q. Wang, Adsorption of lanthanum (III) from aqueous solution using 2-ethylhexyl phosphonic acid mono-2-ethylhexyl ester-grafted magnetic silica na-
nocomposites, J. Hazard. Mater. 260 (2013) 409-419, https://doi.org/10.1016/j. jhazmat.2013.05.042

[62] A. Tadjarodi, V. Jalalat, R. Zare-Dorabei, Adsorption of La(III) in aqueous system by N-(2-hydroxyethyl) salicylaldimine-functionalized mesoporous silica, Mater. 036 Res. Bull. 61 (2015) 113-119, https://doi.org/10.1016/j.materresbull.2014.09.

[63] S.M.A. Koochaki-Mohammadpour, M. Torab-Mostaedi, A. Talebizadeh-Rafsanjani, F. Naderi-Behdani, Adsorption isotherm, kinetic, thermodynamic, and desorption studies of lanthanum and dysprosium on oxidized multiwalled carbon nanotubes, J.
Dispers. Sci. Technol. 35 (2014) 244-254, https://doi.org/10.1080/01932691. 
D.L. Ramasamy et al.

2013.785361

Y. Zhu, Y. Zheng, A. Wang, Preparation of granular hydrogel composite by the redox conple for eficient and fast adsorption of La(III) and Ce(III), J. Enviro

65] I.V. Burakova, A.E. Burakov, A.G. Tkachev, I.D. Troshkina, O.A. Veselova,

A.V. Babkin, W.M. Aung, I. Ali, Kinetics of the adsorption of scandium and cerium
A.
Chemical Engineering Journal 365 (2019) 291-304

ions in sulfuric acid solutions on a nanomodified activated carbon, J. Mol. Liq. 253

D. Avdibegović, M. Regadío, K. Binnemans, Recovery of scandium from diluted aqueous solutions by a supported ionic liquid phase (SILP), $\mathrm{BSC}$ Adv. 7 (2017) 


\title{
Publication VII
}

\author{
D.L.Ramasamy, S.Porada, M.Sillanpää
}

Marine algae: A promising resource for the selective recovery of rare earth elements from aqueous systems

Reprinted with permission from

Chemical Engineering Journal

Vol. 371, pp. 759-768, 2019

(C) 2019, Elsevier 



\begin{tabular}{|c|c|c|}
\hline 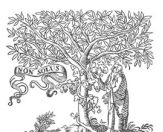 & $\begin{array}{l}\text { Contents lists available at ScienceDirect } \\
\text { Chemical Engineering Journal }\end{array}$ & $\begin{array}{l}\text { CHEMICAL } \\
\text { ENGINERING } \\
\text { JOURNAL } \\
\text { OR }\end{array}$ \\
\hline$\overline{\text { ELSEVIER }}$ & journal homepage: www.elsevier.com/locate/cej & \\
\hline
\end{tabular}

Marine algae: A promising resource for the selective recovery of scandium and rare earth elements from aqueous systems

Deepika Lakshmi Ramasamy $^{\mathrm{a}, \mathrm{b}, *}$, Slawomir Porada ${ }^{\mathrm{a}, \mathrm{c}}$, Mika Sillanpää $^{\mathrm{b}}$

${ }^{a}$ 'Wetsus, European Centre of Excellence for Sustainable Water Technology, Leeuwarden, The Netherlands

Department of Green Chemistry, School of Engineering Science, Lappeenranta-Lahti University of Technology, Finlan

'Department of Science and Technology, Soft Matter, Fluidics and Interfaces (SFI), University of Twente, Enschede, The Netherland

H I G H L I G H T S

- P. oceanica can recover REEs from wastewater without any surface functionalization.

- REE selectivity was enhanced by grafting ligand onto algal biomass.

- $\mathrm{Sc}^{3+}$ adsorption followed Langmuir isotherm and pseudo-second-order kinetic models.

- Intraseries REE affinity trend was investigated.

- REEs were successfully recovered from acidic mine drainage and seawater.

A R T I C L E IN F O

Keywords:

Acidic mine drainage

Adsorptio

Algae

Circular economy

Rare earth elements

Resource
Scandium

\section{A B S T R A C T}

In recent years, the global demand for rare earth elements (REEs) is at a constant raise owing to their critical role in technological advancements. REEs, being listed as one of the critical raw materials, especially scandium (Sc), piques immense research interest in their procurement via secondary resources such as mining effluents and industrial processing residues. Hence, in this study, we explored the feasibility of using green marine algae, Posidonia oceanica, for the selective recovery of Sc and other REEs from diluted waste streams such as acidic mine drainage (AMD) and seawater. The studies were directed towards the investigation of $\mathrm{Sc}^{3+}$ uptake by the algal biomass in a single- and multi-component system for the determination of optimal process conditions such as $\mathrm{pH}$ (1-5), initial feed concentration $(1-200 \mathrm{ppm})$, contact time $(0-24 \mathrm{~h})$ and temperature $\left(20-45^{\circ} \mathrm{C}\right)$. The experimental data on $\mathrm{Sc}^{3+}$ uptake in a single-component system were best described by Langmuir isotherm and pseudo-second-order kinetic models. Further, a major part of the work was focused on understanding the intraseries REE adsorption trend with regard to algal affinity towards the light or heavy REEs. Grafting of 1-(2pyridylazo)-2-naphthol (PAN) onto algal biomass led to the enhancement of overall adsorption capacities and affinities towards all REEs. PAN grafted onto algal biomass (2-algae-P) of this study demonstrated a maximum $\mathrm{Sc}^{3+}$ adsorption capacity of $66.81 \mathrm{mg} / \mathrm{g}\left(\mathrm{pH} 5,20^{\circ} \mathrm{C}, 24 \mathrm{~h}\right.$, dosage $\left.1 \mathrm{~g} / \mathrm{L}\right)$, comparatively higher to the othe algal bio-sorbents found in the literature. Besides, the attachment of the coordination ligand onto the algal biomass also depicted a promising potential to assist the development of optical sensors for the rapid detection of REEs in wastewater.

\section{Introduction}

Since the beginning of the industrial revolution, the establishment of the new-age manufacturing sector is formidably placed on a discerning group of base metals such as magnesium, aluminum, copper, iron, and zinc. The attributes of these metals can be enhanced through the amalgamation of additional metals to obtain a different spectrum of metal properties concerning their strength, ductility, malleability and thermal resistance, desirable for various cutting-edge applications. In this regard, REEs (15 lanthanides, scandium, and yttrium) are considered as technologically significant elements in progressing towards an energy-efficient, green and sustainable future, owing to their unique and rare magnetic and optical properties $[1,2]$. Few remarkable advancements expedited by REEs are echoed in a wide array of applications including metallurgy, superconductors, permanent magnets, batteries, lasers, electrical automotive and light emitting diode (LED)

\footnotetext{
* Corresponding author at: Department of Green Chemistry, School of Engineering Science, Lappeenranta-Lahti University of Technology, Finland.

E-mail address: deepika.ramasamy@lut.fi (D.L. Ramasamy).
}

https://doi.org/10.1016/j.cej.2019.04.106

Received 27 February 2019; Received in revised form 5 April 2019; Accepted 16 April 2019

Available online 16 April 2019

1385-8947/C 2019 Published by Flsevier B.V. 
sources [2]. Particularly, Sc is predominantly used in manufacturing competent metal alloys such as high strength Sc-Al alloys (Sc as a "spice metal"), the high-performance electrolyte in solid oxide fuel cells (scandia-stabilized zirconia), lightweight fighter jets and baseball bats. Although Sc is abundant in earth's crust ("not rare"), the commercially available higher-grade scandium deposits are very scarce. Due to the low resources of high-grade Sc deposits, it is often obtained as byproducts from REE or other metal ore processing. Therefore, the scandium market fluctuates based on the feasibility of mining-associated primary metals. The highly volatile Sc market is reflected in its expensive price (US\$ $5400 / \mathrm{kg}$ scandium oxide, $99.9 \%$ grade) $[3,4]$.

Furthermore, recently in 2014 and 2017, the European Commission identified Sc, light REEs (LREE: La, Ce, Pr, Nd etc.) and heavy REEs (HREE: Y, Dy, Er, Yb, Ho etc.) as one of the critical raw materials (CRM) in their report, published based on the economic importance of the raw materials and their supply to demand ratio. The REEs play a significant role in the establishment of green, sustainable and low-carbon technologies. Besides, the geographical constraints resulting from the perspective of REE resource procurement can impose serious supply risks on future market trends. Therefore, the merits associated with REEs alongside a drastic rise in the market demand has served as a thorough motivation to propel interests from the research as well as the industrial sector, to ensure a steady supply of REEs [5-8]. Further, the complications associated with the current primary mining extraction strategies drive the search for alternate schemes that are efficient and sustainable, to recover REEs from secondary resources such as mine tailings, industrial waste streams, and processing residues. In this line, utilization and re-use of AMD waste hold the potential to function as a viable secondary resource for REE procurement. The typical leaching and hydrometallurgical treatment steps can be evaded via the utilization of acidic solution that is rich in REEs, sulfur, iron, aluminum, magnesium, zinc, cobalt, nickel and uranium $[9,10]$. Hence, in this study, AMD was utilized to assess the applicability of the proposed REE recovery schemes for efficient implementation in real time scenarios. Ad-
ditionally, seawater was also employed for the same validation purpose. ditionally, seawater was also employed for the same validation purpose.
Adsorption would be a relevant and suitable process, particularly for extracting REEs (low concentrated) from diluted streams due to its advantages such as high selectivity, high separation efficiency and low effluent contamination $[11,12]$. Furthermore, there has been a constant search for the identification of commercially viable REE-selective adsorbent materials, which holds the potential to extract REEs in the sorbent materials, which holds the potential to extract REEs in the
presence of varied industrial pollutants. Several organic, inorganic and hybrid adsorbents based on silica, chitosan, activated carbon (AC), carbon nanotubes (CNT) have been explored in the past for the selective recovery of REEs from aqueous systems [12-17]. In this study, we extend the investigation to assess the potential of naturally available algal biomass for the biosorption of REEs. Algal research (green, red or biomass for the biosorption of REEs. Algal research (green, red or
brown) has been extensively directed towards the bioremediation of brown) has been extensively directed towards the bioremediation of
heavy metals and dye components in the wastewater [18]. Very limited studies have been conducted on the recovery of REE from aqueous solutions, as shown in Table 1. These naturally available algae present numerous benefits on its own (without any modification) such as dicapacity, no or fewer pretreatments/usage of harsh chemicals, easily renewable and extremely abundant resource [19].

In this line, we explore green marine algae as a potential highperformance adsorbent for the recovery of REEs from the aqueous systems, in terms of selectivity and adsorption capacity. The affinity towards REEs can be enhanced by the attachment of tailor-made functionalities on the adsorbents' surface. A common example in this regard is the grafting of ligands or complexing agents onto a support matrix to attain higher selectivity towards target elements present in matrix to attain higher selectivity towards target elements present in
the wastewater. Although PAN as a ligand has been investigated previously in our works for REE adsorption, the current work differs from our previous studies in terms of adopted fabrication procedure and host matrix [13-16]. Besides, the algal biomass has been explored for the first time for their interaction with the coordination ligand, PAN, to enhance the selective recovery of REE in this study. Furthermore, there exists no earlier literature reporting on Sc recovery by algal biomass as per the authors' knowledge, which serves as the primary motivation of y presents on the intres trend for algal-REE interactions, which brings new insights to the affinity of algal biomass towards LREE or HREE.

\section{Experimental section}

\subsection{Chemicals and reagents}

Scandium (III) chloride hexahydrate was purchased from VWR international (( $99.9 \%$ metal basis). All the other REE salts used for multicomponent adsorption studies were procured from Sigma Aldrich or VWR in the form of chlorides or nitrates. The REE standard stock solutions of $1000 \mathrm{ppm}$ (in 5\% nitric acid) for ICP calibration curves were obtained from Sigma Aldrich or Alfa Aesar. "PAN solution" was prepared by mixing $0.2 \mathrm{~g}$ of PAN (CAS: $85-85-8$, indicator grade obtained from Sigma Aldrich) in $100 \mathrm{~mL}$ of solvent (Method I: deionized ultrapure water and Method II: reagent-grade acetone). It must be noted that PAN here refers to (1-2(pyridylazo)-2-naphthol) unlike PAN (polyacrylonitrile) referred to in literature. Dowex ${ }^{\circledast} \mathrm{MB}$ mixed ion exchange resin (matrix: styrene-DVB, sulfonic acid, and quaternary amine groups) was purchased from Sigma Aldrich consisting of 1:1 strong acid cation and anion ion exchanger.

The sulfur-rich AMD solution (original $\mathrm{pH}$ of 2; obtained from a mine site in Finland) used in this work was extracted from a sampling depth of $720 \mathrm{~m}$. It contains $\mathrm{Al}^{3+}(1.83 \mathrm{mg} / \mathrm{L}), \mathrm{Cr}^{3+}(1.54 \mathrm{mg} / \mathrm{L}), \mathrm{Co}^{2+}$ $(2.36 \mathrm{mg} / \mathrm{L}), \mathrm{Cu}^{2+}(1.04 \mathrm{mg} / \mathrm{L}), \mathrm{Ni}^{2+}(2.48 \mathrm{mg} / \mathrm{L}), \mathrm{Zn}^{2+}(86.13 \mathrm{mg} / \mathrm{L})$, $\mathrm{Fe}^{2+}(52.6 \mathrm{mg} / \mathrm{L}), \mathrm{Mn}^{2+}(14.9 \mathrm{mg} / \mathrm{L}), \mathrm{Mg}^{2+}(113.17 \mathrm{mg} / \mathrm{L})$ and sulfate $(3470 \mathrm{mg} / \mathrm{L})$ ions. Seawater (certified reference material, CAS: QC3136) was obtained from Sigma Aldrich. The sample (original pH of 6) contains $\mathrm{Ca}^{2+}(11.79 \mathrm{mg} / \mathrm{L}), \mathrm{Mg}^{2+}(19.02 \mathrm{mg} / \mathrm{L}), \mathrm{Cr}^{3+}(2.02 \mathrm{mg} / \mathrm{L})$ 6) contains $\mathrm{Ca}^{2+}(11.79 \mathrm{mg} / \mathrm{L}), \mathrm{Mg}^{2+}(19.02 \mathrm{mg} / \mathrm{L}), \mathrm{Cr}^{3+}(2.02 \mathrm{mg} / \mathrm{L})$
and $\mathrm{K}^{+}(4-40 \mathrm{mg} / \mathrm{L})$ ions. REEs were spiked to the desired concentration of around $2 \mathrm{ppm}$ and adjusted to $\mathrm{pH} 2-5$ based on the test conditions.

\subsection{Ligand grafting procedure}

The marine green algae (Posidonia oceanica, commonly known as Mediterranean tapeweed) used in this work was gathered from the Mediterranean Sea along the coast of Tunisia. The obtained biomass was then cleaned thoroughly and sun-dried. The dry algae were ground in a ball mill and sieved using undersized $200-\mu \mathrm{m}$ mesh, labeled as "unmodified algae". They were subsequently grafted with the ligand, PAN, using two different solvent evaporation procedures resulting in the formation of (a) Method I: "1-algae-P" using heat-induced water evaporation and (b) Method II: "2-algae-P" using acetone evaporation without applying heat or temperature. The method I involves reacting the dried untreated biomass $(5 \mathrm{~g})$ in $100 \mathrm{~mL}$ of PAN-water solution (Refer Section 2.1) by mixing at $220 \mathrm{rpm}$ and $60^{\circ} \mathrm{C}$ until the water evaporated completely. On the other hand, in Method II, the dried biomass was stirred with PAN-acetone solution at room temperature $\left(20^{\circ} \mathrm{C}\right)$ until the acetone solution evaporated completely. The unmodified as well as the ligand-grafted algal biomass samples were then characterized exhaustively and were subjected to REE adsorption studies. The structure of the PAN is provided in Fig. $5 \mathrm{~b}$.

\subsection{Characterization techniques}

Fourier transform infrared spectroscopy (FTIR, Vertex 70 by B Brucker Optics, $4 \mathrm{~cm}^{-1}$ resolution and 100 scans rate per sample) was primarily used to ascertain the PAN functionalization process. Additionally, the FTIR data were also utilized to identify the functional groups of the algal biomass by detecting the variation in the vibrational 


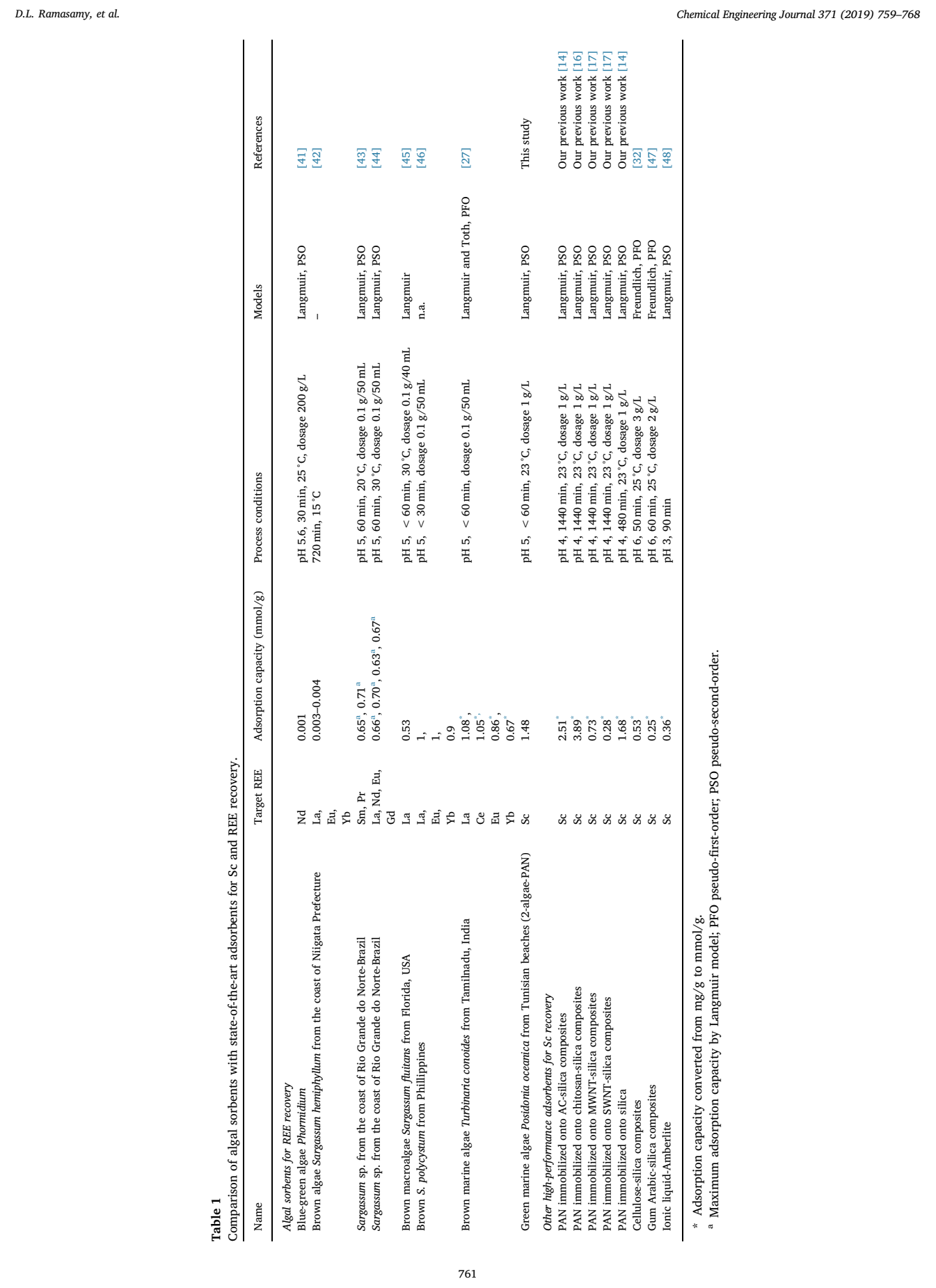


frequencies (from 400 to $4000 \mathrm{~cm}^{-1}$ wavelength) or peak intensities after the REE adsorption process. Besides, X-ray diffraction spectroscopic analysis (XRD, PANalytical instrument with the empyrean program applying CoK $\alpha$ irradiation at $\lambda=1.78 \AA$ ) was also performed to identify changes in the samples before and after PAN functionalization step. The surface characteristics of the biomass such as surface area, pore volume, pore diameter, and pore size distribution were obtained from Brunauer-Emmett-Teller (BET) and Barrett-Joyner-Halenda (BJH) analysis by means of Micromeritics Tristar II plus with VacPrep 061 . The $\%$ weight of $\mathrm{C}, \mathrm{N}, \mathrm{S}$, and $\mathrm{H}$ in biomass samples was determined by the organic elemental analyzer (Flash 2000 Thermo scientific). The surface morphology of the materials was inspected exploiting field emission scanning electron spectroscopy (FESEM; Zeiss Ultra PlusOxford instruments X-MAX with EDS detector) operating at an acceleration voltage of $15 \mathrm{kV}$. Further, the algal biomass samples were also subjected to X-ray photoelectron spectroscopic (XPS; ESCALAB 250XiThermo Fisher with a monochromatic X-ray source employing $\mathrm{Al} \mathrm{Ka}$ radiations of $1486.6 \mathrm{eV}$ ) analysis. The REE or other solute concentration in the aqueus samples was analyzed by induced coupled plasma opwithdetection (LOD) and limit of quantification (LOQ) of 0.0001 and 0.0001-0.0005 ppm, respectively, for REEs.

\subsection{Batch adsorption tests}

The REE adsorption tests were performed by mixing $10 \mathrm{mg}$ of the adsorbent with $10 \mathrm{~mL}$ of adsorbate solution continuously at $220 \mathrm{rpm}$, using a temperature controlled orbital shaker in batch mode for a definite time period or temperature based on the tests performed. The $\mathrm{pH}$ range of 1-5 was opted in this study since Sc or REE precipitation is likely to occur at $\mathrm{pH}>6$. In addition, the initial concentration $\left(\mathrm{C}_{\mathrm{i}}\right)$ of the $\mathrm{pH}$ adjusted REE solutions were verified by ICP-OES before adsorption tests to ascertain that there is no precipitation involved for the sorption tests to ascertain that there is no precipitation involved for the
tested REE concentration. Initially, the optimal process conditions for tested REE concentration. Initially, the optimal process conditions for
maximum Sc uptake was determined by conducting $\mathrm{pH}$ tests (varying $\mathrm{pH} 1-5 ; \mathrm{C}_{\mathrm{i}} 25 \mathrm{ppm} ; \mathrm{t}-24 \mathrm{~h} ; \mathrm{T} 20^{\circ} \mathrm{C}$ ), isotherm tests (varying $\mathrm{C}_{\mathrm{i}}$ $1-200 \mathrm{ppm} ; \mathrm{pH} 5$; t $24 \mathrm{~h} ; \mathrm{T} 20^{\circ} \mathrm{C}$ ) and kinetic tests (varying t 1-24 h; T $20^{\circ} \mathrm{C}$; pH 5; $\mathrm{C}_{\mathrm{i}} 25 \mathrm{ppm}$ ). After the adsorption tests, the final REE concentration $\left(\mathrm{C}_{e}\right)$ in the filtered solutions (using $0.2 \mu \mathrm{m}$ PTFE syringe filter) was determined by ICP analysis. Initially, these tests were conducted in a single component Sc system (Fig. 2) followed by the investigations using multicomponent systems containing 16 REEs (Fig. 3). The REE uptake or adsorption capacity ( $\mathrm{Q}$ in $\mathrm{mg} / \mathrm{g}$ ) was calculated by the mass balance Eq. (1.1):

$Q=\frac{V\left(C_{i}-C_{e}\right)}{M}$

Besides, REE removal efficiency (in \%) was estimated by using Eq. (1.2):

$\%$ REE removal $=\frac{\left(C_{i}-C_{e}\right)}{C_{i}} * 100$

where $\mathrm{C}_{\mathrm{i}}, \mathrm{C}_{\mathrm{e}}, \mathrm{V}$, and $\mathrm{M}$ represent initial adsorbate concentration (mg/L), equilibrium adsorbate concentration $(\mathrm{mg} / \mathrm{L})$, solution volume $(\mathrm{L})$ and dry weight of the biomass $(\mathrm{g})$, respectively.

\section{Results and discussion}

\subsection{Algal biomass characterization}

Grafting of PAN onto algal biomass was confirmed by FTIR and XRD analysis, evidenced by changes in spectra before and after algal biomass modification. Fig. 1a and b illustrate FTIR spectra for unmodified and modified algae samples prior to- and post-REE adsorption. The algal backbone showed the stretching of carboxylic acid $-\mathrm{COO}$ units and polyphenolic/primary amine $-\mathrm{OH}$ groups at $1243 \mathrm{~cm}^{-1}$ and
$3414 \mathrm{~cm}^{-1}$, respectively. Further, the broad bands at $1030 \mathrm{~cm}^{-1}$ and $1638 \mathrm{~cm}^{-1}$ were assigned to aliphatic amine $\mathrm{C}-\mathrm{N}$ and amide I units. Other bands detected at $1418 \mathrm{~cm}^{-1}$ and $2924 \mathrm{~cm}^{-1}$ could be a consequence of aromatic $\mathrm{C}-\mathrm{C}$ and alkane $\mathrm{C}-\mathrm{H}$ stretching, respectively [20]. Upon PAN grafting, slight changes in peak intensities were spotted at $1329 \mathrm{~cm}^{-1}$ and $1500 \mathrm{~cm}^{-1}$ which attributed to $\mathrm{C}=\mathrm{C}$ and $\mathrm{C}=$
$\mathrm{N}$ from PAN moieties, similarly evidenced in prior works with PAN$\mathrm{N}$ from PAN moieties, similarly evidenced in prior works with PAN-
based adsorbents $[15,21]$. After REE sorption, the dispersion of peaks and changes in band intensities were observed in the region around $400-800 \mathrm{~cm}^{-1}$ and $1200-1600 \mathrm{~cm}^{-1}$. XRD spectra (Fig. 1c) display a broad peak at $20-25^{\circ}$, characteristic of amorphous materials. Other distinct diffraction plane) in all the adsorbents [22]. Upon attachment of PAN units, new peaks emerged between 25 and $30^{\circ}$ for 1-algae-P and $35^{\circ}$ for 2-algae-P. The organic elemental CHNS analysis revealed a certain increase in N\% from $1.49 \%$ (unmodified) to $2.45 \%$ (1-algae-P) and $1.97 \%$ (2-algae-P) while $\% \mathrm{C}(\sim 40-42)$ and $\% \mathrm{H}(\sim 5 \%)$ did not undergo apparent changes as a result of grafting procedure. However, after PAN modification, the surface characteristics of the modified adsorbents changed in comparison to the unmodified algal biomass (Fig. 1d). For instance, BET surface area $\left(S_{\mathrm{BET}}=0.47 \mathrm{~m}^{2} / \mathrm{g}\right)$ of 1 -algae-P decreased while $\mathrm{S}_{\mathrm{BET}}$ of 2 algae-P $\left(1.95 \mathrm{~m}^{2} / \mathrm{g}\right)$ increased in comparison to the unmodified biomas $\left(\mathrm{S}_{\mathrm{BET}}=0.98 \mathrm{~m}^{2} / \mathrm{g}\right)$ as a result of PAN grafting process. The obtained lower $\mathrm{S}_{\mathrm{BET}}$ values are expected from bio-sorbents such as chitosan and algae [23]. Further, after PAN grafting, the overall pore diameter of both 1-algae-P and 2-algae-P increased. The reduction in pore volume was observed in 1-algae-P whereas the pore volume of 2-algae-P increased after the surface grafting of PAN units onto the algal biomass via Method II. This can be an indication of blocking of pores in algal biomass when grafting PAN units using Method I. On the other hand, the grafting of PAN moieties onto algal biomass led to the enhancement of the surface area and pore volume when using Method II i.e. acetone evaporation process. For a better understanding of the readers, the pore size distribution of the unmodified and modified algal biomasses can be found in Supplementary Material (Fig. SF1). The similar observations were also made with PAN grafted silica-based adsorbents from our previous works [13-16]. Besides, all the adsorbents followed Type III isotherm (IUPAC classification) which indicated unrestricted multilayer adsorption with these algal samples [14]. Further, the SEM and XPS analysis were performed to elaborate and understand more on the effect of PAN grafting in water vs acetone on algal biomass. The SEM images (Fig. SF2 in Supplementary Material) before and after the adsorption process showed that the surface of the material was coarsened after $\mathrm{Sc}$ binding. The XPS spectra (Fig. 1e) shows carbon $\mathrm{C}-\mathrm{C}\left(\mathrm{sp}^{2}-\mathrm{sp}^{3}\right)$ peaks a $284-285 \mathrm{eV}$ along with weak $\mathrm{C}-\mathrm{O}-\mathrm{C}$ and $\mathrm{O}-\mathrm{C}=\mathrm{O}$ peaks at $\sim 286$ and $288 \mathrm{eV}$, respectively. After PAN functionalization, strong C $-\mathrm{C}$ peaks were observed for both the modified algal biomasses. Especially, for 2algae-P, a significant increase in intensity for $\mathrm{C}-\mathrm{C}$ and $\mathrm{C}-\mathrm{O}-\mathrm{C}$ peaks can be detected as a result of successful grafting procedure [17,24]. These observations are also in line with the oxygen peaks obtained at $\sim 532 \mathrm{eV}$ (Fig. 1f).

3.2. $\mathrm{Sc}^{3+}$ uptake in a single component system:

In general, the adsorption process is predominantly governed by parameters such as initial $\mathrm{pH}$, initial adsorbate concentration, contact time and process temperature [25]. Among these, $\mathrm{pH}$ can play a significant role in regulating the REE adsorption process as the solution $\mathrm{pH}$ exerts a major influence on the binding site dissociation state on the algal biomass as well as the ionization degree of the adsorbates in the solution i.e. the REE solution chemistry [25]. The $\mathrm{pH}$ tests revealed that REE adsorption was achievable from a $\mathrm{pH}$ value of 2 , displaying $\mathrm{Sc}^{3+}$ adsorption efficiencies of about $40-50 \%$ (test conditions mentioned in Section 2.4). This was further enhanced with an increase in $\mathrm{pH}$, reaching the maximum adsorption efficiencies of $>90 \%$ at an optimal $\mathrm{pH}$ value of 5 (Fig. 2a). Similarly, the initial $\mathrm{Sc}^{3+}$ concentration also 


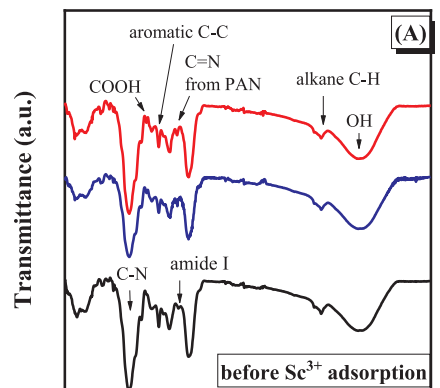

40080012001600200024002800320036004000 Wavelength $\left(\mathrm{cm}^{-1}\right)$
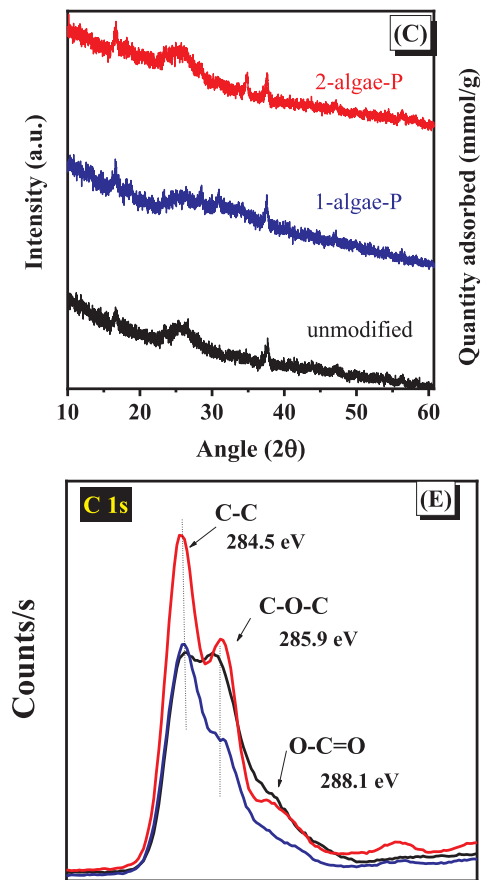

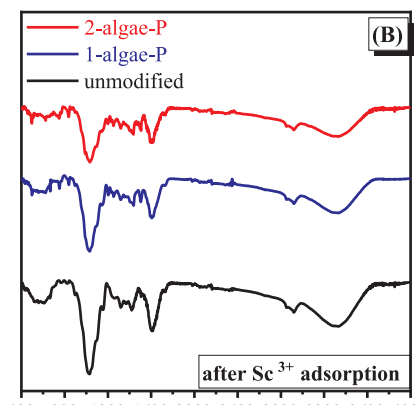

40080012001600200024002800320036004000 Wavelength $\left(\mathrm{cm}^{-1}\right)$
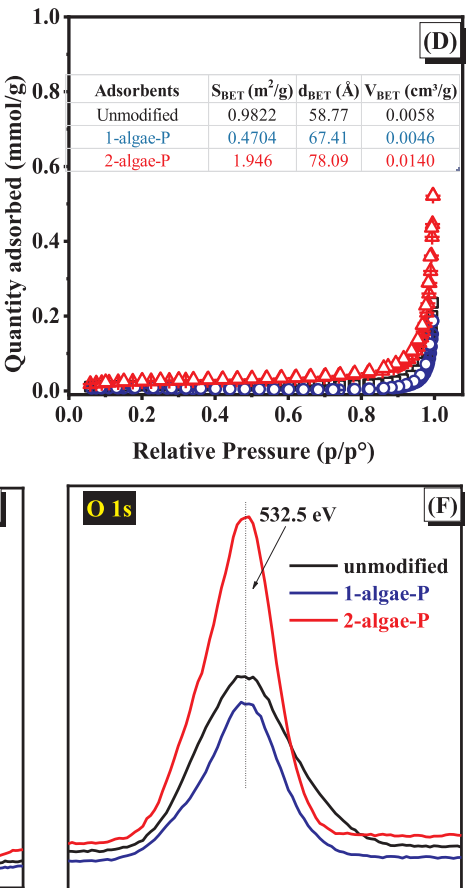

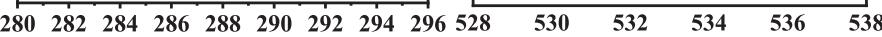

Binding energy (eV)

Fig. 1. Characterization of algal biomass adsorbents using (a) FTIR spectra before Sc sorption (b) FTIR spectra after sorption (c) XRD spectra before Sc sorption (d) BET $\mathrm{N}_{2}$ adsorption-desorption isotherm curves (e) XPS-C1s spectra and (f) XPS-O1s spectra.

plays an important role in estimating the maximum adsorption capacities of the adsorbent materials. Initially (Fig. 2b), the adsorption capacities of the algal biomass increased with increase in $\mathrm{Sc}^{3+}$ concentration due to the availability of the binding sites until equilibrium $(\sim 50-70 \mathrm{mg} / \mathrm{L})$, beyond which a plateau was observed. It was also noticed that the $\mathrm{Sc}^{3+}$ uptake was initially rapid $(\sim 90 \%$ in $30 \mathrm{~min})$ as shown in Fig. 2c. The adsorption efficiencies increased further to $96 \%$ and $98 \%$, over a period of $24 \mathrm{~h}$, for 1 -algae-P and 2 -algae-P, respectively. In a similar manner, rapid REE adsorption by algal biomass within a time period of $60 \mathrm{~min}$ was also reported in prior works elaborating on $\mathrm{REE}\left(\mathrm{La}^{3+}, \mathrm{Ce}^{3+}, \mathrm{Eu}^{3+}, \mathrm{Yb}^{3+}\right)$ sorption for freshwater and borating on $\mathrm{REE}\left(\mathrm{La}^{3+}, \mathrm{Ce}^{3+}, \mathrm{Eu}^{3+}, \mathrm{Yb}^{3+}\right.$ ) sorption for freshwater and
brown algae $[26,27]$. It must be noted that the $\mathrm{Sc}^{3+}$ adsorption was brown algae $[26,27]$. It must be noted that the $\mathrm{Sc}^{3+}$ adsorption was
effectively observed with algal biomass with or without the ligand attachment. Hence, further tests under harsh real wastewater conditions 

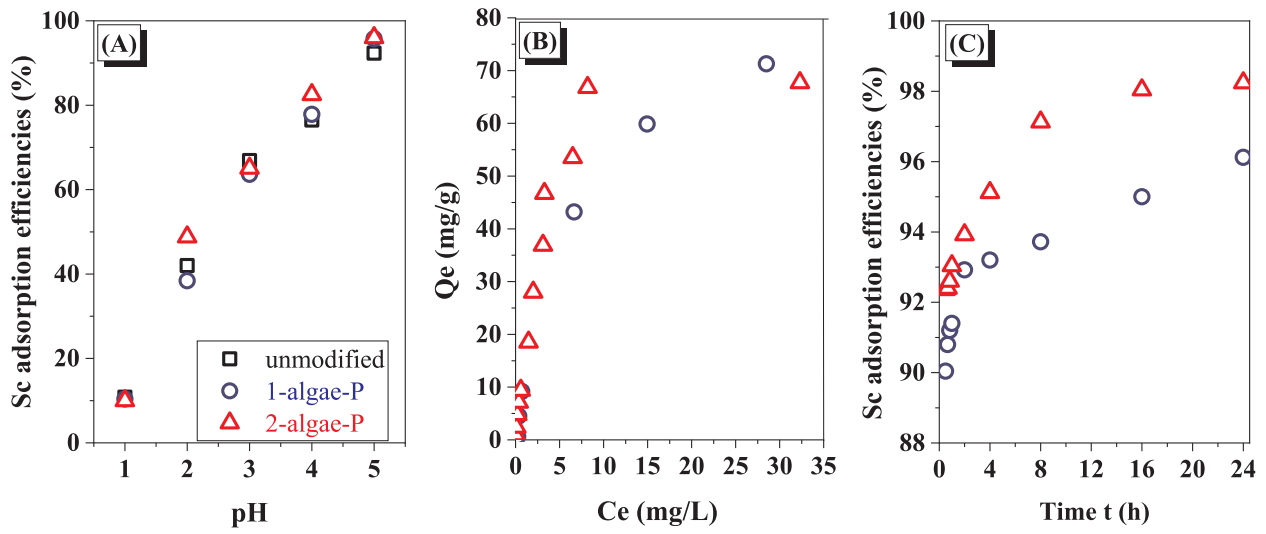

Fig. 2. Single component $\mathrm{Sc}^{3+}$ batch adsorption studies (a) effect of $\mathrm{pH}: \mathrm{C}_{\mathrm{i}}=25 \mathrm{mg} / \mathrm{L}, \mathrm{t}=24 \mathrm{~h}$ and $\mathrm{T}=20^{\circ} \mathrm{C}$ (b) effect of initial Sc${ }^{3+}$ concentration: $\mathrm{pH}=5$, $\mathrm{t}=24 \mathrm{~h}$ and $\mathrm{T}=20^{\circ} \mathrm{C}$ (c) effect of contact time: $\mathrm{pH}=5, \mathrm{C}_{\mathrm{i}}=25 \mathrm{mg} / \mathrm{L}$ and $\mathrm{T}=20^{\circ} \mathrm{C}$. For all these tests, the adsorbent dosage was set to be $1 \mathrm{~g} / \mathrm{L}$.

are required to assess the superiority of the adsorbents.

3.3. $\mathrm{Sc}^{3+}$ uptake in a multi-component REE system:

Generally, $\mathrm{Sc}^{3+}$ exists together with $\mathrm{Y}^{3+}$ and other lanthanides in secondary resources such as e-waste, red mud and other industrial processing residues. Thus, it is necessary to comprehend the adsorption behavior of $\mathrm{Sc}^{3+}$ in the presence of $\mathrm{Y}^{3+}$ and other REEs. Fig. 3a illustrates the potential of marine green algae used in this study to recover both $\mathrm{Sc}^{3+}$ and $\mathrm{Y}^{3+}$ without any surface functionalization in an effortless manner. Besides algae, other commercial adsorbents such as nanoclay, bentonite, and activated charcoal also demonstrated on par (or subordinate) performance, in terms of $\mathrm{Sc}^{3+}$ and $\mathrm{Y}^{3+}$ uptake. Our prior works also reported on the moderate adsorption proficiencies of bare silica, chitosan, CNT and AC towards $\mathrm{Sc}^{3+}$ but not towards any other REE including $\mathrm{Y}^{3+}$ (Fig. 3a). This can be attributed to the lower ionic radii of Sc and varied speciation in aqueous samples in comparison to other REEs $[15,28]$.

Further, intraseries REE adsorption trend is always an object of interest as it depicts the affinity of the host matrix towards REE. From Fig. 3b, it can be understood with clarity that the affinity towards LREE was superior in comparison to HREE. Among REEs, $\mathrm{La}^{3+}$ and $\mathrm{Y}^{3+}$ ions are the least adsorbed ones in all conditions. Similar findings of poor $\mathrm{La}^{3+}$ adsorption was observed with T. conoides $\left(\mathrm{Eu}^{3+}>\mathrm{Ce}^{3+}>\mathrm{La}^{3+}>\mathrm{Yb}^{3+}\right)$ and Pseudomonas aeruginosa $\left(\mathrm{Eu}^{3+}=\mathrm{Yb}^{3+}>\mathrm{La}^{3+}\right)$ biomass [27,29]. Besides, the effect of tem$\left(\mathrm{Eu}^{3+}=\mathrm{Yb}^{3+}>\mathrm{La}^{3+}\right)$ biomass $[27,29]$. Besides, the effect of tem-
perature on REE adsorption is also evident from the figure, especially in the case of 1-algae-P. The enhancement of REE adsorption, particularly in the case of HREEs, was also observed in our prior studies with silica, chitosan and carbon materials $[13,14,16,30]$. Similarly, other authors have also reported on augmented REE uptake or rapid kinetics with an increase in temperature, caused by the reduction in electric double layer thickness or diffusion barrier resistance [31-33].

\subsection{REE recovery from $A M D$ and seawater}

In an ideal sense, REE sorption measurements in a single component system (synthetic laboratory solutions) can serve to determine the adsorption capacities of the materials under study. However, it is of paramount importance to analyze the same in a multi-component system containing varied REEs to realize the affinity/selectivity of the adsorbent thoroughly. It is very much possible that a superior adsorbent in a single component system can fail miserably in the presence of other competing ions due to poor REE selectivity and hence, can provide false image of the actual adsorption performance in real conditions. A very relevant example can be the rapid and exemplary uptake of La by adsorbents in a single-component system, whereas, in a multi-component system, La would be the least adsorbed REE in most cases. Although that the synthetic solutions such as leachate liquor can mimic Although that the synthetic solutions such as leachate liquor can mimic
actual wastewater conditions, additional factors such as dissolved so-
lids, oils, total organic matter, oxidized content, varied molar masses of the adsorbates and anionic impurities can play a prominent role in affecting the overall adsorption process. Thus, it is always essential to valid the syngerizer Besides, being a part of Pearson's class A of hard metals, lanthanides are Besides, being a part of Pearson's class A of hard metals, lanthanides are
expected to undergo co-ionic competition among each other, leading to decreased adsorption of the same in multi-component systems [34]. Hence, to validate the adsorption proficiencies of the marine algal samples, they were further assessed for REE selectivity using AMD and seawater solution (Please refer Section 21 for the sam

On comparing Fig. $3 \mathrm{c}$ and d, it can be realized that the REE adsorption performance was poor in the case of AMD in comparison to seawater. For instance, 2-algae-P recorded REE removal efficiencies of $\sim 60 \%$ with AMD while it was $>85 \%$ when using seawater for the same REE concentration (each REE of $2 \mathrm{mg} / \mathrm{L}$ ). The disparities can be predominantly due to the higher concentrations of competing ions in of the effective competition between REEs and other competing ions in
AMD, thus restricting the accessibility to the limited number of binding sites on adsorbents. As a result, the variation in metal ion affinities deemed to influence the binding or uptake of all REEs (except Sc) onto the adsorbents. This enhanced affinity of algal sorbents towards $\mathrm{Sc}^{3+}$ ions, in comparison to all other REE, can be witnessed in Fig. 3d. It should also be remarked here that the algal biomass (both modified and unmodified) showed negligible co-removal of $\mathrm{Mg}^{2+}, \mathrm{Mn}^{2+}, \mathrm{Ni}^{2+}$

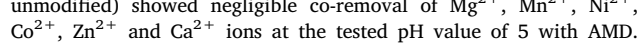
$\mathrm{Co}^{2+}, \mathrm{Zn}^{2+}$ and $\mathrm{Ca}^{2+}$ ions at the tested $\mathrm{pH}$ value of 5 with AMD.
However, the adsorbents displayed affinities ( $>50 \%$ of co-removal) However, the adsorbents displayed affinities ( $>50 \%$ of co-removal)
towards $\mathrm{Al}^{3+}, \mathrm{Cu}^{2+}, \mathrm{Cr}^{3+}$, and $\mathrm{Pb}^{2+}$ ions at this $\mathrm{pH}$, in addition to REE. Similarly, in the case of seawater, the selectivity of algal biomass towards REE was not inhibited by water hardness $\left(\mathrm{Ca}^{2+}\right.$ of $11.79 \mathrm{mg} / \mathrm{L}$ a removal of $\mathrm{Ca}^{2+}$ and $\mathrm{Mg}^{2+}$ ions. Also, in earlier work [29], it was reported that $\mathrm{La}^{3+}, \mathrm{Eu}^{3+}$, and $\mathrm{Yb}^{3+}$ adsorption onto Pseudomonas 
Sc-Y binary system (C $-12.5 \mathrm{ppm}$ each) (A)

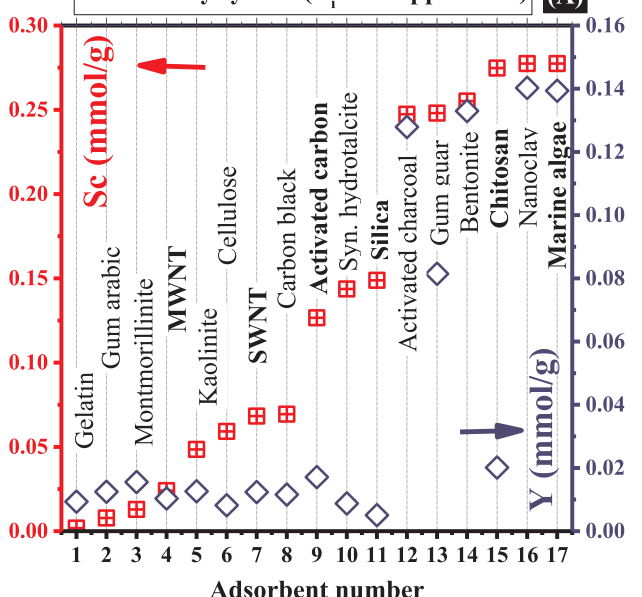

WITHOUT INTERFERENCE (B)

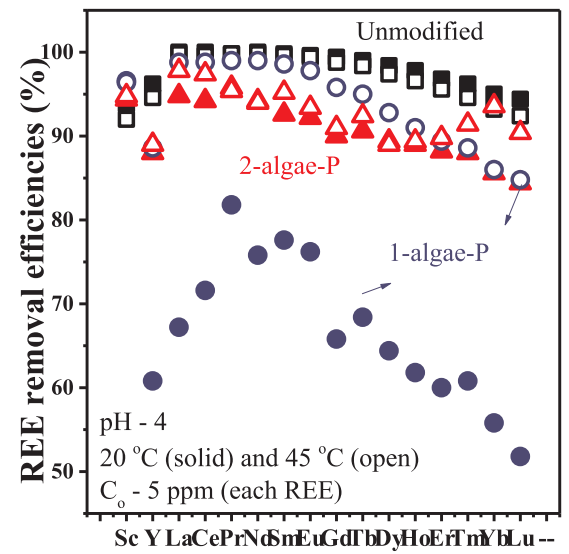

REE series

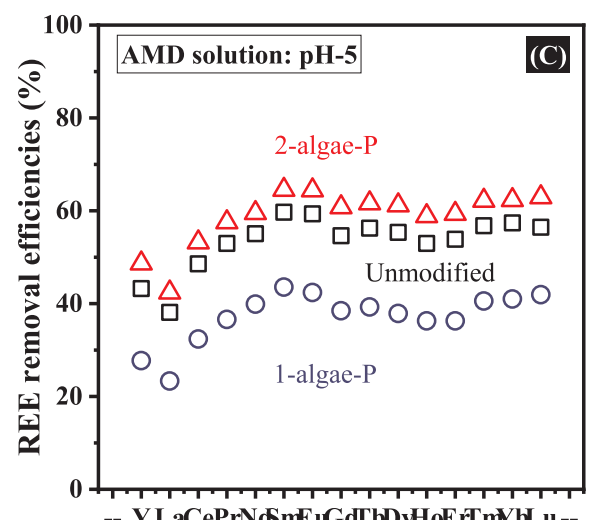

-- Y LaCePrNomEuGdTbDyHoETrmybu --

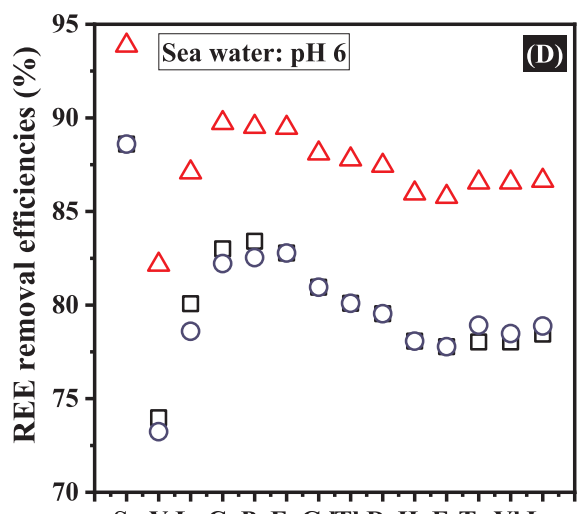

Sc Y LaCePrEuGdTbDyHoErTmYbLu --

Fig. 3. (a) $\mathrm{Sc}^{3+}$ and $\mathrm{Y}^{3+}$ uptake by various commercial adsorbents in a Sc-Y binary system: $\mathrm{pH} 4$ and $\mathrm{T}=20^{\circ} \mathrm{C}$, (b) Effect of temperature on intra-series REE adsorption trend without any interference: $\mathrm{pH} 4$, (c) $\mathrm{REE}$ recovery from $\mathrm{AMD}$ solution: $\mathrm{pH} 5, \mathrm{C}_{\mathrm{REE}}=\sim 2 \mathrm{ppm}$ and $\mathrm{T}=45^{\circ} \mathrm{C}$, and (d) REE recovery from seawater: $\mathrm{pH}$ $6, \mathrm{C}_{\mathrm{REE}}=\sim 2 \mathrm{ppm}$ and $\mathrm{T}=45^{\circ} \mathrm{C}$. For all the tests, the contact time was $1 \mathrm{~h}$ and adsorbent dosage $1 \mathrm{~g} / \mathrm{L}$.

aeruginosa was not hindered by the presence of $\mathrm{Na}^{+}, \mathrm{K}^{+}, \mathrm{Ca}^{2+}, \mathrm{Cl}^{+}$, sulfate and nitrate ions. However, the notable difference in adsorbents' performance could have also resulted from the presence of other anionic/organic impurities in AMD/sea-water, which could have dampened the process of REE binding onto the algal surface. Based on these observations, the REE removal efficiencies of the adsorbent in AMD and seawater can be rated in the following order: 2-algae-P > unmodified algae > 1-algae-P.

\subsection{Intraseries REE behavior}

It is interesting to observe that the adsorbents' affinities were in clined towards LREE over HREE in the absence of competing ion (Fig. 3b), and in the presence of competing ions if existed at lower concentrations (the case of seawater) (Fig. 3d). However, with the increased concentrations of competing ions in AMD (Fig. 3c), the affinity of the adsorbents shifted towards HREE. This change in the affinity trend was also spotted in acac-modified silica-chitosan beads with an increase in competing ions, under wastewater conditions [13]. This intraseries REE adsorption trend might be a consequence of the lanthanide contraction effect, according to which the ionic radii of lanthanides decreases with the increase in atomic number due to the poo shielding of f-sub shells $[28,35]$. These series of investigations indicated that the algal biomass (both unmodified and ligand modified) demonstrated commendable Sc adsorption, followed by the adsorption of LREES or HREEs. Hence, comprehensively, it can be concluded that the Sc adsorption was superior in comparison to other REEs and can be adsorbed effortlessly without any interference from other REEs or competing ions. 
$\begin{array}{ll}\left.\text { (A) sea water ( } \mathrm{C}_{\mathrm{REE}}-2 \mathrm{ppm} \text { each }\right) & \text { (B) AMD solution }\left(\mathrm{C}_{\mathrm{REE}}-2 \mathrm{ppm} \text { each }\right)\end{array}$

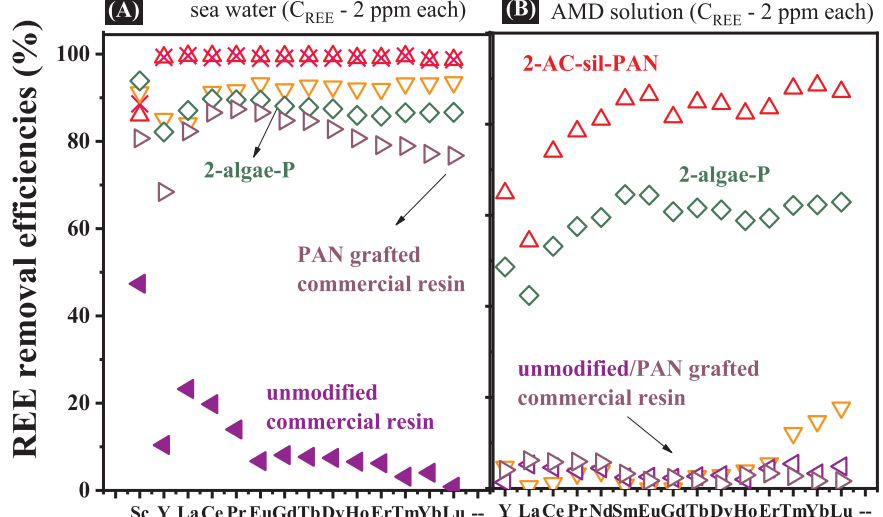

$\triangle$ AC-sil-PAN

$\times$ sil-PAN

$\nabla$ chitosan-sil-PAN (flakes)

$\diamond$ Algae-PAN

commercial mixed bed resin

$\triangleright$ PAN grafted commercial resin

Sc Y LaCe Pr EuGdTbDyHoErTmYbLu -- Y LaCe PrNdSmEuGdTbDyHoErTmYbLu --

Fig. 4. Comparison of algal biomass with the commercial resin performance in terms of REE removal efficiencies with (a) seawater (pH $6,45^{\circ} \mathrm{C}, 1 \mathrm{~h}$ ) and (b) AMD solution (pH $\left.5,45^{\circ} \mathrm{C}, 1 \mathrm{~h}\right)$.

(A)

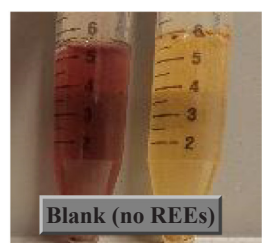

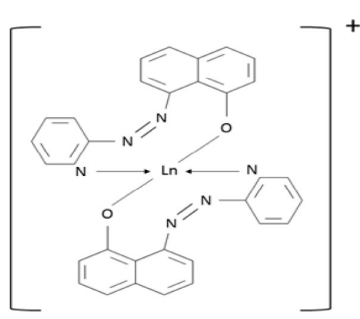

(B)

Fig. 5. (a) 2-algae-P instant reaction with AMD and seawater to yield pink and yellow color, respectively. (b) The quasi-octahedral structure of the PAN (tridentate ligand)-REE chelates, where the common sites for chelation (REE: PAN - 1:2) include $-\mathrm{OH}$ $-\mathrm{C}=\mathrm{N}-$ and pyridyl nitrogen group. (c) 2-algae- $\mathrm{P}$ instant reaction with individual REE in a single component system (C $25 \mathrm{mg} / \mathrm{L} \cdot \mathrm{pH}$ 5). (d) The color formation on various adsorbents' the AMD solution. (For insolon the AmD solutin. (Tor inger ences to color in this figure legend, the

(C)

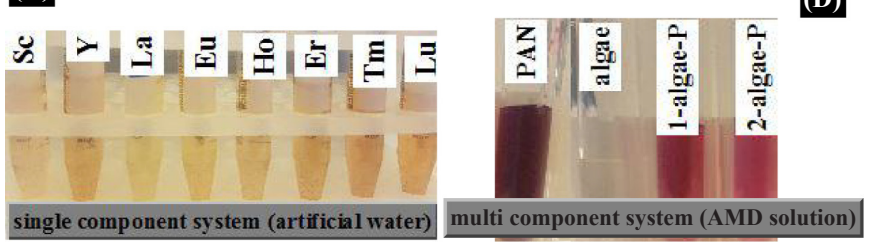

3.6. REE binding mechanism

Several processes can govern the adsorption mechanism involving the algal biomass interaction with the metal ions. According to literature, the adsorbent-adsorbate interactions seem to occur primarily via ion-exchange between the surface functional groups (such as alkali and alkali earth metals like $\mathrm{H}^{+}, \mathrm{Na}^{+}$and $\mathrm{K}^{+}$) on the cell wall of the algal biomass and the REE ions $[26,27,29]$. At increased $\mathrm{pH}$, deprotonation of surface functional groups (such as hydroxyl and carboxyl) facilitates the electrostatic interaction between the negatively charged groups and positively charged REE cations [19]. This is well supported by the exemplary REE adsorption by the unmodified algal biomass without any need for ligand attachment. In case of PAN grafted algal biomass, coordination mechanism between PAN units and REE cations would have additionally facilitated the interactions for an enhanced REE uptake. PAN is a tridentate ligand with the ability to form a quasi-octahedral structure (2 adjacent coordination rings: $\mathrm{N}$ - and $\mathrm{O}-$ donor atoms with
REE cations in Fig. 5.b), with a metal: PAN ratio of $1: 2$ and 1:1 for metals with coordination number 6 (e.g. REEs) and 4, respectively [36]. The three main binding sites, i.e. $-\mathrm{OH},-\mathrm{C}=\mathrm{N}$ and pyridyl nitrogen are expected to involve in the chelation/complexation process. At the acidic $\mathrm{pH}$, azo group undergoes protonation while phenol $-\mathrm{OH}$ group ionization is typically observed at basic $\mathrm{pH}$ [37].

Further, FTIR spectra (Fig. 1b) of the algal biomasses before and after REE adsorption depicted notable reduction in band intensities corresponding to benzenoid $-\mathrm{C}=\mathrm{N}-$ group of PAN $\left(1329 \mathrm{~cm}^{-1}\right)$ and azo $-\mathrm{N}=\mathrm{N}-$ group of PAN $\left(1590 \mathrm{~cm}^{-1}\right)[15,21]$. These changes in intensities denote the involvement of the aforementioned groups in the adsorption process. These realizations imply that REE sorption was also facilitated by chemisorption via PAN coordination mechanism in adstrengthened by the isotherm and kinetic modeling of the experimental data that demonstrated great correspondence to the Langmuir isotherm and pseudo-second-order (PSO) kinetic models $\left(\mathrm{R}^{2}>0.9\right)$, which are 
typical characteristics of a chemisorption reaction (Supplementary material: Fig. SF3). Similar observations with Langmuir-PSO models can be found in Table 1 and were also reported for REE uptake using Stichococcus bacillaris, Chlamydomonas reinhardtii, Chlorella vulgaris, crab shell and grapefruit peel $[26,38,39]$.

\subsection{The superiority of the adsorbents}

\subsubsection{Ease of functionalization and commercialization}

Finally, the algal adsorbents were also compared with commercial resin (Fig. 4) to evaluate the efficacies in recovering REEs from seawater and AMD. Fig. 4.a shows that the bare Dowex ${ }^{\otimes}$ commercial mixed bed resin cannot adsorb REE (only Sc $\sim 50 \%$ ) effectively without surface modification. Upon grafting with PAN (via same grafting procedure via Method II), the resin demonstrated potential to recover REEs from sea water, comparable to 2-algae-P of this study. However, they failed miserably when using AMD solution (Fig. 4.b) with higher concentrations of interfering ions. It is important to note that our high capacity adsorbent chitosan-silica-PAN flakes (Table 1) from our previous studies [16] delivered a poor outcome in terms of REE recovery when using AMD, while 2-algae-P of this study delivers admirable REE adsorption performance. It should also be made clear that algal support is the only one which performed effectively with the direct ligand grafting procedure using PAN to effectively adsorb all REEs. In our previous works, supports such as silica, chitosan, AC have been investigated for their interactions with PAN (adsorbent: support-PAN) as well as for the adsorbent-REE interactions. These mentioned supports well as for the adsorbent-REE interactions. These mentioned supports
required the enhancement of reactive sites on the adsorbents by the required the enhancement of reactive sites on the adsorbents by the
attachment of amino functionalities via 3-aminopropyltriethoxysilane attachment of amino functionalities via 3-aminopropyltriethoxysilane
(APTES), for the further hybridization procedure with other polymers or for the effective functionalization of PAN units. Further, the prior studies with silica gels concluded that only when PAN moieties are chemically immobilized onto silica i.e. linked via aminosilane, the adsorbents display REE adsorption in acidic range $(\mathrm{pH}<7)[15]$. On the sorbents display $\mathrm{REE}$ adsorption in acidic range $(\mathrm{pH}<7)[15]$. On the
other hand, using the same ligand grafting procedure used in the current work, i.e when PAN physically adsorbed/ grafted directly onto silica (silica-PAN) or other supports (e.g. AC-PAN) via acetone evaporation process, they favor only $\mathrm{Sc}^{3+}$ adsorption but at higher $\mathrm{pH}>6$ $[14,16,40]$. However, in this work, we identified that marine algal biomass could be utilized for REE sorption (affinity towards all REEs, not just Sc) even without any surface functionalization at acidic $\mathrm{pH}$. As our work targeted further to enhance the adsorption capacities and selectivity of algal biomass towards REEs, it was accomplished by grafting the right ligand of choice (i.e. PAN according to our previous studies) through a simple, easily reproducible and adept functionalization route (Method II: acetone evaporation process). This can be witnessed in Table 1 which compares the Sc and REE sorption data by algal bio-sorbents to the other organic-inorganic adsorbents in aqueous algal bio-sorbents to the other organic-inorganic adsorbents in aqueous
systems. Overall, it can be stated that the algal biomass, in general, proves to be an effective bio-sorbent for REE recovery, demonstrating REE adsorption capacities on par to the other high-performance hybrid composites reported in the literature. Specifically, herein, we report the highest REE adsorption capacity by an algal sorbent (our modified adsorbent, PAN grafted onto $P$. oceanica) of $1.48 \mathrm{mmol} / \mathrm{g}$ for Sc${ }^{3+}$ uptake from aqueous solutions.

3.7.2. Future direction as an optical sensor for REE detection in wastewater

PAN, being an organic chromophore, can form colored chelate complexes on reaction with REEs and other transition metals. Hence, in our study, PAN grafted adsorbents led to the formation of colored solutions, as shown in Fig. 5. The solutions typically varied within the yellow to orange spectrum in a single component system containing yellow to orange spectrum in a single component system containing
REE only (Fig. 5c). It can be visually seen that the color intensity of the solutions increased with an increase in atomic number among the lanthanides i.e. higher intensity observed for HREEs. On the other hand, in a multicomponent solution i.e. AMD solution containing REEs and other competing ions (Fig. 5d), adsorbent-adsorbate interactions resulted in pink to red coloration with PAN grafted onto algal support and without support, respectively. A similar observation was also stated in the work of Cheng et. al. who reported the colored complexes to be yellow for water matrix, deep red for $\mathrm{Cu}^{2+}$, red for $\mathrm{Pb}^{2+} \mathrm{Ni}^{2+}, \mathrm{La}^{3+}$ $\mathrm{Sc}^{3+}, \mathrm{Eu}^{3+}, \mathrm{Fe}^{2+}$, $\mathrm{Sc}^{3+}$, Eu ${ }^{3}, \mathrm{Fe}^{2+}$ and bright pink for $\mathrm{Zn}^{2}$ ions. No coloration was detected when PAN reacted with metal ions like $\mathrm{Mg}^{2+}, \mathrm{Sb}^{3+}, \mathrm{Al}^{3+}$ $\mathrm{Ca}^{2+}, \mathrm{Li}^{2+}, \mathrm{Na}^{+}, \mathrm{Zr}^{3+}$, sulfate or nitrate according to their findings. Hence, the pink colored solution obtained in AMD could be a manifestation of a relatively higher $\mathrm{Zn}^{2+}$ concentration $(\sim 86 \mathrm{mg} / \mathrm{L})$, which was further confirmed by the obtained pink solution with blank AMD in the absence of REEs (Fig 5a). $\mathrm{Zn}^{2+}$ assays is a relevant example in this line that attempted the detection of metal ions using sensors. Hence, this study can be extended further to enable the development of optical sensors via attachment of PAN onto suitable polymer matrices that can facilitate both qualitative and quantitative detection of REEs in aqueous solutions. However, there exist a few challenges that need to be resolved while designing such cost-effective optical sensors in the future. Some areas of improvement would include enhanced selectivity in the presence of interference, minimizing the noise formation, identification, and classification of multiple analytes, and the betterment of LOD comparable to other state-of-the-art analytical instruments.

\section{Concluding remarks}

In conclusion, the findings from this study suggest that the marine algae $P$. oceanica can be used as the effective low-cost bio-sorbent to effectively recover REEs (especially Sc) from aqueous media. Further, in this work, we demonstrated that the grafting of PAN onto the algal biomass resulted in enhanced adsorption capacity as well as selectivity, evidenced in both single and multi-component systems. It was also understood that under adept synthesis procedures and host support matrix, PAN can function as an effective ligand for REE binding via coordination mechanism forming colored complexes. This scientific knowledge can serve as tools to improve the present REE extraction techniques by the development of optical sensors for rapid detection of REEs in the wastewater. Besides, the strategies proposed in our work to recover REEs from AMD waste and seawater are of great significance from an environmental perspective and can help to fulfill the concept of a circular economy. In contrast to the traditional linear approach, which results in the over-exploitation of the resource with the aim of increase in production, a circular economy focuses on the recycling of material resources. This can eventually help attain a steady transition towards a sustainable future to suffice the energy needs in an efficient manner.

\section{Acknowledgments}

The authors acknowledge the funding from the Academy of Finland (decision number 292542). The authors would also like to thank Ms. Hanen Bessaies affiliated to LUT University, Finland and Tunis El Manar University, Tunisia (for providing us with Posidonia oceanica), Santu Heinilehto (XPS analysis) and Pasi Juntunen (FESEM analysis) from Oulu University, Finland.

\section{Appendix A. Supplementary data}

Supplementary data to this article can be found online at https:// doi.org/10.1016/j.cej.2019.04.106.

\section{References}

[1] T.E. Graedel, E.M. Harper, N.T. Nassar, P. Nuss, B.K. Reck, Criticality of metals and metalloids, Proc. Natt. Acad. Sci. USA 112 (2015) 4257-4262, https://doi.org/10.
1073/pnas.1500415112. 
[2] A. Tukker, Rare earth elements supply restrictions: market failures, not scarcity, hamper their current use in high-tech applications, Environ. Sci. Technol. 48 (2014)

[3] S. Riva, K.V. Yusenko, N.P. Lavery, D.J. Jarvis, S.G.R. Brown, The scandium effect in multicomponent alloys, Int. M2.

[4] W. Wang, Y. Pranolo, C.Y. Cheng, Metallurgical processes for scandium recovery from various resources: a review, Hydrometallurgy 108 (2011) 100-108, https:/ doi.org/10.1016/j.hydromet.2011.03.001.

[5] K. Binnemans, P.T. Jones, B. Blanpain, T. Van Gerven, Y. Pontikes, Towards zerowaste valorisation of rare-earth-containing industrial process residues: a critical review,
02.089 .

[6] K. Binnemans, P.T. Jones, B. Blanpain, T. Van Gerven, Y. Yang, A. Walton, M. Buchert, Recycling of rare earths: a critical review, J. Cleaner Prod. 51 (2013) 1-22, https://doi.org/10.1016/j.j.jepro. 2012.12.037.

[7] X.-J. Li, C.-J. Yan, W.-J. Luo, Q. Gao, Q. Zhou, C. Liu, S. Zhou, Exceptional cerium (III) adsorption performance of poly(acrylic acid) brushes-decorated attapulgite with abundant and highly accessible binding sites, Chem. Eng. J. 284 (2016)

Q. Gao, J.F. Xie, Y.T. Shao, C. Chen, B. Han, K-S. X

high-capacity adsorption of Gd(II) onto inorganic phosph-.. Zhou, Ultrafast and mesoporous SBA-15, Chem. Eng. J. 313 (2017) 197-206, https://doi.org/10.1016
mot j.cej.2016.12.068.

[9] D. Merten, G. Büchel, Determination of rare earth elements in acid mine drainage by inductively coupled plasma mass spectrometry, Microchim. Acta 148 (2004)

163-170, h. Me

from acid mine drainages, Water Res. 31 (1997) 2073-2083, hrtps://doi org /10 from acid mine drainages, Water

[11] I. Anastopoulos, A. Bhatnagar, E.C. Lima, Adsorption of rare earth metals: a review of recent literature, J. Mol. Liq. 221 (2016) 954-962, https://doi.org/10.1016/j.

molliq.2016.06.076.
[12] S. Iftekhar, D.L. Ramasamy, V. Srivastava, M.B. Asif, M. Sillanpää, Understanding he factors affecting the adsorption of Lanthanum using different adsorbents: a
critical review, Chemosphere 204 (2018) 413-430, https:/doi.org $/ 10.1016 / \mathrm{j}$. critical review, Chemosphere

[13] D.L. Ramasamy, V. Puhakka, S. Iftekhar, A. Wojtuś, E. Repo, S. Ben Hammouda, E. Iakovleva, M. Sillanpää, $\mathrm{N}$ - and O-ligand doped mesoporous silica-chitosan hybrid beads for the efficient, sustainable and selective recovery of rare earth elements (REE) from acid mine drainage (AMD): understanding the significance of physical modification and conditioning of the polymer, J. Hazard. Mater. 348 (2018) 84-91,

4] D.L. Ramasamy, V. Puhakka, E. Repo, S. Ben Hammouda, M. Sillanpäa, Two-stage aqueous systems using activated carbon and silica composites: dual applications by tailoring the ligand grafting approach, Chem. Eng. J. 341 (2018) 351-360, https://

doi.org/10.1016/j.cej.2018.02.024.
[15] D.L. Ramasamy, E. Repo, V. Srivastava, M. Sillanpää, Chemically immobilized and physically adsorbed PAN/acetylacetone modified mesoporous silica for the recovery of rare earth elements from the waste water-comparative and optimization
study, Water Res. 114 (2017) 264-276, https://doi.org/10.1016/j. watres 2017.02 study,

[16] D.L. Ramasamy, A. Wojtuś, E. Repo, S. Kalliola, V. Srivastava, M. Sillanpää, Ligand immobilized novel hybrid adsorbents for rare earth elements (REE) removal from waste water: assessing the feasibility of using APTES functionalized silica in the hybridization process with chitosan, Chem. Eng. J. 330 (2017) 1370-1379, https:// doi.org/10.1016/j.cej.2017.08.098.

D. Ramasamy, V. Puhakka, B. Doshi, S. Iftekhar, M. Sillanpää, Fabrication of carbon nanotubes reinforced silica composites with improved rare earth elements
adsorption performance, Chem. Eng. J. 365 (2019) 291-304, https: / doi adsorption performance,

[18] J. He, J.P. Chen, A comprehensive review on biosorption of heavy metals by algal biomass: materials, performances, chemistry, and modeling simulation tools, Bioresour. Technol. 160 (2014) 67-78, https://doi.org/10.1016/j.biortech.2014.

19] M. Bilal,

an interlas Rasheed, J. Sosa-Hernández, A. Raza, F. Nabeel, H. Iqbal, Biosorption: an interplay between marine algae and potentially toxic elen
Drugs. 16 (2018) 65, https://doi.org $/ 10.3390 /$ md16020065.

[20] S. Rajeshkumar, C. Malarkodi, G. Gnanajobitha, K. Paulkumar, M. Vanaja, C. Kannan, G. Annadurai, Seaweed-mediated synthesis of gold nanoparticles usin Turbinaria conoides and its characterization, J. Nanostruct. Chem. 3 (2013) 44,

https://doi.org/10.1186/2193-8865-3-44,

21] A. Kaur, U. Gupta, A preconcentration procedure using 1-(2-pyridylazo)-2-napthol anchored to silica nanoparticle for the analysis of cadmium in different
J. Chem. 5 (2008) 930-939, https://doi.org/10.1155/2008/431916.

[22] K. Babooram, R. Narain, Fabrication of SWNT/silica composites by the sol-gel process, ACS Appl. Mater. Interfaces 1 (2009) 181-186, https://doi.org/10.1021

am8001296.
[23] J. Roosen, J. Spooren, K. Binnemans, Adsorption performance of functionalized chitosan-silica hybrid materials toward rare earths, J. Mater. Chem. A 2 (2014)

[24] S. Li, Z. Wang, J. Jia, C. Hou, X. Hao, H. Zhang, Preparation of hydroxyl and (3- aminopropyl)triethoxysilane functionalized multiwall carbon nanotubes for use as conductive fillers in the polyurethane composite, Polym. Compos. 39 (2018) 1212-1222, hitps://doi.org $/ 10.1002 / \mathrm{pc} .24054$

[25] N. Das, D. Das, Recovery of rare earth metals through biosorption: an overview, J. 26] Z.S. Birungi, E.M.N. Chirwa, The kinetics of uptake and recovery of lanthanum using freshwater algae as biosorbents: comparative analysis, Bioresour. Technol. 160 (2014) 43-51, https://doi.org/10.1016/j.biortech.2014.01.033.

[27] K. Vijayaraghavan, M. Sathishkumar, R. Balasubramanian, Biosorption of lanthanum, cerium, europium, and ytterbium by a brown marine alga, Turbinaria conoides, Ind. Eng.

[28] D.L Ramasny

surface chemistry of Puhakka, E. Repo, S. Khan, M. Sillanpä, Coordination and silica (2-pyridylazo)-2-napththol (PAN) and acetylacetone (acac) immobilized gels, Chem. Eng. J. 324 (2017) 104-112, https://doi.org/10.1016/j.cej.2017.05.025.

[29] A.-C. Texier, Y. Andrès, P. Le Cloirec, Selective biosorption of lanthanide (La, Eu, Yb) ions by Pseudomonas aeruginosa, Environ. Sci. Technol. 33 (1999) 489-495,

[30] D.L. Ramasamy, S. Khan, E. Repo, M. SH

croporous amine and non-amine functionalizää, Synthesis of mesoporous and microporous amine and non-amine functionalized silica gels for the application of rare
earth elements (REE) recovery from the waste water-understanding the role of $\mathrm{pH}$, temperature, calcination and mechanism in Light REE and Heavy REE separation, Chem. Eng. J. 322 (2017) 56-65, https://doi. org / 10.1016/j.cej.2017.03.152.

[31] S. Iftekhar, V. Srivastava, M. Sillanpää, Synthesis and application of LDH intercalated cellulose nanocomposite for separation of rare earth elements (REEs),

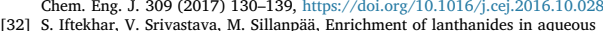
system by cellulose based silica nanocomposite, Chem. Eng. J. 320 (2017) 151-159, https://doi.org/10.1016/j.cej.2017.03.051.

[33] C. Tang, Y. Shu, R. Zhang, X. Li, J. Song, B. Li, Y. Zhang, D. Ou, Comparison of the removal and adsorption mechanisms of cadmium and lead from aqueous solution
by activated carbons prepared from Typha angustifolia and Salix matsudana, RSC Adv. 7 (2017) 16092 prepared from Typha angustifolia and Salix matsudana, 1 SC

[34] R.G. Pearson, Hard and soft acids and bases, J. Am. Chem. Soc. 85 (1963) R.G. Pearson, Hard and soft acids and bases, J. Am,
3533-3539, https://doi.org/10.1021/ja00905a001.

[35] P. Henderson, Rare Earth Element Geochemistry, Elsevier, 2013.

[36] S. Basu, S. Halder, I. Pal, S. Samanta, P. Karmakar, M.G.B. Drew, S. Bhattacharya, 1 (2'-Pyridylazo)-2-naphtholate complexes of ruthenium: synthesis, characterization, and DNA binding properties, Polyhedron 27 (2008) 2943-2951, https://doi.org/10

1016/j.poly.2008.05.023.
[37] S. Tokalioglu, H. Büyükbas, S. Kartal, Preconcentration of trace elements by using 1-(2-Pyridylazo)-2-naphthol functionalized Amberlite XAD-1180 resin and their determination by FAAS, J. Braz. C

[38] V.A. Anagnostopoulos, B.D. Symeopoulos, Sorption of europium by malt spent rootlets, a low cost biosorbent: effect of pH, kinetics and equilibrium studies, J.
Radioanal. Nucl. Chem. 295 (2013) 7-13, https://doi.org/10.1007/s10967-012 1956-y.

[39] E.I. Cadogan, C.-H. Lee, S.R. Popuri, H.-Y. Lin, Efficiencies of chitosan nanoparticles and crab shell particles in europium uptake from aqueous solutions through biosorption: synthesis and characterization, Int. Biodeterior.
232-240, https://doi.org $/ 10.1016 /$ jibiod.2014.06.003.

[40] D.L. Ramasamy, V. Puhakka, E. Repo, M. Sillanpää, Selective separation of scandium from iron, aluminium and gold rich wastewater using various amino and nonamino functionalized silica gels - a comparative study, J. Cleaner Prod. 170 (2018) 890-901, https://doi.org/10.1016/j.jclepro.2017.09.19.

[41] J.-A. Kim, G. Dodbiba, Y. Tanimura, K. Mitsuhashi, N. Fukuda, K. Okaya, S. Matsuo, T. Fujita, Leaching of rare-earth elements and their adsorption by using blue-gree M2011111.

[42] N. Sakamoto, N. Kano, H. Imaizumi, Biosorption of uranium and rare earth elements using biomass of algae, Bioinorg. Chem. Appl. 2008 (2008) 1-8, https://doi. org $/ 10.1155 / 2008 / 706240$

[43] R.C. Oliveira, C. Jouannin, E. Guibal, O. Garcia, Samarium(III) and praseodymium (III) biosorption on Sargassum sp.: batch study, Process Bi

[44] R.C. Oliveira, O. Garcia Jr., Study of biosorption of rare earth metals (La, Nd, Eu, Gd) by Sargassum sp. biomass in batch systems: physicochemical evaluation of kinetics and adsorption models, Adv. Mater. Res. $71-73$ (2009) 605-608 10.4028,
www.scientific net/AMR .71-73.605.

[45] M.C. Palmieri, B. Volesky, O. Garcia, Biosorption of lanthanum using Sargassum fluitans in batch system, Hydrometallurgy 67 (2002) 31-36, https://doi.org/10.

[46] V. Diniz, B. Volesky, Biosorption of La, Eu and Yb using Sargassum biomass, Water Ves. 39 (2005) 239-247, https://doi.org / $10.1016 /$ j.watres.2004.09.009.
Res.

[47] S. Iftekhar, V. Srivastava, A. Casas, M. Sillanpää, Synthesis of novel GA-g-PAM/SiO 2 nanocomposite for the recovery of rare earth elements (REE) ions from aqueous
solution, J. Cleaner Prod. 170 (2018) 251-259, https://doi.org/10.1016/j.jclepro. 2017.09.166.

[48] D. Avdibegović, M. Regadío, K. Binnemans, Recovery of scandium (III) from diluted aqueous solutions by a supported ionic liquid phase, RSC Adv. 7 (2017) 


\section{ACTA UNIVERSITATIS LAPPEENRANTAENSIS}

817. HURSKAINEN, VESA-VILLE. Dynamic analysis of flexible multibody systems using finite elements based on the absolute nodal coordinate formulation. 2018. Diss.

818. VASILYEV, FEDOR. Model-based design and optimisation of hydrometallurgical liquidliquid extraction processes. 2018. Diss.

819. DEMESA, ABAYNEH. Towards sustainable production of value-added chemicals and materials from lignocellulosic biomass: carboxylic acids and cellulose nanocrystals. 2018. Diss.

820. SIKANEN, EERIK. Dynamic analysis of rotating systems including contact and thermalinduced effects. 2018. Diss.

821. LIND, LOTTA. Identifying working capital models in value chains: Towards a generic framework. 2018. Diss.

822. IMMONEN, KIRSI. Ligno-cellulose fibre poly(lactic acid) interfaces in biocomposites. 2018. Diss.

823. YLÄ-KUJALA, ANTTI. Inter-organizational mediums: current state and underlying potential. 2018. Diss.

824. ZAFARI, SAHAR. Segmentation of partially overlapping convex objects in silhouette images. 2018. Diss.

825. MÄLKKI, HELENA. Identifying needs and ways to integrate sustainability into energy degree programmes. 2018. Diss.

826. JUNTUNEN, RAIMO. LCL filter designs for paraller-connected grid inverters. 2018. Diss.

827. RANAEI, SAMIRA. Quantitative approaches for detecting emerging technologies. 2018. Diss.

828. METSO, LASSE. Information-based industrial maintenance - an ecosystem perspective. 2018. Diss.

829. SAREN, ANDREY. Twin boundary dynamics in magnetic shape memory alloy Ni-MnGa five-layered modulated martensite. 2018. Diss.

830. BELONOGOVA, NADEZDA. Active residential customer in a flexible energy system - a methodology to determine the customer behaviour in a multi-objective environment. 2018. Diss.

831. KALLIOLA, SIMO. Modified chitosan nanoparticles at liquid-liquid interface for applications in oil-spill treatment. 2018. Diss.

832. GEYDT, PAVEL. Atomic Force Microscopy of electrical, mechanical and piezo properties of nanowires. 2018. Diss.

833. KARELL, VILLE. Essays on stock market anomalies. 2018. Diss.

834. KURONEN, TONI. Moving object analysis and trajectory processing with applications in human-computer interaction and chemical processes. 2018. Diss.

835. UNT, ANNA. Fiber laser and hybrid welding of T-joint in structural steels. 2018. Diss. 
836. KHAKUREL, JAYDEN. Enhancing the adoption of quantified self-tracking wearable devices. 2018. Diss.

837. SOININEN, HANNE. Improving the environmental safety of ash from bioenergy production plants. 2018. Diss.

838. GOLMAEI, SEYEDMOHAMMAD. Novel treatment methods for green liquor dregs and enhancing circular economy in kraft pulp mills. 2018. Diss.

839. GERAMI TEHRANI, MOHAMMAD. Mechanical design guidelines of an electric vehicle powertrain. 2019. Diss.

840. MUSIIENKO, DENYS. Ni-Mn-Ga magnetic shape memory alloy for precise high-speed actuation in micro-magneto-mechanical systems. 2019. Diss.

841. BELIAEVA, TATIANA. Complementarity and contextualization of firm-level strategic orientations. 2019. Diss.

842. EFIMOV-SOINI, NIKOLAI. Ideation stage in computer-aided design. 2019. Diss.

843. BUZUKU, SHQIPE. Enhancement of decision-making in complex organizations: A systems engineering approach. 2019. Diss.

844. SHCHERBACHEVA, ANNA. Agent-based modelling for epidemiological applications. 2019. Diss.

845. YLIJOKI, OSSI. Big data - towards data-driven business. 2019. Diss.

846. KOISTINEN, KATARIINA. Actors in sustainability transitions. 2019. Diss.

847. GRADOV, DMITRY. Experimentally validated numerical modelling of reacting multiphase flows in stirred tank reactors. 2019. Diss.

848. ALMPANOPOULOU, ARGYRO. Knowledge ecosystem formation: an institutional and organisational perspective. 2019. Diss.

849. AMELI, ALIREZA. Supercritical CO2 numerical modelling and turbomachinery design. 2019. Diss.

850. RENEV, IVAN. Automation of the conceptual design process in construction industry using ideas generation techniques. 2019. Diss.

851. AVRAMENKO, ANNA. CFD-based optimization for wind turbine locations in a wind park. 2019. Diss.

852. RISSANEN, TOMMI. Perspectives on business model experimentation in internationalizing high-tech companies. 2019. Diss.

853. HASSANZADEH, AIDIN. Advanced techniques for unsupervised classification of remote sensing hyperspectral images. 2019. Diss.

854. POPOVIC, TAMARA. Quantitative indicators of social sustainability applicable in process systems engineering. 2019. Diss. 


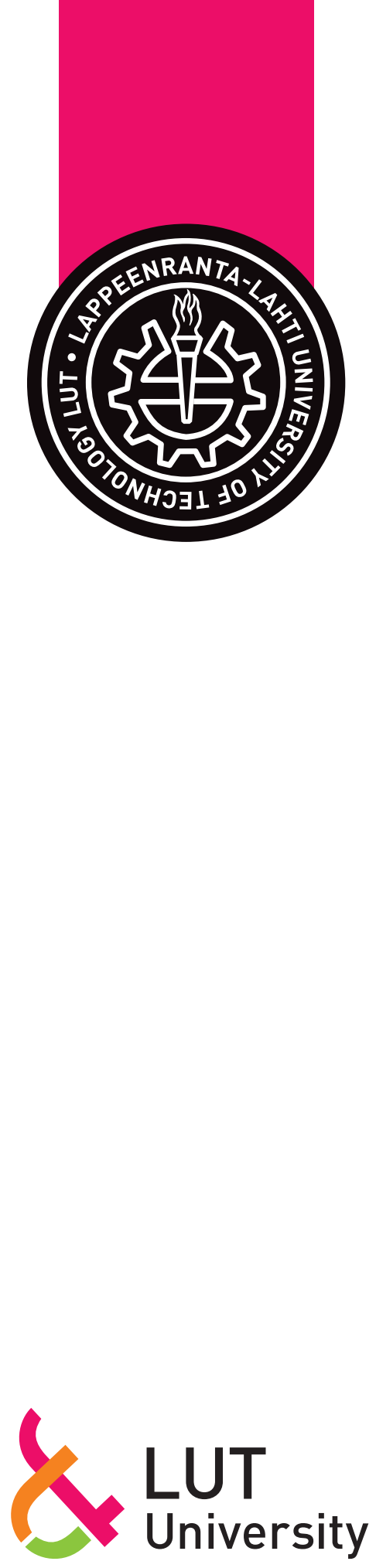

ISBN 978-952-335-376-3

ISBN 978-952-335-377-0 (PDF)

ISSN-L 1456-4491

ISSN 1456-4491

Lappeenranta 2019 